WHC-SP-1180

Revision 0

Volume 1

\title{
Needs Assessment
}

Prepared by

Hughes Associates

3610 Commerce Drive, Suite 817

Baltimore, Maryland 21227-1652

Date Published

April 1996

Prepared for the U.S. Department of Energy

Assistant Secretary for Environmental Management

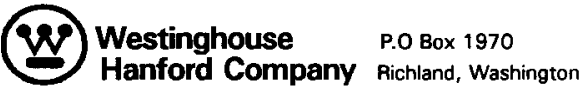

Management and Operations Contractor for the

U.S. Department of Energy under Contract DE-AC06-87RL10930

Approved for public release; distribution is unlimited 
THIS PAGE INTENTIONALLY LEFT BLANK 


\begin{abstract}
LECAL DISCLAMER
This report was prepared as an account of work sponsored by en agency of the United States Government. Neither the United States Government nor any agency thereof, nor any of their employees, nor any of their contractors, subcontractars or theit empioyese, makes any warranty, express or implied, or aseumes anv legel liability or responsibility for the accuracy, completeness, or eny third party's use or the results of such use of any information, epparatus, product, or process disclosed, or represents that its use would not infringe privately owned rights. Reference herein to any specific commercial product, process, or service by trade name, tredemark, manufacturer, or otherwise, does not necessarily constitute or imply its endorsement, recommendation, or favoring by the United States Government or any agency thereof or its contractors or subcontractors. The vews and opirions of authors expressed herein do not necessarily state or reflect those of the Urited States Government or any agency thereof.
\end{abstract}

This report has been reproduced from the best available copy. Available in peper copy and microfiche.

Aveilable to the U.S. Department of Energy and its contractors from

U.S. Department of Energy

Office of Scientific and Techrical Information (OSTI)

P.O. Box 62

Oak Aidge, TN 37831

(615) 576-8401

Printed in the Unitod Stute: of Americe

DISCLM-3.CHP (1-91) 
THIS PAGE INTENTIONALLY LEFT BLANK 


\section{RELEASE AUTHORIZATION}

Document Number: WHC-SP-1180, Rev. 0 Volume 1

Document Title: Hanford Site Emergency Response Needs

Release Date: $\quad 4 / 16 / 96$

This document was reviewed following the procedures described in WHC-CM-3-4 and is:

APPROVED FOR PUBLIC RELEASE

WHC Information Release Administration Specialist:

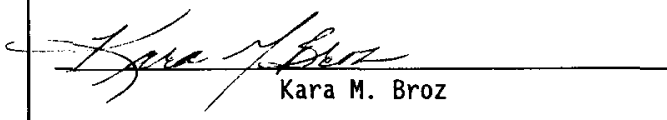

April 16, 1996 
THIS PAGE INTENTIONALLY LEFT BLANK 
THIS PAGE INTENTIONALLY LEFT BLANK 
CONTENTS

Page

FIGURES $\ldots \ldots \ldots \ldots \ldots \ldots \ldots \ldots \ldots \ldots \ldots \ldots \ldots \ldots \ldots \ldots \ldots \ldots$

TABLES $\ldots \ldots \ldots \ldots \ldots \ldots \ldots \ldots \ldots \ldots \ldots \ldots \ldots \ldots \ldots \ldots \ldots \ldots \ldots$

ABBREVIATIONS, ACRONYMS, AND INITIALISMS $\ldots \ldots \ldots \ldots \ldots \ldots$ viii

EXECUTIVE SUMMARY $\ldots \ldots \ldots \ldots \ldots \ldots \ldots \ldots \ldots \ldots \ldots \ldots \ldots \ldots$

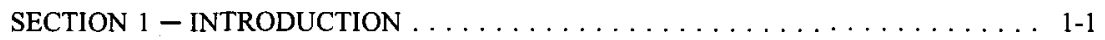

SECTION $2-$ GOALS AND OBJECTIVES $\ldots \ldots \ldots \ldots \ldots \ldots \ldots \ldots \ldots \ldots$

SECTION 3 - SCOPE, ASSUMPTIONS AND LIMITATIONS . . . . . . . . 3-1

SECTION 4 - HFD NEEDS ASSESSMENT PROCEDURE $\ldots \ldots \ldots \ldots \ldots \ldots$ 4-1

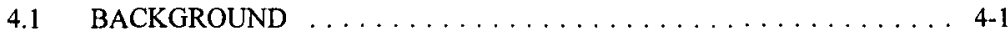

4.2 REPORT DEVELOPMENT $\ldots \ldots \ldots \ldots \ldots \ldots \ldots \ldots \ldots \ldots$ 4-1

SECTION 5 - APPLICABLE REQUIREMENTS/CRITERIA $\ldots \ldots \ldots \ldots \ldots$ 5-1

SECTION 6 - HFD SERVICE AREA DESCRIPTION . . . . . . . . . . 6-1

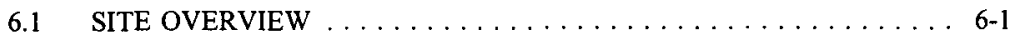

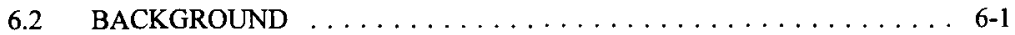

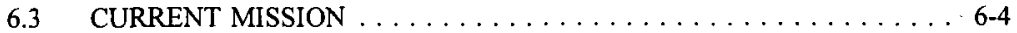

6.4 SUMMARY OPERATIONS DESCRIPTION BY AREA $\ldots \ldots \ldots \ldots 6-5$

6.5 SITE MANAGEMENT STRUCTURE AND POPULATION $\ldots \ldots \ldots 6-6$

6.6 TRI-PARTY AGREEMENT OVERVIEW $\ldots \ldots \ldots \ldots \ldots \ldots \ldots$

SECTION 7 - RISKS: ON- AND OFF-SITE $\ldots \ldots \ldots \ldots \ldots \ldots \ldots \ldots \ldots$ 7-1

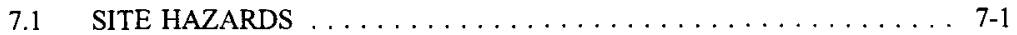

7.2 PROBABILITY AND CONSEQUENCES OF HAZARDOUS EVENTS . 7-3

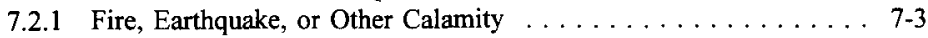

7.2 .2 Wildland Fires $\ldots \ldots \ldots \ldots \ldots \ldots \ldots \ldots \ldots \ldots \ldots \ldots . \ldots \ldots$

7.2.3 Radiological Spills or Spreads Resulting from the Transportation of Radiological Materials . . . . . . . . . . . . 7-3

7.2.4 Spills of Non-radiological or Mixed Chemical Liquid Wastes ... 7-7

7.2.5 Storage and Handling of Ignitable and Reactive Wastes . . . . . . 7-7

7.2 .6 Medical Risks . . . . . . . . . . . . . . . . 7.7

7.2.7 Incident Requiring Rescue Capability $\ldots \ldots \ldots \ldots \ldots \ldots$. . . . . . .

SECTION 8 - HFD FIRE/EMS SERVICE DEMAND HISTORY . . . . . . . 8-1

8.1 BACKGROUND $\ldots \ldots \ldots \ldots \ldots \ldots \ldots \ldots \ldots \ldots \ldots \ldots$.1 
CONTENTS (Continued)

SECTION $9-$ NEEDS ASSESSMENT ................. 9-1

9.1 FIRE DEPARTMENT MISSION \& ORGANIZATIONAL OVERVIEW . 9-1

9.1.1 Mission \& Organizational Overview, Existing Conditions . . . . . . 9-1

9.1.2 Applicable requirements $\ldots \ldots \ldots \ldots \ldots \ldots \ldots \ldots . \ldots .5$

9.1.3 Recommendations . . . . . . . . . . . . . . . 9-5

9.2 ORGANIZATION AND MANAGEMENT $\ldots \ldots \ldots \ldots \ldots \ldots .9 .6$

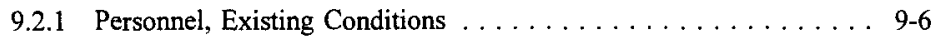

9.2.1.1 Applicable Requirements . . . . . . . . . . . 9-10

9.2.1.2 Recommendations . . . . . . . . . . . . 9-10

9.2.2 Management Information Systems . . . . . . . . . . 9-10

9.2.2.1 Management Information Systems, Existing conditions . . 9-10

9.2.2.2 Applicable requirements . . . . . . . . . . . . 9-11

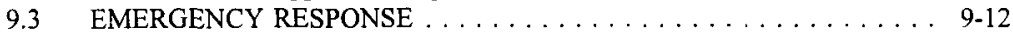

9.3.1 Staffing/Response . . . . . . . . . . . . . . 9-12

9.3.1.1 Staffing Patterns, Existing Conditions $\ldots \ldots \ldots \ldots$. 9-12

9.3.1.2 Response Posture, Existing Conditions . . . . . . . 9-15

9.3.1.3 Response Time Existing Conditions . . . . . . . . 9-18

9.3.2 Applicable requirements . . . . . . . . . . . . . 9-20

9.3.3 Recommendations . . . . . . . . . . . . . . 9. 9-23

9.4 FIRE STATIONS AND RELATED FACILITIES $\ldots \ldots \ldots \ldots \ldots \ldots 9$.

9.4.1 Fire Stations and Related Facilities Description, Existing

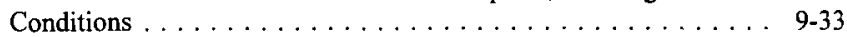

9.4.2 Applicable Requirements/Criteria . . . . . . . . . . 9-35

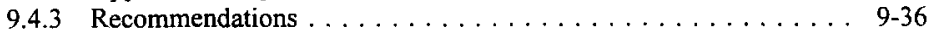

9.5 APPARATUS AND EQUIPMENT $\ldots \ldots \ldots \ldots \ldots \ldots \ldots \ldots .9 .39$

9.5.1 Apparatus and Equipment Description, Existing Conditions . . . 9.39

9.5.2 Procurement and Replacement Procedures ............ 9-45

9.5.3 Vehicle Maintenance and Testing Procedures . . . . . . . . 9-48

9.5.4 Future Development/Changes . . . . . . . . . . . . . . 9-48

9.5.5 Applicable Requirements/Criteria . . . . . . . . . . . . 9-49

9.5.6 Recommendations . . . . . . . . . . . . . . . 9 9-50

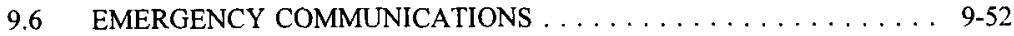

9.6.1 Emergency Communications, Existing conditions ....... 9-52

9.6.2 Applicable Requirements/Criteria . . . . . . . . . . . 9-56

9.6.3 Recommendations . . . . . . . . . . . . . . . . . 9-57

9.7 PRE-EMERGENCY PLANNING $\ldots \ldots \ldots \ldots \ldots \ldots \ldots \ldots \ldots$

9.7.1 Prefire Plans, Existing Conditions .............. 9-60

9.7.2 Building Familiarization Tours, Existing Conditions . . . . . . 9-61

9.7.3 Confined Space Entry, Existing Conditions ........... 9-61

9.7.4 Hazardous Materials Incidents, Existing Conditions . . . . . . 9. 9-62

9.7.5 Emergency Activities in Radiation Zones, Existing Conditions .. 9-63

9.7.6 Other Incidents, Existing Conditions $\ldots \ldots \ldots \ldots \ldots \ldots \ldots$ 9-65 
CONTENTS (Continued)

Page

9.7.7 Pre-incident Exercises/Drills, Existing Conditions . . . . . . . 9-65

9.7 .8 Mutual Aid . . . . . . . . . . . . . . . . . . . . 9-66

9.7.9 Applicable Requirements/Criteria . . . . . . . . . . . . . . . . 9 9-66

9.7.10 Recommendations . . . . . . . . . . . . . . . . . . . . . 9-69

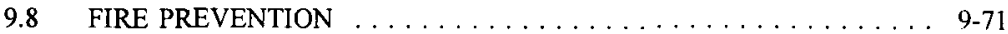

9.8.1 Fire Prevention Program, Existing Conditions . . . . . . . . . . 9-71

9.8.2 Applicable Requirements/Criteria ... . . . . . . . . . . . . . 9-74

9.8.3 Recommendations . . . . . . . . . . . . . . . . . 9-74

9.9 INSPECTION, TESTING AND MAINTENANCE OF FIRE

PROTECTION SYSTEMS $\ldots \ldots \ldots \ldots \ldots \ldots \ldots \ldots$. . . . . . . . . . .

9.9.1 Inspection, Testing and Maintenance, Existing Conditions . . . . 9-76

9.9.2 Applicable Requirements/Criteria . . . . . . . . . . . . . . . 9-81

9.9 .3 Recommendations . . . . . . . . . . . . . . . . . . . . . . 9-82

9.10 TRAINING . . . . . . . . . . . . . . . . . . . 9.83

9.10.1 Training Program, Existing Conditions . . . . . . . . . . . 9-83

9.10.2 Applicable Requirements/Criteria . . . . . . . . . . . . . . . 9-91

9.10.3 Recommendations . . . . . . . . . . . . . . . . . . . . . 9 9-92

9.11 QUALITY ASSURANCE . . . . . . . . . . . . . . . . . 9-96

9.11.1 Applicable Requirements/Criteria . . . . . . . . . . . . . . . . 9-97

9.11.2 Recommendations . . . . . . . . . . . . . . . . . . . . . . 9-97

9.12 SITE PROTECTION WATER SUPPLY . . . . . . . . . . . . . . . 9-99

9.12.1 Site Fire Protection Water Supply, Existing Conditions . . . . . . . 9-99

9.12.2 Applicable Requirements/Criteria . . . . . . . . . . . . . . . 9-100

9.12.3 Recommendations . . . . . . . . . . . . . . . . . . . . 9 9-102

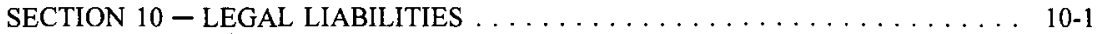

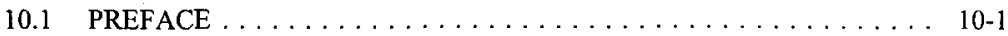

10.2 BACKGROUND AND SUMMARY $\ldots \ldots \ldots \ldots \ldots \ldots \ldots \ldots$ 10-1

10.3 CIVIL TORT LIABILITY FOR FIRE DEPARTMENT EMERGENCY

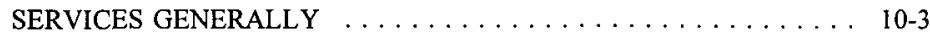

10.4 CIVIL TORT LIABILITY UNDER THE FEDERAL TORT CLAIMS

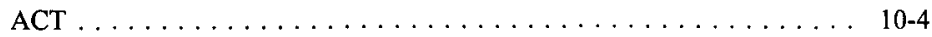

10.5 EXCEPTIONS TO GOVERNMENT LIABILITY: THE "PUBLIC DUTY" DOCTRINE . . . . . . . . . . . . . . . 10-5

10.6 EXCEPTIONS TO GOVERNMENTAL LIABILITY: THE DISCRETIONARY FUNCTION DOCTRINE . . . . . . . . . . 10-6

10.7 REGULATIONS AND STANDARDS AS EVIDENCE OF NEGLIGENT CONDUCT . . . . . . . . . . . . . . . . 10-9

10.8 APPLICATION, ENFORCEMENT, AND PENALTIES FOR VIOLATION OF GOVERNMENTAL REGULATIONS $\ldots \ldots \ldots \ldots$. $10-9$

10.9 WESTINGHOUSE HANFORD COMPANY CONTRACTUAL LIABILITIES AND INDEMNIFICATION CLAUSES . . . . . . . 10-13 
CONTENTS (Continued)

Page

10.10 POTENTIAL LEGAL LIABILITIES AND RESPONSIBILITIES RESULTING FROM CHANGES TO HFD RESOURCES WHICH DEVIATE FROM THOSE SET FORTH IN THE HANFORD FACILITY CONTINGENCY PLAN AND APPENDED TO THE

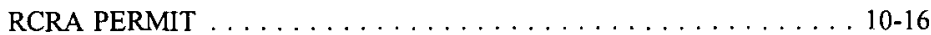

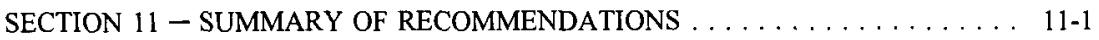

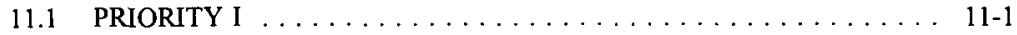

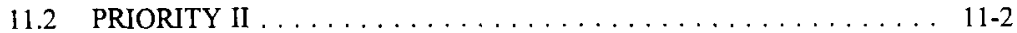

11.3 PRIORITY III $\ldots \ldots \ldots \ldots \ldots \ldots \ldots \ldots \ldots \ldots \ldots \ldots \ldots \ldots \ldots \ldots$

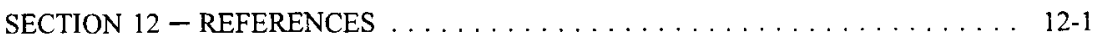

Appendix A - Resumes of HFD Needs Assessment Team $\ldots \ldots \ldots \ldots \ldots \ldots$ A-1

Appendix B - Site Operations and Activities $\ldots \ldots \ldots \ldots \ldots \ldots \ldots \ldots \ldots$ B-1

Appendix $\mathrm{C}-$ Risks On and Off-site by Facility/event Identification $\ldots \ldots \ldots \ldots$ C-1

Appendix D - Emergency Response Times $\ldots \ldots \ldots \ldots \ldots \ldots \ldots \ldots \ldots \ldots \ldots \ldots$ 


\section{FIGURES}

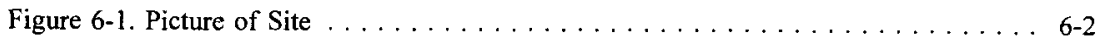

Figure 8-1. Engine responses to various site areas from $1990-1995 \ldots \ldots$. . . . .

Figure 8 -2. Engine responses specified by incident type $\ldots \ldots \ldots \ldots \ldots$.7

Figure 8-3. Engine responses to actual fires to various sites from $1990-1995 \ldots \ldots$. . . 8-8

Figure 8 -4. Actual fires by type $\ldots \ldots \ldots \ldots \ldots \ldots \ldots \ldots \ldots$

Figure $8-5$. Engine responses $\ldots \ldots \ldots \ldots \ldots \ldots \ldots \ldots \ldots \ldots \ldots$. . . . . . . . . .

Figure $8-6$. HFD emergency responses $\ldots \ldots \ldots \ldots \ldots \ldots \ldots \ldots \ldots$

Figure $8-7$. HFD engine response by station $\ldots \ldots \ldots \ldots \ldots \ldots \ldots$

Figure 8-8. Engine response by time of day $\ldots \ldots \ldots \ldots \ldots \ldots \ldots \ldots$

Figure 8-9. Patient contacts and EMS transports vs. actual ambulance responses $\ldots \ldots$ 8-16

Figure $8-10$. Site population and emergency response trends $\ldots \ldots \ldots \ldots \ldots$. . . . . .

Figure 8 -11. EMS patient contacts $\ldots \ldots \ldots \ldots \ldots \ldots \ldots \ldots \ldots$

Figure $8-12$. Patient contacts by EMS severity level $\ldots \ldots \ldots \ldots \ldots \ldots$. $\ldots \ldots$

Figure 8-13. All EMS responses $\ldots \ldots \ldots \ldots \ldots \ldots \ldots \ldots \ldots \ldots$. . . . . . . . . .

Figure $9-1$. Organizational chart $\ldots \ldots \ldots \ldots \ldots \ldots \ldots \ldots \ldots$

Figure $9-2$. Emergency staffing $\ldots \ldots \ldots \ldots \ldots \ldots \ldots \ldots$

Figure 9-3. Hanford Fire Department 3 Year Training Schedule Year $1 \ldots \ldots$. . . . 9-85

Figure 9-4. Hanford Fire Department 3 Year Training Schedule Year 2 . . . . . . 9-86

Figure 9-5. Hanford Fire Department 3 Year Training Schedule Year $3 \ldots \ldots$. . . . 9-87

Figure 9-6. Classes Required By ACES for HFD Members . . . . . . . . . . . 9-90 


\section{TABLES}

Page

Table 6-1. Funding Summary for Fiscal Year $1995 \ldots \ldots \ldots \ldots$. . . . . . . . .

Table 6-2. Estimated Site Area Populations $\ldots \ldots \ldots \ldots \ldots \ldots \ldots \ldots \ldots$ 6-8

Table 7-1. Summary of Representative Hazards by Area $\ldots \ldots \ldots \ldots \ldots \ldots$ 7-2

Table 7-2. Summary of Representative Site Risks $\ldots \ldots \ldots \ldots \ldots \ldots \ldots$ 7-4

Table 7-3. Washington $L \& I$ Risk Rate $\ldots \ldots \ldots \ldots \ldots \ldots \ldots \ldots \ldots \ldots \ldots$

Table 7-4. Washington L\&I Risk Ratings for Expected D\&D Operations . . . . . . 7-8

Table 8-1. Site Fire Loss Summary $\ldots \ldots \ldots \ldots \ldots \ldots \ldots \ldots \ldots \ldots$.

Table 8-2. Average Number of Responses to Actual Fires per Year by Area for period $1990-1994 \ldots \ldots \ldots \ldots \ldots \ldots \ldots \ldots \ldots \ldots \ldots$ 8-11

Table 9-1. EMS Average Area Response Times .................. 9-19

Table 9-2. EMS Within Area Adjusted Average Response Times ..... . . . . . 9-19

Table 9-3. EMS Out of Area Average Response Times ............. 9-20

Table 9-4. Chance of Recovery after cardiac arrest $\ldots \ldots \ldots \ldots \ldots \ldots . . \ldots .32$

Table 9-5.1 HFD Apparatus and Command/Utility Vehicle Inventory . . . . . . 9-40

Table 9-5.2 Site Apparatus Description (First Line) $\ldots \ldots \ldots \ldots \ldots \ldots \ldots$ 9-41

Table 9-5.3 Site Apparatus Description (Reserve) . . . . . . . . . . . 9-42

Table 9-5.4 Deployment of Apparatus by Station . . . . . . . . . . . 9-43

Table 9-5.5 Description of Hanford Site Apparatus Condition .......... 9-46

Table 9-7.1 Emergency Dose Limits $\ldots \ldots \ldots \ldots \ldots \ldots \ldots \ldots \ldots \ldots$ 9-64

Table 9-7.2 Emergency Dose Limits $\ldots \ldots \ldots \ldots \ldots \ldots \ldots \ldots \ldots \ldots$ 9-68

Table 9-12.1 Water Flow Requirements $\ldots \ldots \ldots \ldots \ldots \ldots \ldots \ldots \ldots$ 9-101

Table $9-12.2$ Water Supply Demand $\ldots \ldots \ldots \ldots \ldots \ldots \ldots \ldots \ldots \ldots . \ldots \ldots .102$ 


\begin{tabular}{|c|c|}
\hline ACES & Access Control Data Entry \\
\hline ALS & Advanced Life Support \\
\hline AHJ & Authority Having Jurisdiction \\
\hline ATPs & Acceptance Test Procedures \\
\hline BCS & Boeing Computer Services \\
\hline BLS & Basic Life Support \\
\hline $\mathrm{CAD}$ & Computer Aided Dispatch \\
\hline CERCLA & Comprehensive Environmental Response and Liability Act \\
\hline $\mathrm{CME}$ & Continuing Medical Education \\
\hline $\mathrm{D} \& \mathrm{D}$ & Decontamination and Decommissioning \\
\hline DEA & Drug Enforcement Agency \\
\hline DOE & Department of Energy \\
\hline DOT & Department of Transportation \\
\hline EDF & Emergency Decontamination Facility \\
\hline EMS & Emergency Medical Services \\
\hline EMS-D & Emergency Medical Technician-Defibrillator \\
\hline EMS/TC & Emergency Medical Services Trauma Certified \\
\hline EMT & Emergency Medical Technician \\
\hline ERPG & Emergency Response Planning Guidelines \\
\hline FEMA & Federal Emergency Management Agency \\
\hline FFTF & Fast Flux Test Facility \\
\hline FHA & Fire Hazard Analyses \\
\hline FMEF & Fuels and Materials Examination Facility \\
\hline FRA & Fire Risk Assessments \\
\hline FTE & Full Time Equivalent \\
\hline HEARM & Hanford Emergency Assessment Resource Manual \\
\hline HEHF & Hanford Environmental Health Foundation \\
\hline HFD & Hanford Fire Department \\
\hline HFDC & Hanford Fire Dispatch Center \\
\hline HFM & Hanford Fire Marshal \\
\hline IC & Incident Commander \\
\hline ICS & Incident Command System \\
\hline L\&I & State of Washington Labor \& Industry \\
\hline MCI & Multiple Casualty Incident \\
\hline MDT & Mobile Data Terminals \\
\hline MIS & Management Information Systems \\
\hline MPD & Medical Program Director \\
\hline MPFL & Maximum Possible Fire Loss \\
\hline MVI & Multiple Victim Incident \\
\hline NFPA & National Fire Protection Association \\
\hline OJT & On-the-Job \\
\hline OSRs & Operational Safety Requirements \\
\hline PADI & Personal Alarm Dosimetry Indicator \\
\hline
\end{tabular}


WHC-SP-1180, Vol. 1

ABBREVIATIONS, ACRONYMS, AND INITIALISMS (Concluded)

$\begin{array}{ll}\text { PFP } & \text { Plutonium Finishing Plant } \\ \text { PSAF } & \text { Public Safety Answering Point } \\ \text { Purex } & \text { Plutonium-Uranium Extraction } \\ \text { QA/QI } & \text { Quality Assurance/Quality Improvement } \\ \text { RCT } & \text { Radiological Control Technician } \\ \text { RFAR } & \text { Radio Fire Alarm Reporting } \\ \text { RFP } & \text { Request for Proposal } \\ \text { RL } & \text { The U.S. Department of Energy, Richland Operations Office } \\ \text { RWP } & \text { Radiation Work Procedures } \\ \text { SAR } & \text { Safety Analysis Report } \\ \text { SCBA } & \text { Self-Contained Breathing Apparatus } \\ \text { SRID } & \text { Standard Regulation Identification Document } \\ \text { SWBG } & \text { Solid Waste Burial Ground } \\ \text { T\&S FF } & \text { Testing and Service Firefighters } \\ \text { TRI } & \text { Training Records Information } \\ \text { TRUSAF } & \text { Transuranic Waste Storage and Assay Facility } \\ \text { WAC } & \text { Washington Administrative Code } \\ \text { WHC } & \text { Westinghouse Hanford Company } \\ \text { WPPSS } & \text { Washington Public Power Supply System } \\ \text { WRAM } & \text { Westinghouse Radiation Area Management } \\ \text { WSCF } & \text { Waste Sampling and Characterization Facility }\end{array}$




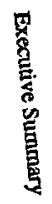


THIS PAGE INTENTIONALLY LEFT BLANK 


\section{EXECUTIVE SUMMARY}

\section{SECTION 1. INTRODUCTION}

This report presents the results of a comprehensive third party needs assessment of the Hanford Fire Department (HFD), conducted by Hughes Associates Inc. The assessment was commissioned with the intent of obtaining an unbiased report which could be used as a basis for identifying needed changes/modifications to the fire department and its services. This report serves several functions: (1) it documents current and future site operations and associated hazards and risks identified as a result of document review, site and facility surveys, and interviews with knowledgeable personnel; (2) describes the HFD in terms of organization, existing resources and response capabilities; (3) identifies regulatory and other requirements that are applicable to the HFD and includes a discussion of associated legal liabilities; and (4) provides recommendations based on applicable requirements and existing conditions. Each recommendation is followed by a supporting statement to clarify the intent or justification of the recommendation.

This report will be followed by a Master Plan document which will present an implementation method for the recommendations (with associated costs) considered to be essential to maintaining adequate, cost effective emergency services at the Hanford site in the next five to seven years.

\section{SECTION 2. GOALS AND OBJECTIVES}

As identified in the task's Statement of Work, there are several goals and objectives of this needs assessment. The goals of the third party assessment are as follows:

(1) Analyze the on- and off-site risks in terms of consequences and potential magnitude, associated with Hanford's current and planned (5 to 7 years), missions and activities.

(2) Provide a basis for determining the level of fire and emergency response services required to adequately respond to the current and the near future (5 to 7 year), risks facing the Hanford site which can be used for development of a master plan. Included in this determination are staffing requirements, recommended fire station locations, and vehicle and equipment needs.

Objectives are detailed in the report.

\section{SECTION 3. SCOPE, ASSUMPTIONS AND LIMITATIONS}

The scope of the report is limited to those services and resources that are currently provided by or considered to be part of the HFD or is required by Department of Energy (DOE) Order, or contractual obligation. It is considered to be a comprehensive report in that it is intended to address all major services and resources of the HFD that are necessary to carry out its intended mission. Evaluation of HFD related services provided by others, such 
as contractor fire protection and site emergency preparedness organizations and fire department procedures, is excluded.

Identification of representative site risks is based on interviews with HFD personnel, cognizant DOE and contractor fire protection engineers, and review of site and facility documentation. Significant changes in the applicable requirements, referenced documents, information provided to the assessment team by WHC, or other information this report is based upon warrant re-evaluation of the conclusions and recommendations of the HFD Needs Assessment.

\section{SECTION 4. HFD NEEDS ASSESSMENT PROCEDURE}

This Report was written by the HFD Needs Assessment Team. The team member make-up (Appendix A) was intended to provide subject matter expertise in all areas detailed in the Request for Proposal (RFP); specifically, fire department services, emergency medical services, site hazards and events, and associated legal liabilities. The content and recommendations of this report result from reviews of available documentation, interviews with selected HFD staff at all levels, interviews with site and facility fire protection representatives, discussions with DOE and WHC staff who work or interface with (by organization necessity) the HFD, walkdowns of representative facilities, and observations of HFD drills, classes and emergency responses.

\section{SECTION 5. APPLICABLE REQUIREMENTS/CRITERIA}

The organization and scope of services of the HFD are determined by regulatory drivers, national standards (primarily those issued by the National Fire Protection Association (NFPA), accepted fire protection industry standards, and expert opinion.

\section{SECTION 6. HFD SERVICE AREA DESCRIPTION}

The Hanford Site is located in the southeast portion of Washington State. The Site occupies an area of 1,450 square kilometers (560 square miles) with the Columbia River flowing through and adjacent to it (Figure 6-1). The Hanford Site is relatively flat and semiarid with a mild climate. The major portions of the site are managed by DOE. Small portions of the Hanford Site are owned, leased, or administered by other governmental agencies.

The current mission of the Hanford Site is to manage the facilities and inventories of special materials and remedy the environmental contamination caused by decades of activities related to plutonium production. Environmental Management efforts are specifically focused on (1) minimizing, processing, and storing radioactive and hazardous wastes generated during the years 1949 through 1972; (2) managing special nuclear fuels and other radiological material; (3) decontaminating and decommissioning facilities no longer in use; (4) Developing technologies that can be used to clean up Hanford and other environmentally contaminated sites, and (5) Remediation of the Site, to the extent possible, to its former state (DOE, 1995a). 
Hanford Site facilities and activities are consolidated within "operating areas" that occupy about $6 \%$ of the Hanford Site's total available area. A general area description is provided below:

- 100 Areas-N Reactor and eight other deactivated plutonium production reactors used in previous nuclear programs. (This includes waste disposal sites associated with the operation of these reactors);

- 200 Areas-Chemical processing and waste management storage, applied technology, and disposal;

- 300 Area-Multiprogram laboratories for research and development;

- 400 Area-Fast Flux Test Facility (FFTF) and related support facilities.

A detailed description of the site, site mission, and facilities is provided in Section 6 and Appendix B.

\section{SECTION 7. RISKS: ON- AND OFF-SITE}

The initial goal of this third party assessment of the fire department was to analyze the on- and off-site risks associated with Hanford's current and planned mission and activities as identified in Section 6. Risk is a measure of fire loss that combines (a) the potential for harm (impact) due to various scenarios and (2) the probability of occurrence of the potential scenario (Hirschler, 1992). Therefore, in order to evaluate the risks associated with the mission, the hazards, the consequences associated with an event, and the probability of that event must be identified. Section 7 addresses each of these components. A detailed listing by facility of relevant risk information obtained from a review of site documentation is contained in Appendix C. Information presented is limited to that identified in existing site documentation.

The HFD, as the designated site emergency organization will invariably be required to respond to these or similar events in order to provide control or mitigating actions. The identified events are not inclusive of all hazard/events which exist or could occur at the site. However, they are considered to be reasonably representative of the postulated accidents of the types of hazard/events that are likely to challenge current fire department resources.

\subsection{SITE HAZARDS}

There are numerous hazards/events that are inherently associated with existing facility and site operations. Tours of facilities, interviews with facility fire protection engineers, review of safety documentation (i.e., Safety Analysis Reports, Interim Safety Analyses, Hazard Assessments), Hanford Emergency Assessment Resource Manual (HEARM), Fire Hazard Analyses (FHA), and Fire Risk Assessments (FRA) resulted in the identification of representative site hazards and/or emergency events. 
Hazards include fires, spills, explosions, structural collapse, and other events that can result in occupational worker exposure to radiation, dose consequences to on-site and off-site personnel, release of toxic material to the environment, occupational injury/illness, and/or significant monetary loss. Table 7-1 summarizes the identified hazards/events by area.

\begin{tabular}{|c|c|c|}
\hline AREA & HAZARDS & SIGNIFICANT FACILITIES \\
\hline 100 & $\begin{array}{l}\text { Fire involving radiological materials; spill of radiological materials; } \\
\text { structural fire; airborne release of radiological and/or hazmat materials; } \\
\text { range fire; operational accidents; construction accidents (includes D\&D } \\
\text { activities); criticality incidents. }\end{array}$ & $\begin{array}{l}\text { K-Basins; } \\
\text { N-Reactor; } \\
\text { C-Reactor \& other D\&D sites }\end{array}$ \\
\hline 200 & $\begin{array}{l}\text { Fire/explosion involving radiological materials; spill of radiological } \\
\text { materials: structural fire; airborne release of radiological and/or hazmat } \\
\text { materials; range fire; operational accidents; construction accidents; } \\
\text { criticality incidents }\end{array}$ & $\begin{array}{l}\text { Central Waste Complex, Tank } \\
\text { Farms. B-Plant, T-Plant, PFP, } \\
\text { 222-S. TRUSAF, Purex, WSCF }\end{array}$ \\
\hline 300 & $\begin{array}{l}\text { Fire/explosion involving radiological materials; spill of radiological } \\
\text { materials; structural fire; sodium/potassium fire; criticality, airborne } \\
\text { release of radiological and/or hazmat materials; range fire; operational } \\
\text { accidents; construction accidents; }\end{array}$ & $\begin{array}{l}\text { Bldg } \#: 324,315,325,327,331 \\
337,340\end{array}$ \\
\hline 400 & $\begin{array}{l}\text { Fire/explosion involving radiological materials; spill of radiological } \\
\text { materials: structural fire; sodium fire; airborne release of radiological } \\
\text { and/or hazmat materials; range fire; operational accident; construction } \\
\text { accidents; }\end{array}$ & $\begin{array}{l}\text { FFTF. FMEF } \\
\text { WPPSS }\end{array}$ \\
\hline $\begin{array}{l}600 / \\
1100\end{array}$ & $\begin{array}{l}\text { Range fire } \\
\text { structure fire } \\
\text { operational accident } \\
\text { Hazmat } \\
\text { Technical Rescue }\end{array}$ & $\begin{array}{l}1100 \text { area; all wilderness areas of } \\
\text { the side }\end{array}$ \\
\hline OTHER & $\begin{array}{l}\text { Transportation accidents throughout site resulting in personnel injuries, } \\
\text { fire, and/or release of radiological or hazardous materials and Technical } \\
\text { Rescue }\end{array}$ & All areas \\
\hline
\end{tabular}

D\&D (Decontamination and Decommissioning)

PFP (Plutonium Finishing Plant)

TRUSAF (Transuranic Waste Storage and Assay Facility)

Purex (Plutonium-Uranium Extraction)

WSCF (Waste Sampling and Characterization Facility)

FFTF (Fast Flux Test Faciiity)

FMEF (Fuels and Materials Examination Facility)

WPPSS (Washington Public Power Supply System)

EMS (Emergency Medical Services) 


\subsection{PROBABILITY AND CONSEQUENCES OF HAZARDOUS EVENTS}

Section 7.2 identifies the on- and off-site risks in terms of probability and consequences of hazards/events associated with the current and planned site/facility missions and operations. Table 7-2 summarizes information obtained from documentation of site hazards. These hazards and events are identified by facility in greater detail in Appendix C.

There are numerous credible events that have been identified with significant on-site and/or off-site consequences which will require HFD control and/or mitigation. Further, nearly all of the events which have the potential for significant on-site and/or off-site consequences will require a Hazmat response in order to mitigate the event.

\subsubsection{Fire, Earthquake, or Other Calamity}

The majority of information available to the assessment team related to the risks associated with fire, earthquake, or other calamities. The consequences range from lethal exposures on-site and major illness off-site to limited exposure to on-site employees. Exposures thought to result in major injuries (i.e., Category I) are classified as extremely unlikely to occur (i.e., $10^{-6}$ to $10^{-4}$ possibility) or incredible (i.e., $<10^{-6}$ possibility). However, fires are credible events in all areas of the site.

\subsubsection{Wildland Fires}

Wildland fires are a current and anticipated event. The on- and off-site risks associated with range fires exist in all areas. The wildland fire can result in a radiological or hazardous material release affecting on- and off-site. History indicates that the largest fire department response has been the result of range fires. Several site facilities (e.g., Solid Waste Burial Ground (SWBG)) use range fires as a design basis or FHA exposure fire.

\subsubsection{Radiological Spills or Spreads Resulting from the Transportation of Radiological Materials}

Approximately 10,000 radioactive shipments occur each year on the Hanford site. Allowable radioactive inventory in each type of transportation container is specified in the Safety Analysis Report (SAR) for packaging by Department of Transportation (DOT) regulation. However, the possible release and on- and off-site exposure is postulated.

Radiological materials transported include plutonium samples, TRU waste containers, and contaminated D\&D materials. Methods of transportation include railcars and vehicles. Spills or spreads resulting from transportation of radiological materials can result in a $290 \mathrm{rem}$ dose, $1 \mathrm{~km}(3290 \mathrm{ft})$ from the accident.

\subsubsection{Spills of Non-radiological or Mixed Chemical Liquid Wastes}

Spills of non-radiological or mixed chemical liquid wastes can result from transportation accidents, leaks, or other incidents. Hazardous material spills are classified as credible. Materials include sodium, chloride, nitric acid, and other materials. Exposures can 
include releases into the air. Examples of levels of exposure include a $13,000 \mathrm{ppm}$ chlorine concentration at $1 \mathrm{~km}(3290 \mathrm{ft})$ from the spill.

\subsubsection{Storage and Handling of Ignitable and Reactive Wastes}

The risks associated with the storage and handling of ignitable and reactive wastes are documented in Safety Basis documents. Incidents involving the mechanical release from gas buildup in swollen drums is postulated in TRUSAF and other facilities. Hazardous events involving ignitable and reactive waste are considered credible and can result in severe injuries on-site, and off-site exposures below annual limits (Category II).

\subsubsection{Medical Risks}

Occupational injuries and illnesses related to the Hanford site are well delineated in the Westinghouse Hanford Company Health and Safety Performance Report (WHC-SP-0564-37) for first quarter 1995. The majority of the medical conditions listed are minor in nature and are well cared for under the current system of emergency response, triage, and transport by the HFD, and on-site treatment by the Hanford Environmental Health Foundation (HEHF).

The site mission is shifting toward D\&D. Therefore, the number of technical, craft, laborer, and operator positions are expected to increase as the mission life cycle matures. Thus, it is concluded that as the mission shifts toward D\&D, a shift in the potential injury categories will occur. If these follow the State of Washington Labor \& Industry (L\&I) risk profile, an increase in the risk of injuries is expected. This risk will be magnified by the evolutionary nature of the future mission. Rather than a stable work force and job pattern, there will be a trend toward an increase in subcontractors and a transitory nature of portions of the work force. This may result in an increased injury rate due to diminished hazard familiarity, a diminished ability to educate and monitor a transitory work force and the nature of the jobs performed.

The current mission of the HFD in EMS is categorized as follows:

(1) Care of medical and traumatic emergencies,

(2) Care of job related injuries of a lesser nature,

(3) Response to hazardous material or radiation emergencies, and

(4) Response to an Multiple Casualty Incident (MCI) or Multiple Victim Incident (MVI).

Category (1) and (2) medical and traumatic injuries and illness are expected to increase as noted above. Category (3) is expected to increase with the increased interaction with outdated facilities and outmoded technology inherent in the transfer and storage mission. Category (4) is difficult to quantify as it is extremely rare on-site other than motor vehicle accidents which are in direct relation to the number of vehicles and the miles driven. 


\subsubsection{Incident Requiring Rescue Capability}

Rescue capabilities are not typically discussed in site accident analysis documentation. However, incidents including vehicle accidents and construction incidents can result in rescue services being required. Detailed data to evaluate the probability of a rescue incident is not available. Data in the last two years indicate approximately 100 patient contacts for EMS as a result of vehicle accidents. In addition, the number of identified confined spaces is increasing, and as D\&D progresses and trench construction increases, additional cave-in and rescue possibilities exist. There were no identified incidents involving confined spaces or unique rescue capabilities to date.

\section{SECTION 8. HFD FIRE/EMS SERVICE DEMAND HISTORY}

A discussion of site fire demand and responsibility is provided. The number of calls responded to by station and type is provided. The 100 area responds to fewer calls to actual fires and EMS incidents than other areas. The 200 and 300 area stations respond to the most calls.

Over the last five years, Westinghouse Hanford Company (WHC) averages 72 fires per year. More than half of the fires are classified as structural or natural cover fires.

\section{SECTION 9. NEEDS ASSESSMENT}

Section 9 details the existing conditions, applicable requirements, recommendations, and supporting statements for each aspect of the HFD evaluated. A summary of the recommendations is provided in Section 11.

\section{SECTION 10. LEGAL LIABILITIES}

Section 5 identifies a series of federal regulations, principally involving worker safety and other Occupational Safety and Health Administration concerns, with which the Hanford Fire Department must comply. Failure to comply with these requirements could result in civil penalties and other liabilities imposed under federal statutes, specifically, 29 U.S.C. $§ 651$.

In addition, Section 5 identifies a series of regulations dealing, typically, with storage, handling, or transportation of oil, hazardous wastes, or extremely hazardous substances, as variously defined by federal regulation. These regulations do not, on their face, apply to the operations of the Hanford Fire Department as a distinct entity. However, if the Hanford Fire Department is the mechanism through which another entity, to wit, Westinghouse Hanford Company, means to comply with such requirements, then consideration must be given to the imposition of civil and criminal penalties, set forth in those regulations, for noncompliance.

Lastly, Section 5 identifies national standards, typically promulgated by the National Fire Protection Association, which apply to specific fire fighting apparatus, equipment, organization, training, or other procedures. These standards, even if referenced in other regulations, do not have the force of law and do not carry with them any specific penalties or other liabilities for noncompliance. 
However, such standards, together with regulations carrying their own penalties, are important for another reason bearing on potential legal liability: A person or other entity injured as a result of or in conjunction with Hanford Fire Department activities could bring a claim based upon the failure of the Hanford Fire Department to meet such standards and regulations. In that event, the standards and regulations would be admissible as evidence of a minimum standard of care to which the Hanford Fire Department, and it otherwise could be adjudged negligent and liable to the injured party. In the event of a claim brought against the Hanford Fire Department, the Westinghouse Hanford Company, or the Department of Energy, under either Washington law or under the Federal Tort Claims Act, a claimant thus would be entitled to introduce into evidence and refer to both applicable regulations and national standards, and compare the capabilities and performance of the Hanford Fire Department against those criteria. While a violation of a regulation or standard would not be conclusive on the issue of negligence or liability, it would be admissible into evidence and certainly would be argued to be the appropriate standard to which the Hanford Fire Department should be held.

Individuals employed by the company or fire department also could be subject to civil tort liability for actions which resulted in the provision of services falling below a recognized standard of care, i.e., for their negligence. Such individuals would not be liable as a consequence of the company's liability, but rather, the reverse is true. The company and the fire department only can act through employees, and their liability generally would be the result of one or more of their employees having acted negligently. Such an employee also would be liable for injuries resulting from that negligence, and this would not be affected by the fact that liability also may be imposed upon the employer. While several practical reasons often come into play which tend to make companies, rather than individual employees, the subject of lawsuits, no legal immunity is afforded individuals for liabilities arising from their negligence just because that negligence was committed during the course of employment rather than during purely personal activities.

While there are express indemnity provisions within the contract, they only apply to a limited category of "nuclear incidents." However, the Contract's allowance of costs to the paid by the Department of Energy encompasses all of the potential liabilities to the company identified in the needs assessment. In addition, it is stated "Government Policy" to defend claims brought against "any Contractor protective force or other employee" as a result of conduct undertaken in good faith performance of employment duties.

Applicable regulations requiring a contingency plan do not require that the plan conform to any particular regulation or standard. In the first place, a change in Hanford Fire Department resources would not automatically require an amendment to the Hanford Facility Contingency Plan (hereinafter "the Plan"). While certain categories of change -- reduction in emergency equipment, for example -- definitely would require an amendment, others are tested by a more subjective standard and only would require an amendment if they increased hazards associated with fire or dangerous wastes. If changes resulted in a Plan amendment, it would be necessary to request a modification of the Hanford Facility's RCRA Permit, a process which could entail public notice, comment, and hearing procedures. Even then, the request would be governed by regulations espousing performance standards (albeit stringent ones) rather than regulations or standards setting forth particular or arbitrary resource levels. 


\section{SECTION 11. SUMMARY OF RECOMMENDATIONS}

An assessment of the HFD was performed to evaluate the service level provided based on the site risks, response history, and applicable standards. Based on this assessment, recommendations were provided to address issues. A summary of the recommendations follows. Incorporation of the recommendations will result in a level of service complying with the intent of the applicable regulations, referenced criteria, and professional judgement.

These recommendations are summarized based on a priority scheme that allows incorporation of changes in an appropriate manner. The priority levels are defined as follows:

Priority I These recommendations result from requirements reflected in mandatory criteria. Additionally, these recommendations may stem from conditions, events or risks which if left unchanged could result in an imminent hazard to site employees, HFD firefighters, or could result in an environmental release in excess of allowed limits. Priority I items are considered an emergency condition and should receive highest priority for implementation.

Priority II These recommendations result from the professional judgement of the needs assessment team members and stem from conditions, events or risks which if left unchanged could reduce the level of fire/EMS protection below baseline levels. Priority II items impact baseline levels of fire/EMS protection and therefore should be implemented as soon as possible. However, when qualitatively evaluated in the context of site history and experience, these items are not considered to represent an immediate emergency condition.

Priority III These recommendations result from the professional judgement of needs assessment team members and stem from conditions, events or risks which if left unchanged could reduce the desirable level of fire/EMS protection, but not below baseline levels. Priority III items should be scheduled for implementation with due consideration of funds and resources.

\subsection{PRIORITY I}

I.1. Clarification is needed concerning firefighters returned to "full duty" by HEHF, but not allowed full duty assignments. HFD and HEHF officials must clear up this problematical situation ( $\operatorname{Rec}$ 9.3.3.6).

I.2. Site supervisory personnel must be made aware of the need to call 911 when medical situations occur and not transport a potentially critical and unstable patient to a first aid location. Medical situations shall include all cardiac complaints, serious injuries, or injuries with a potential neurological component and all severe respiratory complaints (Rec 9.3.3.7).

1.3. The HFD shall adhere to EMS patient care procedures, protocols, and guidelines established by the Benton Franklin county protocols and the State of Washington as stipulated by the Medical Program Director (MPD) (Rec. 9.3.3.9) 
I.4. Consolidate the entire fire dispatch and emergency communications system function so that its functions are overseen by the HFD. Alternatively, reestablish a site emergency alarm-dispatch-communications feasibility task force which allows for equitable participation of all possible users and which examines, the feasibility of a Site-wide facility controlled by an equitable multi-agency policy board (Rec 9.6.3.3).

1.5. The HFD shall be provided with the capability of ensuring (and validating) that all emergency services can be performed within the applicable dose limitations (Rec 9.7.10.5).

I.6. The HFD dose limits shall be revised to reflect the criteria stipulated by 10 CFR 835 (Rec 9.7.10.6).

1.7. The following EMS Skills maintenance items shall be made a priority for the EMS System.

- $\quad$ Close monitoring of Continuing Medical Education and field performance.

- All paramedics should be required to perform ride along or hospital time on a monthly basis.

- A medical director should be providing the paramedic OTEP training as well as overseeing the upgrading and maintenance of skills.

- $\quad \mathrm{QA} / \mathrm{QI}$ should focus on the issue of skills maintenance and appropriate procedural evaluations.

(Rec 9.10.3.9)

I.8. A medical director should be responsible for all aspects of the initial QA/QI and should work towards developing a program of $\mathrm{CQI}$ (continuous quality improvement) (Rec 9.11.2.1).

I.9. A stand alone procedure shall be developed and implemented which provides independent validation that applicable HFD procedures are being followed. (Rec 9.11.2.2).

\subsection{PRIORITY II}

II.1. There shall be 17 response personnel on duty assigned to stations to handle, simultaneously, one hazardous materials or fire incident and one EMS incident(this number includes the Battalion Chief, but excludes the dispatcher). Actual deployment of the 17 baseline personnel shall be determined by HFD management, in order to achieve the service capabilities cited in Recommendation 9.3.3.2. A staffing multiplier to determine actual minimum on-duty staffing levels shall be developed by HFD officials to account for time off allowed by contract, shift arrangements, sick days lost, light duty personnel, station configuration and crew deployment, shifts in area populations and occupancies, activity, and resulting workloads, recalls, training assignments, fire watches, etc.(Rec 9.3.3.1) 
WHC-SP-1180, Vol. 1

II.2. Based on the existing and predicted hazards and conditions of the Site, critical baseline fire station operating times and service capabilities shall not be less than the following:

\section{$\underline{\text { Stations }}$}

100 Station: Open weekdays -fire and BLS-D (defibrillator) response capability; closed at times of low area population and activities; currently, nights, weekends, and holidays.

200 Station: Open 24 hours - 7 days/week for fire response and *ALS response capability.

300 Station: Open 24 hours - 7 days/week for fire, and BLS-D response capability.

400 Station: Open 24 hours -7 days/week for fire response and *ALS response capability.

*ALS is the preferred level of service at this station. This service level, at the HFD management discretion could be relocated to adjust to a change in site populations, activity or risk ( $\operatorname{Rec} \mathbf{9 . 3 . 3 . 2}$ ).

II.3. A trained incident command officer at the Battalion Chief (BC) level must be on duty at all times. This person will respond as Incident Commander to each reported working incident, all times, all shifts. Until the $\mathrm{BC}$ arrives on the scene, the first responding Captain shall assume the role of temporary incident commander as now ( $\operatorname{Rec}$ 9.3.3.3).

II.4. A trained Safety Officer must be available on each shift for attendance at working incidents. Captains shall be so trained, since HFD protocols assign them this responsibility. Additional personnel also should be so trained so that the assignment may de delegated. (Rec 9.3.3.4).

II.5. Sufficient personnel must be trained as hazmat technicians to assure a six person response force available each shift, as now $(\operatorname{Rec}$ 9.3.3.5).

II.6. The appropriate recommendations of the Draft Hanford Site Emergency Medical Plan identified below shall be instituted.

- $\quad$ Each DOE-RL and contractor supervisor is responsible for the safety of his/her work group. This responsibility includes the communication of designated first responders and the location of and procedures for use of the first aid kits. Contractors are responsible for insuring employees are knowledgeable in the use of the 911 system.

- $\quad$ Each employee is responsible for recognizing and responding to a life or limb threatening illness/injury in a co-worker by activating 911 for emergency medical response. 
WHC-SP-1180, Vol. 1

- $\quad$ Each employee is responsible for knowledge of and access to the work group's designated first-responder to initiate immediate first-aid and CPR (if needed) while awaiting the arrival of Hanford site EMS.

$(\operatorname{Rec}$ 9.3.3.8)

II.7. The HFD and the signatory departments shall delineate--if necessary any and all restrictions related to the mutual aid that are defined in the mutual aid agreements (Rec 9.3.3.12)

II.8. The 100 Area Station shall undergo only those modifications necessary to meet applicable OSHA, Life Safety code, and structural integrity requirements ( $\operatorname{Rec}$ 9.4.3.1).

II.9. Upgrade the existing 200 Area Station to meet all applicable codes and standards, or construct a new station at or near that site $(\operatorname{Rec}$ 9.4.3.2).

II.10. If new construction takes place at the 200 Station Site, the design shall incorporate adequate provisions for a communications/alarm/dispatch facility. Should the communications function be moved to another location, all applicable provisions shall be met $(\operatorname{Rec} 9.4 .3 .4)$.

II.11. The 400 Area Station shall undergo those modification necessary to meet applicable OSHA, Life Safety Code and structural integrity requirements (Rec 9.4.3.6).

II.12. Postpone the decision to construct a new 300 Area Station until a decision is made concerning a Richland-HFD combined Station or an outsourcing arrangement. If such a decision is not forthcoming, proceed with planning for a new 300 Area Station on site (Rec 9.4.3.7).

II.13. Maintain as a minimum, one first-line Quint at each operational fire station (Rec 9.5.6.1).

II.14. Maintain a minimum of four reserve triple combination pumpers for the entire Hanford site ( $\operatorname{Rec}$ 9.5.6.2).

II.15. Maintain a minimum of one reserve ambulance unit for the entire Hanford site (Rec 9.5.6.3).

II.16. The HFD alarm, dispatch, and emergency communication systems for fire, rescue, and EMS services shall comply with the applicable requirements of NFPA 1221 and shall have as a minimum the following performance characteristics:

1. Fast, direct access by automatic alarm systems (as now) and by telephone callers (not now available).

2. Call switch-over capability from the 9-1-1 call taker (Public Safety Answering Point or PSAP).

3. Customized computer aided dispatch (CAD) hardware and software. 
4. Customized computer aided systems to handle automatic alarm supervision and testing quickly and accurately.

5. Radio communication capability throughout the service area, with sufficient frequencies to handle routine business, emergency dispatch, tactical incidents, mutual aid communication, and recall of off-duty personnel by two-way pagers.

6. Capability to efficiently transmit data to the MDTs.

7. FAX capability to Stations, and MDT print-out capability to vehicles.

8. System redundancy.

9. Capability of being operated by a single dispatcher in medium volume call situations.

$(\operatorname{Rec}$ 9.6.3.1)

II.17. The HFD alarm, dispatch, and emergency communications system shall have the following process characteristics:

1. Capability of handling simultaneous events.

2. Capability of maintaining a continuous flow of information during a working incident while handling additional dispatches and firefighter recalls.

3. Capability of announcing relevant weather conditions, including wind speed and direction, during incidents for tactical purposes as now.

4. Capability of announcing "time into incident" in five minute increments for incident command purposes as now.

5. Capability of handling all calls for mutual aid.

6. Capability of notifying all relevant agencies promptly of incidents, and coordinating all responses as now.

7. Capability of handling EMS dispatches using standard protocols for advising EMS callers.

$(\operatorname{Rec}$ 9.6.3.2).

II.18. Design and implement a selective off-duty recall system with the following features:

- Rapid and simple transmission of the recall by single person

- $\quad$ Selective or small group or large group recall

- Recall transmission capability over long distances

- Responder to transmission point feedback capability

$(\operatorname{Rec}$ 9.6.3.7).

II.19. Quick Access prefire plans shall be accessible for personnel use within all first run units (Rec 9.7.10.1).

II.20. Prefire plans and quick access prefire plans shall be developed for all facilities and areas with significant hazards (Rec 9.7.10.2).

II.21. Hazmat incident operating guidelines shall be completed ( $\operatorname{Rec} 9.7 .10 .4)$.

II.22. The pre-incident exercises and drills which involve the HFD should as a minimum be continued at a level and frequency which currently exists ( $\operatorname{Rec} 9.7 .10 .7)$. 
II.23. Periodic large scale training exercises which activate the firefighter rapid recall system, and utilize T\&S FF in line positions shall be conducted (Rec 9.7.10.10).

II.24. The HFM Office shall be modified to incorporate the following:

- Increase the number of fire inspector positions from one to two FTEs.

- Assign one FTE secretary to the Fire Marshal's office

- Remove administration and supervision of the HFD training program from the Fire Marshal's office.

- Augment the Site's Public Safety Education program by assigning 0.5 FTE time of one Fire Inspector to the program, including teaching fire extinguisher and related safety classes to workers.

- Maintain coordination between the Fire Marshal's office and the Hanford Fire Protection Forum.

- $\quad$ Establish an HFD internal standing committee (chaired by the Fire Marshal, with HFD officer representation) charged with on-going responsibility for maintaining inter-shift coordination of prevention efforts.

(Rec 9.8.3.1).

II.25. The following recommendations are designed to help assure continuing compliance Site-wide with the necessary and relevant fire and related safety codes and directives:

- $\quad$ Expand the permitting system to include the process outlined in NFPA 1, section 1-15. These may include: explosives, LP-gases, storage of oxidizers and organic peroxides, and use of tar kettles on roofs.

- Ensure that FM authority extends to private businesses moving onto the Site and to all contractors. Include construction plan approval.

- Operate as large municipalities do, and be sure the Fire Marshal's responsibility and authority extend to all new operations--public or private--which locate on the Site.

- Prepare a booklet--"Advice from the Hanford Fire Marshal"--for widespread distribution on site.

- Prepare a fire and related safety video tape for showing to new employees and at manager's meetings.

(Rec 9.8.3.2)

II.26. When it is evident that continuing medical education and firefighter training for T\&S FF may result in a failure to meet applicable fire protection system requirements, applicable training shall be conducted on off-shift hours ( $\operatorname{Rec}$ 9.9.3.3).

II.27. The Training and Resources Section shall be reorganized under a Team Leader Training Officer, with one additional full time Training Officer, and a full-time secretary. The Team Leader shall report to the Deputy Fire Chief (Rec 9.10.3.1). 
II.28. The existing three year training topic outline requires expansion by a representative training curriculum task force. The expansion shall relate each training topic to a comprehensive performance based plan which provides for all components of the training program (Rec 9.10.3.3).

II.29. The following specialized training needs for HFD emergency response personnel (some of which are already addressed in the training curricula) shall be met:

- Advanced work in hazardous materials incident mitigation

- Advanced work in radiological incident mitigation

- Personnel safety in work environments containing hazardous materials and radioactive materials

- $\quad$ Fire suppression and mitigation efforts using a variety of extinguishing agents

- Extensive application of regulatory and national standard drivers

- $\quad$ Advanced technical rescue specialties including confined space entry and rescue

- Wildland fire suppression

- Ground cover fires at hazardous waste storage sites

- Work with advanced built-in fire protection systems

- $\quad$ Rope rescue

(Rec 9.10.3.4)

II.30. Upgrade the centralized HFD training facility to accommodate the various types of hands-on training required by response personnel or provide alternate locations for all training (Rec 9.4.3.5 and 9.10.3.6).

II.31. Identify areas or specific fire hydrants on specific systems where insufficient water is available for fire protection purposes. Hydrants which will not meet the fire departments' needs should be easily field identifiable (e.g. painted a specific color). Develop a plan to address fire department activities based on water supply limitations (Rec 9.12.3.1).

II.32. Upgrade the existing water supply systems to provide adequate water for fire protection needs (See WSA for details) (Rec 9.12.3.2).

II.33. Assure limitations of water supply at specific facilities are addressed in prefire plans (Rec 9.12.3.3). 


\subsection{PRIORITY III}

III.1. Maintain record keeping in accordance with national fire incident reporting system formats (NFPA 901) (Rec 9.2.2.3.1).

III.2. The Site shall implement a CPR training program which ensures that a cadre of personnel at each facility, or work site are CPR qualified and equipped to provide emergency CPR during normal hours of occupancy (Rec 9.3.3.10).

III.3. As the site operations change or transition, HFD should examine methods to minimize the response time to an EMS incident $(\operatorname{Rec}$ 9.3.3.11).

III.4. Provide additional administrative space and restroom facilities to the existing administrative wing or construct an administrative building at an approved site (Rec 9.4.3.3).

III.5. Perform seismic evaluations to determine the ability of all fire stations to maintain all essential services immediately following a seismic event. Criteria for evaluation shall as a minimum, reflect requirements stipulated by the 1991 UBC for Essential Facilities or site specific seismic requirements approved by DOE. Perform any and all required station modifications necessary to maintain all essential services immediately following a seismic event $(\operatorname{Rec}$ 9.4.3.8).

III.6. Obtain a mobile emergency Command-communications vehicle for use by all emergency agencies on Site (Rec 9.5.6.4).

III.7. Obtain a mobile decontamination unit for use at emergency hazardous material incidents and the decontamination of personnel (Rec 9.5.6.5).

III.8. Expand the SRID to include a complete inventory of the required items for Access and Cardiac Care stipulated by WAC-246-976-390 (Rec 9.5.6.6).

III.9. The dispatcher job shall be assigned to a minimum of one trained person on each shift. There also must be a quick responding back-up dispatcher for each shift ( $\operatorname{Rec}$ 9.6.3.4).

III.10. Install a "quick-call" trouble buzzer system in the communications room and a deadman notification system on all in-coming alarms and 911 calls ( $\operatorname{Rec}$ 9.6.3.5).

III.11. EMS Dispatchers shall be trained in EMS dispatch operations, procedures, and protocols ( $\operatorname{Rec}$ 9.6.3.6).

III.12. The HFD shall evaluate the necessity of HFD notification 24-hours in advance of confined space entry $(\operatorname{Rec} 9.7 .10 .3)$.

III.13. The HFD shall evaluate the feasibility of providing preventive, maintenance and repair services to PNL and FFTF facilities (Rec 9.9.3.1). 
III.14. Applicant certification requirements should include the following:

- Firefighter level 1 (as stipulated by NFPA 1001)

- EMT, "First Responder" level (as stipulated by WAC-246-976) (Rec 9.9.3.2)

III.15. The HFD Programs for providing Fire Protection Systems Administration and Testing and Fire Protection Systems Maintenance shall be evaluated periodically to ensure that personnel resources are commensurate with the level of service that is required (Rec 9.9.3.4).

III.16. All Station Captains and Battalion Chiefs shall maintain current certification at the fire instructors level 1 (as defined by NFPA 1041) in order to conduct in-service training and the necessary monitoring and oversight $(\operatorname{Rec}$ 9.10.3.2).

III.17. Appoint a standing advisory committee on training, with representation from all levels and types of HFD members, having the Deputy Chief as chair. This group would meet periodically to review training needs from the various types and levels of members, the training curriculum and training schedule, performance evaluations, and training resources.

$(\operatorname{Rec}$ 9.10.3.5)

III.18. The following recommendations are made to improve the quality of the in-station training program:

- Hold all stations to a minimum of one hour daily in-service training set by a mandated lesson plan. This training will be evaluated.

- Develop standardized instructional packages to be sent or transmitted to each station, such as video lessons, slide packages, and self-instruction and evaluation booklets.

(Rec 9.10.3.7)

III.19. Use selected off-Site training and visiting experts to enhance HFD training. Continue programs which send HFD Training Officers and in-service instructors to specialized "train-the-trainer" programs for advanced course work (Rec 9.10.3.8). 
THIS PAGE INTENTIONALLY LEFT BLANK 


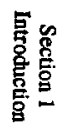

展 - 
THIS PAGE INTENTIONALLY LEFT BLANK 


\section{SECTION 1 - INTRODUCTION}

This report presents the results of a comprehensive third party needs assessment of the Hanford Fire Department (HFD), conducted by Hughes Associates Inc. The assessment was commissioned with the intent of obtaining an unbiased report which could be used as a basis for identifying needed changes/modifications to the fire department and its services. This report serves several functions: (1) it documents current and future site operations and associated hazards and risks identified as a result of document review, site and facility surveys, and interviews with knowledgeable personnel; (2) it describes the HFD in terms of organization, existing resources and response capabilities; (3) it identifies regulatory and other requirements that are applicable to the HFD and includes a discussion of associated legal liabilities; and (4) it provides recommendations based on applicable requirements and existing conditions. Each recommendation is followed by a supporting statement to clarify the intent or justification of the recommendation.

This report will be followed by a Master Plan document which will present an implementation method for the recommendations (with associated costs) considered to be essential to maintaining adequate, cost effective emergency services at the Hanford site in the next five to seven years. 
THIS PAGE INTENTIONALLY LEFT BLANK 


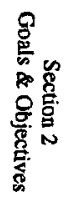


THIS PAGE INTENTIONALLY LEFT BLANK 


\section{SECTION 2 - GOALS AND OBJECTIVES}

As identified in the task's Statement of Work, there are several goals and objectives associated with this effort. Goals are as follows:

(1) Analyze the on- and off-site risks in terms of consequences and potential magnitude, associated with Hanford's current and planned (5 to 7 years), missions and activities. Risks within the scope of this report include the following:

- fire, earthquake, or other calamity in site buildings and facilities including radiologically contaminated facilities and tank farms;

- $\quad$ wildland fires;

- incidents or accidents involving radiation spills or spreads resulting from the on or off site transportation of radiological material;

- spills of non-radiological or mixed chemical wastes;

- risks associated with the storage and handling of ignitable and reactive waste (includes risks associated with tasks such as the repackaging of swollen waste containers);

- medical risks associated with a work force of 10,000 to 12,000 performing a wide range of tasks including decontamination and demolition activities in aging facilities with limited maintenance; and

- rescue incidents involving the need for specialized equipment and training. These include confined space, high-angle, cave-ins, and other rescue incidents that are typically addressed only by emergency teams who are appropriately trained and equipped.

(2) Provide a basis for determining the level of fire and emergency response services required to adequately respond to the current and the near future (5 to 7 year) risks facing the Hanford site which can be used for development of a master plan. Included in this determination are staffing requirements, recommended fire station locations, vehicle and equipment needs;

Once the Needs Assessment is completed, the final goal of the Third Party Assessment is the development of a master plan which can be used to implement changes in service recommendations. This plan will be provided in a separate document. 
Objectives to achieve these goals are also defined in the Statement of Work. Objectives include the following:

(1) Identify the level of fire suppression, fire prevention, emergency medical, rescue, HAZMAT, fire system testing and maintenance services and other services required to be in place at Hanford in order to be in compliance with DOE Order 5480.7A, Fire Protection and other DOE, state and national requirements applicable at the time of the assessment;

(2) Evaluate the legal liabilities to the company, the government, and fire department management that could result from providing emergency services at a level less than that required;

(3) Evaluate the current capabilities of the HFD to meet the levels of services defined above;

(4) Identify any shortcomings in meeting the specified levels of service;

(5) Recommend changes considered beneficial from the standpoint of good practice or cost effectiveness.

Additional objectives are also provided in the Statement of Work for the Master Plan phase.

Each goal and objective is addressed in this Needs Assessment. The report is formatted to assist in identification of the goals and objectives.

Report presentation is as follows:

- $\quad$ Section 1 is the introduction;

- Section 2 identifies the goals and objectives;

- Section 3 summarizes the assumptions and limitations;

- $\quad$ Section 4 describes the assessment procedure;

- Section 5 describes the Requirements and Criteria that apply to the HFD;

- Section 6 is a service area description. It summarizes the current and planned ( 5 to 7 years) mission and activities of the Hanford Site to address in the analyses (Goal 1);

- Section 7 analyzes the on- and off-site risks associated with the mission described in Section 6 as required by Goal 1;

- Section 8 summarizes the HFD service demand history to allow quantification of current demands; 
- Section 9 contains the Needs Assessment. This section (1) summarizes existing HFD conditions by functionai area, (2) cites applicable requirements/criteria (Goal 2 and Objective 1), and (3) provides recommendations for upgrades to comply with recommended levels of service (Objectives 3,4 , and 5);

- Section 10 addresses Objective 2 by identifying the legal liabilities that could result from providing emergency services at a level less than that required; and

- Section 11 summarizes the recommendations which are provided as a result of the assessment. 
THIS PAGE INTENTIONALLY LEFT BLANK 
THIS PAGE INTENTIONALLY LEFT BLANK 


\section{SECTION 3 - SCOPE, ASSUMPTIONS AND LIMITATIONS}

The scope of the report is limited to those services and resources that are currently provided by or considered to be part of the HFD or is required by DOE Order, or contractual obligation. This is considered to be comprehensive in that it is intended to address all major services and resources of the HFD that are necessary to carry out its intended mission. Evaluation of HFD related services and specific fire department procedures provided by others, such as contractor fire protection and site emergency preparedness organizations, is excluded.

Background information regarding site missions and operations is based on information found in the 1996 Baseline Environmental Management Report (draft) (DOE, 1995). This information is considered to be the most representative indicator of the site's current and near future mission, goals, and objectives. Information relating to the HFD organization, personnel, resources, and services is based on interviews with HFD management staff and the most current documentation available at the time of assessment.

Identification of representative site risks is based on interviews with HFD personnel, cognizant DOE and contractor fire protection engineers, and review of site and facility documentation. Analysis of site risks, in terms of consequences and potential magnitude is wholly reliant upon information provided in the Hanford Emergency Assessment Resource Manual (HEARM), facility Safety Analysis Reports (SARs) and other safety analysis documentation, Fire Hazard Analysis (FHAs), Fire Risk Assessments, and prefire plan documentation.

The site water supply description and associated conclusions and recommendations are based on existing documentation available at the time of the assessment. This assessment excludes evaluation of hydrant spacing and placement. Water supply information provided in the prefire plans is assumed to be given at $20 \mathrm{psi}$ residual (at the hydrant when flowing the stated gallons per minute) and reasonably representative of the available water supply.

DOE Order 5480.7A, Fire Protection has been canceled by DOE Headquarters. DOE Orders 420.1, Facility Safety and 440.1, Worker Protection Management for DOE Federal and Contractor Employees are expected to replace this order. Cancellation of the an Order by DOE Headquarters does not, by itself modify or otherwise affect any contractual obligation to comply with such an order. The cancelled order is assumed to remain in effect until the WHC contract is modified to delete the reference to the requirements of the canceled order.

With the noted exception of DOE Orders 420.1, 440.1, and the DOE Implementation Guide, identification of major requirements from Federal, State, and other sources, as well as nationally recognized industry standards and expert opinion, is based on criteria which are considered to apply at the time of the assessment. References to criteria cited by 420.1 and 440.1 are provided under the assumption that the HFD will eventually be subject to compliance with the requirements of these orders. 
Based upon guidance stipulated within the DOE 420 Implementation Guide, this needs assessment assumes that there is only one emergency incident (such as a fire) occurring on site, with a casualty requiring emergency medical assistance. Simultaneous responses to separate events (such as dual Hazmat incidents) are not considered to be a requirement of HFD baseline resources and could exceed HFD first response capabilities. However, the needs assessment describes how the HFD can respond if a second incident occurred while the first was underway. Consequences from a sitewide catastrophic event have not been previously analyzed and are not considered to be within the scope of the baseline needs assessment. However, the needs assessment describes existing HFD capabilities to handle mass casualty incidents.

Significant changes in the applicable requirements, referenced documents, information provided to the assessment team by WHC, or other information that this report is based upon warrant re-evaluation of the conclusions and recommendations of the HFD Needs Assessment.

WHC prepared a Standards/Requirements Identification Document (WHC, 1995c) for the Fire Protection Functional Area. While this document was supplied to the Assessment Team, review and/or evaluation of the adequacy of this document as it relates to the HFD is not within the scope of this assessment.

The Washington Public Power Supply System maintains a fire brigade. Review of the fire brigade functions and capabilities is not part of this assessment. 
葸

密

융 
THIS PAGE INTENTIONALLY LEFT BLANK 


\section{SECTION 4 - HFD NEEDS ASSESSMENT PROCEDURE}

\subsection{BACKGROUND}

This report was written by the HFD Needs Assessment Team. The team member make-up (Appendix A) was intended to provide subject matter expertise in all areas detailed in the RFP; specifically, fire department services, emergency medical services, site hazards and events, and associated legal liabilities. The content and recommendations of this Report result from reviews of available documentation, interviews with select HFD staff at all levels, interviews with site and facility fire protection representatives, discussions with DOE and WHC staff who work or interface with (by organization necessity) the HFD, walkdowns of representative facilities, and observations of HFD drills, classes and emergency responses.

\subsection{REPORT DEVELOPMENT}

Prior to initiation of the needs assessment, a general report outline and a list of required documentation were developed by the HFD needs assessment team and submitted to the HFD senior management. A kick-off meeting with representatives of DOE fire protection, HFD senior management, facility fire protection and general site support was conducted to discuss the scope and purpose of this effort and to identify points of contacts for future interviews, and information gathering. For coordination and information management purposes, virtually all documentation that was requested in support of the needs assessment was routed through HFD management. A temporary office was established at the 200 Area station to facilitate the collection and processing of numerous documents, to conduct interviews and serve as a meeting place for team member discussions. Team members were afforded opportunities to visit any "unclassified" facility or area that did not require security clearances or specialized training and interview HFD, facility, or site personnel deemed necessary to the completion of the needs assessment. Full support in these efforts was provided by HFD senior management.

Questionnaires relating to site hazards, emergency events, fire department operations, etc. were prepared by the HFD needs assessment team and distributed to HFD and site personnel who were identified as points-of-contact in the kick-off meeting. The questionnaires were intended to solicit pertinent information relating to the HFD. Information obtained by distribution of the questionnaire was followed by HFD Needs Assessment Team member interviews in order to clarify or document specific events, and/or information that were provided by HFD senior management.

Upon substantial completion of the information gathering phase of the assessment, each team member was tasked (by area of expertise) with describing and evaluating HFD service levels and capabilities. This evaluation was based on applicable Federal, State, Contractual and other requirements as well as the potential site hazard and events that were identified. The codes, standards, orders, and other criteria cited in the applicable requirements/criteria subsection (of section 9) are not meant to be all inclusive, but rather illustrate codes, standards or other major criteria applicable to the recommendations and supporting statements that are provided. Recommendations resulting from these evaluations 
WHC-SP-1180, Vol. 1

were presented in a Needs Assessment Team meeting for discussion. Recommendations presented in this report reflect the majority or unanimous consensus of the Needs Assessment Team. Supporting statements which accompany the recommendations are provided to substantiate and/or explain the recommendation.

A draft report was submitted to HFD senior management for distribution and review by cognizant site personnel. All comments which were generated in Response Comment Record (RCR) format were formally dispositioned by consensus of the Needs Assessment Team and are reflected accordingly in the final report. 


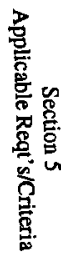


THIS PAGE INTENTIONALLY

\section{LEFT BLANK}




\section{SECTION 5 - APPLICABLE REQUIREMENTS/CRITERIA}

The organization and scope of services of the HFD are determined by regulatory requirements, national standards (primarily those issued by the National Fire Protection Association (NFPA)), accepted fire protection industry standards, and expert opinion. The following primarily govern and impact on the organization, deployment, operations, and practices of the HFD:

\section{Mandatory Requirements (Firefighting):}

DOE ORDER 5480.7A states that "a fully staffed, trained and equipped fire department/brigade shall service all DOE facilities, except as determined by the PSO" (staffing levels are included in the DOE Resource Manual). It also states a mutual aid contract may be entered into. Additionally, this order states that all NFPA codes and standards are mandatory. NOTE: At the time of writing, 5480.7A was the current applicable order at the Site. However, 5480.7A has been replaced by DOE Orders 420.1 and 440.1 and the associated implementation guide. The site has not officially modified WHC's contract to incorporate 420.1 or 440.1 . The content of the Orders is similar to that of DOE Order $5480.7 \mathrm{~A}$ as are the resulting implications for the HFD.

DOE Order 5480.5 (January 1991) Safety of Nuclear Facilities," requires "Operational Safety Requirements (OSR) setting forth the approved limitation of safe operations." Hanford OSRs are based on the ability of the site fire department to respond to and suppress a fire within a timely manner.

Westinghouse Hanford Company Standards/Requirements Identification Document (S/RID)(WHC, 1996). This document identifies standards/requirements developed by Westinghouse Hanford Company which are considered necessary for the safe operation of the site and its associated facilities. This document, if approved by DOE requires that the fire department adhere with the requirements specified in the Washington State Administrative Code (WAC). Also, the WACs are to be reviewed at regular intervals to verify that Fire Department activities comply with the specified requirements.

Applicable National Fire Protection Association Codes and Standards are Mandatory as stipulated by DOE Order $5480.7 \mathrm{~A}$.

DOE Order 5480.3A (July 1985), "Planning and Preparedness for Operational Emergencies," requires development and maintenance of emergency planning, preparedness, and response capabilities in order to minimize the consequences to workers, national security, the public, and the environment from incidents involving DOE operations.

DOE Order 151.1 (September 1995), "Comprehensive Emergency Management System," has many references that address the requirement of the emergency response organization in all types of emergencies. It also addresses the issue of having an Incident Command Structure within the organization. 
DOE Order 6430.1A sets forth the level of competency for any organization providing manual fire fighting for a DOE Facility (must meet NFPA 1410).

DOE Order 5480.4, "Environmental Protection, Safety and Health Protection" (5/15/84), provides requirements for the application of mandatory standards, and references environmental protection, safety, and health standards.

10 CFR Part 835.1302, "Emergency Exposure Situations," stipulates that the risk of injury to individuals involved in rescue and recovery operations shall be minimized and provides dose limit guidelines for control of emergency exposures.

OSHA 29 CFR 1910.38, "Employee Emergency Plans and Fire Prevention," requires preplanning for fire emergencies and the training of employees in fire prevention plus extinguisher training.

OSHA 29 CFR 1910.134, "Respiratory Protection," addresses all the requirements relating to respiratory protection.

EPA Superfund Amendment and Reauthorization Act (SARA) Title III requires that employers, building and site managers must make MSDS information available for fire department use.

\section{Non-mandatory requirements but recommended practices:}

Federal Emergency Management Agency (FEMA) Integrated Emergency Management System (IEMS) addresses Incident Command.

American National Standards Institute (ANSI) 3.8.4-1987 Criteria addresses maintaining emergency response capabilities.

ANSI 3.8.3 Criteria relates to emergency response plans and implementing procedures.

\section{Mandatory Requirements (Emergency Medical Service):}

DOE Order 5480.8A (October 1992), "Contractor Occupational Medical Program," outlines requirements of emergency medical response capabilities, first aid and other services performed by fire department paramedics.

DOE Order 151.1, "Comprehensive Emergency Management System," has several issues that address response to operational emergencies and the necessity to be prepared to handle these.

DOE Order 5500.3A (April 1991), "Planning and Preparedness for Operational Emergencies," has requirements setting forth emergency medical support necessary on site at emergencies.

OSHA 29 CFR 1910.120, "Hazardous Waste Operations and Emergency Response," requires medical personnel on the scene of hazardous material emergency response operations. 
OSHA 29 CFR 1910.119, "Process Safety Management of Highly Hazardous Chemical," addresses the need for planning emergency response to accidents.

OSHA 29 CFR 1910.151, "Medical Service and First Aid," addresses medical services and first aid requirements for a site such as Hanford.

OSHA 29 CFR 1910.1030, "Occupational Exposure to Bloodborne Pathogen," addresses how to handle bloodborne pathogen.

OSHA 29 CFR 1910.134, "Respiratory Protection Requirements," includes a number of drivers for firefighters, both in training and performance.

Department of Transportation (DOT), "Emergency Medical Technician Training Program." This document sets the level of training required for emergency medical technicians.

Additional requirements of Washington State and the local counties are listed in EMS sections.

\section{Additional Requirements (Hazardous Material Mitigation):}

DOE 5480.7A, "Fire Protection," requires contractors to establish a capability to ensure that there not be "...an on-site or off-site release of radiological and other hazardous material that will threaten the public health and safety or the environment."

DOE Order 151.1, "Comprehensive Emergency Management System," requires all DOE Sites to plan for and declare an operational emergency when an event or condition requires time urgent response from outside the immediate/affected site/facility or area of incident. Mitigation of incident is part of the planning effort.

DOE Order 5480.11 (June 1992), "Radiation Protection for Occupational Workers," outlines the training requirements for emergency responders.

OSHA 29 CFR 1910.120, "Hazardous Waste Operations and Emergency Response," provides protection for workers who respond to hazardous materials events from their regular workstations (fire brigades, emergency medical teams, etc.) by requiring response personnel to be trained to a particular level. According to the regulation, a facility must have an emergency response training program for emergency responders.

40 CFR 300-311, "Comprehensive Environmental Response and Liability Act," (CERCLA) (1980) is commonly known as "Superfund." The main thrust of CERCLA is to ensure proper response to and cleanup of hazardous material spills and to restore abandoned hazardous waste disposal sites.

40 CFR 350-372 SARA Title III, the Emergency Planning and Community Right-to-Know Act of 1986, is often referred to as EPCRA or SARA Title III. SARA Title III contains four major sections. It specifies requirements for state and local governments which impact fire departments. 
40 CFR 240-280, "Resource Conservation and Recovery Act." This law is intended to be a "cradle to grave" concept for hazardous waste that includes recycling, conservation, and minimization. Subtitle $\mathrm{C}$ of RCRA states standards and regulations for proper management of hazardous wastes by the generator and transporter. It includes standards for the treatment. storage and disposal of the wastes; for contingency planning; for emergency response equipment; and for emergency response organizations.

49 CFR 171-195, "Hazardous Material Transportation Act," regulates transportation by all modes except bulk shipments on waterways. Regulations provide guidance in the area of placarding and labeling of vehicles and containers, preparation of shipping papers and manifests, and packaging requirements. Emergency responders need to be knowledgeable of the placarding and labeling of vehicles and containers required in this act in the event they respond to a transportation event involving hazardous material.

40 CFR 112, "Spill Prevention Control and Countermeasure" (SPCC), addresses the issue of developing plans on how one intends to handle spills. Mainly deals with petroleum-based products.

\section{Mandatory Requirements (Environmental Protection Agency (EPA)):}

40 CFR 68, "Risk Management Program for Chemical Accidents Release Prevention," addresses training requirements for all emergency response personnel who may respond to an accidental release.

\section{Mandatory Requirements (Confined Space and Technical Rescue):}

DOE Order 5480.7A, "Fire Protection," requires that all sites "have access to a fully staffed, trained and equipped emergency response force." Section 4.C requires the contractor to establish a capability to "...provide an acceptable degree of life safety to DOE and contractor personnel and that there be no undue hazards to the public..."

OSHA 29 CFR 1910.146, "Confined Space," requires employers to prepare for emergency rescue of confined space workers.

\section{Mandatory Requirements (Incident Command):}

OSHA 29 CFR Rules and Regulations state "The Incident Command System shall be established by those employers for the incidents that will be under their control and shall be interfaced with the other organizations or agencies who may respond to such an incident."

\section{National Standards and Recommended Practices (General and Specific):}

Applicable National Fire Protection Association codes and standards are mandatory as stipulated by DOE Order 5480.7A. The National Fire Protection Association standards listed here are self-explanatory. Each has some impact on HFD operations. 
NFPA 1410 Training Standard on Initial Fire Attack

NFPA 1561 Fire Department Incident Management System

NFPA 1500 Fire Department Occupational Safety \& Health Program

NFPA 1521 Fire Department Safety Officer

NFPA 1002 Fire Department Vehicle Driver/Operator Professional Qualifications

NFPA 1001 Firefighter Professional Qualifications

NFPA 1021 Fire Officer Professional Qualifications

NFPA 1041 Fire Service Instructor Professional Qualifications

NFPA 471 Responding to Hazardous Materials Incidents

- $\quad$ Training

NFPA 473 Competencies for EMS Personnel

NFPA 1410 Training Standard on Initial Fire Attack

NFPA 1561 Fire Department Incident Management System

NFPA 1500 Fire Department Occupational Safety \& Health Program

NFPA 1521 Fire Department Safety Officer

NFPA 1404 Fire Department Self-Contained Breathing Apparatus Program

NFPA 1002 Fire Department Vehicle Driver/Operator Professional Qualifications

NFPA 1001 Fire Fighter Professional Qualifications

NFPA 1021 Fire Officer Professional Qualifications

NFPA 1041 Fire Service Instructor Professional Qualifications

NFPA 472 Professional Competence of Responders to Hazardous Materials Incidents

NFPA 1403 Live Fire Training Evolutions in Structures

NFPA 1406 Outside Live Fire Training Evolutions

NFPA 1420 Pre-Incident Planning for Warehouse Occupancies

NFPA 1035 Public Fire and Life Safety Educator Professional Qualifications

NFPA 1470 Search and Rescue for Structural Collapse Incidents

- Apparatus/Equipment

NFPA 1904 Aerial Ladder and Elevating Platform Fire Apparatus

NFPA 1901 Pumper Fire Apparatus

NFPA 1931 Design and Design Verification Tests for Fire Department Ground Ladders

NFPA 1932 Use, Maintenance and Service Testing of Fire Department Ground Ladders

NFPA 1500 Fire Department Occupational Safety \& Health Program

NFPA 1404 Fire Department Self-Contained Breathing Apparatus Program

NFPA 1961 Fire Hose

NFPA 1962 Care, Use and Service Testing of Fire Hose Including Connections and Nozzles

NFPA 1983 Fire Service Life Safety Rope

NFPA 11C Mobile Foam Apparatus 
NFPA 298 Foam Chemicals for Wildland Fire Control

NFPA 1972 Helmets for Structural Fire Fighting

NFPA 1902 Initial Attack Fire Apparatus

NFPA 1903 Mobile Water Supply Fire Apparatus

NFPA 1911 Service Tests of Pumps on Fire Department Apparatus

NFPA 18 Wetting Agents

- Off-Site Responses

NFPA 13E Fire Department Operations in Properties Protected by Sprinkler and Standpipe Systems

- Special Hazards

NFPA 1992 Liquid Splash-Protective Suits for Hazardous Chemical Emergencies

NFPA 1991 Vapor-Protective Suits for Hazardous Chemical Emergencies

- Personal Protective Equipment

NFPA 1999 Protective Clothing for Medical Emergency Operations

NFPA 1976 Protective Clothing for Proximity Fire Fighting

NFPA 1971 Protective Clothing for Structural Fire Fighting

NFPA 1500 Fire Department Occupational Safety \& Health Program

NFPA 1974 Protective Footwear for Structural Fire Fighting

NFPA 1973 Gloves for Structural Fire Fighting

NFPA 1992 Liquid Splash-Protective Suits for Hazardous Chemical Emergencies

NFPA 1981 Open-Circuit Self-Contained Breathing Apparatus for Fire Fighters

NFPA 1982 Personal Alert Safety Systems (PASS) for Fire Fighters

NFPA 1977 Protective Clothing and Equipment for Wildland Fire Fighting

NFPA 1975 Station/Work Uniforms

NFPA 1991 Vapor-Protective Suits for Hazardous Chemical Emergencies

OSHA 29 CFR 1910.120 Hazardous Waste Operation and Emergency Response

- Collateral Duties

NFPA 473 Competencies for EMS Personnel

NFPA 1581 Fire Department Infection Control Program

NFPA 472 Professional Competence of Responders for Hazardous Materials Incidents

NFPA 471 Responding to Hazardous Materials Incidents

\section{- $\quad$ Fitness/Medical}

NFPA 1500 Fire Department Occupational Safety \& Health Program

NFPA 1404 Fire Department Self-Contained Breathing Apparatus Program

NFPA 600 Industrial Fire Brigades

NFPA 1582 Medical Requirements for Fire Fighters 


\section{- $\quad$ Facilities}

NFPA 1500 Fire Department Occupational Safety and Health Policy

Note: The Westinghouse Hanford Company document, "Standards Requirements Identification Document for the Fire Protection Functional Area (SRID Draft C, 8/16/95) identifies the standards/requirements considered applicable to the HFD.

The S/RID is intended to be used as a baseline from which to compare the existing Fire Protection Program (of which the HFD is a part) for determination of the level of program definition and maturity, generation of implementing requirements and documents, existence of an overall site infrastructure and clearly defined interfaces with other relevant functional areas (WHC, 1995c).

\section{- Emergency Medical Service Program}

Washington Administrative Code (WAC) 246-976 delineates requirements for Ambulance Services. 
THIS PAGE INTENTIONALLY LEFT BLANK 
THIS PAGE INTENTIONALLY LEFT BLANK 


\section{SECTION 6 - HFD SERVICE AREA DESCRIPTION}

This section summarizes the major activities of the Hanford Site. A more detailed description of facilities and activities is provided in Appendix B. The purpose of this section is to identify the current mission and activities at the site.

\subsection{SITE OVERVIEW}

The Hanford Site is located in the southeast portion of Washington State. The Site occupies an area of 1,450 square kilometers (560 square miles) with the Columbia River flowing through and adjacent to it (Figure 6-1). The Hanford Site is relatively flat and semiarid with a mild climate. The major portions of the site are managed by DOE. Small portions of the Hanford Site are owned, leased, or administered by other governmental agencies.

The Tri-Cities is located directly downstream from the Hanford Site near the confluences of the Yakima, Snake, and Columbia river (DOE, 1993). Just southeast of the Site, approximately 100,000 people occupy the cities of Richland (southeast border of the Site), Kennewick (15 miles to the southeast), and Pasco (11 miles to the southeast)(DOE, 1995a).

\subsection{BACKGROUND}

In January 1943, the U.S. Army Corp of Engineers selected the Columbia Basin as the location for the Nation's first full-sized plutonium production operation. Selection criteria developed in 1942 called for a large, remote tract of land with room for a manufacturing area measuring at least 12 by 16 miles, space for laboratory facilities at least 8 miles from the nearest reactor or processing plant, and abundant water and electricity. The Hanford Site met these criteria, and plans soon were developed for building production reactors along the Columbia River (100 Area); processing plants and associated facilities on a plateau near the center of the Site (200 Area); and the fuel fabrication buildings, laboratories, and other support facilities near the Site's southern boundary (300 Area).

The U.S. Government established (in 1943) the Hanford Engineering Works along the banks of the Columbia River in Washington State to support the Nation's war-time effort to produce plutonium for the world's first nuclear weapons. In 30 months, three reactors, three chemical processing plants for recovering plutonium from irradiated fuel, and 64 underground storage tanks were constructed. A production facility was also built to support reactor fuel fabrication and other activities.

In the late 1940's, the Federal Government initiated a major expansion program in response to post-war tensions and the acquisition of nuclear technology by the Soviet Union. Between 1947 and 1955, additional plutonium production reactors were constructed, as well as 2 chemical fuel processing plants, 1 plutonium finishing plant, and 81 additional underground waste storage tanks. A ninth reactor ( $\mathrm{N}$ reactor) was built between 1959 and 1963 (DOE, 1995a). 
WHC-SP-1180, Vol. 1

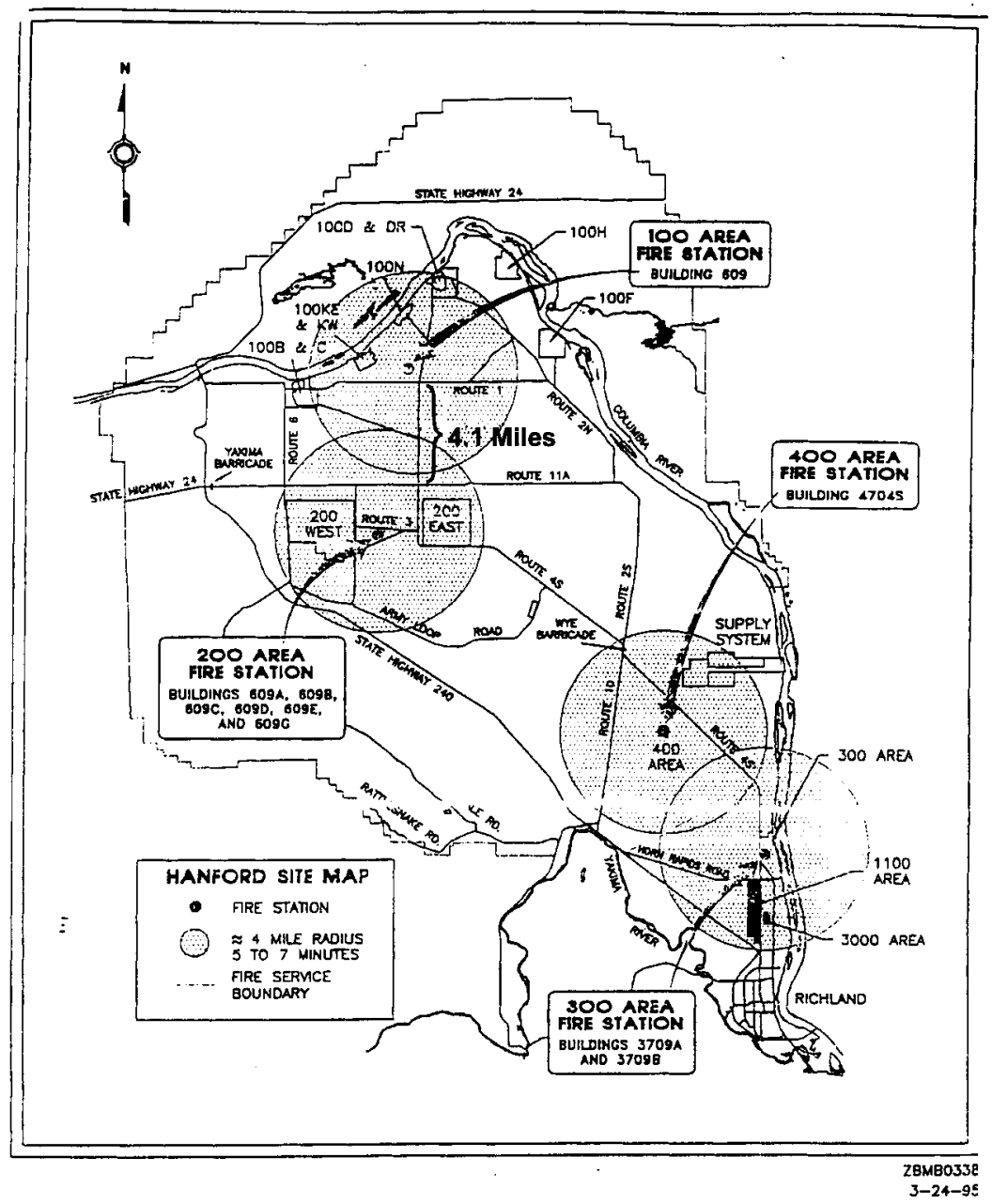

Figure 6-1. Picture of Site 


\section{Fuel Fabrication}

The uranium fuel fabrication processes for the first full-scale plutonium reproduction process in history were housed in the 313 Metal Fabrication Building and 314 Press Building. The mission of the 313 Building was to machine bare uranium rods to desired dimensions for use in Hanford's reactors, jacket ("can") the sized fuel elements, and test the jackets for proper bonding and sealing. The 314 Building contained equipment to extrude raw uranium billets into rods and then straighten and outgas them. Autoclaves that performed a final test on the jacket elements were also located in the 314 Building.

These new, untried, and unique fuel fabrication activities went through many process improvements and changes including the coextrusion fabrication process, developed in the early 1960s, for N Reactor fuel elements. The mission of the 333 Fuels Manufacturing Building was to manufacture fuel elements for the $\mathrm{N}$ Reactor using the new coextrusion process (DOE, 1995a).

\section{Fuel Irradiation}

Eight reactors were built in the 100 Areas in the 1940s and 1950s. The fuel fabricated in the 300 Area was inserted into these reactors and irradiated. Irradiated uranium discharged from the reactors was then chemically processed to recovered uranium and plutonium. A ninth reactor, N Reactor, became operational in 1963 and was used for both fuel production and steam generation. In addition to the production reactors, a test breeder reactor, the Fast Flux Test Facility is located in the 400 Area. This reactor was used to conduct fuel, materials, isotope and power experiments (DOE, 1995a).

\section{Chemical Processing}

Once the fabricated fuel had been irradiated in the production reactors, the fuel slugs were dissolved in acid and sent though chemical separation processes in facilities in the 200 Area where the plutonium was extracted. The processing buildings include the Plutonium Uranium Extraction Plant (PUREX), where spent fuel was processed to extract plutonium and unused uranium; the Uranium-Oxide Plant, to convert uranium nitrate to uranium oxide powder for recycling; and the Plutonium Finishing Plant (PFP) where plutonium metal was fashioned. In addition, Hanford had the use of B-Plant for bismuth phosphate processing and to separate and purify cesium and strontium for encapsulation; C-Plant (Strontium Semiworks) for separation and process development; S-Plant for separation through solvent extraction; TPlant for bismuth phosphate process separation and subsequently as a decontamination and repair facility; and U-Plant for chemical separation and processing (DOE, 1995a).

Beginning in 1964, plutonium production was sharply curtailed in response to the Nation's changing defense needs. By 1971, eight of the nine production reactors had been shut down. By 1972, all related fuel separation facilities, including the Plutonium-Uranium Extraction Plant, had ceased operations. In the early 1980s, the Plutonium-Uranium Extraction Plant and the Uranium Oxide Plant were briefly restarted but are now permanently shut down (DOE, 1995a). 
As a result of the reduction of plutonium production activities, the resources and capabilities of the Hanford Site were refocused toward developing nonmilitary applications of nuclear energy. Research programs included nuclear waste management, biological sciences, and environmental sciences. In the 1970s, the Energy Research \& Development Administration continued to emphasize energy research programs. During this period, a fullsize advanced test reactor, the Fast Flux Test Facility, and the Fuels and Materials Examination Facility were added in the 400 Area for large-scale nuclear fuels testing support of nuclear energy research (DOE, 1995a).

In 1989, the defense-related, plutonium production mission at Hanford ended. However, by that time, 40 years of production, using operating practices that were standard for the times, had resulted in the discharge of contaminated liquids into the soil, ground water, and the Columbia River; the disposal of millions of cubic yards of solid wastes throughout the area; and the accumulation of two-thirds of the Nation's stored inventory of all weapons-related radioactive waste (by volume). In addition, many industrial buildings remain (approximately 1,730), requiring significant annual resources for maintenance, monitoring, and stabilization (DOE, 1995a)).

On-site programmatic and general-purpose facilities total approximately 799,337 square meters $(8,604,000$ square feet) of space. Fifty-one percent is general-purpose space, such as office, support laboratory, shop, warehouse, and other support facilities. The remaining space are programmatic facilities such as processing, evaporator, filter, waste recovery, waste treatment, waste storage facilities, and research and development laboratories. More than half of the general-purpose and programmatic facilities are older than 30 years. Facilities designed to perform previous missions are being evaluated for reuse in the cleanup mission (DOE, 1993)

\subsection{CURRENT MISSION}

The current mission of the Hanford Site is to manage the facilities and inventories of special materials and remedy the environmental contamination caused by decades of activities related to plutonium production. Environmental Management efforts are specifically focused on (1) minimizing, processing, and storing radioactive and hazardous wastes generated during the years 1949 through 1972; (2) managing special nuclear fuels and material; (3) decontaminating and decommissioning facilities no longer in use; (4) Developing technologies that can be used to clean up Hanford and other environmentally contaminated sites, and (5) Remediation of the Site, to the extent possible, to its former state (DOE, 1995a). 
WHC-SP-1180, Vol. 1

A funding summary for fiscal year 1995 by program is illustrated in Table 6-1 beiow:

Table 6-1. Funding Summary for Fiscal Year 1995 (DOE, 1995b)

\begin{tabular}{|c|c|}
\hline $\begin{array}{l}\text { Fiscal Year } 1995 \text { Funding Summar } \\
\text { (as of October 1, 1994) }\end{array}$ & \\
\hline Programs & \$millions \\
\hline Environmental Management: & \\
\hline Waste Management & 1,000 \\
\hline Facilities Transition & 300 \\
\hline Environmental Restoration & 201 \\
\hline Technology Development & 73 \\
\hline Energy Research & 156 \\
\hline Other Programs & 203 \\
\hline Total & 1,933 \\
\hline
\end{tabular}

Future budget levels are expected to remain at FY 1995 levels or lower. Budgets are expected to reflect DOE's commitment to meet budget and legal obligations through costsaving measures, such as restructuring contractor workforces to achieve higher productivity and showing more results through increased efficiency (DOE, 1995b).

\subsection{SUMMARY OPERATIONS DESCRIPTION BY AREA}

Hanford Site facilities and activities are consolidated within "operating areas" that occupy about $6 \%$ of the Hanford Site's total available area. A general area description is provided below:

- 100 Areas-N Reactor and eight other deactivated plutonium production reactors used in previous nuclear programs. (This includes waste disposal sites associated with the operation of these reactors);

- 200 Areas-Chemical processing facilities; liquid and solid waste processing, packaging and storage facilities; applied technology facilities; and the main office buildings for Hanford's outer areas.

- 300 Area-Multiprogram laboratories for research and development; and

- 400 Area-Fast Flux Test Facility (FFTF) and related support facilities.

The main operating areas $(100,200,300,400)$ occupy only a small fraction of the Hanford Site. Other areas of the Site are covered by the 1100, 700 and 3000 Areas. The 
1100 Areas have been used primarily for nonweapons support operations (offices, bus garages, buffer spaces, research, warehouses, etc.) and have been very lightly developed. The Department of Energy's management headquarters and the Pacific Northwest Laboratory are located in the 700 and 3000 Areas (DOE, 1995a) Since the 700 and 3000 Areas are outside the initial response area of the HFD, descriptions of activities and operations within these areas are not provided in this report. The 600 Area includes all property within the boundaries of the Hanford Site not classified as a portion of another area.

\subsection{SITE MANAGEMENT STRUCTURE AND POPULATION}

The Hanford Site is operated by the U.S. Department of Energy, Richland Operations Office (RL). Operations and activities on the Hanford Site are managed by the Richland Operation Office through four prime contractors and numerous subcontractors (PNL, 1995). The principal contractors include:

- Battelle Memorial Institute (Battelle) operates the Pacific Northwest Laboratory (PNL), one of five national multiprogram energy research laboratories in the DOE complex and the research and development center for the Hanford Site.

- Bechtel Hanford Inc. (Bechtel) provides site environmental restoration activities as the Environmental Restoration Contractor. The Bechtel Environmental Restoration team includes three preselected subcontractors: CH2M Hill, IT Corporation, and ThermoAnalytical, INC (PNL, 1995).

- Hanford Environmental Health Foundation (HEHF) provides occupational health and environmental monitoring services.

- Westinghouse Hanford Company (WHC) (with ICF Kaiser Hanford Company and Boeing Computer Services, Richland, Inc. as subcontractors) provides engineering, operation, construction, maintenance, and computer services (DOE, 1995b).

The Hanford Site is currently managed through contracts with the contractors listed above. The major contractor on-site (WHC) is a management and operating contractor with the responsibility for managing the overall waste management and nuclear facilities and stabilization activities as well as the basic Site infrastructure components. In addition, the environmental restoration contractor (Bechtel) is in charge of all environmental restoration activities. A multi-program, national laboratory (PNL) supports the Environmental Management programs at Hanford. Occupational health and medical services are provided by the health services contractor (HEHF) (DOE, 1995a).

The DOE's contract reform initiatives have influenced the current contracting strategy at Hanford. Recently, the existing management and operations contract was renegotiated to include performance-based incentives and incentives for outsourcing various activities. In addition, a major piece of the Tank Waste Remediation Systems program is expected to be privatized. The current management and operations contract at the Site expires in March 1997, and the Department plans to award a new contract by June 1996 (duties will be 
transferred by October 1,1996). The request for proposal has a significantly different focus than the previous contract, emphasizing management of and integration with "best in class" subcontractors (DOE, 1995a).

Non-DOE operations and activities on the Hanford Site leased land include the commercial power production by the Washington Public Power Supply System WNP-2 reactor, and operation of a commercial low-level radioactive waste burial site by US Ecology, Inc. Immediately adjacent to the southern boundary of the Hanford Site, Siemens Power Corporation operates a commercial nuclear fuel fabrication facility, and a low-level radioactive waste decontamination, super compaction and packaging disposal facility. Kaiser Aluminum and Chemical Corporation is leasing the 313 Building in the 300 Area to use an extrusion press that was formerly DOE-owned. The National Science Foundation is building the Laser Interferometer Gravitational-Wave Observatory (LIGO) facility on the Hanford Site for gravitational wave studies (PNL, 1995).

\section{Site Population}

In October 1995, the estimated personnel population for the site excluding the 700 and 3000 areas, and the Washington Public Power Supply System, was 9,018, down from the 1994 population of 10,725 (Kaiser, 1995a). Estimates for existing and projected populations of each area are presented in Table 6-2. The existing population estimate shown in table 6-2 is a result of a "headcount" of personnel in occupied buildings within the HFD first responding area. The data are contained in Hanford "Soft Report (HFCR208R)" as of October 23, 1995. It excludes headcounts of personnel within the 700,3000, Richland, and Kennewick areas. The "headcount" population estimate compares reasonably well with the Kaiser population estimate report dated May 31, 1995 prepared for Westinghouse Hanford Company which provides a 1995 population estimate of 8,115 personnel for the 100,200 , 300,400 and 1100 areas (combined). The data in the Kaiser report is presented as establishing "...the baseline for developing short and long-term infrastructure plans for the Hanford Site." Per the Kaiser report, the projection was "...developed using all available information. Human resource, budget integration, and strategic planning information, as well as information direct from the programs." The Kaiser report includes a 30 year population projection for the site and a 5-year population projection by area. The 5-year data are illustrated in Table 6-2. As the mission life cycles matures, site planners expect a downward trend in the number of managerial, administrative, engineering, research, and other professional positions, and an upward trend in the number of technical, craft, laborer, and operator positions (DOE, 1995a). 
Table 6-2. Estimated Site Area Populations

\begin{tabular}{|c|c|c||}
\hline SITE AREA & $\begin{array}{c}\text { EXISTING POPULATION } \\
\text { (OCTOBER, 1995) }\end{array}$ & $\begin{array}{c}\text { PROJECTED } \\
\text { POPULATION (YR 2000) }\end{array}$ \\
\hline \hline 100 & 696 persons & $500-525$ persons \\
\hline 200 & 5007 & $3700-4,110$ \\
\hline 400 & 503 & $225-345$ \\
\hline 300 & 1869 & $1425-1710$ \\
\hline 1100 & 563 & $380-465$ \\
\hline 600 & 380 & $200-230$ \\
\hline \hline SITE AREAs TOTAL & 9018 & $6430-7385$ \\
\hline
\end{tabular}

\subsection{TRI-PARTY AGREEMENT OVERVIEW}

Many applicable regulations direct or control the cleanup of the Hanford Site. A key element in Hanford's compliance program is the Hanford Federal Facility Agreement and Consent Order. The Hanford Federal Facility Agreement and Consent Order, also referred to as the Tri-Party Agreement is particularly important because it includes specific milestones that drive a number of site cleanup activities. The Tri-Party Agreement is a legal agreement between the Washington State Department of Ecology, the U.S. Environmental Protection Agency (EPA), and DOE. The primary purpose of the Tri-Party Agreement is to provide a framework for coordination among these agencies to ensure compliance with the Resource Conservation and Recovery Act of 1976 (RCRA), and the Comprehensive Environmental Response, Compensation and Liability Act of 1980 (CERCLA). The Tri-Party Agreement outlines a program to clean up much of the Hanford Site (DOE, 1993). 


\section{THIS PAGE INTENTIONALLY}

LEFT BLANK 


\section{SECTION 7 - RISKS: ON- AND OFF-SITE}

The initial goal of this third party assessment of the fire department is to analyze the on- and off-site risks associated with Hanford's current and planned mission and activities as identified in Section 6. Risk is a measure of fire loss that combines (a) the potential for harm in the various scenarios and (2) the probability of occurrence of the potential scenario (Hirschler, 1992). Therefore, in order to evaluate the risks associated with the mission, the hazards, the consequences associated with an event, and the probability of that event must be identified. Section 7 addresses each of these components. A detailed listing by facility of the information obtained from a review of site documentation is contained in Appendix $C$. Information presented is limited to that identified in existing site documentation.

The HFD, as the designated site emergency organization will invariably be required to respond to these or similar events in order to provide control or mitigating actions. The identified events are not inclusive of all hazard/events which exist or could occur at the site. However, they are considered to be reasonably representative of the postulated accidents of the types of hazard/events that are likely to chailenge current fire department resources.

\subsection{SITE HAZARDS}

There are numerous hazards/events that are inherently associated with existing facility and site operations. Tours of facilities, interviews with facility fire protection engineers, review of safety documentation (i.e., Safety Analysis Reports, Interim Safety Analyses, Hazard Assessments), Hanford Emergency Assessment Resource Manual (HEARM), Fire Hazard Analyses, and Fire Risk Assessments resulted in the identification of representative site hazards and/or emergency events.

Hazards include fires, spills, explosions, structural collapse, and other events that can result in occupational worker exposure to radiation, dose consequences to on-site and off-site personnel, release of toxic material to the environment, occupational injury/illness, and/or significant monetary loss. Table 7-1 summarizes the identified hazards/events by area. 


\begin{tabular}{|c|c|c|}
\hline \multicolumn{3}{|c|}{ Table 7-1 Summary of Representative Hazards by Area } \\
\hline AREA & HAZARDS & SIGNIFICANT FACILITIES \\
\hline 100 & $\begin{array}{l}\text { Fire involving radiological materials; spill of radiological } \\
\text { materials; structural fire; airborne release of radiological } \\
\text { and/or hazmat materials; range fire; operational accidents; } \\
\text { construction accidents (includes D\&D activities); criticality } \\
\text { incidents. }\end{array}$ & $\begin{array}{l}\text { K-Basins; } \\
\text { N-Reactor; } \\
\text { C-Reactor \& other D\&D sites }\end{array}$ \\
\hline 200 & $\begin{array}{l}\text { Fire/explosion involving radiological materials; spill of } \\
\text { radiological materials; structural fire; airborne release of } \\
\text { radiological and/or hazmat materials; range fire; operational } \\
\text { accidents; construction accidents; criticality incidents. }\end{array}$ & $\begin{array}{l}\text { Central Waste Complex, Tank } \\
\text { Farms, B-Plant, T-Plant, PFP, } \\
\text { 222-S, TRUSAF, Purex, WSCF }\end{array}$ \\
\hline 300 & $\begin{array}{l}\text { Fire/explosion involving radiological materials; spill of } \\
\text { radiological materials; structural fire; sodium/potassium fire; } \\
\text { criticality, airborne release of radiological and/or hazmat } \\
\text { materials; range fire; operational accidents; construction } \\
\text { accidents; }\end{array}$ & $\begin{array}{l}\text { Bldg \#: } 324,315,325,327,331 \text {, } \\
337,340\end{array}$ \\
\hline 400 & $\begin{array}{l}\text { Fire/explosion involving radiological materials; spill of } \\
\text { radiological materials; structural fire; sodium fire; airborne } \\
\text { release of radiological and/or hazmat materials; range fire; } \\
\text { operational accident; construction accidents; }\end{array}$ & $\begin{array}{l}\text { FFTF, FMEF } \\
\text { WPPSS }\end{array}$ \\
\hline $\begin{array}{l}600 / \\
1100\end{array}$ & $\begin{array}{l}\text { Range fire } \\
\text { structure fire } \\
\text { operational accident }\end{array}$ & $\begin{array}{l}1100 \text { area; all wilderness areas } \\
\text { of the side }\end{array}$ \\
\hline OTHER & $\begin{array}{l}\text { Transportation accidents throughout site resulting in personnel } \\
\text { injuries, fire, and/or release of radiological or hazardous materials, } \\
\text { and technical rescue. }\end{array}$ & All areas \\
\hline
\end{tabular}

D\&D (Demolition and Decontamination)

PFP (Plutonium Finishing Plant)

TRUSAF (Transuranic Waste Storage and Assay Facility)

Purex (Plutonium-Uranium Extraction)

WSCF (Waste Sampling and Characterization Facility)

FFTF (Fast Flux Test Facility)

FMEF (Fuels and Materials Examination Facility)

WPPSS (Washington Public Power Supply System)

EMS (Emergency Medical Services) 


\subsection{PROBABILITY AND CONSEQUENCES OF HAZARDOUS EVENTS}

Section 7.2 identifies the on- and off-site risks in terms of probability and consequences of hazards/events associated with the current and planned site/facility missions and operations. Table 7-2 summarizes information obtained from documentation of site hazards. These hazards and events are identified by facility in greater detail in Appendix C. In addition, event classifications and probability and severity categories are defined in Appendix C.

The documentation identifies numerous credible events with significant on-site and/or off-site consequences. Intervention by the HFD is not specifically required by the existing documentation to allow the facilities to remain within their safety basis. However, it was noted that the FHA for Building 222-S credits the HFD for redundant fire protection and identifies the MPFL as $>\$ 50$ million. Irrespective of credit given by the fire hazard analysis and safety documentation, nearly all of the identified events which have the potential for significant on-site and/or off-site consequences will require an HFD Hazmat response in order to control or mitigate the event.

\subsubsection{Fire, Earthquake, or Other Calamity}

The majority of information available to the assessment team related to the risks associated with fire, earthquake, or other calamities. The consequences range from lethal exposures on-site and major illness off-site to limited exposure to on-site employees. Exposures thought to result in major injuries (i.e., Category I) are classified as extremely unlikely to occur (i.e., $10^{-6}$ to $10^{-4}$ possibility) or incredible (i.e., $<10^{-6}$ possibility). However, fires are credible events in all areas of the site.

\subsubsection{Wildland Fires}

Wildland fires are a current and anticipated event. The on- and off-site risks associated with range fires exist in all areas. The wildland fire can result in a radiological or hazardous material release affecting on- and off-site. History indicates that the largest fire department response has been the result of range fires. Several site facilities (e.g., SWBG) use range fires as a design basis or Fire Hazard Analysis exposure fire.

\subsubsection{Radiological Spills or Spreads Resulting from the Transportation of Radiological Materials}

Approximately 10,000 radioactive shipments occur each year on the Hanford site. Allowable radioactive inventory in each type of transportation container is specified in the SAR for packaging by DOT regulation. However, the possible release and on- and off-site exposure is postulated. 
WHC-SP-1180, Vol. 1

\begin{tabular}{|c|c|c|c|c|}
\hline \multicolumn{5}{|c|}{ Table 7-2 Summary of Representative Site Risks (Page I of 3) } \\
\hline $\begin{array}{l}\text { Potential } \\
\text { Risk }\end{array}$ & Hazard & Location & Probability & Potential Consequences \\
\hline 1 & Fire involving $\mathrm{K}$ Basin fuel & $\begin{array}{l}\text { 105K Fuel Storage } \\
\text { Basins }\end{array}$ & credible & $\begin{array}{l}\text { on and offsite release of } \\
\text { radionuclides }\end{array}$ \\
\hline 1 & $\begin{array}{l}\text { Fire involving mixed waste } \\
\text { materials }\end{array}$ & $\begin{array}{l}\text { Central Waste } \\
\text { Complex }\end{array}$ & $\begin{array}{l}\text { Extremely } \\
\text { unlikely }\end{array}$ & $\begin{array}{l}\text { On and offsite release of } \\
\text { radiological and/or hazardous } \\
\text { materials }\end{array}$ \\
\hline 1 & $\begin{array}{l}\text { Seismic event: rupture of } \\
\text { nitric acid tank, collapse off } \\
\text { burial tunnel }\end{array}$ & Purex & Credible & $\begin{array}{l}\text { Release of hazmat materials. } \\
\text { Acute release of radiological } \\
\text { materiais. }\end{array}$ \\
\hline 1 & Fire in glovebox & PFP & Credible & $\begin{array}{l}\text { Significantly below risk } \\
\text { acceptance guidelines }\end{array}$ \\
\hline 1 & Seismic event: glovebox fire & PFP & Credible & $\begin{array}{l}\text { Release of radiological } \\
\text { material. Possible personnel } \\
\text { injury. }\end{array}$ \\
\hline 1 & $\begin{array}{l}\text { Seismic event: structural } \\
\text { failure, container rupture, fire }\end{array}$ & TRUSAF & Unlikely & $\begin{array}{l}\text { On and offsite release of } \\
\text { radiological material }\end{array}$ \\
\hline 1 & Ventilation System fire & Bldg 222-S & Credible & $\begin{array}{l}\text { Airborne release of radiological } \\
\text { material }\end{array}$ \\
\hline 1 & Seismic Event w/fire & $222-S$ & Credible & $\begin{array}{l}\text { Airborne release of radiological } \\
\text { material }\end{array}$ \\
\hline 1 & $\begin{array}{l}\text { Seismic Event: fire involving } \\
525 \text { lbs of hydrochloric acid }\end{array}$ & WSCF & Credible & Release of chlorine \\
\hline
\end{tabular}

Potential Risk Definitions: 1 Fire, earthquake, or other calamity

2 Wildland fires

3 Radiological spills or spreads

4 Spills of non-radiological or mixed chemical wastes

5 Storage and handling of ignitable and reactive waste 
WHC-SP-1180, Vol. 1

\begin{tabular}{|c|c|c|c|c|}
\hline $\begin{array}{l}\text { Potential } \\
\text { Risk }\end{array}$ & Hazard & Location & Probability & Potential Consequences \\
\hline 1 & Seismic Event: fire & Bldg 324 & Credible & Release of radiological material \\
\hline 1 & Glovebox fire & Bldg 325 & Credible & Release of radiological material \\
\hline 1 & Seismic Event: fire & Bldg 325 & Credible & Release of radiological material \\
\hline 1 & Fire in hot cell & B!dg 327 & Credible & Release of radiological material \\
\hline 1 & $\begin{array}{l}\text { Fire in Radioisotope } \\
\text { Laboratory }\end{array}$ & Bldg 331 & Credible & Release of radiological material \\
\hline 1 & $\begin{array}{l}\text { Seismic event: crush } \\
\text { and breach of fuel pins }\end{array}$ & FFTF & Credible & Release of radiological materials \\
\hline $1 / 4 / 5$ & Sodium fire & FFTF & Credible & Release of sodium hydroxide \\
\hline 2 & Range fire & $\begin{array}{l}\text { Potentially all site } \\
\text { areas }\end{array}$ & Anticipated & $\begin{array}{l}\text { On and offsite release of } \\
\text { radiological and/or hazardous } \\
\text { materials }\end{array}$ \\
\hline 3 & $\begin{array}{l}\text { Mechanical release of } \\
\text { radiological materials }\end{array}$ & TRUSAF & Anticipated & $\begin{array}{l}\text { On and offsite release of } \\
\text { radiological and/or hazardous } \\
\text { materials. Potential injury to } \\
\text { worker. }\end{array}$ \\
\hline 3 & Chlorine leak & $\begin{array}{l}\text { On-site } \\
\text { transportation } \\
\text { Chlorine tank }\end{array}$ & Credible & Release of hazardous materials \\
\hline 3 & $\begin{array}{l}\text { Rail/tank car with liquid } \\
\text { waste: release w/fire }\end{array}$ & Bldg 337 & Credible & Release of radiological materials \\
\hline $3 / 4$ & $\begin{array}{l}\text { Liquid waste rail car } \\
\text { leak }\end{array}$ & $\begin{array}{l}\text { On-site } \\
\text { transportation Site } \\
\text { rail system }\end{array}$ & Credible & Release of radiological materials \\
\hline
\end{tabular}

Potential Risk Definitions: 1 Fire, earthquake, or other calamity

2 Wildland fires

3 Radiological spills or spreads

4 Spills of non-radiological or mixed chemical wastes

5 Storage and handling of ignitable and reactive waste 
WHC-SP-1180, Vol. 1

\begin{tabular}{|c|c|c|c|c|}
\hline $\begin{array}{l}\text { Potential } \\
\text { Risk }\end{array}$ & Hazard & Location & Probability & Potential Consequences \\
\hline 4 & $\begin{array}{l}\text { Failure of chlorine } \\
\text { storage vessel/valve of } \\
\text { chlorine }\end{array}$ & Bldg 315 & Credible & Release of chlorine \\
\hline 4 & $\begin{array}{l}\text { Fuel element spill } \\
\text { from operations } \\
\text { accident }\end{array}$ & $\begin{array}{l}\text { 105K Fuel Storage } \\
\text { Basins }\end{array}$ & Credible & on and of fsite release of radionuclides \\
\hline 4 & $150 \mathrm{lb}$ chlorine release & $\begin{array}{l}100 \mathrm{~K} \text { water } \\
\text { treatment system }\end{array}$ & credible & On and offsite release of chlorine \\
\hline 4 & $\begin{array}{l}\text { Failure of chlorine } \\
\text { storage vessel/valve of } \\
\text { chlorine }\end{array}$ & Bldg 315 & Credible & Release of chlorine \\
\hline 4 & $\begin{array}{l}\text { Fuel element spill } \\
\text { from operations } \\
\text { accident }\end{array}$ & $\begin{array}{l}\text { 105K Fuel Storage } \\
\text { Basins }\end{array}$ & credible & on and offsite release of radionuclides \\
\hline 4 & $150 \mathrm{lb}$ chlorine release & $\begin{array}{l}100 \mathrm{~K} \text { water } \\
\text { treatment system }\end{array}$ & credible & On and offsite release of chlorine \\
\hline $4 / 5$ & $\begin{array}{l}\text { Sodium/ } \\
\text { hydrogen explosion }\end{array}$ & Bldg 337 & Credible & Release of hazardous materials \\
\hline $4 / 5$ & $\begin{array}{l}\text { Sodium/ } \\
\text { potassium spill/fire }\end{array}$ & Bldg 337 & Credible & Release of hazardous materials \\
\hline 5 & $\begin{array}{l}\text { Loss of capsule pool } \\
\text { water }\end{array}$ & B Plant/WESF & Credible & $\begin{array}{l}\text { No retease assumed. Very high dose } \\
\text { rates }\end{array}$ \\
\hline
\end{tabular}

Potential Risk Definitions: 1 Fire, earthquake, or other calamity

2 Wildland fires

3 Radiological spills or spreads

4 Spills of non-radiological or mixed chemical wastes

5 Storage and handling of ignitable and reactive waste 
Radiological materials transported include plutonium samples, TRU waste containers. and contaminated D\&D materials. Methods of transportation include railcars and vehicles. Spills or spreads resulting from transportation of radiological materials can result in a $290 \mathrm{rem}$ dose, $1 \mathrm{~km}(3290 \mathrm{ft})$ from the accident.

\subsubsection{Spills of Non-radiological or Mixed Chemical Liquid Wastes}

Spills of non-radiological or mixed chemical liquid wastes can result from transportation accidents, leaks, or other incidents. Hazardous material spills are classified as credible. Materials include sodium, chloride, nitric acid, and other materials. Exposures can include releases into the air. Examples of levels of exposure include a 13,000 ppm chlorine concentration at $1 \mathrm{~km}(3290 \mathrm{ft})$ from the spill.

\subsubsection{Storage and Handling of Ignitable and Reactive Wastes}

The risks associated with the storage and handling of ignitable and reactive wastes are documented in Safety Basis documents. Mechanical release from gas buildup in swollen drums is presented in TRUSAF and other facilities. Events are considered credible and can result in severe injuries on-site and off-site exposures below annual limits (Category II).

\subsubsection{Medical Risks}

Occupational injuries and illnesses related to the Hanford site are well delineated in the Westinghouse Hanford Company Health and Safety Performance Report (WHC-SP-0564-37) for first quarter 1995. The majority of the medical conditions listed are minor in nature and are well cared for under the current system of emergency response, triage, and transport by the HFD, and on-site treatment by the HEHF.

As the site moves from its present mission to decommissioning and demolition (D\&D), a change in the injury pattern and incidence is expected. Both the WHC Safety Manager and the Site Medical Director were questioned regarding the possible change in types and numbers of injuries in relation to change in mission. Both individuals felt empirically that there would be an increase in injury risk and numbers as the work force dealt with the decommissioning of outdated facilities and the demolition of physical plants as well as the transfer/storage of byproducts. Neither had any specific studies to validate this opinion.

Actual relative risk by profession can be evaluated using the State of Washington Labor and Industries (L\&I) risk rates. These rates are Washington State Department of Labor and Industries hourly rates by profession or "risk class" charged by the state for worker's compensation premiums. Premiums are based on accident history and compensable claims accepted by the department for each profession as well as the frequency and severity of workrelated injuries and the exposure hours over which those costs can be spread (Washington, 1994). It can be concluded that the risk of either injury or serious injury is highest with those professions or "risk classes" that have a high risk rate. The rates for representative professions are provided in Table 7-3. 
Table 7-3 Washington L\&I Risk Rate

\begin{tabular}{|c|c||}
\hline Profession & Risk Rate \\
\hline Counties all other employees & 0.6426 \\
\hline Clerical office & 0.0907 \\
\hline Parcel package delivery & 0.9490 \\
\hline Trucking other & 2.1193 \\
\hline Firefighter & 0.4188 \\
\hline Plummer/pipefitter & 1.7339 \\
\hline Law enforcement officer & 0.4771 \\
\hline
\end{tabular}

As noted in Section 6, the site mission is shifting toward D\&D. Therefore, the number of technical, craft, laborer, and operator positions are expected to increase as the mission life cycle matures. These positions typically have relatively higher risk rates than other site occupations. For example, professions classed as "temporary help-hazardous waste" have a rate over 100 times higher than professions classed as "Clerical Office." As the site shifts toward D\&D, an increase in the population of workers categorized with higher risk ratings is expected. If these follow the L\&I risk profile, an increase in the risk of injuries is expected. This risk will be magnified by the evolutionary nature of the future mission. Rather than a stable work force and job pattern, there will be a trend toward an increase in subcontractors and a transitory nature of portions of the work force. This may result in an increased injury rate due to diminished hazard familiarity, a diminished ability to educate and monitor a transitory work force and the nature of the jobs performed.

The relative risk of several expected occupations in D\&D is provided in Table 7-4.

Table 7-4 Washington L\&I Risk Ratings for Expected D\&D Operations

\begin{tabular}{|c|c|}
\hline Profession & Risk Rate \\
\hline \hline Temporary help-hazardous waste & 9.5281 \\
\hline Building demolition & 7.3864 \\
\hline Temporary help-construction & 4.9988 \\
\hline Temporary help-machine operation & 2.7131 \\
\hline
\end{tabular}

Although it is difficult to make any prediction regarding future performance, it is expected that the transition to D\&D may entail increases in the injury pattern during operation hours. 
The current mission of the HFD in EMS is categorized as follows:

(1) Care of medical and traumatic emergencies,

(2) Care of job related injuries of a lesser nature,

(3) Response to hazardous material or radiation emergencies, and

(4) Response to an Multiple Casualty Incident (MCI).

Category (1) and (2) medical and traumatic injuries and illness are expected to increase as noted above. Category (3) is expected to increase with the increased interaction with outdated facilities and outmoded technology inherent in the transfer and storage mission. Category (4) is difficult to quantify as it is extremely rare on site other than motor vehicle accidents which are in direct relation to the number of vehicles and the miles driven.

\subsubsection{Incident Requiring Rescue Capability}

Rescue capabilities are not typically discussed in site accident analysis documentation. However, incidents ranging from vehicle accidents to construction incidents can result in rescue services being required. Detailed data to evaluate the probability of a rescue incident is not available. Data in the last two years indicate approximately 100 patient contacts for EMS as a result of vehicle accidents. In addition, HFD personnel indicate that the number of confined spaces on site exceeds 500 as of the date of the report and is increasing. As D\&D progresses and trench construction increases, additional cave-in and rescue possibilities exist. There were no identified incidents involving confined spaces or unique rescue capabilities to date. 
THIS PAGE INTENTIONALLY LEFT BLANK 
THIS PAGE INTENTIONALLY

LEFT BLANK 


\section{SECTION 8 - HFD FIRE/EMS SERVICE DEMAND HISTORY}

In order to evaluate the level of services required from the HFD, a brief review of historical fire department data is useful. The information presented in Section 8 and other data are utilized to support the recommendations presented in the needs assessment. Figures and details on HFD responses are provided by the HFD.

\subsection{BACKGROUND}

Available site Atomic Energy Commission/Department of Energy (AEC/DOE) fire loss records dating back to 1949 were reviewed. A site fire loss history summary is provided in Table 8-1 (AEC/DOE Richland, 1951-94). Fires with significant loss have been footnoted and summarized for qualitative evaluation. 
WHC-SP-1180, Vol. 1

\begin{tabular}{|c|c|c|c|}
\hline \multicolumn{4}{|c|}{ Table 8.1 Site Fire Loss Summary (page 1 of 3 ) } \\
\hline Year & Fire Loss (Dollars) & Number of Fires & $\begin{array}{l}\text { Fire loss in cents per } \$ 100 \text { of } \\
\text { AEC/DOE property evaluation }\end{array}$ \\
\hline 1949 & 30,058 & 122 & 0.41 \\
\hline 1950 & 158 & 65 & 0.0034 \\
\hline 1951 & 21,051 & 61 & 0.78 \\
\hline 1952 & *no data identified & no data identified & 5.08 \\
\hline 1953 & 8,732 & 95 & 0.17 \\
\hline 1954 & 84,851 & 125 & 1.41 \\
\hline 1955 & 25,813 & 79 & $\begin{array}{c}0.20 \\
\text { (first year contamination by fire in } \\
\text { radioactive materials were included) }\end{array}$ \\
\hline 1956 & 42,344 & 71 & 0.31 \\
\hline 1957 & 16,158 & 73 & 0.12 \\
\hline 1958 & 2,347 & 65 & 0.017 \\
\hline 1959 & 15,237 & 60 & 0.107 \\
\hline 1960 & $* 275,578$ & 80 & 1.78 \\
\hline 1961 & 88,559 & $\begin{array}{l}142 \\
\text { (includes } 62 \text { range fires } \\
\text { Aug } 14-17 \text { ) }\end{array}$ & 0.53 \\
\hline 1962 & 31,511 & 62 & 0.16 \\
\hline 1963 & $* 415,744$ & 88 & 2.304 \\
\hline 1964 & $* 323,202$ & 84 & 1.641 \\
\hline
\end{tabular}

- 1952 A fire involving an unsprinklered one-story $75^{\prime} \times 1401$ frame construction warehouse is documented in a report issued by the Atomic Energy Commission (AEC, 1975). The fire occurred at the site on January 28, 1952 and caused property damage estimated at $\$ 269,578$. The report indicates that the cause of the fire was unknown, but its spread was aided by an apparent explosion of $20 \mathrm{~J}$-galion cans of Glyptol thinner. The fire department responded promptly upon notification by a patrolman. The fire was brought under control about two hours later (AEC, 1952)

- 1960 Major pyrophoric process metal fire in a confined vessel (Redox dissolver). Half of identified loss were in renovation and decontamination costs. Note: report notes increasing number of serious loss incidents: from 12 in 1958 to 17 in 1959 to 22 in 1960.

- 1963 Major fire in plutonium chemical processing facility. Accident occurred at about 1:23 a.m. November 6, when a portion of resin became hot enough to trigger rapid pyrolysis of the plutonium and dichromate-loaded resin. Fire ignited contaminated laundry, waste cartons, and plastic panels on lower levels. Bumed at low intensity until about 1:50 a.m. when it was detected by two radiation monitors and reported. Firemen were advised by shift supervisor not to use water except as a last resort because of possible criticality risks. Fire extinguished I $1 / 2$ hours later by firemen using about 500 lbs of class B-C dry powder and no water. All firemen fighting the blaze received some skin and clothing contamination. Two firemen showed positive nasal smears. Ten firemen and three operating personnel made entries to the building during the progress of the fire (AEC, 1964).

1964 Major fire in laboratory housing aquatic biology and ecology experiments and offices. Ignition source unknown but assumed electrical above the ceiling. Entire heavy frame roof eventually consumed by fire in spite of intensive fire fighting. Serious loss of equipment ecology samples, and program. Total loss of aquatic animals and stight loss of records. No spread of contamination. 


\begin{tabular}{|c|c|c|c|}
\hline \multicolumn{4}{|c|}{ Table 8-1 Site Fire Loss Summary Continued (page 2 of 3 ) } \\
\hline Year & Fire Loss (Dollars) & Number of Fires & $\begin{array}{l}\text { Fire loss in cents per } \$ 100 \text { of AEC property } \\
\text { evaluation }\end{array}$ \\
\hline 1965 & 445 & 43 & 0.002 \\
\hline 1966 & 9,715 & 51 & 0.044 \\
\hline 1967 & $* 192,243$ & 51 & 0.997 \\
\hline 1968 & 6,189 & 58 & 0.03 \\
\hline 1969 & 19,740 & 52 & 0.084 \\
\hline 1970 & 5,672 & 61 & 0.022 \\
\hline 1971 & 16,229 & 35 & 0.060 \\
\hline 1972 & 4,743 & 63 & 0.015 \\
\hline 1973 & 49,840 & 38 & 0.164 \\
\hline 1974 & 10,192 & 45 & 0.031 \\
\hline 1975 & 7,945 & 61 & 0.021 \\
\hline 1976 & 21,033 & 47 & 0.052 \\
\hline 1977 & 3,000 & 78 & 0.007 \\
\hline 1978 & $* 248,658$ & 75 & 0.494 \\
\hline 1979 & 28,228 & 90 & 0.071 \\
\hline 1980 & $* 658,735$ & 42 & 1.52 \\
\hline 1981 & 43,078 & 81 & 0.086 \\
\hline 1982 & 359,190 & 75 & 0.72 \\
\hline 1983 & 41,800 & 64 & 0.089 \\
\hline 1984 & $* 266,769$ & 64 & 0.53 \\
\hline
\end{tabular}

* 1967 109-N Building; Fire in heat exchanger room from lubrication oil system leak. Accidental closure of an unsupervised valve in an oil lubrication loop to a primary coolant pump resulted in a fire. Back pressure forced approximately 80 gallons of oil out the ventilation breathing vents. Fire loss estimated at $\$ 185,000$.

- 1978 Fire in 1171 building. Estimated fire loss at $\$ 243,000$. Sprinkler system and fire wall credited for preventing loss from reaching several million dollars (no other details identified).

- 1980 Ignition of enriched uranium/piutonium scrap residues and subsequent rupture of I lb container on October 9, in building 234-Z. $\mathrm{Rm} 230$-C. Damage from contamination estimated at $\$ 654,360$. (Note: this incident was dropped from subsequent fire loss history data tables)

- 1982 Exhaust duct fire on March 31, at 2:10 PM in building 320. Caused by open flame from a propane torch which resulted in an exhaust duct fire. Fire Department notification via manual pull box. Response was considered to be prompt. Fire controlled by automatic sprinklers. (Per the report, radioactive material were not released by the fire, either inside or outside of the 320 building.) (PNL, May, 1982)

- 1984 A spontaneous ignition fire of soiled laundry in building 221-T (T Plant), R-19 stairwell caused significant smoke damage to the buildings HEPA filtration system. The fire loss was estimated at \$87,478. On August 12 , lighting caused a grass fire southwest of the Hanford Site. Winds and extremely dry vegetation resulted in the fire entering the site uncontrolled. The fire passed through the Site causing loss of power poles, railroad ties, trailers, etc. HFD brush trucks and Forest Service air drops were used to protect major facilities. The fire was not controlled until it reached the Columbia River and the south end of the site. Approximately 200,000 acres were burned. The fire loss was estimated at $\$ 156,346$. 
WHC-SP-1180, Vol. 1

\begin{tabular}{||c|c|c|c|}
\hline \multicolumn{3}{|c|}{ Table 8-1 Site Fire Loss Summary Continued (page 3 of 3) } \\
\hline Year & Fire Loss (Dollars) & Number of Fires & $\begin{array}{c}\text { Fire loss in cents per \$100 of } \\
\text { AEC property evaluation }\end{array}$ \\
\hline 1985 & 45,385 & $\begin{array}{c}\text { lo } \\
\text { (over \$1.000 } \\
\text { in loss) }\end{array}$ & 0.079 \\
\hline 1986 & & 37 & 0.004 \\
\hline 1987 & 2,500 & 72 & 0.161 \\
\hline 1988 & 91,905 & 65 & 0.00 \\
\hline 1989 & 0.00 & 50 & 0.0001 \\
\hline 1990 & 10,935 & 62 & 0.0171 \\
\hline 1991 & 14,700 & 76 & 0.0429 \\
\hline 1992 & 32,928 & 78 & 0.0013 \\
\hline 1993 & 19,024 & not available & 0.0246 \\
\hline 1994 & 20,111 & 78 & 0.0231 \\
\hline & not available & not available \\
\hline
\end{tabular}

The average fire loss ratio $(\$ / \$ 100)$ excluding 1952 for which no explanatory data was identified was 0.34 . Thus, site fire loss ratios, tend to be significantly below "Improved Risk" experience ratios cited by large insurance companies (example: for 1964-1968, compare at 2.73)(AEC, 1969). The average annual fire loss ratio for the period 1985-1993 was 0.04 indicating a general trend toward reduced fire losses over previous years. However, fire losses tended to be significant when radiological materials were involved.

Comparison of actual number of fires can be misleading since in any given year the number of grass/range fires can significantly increase or decrease as was noted in 1961 when there were 62 recorded range fires in three days. Nevertheless, the average number of fires per year over the approximate 45 year period is 66 . During, the last five year period, the site has had an average of 72 fires. Thus, the average number of fires per year at site continues to remain relatively constant.

\section{Engine Responses to Fire}

Engine response to site areas for 1980-1995 are shown in Figure 8-1. Figure 8-2 indicates that most engine responses are for incidents categorized as "fire." Engine responses to actual fires by area for 1990-1995 are shown in Figure 8-3. Though some areas have significant changes in the number of responses per year, a 5-year comparison indicates the responses to actual fires appears to be relatively constant. Average number of responses by area for this period is shown in Table 8-2. Actual number of fires by type for the same period are illustrated in Figure 8-4. More than half of the fires are either classified as structural or natural cover (i.e. grass/range fires). 

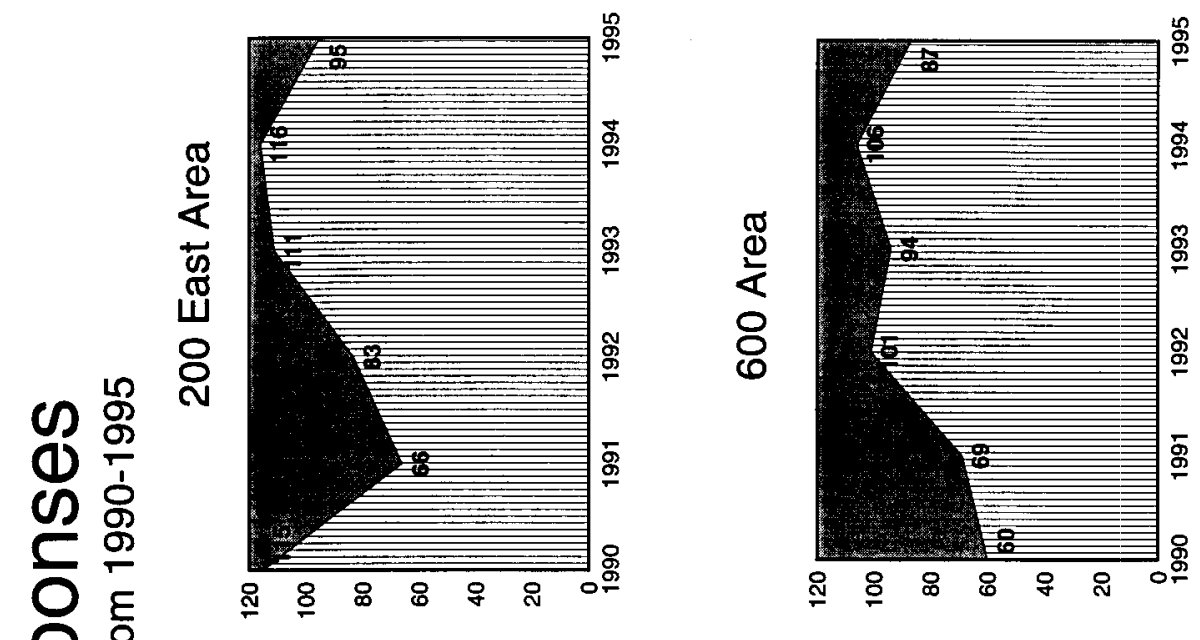

哭
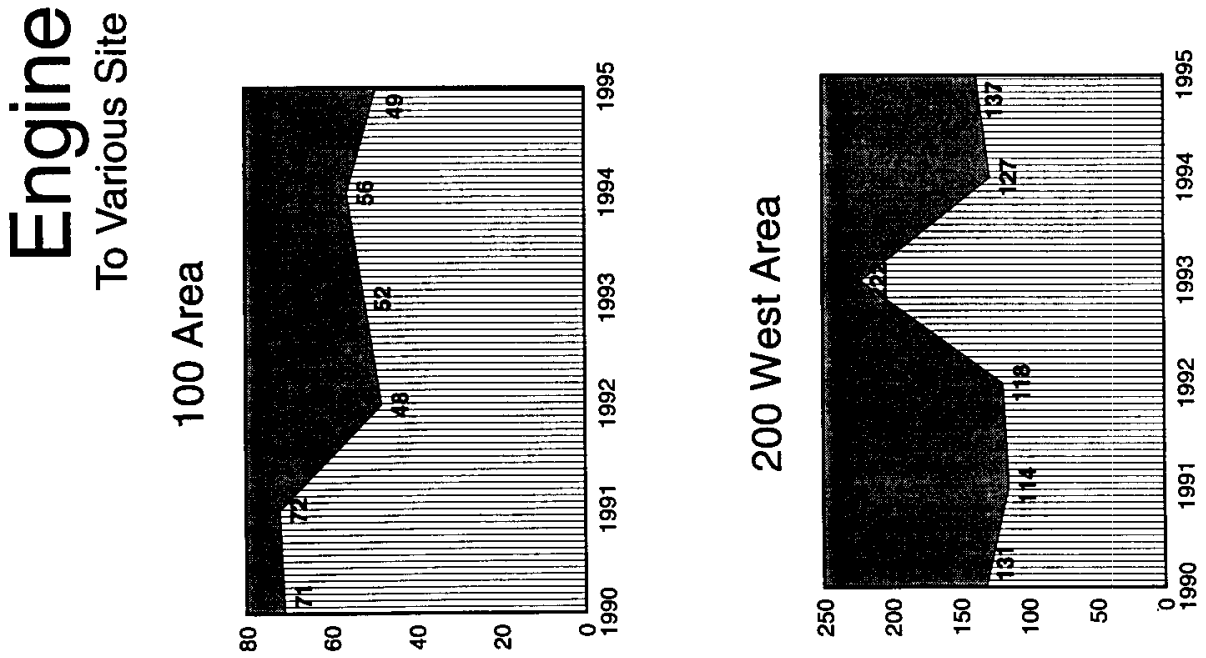

Figure 8-1 (page 1 of 2) 

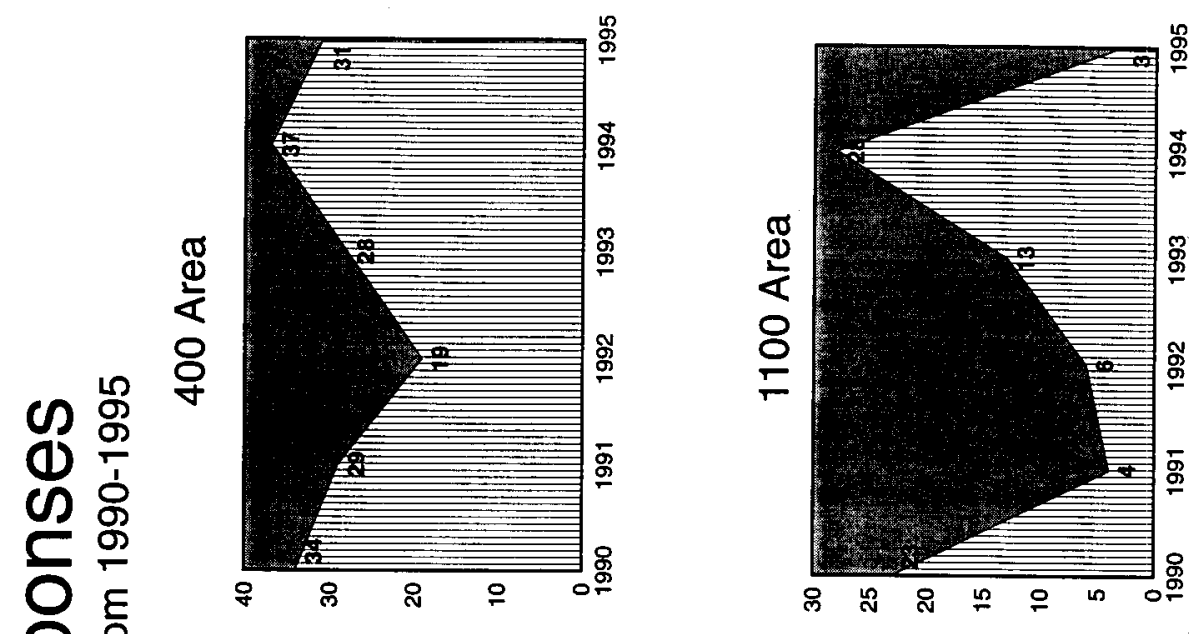

$\frac{\sqrt{2}}{2}$

造
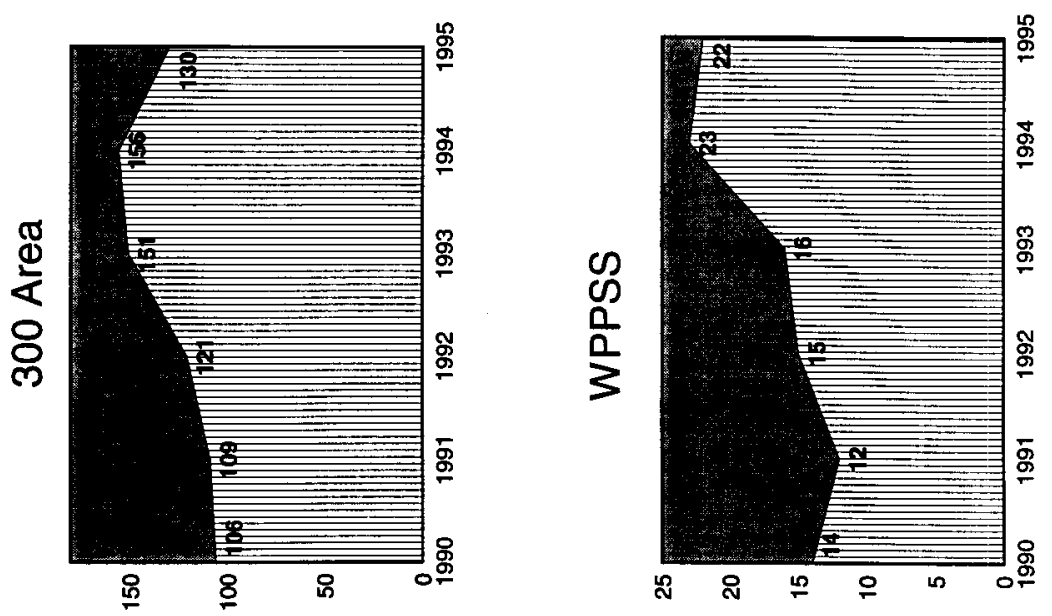

Figure 8-1 (page 2 of 2) 


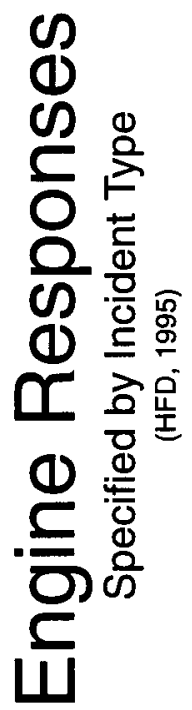

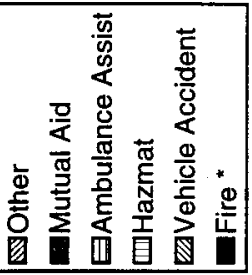

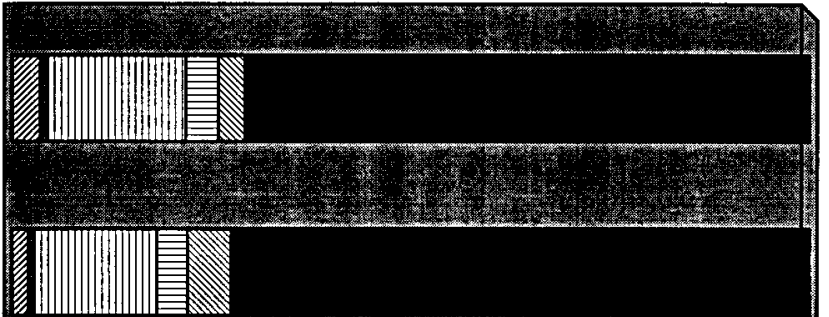

요

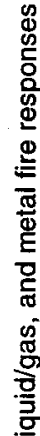

$+\quad$ ơ

Ð

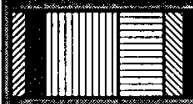

\%

으

$\frac{\Phi}{0}$

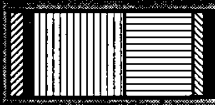

๙ু ฐัँ

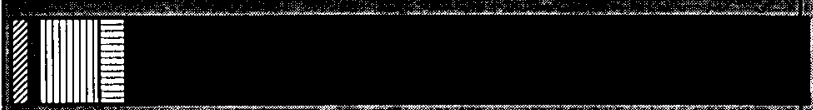

孚 壱

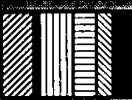

용 $\frac{9}{9}$

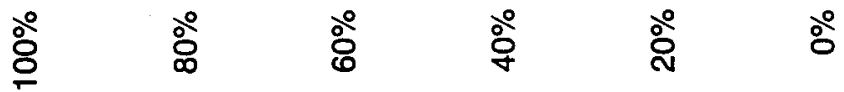

Figure 8-2 
WHC-SP-1180, Vol. 1
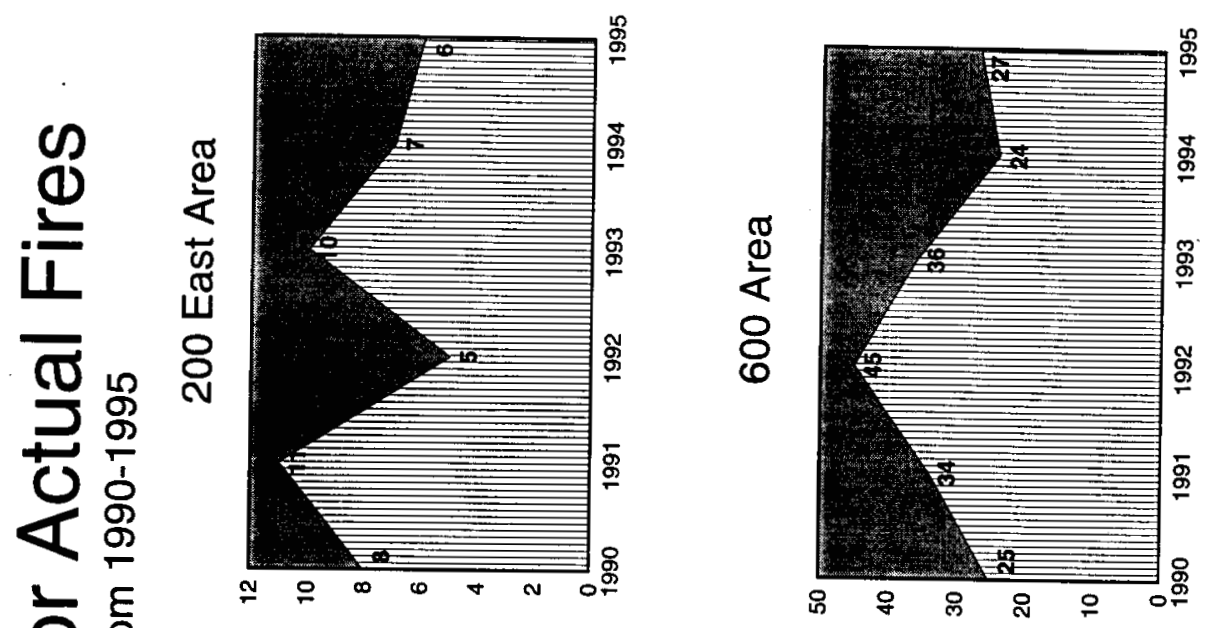

을
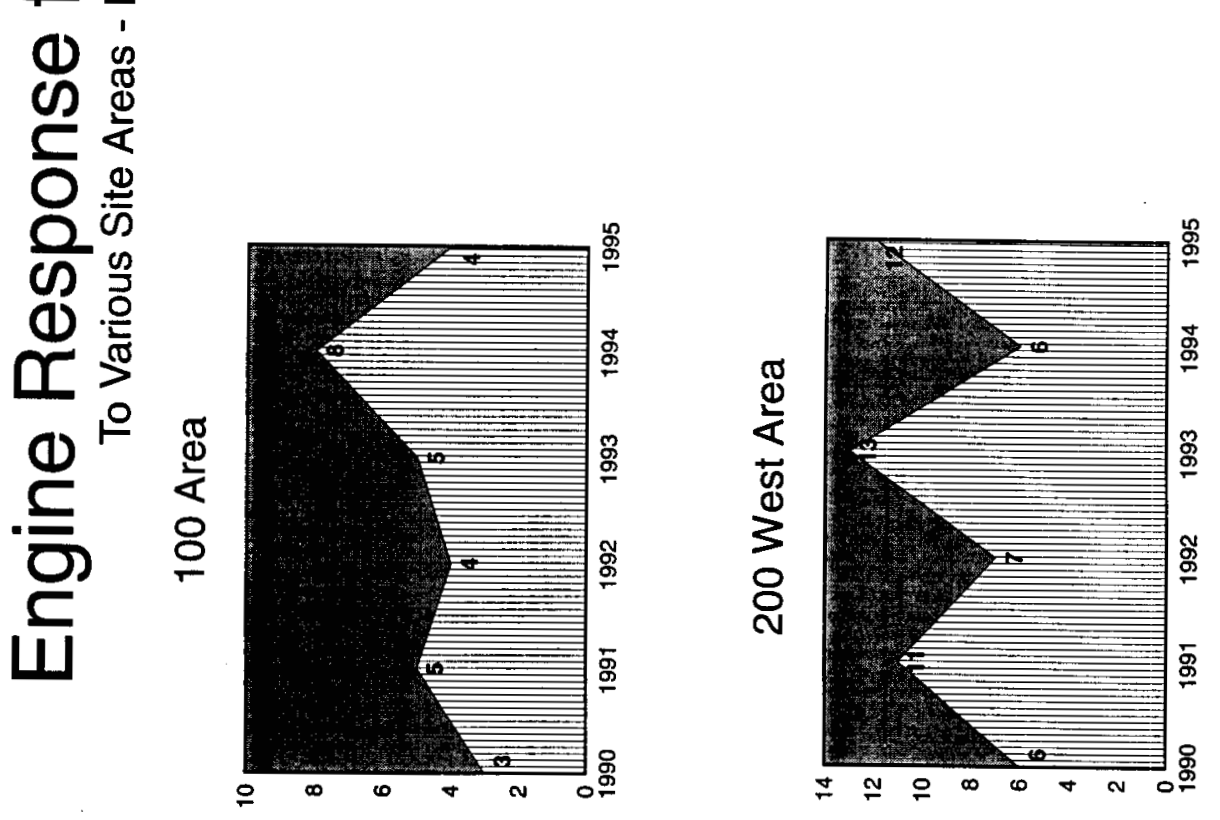

Figure 8-3 (page 1 of 2 ) 

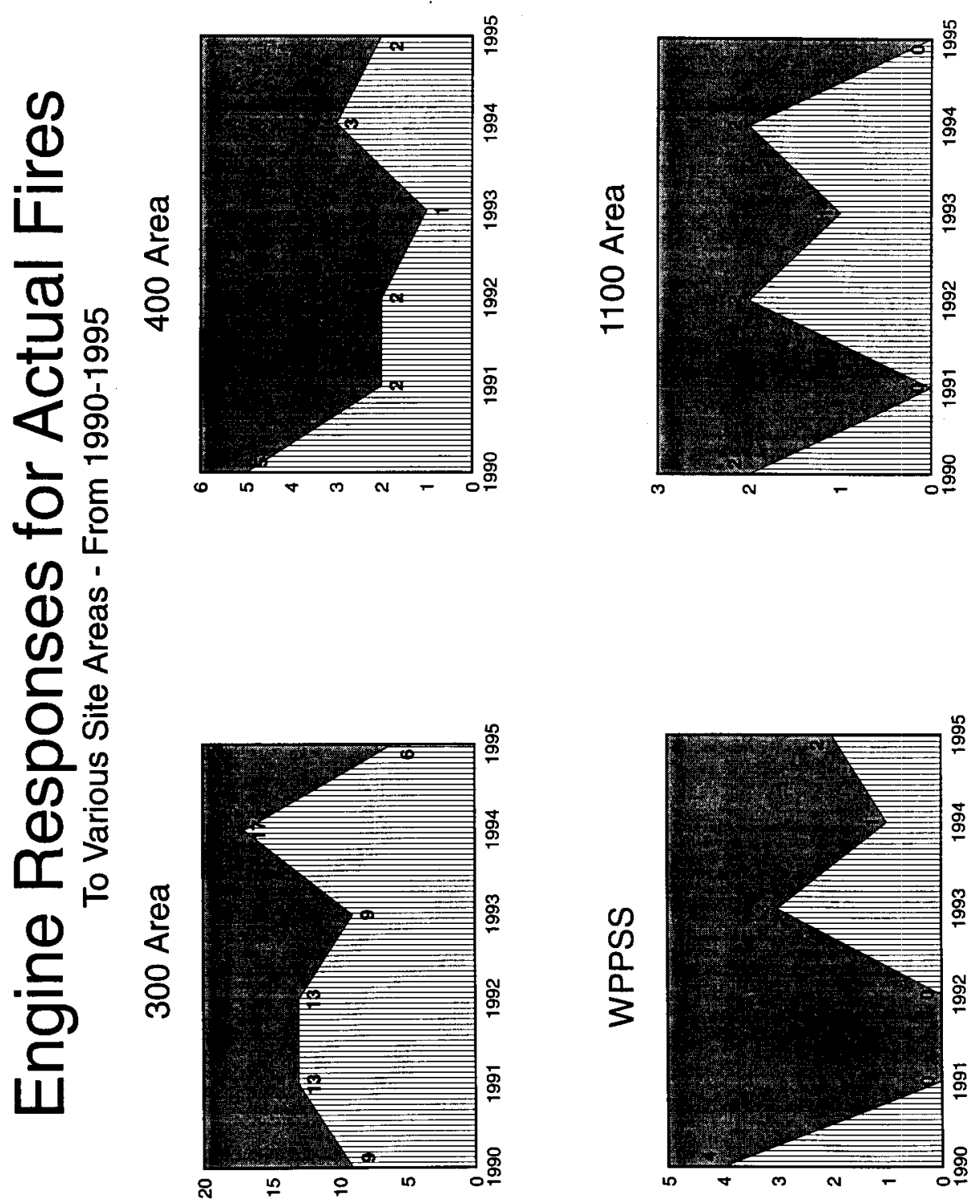

Figure 8-3 (page 2 of 2) 
WHC-SP-1180, Vol. 1
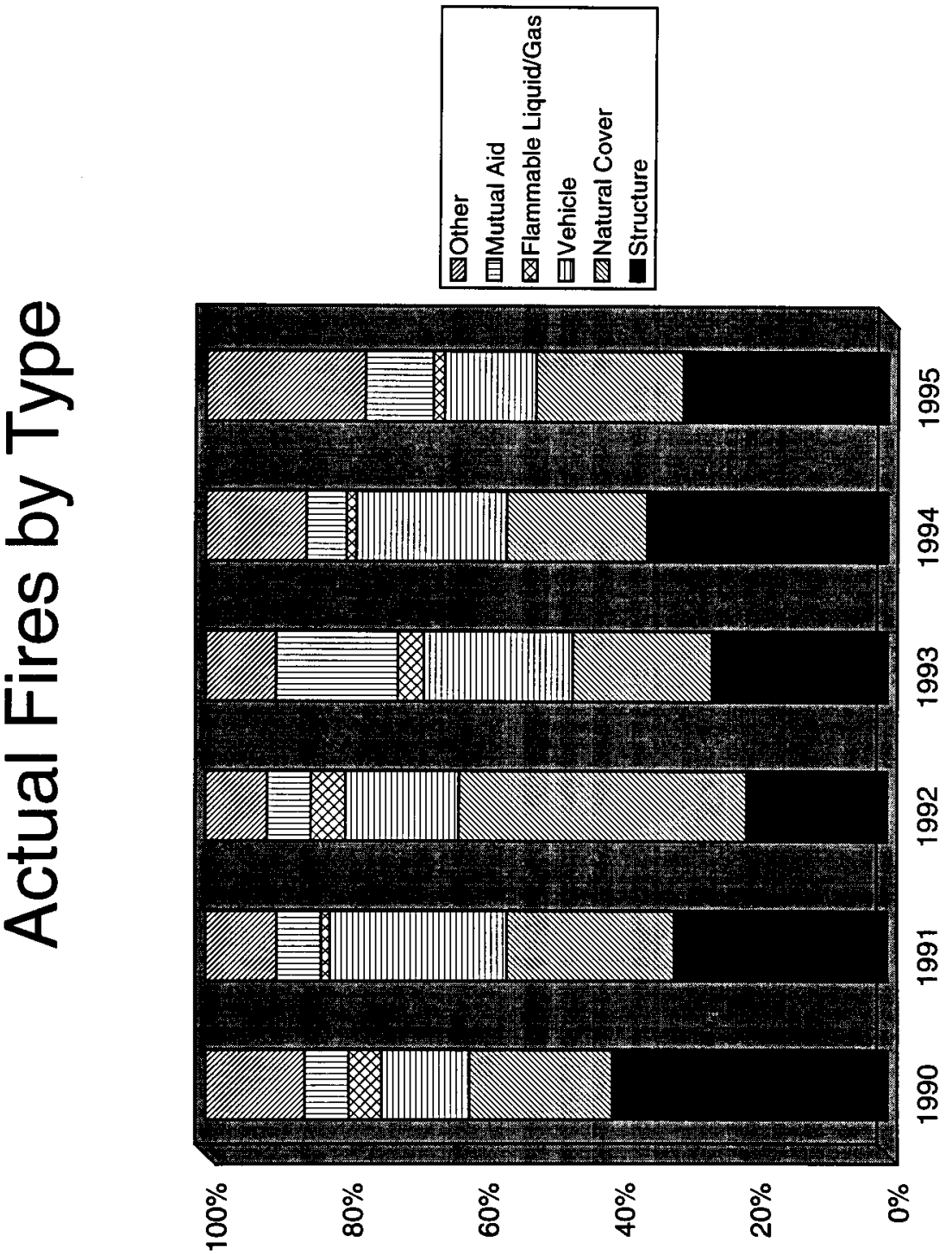

Figure 8-4 


\begin{tabular}{|c|c|}
\hline Area & \# of Responses \\
\hline 100 & 5 \\
\hline 200 & 17 \\
\hline $\begin{array}{c}300 \\
\text { (includes } 1100 \text { area) }\end{array}$ & 14 \\
\hline $\begin{array}{c}400 \\
\text { (includes WPPS) }\end{array}$ & 4 \\
\hline $\begin{array}{l}600 \\
\text { (includes all fires throughout the site not covered } \\
\text { by the areas cited above) }\end{array}$ & 33 \\
\hline Total Number of Average Fires per Year & 73 \\
\hline
\end{tabular}

\section{Total Engine Responses}

Total engine response to an emergency (fire, hazardous materials, vehicle accidents, fire protection system activations, ambulance assists, etc.) for the period 1990-1995 are shown in Figure 8-5. Engine response reached a six year high in 1993 and only decreased slightly in 1994. Since the number of actual fires did not vary significantly over the period, the increase in engine response is due to other emergency responses. These are illustrated in Figure 8-6 for the period 1993-1995. "Unwanted alarms" represent the vast majority of all responses.

Figure 8-7 illustrates HFD engine response to all events by station. The 200 Area fire stations have a significantly higher number of engine responses for each of the past three years. The 300 Area fire station has the second highest response number with approximately 100 fewer responses per year than the 200 Area fire station. The 100 and 400 area stations have the least number of responses with approximately 200 fewer responses per year than the 200 Area fire station. A comparison of engine responses by time of day by fire station is provided in Figure 8-8. For the 1993-94 period $>60$ percent of all engine responses occur between 0800 and $1600 \mathrm{hrs}$. The data shows a general trend toward a slight increase in the percentage of responses that occur between 0800 and 1600 hours.

\section{EMS Responses}

Figure 8-9 illustrates ambulance responses, patient contacts and actual patient transports for the 1990-95 period. EMS activity has increased over the past five years, although the projected EMS activity shows a slight decline in 1995. This decline could correspond to the significant decrease in population that occurred in 1995. Figure 8-10 projects EMS activity as a percent of population. Given the present site population projection, this figure would indicate that EMS activity will decline slightly as the site population declines. However, as noted in Section 7, there may be an increase in the injury rate as the site mission shifts toward more D\&D activities. 


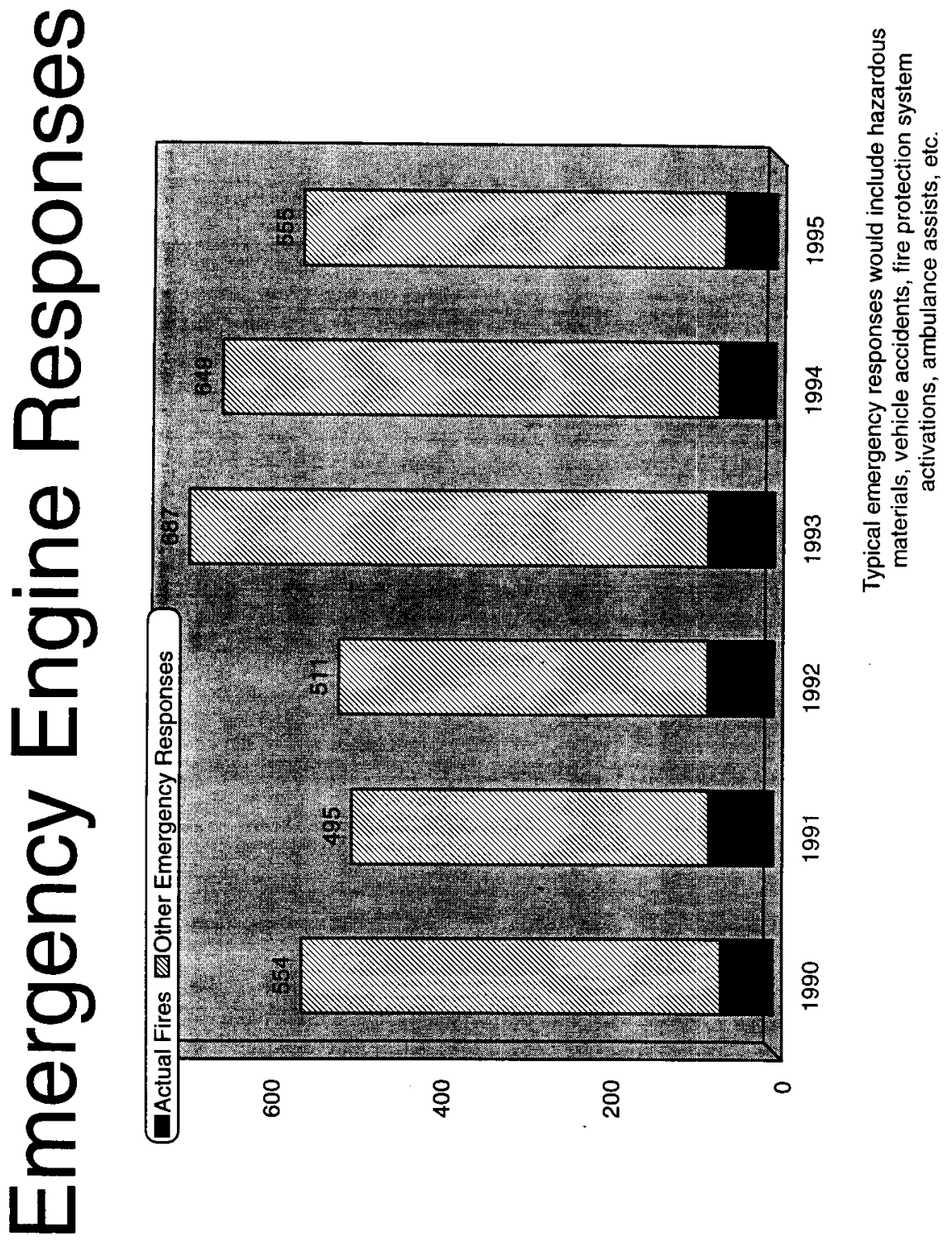

Figure 8-5 
WHC-SP-1180, Vol. 1
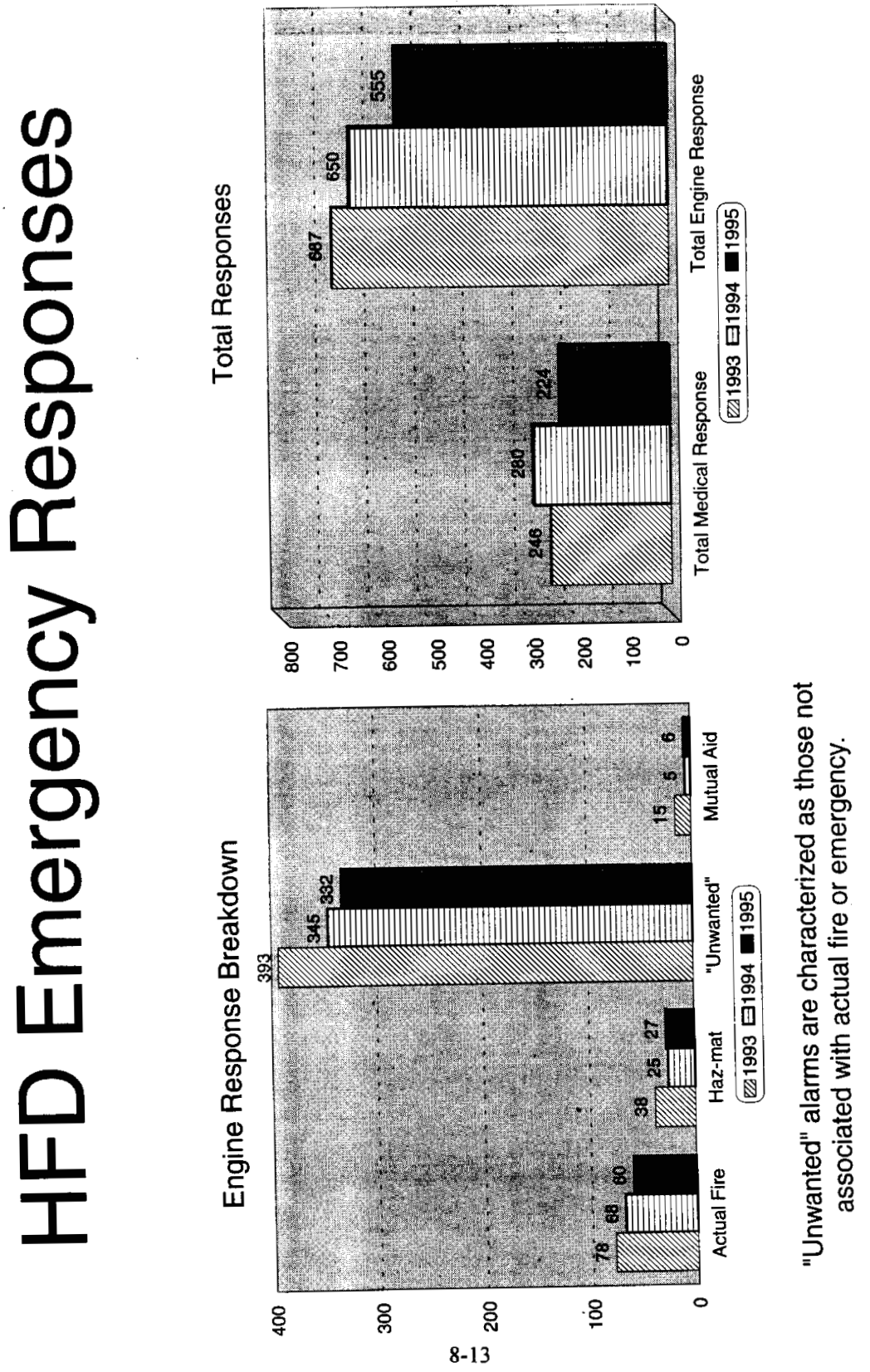

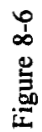

(1)
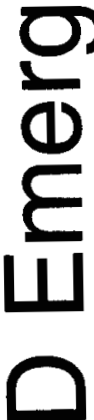

노 
WHC-SP-1180, Vol. 1
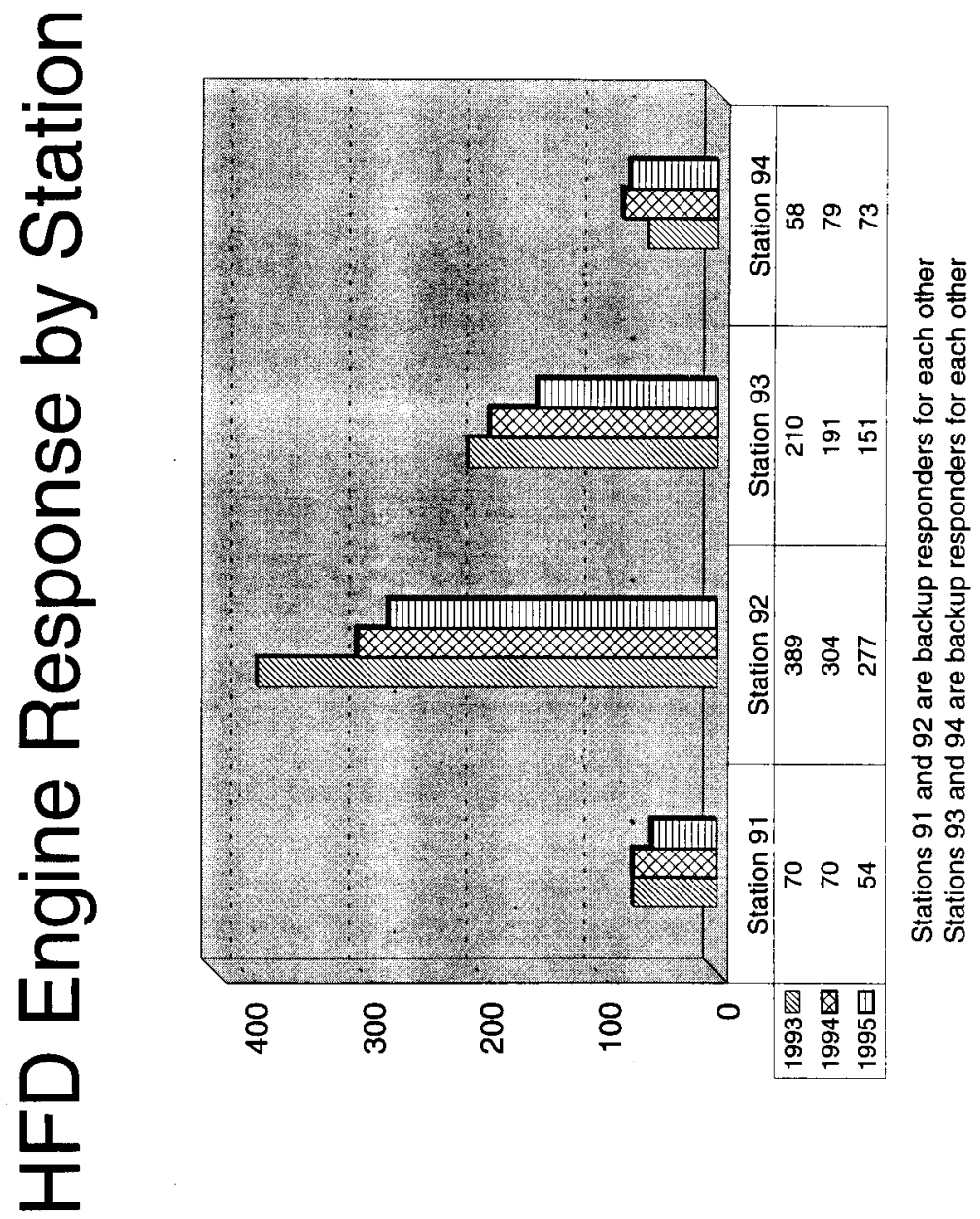

Figure 8-7 
WHC-SP-1180, Vol, 1
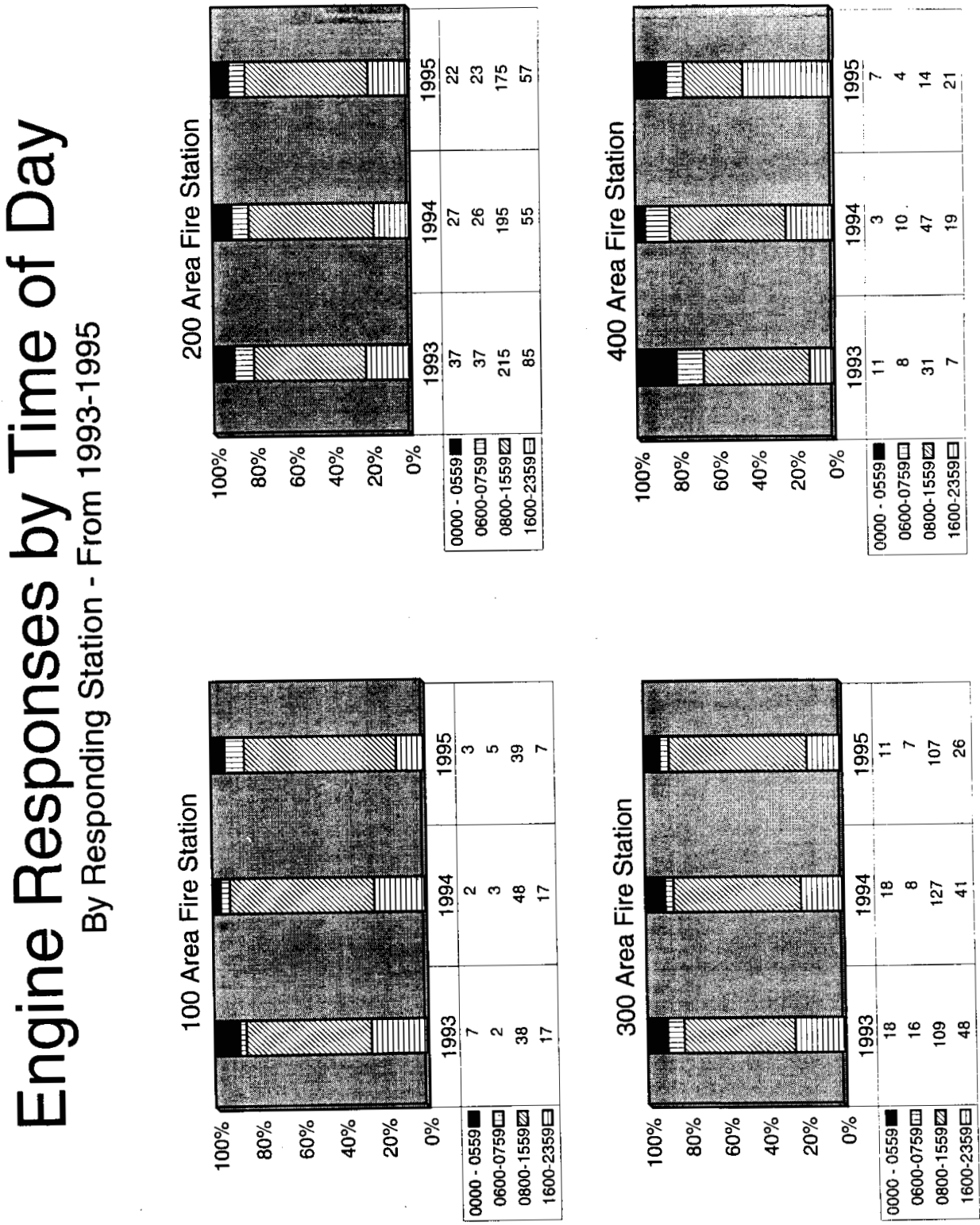

Figure 8-8 
WHC-SP-1180, Vol. 1
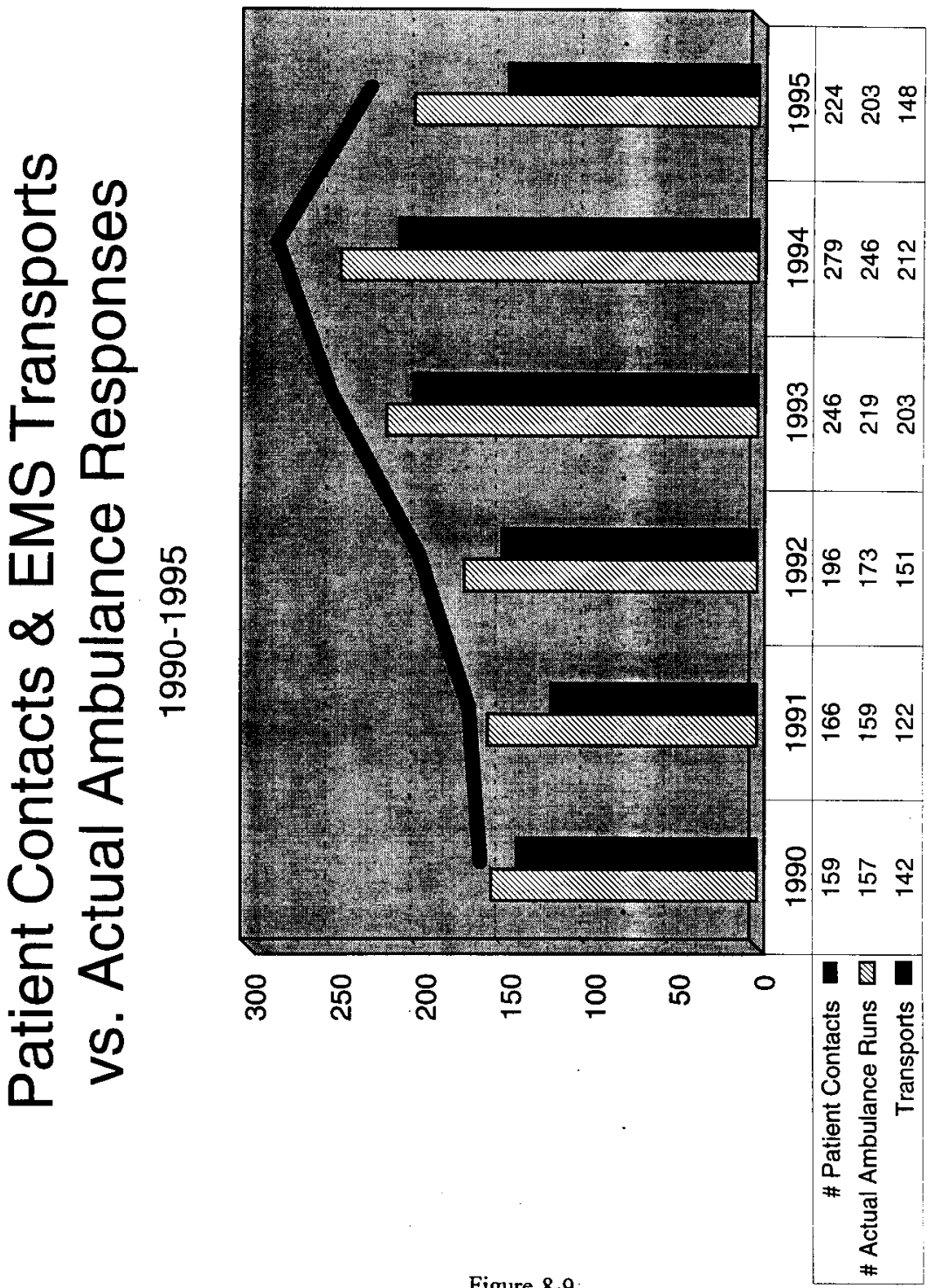

Figure 8-9 


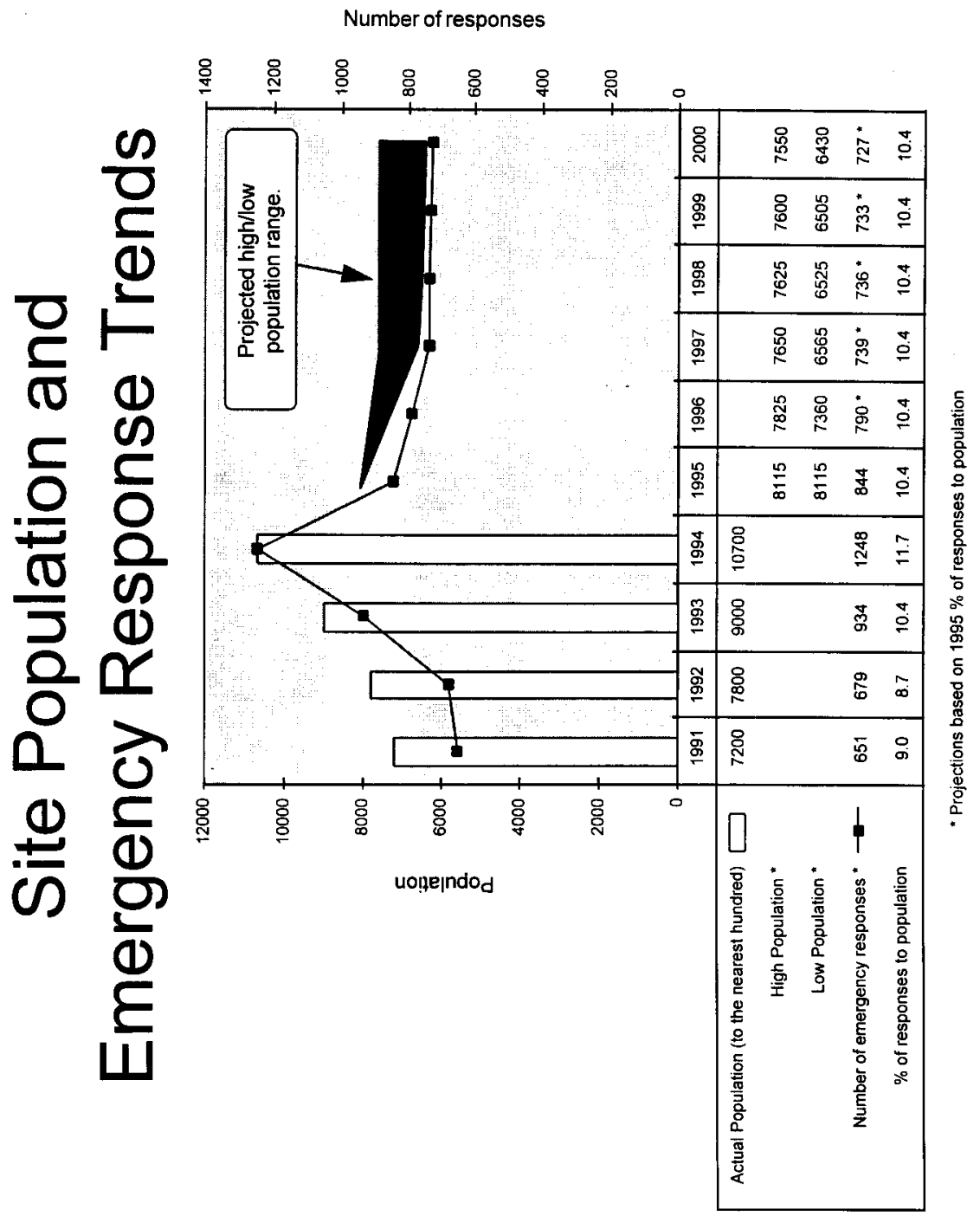

Figure $8-10$ 
Figure 8-11 illustrates EMS patient contacts by area for period 1993-95. The 200 areas had the greatest number of patient contacts ( 200 area fire station). The combined 300 and 1100 areas ( 300 area fire station) had roughly the same number of patient contacts as the combined 400 and WPPSS areas (averaging approximately 30 ). The 100 area had significantly fewer patient contacts than the other areas.

Figure 8-12 illustrates EMS patient contacts as a function of EMS severity level for the period 1990-95. This figure shows a relatively steady number of level 2 (requires immediate medical attention) patient contacts.

Figure 8-13 illustrates the type of EMS responses for the period 1994-95. The majority of EMS responses are for cardiopulmonary emergencies, vehicle accidents, and personal illness.

\section{Summary}

The Hanford site has a fire loss history that is generally better "improved risk" properly. The HFD responds to a variety of calls including fire suppression, EMS and rescue. Over the last three years, the general trend is for most engine responses to be provided by the 200 area stations. The 100 area has the fewest number of responses with a decreasing trend in the number of responses. 
WHC-SP-1180, Vol. 1
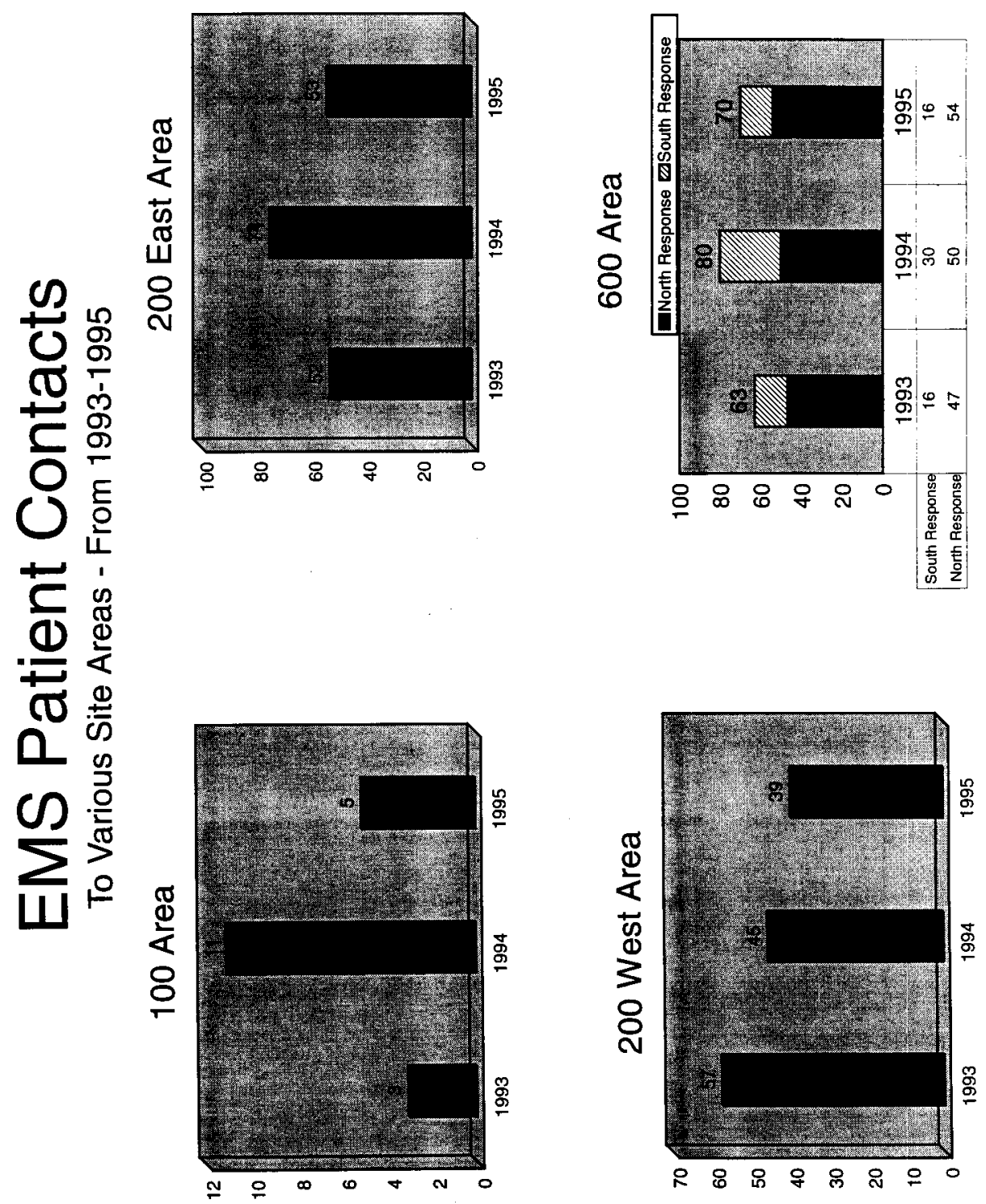

Figure 8-11 (page 1 of 2) 
WHC-SP-1180, Vol. 1
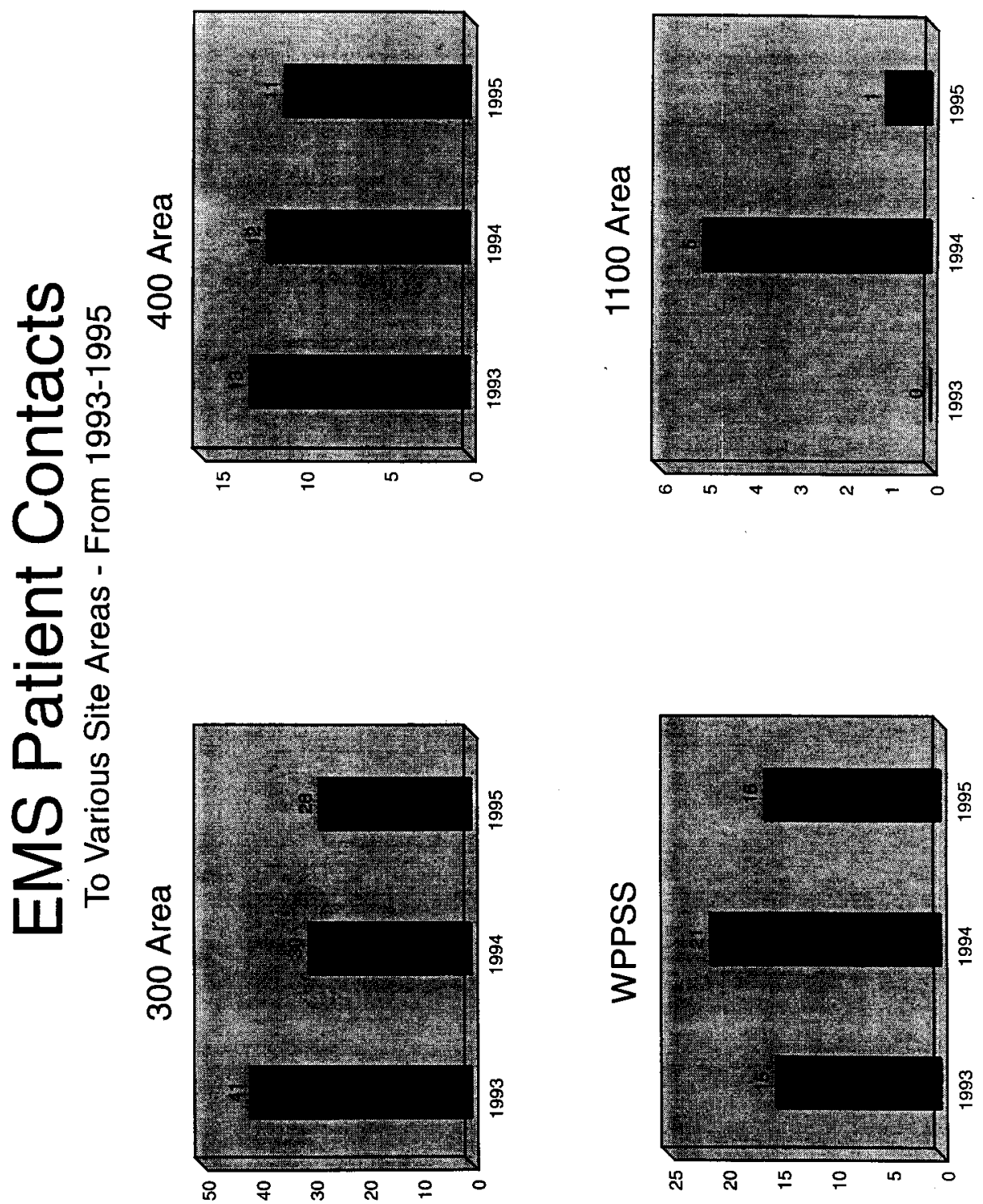

Figure 8-11 (page 2 of 2) 
WHC-SP-1 180, Vol. 1

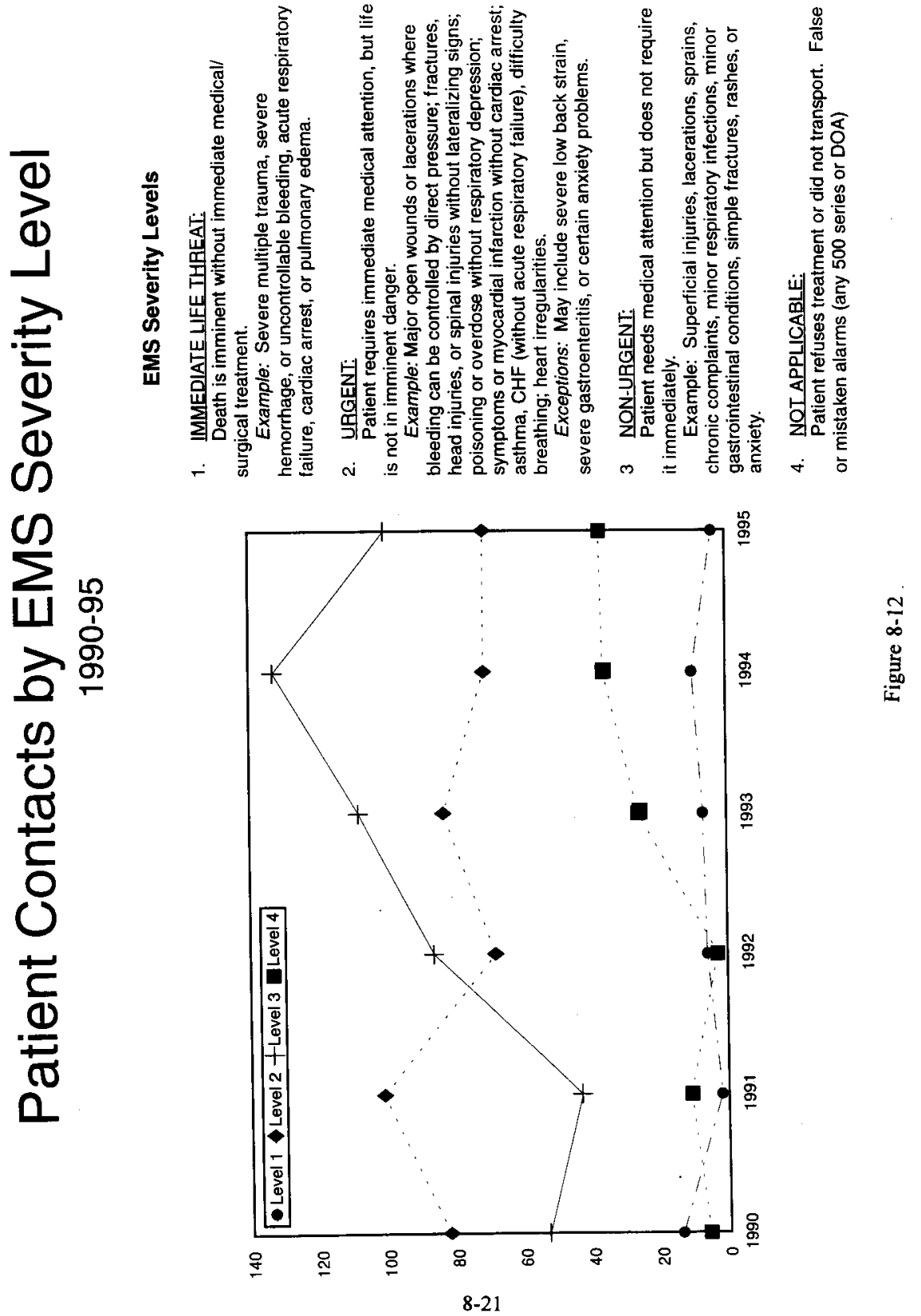


WHC-SP-1 180, Vol. 1

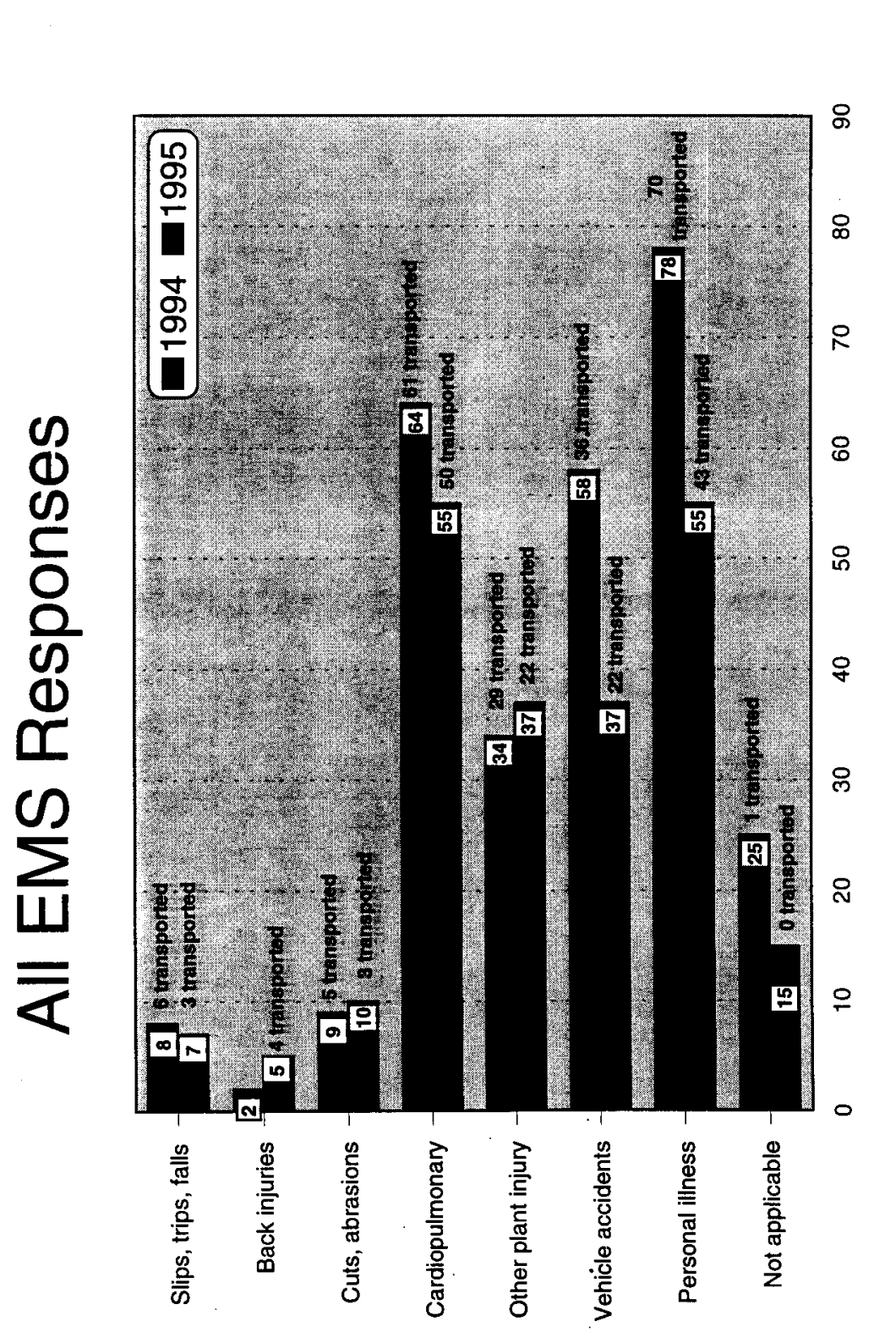

용

모

응

톤

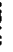

들

竞

능
$0 \quad \frac{0}{0}$

온

菅

产

르

$\stackrel{\Phi}{ \pm}$

ष्ठ

芯

응

롤

옳

능

Figure 8-13 
ह

容

害 
THIS PAGE INTENTIONALLY LEFT BLANK 
SECTION 9 - NEEDS ASSESSMENT

\subsection{FIRE DEPARTMENT MISSION \& ORGANIZATIONAL OVERVIEW}

\subsubsection{Mission \& Organizational Overview, Existing Conditions}

The HFD provides services to the Hanford site under contract agreement between the WHC and the DOE. The HFD is an emergency service organization whose mission is to provide fire suppression, emergency rescue, basic and advanced life support, ambulance service, and hazardous material responses capable of dealing with and terminating emergency situations which threaten the employees, operations, environment, or interest of the Department of Energy (DOE.) Hanford Site (DOE, 1994). These services include emergency support to Bonneville Power Administration facilities, response to surrounding fire districts under a mutual aid agreement, and contractual fire fighting and ambulance response to the Washington Public Power Supply System (WPPSS), the Laser Interferometry Gravity-wave Observatory, the Port of Benton County 400 Area Incubator Project, the Kaiser Aluminum activity in the 300 Area, the US Ecology activity in the 200 Area, as well as other non-DOE governmental agencies and private contractors operating on the site. The HFD is also responsible for site-wide fire safety and fire prevention programs including fire alarm system functional testing and inspection, self contained breathing apparatus maintenance, building tours and inspections, pre-fire planning, providing wound protection through application of occlusive (CIZ) dressing to workers in potentially contaminated areas and employee fire safety training. These include fire alarm and fire suppression systems installed in facilities managed by WHC, Bechtel Hanford Inc., ICF Kaiser Hanford Company, all on-site private business entities, and the Bonneville Power Administration Ashe substation. In providing these services, the HFD has the objective of meeting or exceeding all applicable federal, state, and DOE mandated standards, requirements and guidelines.

The HFD Organization is comprised of 5 division/units:

1. Operations Division

2. Prevention Division

3. Administration Division

4. Managerial Unit

5. Fire Systems Testing and Maintenance Division

\section{Operations Division}

The Operations Division is the emergency response element of the department and is responsible for mitigating emergency situations that threaten the operations, employees, or interest of the DOE-operated Hanford Site. Duties include the following:

- $\quad$ Fire suppression

- Hazardous materials response

- Emergency medical response

- Special rescue activities 
- $\quad$ Pre-fire planning

- Hydrant flow testing

\section{Prevention Division}

The Prevention Division is responsible for all fire prevention activities. The Hanford Fire Marshal is the Team Leader of this division and has the authority to enforce the fire prevention program for the Hanford Site. Fire prevention activities performed include the following:

- $\quad$ Fire prevention and housekeeping inspections

- $\quad$ Employee fire safety education

- $\quad$ Fire system acceptance test procedure review and approval

- Fire investigation

- Hazardous waste storage inspections

- Inspection, testing, and maintenance procedure review and approval

- Fire extinguisher training

- $\quad$ Establishing fire lane criteria.

\section{Administration Division}

The Administration Division is responsible for the training, fire safety, logistical, and physical fitness elements of the Hanford Fire Department. This division

- Provides administrative, professional, and technical support to ail fire department programs

- $\quad$ Manages long-range strategic plans for the fire department

- Plans and implements personal and professional development and motivational programs to enhance career growth opportunities

- Ensures that all HFD activities are performed safely

- Develops and implements appropriate health and fitness programs to assure department members maintain an appropriate level of fitness

- Directs, supervises, and maintains control over an ongoing physical fitness training program and remedial program for department members

- Assures that the necessary equipment and resources are available for efficient and effective HFD operations

- Develops, administers, and schedules required training for all HFD personnel. This includes, in house, other company, and off site training. Maintain all training records and certifications.

- Provides budgeting, cost accounting and cost control and reporting services for the department. 
Managerial Unit

The Hanford Fire Department Managerial Unit

- Performs those senior-level management activities necessary to ensure that the interests of the Hanford Site are maintained in accordance with prescribed criteria as related to fire protection and prevention

- $\quad$ Provides technical expertise to achieve the DOE's fire protection goals and requirements

- Maintains adequate staffing and budgetary levels

- Establishes requirements that provide an acceptable degree of fire safety to DOE and contractor personnel and to the public in DOE facilities

- $\quad$ Provides continuous oversight to all department programs

- Provides overall leadership and control of fire, hazardous materials, and medical emergencies as the senior command officer in charge

- Is empowered by RL (DOE Richland Office) to act as the Hanford Site authority to implement whatever actions are deemed necessary to prevent loss of life, minimize damage, and terminate fire, hazardous waste, and medical response emergencies

- Acts as the facility manager representative for all fire alarm, suppression systems, fire hydrants, and fire valves in WHC landlord areas and facilities.

\section{Fire Systems Testing and Maintenance}

In order to maintain compliance with the National Fire Protection Association (NFPA) and DOE criteria, the Fire Systems Testing and Maintenance division performs the following activities:

- Functional testing, and inspection, for the Hanford site fire detection and fire suppression systems

- Preventive and repair services for all site fire detection and fire suppression systems including hydrants and ground valves, with the exception of those facilities managed by the PNL, the facilities inside the FFTF reactor containment fence, and the WPPSS complex

- Operational configuration control of the fire systems

- Management of the site fire system impairment program

- Support to facility managers for deactivation/reactivation of fire systems as needed for facility operations

- Annual inspection of site fire extinguishers

- Maintains all inspection and testing records for Hanford site fire systems, and maintains all maintenance records for all site facilities except those managed by PNL, FFTF, and WPPSS

- Provides cognizant engineering authority services for all landlord facilities

- Maintains the spare parts inventory for all site facilities except for those managed by PNL, FFTF, and WPPSS. 
- Maintains individual firefighter/Emergency Medical Technician (EMT) proficiency and certifications of technicians in order to provide immediate backup support for fire suppression and emergency medical services

- Maintains and operates a work control center to support the testing and maintenance of fire systems

- Administers the site-wide vendor contract for the testing and maintenance of special chemical fire systems

- Develops and maintains fire system testing and maintenance procedures

- $\quad$ Provides all required testing, inspection, and repair of the SCBA and respiratory protection equipment used by all site contractors. This service includes refilling of empty cylinders, and sending cylinders off site for periodic hydrostatic testing (WHC, 1993).

\section{Other Organizational Activities}

The EMS program at the Hanford site is administered by the HFD but interfaces with HEHF, security, site operations and management, as well as county authorities. The HFD provides Prehospital Emergency Medical Services to all individuals on the Hanford reservation. The EMS program provides both Advanced Life Support (ALS) and Basic Life Support (BLS) services to the site. It is under the medical direction of HEHF for off-line control and the Benton-Franklin County EMS office for on-line control. Geographically, the HFD is within the South Central EMS and Trauma Region of the State of Washington. All EMS personnel are certified and act under the license of the Medical Program Director (MPD). HFD acts through the authority of Benton-Franklin County MPD Dr. Jose Loera. The county MPD provides services which include standing orders, treatment protocols, transport and no-transport protocols, air transport protocols, triage and Multiple Casualty Incident $(\mathrm{MCl})$ protocols, dead at the scene protocols, physician at the scene policy, systems Quality Assurance/Quality Improvement (QA/QI), liaison with State and Regional EMS authority, and development and enforcement of systems standards. The On-line medical direction is provided by Dr. Hurley through monthly meetings at Kadlec Hospital with EMS providers in the Richland area. (Note: Attendance at these meetings is not mandatory). "On line medical direction provides supervision of the prehospital provider by physicians using communications equipment such as radio, land line telephones or cellular phones." (Roush, 1994). This is a shared responsibility by the emergency physicians at Kadlec hospital and with Dr. Hurley serving as the coordinator and county MPD. Off-line medical direction is provided by Dr. Ross Ronish, the Site Medical Director who reviews all MCIs. Off-line duties which have been delegated and documented by letter of delegation to $\mathrm{Dr}$, Ronish, the Site Medical Director are as follows:

- $\quad$ Provide guidance and training for ALS and BLS personnel.

- Audit educational performance and skill maintenance of EMS personnel.

- Conduct run reviews with ALS personnel and maintain a quality assurance mechanism.

- Audit storing, dispensing and administering controlled substances, in accordance with state and federal regulations and guidelines.

- Assist with the development and up-date of written patient care protocols. 
From discussions with HFD personnel, there appear to be discrepancies between county protocols and guidance provided by the site medical director. Further, there appear to be potential discrepancies between authorities and responsibilities stipulations in the Hanford Site Emergency Medical Plan and those that have been delegated to the site medical director by the MPD.

\subsubsection{Applicable requirements}

The organization and scope of services of the HFD are determined by regulatory drivers, national standards--primarily those issued by the National Fire Protection Association (NFPA), accepted fire protection industry standards, and expert opinion. The following apply to or impact the organization, deployment, operations, and practices of the HFD:

DOE ORDER 5480.7A (2/17/93) stipulates that a fully staffed, trained and equipped fire department/brigade shall service all DOE facilities. Additionally, this order states that all NFPA codes and standards are mandatory. NOTE: At the time of writing, DOE ORDER 5480.7A has been canceled. It has been replaced by DOE Orders 420.1 and 440.1 and the associated implementation guides. The content of these is similar, as are the resulting implications for the HFD. However, the canceled order is considered to remain in effect until the WHC contract is modified to delete the reference to the requirements in the canceled orders.

RLID 5480.7 (Jan. 1994), "Fire Protection," supplements and implements the requirements of DOE Order 5480.7A, FIRE PROTECTION, of 2/17/93, assigns responsibilities, and provides requirements for an effective fire protection program at The U.S. Department of Energy, Richland Operations Office (RL).

WHC-CM-4-41, (9/30/93), "Fire Protection Program Manual," describes the organization, responsibilities, programs, support services, and authorities of the HFD.

Washington Administrative Code (WAC). EMS programs in the state of Washington are subject to multiple layers of control for all aspects of the programs. These layers inciude Federal, State and local regulations and licensing requirements as well as national standards and organization specific standards. Ambulance services in the state of Washington must be licensed under WAC 246-976-260 (Statutory Authority: RCW 43.70.040 and RCW 93.01.148) and have a medical program director (WAC 246-976-920). WAC-246-976-920 defines the role of the medical director for EMS Trauma Certified Personnel. Section 3 allows for the delegation in writing "any duties, other than those described in subsection (2) c, j, and k of this section to other physicians." This provides the basis for Dr. Hurley and Dr. Ronish to act as on and off line control.

\subsubsection{Recommendations}

None. Recommendations which may impact the organization are cited in other sections. 
WHC-SP-1180, Vol. 1

\subsection{ORGANIZATION AND MANAGEMENT}

\subsubsection{Personnel, Existing Conditions}

As of January 1, 1996, the HFD had a total of 149 Full Time Equivalent (FTE) positions. Personnel are distributed within the HFD by organizational division/unit as illustrated in Figure 9-1.

Seventy-seven personnel of the 149 HFD FTE count are assigned to the three emergency response shifts. Sixty-one personnel including 28 firefighter trained positions of the total FTE personnel count are assigned to Fire Protection System Administration, Testing, and Maintenance. The 28 FTE firefighter personnel assigned to Fire Protection Systems Administration and Testing have work associated with fire protection system inspection and testing as their primary responsibility. However, these personnel are trained, and equipped as emergency response firefighters. They can be activated during their work day, or by recall, to augment the station firefighter response crews.

Two personnel are assigned to all comprehensive fire prevention activities not related directly to the fire protection systems, and two are assigned as training officers. One secretarial position supports these. Five FTE positions provide overall Departmental leadership and "central office" support.

Non-uniformed HFD personnel include the following: (1) three positions in the Chief's office (staff assistant, secretary, and program administrator), (2) twenty positions including the maintenance manager, 8 electricians, 8 pipe fitters, and 3 schedulers of the Fire Protection Systems Maintenance unit, and (3) approximately 13 additional personnel serving as fire protection/plant maintenance engineers, and support staff.

All members of the HFD, (uniformed and non-uniformed) are employees of WHC. Firefighters are represented by the International Association of Fire Fighters, Local \#1-24. Captains and ranks above that level are considered exempt management. All electricians are represented by the International Association of Electrical workers, Local \#77. The pipefitters are represented by the Plumbers and Steam Fitters Union, Local \#598.

\section{HFD Management and Responsibilities Summary}

\section{Chief}

The Chief is responsible for overall management of the HFD. Primary duties and responsibilities include providing overall leadership and control of emergency events as the senior command officer in charge; overseeing all department programs; coordinating off-site mutual aid responses with outside emergency agencies; administering the HFD budget; forecasting manpower and equipment requirements; directing and managing personnel activities; establishing and maintaining contact with on- and offsite agencies; maintaining a comprehensive knowledge of site geography, operations and facilities for use in emergency response situations; directing the comprehensive investigation of job injuries and first aid 


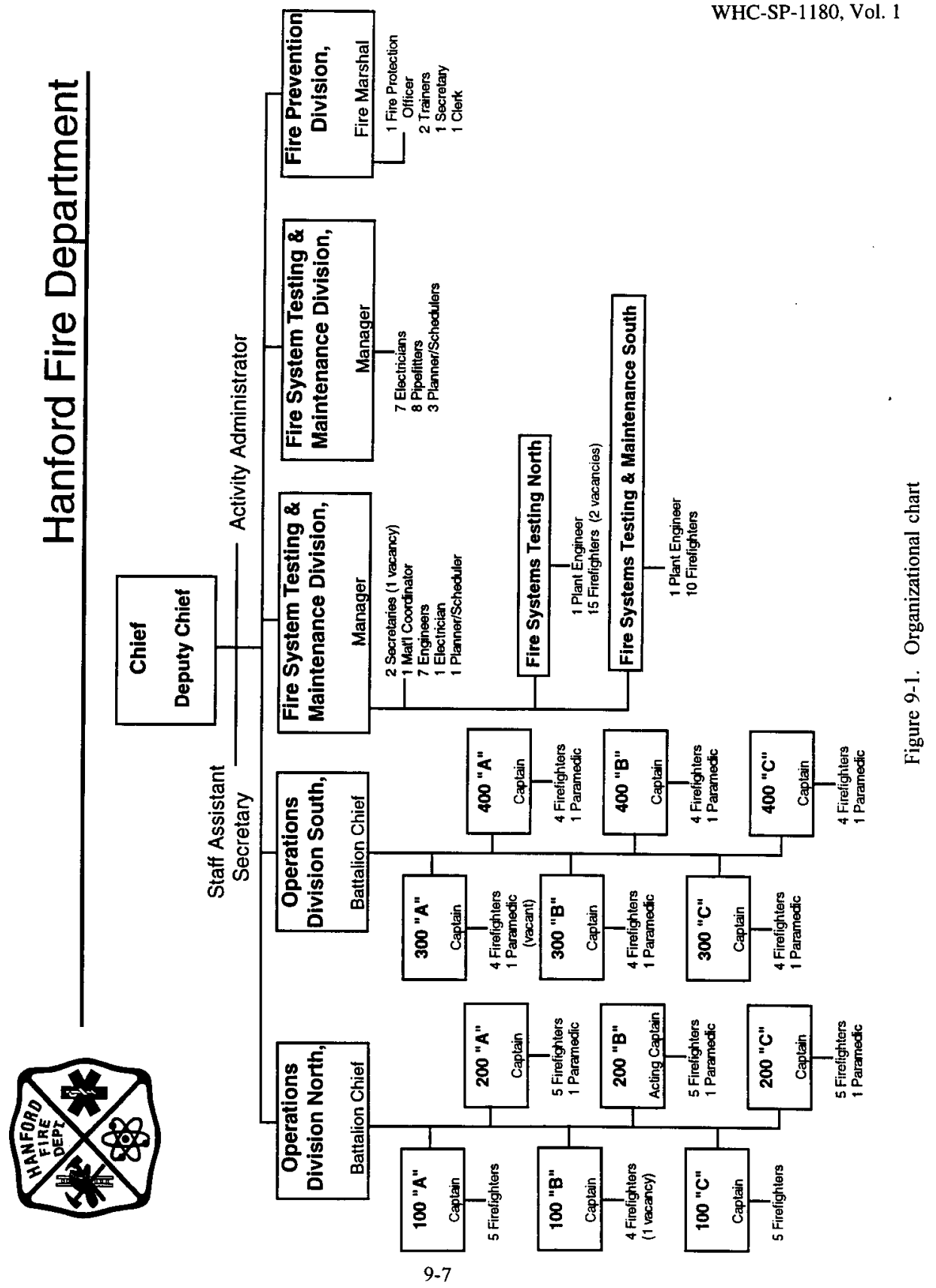


cases; and assuring the achievement of company, departmental and DOE-RL goals. The C/HFD is the Interpretive Authority of Codes and Standards on fire protection for WHC.

\section{Deputy Chief}

The Deputy Chief is responsible for assisting in the overall administrative and management responsibilities of the HFD. Primary duties and responsibilities include: In the absence of the chief, providing the overall leadership to the organization as well as integration of associated activities across the site; directing the planning and implementation of personnel development and motivational programs; directing and overseeing the organization programs, including small capital projects, line items projects, replacement of emergency response vehicles, apparatus, training programs, fire station maintenance and repairs, and personnel life safety protection equipment, managing personnel activities; ensuring line management consistently applies company and department policies and procedures; establishing and maintaining contact with on- and off-site agencies; directing and overseeing the comprehensive investigation of job injuries and first aid cases; and maintaining a general knowledge of site geography, operations and facilities for use in emergency response situations and budgeting activities.

\section{Program Administrator}

The Program Administrator represents the deputy chief's office as the point-of-contact for developing, implementing, tracking and/or reporting all administrative and financial policies, programs and requirements, including the site management system, enhanced performance measurement, productivity improvements, employing consolidated and cost effective leadership, and the Great Ideas program. Program administrator duties also include overseeing the development of departmental plans, developing the format for the plans, and tracking the plans to completion; coordinating the development of the site support program plan and the fiscal year work plan; identifying requirements and actions to support RL expectations for the FYWP; developing and tracking substantive milestones within the site management system that are integrated with other program requirements; and working with all department functions to develop milestones, actions plans, and staffing requirements.

\section{Fire Marshal}

The purpose and objective of the Fire Marshal position is to enhance the fire prevention aspects of a fire protection program. Duties include establishing good practice measures that are designed to reduce potential fires and fire duration; developing inspection programs, procedures, and training to comply with applicable regulations, codes and standards; periodically evaluating all department inspection programs; reviewing and interpreting all changes to applicable codes and regulations affecting the department, and developing and implementing required actions to ensure compliance. By DOE/RL letter of delegation of authority dated March 12,1991, the Fire Marshal has the authority to administer and enforce the Fire Prevention Program for the Hanford Site as granted by DOE/RL. 
The manager, Fire Protection Systems Administration and Testing is accountable for operating a comprehensive site-wide functional testing and maintenance program for fire protection systems. Principal responsibilities include oversight of the preventive maintenance and corrective maintenance program for fire protection systems in accordance with applicable requirements of national codes, standards and DOE Orders. They also include the hiring, development, and retention of quality employees as required to complete the tasks, as well as integration of associated activities across the site to ensure efficient use of resources, coordination of activities, and satisfaction of commitments to DOE.

\section{Manager, FP System Maintenance}

This position is accountable for maintaining the reliability of the Fire Protection Safety Systems. Principle responsibilities include directing the preventive maintenance program for fire protection systems in accordance with the applicable requirements of NFPA codes and standards and applicable DOE Orders. Other responsibilities include: managing the spare parts inventory, providing 24 hour/day response to repair impaired fire systems, and managing the freeze protection program for all site facilities with the exception of facilities managed by FFTF, PNL, and WPPSS.

\section{Battalion Chief}

The Battalion chiefs are responsible for ensuring that at least one staff command officer is available to respond to emergencies at all times. This person is accountable for directing, managing, and overseeing a command structure and initiating appropriate actions on all site emergency incidents, including fires, emergency medical concerns, hazardous material events, rescues, and mutual aid responses. The Battalion Chiefs are responsible for ensuring all emergency response crews are adequately trained and equipped to handle site emergencies, and that all fire apparatus are maintained to ensure readiness for emergency use.

Responsibilities include coverage of the entire site on a 24-hour basis and assisting with command responsibilities on off-site mutual aid incidents.

\section{Captain}

The fire captains are responsible for the leadership, preparation, and reliability of their emergency response crews. Captains must train their crews, complete response reports, ensure apparatus are restored to duty after emergency events, write employee evaluations, and act as the initial incident commander when they are the first officer on the scene of an emergency event. Captains must maintain a formal logbook of station activities, conduct building inspections, perform prefire planning, enforce all company and department policies, and oversee daily and weekly inspections of emergency response vehicles and equipment. Station captains are responsible for ensuring the station, outside grounds, and ancillary facilities are kept clean. 


\subsubsection{Applicable Requirements}

DOE Order 5480.7A stipulates that a fully staffed, trained, and equipped fire department/brigade shall service all DOE facilities.

DOE RLID 5480.7 stipulates specific requirements for the HFD.

\subsubsection{Recommendations}

None. Recommendations are addressed in other sections of this report.

\subsubsection{Management Information Systems}

\subsubsection{Management Information Systems, Existing conditions}

The HFD utilizes Management Information Systems (MIS) for several purposes. The HFD is able to document all critical elements of workload and budget, plus a wide variety of other operating data, through its computerized MIS. The HFD maintains a number of data base management applications for the purposes of recording, tracking and trending such data elements and statistics as fire alarm and emergency medical responses, fire protection system testing and maintenance, and training certifications/recertifications. In addition, other base administrative elements of the HFD's work scope are automated at a variety of levels.

Emergency response statistics are maintained in a database. The format of the database is unique to the site. Information in the database is limited to basic background information such as date, area, alarm number, type, cause, description, activating device, station responding, building number, and number of man hours.

The hazardous materials response vehicle is equipped with a computer and CAMEO software. CAMEO provides background information on hazardous chemicals and materials, plus evacuation parameters for use during hazardous materials emergency responses.

With the exception of the 100 Area Fire Station, all HFD facilities are connected to the Hanford Local Area Network (HLAN) and have access to electronic mail, electronic site forms, electronic calendaring and a variety of other generic site-wide applications. Because of its remote location, the 100 Area Fire Station has access to electronic mail through the use of a modem and standard telephone equipment.

As an element of the Westinghouse Hanford Company, the HFD does not process its own payroll or perform other generic human resource activities. These activities are all performed by WHC. HFD members do, however, submit their individual time cards electronically, utilizing electronic signature technology.

The site currently standardizes nearly all software packages procured and used at the site. Consequently, the ability to purchase unique software which may be beneficial only to the HFD is limited. The fire department has, since 1985, maintained a technological status 
quo under site technology standards, established and monitored by WHC and Boeing Computer Services (BCS) with RL approval.

Personnel are currently tracked at working incidents using a Passport system which meets the requirements of WHC-IP-0939, Section 1.14 "Passport Accountability System" and NFPA 1982 as indicated by HFD officials.

\subsubsection{Applicable requirements}

NFPA Codes and Standards stipulate appropriate data collection and record keeping in such areas as training (NFPA 1401), equipment testing (NFPA 1914; 1932), vehicle testing (NFPA 1911), firefighter health and safety (NFPA 1500), and fire reporting (NFPA 901).

SARA Title III and related OSHA regulations stipulate management information systems involving all aspects of hazardous materials response planning, preparation, and response.

The HFD Fire Protection Program Manual (WHC-CM-4-41) September 30, 1993 outlines records and data to be gathered and processed by the five HFD operating Divisions.

NFPA 1561 and NFPA 1500 call for an on-scene personnel accountability system. NFPA 1500 states "The incident commander shall initiate an accountability and inventory worksheet at the very beginning of operations and shall maintain that system throughout operations. (6-3.3) Company officers shall maintain an ongoing awareness of the location and condition of all company members. (6-3.3.3)

\subsubsection{Recommendations}

9.2.2.3.1 Maintain record keeping in accordance with national fire incident reporting system formats (NFPA 901).

\section{$\underline{\text { Supporting Statement }}$}

Maintenance of fire records in an universal style assures completeness of information obtained and contributes to the National data base of fire history. NFPA 901, Uniform Coding for Fire Protection, provides a common fire reporting language with a method for systematic information collection, processing, and use in order to comprise a complete fire reporting system. The purpose is to ensure that various fire service organizations will report their information in a manner which is compatible with other regional, national, and international fire and emergency organizations. The reporting system used at WHC does not comply with the definitions and coding structure outlined in NFPA 901. WHC uses an abbreviated reporting system using non-standard definitions and categories. The WHC coding structure generally utilizes broad categories and does not provide the level of detail found in NFPA 901. Whereas the existing reporting structure may meet the local requirements of WHC, the information is not compatible with other standard reporting systems. NFPA 901 references using the fire reporting system and incident reporting described in NFPA 902M. This is consistent with guidance provided by the DOE Order 420.1 and 440.1 Implementation 
Guide which states that: 'Emergency response records should conform with DOE reporting requirements and should be based on national standards of fire incident reporting (NFPA 902M) in lieu of site-specific reporting formats. This will facilitate consistent reporting across the Department.'

\subsection{EMERGENCY RESPONSE}

\subsubsection{Staffing/Response}

\subsubsection{Staffing Patterns, Existing Conditions}

During week-days, one Battalion Chief (BC) is assigned to cover the north area of the Site and one the south area. The North BC operates from the 200 Area Station and is responsible for the 100 and 200 Area Stations. The South BC operates from the 300 Area Station and is responsible for the 300 and 400 Area Stations. When only one BC is present on the Site, that person is responsible for all station areas. Fill-ins for long absences of a BC are provided by a selected Captain.

For immediate emergency response, the HFD assigns one Captain and five firefighters to each of the four stations, per shift. Time off may reduce the total number of responders from a station from six to five. Other responders are available on a back-up basis.

Possible response personnel, including shift firefighters, Testing and Services Firefighters (T\&SFF), and staff officers and personnel assigned to a 40-hour week-day shift (as noted) are:

- On-duty shift firefighters/EMTs/Paramedics/Driver-Operators: 16 to 20 per 24hour shift

- On-duty Captains/Acting Captains: 4 per 24-hour shift

- On-duty Battalion chiefs, on-site: 2 , week-days only

- On-duty Testing and Service Firefighters (T\&S FF),

12 (approx), 10-hour day shift Monday and Friday

24 (approx), 10-hour day shift Tuesday through Thursday

- On-duty Training Officers, 1 , week days only

Senior Staff are also response personnel.

Senior staff emergency responders, (any of whom may assume incident command), are: the Chief, Deputy Chief, Fire Marshal, and FSTM Battalion Chief. Senior staff are in addition to the operations Battalion chiefs, one of whom is always on call evenings, weekends, and holidays, to respond to the site as incident commander. The Chief is always on call unless the duty has been delegated to the Deputy chief. The Fire Marshal and FSTM Battalion Chief work a 40-hour week-day schedule.

The next due-to-work platoon can be recalled. There are no historical data available on number responding or time to site. Recall of next platoon personnel was used for wildland fire incidents approximately 7 times in 1994 and approximately 4 times in 1995 . Off-duty 
hazmat team members may be specifically called back to the Site. This occurred one time in 1994 and one time in 1995.

Mutual aid fire companies and/or ambulances are available, but are reported by HFD personnel to be limited to providing direct aid to non-radiological and non-hazardous materials incidents. Those limitations are not described in the current mutual aid agreements listed below:

- A 1994 Kennewick-HFD agreement for an ambulance ride along program.

- A 1994 Franklin County District 5 - HFD agreement for joint use of a multiple casualty incident trailer.

- A 1993 contract wherein HFD provides fire and EMS service delivery to WPPSS facilities on Site.

- A 1990 Tri-County Multiple Casualty Incident Plan.

- A 1986 agreement between HFD (DOE) and the Rattlesnake Fire Protection association for wildland fire mutual aid.

- A draft undated (1995) and unsigned automatic aid agreement between HFD and the City of Richland. (Agreed that "...During incidents involving radiological, mixed hazardous waste, and the treatment and transport of contaminated patients, Richland will provide a support function to Hanford Fire.")

- A Tri-County Mutual Aid Agreement (1995).

The Needs Assessment Team notes that the "Agreement for Automatic Reciprocal Fire Department Assistance," still in draft form, undated, and unsigned by either the City of Richland or WHC, states "during incidents involving radiological, mixed hazardous waste, and the treatment and transportation of contaminated patients, Richland will provide a support function to Hanford Fire."

The number of HFD on-duty emergency response personnel per shift may vary from 20 to 26. Augmentation during week days from T\&S FF and staff personnel can range from a low of approximately ten to a high of approximately 29 . A week day mutual aid call for a non-hazmat structural fire incident or wildland fire on-site likely is estimated to produce approximately 25 to 30 personnel from the nine surrounding departments as an initial assignment.

A major incident occurring at night or on a weekend could resuit in the deployment of 20 to 24 responders. A recall of off-duty personnel, depending on the incident location on the site, could take 60 minutes for staff augmentation at the incident scene. Under existing operating protocols, personnel are recalled by individual telephone calls. They then drive to their duty fire station on site to obtain their protective clothing. If so instructed, they then proceed to the incident location. The time required for mutual aid departments to arrive could be similar, although they would proceed either to the incident directly, or to cover an HFD station.

The T\&S FF may crew the fire apparatus to respond to an emergency, and act as backup crews for second alarms or to fill in for a station firefighter for short-term absences. 
T\&S FF have been recalled during the day 4-7 times per "active" wildland fire season. They also respond to hazmat events when needed, approximately 5-10 times per year. Other emergency incidents requiring T\&S FF support, including structure fires, mutual aid requests, and other emergencies, average 6-10 per year. Thus, overall, emergencies may require T\&S FF to man backup fire apparatus approximately 15-27 times per year to respond to emergencies. They are called in from the field to crew the reserve pumpers at the stations approximately 15-20 times per year. Commonly, this occurs when station personnel are tied up on multiple incidents, particularly EMS responses.

T\&S FF also cover short term absences of station firefighters. In some cases, T\&S FF can respond from the field in their vehicles. If a key position must be filled (pumper operator, EMT, paramedic), the T\&S FF must report to the station and remain with the response crew.

$\underline{\text { EMS }}$

The Hanford fire department provides prehospital emergency medical services to all individuals on the Hanford reservation. These services are provided by utilizing fire suppression personnel and cross-training them to be able to perform these essential life support tasks. These services include basic (BLS) and advanced life support (ALS). The 200 and 400 area stations provide Advanced Life Support (ALS) response utilizing paramedics and transport capable vehicles on a full time basis. Presently, the 300 area station provides an ALS response only $2 / 3 \mathrm{~s}$ of the time since a paramedic position is vacant. When an ALS response is not provided, the 300 station provides a basic life support (BLS) response utilizing firefighter/EMT-D personnel. The 100 Area station provides a BLS response utilizing firefighter/EMT personnel.

\section{$\underline{\text { HAZMAT }}$}

Currently, on each shift, at least six personnel must be hazmat technicians, not counting team leaders. In addition, at least one hazmat team leader must be on duty at all times.

\section{$\underline{\text { Mutual Aid }}$}

Mutual Aid is provided to surrounding jurisdictions as detailed in Section 9.7.8. In situations such as a mutual aid call off Site, or where state mobilization has been called, minimum staffing may consist of six personnel at the 200 area Station and five at the 400 area Station. Under those conditions of minimum site protection, a recall of off-duty personnel is sounded immediately.

\section{Training}

Training activities, pre-planning, and similar tasks necessitate that crew members and selected apparatus leave their station at time, while remaining available (in-service) to respond to an emergency call. Should training at the HAMMER site occur--as currently contemplated- 
-HFD management will adjust deployment to provide area coverage. Methodologies include the use of fill-in personnel as is currently done.

\section{Medical/Fitness}

The number of firefighters who are on permanent light duty and unable to perform as firefighters ranges from one to three. The shift dispatch positions have traditionally been manned by those on permanent light duty.

In addition, there is at least one firefighter on temporary light duty 50 percent of the time. This is often the result of an injury, surgery, or illness, and is of a limited duration. By policy, an Operations firefighter will be put on days if the light duty period exceeds one week.

There are a number of firefighters who have been cleared for full duty by the Hanford Environmental Health Foundation (HEHF) but have work restrictions. For example, a firefighter may be cleared for full duty but not be allowed to participate in the voluntary physical fitness program due to medical concerns.

There also are firefighters who have been precluded from duty involving confined spaces or wearing of self-contained breathing apparatus. In some cases, these firefighters have shown evidence of apparent claustrophobia. HEHF has placed restrictions on using these firefighters in SCBA or confined spaces, but cleared them for full firefighter duty.

Due to the cited duty constraints, the firefighters are not utilized in emergency operations. Nevertheless, they are not placed in "limited duty status" since they have been cleared for "full duty". HFD management personnel report that "fill-in personnel" are provided (through expenditure of overtime funds) to enable HFD to maintain a fully functioning response capability.

\subsubsection{Response Posture, Existing Conditions}

The current protocol to a fire call dispatches a quint apparatus (aerial device/pumper) and an ambulance from the nearest station, and a quint from the next closest station. This response produces six to eight personnel on the two quints and two personnel on the ambulance. A second alarm response would come from the remaining ambulance and from the quint in the third closest station.

Depending on the nature of the incident (medical, hazmat, range fire, etc.) and what is housed in that particular station, some other type of apparatus may be selected by the crew. For calls involving hazardous materials, or for other types of non-fire calls, the appropriate vehicle (other than the quint) responds, in addition to the ambulance. For brush fires, the smaller brush trucks, the larger pumper-tankers, and the water tender respond.

Expected HFD Emergency Responder staff levels have been determined by HFD officials for different emergency events. They are summarized below and illustrated in Figure 9-2. 
WHC-SP-1180, Vol. 1

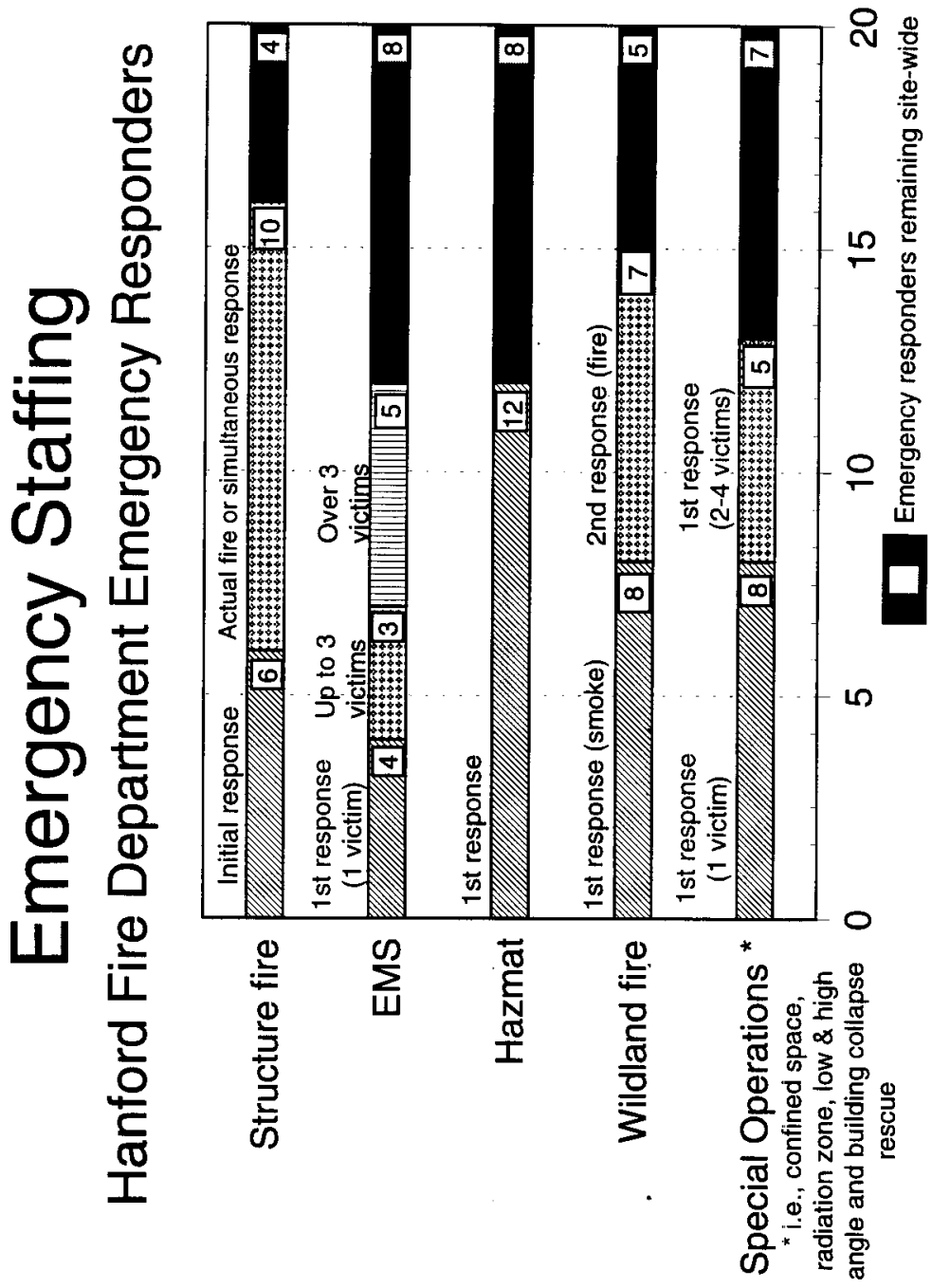

Figure 9-2. 
$\underline{\text { Structure fire }}$

- Initial Response

8-10 responders (6-8 on two quints; 2 on ambulance)

- $\quad$ Second Alarm

5-6 responders (3-4 on third quint; 2 on ambulance)

$\underline{\text { EMS }}$

- $\quad$ First Response

7-8 responders (3-4 on quint; 2 on initial ambulance; 2 on move-up ambulance)

- Up to 3 victims

3 additional responders ( 3 on second ambulance [ 2 patient attendants])

- $\quad$ Over 3 Victims

4 additional responders ( 2 on third ambulance; 2 on fourth ambulance)

\section{HAZMAT}

- $\quad$ First Response

12 responders ( 1 incident commander; 1 team leader; 1 safety officer; 2 entry team; 2 backup entry team; 1 medical; 2 decon team; 1 decon team leader; 1 resource leader)

\section{Wildland Fire}

- $\quad$ First Response (smoke)

8 responders ( 1 incident commander; 2 each on three pumper tankers; 1 on grass unit)

- $\quad$ Second Response (fire)

10 additional responders ( 2 each on three additional pumper tankers; 1 each on two additional grass units; 1 medical and 1 staging officer)

\section{Special Operations}

- $\quad$ First response (1 victim)

8 responders ( 4 on engine; 2 medical; 2 on squad/rescue unit)

- $\quad$ First response (2-4 victims)

5 additional responders ( 3 engine; 2 medical)

\section{Incident Command}

The HFD currently is the designated lead response agency for all Site fires, hazardous material incidents/emergencies, emergency medical and ambulance service, and special emergency rescue (RLID 5480.7). The HFD is now being considered as the lead response agency for all emergencies with the sole exception of declared security incidents. 
Incident Commander

The duties assigned to the Incident Commander (IC) are many and varied. They are defined in WHC-IP-0939, Section 2.3, Incident Command. To summarize, the IC is responsible for overall management of the incident. The IC must perform the following: (1) assess incident priorities, determine strategic goals, determine tactical objectives, and develop an incident action plan; (2) determine the appropriate organizational structure for the incident and manage resources accordingly; (3) organize the overall emergency activities while ensuring firefighter safety and coordinating with outside agencies; and (4) act as the Operations, Planning, and Logistics officer until such time as those positions are appointed.

On all incidents, the IC will be the first-in fire officer until relieved by a higherranking officer.

\section{On-Scene Safety}

On-scene safety is the responsibility of all responders, but the scene safety officer has this as the sole responsibility. WHC-IP-0939 describes the responsibilities of the safety officer. In summary, the Safety Officer is a member of the general staff and acts as the primary safety advisor to the Incident commander. The Safety Officer is responsible for monitoring and assessing hazardous and unsafe situations and developing measures for assuring personnel safety. The Safety Officer must be aware of active and developing situations. The Safety Officer has the authority to stop or prevent unsafe acts immediately, although the officer will generally correct such acts through the normal chain of command.

The HFD does not have trained safety officers, and there are no designated Safety Officers on each shift. No HFD personnel are members of the national safety officers professional association. At working incidents, an ad hoc safety officer is appointed, unless the Fire Inspector is present, in which case he takes the assignment.

\subsubsection{Response Time Existing Conditions}

\section{General}

Response times vary by area. For purposes of this analysis, response time is the time for an HFD vehicle to reach the incident once the HFD has received the initial notification of the incident at the alarm dispatch center. Quantitative analysis of actual response times is limited since precise response time records are not maintained. The computer aided dispatch system currently in use by the HFD records response times in minutes only. Thus, it is possible for records to be inaccurate up to 1 minute and 59 seconds.

To analyze response times, a time-speed distance computer generated analysis was utilized. An explanation of the analysis is detailed in Appendix D. To summarize, emergency response run times to most site facilities from the first due station are calculated assuming an average speed of $45 \mathrm{mph}$ for fire apparatus and $50 \mathrm{mph}$ for ambulance vehicles. Distances are analyzed only along major response routes. Lower speeds are assumed within fenced site areas. Initial response times to most site facilities in the WPSS, 200 East, 300 and 
400 Areas are determined to be less than 5 minutes. Run times to most facilities in the 200 West and 100 Areas from the first due station have been calculated to be less than 10 minutes with the majority of structures reachable in less than 7 minutes travel time. Note: Additional time associated with dispatch, and station departure will cause actual response times to be longer than calculated run times. Theoretical response times can be estimated by adding 1 minute for dispatch and I minute for station departure to the calculated run time.

Second due units respond from the surrounding station(s). Second due unit response times vary. Run times from the 200 station to all 100 area facilities with the noted exception of $100 \mathrm{H}$ and $100 \mathrm{~F}$ area facilities have been estimated as less than 11.5 minutes. Run times from the 400 area station to the 300 area facilities and most 1100 area facilities and from the 300 area to most 400 area facilities have also been estimated to be less than 11.5 minutes. Run time from the 300 area to the WPPS facilities has been calculated to be less than 12 minutes.

\section{EMS Actual Response Time Analysis}

An analysis of EMS response times was conducted based on Medical Incident Report data for 1994. Average response times for all calls by station is shown in Table 9-1 below:

Table 9-1. EMS Average Area Response Times

\begin{tabular}{|c|c|}
\hline Station & Response Time (minutes) \\
\hline \hline 100 Area & 8.2 \\
\hline 200 Area & 4.2 \\
\hline 300 Area & 4.3 \\
\hline 400 Area & 7.6 \\
\hline
\end{tabular}

When adjusted to exclude response times to destinations outside their respective areas, the 100 and 300 Area stations response times are significantly lower, as noted in Table 9-2.

Tabie 9-2. EMS Within Area Adjusted Average Response Times

\begin{tabular}{||c|c|}
\hline Station & Adjusted Response Time \\
\hline 100 Area & 6.5 minutes \\
\hline 400 Area & 5.7 minutes \\
\hline
\end{tabular}

Out of area calls are the result of a unit being out of service, the 300 area station initially responding with BLS (EMT) service and requesting ALS (paramedic) service from the 400 Area station, or for motor vehicle incidents. The average response times for these occurrences is noted in Table $9-3$ below: 
Table 9-3. EMS Out of Area Average Response Times

\begin{tabular}{|c|c|}
\hline Station & Out of Area Average Response Time \\
\hline 100 & 13.3 minutes \\
\hline 400 & 17.2 minutes \\
\hline
\end{tabular}

Note: In a two month review of all EMS responses, the majority of the responses for potentially critical complaints (chest pain, allergic reaction, and seizure) were to the First Aid Station of the area, rather than the job site.

\subsubsection{Applicable requirements}

DOE 420.1 stipulates a Site needs assessment to determine recommended response numbers and other critical variables. The assessment is required to be based on response to a single incident (e.g., a fire) involving emergency medical assistance.

DOE-RL Fire Department Emergency Service Description quantifies the minimum acceptable response crew size for building fires requiring an internal attack to be 5 . Responding fire crews are expected to be at the fire scene within 5 to 7 minutes. Any required back up crews are expected to arrive within 10 to 12 minutes from the time of initial alarm.

The "DOE Implementation Guide for use with DOE Order 420.1, Fire Safety Program," (DOE, 1995c) It states "The minimum number of trained firefighters necessary to begin interior structural firefighting should be five, in line with long standing DOE policy."

In addition, the Implementation Guide states "The minimum number of personnel required for exterior firefighting, hazardous material incidents, specialized rescue or other related events should be based on pre-planning where possible and the judgment of trained and experienced fire department officers."

NFPA 1500, "Fire Department Occupational Safety and Health Program," is relevant to the issue of firefighter safety and provides further detailed requirements for the industry.

In summary, NFPA 1500 requires four firefighters on the scene before performing interior structural firefighting operations; and, when firefighters or other personnel actually perform interior attack, they are to enter the hazardous area using teams of at least two members. An exception exists which states that if, upon arrival at the scene, members find an imminent life-threatening situation where immediate action may prevent the loss of life or serious injury, such action shall be permitted with less than four persons on the scene, when conducted in accordance with the provisions of Section 6-2 ("Risk Management During Emergency Operations").

NFPA 1500 requires a fire officer to be the incident manager. This NFPA requirement, along with the other requirements discussed above, results in a minimum of four members on the scene before beginning to fight interior structural fires: two inside as a team. 
operating in the hazardous area; two outside the hazardous area, where one is standing by and another may be performing another function, such as managing the incident, as long as its performance does not interfere with the second outside person's ability to assist in the event of an emergency.

Members who arrive on the scene of a working structural fire prior to the assembling of four persons may initiate exterior actions in preparation for an interior attack. These actions may include, but are not limited to, establishment of a water supply, shutting off of utilities, placement of ladders, laying of the attack line to the entrance of the structure, or exposure protection.

OSHA "Interpretation on Interior Structural Fire Fighting and Accountability: Response to IDLH (immediately dangerous to life and health) Atmospheres," (5/1/95). Clarifies Hazwoper, 29 CFR 1910.120, and other sections. It states the following:

"Firefighters are often involved in emergency response operations when serving as members of an organized Hazmat team, and as such, would be covered by the Hazwoper standard.

Paragraph $(q)(3)(v)$ of Hazwoper requires that 'operations in hazardous areas shall be performed using the buddy system in groups of two or more.' In addition, paragraph $(q)(3)(v i)$ states that 'back up personnel shall stand by with equipment ready to provide assistance or rescue.' This section means that as a minimum the buddy system must be used within the hazardous area (entry by at least two persons) and at least two additional personnel shall stand by outside the hazardous area. Thus, there must be a least four individuals at the site. One of the two individuals outside the hazard area can be assigned to another task, provided that the second assignment does not interfere with the performance of the standby role.

One of the individuals outside of the hazard area may be assigned more than one role, such as the incident commander in charge of the emergency or operator of fire apparatus, where it does not jeopardize worker safety and health.

Incipient fires, which do not create IDLH atmospheres or require the use of SCBA's, or firefighting activities conducted from outside a structure are not addressed by this standard interpretation."

Comparing the DOE and NFPA minimum personnel requirements for interior structural firefighting, the primary distinction appears to be the DOE requirement for a command officer in addition to the two teams of fire fighters.

OSHA 1910.120 (q)(3)(i) and the SARA Title III legislation call for a trained hazmat incident commander at each hazmat call. A designated "safety official" is required under OSHA. 
NFPA 1521, Standard for Fire Department Safety Officer, lists the requirements of the position, and the responsibilities.

NFPA 1500, Standard on Fire Department Safety and Health Program calls for the appointment of "a designated fire department safety officer to comply with NFPA 1531."

NFPA Standards 471 and 472 describe incident management procedures and incident commander responsibilities at hazmat incidents.

NFPA 1561, Standard on Fire Department Management System, provides details of the incident command system and operations.

NFPA 1500 calls for an incident commander to be "responsible for the overall safety of all members and all activities occurring at the scene" (sect 6-1.3).

HFD is licensed by the state of Washington as a verified ambulance service under WAC 246976-240 and WAC 246-976-390. The South Central Region has defined the Hanford site area as a suburban area for the purpose of trauma verification. Suburban areas mandate an EMS/TC response time of 20 minutes for trauma. Verified Ambulance Service is stipulated to meet the minimum agency response times $80 \%$ of the time.

DOE criteria also reference the potential application of DOD criteria. DOD 6055.5 specifies fire department response time and capability criteria.

DOD Instruction 6055.6, (DOD, 1988). DODI 6055.6 specifies the maximum number of allowed first-line pumpers based on the estimated fire flow for buildings of strategic importance to the site mission. The fire flow requirement is the primary but not the sole determinant for calculating the number of pumpers. Whereas an activity of great mission importance would be assigned the full number of manned pumpers indicated under the fire flow calculation technique, activities of lesser mission importance would receive fewer pumpers even though it might have the same calculated fire flow requirement. Likewise, additional pumpers may be required based on DOD prescribed response time and distance criteria.

The maximum water flows for determining fire department pumper requirements are based on occupancy classification, type of construction, and automatic sprinkler protection. Most buildings which were formerly considered to have strategic importance at the Hanford site are non-combustible, industrial structures equipped with automatic sprinkler systems. The maximum water flow, based on DODI 6055.6, for noncombustible/sprinklered structures is $1,500 \mathrm{gpm}$. This water flow requirement corresponds to a maximum of 1 manned pumper based on DODI 6055.6.

DODI 6055.6 prescribes the maximum travel distances and/or response times for structural fire companies. For industrial buildings, the maximum travel distance is 2 miles and the maximum response time is 4.5 minutes for half the required fire companies. The remaining half of the required fire companies have a maximum response time of 8 minutes. The number of allowed pumpers based on the fire flow calculation technique is increased in order to meet 
the prescribed travel distances and/or response times. Again, the total number of pumpers may be reduced based on the mission importance of the buildings being serviced.

\subsubsection{Recommendations}

9.3.3.1 There shall be 17 response personnel on duty assigned to stations to handle, simultaneously, one hazardous materials or fire incident and one EMS incident(this number includes the Battalion Chief, but excludes the dispatcher). Actual deployment of the 17 baseline personnel shall be determined by HFD management, in order to achieve the services capabilities cited in Recommendation 9.3.3.2. A staffing multiplier to determine actual minimum on-duty staffing levels shall be developed by HFD officials to account for time off allowed by contract, shift arrangements, sick days lost, light duty personnel, station configuration and crew deployment, shifts in area populations and occupancies, activity, and resulting workloads, recalls, training assignments, fire watches, etc.

\section{Supporting Statement}

As required by the DOE Implementation Guide, the recommended responders provide initial coverage, based on HFD Emergency Response staff levels, for a credible incident scenario (i.e., Hazmat or fire) involving a casualty requiring emergency medical assistance. Section 7, Site Hazard/Event Identification, documents numerous hazardous materials incidents which would require a Hazmat response and which could involve a casualty requiring emergency medical assistance. Site operations performed at night and on weekends invariably involve work with hazardous material and warrant maintaining a continuous (24hour/day, seven days/week) minimum incident response capability to address this most demanding first response.

A working structure fire or other serious incident may require more than the 17 personnel cited in recommendation 9.3.3.1. In addition to the 17 response personnel stipulated in Recommendation 9.3.3.1, there are from 15 to 30 additional responders on site during week-days, comprised of the T\&S FF and senior HFD staff, all of whom are considered by HFD as trained and equipped firefighters/EMTs/Officers and could respond to an incident. In addition, it is expected that sufficient off-duty personnel, including T\&S FF can be recalled and on site within 60 minutes, depending upon incident location. Mutual aid fire departments, with on-duty personnel, can be dispatched immediately from Richland, Kennewick, and Pasco. Volunteer fire departments can be dispatched from the mutual aid signatories. Since T\&S FF and 40-hour week-day staff currently are not present on site during week nights, week-ends, or certain holidays, a working structure fire occurring during those hours can result in an immediate recall of HFD personnel and/or selected mutual aid fire departments. Until the arrival of additional personnel, initial attack personnel will continue control and mitigation efforts commensurate with the resources that are available.

As previously noted, the critical baseline staffing capability of 17 consists of a fire or hazardous materials incident, and one EMS incident. The critical baseline service capability cited in recommendation 9.3.3.2 establishes the service capabilities by station for the site, but allows HFD management to establish and adjust station staffing levels to meet service demand. 
In order to handle a second incident or an incident which exceeds critical baseline staffing capabilities, T\&S FFs and staff personnel are available during week days. For all other time periods, an automatic recall system as recommended in this section must be incorporated. (It is recognized that there have been few identified recalls of personnel to the Site in recent years.) If necessary, a defensive posture could be maintained at a fire incident until additional personnel or mutual aid respond to the incident.

Extensive use of automatic detection and extinguishing systems throughout the Site provides the planned-for assurance that most fires can be handled by crews of fewer number than typically necessary when higher gallon per minute flows are required in non-sprinklered occupancies, as are common in municipalities. Differentiated and reduced staffing appear feasible due to (1) the relatively small number of technical rescue calls, (2) the number of EMS calls, (3) the relative small number of simultaneous calls, and (4) the lack of mission important buildings in the 100 Area. In working structure fire incidents, the first arriving station response crew, if fewer than five personnel, will be setting up for any needed interior structural fire-fighting until the second responding station arrives or the DOE minimum number of 5 trained fire fighters is met. Thus any time delay in initiating interior structural fire-fighting is expected to be minimal.

Operations performed by the critical baseline staffing assume and incorporate the following, with certain of these described in more detail elsewhere in this Report:

1. A Battalion Chief/Incident Commander is present on the Site at all times;

2. Should fewer than five responders arrive initially on the scene, incident size up and outside preparatory work may be conducted prior to interior attack until a fifth responder arrives. If deemed necessary and safe to do so by the on-scene commander, rescue entry may be made by no fewer than two personnel;

3. For fire calls, the dispatch for a first alarm assignment is two quints and an ambulance;

4. For fire calls, the first alarm assignment includes a quint from the second nearest station;

5. T\&S FF working weekdays may be activated for response to the scene and to crew the reserve pumpers for stand-by at the stations, as now;

6. Weekday support and command staff, such as Training Officers and Inspectors, are capable of being activated for response as in (5) above.

7. When warranted, night and weekend working incidents can initiate an immediate recall of selected, or all, off-duty personnel, including T\&S FF;

8. Mutual aid from fire departments which have agreed to assist with ordinary structure fires, wildland fires, and with non-contaminated EMS victims will be requested when 
warranted. Mutual aid, when warranted, will also be requested for support work at hazmat incidents, and for station coverage, as now;

9. Mutual aid sent from HFD shall not reduce on-duty response personnel below baseline deployment.

10. All HFD response personnel eventually will be trained to the hazmat technician level; all non-paramedic firefighters eventually will be trained to the EMT-D (defibrillator) level; each shift will have the Captains trained as incident safety officers, in keeping with NFPA 1500, 6-2.3 and A-6.2.3 and with NFPA 1521 (Safety Officer).

Additional personnel also shall be trained as incident Safety Officers, so that Captains may delegate that responsibility at larger scale incidents; All Captains are trained in both response tactics and incident command;

11. Back-up paramedic ambulances will respond from adjoining Mutual aid fire departments. Per mutual aid agreement, a Richland ALS ambulance will back up the 300 area BLS-D ambulance;

12. All baseline level response personnel are medically qualified to perform any and all duties normally required at an incident.

13. The Battalion Chief/Incident Commander is not responsible for coordinating and integrating significant mitigation activities performed by non-HFD personnel.

Assumption of these types of responsibilities by the Battalion Chief/Incident Commander constitutes a new role and may necessitate an additional incident staff person to support the effective integration of HFD and non-HFD activities.

During the next 50 years, the existing major structural hazards on Site will undergo decontamination and decommissioning (D\&D). As buildings, facilities and associated hazards are eliminated, the site's population is planned to decrease. The active 1994 population of 10,700 is scheduled to decrease to approximately 7,550 by the year 2000 . This population decrease may result in an overall reduction in the incidence of emergency service calls. Based on projected activities, the increase in construction activities may result in an increase in technical rescue and EMS incidents during the D\&D stages of Site transition. As reductions in workload take place, shifts and overall reductions in emergency response services should be possible. The number of response personnel on duty at the site during any period should not fall below 17, the number necessary for the most demanding initial response (combined hazmat (12) and EMS (4) and one (1) battalion chief)."

9.3.3.2 Based on the existing and predicted hazards and conditions of the Site, critical baseline fire station operating times and service capabilities shall not be less than the following:

\section{$\underline{\text { Stations }}$}

100 Station: Open weekdays -fire and BLS-D (defibrillator) response capability; closed at times of low area population and activities; currently, nights, weekends, and holidays. 
200 Station: Open 24 hours - 7 days/week for fire response and *ALS response capability.

300 Station: Open 24 hours - 7 days/week for fire, and BLS-D capability.

400 Station: Open 24 hours - 7 days/week for fire response and *ALS response capability.

*ALS is the preferred level of service at this station. This service level, at the HFD management discretion could be relocated to adjust to a change in site populations, activity or risk.

\section{Supporting Statement}

The baseline station operating times and service capabilities are considered to be critical minimum baseline levels necessary to provide adequate initial response to credible Site events.

The baseline station operating times and service capabilities for the 100 Area fire station stipulate that the station be open on weekdays to provide fire and basic life support (BLS-D) response capability and closed at times of low area population and activities such as nights, weekends, and holidays. This recommended change from existing station response capability is based upon the 100 Area HFD response history, the current and projected 100 Area population as well as current and projected 100 Area activities and is summarized below.

Table 8-3 indicates that the average number of responses to actual fires per year for the 100 Area from 1990-1994 is 4 . Of the 17 actual fires that occurred during the last three years, $12(71 \%)$ incurred a response by the HFD between the period 0800-1559 hours. Figure 8-11 indicates that the average number of patient contacts per year for the 100 Area for the period 1993-1995 is 6. This is significantly fewer patient contacts when compared with the 200, 400(includes WPPS) and 300(includes 1100) areas. Further, of the 19 patient contacts that occurred during the last three years $15(79 \%)$ occurred between the period 0800-1559 hours.

For the period 1993 to 1995 , Figure 8-8 of the FDNA shows that the majority of responses (fire hazardous materials, vehicle accidents, fire protection system activations, ambulance assists, etc.) served by the 100 Area occur during the hours of $0800-1600$ (daytime shift). The relatively low number of responses to actual fires and the relatively low number of patient contacts that occur during non-daytime shift hours, warrants establishing HFD baseline levels which maintain staffing at the 100 Area station only during those periods of peak population and peak operations when most HFD responses are expected to occur. As noted in Appendix section B1.2, the majority of the estimated 100 Area Population, work during day shifts.

Since Safety Analysis Reports (SARs) and Fire Hazard Analyses (FHAs) do not rely upon emergency responses from the 100 Area fire station, it is concluded that an increase in 
initial response time to 100 area fires, during periods when the 100 Area fire station is closed, will not affect the safety basis of the 100 Area nuclear facilities nor result in an unacceptable increase in risk. Nevertheless, it is noted that the increase in response time to the 100 Areas may result in an increase in the severity of the event and its consequences, particularly fires. Should times of peak population and activities change such that a significant increase in patient contacts and an unacceptable fire loss is expected (particularly due to increased response time) then a reexamination of operational hours for the 100 Area Station is warranted.

The Hanford site's 200 area includes both the 200 East and the 200 West facility complexes, each with a significant number of facilities and population requiring emergency services provided by the 200 Area fire station. The station's location, approximately at midpoint between the two areas, minimizes response time to both facility complexes, with most of the 200 Area reachable within five minutes running time, and the remainder of the built-up 200 area reachable within ten minutes.

In addition, the 200 Area station allows running times to much of the 100 Area within approximately twelve minutes, thus providing either initial response to fire and EMS during offshift hours, or full initial response (second apparatus) coverage when the 100 Area Station is staffed.

The 200 Area station is necessary in order to maintain the existing response times and patterns of coverage for the Site areas north of the Wye Barricade. In addition, the 200 Area Station houses vehicles necessary for that area's protection, as well as the HFD communications center and the outdoor training area.

The 400 Area station location minimizes the response times to the 400 Area facilities, keeping the running times to most primary hazards within five minutes, and within approximately ten minutes for the remainder of its initial response zone. The existing location also enables apparatus and the ambulance from the 400 Area Station to provide back-up coverage within approximately ten minutes to the highway area immediately north of the Wye Barricade.

The 400 Area station also provides both initial response of fire apparatus and back-up response of apparatus and ambulance to the 300 Area, with those running times minimized to an acceptable level of approximately ten minutes to the north section of the 300 Area and approximately twelve minutes to the central 300 Area.

Assuming that a joint Richland-Hanford Fire Station is not planned, an HFD 300 Area Station is essential to provide acceptable initial service response times of five minutes to the 300 Area's major facilities both north and south of the existing station's location. A minimized running time of approximately ten minutes is facilitated to the extended 300 Area and those other designated Site Areas (such as the 1100 Area) where HFD response is necessary.

Additionally, the 300 Area Station's location minimizes back-up service running time to the 400 Area, and also allows for timely mutual aid response to the City of Richland. 
Relative to EMS response times, the WAC section 246-976 stipulates response times for verified ground ambulance services based on area populations and population densities. For areas with a population of ten thousand to twenty-nine thousand or an area with a population density of one thousand to two thousand people per square mile, a response time of twenty minutes or less, eighty percent of the time is stipulated. For populations with total populations less than ten thousand people, or with a population density of less than one thousand people per square mile, a response time of 45 minutes or less, $80 \%$ of the time is stipulated. The proposed critical baseline of personnel and resources is intended to meet the stipulated criteria for verified ground ambulance response of 20 minutes to all site facilities $80 \%$ of the time.

Relative to fire response time, there is no national consensus standard regarding minimum response time necessary to begin active fire suppression activities. Further, there is no explicit DOE criteria for establishing minimum response time necessary to begin active fire suppression activities.

Nationally accepted guidelines for urban emergency fire response, as expressed by the 30 fire chief members of the NFPA "Urban Fire Forum", generally cite the time requirement of 4 or 5 minutes for the arrival of the first due pumper (from receipt of the alarm) at the station and/or 8 to 10 minutes for the arrival of the entire first alarm assignment. Because of the lack of "vital" buildings in areas with extended response times and the limited number of responses reflective of a suburban setting, the existing response times appear acceptable.

DOD 6055.6 criteria also cites response time requirements to the majority of structures. For industrial buildings, a 4.5 minute response is required for one-half the initial response. An 8 minute response time is required for the second $50 \%$ response. Existing fire station deployment does not comply with these criteria. However, DOD allows reduced level of service for buildings based on their lack of strategic importance.

DOE-RL Fire Department Emergency Service Description stipulates crews within 7 minutes with backup crews expected to arrive within 12 minutes. When running times are considered, most 200,300, and 400 area buildings meet the intent of these criteria. During nights, weekends, and holidays, the 100 area will not meet these criteria. However, this condition is considered acceptable for the reasons which have been cited.

9.3.3.3 A trained incident command officer at the Battalion Chief (BC) level must be on duty at all times. This person will respond as Incident Commander (IC) to each reported working incident, all times, all shifts. Until the $\mathrm{BC}$ arrives on the scene, the first responding Captain shall assume the role of temporary incident commander as now.

\section{Supporting Statement}

A senior level officer is needed to provide a decision-making and reporting hierarchy when multiple stations are open on a 24-hour basis. Further, in conformance with NFPA 1500 , a fire officer is the incident manager (Commander). Since any type of incident can occur at any time, a qualified incident commander is necessary to conduct command functions. Under the baseline deployment model, the responding Battalion Chief may serve as the fifth person at the scene. In a major incident, the IC responsibilities are markedly different from those of the first 
arriving captain. The captain must conduct initial size-up, direct the activities of the first arriving unit and assist with the initial incident work. In contrast, the IC must consult with the facility manager, assess incident priorities, determine strategic goals, determine tactical objectives, and quickly develop an incident plan. Due to the number or potential Hazmat Incidents that have been identified, consideration should be given to having the IC trained Hazmat Incident Command. While the captains may be so designated, they may not be in a position to manage all incident operations including EMS and decontamination activities.

The Incident Command System (ICS) promulgated by the Federal Emergency management Agency calls for a variety of sub and sector commanders reporting to and commanded by the Incident Commander. Although full-scale incident command protocols are neither called for nor possible at incidents requiring minimal resources.

The arrival of a second Captain to an incident might be the first opportunity for full IC work to commence. In this instance, the second Captain might have to assume command of two companies so that the first captain can devote more effort to incident command. Should the incident continue to escalate, the duties of the IC will increase as more resources are required. These include attending to such needs as liaison, logistics, medical, operations, planning, public information, resources, safety public staging, and water supply. Additionally, coordination with outside agencies, as well as coordination with other site organizations will require that the IC be fully cognizant of all duties and responsibilities that can be delegated to each of these entities. Ensuring that the IC role can be readily assumed by a BC level officer provides reasonable assurance that the myriad of IC duties can be carried out effectively.

9.3.3.4 A trained Safety Officer must be available on each shift for attendance at working incidents. Captains shall be so trained, since HFD protocols assign them this responsibility. Additional personnel also should be so trained so that the assignment may de delegated.

\section{Supporting Statement}

Designating a Safety Officer fulfills national standards and OSHA requirements. NFPA 1521 describes suitable training. Personnel safety at incidents is of prime importance. Proper incident management is attained through use of the nationally approved incident command system. Adequate scene safety is attained through the use of a trained Safety Officer who provides constant monitoring as part of the incident command system. The Safety officer functions as senior advisor on safety matters to the IC.

9.3.3.5 Sufficient personnel must be trained as hazmat technicians to assure a six person response force available each shift, as now.

\section{Supporting Statement}

This number provides sufficient personnel for work within a hazardous area, plus a backup team as required by HAZMAT. 
WHC-SP-1180, Vol. 1

9.3.3.6 Clarification is needed concerning firefighters returned to "full duty" by HEHF, but not allowed full duty assignments. HFD and HEHF officials must clear up this problematical situation.

\section{Supporting Statement}

A firefighter should not be returned to full duty and not be allowed to perform full duty assignments. Additionally, personnel should not be directed to perform tasks beyond their health capacity. Neither should baseline level responding crews be partly staffed by restricted duty personnel. In a working incident, all baseline level personnel are expected to be able to provide a level of service normally associated with firefighter operations. Failure to have this baseline service level could put fellow firefighters at undue risk and may impair incident operations.

Failure to implement NFPA 1582 could present significant labor and legal issues since the standard specifies minimum medical requirements for candidates and current firefighters. Concerns relating to implementation were noted in a letter from DOE/RL Manager John Wagoner to DOE Hq. Assistant Secretary, EM-1 Leo Duffy dated October, 1992. Guidance from DO Hq. Assistant Secretary, Tara O'Toole, MD, M.P.H., to Thomas Grumbly, EM-1 (and others), dated April 14, 1995 states that "...NFPA 1582...has been in effect since its promulgation in 1992 and has been applicable to the DOE through the requirements delineated in DOE 5480.4, "Environmental Protection, Safety and Health Protection Standards," and DOE Order 5480.7A, "Fire Protection". The memo includes as an attachment DOE's "Implementation Guide of Medical Standards for Department of Energy Firefighters". The memo also states that alternative approaches can be implemented based on the "Equivalency Concept" that is sanctioned by DOE Order 5480.7A and NFPA. Failure to implement the standard or an alternative equivalency concept approach could lead to significant labor and/or legal issues. As noted in section 10 of the needs assessment report, "A person or other entity injured as a result of or in conjunction with Hanford Fire Department activities could bring a claim based upon the failure of the Hanford Fire Department to meet such standards and regulations.

9.3.3.7 Site supervisory personnel must be made aware of the need to call 911 when medical situations occur and not transport a potentially critical and unstable patient to a first aid location. Medical situations shall include all cardiac complaints, serious injuries, or injuries with a potential neurological component and all severe respiratory complaints.

\section{Supporting Statement}

There appears to be a lack of recognition of the full scope of the responsibility and services of the HFD by personnel on the site. Increased visibility through education and prevention activities would be a positive step. More formalized communications such as issuance of a sitewide management directive may be warranted. The two month review of all EMS responses as well as discussions with various site personnel indicate that a significant number of personnel with exhibiting signs and symptoms of potentially serious injury (e.g. chest pain, allergic reaction, and seizure) were transmitted via personal car to the first aid center. Transportation via personal car of an individual with chest pain or other potentially serious medical condition only delays activation of the EMS system (and system personnel) and potentially jeopardizes the safety and health of the individual. 
9.3.3.8 The appropriate recommendations of the Draft Hanford Site Emergency Medical Plan identified below shall be instituted.

- $\quad$ Each DOE-RL and contractor supervisor is responsible for the safety of his/her work group. This responsibility includes the communication of designated first responders and the location of and procedures for use of the first aid kits. Contractors are responsible for insuring employees are knowledgeable in the use of the 911 system.

- $\quad$ Each employee is responsible for recognizing and responding to a life or limb threatening illness/injury in a co-worker by activating 911 for emergency medical response.

- Each employee is responsible for knowledge of and access to the work group's designated first-responder to initiate immediate first-aid and CPR (if needed) while awaiting the arrival of Hanford site EMS.

\section{Supporting Statement}

The recommendations are consistent with ensuring that all site personnel are aware of the EMS system and their personal responsibilities associated with activating the system. Failure to immediately activate the EMS system in a medical emergency situation delays response and consequently may put the patient at undue risk.

9.3.3.9 The HFD shall adhere to EMS patient care procedures, protocols, and guidelines established by the Benton Franklin county protocols and the State of Washington as stipulated by the Medical Program Director (MPD).

\section{Supporting Statement}

It should be clear that where conflicts involve the HFD EMS personnel, the EMS patient care procedures, protocols and guidelines established by the MPD take precedence in all cases. This is inherent to the existing EMS system which certifies EMS personnel and requires them to act under the license of the MPD granted by the State of Washington.

9.3.3.10 The site shall implement a CPR training program which ensures that a cadre of personnel at each facility, or work site, are CPR qualified and equipped to provide emergency CPR during normal hours of occupancy.

\section{Supporting Statement}

The chance of recovery immediately following cardiac arrest diminishes as time to administer basic life support increases. This is illustrated in Table 9-4 below (Weaver, 1986). 
Table 9.4 Chance of Recovery after cardiac arrest

\begin{tabular}{|c|c|}
\hline Chance of Recovery & Response Time to BLS \\
\hline \hline $98 \%$ & 1 minute \\
\hline $92 \%$ & 2 minute \\
\hline $72 \%$ & 3 minutes \\
\hline $50 \%$ & 4 minutes \\
\hline $25 \%$ & 5 minutes \\
\hline $11 \%$ & 6 minutes \\
\hline $8 \%$ & 7 minutes \\
\hline
\end{tabular}

A HFD response to a cardiac arrest with BLS within 5 minutes, only results in a $25 \%$ chance of patient recovery. The best way to increase the chance of patient recovery immediately following cardiac arrest is to initiate CPR immediately. Training a cadre of site workers in CPR would increase the probability that personnel qualified in CPR would be readily available at the time of cardiac arrest. The cadre should be a sufficient number of personnel at each facility to ensure reasonable facility coverage during all work shifts, periods of illness, vacation, transfer or other absences from work. A plaque or means identification (such as a tag on the ID badge) should be issued to individuals trained in CPR. The CPR training program should be coordinated with the HFD to the extent that HFD is kept apprized of the training program curriculum, the extent of site contractor involvement and any reporting relating to $\mathrm{CPR}$ training program effectiveness.

9.3.3.11 As the site operations change or transition, HFD should examine methods to minimize the response time to an EMS incident.

\section{Supporting Statement}

As the site mission changes, redeployment of EMS resources to areas of high risk activities or during periods of high risk activities with the purpose of minimizing response time or other methods should be examined. Delays in 911 notification, dispatch, and HFD unit departure can delay the arrival time of EMS and can impact the effectiveness of emergency care. There appears to be an expectation among the site workers for adequate care. As noted by others, "...professional EMS systems are less than two decades old, (yet) they are now as much an expected part of life as police protection and public schools" (Peppe, 1990). The apparent perceptions of site workers and the general public substantiate the need to ensure that emergency care is provided with minimal response time.

9.3.3.12 The HFD and the signatory departments shall delineate, if necessary, any and all restrictions related to the mutual aid that are defined in the mutual aid agreements.

\section{Supporting Statement}

The mutual aid documents furnished by HFD, entitled "Tri-Cities/County Mutual Aid Agreement" and dated 26 April 1985 and 6 June 1995, each signed by representative of HFD, 
WHC-SP-1180, Vol. 1

Richland, Kennewick, Pasco, Benton County Fire Protection districts 1,2,3,4.5 and 6, Franklin County 3, and Walla Walla County 5 do not appear to restrict response activities in any way. The Needs Assessment Team notes that what it has seen in writing is typical of regular mutual aid agreements and, except for the draft automatic aid document, lists no restrictions. We are told, however that restrictions do operate. Delineating these restrictions in the Mutual Agreement is critical to understanding and making reasoned judgements regarding the effective utilization of all available mutual aid resources.

\subsection{FIRE STATIONS AND RELATED FACILITIES}

\subsubsection{Fire Stations and Related Facilities Description, Existing Conditions}

The following stations and structures comprise the HFD facilities:

$\begin{array}{lllll}\underline{\text { Area }} & \underline{\text { Bldg }} & \underline{\text { Built }} & \underline{\underline{\mathrm{S} g \mathrm{Ft}}} & \underline{\text { Purpose }} \\ 100 & 609 & 1961 & 10,800 & \text { 100 Area Station } \\ 200 & 609 \mathrm{~A} & 1965 & 8,350+ & \text { 200 Area Station/Dispatch } \\ 300 & 3709 \mathrm{~A} & 1964 & 8,350 & \text { 300 Area Station } \\ 400 & 4704 \mathrm{~S} & 1982 & 8,164 & \text { 400 Area Station } \\ 200 & 609 \mathrm{D} & 1985 & & \text { 4 Story Training Tower } \\ 200 & 609 \mathrm{E} & 1988 & 1800 & \text { Storage } \\ 200 & 609 \mathrm{G} & 1983 / 90 & 1800 & \text { Misc. } \\ 200 & 609 \mathrm{~B} & & & \\ 200 & 609 \mathrm{C} & 1985 & 1560 & \\ 200 & 2721 \mathrm{EA} & 1993 & 7500 & \text { Maintenance Shops and Offices } \\ 200 & \text { MO-388 } & 1993 & 1440 & \text { Office Space } \\ 300 & 3709 \mathrm{~A} & 1977 & 600 & \text { Storage }\end{array}$

The County fire department designation number for HFD is "9". HFD Stations are identified as \#91-94 corresponding to the 100 Area through 400 Area stations respectively.

The fire ground training facility, which contains a four story enclosed training/drill tower (Bldg 609D) and a small horizontal cylinder used for confined space rescue training, is adjacent to the 200 Area Station.

An administrative wing, containing a small conference/training room, a copy room, and approximately eight offices is adjacent to and attached to the 200 Area Station (Bldg 609A). No toilet facilities are located in the administration wing. Additional HFD space for administrative and support functions are maintained in two satellite offices near Bldg 609A.

\section{Area Station}

The 100 Area fire station (BIdg 609) provides fire protection, EMS, and special rescue services. EMS is provided to all 100 and 600 Area personnel and facilities/buildings located north of Route 11-A. This station provides these services outside the Hanford boundaries on SR 240 and they are extended to include the rangelands within this geographic area. Six persons are assigned for a 24 hour shift. As noted in a recent test report: "the 
WHC-SP-1180, Vol. 1

structure does not meet code and was not built to house employees on a 24 hour basis" (WHC, 1993b).

\section{Area Station}

The 200 Area fire station (Bldg 609A) provides fire protection, EMS, hazardous materials response, and special rescue services. EMS is provided to all 200 and 600 Area personnel and facilities/buildings located south of Route 11-A and North of the Wye barricade. This station provides these services outside the Hanford boundaries on SR 240 and they are extended to include the rangelands within this geographic area.

Dispatching and emergency notification for fire department emergencies are also performed on a 24 hour basis from this fire station. This communications room is adjacent to the apparatus room. An administrative wing is attached to the building. There are 7 firefighters on a 24 hour shift. Per a recent facility evaluation, "The structure does not meet the NEC code and was not built to house employees on a 24 hour basis" (WHC, 1993b).

\section{Area Station}

The 300 Area fire station (Bldg 3709A) provides fire protection, EMS, hazardous materials response, and special rescue services. These services are provided to all 300,500 , and 1100 Areas personnel and facilities/buildings located south of the Fast Flux Test Facility (FFTF), to the western boundary of the 1100 Area to Spengler Street in Richland. Fire protection, EMS, and hazardous materials response services are provided outside the Hanford boundaries to maintain mutual aid agreements with 10 different agencies, cities, and counties. All rangelands located within this geographic area are also protected by this station and provided with the above services. As noted in a recent report, "The structure does not meet code and was not built to house employees on a 24 hour basis" (WHC, 1993b).

\section{Area Station}

The 400 Area fire station (Bldg 4704S) provides fire protection, EMS, and rescue services. These services are provided to all 400 Area and Washington Public Power Supply system personnel. The 600 Area personnel and facilities located south of the Wye Barricade to the 300 Area also receive these services. This station also provides fire and EMS services outside the Hanford boundaries on SR 240 to the Benton City highway and to Richland. All rangelands, including the Rattlesnake Mountain and flatlands, are also protected by this station and provided with the above services within this geographical area. Per HFD documentation, "This station meets code requirements but has structural roof deficiencies" (WHC, undated).

\section{Summary of Existing Station Conditions}

Engineering assessments of stations and the training facility are reported in "Functional Design Criteria - HFD Facilities" (WHC, 1993b) and are summarized below:

"An assessment of the existing fire stations for compliance with the National Electrical Codes (NEC), "Evaluation of Hanford Fire System," Engineering Report (Reference 
3), and Reference 5, have revealed significant deficiencies. The electrical systems did not comply with the NEC when the stations were designed and constructed.

Alternative designs were allowed at the time of construction. As a result the present electrical systems do not comply with the NEC, nor are they based on acceptable engineering practices. The existing fire stations are in violation of NFPA standards for air circulation and space limitations. The ceilings throughout the personnel quarters, rest rooms, kitchen, day room, and halls contain asbestos."

Additionally, the stations do not meet OSHA requirements or NFPA 1500 requirements for safeguarding the crew areas from the apparatus bay area exhaust gases. Only the 200 Area Station has a vehicle exhaust system. Insufficient bay areas do not allow any of the stations to house all of the apparatus assigned. Some vehicles are parked outdoors at each station. Numerous other deficiencies exist, especially when the stations are judged by contemporary station design criteria. From discussions with HFD management, the existing fire stations may not meet applicable seismic requirements stipulated by the 1991 Uniform Building Code. All stations are reported to have alternate power sources, either standby generators or duplicate feeds.

The training area is located to the east of the 200 Area Station. It contains a four story tower which provides for several types of training and fire ground drills. The portion of the tower designated as a "burn room" is reported as unusable due to design flaws which cause warping of access door hinges under fire/heat conditions, making the doors inoperative. As a result, HFD has been using a WPPSS live fire training facility. A confined space rescue "tube" appears inadequate and makeshift. Other types of permanent training aids are either lacking or makeshift. Complete and comprehensive training for all aspects of HFD service operations, including technical rescue specialties and EMS, is not possible at this site, although sufficient room is available (WHC, 1993b).

HFD facilities planning at this time include the following:

- Application for the construction of a new 200 Area Station plus an adjacent HFD administrative building (on hold);

- Application for the construction of a new 300 Area Station (on hold);

- Consideration of the construction of a combined station with Richland, to replace the 300 Area Station (under study);

- Proposal to bring the 400 Area Station up to desired standards.

A discussion and analysis of station locations and emergency response times is provided in Appendix D.

\subsubsection{Applicable Requirements/Criteria}

The Implementation Guide for DOE Orders 420.1 and $440.1,9 / 30 / 95$, Section 6.13 states: "Fire stations, where provided, should be designed to provide sufficient capacity for 
mobile apparatus, including maintenance functions. Living quarters should provide a comfortable, private and safe environment for personnel, consistent with industry norms. This includes adequate sleeping quarters, kitchen facilities, training rooms, physical fitness areas and other ancillary needs. To the extent that related occupancies such as alarm rooms, maintenance rooms, and personnel areas are co-located within the same facility, appropriate fire-rated physical separation, ventilation and exhaust, and other fire protection features should be provided to prevent interference and to ensure the viability of individual areas in the event of a fire."

NFPA Standard 1221, Standard for the Installation, Maintenance, and Use of Public Fire Service Communication Systems, 1994 Edition. Section 2-1.2.5 stipulates that the communication center be protected against damage due to vandalism and civil disturbances. The door opening is required to be not less than a 1-hour listed, self-closing fire door assembly. Entry is to be restricted to authorized personnel only.

Other applicable criteria reviewed include the following:

- Fire Chiefs handbook, "Fire Station and Facility Design"

- Uniform Building Code, 1991, including Seismic Requirement for Essential Facilities

- 29 CFR 1910, Sections on health and safety in response facilities

- $\quad$ DOE 420.1, Facility Safety, Section 4.4.4, Natural Phenomena Hazards Assessment

- $\quad$ NFPA Standard 1402, Building Fire Service Training Centers

- $\quad$ NFPA Fire Protection Handbook, 9/10, "Fire Department Facilities and Fire Training Facilities"

- $\quad$ NFPA Recommended Practices on fire station design; International Association of Fire Chiefs "Fire Station Design Criteria" Recommendations

\subsubsection{Recommendations}

9.4.3.1 The 100 Area Station shall undergo only those modifications necessary to meet applicable OSHA, Life Safety code, and structural integrity requirements.

\section{Supporting Statement}

Current projections for the 100 Area indicate a relatively constant worker population and a possible reduction in the level of services required by the HFD. Only those modifications necessary to provide an acceptable level of safety for HFD personnel as stipulated by applicable codes and standards are required. 
9.4.3.2 Upgrade the existing 200 Area Station to meet all applicable codes and standards, or construct a new station at or near that site.

\section{Supporting Statement}

Modifications necessary to provide an acceptable level of safety for HFD personnel as stipulated by applicable codes and standards are required. Additional requirements cited by other recommendations in this report may warrant construction of a new station at or near the site.

9.4.3.3 Provide additional administrative space and restroom facilities to the existing administrative wing or construct an administrative building at an approved site.

\section{Supporting Statement}

WHC studies have demonstrated that the existing administrative wing is inadequate. Administrative functions, including support work, and staff services ranging from training to budget analysis, all need adequate space and proximity, plus space for meetings, office equipment, mail distribution, rest rooms, files, storage, etc. Task completion takes longer and quality diminishes when work space is inadequate.

9.4.3.4 If new construction takes place at the 200 Station Site, the design shall incorporate adequate provisions for a communications/alarm/dispatch facility. Should the communications function be moved to another location, all applicable provisions shall be met.

\section{Supporting Statement}

The communications-alarm room should meet all code and standard requirements and should be large enough to contain a console configuration which enables the one assigned dispatcher to perform the required tasks efficiently and effectively, with the required equipment conveniently placed. All applicable provisions of NFPA 1221 are required to be met.

9.4.3.5 Upgrade the existing 200 Area training facility and drill area, to provide adequate training aids for major technical rescue exercises (includes live fire training, confined space and collapse work, hazmat incident response, and radiological incident simulation). Alternatively, make provisions to obtain the necessary training at an alternative facility. An alternate facility for live fire training already used by HFD and other nearby fire departments is located at WPPSS.

\section{Supporting Statement}

Adequate training and exercises are essential to the success of the emergency responders. Training facilities must provide accurate training replicas of the primary response duties, particularly in such areas as technical rescue and hazmat response. Providing this training capability at the 200 Area station maximizes the HFD's ability to adapt training and training replicas to match specific site hazards and conditions. Should providing this 
capability at the HFD station be determined to not be feasible or cost effective, the appropriate training and drilling should be obtained at an alternative location (such as HAMMER).

9.4.3.6 The 400 Area Station shall undergo those modification necessary to meet applicable OSHA, Life Safety Code and structural integrity requirements.

\section{Supporting Statement}

Modifications necessary to provide an acceptable level of safety for HFD personnel as stipulated by applicable codes and standards are required.

9.4.3.7 Postpone the decision to construct a new 300 Area Station until a decision is made concerning a Richland-HFD combined Station or an outsourcing arrangement. If such a decision is not forthcoming, proceed with planning for a new 300 Area Station on site.

\section{Supporting Statement}

A Feasibility Study of the Transfer of Hanford Site Fire and Emergency Services to the City of Richland, has been initiated by DOE. The conclusions of this study may impact the decision to construct a Richland-HFD combined Station, located in northern Richland. A relocation of the 300 Area Station must take into consideration any increased running times of those units--not only into their "first due" zone, but as back-up for incidents occurring to the north of the 300 response area. Appendix D provides run time diagrams to assist in this analysis.

Currently, any major existing building, NFPA, and OSHA code deficiencies identified in the 300 Area Station, that present health and safety problems to personnel require corrective action.

9.4.3.8 Perform seismic evaluations to determine the ability of all fire stations to maintain all essential services immediately following a seismic event. Criteria for evaluation shall as a minimum, reflect requirements stipulated by the 1991 UBC for Essential Facilities or site specific seismic requirements approved by DOE. Perform any and all required station modifications necessary to maintain all essential services immediately following a seismic event.

\section{Supporting Statement}

Many of the facility hazards and accidents which cause significant consequences result form the occurrence of a seismic event (i.e. earthquake). Also, of all common mode events affecting the site, the seismic event appears to have the greatest potential to challenge HFD resources. Seismic events in the region are a known phenomenon. Between the period of July 15,1982 and November 8,1995 , there have been 8 earthquakes that measured between 3.0 and 3.99 (Richter Scale). Between July 15, 1982 and July 15, 1995, there have been 45 earthquakes which measured between 2.0 and 2.99 and 182 which measured between 1.0 and 1.99 (HTS, 1995). Recent trenches dug across faults on Toppenish Ridge in south-central 
Washington show evidence of four different earthquakes. The youngest earthquake occurred 500-700 years ago and may have reached 7.0 on the Richter scale (Campbell, et al, not dated). Many site facility safety analyses postulate seismic induced accidents. Though most are considered to be unlikely events, they are still considered credible (i.e. frequency $>10^{-6}$ /year). Given that a minor or major seismic event is credible, the HFD must be able to respond with no or minimal delay and with no significant impairments to service resulting from seismic induced station damage.

The 1991 UBC (Table No. 23-K) stipulates specific seismic requirements for facilities classified as "Essential Facilities". The UBC explicitly defines fire stations as essential facilities. The 1991 UBC is not the "Code of Record" for any of the fire stations.

Nevertheless, it points out the need to ensure that fire stations remain fully operable following a seismic event. Further, Executive Order 1294, (12/1/94) stipulates adoption of minimum standards of seismic safety for existing federally owned or leased buildings. Per the order, these standards are to be applied as a minimum to those buildings identified in the standards as requiring evaluation, and if necessary, mitigation. DOE 420.1, Facility Safety, Section 4.4.4, Natural Phenomena Hazards Assessment and section 7.4 of the Implementation Guide substantiate the need to consider implementing seismic requirements which may exceed those stipulated by the code of record.

\subsection{APPARATUS AND EQUIPMENT}

\subsubsection{Apparatus and Equipment Description, Existing Conditions}

The HFD maintains a total of 40 vehicles, representing a diversified range of capabilities. Table 9-5.1 summarizes the apparatus inventory maintained at the Hanford site. Of the 40 vehicles, 30 are specially equipped fire/emergency response apparatus; twenty-two are first-line apparatus and 8 are listed as back-up (reserve or second line) apparatus. The initial response (first-line) vehicles in each station are combination aerial device/pumper units, which commonly are referred to as "Quints" (meaning each vehicles has a pump, a water tank, hose, and a hydraulic aerial ladder or boom), or by the trade-name Telesquirt.

The remaining four engines (one in each station) are designated as back-up (reserve or second line). Pumpers typically equipped with a pump, a water tank, and hose--but without a hydraulic aerial ladder or boom--are sometimes referred to as "triple combination pumpers." The four reserve pumpers of the HFD are triple combination pumpers. The terms "pumper" and "engine" are used interchangeably in the literature, the technical difference being that a "pumper" is a vehicle and an "engine" is that same vehicle with a crew.

Tables 9.5.2, 9.5.3, and 9.5.4 provide a description of the HFD first-line and back-up fire/emergency response vehicles. The HFD maintains equipment lists by compartment locations for all apparatus. 
WHC-SP-1180, Vol. 1

Table 9-5.1 HFD Apparatus and Command/Utility Vehicle Inventory

\begin{tabular}{||l|c|}
\hline \multicolumn{1}{|c|}{ Category } & Number of Vehicles \\
\hline \hline Quint & 4 \\
\hline Triplecombination Pumpers & 4 \\
\hline Ambulance & 6 \\
\hline Rescue & 1 \\
\hline HAZMAT & 1 \\
\hline Brush Truck & 4 \\
\hline Brush Tanker/Pumper & 6 \\
\hline Water Tender & 1 \\
\hline Chemical (Metal-x) & 1 \\
\hline Cascade & 1 \\
\hline Foam/D-C Powder Fast Attack & 1 \\
\hline Command/Utility & 10 \\
\hline Total & 40 \\
\hline
\end{tabular}

The four quints are used as the first response units because of their aerial capabilities. The quints, or telesquirts, can be used to set up a water curtain or provide roof access during the initial response. In some cases, the quints have also been used for rescue operations. The four triple combination pumpers do not have aerial capabilities and are dispatched only if needed to assist the first response quint apparatus. Second line apparatus are also manned by T\&S Firefighters when first line apparatus are called from the station.

Six modular ambulances are located throughout the fire stations with one assigned as first response in 100,200,300, and 400 area fire stations and one on standby (reserve) in each the 200 and 300 area stations. Four vehicles are maintained in service at all times with two vehicles in reserve or undergoing routine and as needed maintenance. These vehicles are designed as a specialty van with a modular ambulance body mounted and external lamp and reflectors in accordance with standard 108 of the Federal Ambulance Specifications KKK-A1822. These ambulances are equipped with direct radio communications to the local hospital emergency room. All ambulances are licensed by Washington State Emergency Services and carry medical supplies and equipment capable of providing advanced life support. Equipment and supplies representative of those carried by a medical ambulance are identified by ambulance compartment location in Appendix E. Of particular note is the distinction in defibrillators carried on BLS and ALS units. The 100 Area BLS ambulance (referred to as AID 91) carries the life pack 300 auto-defibrillator. The ALS ambulances (Medic 92, 93, and 94) carry the life pack 10 defibrillator. 


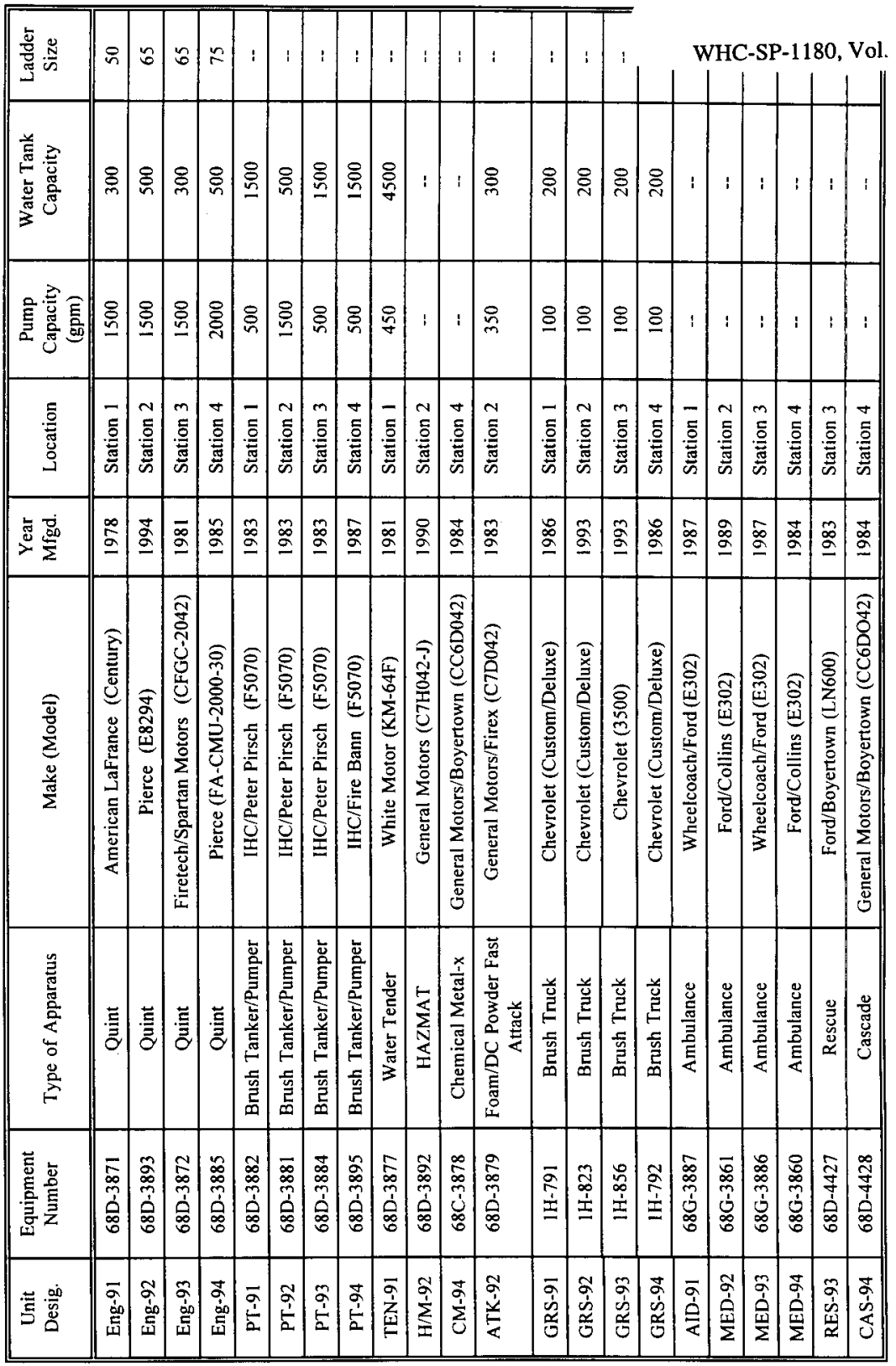




\begin{tabular}{|c|c|c|c|c|c|c|c|c|}
\hline 兽 & : & $i$ & i & ! & : & : & & \\
\hline 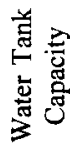 & 号 & 8 & 8 & 8 & $\stackrel{8}{8}$ & 8 & & i \\
\hline 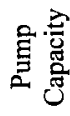 & $\begin{array}{l}8 \\
0 \\
0\end{array}$ & 总 & 总 & 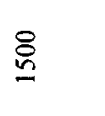 & 号 & 8 & $:$ & i \\
\hline .气 & 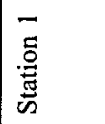 & 告 & m & 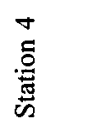 & 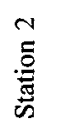 & 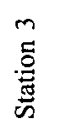 & 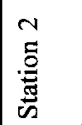 & m \\
\hline 芭焉 & 官 & $\vec{\infty}$ & $\stackrel{\infty}{\varrho}$ & ڤ̊ & $\stackrel{\infty}{2}$ & $\stackrel{\mathscr{\infty}}{\varrho}$ & $\stackrel{\infty}{\stackrel{2}{2}}$ & $\stackrel{\infty}{\sigma}$ \\
\hline $\begin{array}{l}\hat{\bar{g}} \\
\sum_{\bar{g}}^{0} \\
\text { 竞 }\end{array}$ & 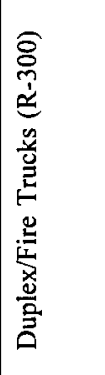 & 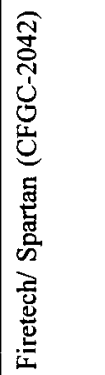 & 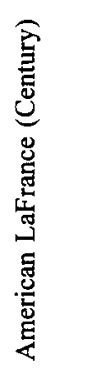 & 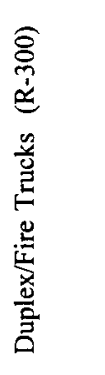 & 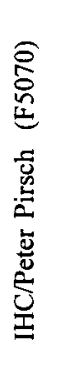 & 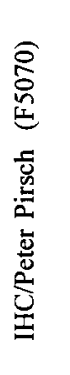 & 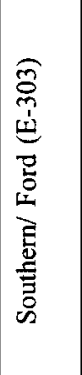 & 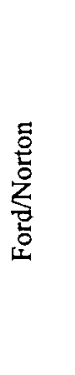 \\
\hline 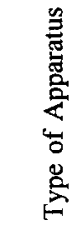 & 을 & 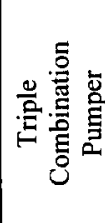 & 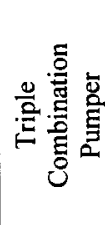 & 을 & 悹 & 害总 & 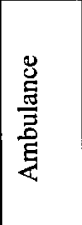 & 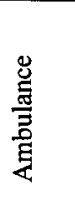 \\
\hline 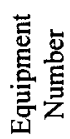 & $\begin{array}{l}n \\
\infty \\
\tilde{c} \\
\infty \\
\infty \\
0\end{array}$ & 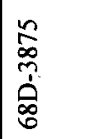 & $\begin{array}{l}\stackrel{0}{\infty} \\
\infty \\
\dot{\infty} \\
\infty \\
0\end{array}$ & 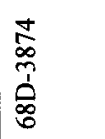 & $\begin{array}{l}\infty \\
\infty \\
\infty \\
\stackrel{\infty}{\infty} \\
\infty \\
0\end{array}$ & $\begin{array}{l}8 \\
\infty \\
\infty \\
1 \\
0 \\
\infty \\
0\end{array}$ & $\begin{array}{l}\not{5} \\
\infty \\
0 \\
\vdots \\
0 \\
0\end{array}$ & $\begin{array}{l}\infty \\
\infty \\
\infty \\
0 \\
0 \\
0 \\
0\end{array}$ \\
\hline 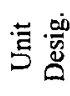 & $\sum_{i=1}^{b} \sigma$ & $\sum_{i=1}^{\dot{j}} \approx$ & $\sum_{i=1}^{j}$ & $\sum_{i=1}^{\dot{I}} \mathcal{Z}$ & 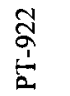 & ลิ & 安令 & 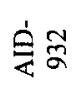 \\
\hline
\end{tabular}


Table 9-5.4 Deployment of Apparatus by Station

\begin{tabular}{|c|c|c|c|c|}
\hline Apparatus Type & Station I & Station 2 & Station 3 & Station 4 \\
\hline Quint & $\begin{array}{l}\text { ENG-91 } \\
(68 D-3871)\end{array}$ & ENG-92 (68D-3893) & ENG-93 (68D-3872) & ENG-94 (68D-3885) \\
\hline $\begin{array}{l}\text { Triple Combination } \\
\text { Pumper }\end{array}$ & $\left\{\begin{array}{l}\text { ENG-912 } \\
(68 \mathrm{D}-3873)\end{array}\right.$ & ENG-922 (68D-3875) & $\begin{array}{l}\text { ENG-932 (68D- } \\
3876)\end{array}$ & ENG-942 (68D-3874) \\
\hline Ambulance & $\begin{array}{l}\text { AID-91 } \\
(68 G-3887)\end{array}$ & $\begin{array}{l}\text { MED-92 (68G-3861) } \\
\text { AID-922 (68G-3894) }\end{array}$ & $\begin{array}{l}\text { MED-93 (68G-3886) } \\
\text { AID-932 (68G-3889) }\end{array}$ & MED-94 (68G-3860) \\
\hline Brush Tanker/Pumper & $\begin{array}{l}\text { PT-91 } \\
(68 D-3882)\end{array}$ & $\begin{array}{l}\text { PT-92 (68D-3881) } \\
\text { PT-922 (68D-3883) }\end{array}$ & $\begin{array}{l}\text { PT-93 (68D-3884) } \\
\text { PT-932 (68D-3880) }\end{array}$ & PT-94 (68D-3895) \\
\hline Brush Truck & $\begin{array}{l}\text { GRS-91 } \\
(1 \mathrm{H}-791)\end{array}$ & GRS-92 (1H-823) & GRS-93 (1H-856) & GRS-94 (1H-792) \\
\hline Water Tender & $\begin{array}{l}\text { TEN-91 } \\
(68 \mathrm{D}-3877)\end{array}$ & -- & - & -- \\
\hline HAZMAT & -- & H/M-92 (68D-3892) & -- & - \\
\hline Chemical Metal- $x$ & - & -. & -. & CM-94 (68C-3878) \\
\hline $\begin{array}{l}\text { Foam/DC Powder } \\
\text { Fast Attack }\end{array}$ & -- & ATK-92 (68D-3879) & -- & - \\
\hline Rescue & -- & -- & RES-93 (68D-4427) & - \\
\hline Cascade & -- & - & - & CAS-94 (68D-4428) \\
\hline
\end{tabular}

The rescue truck is used for specialized rescue operations. It contains various types of equipment. This unit also acts as a support vehicle at HAZMAT incidents.

The HAZMAT unit is equipped with specialized equipment, clothing, tools, diking materials, adsorbents, plug and patch kits, sniffers and a computerized database with specific response information.

The brush trucks are equipped with a portable fire pump and a 200-gallon water tank. These units provide quick attack capabilities for extinguishing small spot fires.

The brush tanker/pumps are used for range land fire fighting. These units are capable of providing either fire attack or resupply services. All units are equipped with diesel auxiliary engines and $500 \mathrm{gal} / \mathrm{min}$ Hale pumps. They carry 1,500 gallons of water and have one remote-controlled nozzle and one manual nozzle located on the top mounted turret. The all-wheel drive trucks are designed for the sandy, rough terrain common on the Hanford site and are stationed strategically across the site to control the annual wildland fires affecting the site. 
The water tender is diesel powered with a $450 \mathrm{gal} / \mathrm{min}$ pump and is capable of carrying 4,500 gallons of water. This unit is primarily used to supply brush tankers during range fire activities.

The Chemical/Metal-X truck is used for extinguishing sodium and lithium fires and is equipped with a 500 pound spherical container of the inverting type of NAX dry chemical. There is an electrical hose reel with 250 feet of one-inch hose and nozzle for each agent. Three 300 cubic-foot nitrogen cylinders are used for discharging the NAX dry chemical and one 300 cubic-foot Argon cylinder is used for discharging the carbon microspheres.

The Cascade unit is a Self-Contained Breathing Apparatus (SCBA) refill truck capable of filling air bottles at any location. It is equipped with both a compressor and cascade air system.

The foam/D-C powder fast attack truck is equipped with 300 gallons of premixed Aqueous Film Forming Foam (AFFF), 300 gallons of AFFF concentrate, and 450 pounds of dry chemical. This unit can discharge AFFF and dry chemical at the same time through a dual barrel turret mounted on the roof. All agents can also be discharged through hand lines. This truck has a single stage $350 \mathrm{gpm}$ pump and a proportioning system that is used in conjunction with the 300 gallons of AFFF pure concentrate foam, and has the capability of producing 10,000 gallons of workable fire fighting foam. This unit is designed to handle downed aircraft, hazardous materials incidents, and flammable liquids fires.

The command/utility vehicles consists of ten 4-wheel drive trucks which are stationed at each of the 4 stations and other site locations as to provide easy access to fire department personnel responding to an alarm from off-site.

Each of the 4 stations house a first-line Quint (telesquirt), a reserve triple combination pumper, an ambulance, and a brush tanker/pumper. The reserve ambulances (AID-922 and AID-932) and brush tanker/pumpers (PT-922 and PT932) are located as to provide backup support to both the north (100 and 200 areas) and south areas (300 and 400 areas) of the site.

The HAZMAT truck is located in station 2 primarily because the largest transit supply of hazardous materials is located in this area (i.e., building 616). In addition, this location is near the tank farms which are potentially high hazard areas. The HAZMAT truck is also equipped with rescue equipment. As such, the unit can serve as the first response rescue unit to the north areas of the site until the rescue truck arrives from station 3. Likewise, the rescue truck in station 3 is equipped with some hazmat equipment and can serve as the first response hazmat unit for the south areas of the site. In some cases, if a high hazard activity is underway, the rescue truck can be stationed near the hazard area as needed.

The chemical metal-x truck is allocated to station 4 because the 400 area has the largest sodium storage facilities on the site. Also located in station 4 is the cascade truck. This serves as a central dispatch for the entire site. The foam/DC powder fast attack unit was originally used for off road travel to respond to a helicopter accident when helicopters were used onsite. Now the unit is used for vehicle fires and is available in case of an airplane crash now that the air space above the site is no longer restricted. 


\subsubsection{Procurement and Replacement Procedures}

In order to procure new apparatus and equipment, the HFD must request capital funding from DOE, Kaiser, and WHC. The need for new equipment is determined by the fire department senior staff. A Capital Equipment Request is submitted for a multi-contractor review (i.e., DOE, Kaiser, and WHC) in which the need for the new equipment must be demonstrated. The review board determines the need for additional funding based on the potential benefit to the site (for example, would the money be better spent on providing additional equipment for decontamination and decommissioning). In some cases, the review process can take up to 5 years prior to approval.

Existing fire trucks and engines are replaced based on a 15 to 20 year trade out schedule. Funding for such replacements is budgeted by Kaiser and approved by the Infrastructure Programs Group and DOE. In the past, money has generally been available to maintain the trade out schedule. However, currently the department is going on its third year without funding. As such, several older vehicles have not yet been replaced.

Westinghouse Fleet and Site Support Planning is responsible for preparing all fire/emergency apparatus specifications and establishing apparatus replacement dates. It utilizes the General Services Administration (GSA) Federal Supply Service for ordering and procuring all apparatus. To the maximum extent possible, fleet management adheres to the minimum federal replacement standards found in CFR 101-38.402 as a basis for establishing replacement dates for select apparatus: seven years for ambulances, six years for 4-wheel drive vehicles (brush trucks). Westinghouse Fleet and Site Support Planning has set the life expectancy for fire apparatus at 15 years.

To the extent deemed necessary, replacement dates are adjusted based on actual use and maintenance records. Scheduled replacement dates for each apparatus are identified in Table 9-5.5. Based on the current replacement schedule, the average replacement age for select HFD apparatus is identified as follows:

\begin{tabular}{lcl} 
Apparatus & \multicolumn{2}{c}{ Replacement Age } \\
\cline { 2 - 3 } Ambulance & 9 & years \\
Quints/Pumpers & 17 & years \\
Water Tender & 15 & years \\
Brush Trucks & 10 & years
\end{tabular}

All existing HFD apparatus were ordered and specified to meet the latest NFPA requirements when purchased. All new/replacement apparatus specifications require compliance with the requirements of the most current and applicable NFPA standards. 
WHC-SP-1180, Vol. 1

\begin{tabular}{|c|c|c|c|c|c|c|c|c|c|c|c|c|c|c|c|c|c|c|c|c|}
\hline 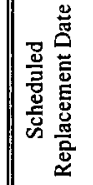 & $\frac{J}{d}$ & 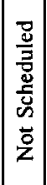 & 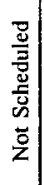 & 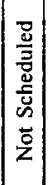 & $\left|\begin{array}{l}\frac{0}{0} \\
0 \\
0\end{array}\right|$ & 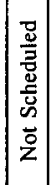 & 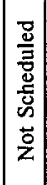 & 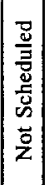 & 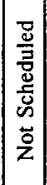 & $\mid \begin{array}{l}\overline{5} \\
0 \\
0 \\
0\end{array}$ & ڤ̊ & 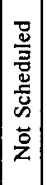 & 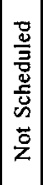 & 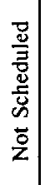 & : & 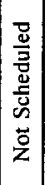 & 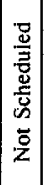 & $\stackrel{2}{\circ}$ & 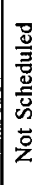 & \\
\hline
\end{tabular}

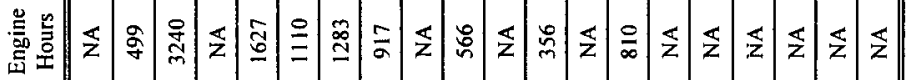

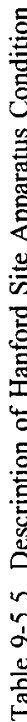

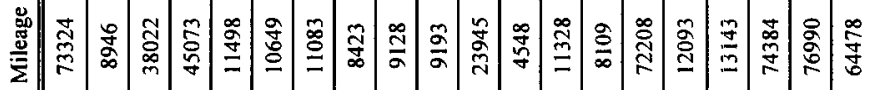

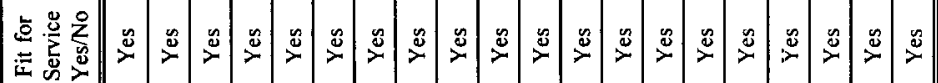

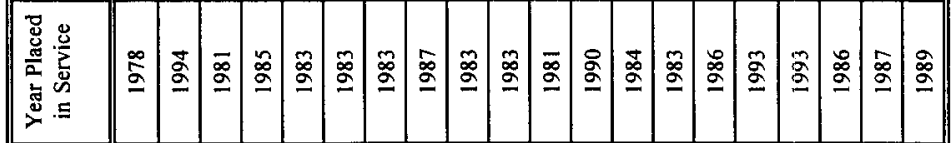

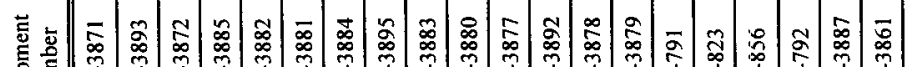

言兒 容

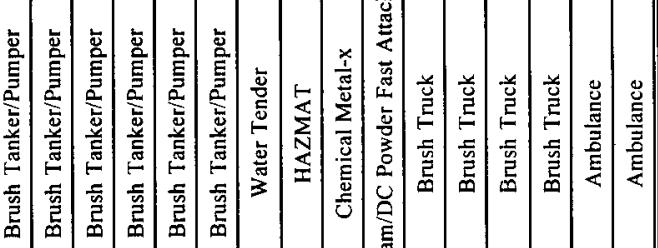

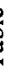

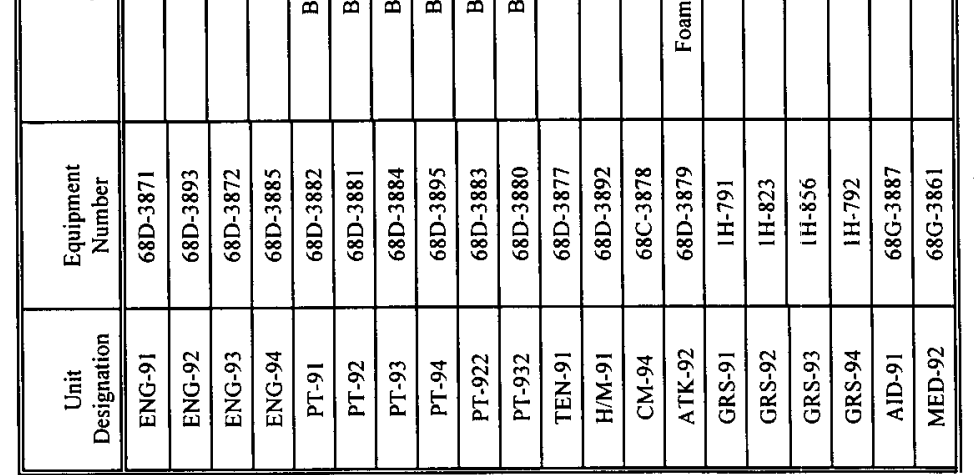

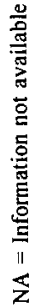


WHC-SP-1180, Vol. 1

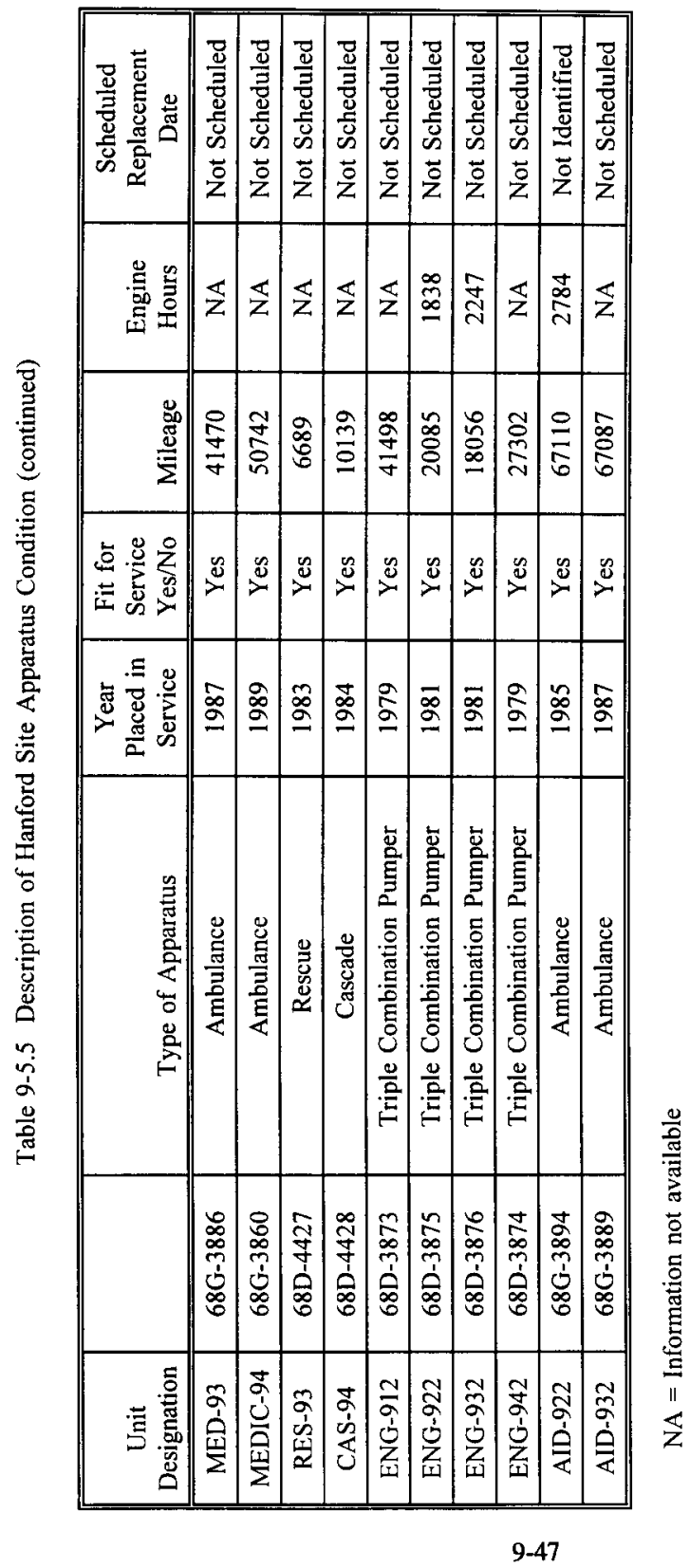


One apparatus procurement worthy of note involved the purchase of engines 912 and 942. Both were procured/purchased via the GSA Federal Supply Service in 1978. Procurement procedures in effect at that time resulted in HFD purchasing two apparatus designed and constructed with inadequate space for fire fighters to be seated in the rear jump seats. These deficiencies along with many others were immediately identified by HFD and significant efforts (all documented) to correct them were initiated via appropriate contractual channels in effect at that time. However, the significant deficiencies were never corrected and HFD was forced to accept deficient apparatus. As a result, HFD has designated these apparatus as reserve units.

\subsubsection{Vehicle Maintenance and Testing Procedures}

HFD personnel perform daily checks of fluid leveis, pump operations, operation of lights and warning devices, etc. The daily apparatus check is performed at approximately 8:00 AM by the newly arriving designated shift operator/driver. The check ensures the basic readiness of the apparatus and equipment. A daily check sheet is submitted to the on-duty captain. Any deficiencies noted are brought to the Battalion Chief's attention. A more detailed check is performed on a weekly basis by the designated shift operator/driver. A weekly check sheet is submitted to the on-duty Captain. Any deficiencies noted are brought to the Battalion Chief's attention. Whenever a piece of equipment is removed from any apparatus, an Apparatus Inventory form is completed and submitted to the station captain and is reviewed by the Battalion Chief.

Routine maintenance of the HFD apparatus is performed by the Westinghouse Fleet and Site Support Planning. Class A-Comprehensive inspection and service on all apparatus is completed annually or every 25,000 miles whichever comes first. Class B-Fluid and tune-up services is completed semi-annually or 2,500 miles whichever is first. Ambulances receive a minimum of Class $B$ service every 120 days. Fire station line managers may request maintenance and repairs to apparatus as necessary. Unscheduled repairs to first line and reserve apparatus can be performed on a priority basis.

Major apparatus repairs or modifications require approval by the Deputy Chief. The Deputy Chief has the responsibility for ensuring that all major apparatus repairs or modifications are in accordance with appropriate manufacturer guidelines, certifications, or applicable laws and regulations regarding road worthiness.

Annual fire pump performance tests on the four Quint apparatus, the four triple combination pumpers and the seven pumper tankers are conducted by an independent company (presently, United Fire Service Inc.) on an annual basis. The tests are performed in accordance with the applicable requirements of NFPA 1911, Service Test on Fire Department Apparatus. Any deficiencies identified are corrected in an expeditious manner.

\subsubsection{Future Development/Changes}

Two capital equipment requests have been submitted for fiscal years 1997 and 1998 . The 1997 request is for a mobile hazardous material incident decontamination unit. The 1998 request is for a mobile tactical incident command unit. 
The mobile decontamination unit will be used for safe essential decontamination process at emergency hazardous material incidents and the decontamination of personnel, when injured, who require decontamination prior to being transported to a hospital.

The mobile tactical incident command unit will enhance the fire department's ability to control tactical information during emergency operations. The unit will be a motor home body with various computer work stations, fax machines, radios, telephone equipment and technical reference books and files.

\subsubsection{Applicable Requirements/Criteria}

Requirements for fire department apparatus and equipment is based on several methods. Methods for determining appropriate apparatus/equipment inventories and their testing schedules and procedures include the following:

- DOD Instruction 6055.6, (DOD, 1988). DODI 6055.6 specifies the maximum number of allowed first-line pumpers based on the estimated fire flow for buildings of strategic importance to the site mission. The fire flow requirement is the primary but not the sole determinant for calculating the number of pumpers. Whereas an activity of great mission importance would be assigned the full number of manned pumpers indicated under the fire flow calculation technique, activities of lesser mission importance would receive fewer pumpers even though it might have the same calculated fire flow requirement. Likewise, additional pumpers may be required based on DOD prescribed response time and distance criteria.

The maximum water flows for determining fire department pumper requirements are based on occupancy classification, type of construction, and automatic sprinkler protection. Most buildings which were formerly considered to have strategic importance at the Hanford site are non-combustible, industrial structures equipped with automatic sprinkler systems. The maximum water flow, based on DODI 6055.6 , for noncombustible/sprinklered structures is $1,500 \mathrm{gpm}$. This water flow requirement corresponds to a maximum of 1 manned pumper based on DODI 6055.6.

DODI 6055.6 prescribes the maximum travel distances and/or response times for structural fire companies. For industrial buildings, the maximum travel distance is 2 miles and the maximum response time is 4.5 minutes for half the required fire companies. The remaining half of the required fire companies have a maximum response time of 8 minutes. The number of allowed pumpers based on the fire flow calculation technique is increased in order to meet the prescribed travel distances and/or response times. Again, the total number of pumpers may be reduced based on the mission importance of the buildings being serviced.

DOE Implementation Guide for use with DOE Order 420.1 and 440.1 stipulates that the fleet of fire department apparatus should reflect all site-specific response requirements. 
The Federal Emergency Medical Care Vehicle Specifications KKK-A-1822 is considered the standard by which all ambulances purchased with federal highway safety funds are required to comply. The KKK standards remain the specifications by which federal agencies purchase their vehicles and have thus been adopted as an industry standard.

WAC-246-976-300, Basic Life Support, stipulates all equipment and supplies to be carried and maintained by BLS ambulances.

The indications for utilization, dosage, contraindications, and mechanism of action are outlined in the Benton-Franklin County Protocois. These are the drivers for utilization of medications and serve as the baseline for Continuous Quality Improvement of incidents of adverse effect and outcome studies. Medications carried on the Ambulances must conform to the Benton-Franklin County protocols as outlined in the Bi-county EMP Policy and Procedure Manual as mandated by RCW 18.71.

Utilization, storage, replacement and disposal of Narcotic medications is subject to federal control through the Federal Drug Enforcement Agency (DEA). The control and monitoring of Narcotic usage is specific and must follow DEA guidelines.

WAC-246-9776-920 establishes protocols for storing, dispensing and administering controlled substances, in accordance with state, and federal regulations.

Other standards reviewed include the following:

- $\quad$ NFPA 1901, Standard for Pumper Fire Apparatus, (1991)

- $\quad$ NFPA 1902, Standard for Initial Attack Fire Apparatus, (1991)

- $\quad$ NFPA 1903, Standard for Mobile Water Supplies, (1991)

- $\quad$ NFPA 1904, Standard for Aerial Ladder \& Elevating Platforms Fire Apparatus, (1991)

- NFPA 1911, Standard on Service Tests of Pumps on Fire Department Apparatus, (1991)

- $\quad$ NFPA 1914, Standard for Testing Fire Department Aerial Devices, (1991)

- $\quad$ NFPA 1921, Standard for Fire Department Portable Pumping Units, (1991)

\subsubsection{Recommendations}

9.5.6.1 Maintain as a minimum, one first-line Quint at each operational fire station.

\section{Supporting Statement}

There are structures in each area which require roof access and/or elevated fire stream and warrant maintaining a quint in each area. Pumper requirements can be based on requirements stipulated by DODI 6055.6. Since most buildings which were formerly considered to have strategic importance at the Hanford site are non-combustible, industrial structures equipped with automatic sprinkler systems, the practice of maintaining one first-line manned pumper with $1500 \mathrm{gpm}$ pumping capacity at each operational fire station is considered to be consistent with the cited DOD criteria. Increasing the number of pumpers to 
meet explicit DOD criteria for response time and travel distance is not recommended for the following reasons:

- The cited DOD criteria, though not explicit in its instruction allows fewer pumpers and manpower than stipulated for activities of lesser mission importance. DOE Order 5480.7A, does not define fire protection criteria for buildings in terms of "strategic importance". Rather, it stipulates that: "vital DOE programs will not suffer unacceptable delays as a result of fire and its effects. Currently there are no site facilities that are identified as being part of a vital DOE program. Equating the DOD term "strategic importance" with the DOE term "vital DOE programs", may justify allowance of longer response times and distances than those cited by DOD criteria.

- The cited DOD criteria, does not account for the safety analyses which are typically conducted for DOE facilities handling radiological materials. These analyses typically identify facility risks in terms of accident probability and consequences. There were no analyses identified which stipulated a minimum fire department response time nor a maximum travel distance in order to maintain the facility at an acceptable level of risk.

- Alternative methods to limit fire spread to an acceptable level typically exists for most site facilities. For example, DOE $5480.7 \mathrm{~A}$ requires automatic fire suppression systems in structures having a maximum possible fire loss (MPFL) greater than $\$ 1$ million.

9.5.6.2 Maintain a minimum of four reserve triple combination pumpers for the entire Hanford site.

\section{Supporting Statement}

Presently, there are four reserve (or second line) triple combination pumper apparatus, one for each of the four fire stations. These apparatus are intended to be used by recalled firefighters and/or $T \& S$ firefighters who are called to respond to an ongoing incident, to provide mutual off Site, or to cover the stations in the event of additional alarms. Without these four apparatus, emergency responders would be without structural firefighting vehicles and the equipment they carry. Each of the four stations needs a reserve vehicle. In addition, these vehicles are used to replace first-line apparatus undergoing maintenance and repair, which is sometimes lengthy.

9.5.6.3 Maintain a minimum of one reserve ambulance unit for the entire Hanford site.

\section{$\underline{\text { Supporting Statement }}$}

Currently there are 2 reserve ambulance units, one located at Station 200 and the other at Station 300. The reserve ambulances are not used as backup and are only utilized when one of the first-line units is out of service. DOD criteria for reserve apparatus, stipulates only one reserve for every 4 required first-line units. 
9.5.6.4 Obtain a mobile emergency Command-communications vehicle for use by all emergency agencies on Site.

\section{Supporting Statement}

As previously noted by the HFD, a centralized command unit is needed to coordinate communications and tactical planning during an emergency event. Based on the hazards and events identified in section 7 , a credible event could involve a number of responding agencies and key individuals over a period of hours or days, necessitates an on-scene communications/command post and conference vehicle be available. Such an arrangement free-up the permanent Site communication-dispatch centers for normal functions. Maintained and positioned by the HFD, the vehicle could also be available to all emergency organizations on site.

9.5.6.5 Obtain a mobile decontamination unit for use at emergency hazardous material incidents and the decontamination of personnel.

\section{Supporting Statement}

As previously noted by the HFD, the mobile decontamination unit will be used for decontamination process at emergency hazardous material incidents and the decontamination of personnel, when injured, who require decontamination prior to being transported to a hospital. The identified site hazards illustrate numerous instances where deployment of a mobile decontamination unit would be expected and warrants procurement of this unit. The unit would also serve to limit the spread of contamination to other persons and areas and limit the exposure to the injured persons.

9.5.6.6 Expand the SRID to include a complete inventory of the required items for Access and Cardiac Care stipulated by WAC-246-976-390.

\section{Supporting Statement}

The cited materials and supplies are mandated by WAC-246-976-390. The ambulances were noted to contain those items necessary for paramedic function as required with the noted exceptions: Aid 91 carries the life pack 300 auto-defibrator. The ALS ambulances carry life pack 10 defibrillators. This equipment is considered appropriate and adequate for service.

\subsection{EMERGENCY COMMUNICATIONS}

\subsubsection{Emergency Communications, Existing conditions}

Emergency and other communications; including the receipt of alarms, the dispatching of Station crews to incidents, and the recall of off-duty personnel; are conducted by HFD personnel in their own facility, the Hanford Fire Dispatch Center (HFDC). 
The HFDC is located at the 200 Area fire station and is the main communication center for fire, ambulance, technical rescue, and hazardous material emergencies on the Hanford site. The HFDC is continuously manned by one assigned firefighter $(24 \mathrm{hr} /$ day, 7 days/week) and is under the control and direction of the HFD. The HFDC has the responsibility to

- Maintain command of emergency response forces to perform the necessary actions to control and terminate fire related incidents, to provide emergency medical patient care, and to act as the incident command agency for hazardous materials emergency incidents.

- Direct, advise, and assist in the investigation and resolution of accidents, occurrences, and adverse conditions related to health, safety, or fire protection.

- Monitor the status of automatic fire protection and fire safety systems across the site.

Of the three dispatchers, two currently are light duty personnel. The remaining shift rotates members into the dispatch position.

All telephone alarms are received at the Hanford Patrol Operations Center, which is the 9-1-1 Public Safety Answering Point (PSAP) for the site. For calls requiring response by fire, rescue, or EMS units of the HFD, the Patrol "dispatcher" takes the information from the caller. That dispatcher then calls HFDC and repeats the caller's information. At times the HFD needs or wants additional information concerning the nature of the original call. The Patrol dispatcher may telephone the original caller back for more details, or may have kept that person on "hold". The existing protocol does not allow the HFD dispatcher to talk with the person calling for help, even for EMS calls.

Multiple computer systems are used to monitor approximately 310 fire alarm boxes and to aid in the dispatching of the emergency vehicles. The computer systems are linked together via microwave and telephone communication networks. Automatic alarms from facility fire detection and alarm devices are transmitted directly to the HFDC via a computerized Radio Fire Alarm Reporting (RFAR) system.

The main purpose of the RFAR is to receive and record fire related alarms. The system is located at each of the three outlying fire stations as well as in the HFDC. The RFAR system decodes, displays, records, and annunciates alarms, monitors the alarm box status, generates reports, and configures the system.

The HFD has loud speakers in the stations, and through these crews hear the Patrol dispatcher calling the HFD dispatcher. This serves as a pre-dispatch alert. The HFD dispatcher announces over the station speakers the telephone alarms relayed from Patrol, automatic alarm system calls, and the calls reported in person directly to a station. That announcement serves to dispatch the appropriate station and provides information needed by Captains to select the type of apparatus best suited to the call. During week days the appropriate Battalion Chief is dispatched to most calls. 
The HFD Computer Aided Dispatch (CAD) system is interfaced with the RFAR system and provides the dispatcher with the following information relevant to that alarm box:

- Radio fire alarm box number

- Building identification

- Fire zone

- Time alarm was detected

- Date alarm was detected

- Recommended response equipment information

- Hazards

- Exposures (adjacent structures that may be threatened)

- Graph display of building and fire zone

- Types of alarm devices in zone (smoke detectors, pull boxes, etc.)

- Special exposures (i.e. propane tank)

- Radiation hazards

As back up to the main system, there is a secondary CAD. The CAD system monitors its backup system plus the three satellite CAD systems at the other fire stations and two RFAR systems.

An upgrade of the mobile data terminal (MDT) is underway and will consist of three phases. The hardware and software for Phase 1 have already been purchased. They will be installed beginning in November, 1995. Phase 2 and 3 hardware and software will be purchased in FY 1996 using capital funds. The purchase requisitions for these items are currently being prepared by Telecommunications Engineering. It is expected the orders will be placed in January 1996.

Phase 1 consists of an upgrade to the Network Control Processor. The Phase 1 upgrade will replace the AT computer with a newer unit, a 486 computer with updated Motorola boards. The new unit will operate from a hard drive, rather than from a floppy disk. The current unit operates only from the floppy disk drive. The upgrade will bring the communications software up to date and improve the data transfer between the MDT and the transceivers. Other changes to the transceivers will increase the data throughput rate through retuning and configuration changes for increased speed.

Phase 2 will replace the transceivers with newer, faster units. The new transceivers will be duplex, rather than simplex. This will allow the transmitters to send and receive at the same time, which will improve the data throughput. Other hardware changes are included in this phase to increase the data transmission speeds.

Phase 3 will replace the existing Mobile Data Terminals (MDT) in the vehicles with newer 486 computers. These new units will include on-board storage capacity, unlike the current MDTs. The current units are equipped with $32 \mathrm{~K}$ of RAM but are not equipped with hard drives. Thus, all information, including the display screens, the programming, and the data, must be transmitted to the MDTs before they will display alarm information. From consultations with HFD personnel, this process has proven to be too slow and unwieldy to be of use in alarm response. The new computers will retain the programming and display 
screens on their built-in hard drives, and should greatly increase their ability to quickly display alarm information. The graphics capability is expected to be improved dramatically, since the current units do not have a graphics screen as such. Instead, an alternate character set is used to build graphics. The display is limited to 10 characters high by 40 wide, and makes it difficult to maintain any realistic perspective when displaying drawings. The new computers will have display capability allowing them to use the same graphics as are currently displayed on the main CAD computer.

When the upgrade is completed, the new equipment may be capable of being used by other site organizations. The Access Control Data Entry System (ACES) program is one possible candidate, as use of similar equipment would allow Health Physics to use ACES in remote locations.

The HFD has equipped all vehicles with transceiver radios. Portable, handheld, radios are issued to all officers and interior attack crews. Each of the four fire stations is equipped to communicate with the vehicles and the portable radios.

The HFD is allocated three radio frequencies, two in the VHF range category and one in the UHF range. The primary VHF frequency is used for all dispatching and communication purposes. The second VHF frequency is a low wattage, short distance tactical frequency for use at a working incident. The third UHF frequency is a low wattage frequency used for the testing and servicing of alarm systems.

Having both VHF and UHF range frequencies assigned requires the use of separate transceivers. This presents difficulties in that the HFD does not have the desirable flexibility in its existing equipment and maintains two separate radio systems (base station, mobile units, and portable units).

There is compatibility with the adjacent, mutual aid fire departments from base stations and from vehicles. All fire stations are linked by telephone.

A proposal now exists to combine the Hanford patrol dispatch operation with that of the HFD. A new facility would be constructed and new hardware and software selected. This facility, which would eliminate the HFDC and its functions, would be operated by the Hanford Patrol. All existing major functions conducted by the HFDC would be assumed by the new center. The proposal is still under consideration.

Fire personnel appear uneasy about the prospect of losing their existing single purpose facility. It has been reported that the firefighters' union is raising questions concerning whether the proposed dispatching positions will be "exempt", as is proposed, which may cause conflict.

Telephone communication is used by the HFDC to contact the dispatch centers of the mutual aid departments, and to recall off-duty firefighters. 


\subsubsection{Applicable Requirements/Criteria}

DOE Implementation Guide for use with DOE Orders 420.1 and 440.1 recommends that emergency radio communication be compatible with other emergency organizations involved with emergency response and should be designed to be effective in areas subject to structural interference.

NFPA 1221, Standard for the Installation, Maintenance and Use of Public Fire Service Communications Systems, 1994 Edition. This Standard covers the installation, maintenance, and use of public fire service communications systems and facilities. Provisions prescribed by this standard for fire service communications systems and facilities include the following:

- Where the communication center is not the primary answering agency for fire calls, the answering agency shall transfer the call directly to the fire alarm operator and remain on the line until assured that the transfer is effected. This transfer shall be used instead of relaying the information to the operator.

- A minimum of two incoming 9-1-1 circuits to the Public Safety Answering Point (PSAP)

- Automatic recording of all fire calls received by telephone with the capability of instant playback.

- Automatic record of the time of receipt of each alarm.

- The Computer-Aided Dispatching (CAD) system shall be dedicated pieces of equipment whose use serves only to enhance fire services dispatching operations and shall have qualified technical assistance available for trouble analysis and repair by in-house personnel or by authorized outside contract maintenance services.

- An up-to-date hard copy file of stored information to support the dispatching system should the CAD system fail shall be located on the premises.

- The system response time, full load, measured from the time a console operator completes a keyboard entry to the completion of the return of the system response to the CRT screen, shall not exceed five seconds.

- The CRT display shall have graphics capability suitable for at lease the partitioning of the screen with boundary lines and the display of simple map and floor plan line drawings.

- The CAD system shall include printers for dispatching logging, and administrative utility functions. 
- Data communications systems interfaced with the CAD system such as mobile fire department vehicles shall transmit at a rate of not less than 600 baud.

\subsubsection{Recommendations}

9.6.3.1 The HFD alarm, dispatch, and emergency communication systems for fire, rescue, and EMS services shall comply with the applicable requirements of NFPA 1221 and shall have as a minimum the following performance characteristics:

1. Fast, direct access by automatic alarms systems (as now) and by telephone callers (not now available).

2. Call switch-over capability from the 9-1-1 call taker (Public Safety Answering Point or PSAP).

3. Customized computer aided dispatch (CAD) hardware and software.

4. Customized computer aided dispatch systems to handle automatic alarm supervision and testing quickly and accurately.

5. Radio communication capability throughout the service area, with sufficient frequencies to handle routine business, emergency dispatch, tactical incidents, mutual aid communication, and recall of off-duty personnel by twoway pagers.

6. Capability to efficiently transmit data to the MDTs.

7. FAX capability to Stations, and MDT print-out capability to vehicles.

8. System redundancy.

9. Capability of being operated by a single dispatcher in medium volume call situations.

\section{Supporting Statement}

The existing HFDC does not meet criteria items 1,2,5, 6, \& 7. (System upgrading already begun will satisfy item 6 and will improve overall CAD capability). It is recommended that the HFDC system be further upgraded to satisfy all items for the following reasons:

- The time spent to dispatch apparatus/personnel should be minimized. This is especially true at the site, where some response distances are relatively long. An extra minute of dispatch time is roughly equivalent to adding three-fourths of a mile to the response distance. Consequently, reducing call taking, dispatch, and "get-out" time from the stations, helps insure timely arrival of the crews. This is one strong asset of the existing automatic alarm configuration, which rings directly at the HFD dispatch center.

- Immediate direct contact between the HFD dispatcher and the caller reduces dispatch time and enables the HFD dispatcher to direct any specific questions or concerns to the caller rather than through a third party.

- With complex hazards, it is important for responding officers to have immediate access to pre-plans, graphics, and other relevant data concerning the 
facility. High speed MDTs able to communicate with the CAD system provide the an effective and efficient access system.

- $\quad$ MDT printout capability enables incident command personnel the flexibility to work from "hard" copy. FAX capability enables incident command personnel access to other information sources that may not be available to the $\mathrm{CAD}$ system.

9.6.3.2 The HFD alarm, dispatch, and emergency communications system shall have the following process characteristics:

1. Capability of handling simultaneous events.

2. Capability of maintaining a continuous flow of information during a working incident while handling additional dispatches and firefighter recalls.

3. Capability of announcing relevant weather conditions, including wind speed and direction, during incidents for tactical purposes as now.

4. Capability of announcing "time into incident" in five minute increments for incident command purposes as now.

5. Capability of handling all calls for mutual aid.

6. Capability of notifying all relevant agencies of incidents, and coordinating all responses as now.

7. Capability of handling EMS dispatches using standard protocols for advising EMS callers.

\section{Supporting Statement}

Presently, process characteristics \#2, and 7 , are not being met by the existing system. It is recommended that the HFDC system have these process capabilities for the following reasons:

- Although simultaneous working incidents are not common at the site, the HFDC and the assigned dispatchers need the training and experience (simulated, if necessary) to handle more than one incident at the same time. Mishandling such an event could result in serious consequences.

- It may be necessary to notify other agencies on Site of a particular incident. Also, recall or emergency assignment of off-duty or staff personnel must be handled quickly. The transmission of useful information to the scene, by MRT or radio, also is a necessary dispatch function.

- Being able to advise EMS callers using standard protocols, is critical to ensuring that all appropriate consultations are provided to the caller immediately upon activation of the EMS system.

Note: The following recommendations (9.6.3.3-.9) are provided in support of Recommendations 9.6.3.1 and 9.6.3.2. 
9.6.3.3 Consolidate the entire fire dispatch and emergency communications system function so that its functions are overseen by the HFD. Alternatively, reestablish a site emergency alarm-dispatch-communications feasibility task force which allows for equitable participation of all possible users and which examines, the feasibility of a Site-wide facility controlled by an equitable multi-agency policy board.

\section{Supporting Statement}

Dispatch centers which service several response agencies but which are controlled and run by only one of the agencies frequently demonstrate their inability to provide efficient and effective service for all user groups--and thus for the "customers." Long time national experience indicates that cost-savings are possible through the use of combined centers, but adequate performance comes only when the center is governed and controlled by an equitably formed "user board", and not by the officials of one user agency. For this reason, municipal combined centers often are operated by a free standing "communications department" using a user policy group.

9.6.3.4 The dispatcher job shall be assigned to a minimum of one trained person on each shift. There also must be a quick responding back-up dispatcher for each shift.

\section{Supporting Statement}

Dispatchers must be qualified and trained professionals to handle the myriad of calls that will vary in need and complexity. Having the capability to quickly recall a back-up dispatcher prepares the site for a situation where the primary dispatcher is incapacitated (due to illness or other cause) or becomes overworked.

9.6.3.5 Install a "quick-call" trouble buzzer system in the communications room and a deadman notification system on all in-coming alarms and 911 calls.

\section{Supporting Statement}

This feature ensures that the dispatcher can alert appropriate personnel that help is needed and safeguards against the situation where the dispatcher is suddenly overworked or incapacitated. The dead-man feature notifies external individuals should a dispatcher fail to acknowledge an incoming alarm.

9.6.3.6 EMS Dispatchers shall be trained in EMS dispatch operations, procedures, and protocols.

\section{Supporting Statement}

This recommendation presumes that dispatchers are in the use of the emergency medical protocol call takers book and may be required to provide technical consultations to the caller. Having the dispatchers EMT "dispatch" trained, increases their understanding of the protocol and may enhance their ability to provided effective consultations to the caller. 
9.6.3.7 Design and implement a selective off-duty recall system with the following features:

- Rapid and simple transmission of the recall by single person

- Selective or small group or large group recall

- Recall transmission capability over long distances

- Responder to transmission point feedback capability

\section{Supporting Statement}

HFD has always considered the recall of off-duty personnel as necessary in the event of large scale and/or long lasting incidents. This concept will remain valid, but a more efficient and effective recall system is necessary if the baseline staffing is utilized. An effective recall system allows the quick recall of key individuals or pre-selected groups through the pressing of one transmitter button. The dispatcher should be able to recall personnel by a single transmission and quickly determine how many are responding. If an insufficient number respond, a larger group can be recalled. Because of travel distances involved, personnel should be required to notify the dispatcher indicating they are responding. All potential response personnel, including T\&S FF, should be equipped with the necessary paging device. Radio type devices typically offer the best capability.

\subsection{PRE-EMERGENCY PLANNING}

\subsubsection{Prefire Plans, Existing Conditions}

Written prefire plans are developed by HFD members, exclusively for use by fire department members. The plan supplies important information concerning the occupancy of the building, type of building construction, water supply, fire protection features, types of hazards contained within the structure and building layout for access and escape routes. The plan provides knowledge of factors and conditions that enable command officers to make educated fire behavior predictions and reliable estimates of the resources they will need to control the situation (WHC, 1995b). Presently, there are 658 prefire plans that are being maintained by the HFD.

\section{Development}

Shift officers are responsible for development, review and updating of prefire plans as assigned within their immediate response area. Battalion Commanders are responsible for assigning prefire plans for update and ensuring all prefire plans are completed, thoroughly reviewed, approved and distributed in a timely fashion. Additionally, they are responsible for ensuring that all prefire plans are updated in accordance with the established schedule.

The department administrative assistant is responsible for final typing, original document control, filing, distribution, and tracking for all prefire plans.

The HFM by charter has the final authority for pre-fire plans. Captains write and update the prefire plans. The current method of preparing and updating prefire plans involves 
preparation by response personnel, review by Battalion Chiefs and review and signature by building management.

\section{Updating}

Updating of pre-fire plans are performed at a frequency based on the facility replacement cost value (including contents). Prefire plans for in-use facilities having a replacement cost value equal to or greater than $\$ 50$ million are required to be updated annually. Those with a replacement cost value from $\$ 10$ to $\$ 50$ million dollars are required to be updated every two years. Those with a replacement cost value of $\$ 1$ to $\$ 10$ million are required to be updated every three years. Those with a replacement cost value of less than $\$ 1$ million dollars are required to be updated every five years.

Prefire plans for facilities listed for Decontamination and Decommissioning are retained prior to change in status. The frequency for updating these prefire plans is adjusted to five years. When all alarm functions and utility services have been disconnected from the facility, prefire plans will be discontinued.

\section{$\underline{\text { Use }}$}

The prefire plans are intended to provide knowledge of factors and conditions that enable command officers to make educated fire behavior predictions and reliable estimates of the resources they will need to control the situation. They are maintained at each station for use by fire department officers. Due to the extensive information that is covered, copies are typically not maintained in the first run units and therefore their use in an emergency response is limited.

\section{Future Changes}

A quick access prefire plan, is being developed to supplement existing prefire plans. This plan summarizes in a single sheet, pertinent information that can be placed in each first due engine and readily accessed and used by incident command officers at the scene of the incident. The plans are put in place as existing prefire plans are updated. The HFD expects the process to continue until 2000.

\subsubsection{Building Familiarization Tours, Existing Conditions}

Building familiarization tours of all site buildings and facilities are performed on an annual basis. These tours are performed by HFD platoons and provide an opportunity for the HFD to become familiar with the hazards and layout of each building or facility as well as assist in prefire plan development.

\subsubsection{Confined Space Entry, Existing Conditions}

The HFD maintains a list of all identified "permitted" confined spaces. As of January 1996, the HFD notes that there are over 500 permitted confined spaces identified on the Hanford Site. All Hanford contractors are required to provide the HFD a current listing of 
the location of permanent permit-required confined spaces on an annual basis. Additionally, all Hanford contractors must provide information to the HFD on new permanent or temporary permit-required confined space locations on a case-by-case basis before they are entered. If on rare occasions, a space to be entered is found to present unusual rescue problems that have not been previously practiced, HFD can require that they be given the opportunity to resolve the problems and conduct any needed practice rescues before normal entry operations commence. (Internal DOE Memo, November, 1993).

\subsubsection{Hazardous Materials Incidents, Existing Conditions}

A hazardous materials Emergency Response Plan and a hazardous materials Operation Plan have been developed by the HFD. The Emergency Response Plan is a general outline for all hazardous materials responses designed to meet the requirements of NFPA 472 . The Operations Plan is a detailed step-by-step procedure listing specific actions that need to be taken during an incident. The steps in the Emergency Response Plan must be followed for all responses, while the Operational Plan is to be viewed as a guideline, with good general steps to be followed (HFD Hazardous Materials Notebook, not dated). The Emergency Response Plan and Operations Plan:

- describe operational concepts, organization, and support systems required to implement the plan.

- Identify authority, responsibility, and actions of Federal, State and Hanford Site Contractors necessary to minimize damage to human health, natural systems, and property and to aid in mitigating the hazard.

- Establish an operational structure that has the ability to function within the boundaries of the Hanford site and on mutual aid responses.

- Identify and utilize HFD officers and members who have been trained to handle hazardous materials incidents.

- Establishes lines of authority and management for a hazardous materials incident.

HFD preplanning for potential hazardous materials incidents is documented in the HFD Hazardous Materials Response Plan. Presently, twenty-one topics have been identified for inclusion into the Operations Plan, but have yet to be developed and/or approved for inclusion. Known hazardous materials and radiation hazards are summarized in the building pre-fire plans.

Implementing Procedures which establish a general operational and tactical approach to Hazardous Materials incidents have been drafted (HFD, 1995b). The procedures identify specific duties and responsibilities for dispatch, and the first arriving unit as well as provide guidance in incident size-up, formulation of an action plan, establishing hazard control zones, use of non-fire department personnel, and general tactics based on the level of incident severity. 


\section{Transport of Hazardous Materials}

The HFD may be notified when hazardous materials are being transported on the site. There are established requirements for notification and a formal process for HFD notification as delineated in WHC-CM-2-14 part iv.

\subsubsection{Emergency Activities in Radiation Zones, Existing Conditions}

A policy regarding requirements and responsibilities for firefighting and other emergency activities in radiation zones has been established (HFD, 1994). The policy applies to all members of the Hanford Fire Department and covers emergency operations and training. The policy identifies personnel responsibilities, precautions for wildland fires involving radiation zones, requirements for protective equipment, dosimetry and emergency dose limits. These are summarized below:

\section{HFD Personnel Responsibilities}

In the absence of a Health Physics Technician or qualified facility representative, the ranking fire officer assumes responsibility for radiation protection of HFD crews. Within the limits of safe firefighting and emergency practices, the number of personnel assigned to enter a radiation zone will be kept to a minimum. Other personnel must be present to support the entry team, with SCBA bottle change out, contamination control zones, and exit from the zone.

\section{Wildland Fire Precautions}

All HFD personnel must be cognizant of posted exterior radiation zones, such as burial ground, cribs, drainage ditches, and facility perimeter areas. Entry is contingent upon appropriate protective clothing and respiratory protection (e.g., Nomex jumpsuits, and airpurifying respirators. Health Physics personnel must be present and consulted before personnel or vehicles leave the area.

\section{Protective Equipment}

Minimum personal protective clothing is stipulated by posted Radiation Work Procedures (RWP) and adherence to posted radiation zone signs. Fire department bunker gear provides an equal level of protection when used with Self-Contained Breathing Apparatus (SCBA). Full bunker gear and SCBA is mandatory when a response might involve the potential for firefighting in a radiation zone.

\section{$\underline{\text { Dosimetry }}$}

In addition to RWP-required personal dosimetry, fire department personnel entering a potential radiation environment will use both the self-reading pencil dosimeter and the Personal Alarm Dosimetry Indicator (PADI), which provides an audible alert should radiation exposure exceed certain pre-set limits. The PADIs have two alarms. A dose rate alarm sounds in an area receiving $5 \mathrm{R}$ per hour or greater. This alarm can be silenced. A second 
alarm sounds when a dose of 2.5 REM has been measured. This alarm cannot be silenced in the field.

\section{Emergency Dose Limits}

Emergency dose limits are identified Table 9-7.1 below (HFD, 1994) and apply only in an emergency. Every effort will be made to maintain doses as low as reasonably achievable. For comparison purposes, DOE whole body radiation dose limit for routine conditions is $5 \mathrm{rem} / \mathrm{year}$. WHC whole body administrative control levels are $\mathbf{5 0 0} \mathbf{~ m r e m} / \mathbf{y r}$ and 1,000 mrem $\mathbf{x}$ age (WHC, 1993). Note: Other more conservative values are cited by 10 CFR 835 (Table 9-7.2) and noted in other documentation such as the WHC Radiological Worker II, Initial Training Manual (June 1993), and the ANL-E Radiological Control Manual, (May, 1995).

\begin{tabular}{|l|c|}
\hline \multicolumn{1}{|c|}{ Table 9-7.1 Emergency Dose Limits (WHC-IP-0939) } \\
\hline \multicolumn{1}{|c|}{ Circumstances of Exposure } & $\begin{array}{c}\text { Maximum Single Dose } \\
\text { (whole body) }\end{array}$ \\
\hline \hline Action to control and confirm an emergency event & $3 \mathrm{rem}$ \\
\hline $\begin{array}{l}\text { Recovery of vital equipment or to prevent property } \\
\text { loss or reduce hazard }\end{array}$ & $10 \mathrm{rem}$ \\
\hline $\begin{array}{l}\text { In special circumstances, to reduce hazard or prevent } \\
\text { substantial property loss }\end{array}$ & $25 \mathrm{rem}$ \\
\hline $\begin{array}{l}\text { To save a life or prevent severe effects on health or } \\
\text { safety of the public }\end{array}$ & $100 \mathrm{rem}$ \\
\hline
\end{tabular}

No personnel may enter any potentially contaminated area if they have an open cut, wound, or other significant breech in the skin.

\section{Radiologically Contaminated Patients}

An incident involving radiation or internal depositions of radionuclides may require activation of the Emergency Decontamination Facility (EDF). The HEHF physician-on-call is responsible for determining whether or not to activate the EDF (WHC, 1992)

\section{$\underline{\text { Criticality }}$}

The potential for a criticality incident (an accidental, self-sustained atomic chain reaction) and related HFD response concerns are identified in the pre-fire plans. 


\subsubsection{Other Incidents, Existing Conditions}

The HFD has developed a pre-emergency plan for rail car shipments. WHC Emergency Preparedness identifies potential emergency events and prepares specific incident plans. These events typically cover seismic, wind, acts of sabotage, etc. The HFD assists this organization in incident planning development. There is a Tri-Cities Mass Casualty Plan developed by the Benton County Department of Emergency Management. This plan is revised by the HFD every five years. The city of Pasco also has an Airport Mass Casualty Plan.

\section{Mass Casualty Incident Capabilities:}

Response to mass casualty incidents is not specifically addressed in an HFD procedure. HEHF has developed a plan for the site. The plan was approved by DOE without any input by the HFD. Existing resources that HFD could utilize in a mass casualty event are noted below:

The HFD has six ambulances available for mass casualty incidents. Four of these are staffed full-time, with the other two kept in reserve. The reserve units could be staffed very quickly during shifts using FSTM personnel. Currently, there is one paramedic within the FSTM personnel. Another FSTM firefighter has recently completed the paramedic course but has not yet been certified, pending completion of ambulance "ride time". All other FSTM firefighters are either EMTs or First Responders.

The HFD currently houses a mass casualty trailer in Station 91. The trailer inventory is partially owned by the HFD with the balance of the equipment belong to Franklin County Fire Protection District \#3. This trailer is available to be moved to the site of any mass casualty incident on the site or within the mutual aid area.

Mutual aid units are available for use in mass casualty incidents. This includes paramedic and BLS units from 10 surrounding fire districts. Incidents that are too large to be handled by our mutual aid area would be escalated to the state level through the Kennewick emergency dispatch center.

In a mass casualty incident situation, patients can be transported to Kadlec, Kennewick General, Our Lady of Lourdes in Pasco, and to the two Yakima area hospitals. The MAST helicopter from the Yakima Training Center is available for mutual aid. hospitals.

Local air ambulance service is also available for transport to Spokane or Seattle area

\subsubsection{Pre-incident Exercises/Drills, Existing Conditions}

In association with the site emergency preparedness organization, the HFD may participate in site emergency exercises. These exercises are managed by the site emergency preparedness organization and are scheduled on a monthly basis. Field exercises requiring full HFD participation are typically conducted on a quarterly basis. Desktop exercises requiring 
HFD participation in the form of representation (typically, by an incident commander) are generally conducted on an annual basis. The HFD may be asked by the building/facility manager to participate in building fire drills.

\subsubsection{Mutual Aid}

The HFD participates in formal and approved mutual aid agreements with both fulltime and volunteer fire departments in Benton, Franklin, and Walla Walla Counties. The fulltime fire departments are located in Richland, Pasco, and Kennewick, with the remaining eight departments being volunteer. There is also an agreement for mutual protection from wildland fires with property owners in the Rattlesnake Area.

All of these groups will assist on Site property with "wildland" ground cover fires, but will not participate directly in operations involving hazardous materials or radioactive incidents. The full-time departments will provide assistance with ordinary structural firefighting, but support work only at hazmat and radiation incidents. While there is a newly developed automatic mutual aid draft agreement with Richland, simultaneous dispatch is not taking place and "automatic" aid is not operating (Mutual Aid, 1995).

To date, the outside departments have responded only to wildland fires on site. HFD has been called to assist at several structure fires in Richland. There is a Benton County "hazmat team", but there is no HFD mutual aid agreement with it. The team does not function as part of any County fire department.

\subsubsection{Applicable Requirements/Criteria}

\section{Building Pre-Fire Plans}

RLID 5480.7 requires the HFD to develop and maintain prefire plans for all major Hanford facilities and operations.

HFD policy regarding development of prefire plans is identified in WHC-IP-13.2.

DOE Fire Protection Resource Manual recommends the frequency for updating prefire plans.

The draft DOE Order 420.1, Facility Safety, section 4.2.1 paragraph 8 stipulates that written pre-fire strategies, plans, and standard operating procedures to enhance the effectiveness of site fire fighting forces shall be provided. Such procedures shall include those governing the use of fire fighting water or other neutron moderating materials to suppress fire within or adjacent to moderation controlled areas. Restrictions on the use of water shall be fully justified on the basis of criticality safety. The Order also states that the fire protection program shall establish guidelines for fire fighting with, or adjacent to, moderation controlled areas. The guidelines shall be based on comparisons of risks and consequences of a criticality accident with the risks and consequences of postulated fires for the respective area(s). 
The DOE Implementation Guide for DOE Orders 420.1 and 440.1 recommends that a current file of fire pre-plans be maintained. It also recommends that pre-plans be developed on the basis of input from the site fire protection engineering staff as well as emergency responders.

\section{Building Familiarization Tours}

The draft DOE Order 420.1, Facility Safety (October 10, 1995) recommends that regular facility tours be conducted utilizing current pre-plans to enable them to deal effectively with the unique conditions which characterize DOE facilities. Building tours are required to be documented and performed annually on a minimum of $25 \%$ of the total number of buildings by the DOE Fire Protection Resource Manual.

\section{Confined Space Entry}

The draft DOE Order 420.1, Facility Safety (October 10, 1995) stipulate the responsibilities of DOE fire-fighting forces to include confined space entry. The HFD is required by RLID 5480.7 to maintain confined space entry and other emergency rescue readiness, as required by 29CFR 1910. The WHC-CM-4-40, Industrial Hygiene Manual (September 19, 1994) requires (for "permit" spaces) notification of the HFD or other authorized rescue team of the entry schedule, the potential hazards within the space, and any special provisions of the emergency plan. At least 24 hours advance notice is to be provided when possible. The Industrial Hygiene Manual stipulates that the HFD Fire Marshal (or designated representative) may inspect the confined space prior to entry to determine if a successful rescue is feasible. If a successful rescue is not feasible, the entry shall not be made.

\section{Hazardous Materials}

DOE-RLID 5480.7, stipulates the HFD is the designated hazardous materials incident command agency for the Hanford site.

The DOE Fire Protection Resource Manual stipulates that a hazardous material program be in place consistent with the requirements of OSHA 1910.120 and NFPA 472 .

The draft DOE Order 420.1, Facility Safety (October 10, 1995) stipulates responsibility for Hazmat response (where assigned) to DOE firefighting forces.

- $\quad 29$ CFR 1910.120 "Hazardous Waste Operations and Emergency Response Requirements"

- Hanford Federal Facility Agreement and Consent Order

- NFPA 471 (1992) Responding to Hazmat Incidents

- SARA Title III, Response capabilities, information filing, etc.

- Nuclear Regulatory Guide CFR 835, Training

- $\quad$ OSHA CFR $1910.120 ; 1910.119 ; 1910.151$, Various recommended practices

- The requirements for a designated incident command agency are given in Chapter 173-303, Washington Administrative Code, "Dangerous Waste Regulations." The majority of criteria for team training is specified by 29 CFR 
1010.120 and NFPA 472, "Professional Competence of Responders to Hazardous Materials Incidents."

\section{Emergency Activities in Radiation Zones}

10 CFR Part 835, Occupational Radiation Protection stipulates that the risk of injury to those individuals involved in rescue and recovery operations shall be minimized. It issues the guidelines cited in Table 9-7.2 cited below. It also stipulates that rescue action that might involve substantial personal risk shall be performed by volunteers.

\begin{tabular}{||c|c|c||}
\hline \multicolumn{2}{|c|}{ Table 9-7.2 } & Emergency Dose Limits (10 CFR 835) \\
\hline ACTIVITY PERFORMED & CONDITIONS & $\begin{array}{c}\text { DOSE LIMIT } \\
\text { (Total Effective Dose } \\
\text { Equivalent) }\end{array}$ \\
\hline All & All & 5 \\
\hline $\begin{array}{c}\text { Protecting Major Property } \\
\text { Lifesaving or protection of } \\
\text { large populations }\end{array}$ & $\begin{array}{c}\text { Where lower dose limit not } \\
\text { practicable. }\end{array}$ & 10 rem \\
practicable. & 25 rem \\
\hline $\begin{array}{c}\text { Lifesaving or protection of } \\
\text { large populations }\end{array}$ & $\begin{array}{c}\text { Only on a voluntary basis to } \\
\text { personnel fully aware of the } \\
\text { risks involved }\end{array}$ & $>25$ rem \\
\hline
\end{tabular}

\section{Pre-Incident Exercises/Drills}

DOE 5480.7A stipulates that the facility fire protection organization shall be involved in the development of the Emergency plan and in all related training and drills. DOE Implementation Guide for DOE 420.1 recommends that drills and exercises be structured to emphasize realistic scenarios and feature standard fire department tactical evolutions.

\section{Mutual Aid Agreements}

DOE Order 5480.7A, Fire Protection states that DOE or Contractor-operated organizations with the responsibility for providing fire protection for DOE property may enter into mutual aid agreements with other fire departments in accordance with Public Law 46 (Title 42 USC Section 1856).

RLID 5480.7 Section 6.3 stipulates maintaining mutual aid agreements with surrounding area fire districts. 
DOE 420, Facility Safety section 4.2.1 paragraph 7 cites identification of off-site assistance requirements.

DOE Implementation Guide for DOE 420.1 and DOE 440.1 recommends that "... when reliance will be placed on off-site fire departments, a plan should be developed that details how such forces will be expected to respond in conjunction with the site emergency plan and how appropriate training and site familiarization will be provided to ensure that the off-site departments will be prepared for fires that occur on site. Appropriate drills should be performed periodically to verify the effectiveness of the plan."

\subsubsection{Recommendations}

Pre-fire Plans

9.7.10.1 Quick Access prefire plans shall be accessible for personnel use within all first run units.

\section{Supporting Statement}

A current file of prefire plans is maintained. The frequency for updating the plans conforms with the criteria cited in the DOE Fire Protection Resource Manual. Presently, prefire plans are not carried on the first responding vehicles, presumably due to the significant size and detail contained in the plan. The quick access prefire plan has condensed the facility information in the prefire plan to one double-side page. It contains only those elements that are deemed critical in incident decisions. DOE 420.1 section 4.3.3 paragraph $\mathrm{k}$ stipulates that firefighting guidelines be based on comparisons of risk and consequences of a criticality incident and that the basis for the guidelines be documented. Also, there are a significant number of facilities handling radiological material. Thus consideration should be given to identifying any firefighting guidelines specifically for radiation hazards, and the issue of criticality within the quick access prefire plan. The basis for the guideline could be documented in the prefire plan. For incident coordination purposes, the quick access prefire plan may want to include the name and phone number of the building emergency director.

9.7.10.2 Prefire plans and quick access prefire plans shall be developed for all facilities and areas with significant hazards.

\section{Supporting Statement}

Presently, only those facilities with significant replacement costs are required to have a prefire plan. Areas where this doesn't apply are typically not addressed (e.g. the burial grounds, ERDF, and the WPPSS outlying buildings). These facilities and areas have significant hazards that are often unique and may require special tactics in hazard mitigation and therefore warrant development of a prefire plan and quick access prefire plan.

Confined Space Entry 
WHC-SP-1180, Vol. 1

9.7.10.3 The HFD shall evaluate the necessity of HFD notification 24-hours in advance of confined space entry.

\section{Supporting Statement}

From discussions with HFD management, the Industrial Hygiene requirement for 24hour notification is not enforced by the HFD nor is this requirement in any HFD implementing procedure. Further, it was not clear that an additional level of HFD preparedness is achieved by this notification. Nevertheless, an apparent discrepancy exists between what is expected to occur to comply with the Industrial Hygiene requirement and what actually occurs.

\section{Hazmat}

9.7.10.4 Hazmat incident operating guidelines shall be completed.

\section{Supporting Statement}

A complete Hazmat Operations Manual is necessary for crew member orientation and training. Completed guidelines demonstrate a degree of HFD readiness to mitigate identified hazmat events.

\section{Emergency Activities in Radiation Zones}

9.7.10.5 The HFD shall be provided with the capability of ensuring (and validating) that all emergency services can be performed within the applicable dose limitations.

\section{Supporting Statement}

Presently, the HFD has minimum capability (self-reading pencil dosimeters and PADIs set at $2.5 \mathrm{Rem}$ ) for ensuring that emergency services can be performed within the prescribed DOE dose limitations. Providing additional radiological equipment (and training) to first responders so that they can make appropriate decisions regarding radiological exposures. Assignment of a Radiological Control Technician (RCT) who responds as a first responder to all radiological incidents would also serve to meet this recommendation provided they are trained in the use of SCBA and PPE.

9.7.10.6 The HFD dose limits shall be revised to reflect the criteria stipulated by 10 CFR 835 .

\section{Supporting Statement}

The HFD emergency dose limits exceed the guidelines of 10 CFR 835 . Therefore, it may be inappropriate to be utilizing less conservative does limits without formal DOE approval. It should be noted that EPA 520/1-75-001, Manual of Protective Action Guide and Protective Actions for Nuclear Incidents, recommends that, in a life-saving action, such as search for and removal of injured persons or entry to prevent conditions that would injure or kill numerous persons, the planned dose to the whole body should not exceed 75 rems. 
During circumstances that are less threatening to life, where it is still desirable to enter a hazardous area to protect facilities, to eliminate further escape of effluents, or to control fires, it is recommended that the planned dose to the whole body should not exceed 25 rems (NFPA 1995)

Pre-Incident Exercises/Drills

9.7.10.7 The pre-incident exercises and drills which involve the HFD should as a minimum be continued at a level and frequency which currently exists.

\section{Supporting Statement}

The hazards identified in Section 7 represent a myriad of accidents which require adequate training and preparedness to be mitigated safely and effectively. Continuous exercises of as many different accident scenarios provides a mechanism for identifying HFD strengths and weaknesses relative to incident preparedness.

\subsection{FIRE PREVENTION}

\subsubsection{Fire Prevention Program, Existing Conditions}

The Fire Prevention Program of the HFD is administered and enforced under the authorities granted by DOE-RL to the Hanford Fire Marshal (HFM) as identified in RLID 5480.7. The primary duties of the HFM, developed in coordination with the Hanford Fire Protection Forum are outlined below and constitute the primary elements of the HFD fire prevention program:

- Administration and enforcement of the "Fire Prevention Program". This is based on NFPA 1, the Fire Prevention Code.

- Act as technical advisor and administrator for the Hanford Fire Department and DOE-RL for developing NFPA code related fire prevention programs. This includes authority to require that fire watch be conducted when conditions warrant.

- $\quad$ Final authority for pre-fire plans.

- Develops and Directs fire prevention inspection programs for

- Storage, use, and disposal of combustible, flammable, explosive or reactive material.

- Hydrant flow testing

- HFD Building Tour and Inspections

- Flammable and Reactive Waste Site Inspections (in WHC facilities)

- Schedules (as necessary) inspections with the cognizant building manager to ensure compliance with building restrictions and policies. 
- Reviews and approves all Acceptance Test Procedures (ATPs) for all fire alarm and suppression systems and equipment in all facilities including new or proposed installations on the Hanford Site.

- Witnesses (or designated representative) the performance of ATPs.

- Reviews and approves all fire department inspection and test procedures for fire suppression and alarm systems.

- Conducts maintenance, test, and inspection record audits on an unspecified number of facilities annually in a random selection process.

- Inspect or direct the inspection of exits in accordance with Chapter 31 of the NFPA 101 Life Safety Code.

- Authorize the establishment of permanent fire lanes for fire department equipment access.

- Inspect or direct the inspection of all construction and/or demolition sites to ensure that applicable codes and standards regarding fire prevention are being followed. (Resolution of any issues is via the engineer/construction contractor.)

- Develop and maintain a current database for all HFD fire prevention inspection records, findings, and resolutions.

- Issue or direct the issuance of permits for fire protection systems, bonfires and outdoor rubbish fires, combustible fibers, compressed gases, cutting and welding, dust explosion prevention, explosives, flammable and combustible liquids, LP-Gas, and other applicable operations identified in NFPA 1, section $1-15.16$.

- Issue Fire Prevention Findings which may result from the fire prevention inspection program with the intent of identifying deficient items that can and should be corrected immediately.

- Participate in investigations of all fires.

- When arson is suspected, protect all physical evidence taken from the scene of the fire until placed into the custody of the Hanford Patrol or the Benton County Sheriff's Office.

- Sign all fire investigation reports.

- In conjunction with the fire department training officer, develop and provide an ongoing training course for all fire department members which deals with NFPA codes and standards. (letter-from R.A. Holten dated 3/12/91) 


\section{Other Elements of the fire prevention program}

- In support of building manager responsibilities, perform code-required annual inspection of ignitable/reactive waste sites (WHC-CM-4-41, section 8.1.5.2.7)

- Inspection (as requested by the facility) of confined spaces for rescue feasibility (WHC-CM-4-40 section 3.1 Sept. 19, 1994)

Implementation of most of the fire marshal duties is formally defined by WHC-CM-441 section 8.1. Fire Prevention Program elements explicitly defined by HFD implementing procedures are Fire Investigation, and Prefire plans. Areas of enforcement of fire prevention findings is negotiated separately with each company which works at the site. Areas of negotiation are: time limits for correction and the type of form to be used for reporting. The HFM is a member of the Hanford Site Selection Review Board. This position is presently used as a means of reviewing and approving all site projects for compliance with the applicable provisions of the fire prevention program.

Human resources dedicated to implementing the Hanford Site fire prevention program are the HFM, and one fire prevention officer (secretarial support is shared w/platoon and training). The HFM relies on other resources in order to implement the fire prevention program outlined above. Hanford Fire Protection Program engineers are relied upon to provide consultations with regard to design and plans review of construction documents, shop drawings, etc, as they relate to the HFD fire prevention program. Formal design and plans review is presently not an element of the HFD fire prevention program.

Many building inspections are delegated to the Battalion chiefs and performed by HFD platoon members. This represents approximately $90 \%$ of all building inspections. The remaining $10 \%$ of inspections are performed by the HFM, the fire prevention officer or senior HFD staff. This inspection procedure enables all occupied buildings to be inspected on an annual basis. Major buildings or facilities with significant hazards are inspected on a quarterly basis.

Twenty-four maintenance, test, and inspection record random audits are typically done on an annual basis. Witnessing of acceptance test procedures has been delegated to the Manager, Fire Protection Systems Administration and Testing. To date, forty-eight tests have been witnessed in calendar year 1995. Approximately ten to twelve follow-up inspections of fire prevention findings or code violations are performed each year. These are typically delegated to others, (often, contractor fire protection engineers or other contractor employees). Explicit inspection of exits in accordance with Chapter 31 of the NFPA 101 Life Safety Code is not typically conducted since this requirement is covered by other aspects of the sitewide fire protection program such as the building fire protection assessments required by RLID 5480.7 and DOE 5480.7A. The use of a formal permitting process as outlined in NFPA 1 section $1-15$, is limited. 
$\underline{\text { Records }}$

The HFM maintains records on the following items:

- general examinations and approvals conducted by the HFM

- fire prevention inspections and findings

- $\quad$ "permitted" areas or operations

- fire investigations

- fires

- $\quad$ site project reviews in support of the site selection review board

Records of all fire protection system acceptance testing is maintained by the HFD manager, Fire Protection Systems Administration and Testing.

\section{$\underline{\text { Future Activities }}$}

From discussion with the HFM, the Hanford Fire Protection Forum may be petitioned to consider revising the HFM charter originally released March 12,1991. Significant revisions may include an expansion of the "permitting" activities to coincide with those identified in NFPA 1. The HFM is beginning "permitting" activities for LP gases and explosives. Random audits of maintenance, test and inspection records for 1996 are being scheduled on a monthly basis.

\subsubsection{Applicable Requirements/Criteria}

RLID 5480.7 stipulates the development, administration, and enforcement of a Fire Prevention Program for the Hanford Site.

NFPA 1, Fire Prevention Code, prescribes minimum requirements necessary to establish a reasonable level of fire safety and property protection from the hazards created by fire and explosion.

\subsubsection{Recommendations}

9.8.3.1 The HFM Office shall be modified to incorporate the following:

- Increase the number of fire inspector positions from one to two FTEs.

- $\quad$ Assign one FTE secretary to the Fire Marshal's office

- Remove administration and supervision of the HFD training program from the Fire Marshal's office.

- Augment the Site's Public Safety Education program by assigning 0.5 FTE time of one Fire Inspector to the program, including teaching fire extinguisher and related safety classes to workers.

- Maintain coordination between the Fire Marshal's office and the Hanford Fire Protection Forum. 
- Establish an HFD internal standing committee (chaired by the Fire Marshal, with HFD officer representation) charged with on-going responsibility for maintaining inter-shift coordination of prevention efforts.

\section{Supporting Statement}

The myriad of duties assigned to the fire marshall appears to warrant additional staff support. Further, as DOE continues to increase the number of contractors, the Fire Marshall will need the time and resources to devote to an ever increasing fire prevention program. Efforts to optimize inspections and subsequent reports should be considered.

9.8.3.2 The following recommendations are designed to help assure continuing compliance Site-wide with the necessary and relevant fire and related safety codes and directives:

- $\quad$ Expand the permitting system to include the process outlined in NFPA 1, section 1-15. These may include: explosives, LP-gases, storage of oxidizers and organic peroxides, and use of tar kettles on roofs.

- Operate as large municipalities do, and be sure the Fire Marshal's responsibility and authority extend to all new operations--public or private--which locate on the Site. Include construction plan approval.

- Prepare a booklet--"Advice from the Hanford Fire Marshal"--for widespread distribution on site.

- Prepare a fire and related safety video tape for showing to new employees and at manager's meetings.

\section{Supporting Statement}

The permitting system outlined in NFPA 1 encompasses much more areas than are presently addressed and can be effectively applied to the site fire prevention program. Currently, there are private business moving onto the site that may be unfamiliar with the inherent hazards of the site. For the sake of site activities as well as their own, these business need to be subject to the applicable fire prevention program requirements. Finally, in order to maintain an effective site fire prevention program, the fire marshall's authority should extend to all contractors, site populations, areas and aspects of the site. Site populations, areas or contractors which are exempt may inadvertently expose other areas to undue hazard and risk. This was evidenced recently when it was discovered that a contractor had transported high explosives onto the site without notification or approval of the Hanford Fire Marshall. Expanding the site public safety education program through development and distribution of fundamental fire prevention "advice" and/or requirements may be an effective way to achieving some of the fire prevention program goals. Fire Marshal staffing levels may require reevaluation as these recommendations are implemented. 


\subsection{INSPECTION, TESTING AND MAINTENANCE OF FIRE PROTECTION SYSTEMS}

\subsubsection{Inspection, Testing and Maintenance, Existing Conditions}

The HFD provides inspection, testing and maintenance of services for fire protection systems. Inspection and testing service coverage includes all systems located within the site boundaries and DOE owned facilities within the 700 areas (which are located within the city limits of Richland). Maintenance service coverage includes all systems located within the site boundaries with the noted exception of those located within PNL operated facilities, FFTF and WPPSS facilities located within the site boundaries.

\section{$\underline{\text { Administration and Personnel }}$}

Presently, these services are provided by two branches: Fire Protection Systems Administration and Testing, and Fire Protection Systems Maintenance. "Administration and Testing" is comprised of a "Battalion Chief" level manager, two secretaries, two plant engineers, 26 testing and services firefighters, a materials coordinator, 6 maintenance engineers and one scheduler/planner. "Maintenance" is comprised of a manager, three scheduler/planners, 8 electricians, and 8 pipefitters. Collectively, the two branches are referred to as the Fire Systems Testing and Maintenance group.

\section{Background}

Historically, site firefighters have been delegated the responsibility of fire protection system inspection and testing. Records dating back to the early 1960's show firefighters performing this work.

Having the HFD provide maintenance services on fire protection systems is a relatively new phenomenon. Prior to 1989, preventive maintenance on fire systems was performed in only a few facilities on site, including FFTF, $100 \mathrm{~N}$ Reactor, and possibly PNL facilities. Fire protection systems were tested regularly, based on DOE required testing frequencies, but maintenance appears to have been primarily corrective. Also, craft personnel assigned to fix the systems appear to have had no special training on fire systems.

Concerns and problems relating to the fire protection system maintenance were identified in as many as six audits appraisals and evaluations between the time period of 1963 through 1992 (Chronology of Audits and Appraisals, not dated). Prior to 1992, a group known as fire systems maintenance was part of the site maintenance organization, Operations Support Services. In 1992, a decision was made to move the fire systems maintenance group into the fire department. This move was considered to be cost effective since the use of common management, planners and maintenance engineers would allow a reduction in manpower needs to perform the work. The two services were integrated under the "Testing and Maintenance" group.

From discussions with the "Administration and Testing" manager, since the services were integrated, 17 positions were eliminated reducing the original maintenance group 
headcount to 33. An additional 17 other support positions previously funded from outside the group were reportedly eliminated and the work integrated into the Fire Systems Testing and Maintenance Organization. Also, productivity has been considered to have increased. The completion percentage for preventative maintenance averaged over $90 \%$ for FY 1995 , which included those that were not performed due to circumstances beyond the control of "Testing and Maintenance". Some of the productivity increases were attributed to implementation of suggestions from a 1995 management audit and a value analysis exercise. These included better integration with the plants (including allowing the Fire Systems Testing Maintenance Organization prepare and approve work packages on the their servers, rather than on facility servers), limiting the "wait time" in a facility to 30 minutes, and work flow improvement within the organization itself.

\section{$\underline{\text { Summary Description of Services }}$}

The Testing and Maintenance group provides or performs the following services:

- Functional testing, and inspection, for the Hanford site fire detection and fire suppression systems;

- Perform preventive and repair maintenance in all facilities located on the site with the exception of PNL, FFTF and WPPSS managed facilities. This includes 24-hour emergency repair service of failed fire detection and suppression systems;

- Operational configuration control of the fire systems;

- Management of the site fire system impairment program;

- Support to facility managers for deactivation/reactivation of fire systems as needed for facility operations;

- Annual inspection of site fire extinguishers.

- Maintains all inspection and testing records for Hanford site fire systems, and maintains all maintenance records for WHC landlord facilities, in accordance with WHC-CM-4-2, QR 17.0.

- Provides cognizant engineering authority (w/respect to fire protection systems) for all WHC landlord facilities.

- Maintains the spare part inventory for facility fire systems located on the site with the exception of PNL, FFTF and WPPSS managed facilities;

- Maintains individual firefighter/EMT proficiency and certifications in order to provide immediate backup support for fire suppression and emergency medical services. 
- Administrates the site-wide vendor contract for the testing and maintenance of special chemical fire systems.

- Develops and maintains fire system testing and maintenance procedures.

- Provides all required testing, inspection and repair of the SCBA and respiratory protection equipment used by all site contractors. This service includes refilling of empty cylinders, and sending of cylinders off-site for periodic hydrostatic testing.

Based on HFD inventory records, the HFD has inspection, testing, and maintenance responsibilities for approximately:

- $\quad 334$ Radio Fire Alarm Reporters (RFARs)

- 355 Post Indicator Valves (PIVs)

- 62 Backflow Preventers

- $\quad 350$ Outside Stem and Yoke (OS\&Y) valves

- 31 Butterfly valves

- 319 Fire Department Connections

- $\quad 267$ Mechanical Flow switches

- 70 Potter flow switches

- 60 Excess Pressure Pump

- 62 Air compressors

- 533 Inspectors Test Valve

- $\quad 275$ Fire Alarm Control Panels

- 1623 Fire Alarm zones

- 1936 Heat Detectors

- 2515 Smoke Detectors

- 21 Flame Detectors

- $\quad 2022$ Manual Pull Stations (Auxiliary Boxes)

- $\quad 318$ Wet pipe sprinkler systems

- 19 Limited water sprinkler systems

- $\quad 71$ Dry Pipe sprinkler systems

- 20 Deluge sprinkler systems

- 15 Preaction sprinkler systems

- $\quad 311$ Pressure Switches

- 304 Flow Switches

- 27 Halon Switches

- 7 Carbon Dioxide Systems

- 2 Foam Systems

- 13 Dry Chemical Systems

- $\quad 36$ House Hose lines

- $\quad 38$ Fire Doors (arranged to close upon system actuation) and

- 2192 Alarm Bells 
A comparison of the number of devices serviced by the HFD during 1994 and 1995 was performed by HFD and is summarized below:

Device

RFARS

FACPs

Initiating Devices

Misc. Equipment

Existing fire suppression systems

Buildings Monitored
Change over 1994

None

increase of 25

increase of 410

decrease of 10

decrease of 9

increase of 1

HFD management indicated that the Fiscal year 1995 budget for inspection, testing, and maintenance services was reduced by $33 \%$ over the Fiscal year 1994 budget. Further the 1995 headcount of personnel performing these services was reduced $39 \%$ when compared with the 1994 headcount.

\section{Inspection. Testing and Maintenance Frequencies}

Fire Protection inspection, testing and maintenance frequencies for all fire protection systems, and devices are stipulated in WHC-CM-4-41, section 4.2, Rev.1. Activities and frequencies are primarily those stipulated or recommended by the applicable NFPA Code or Standard. There are 13 items where test/inspection frequencies are at less than what is stipulated or recommended by the NFPA code or standard. In these instances, exemptions to these NFPA criteria have been granted by the authority having jurisdiction (DOE).

\section{Fire Protection System Discrepancies}

The HFD adheres to the applicable requirements and responsibilities stipulated by the Fire Protection System Discrepancy standard in WHC-CM-4-41, section 4.3, Rev.2, Change 1. This standard establishes requirements for minimizing the duration and impact of fire protection system discrepancies. Primary HFD requirements and responsibilities are:

- Maintain a log of all emergency impairments and system restrictions involving fire suppression or alarm systems.

- Enter information concerning emergency response requirements for all emergency impairments into the Fire Department computer-aided dispatch system.

- Maintain tracking systems that provide status of planned impairments and deactivations of fire suppression and alarm systems.

- Categorize each fire suppression or alarm system discrepancy (emergency impairment or system restriction) for tracking purposes.

- Have the categorization validated by the HFD point of contact for fire protection and refer system deficiencies to the fire protection point of contact 
for disposition.

Summary of Requirements for Correction/Restoration of Impairments and System Restrictions

Discrepancies categorized as emergency impairments shall be repaired in 24 hours or less, and the duration of the impairments minimized. If system is not restored within 24 hours, facility management must submit a corrective action plan to the HFD and compensatory measures must be used to reduce the potential consequences of a fire.

Discrepancies categorized as system restrictions shall be repaired within 15 business days. If the facility cannot meet this requirement, then facility management must submit a corrective action plan to the HFD within 48 hours. Failure to submit a plan will be reported to management as a delinquency on HFD impairment reports.

Planned impairments required notification of the HFD at least 24 hours in advance of planned impairments.

\section{Recent Reorganization of the Fire Systems Testing and Maintenance Group}

A recent WHC company management exercise required all site organization including the HFD to have a minimum 12/1 labor/management ratio. The Operations group within the HFD was considered to be unable to meet this requirement presumably due to the typical captain/firefighter ratio at each station of $1 / 5$ (or 6). Presumably, the fire systems maintenance organization appeared to lend itself to a high labor/management ratio and was subsequently reorganized. This has resulted in the Fire System Testing and Maintenance Group being divided into two branches: the Fire Protection Systems Maintenance Group with a 19/1 labor/management ratio and the Fire Protection Systems Administration and Testing branch with a $40 / 1$ labor/management ratio.

Currently, the "Administration and Testing labor force is split into three widely separated locations with 10 at Station 3,11 at Station 2, and 6 at the 2721-EA maintenance shop. It appears that two fire officers work in the role of supervisors of the Station 2 and Station 3 group. In effect, the two fire officers are still being used in the same capacity as before the reorganization, but without the "manager" title.

HFD officials report that the total workload and training program for T\&S FF creates time problems, with respect to allocating sufficient training hours to allow those personnel to maintain necessary certification in testing and service work, while maintaining and/or upgrading emergency response skills. This is particularly evident in newly hired firefighters who typically are appointed to the T\&S FF group, and thus require fairly extensive initial training in both aspects. Initial training is typically initiated immediately. New hires can impact the ability of the Testing and Maintenance group to meet the applicable fire protection system testing and maintenance requirements. 


\section{$\underline{\text { Recent Assessment }}$}

A recent assessment of the Fire System Testing and Maintenance work practices was recently conducted and documented in an industrial engineering study (Kaiser, 1995b). The study concludes that hands on work time averages $44 \%$ of the available hours and makes the group cost competitive. The study notes that recommended improvements committed to could make them a Fire Maintenance Industry Leader. The primary recommended improvements are as follows:

(1) Establish an "all or nothing" service policy. (This refers to FFTF, PNL, and Kaiser maintained facilities)

(2) Originate Job Control System work packages in the fire system testing and maintenance group

(3) Cap delay time

(4) Plan multiple dispatches

(5) Break complex jobs into smaller practical increments.

From discussions with the manager, Fire Protection Systems Administration \& Testing, all recommended improvements with the exception of item (1) are in various stages of implementation. Implementation of item (1) was considered beyond the scope of the HFD. The study also notes that the HFD group has a competitive edge over outside competition in site system knowledge, radcon training and experience, and versatility (since it maintains every type of alarm and valve system).

\subsubsection{Applicable Requirements/Criteria}

DOE 5480.7A, paragraph 9.b.(5) stipulates that fire protection systems be tested and maintained in accordance with applicable NFPA standards and as supplemented by criteria in the DOE Fire Protection Resource Manual.

DOE Fire Protection Resource Manual stipulates inspection, testing, and maintenance in accordance with NFPA 72H, NFPA 13A and other applicable NFPA standards.

DOE-RLID 5480.7 section 6.3, paragraph e. stipulates that the HFD shall provided appropriate sitewide fire protection system inspection, testing, and maintenance for fire alarm and fire suppression systems.

DOE Order 420.1, Facility Safety (October 10, 1995), section 4.2.2, stipulates automatic fire extinguishing systems throughout all significant facilities, a means to summon the fire department in the event of a fire, and a means to notify and evacuate building occupants in the event of a fire. Section 4.2.1.2 stipulates that DOE elements and contractors develop and implement an acceptable fire protection program which includes written criteria which includes requirements for inspection, maintenance and testing of fire protection systems. 
DOE Implementation Guide for DOE Orders 420.1 and 440.1 recommends that the inspection, testing and maintenance program for fire protection features be based on industry standards such as those established by the NFPA unless an adequate technical basis exists to justify deviations from the inspection and test frequencies.

\subsubsection{Recommendations}

9.9.3.1 The HFD shall evaluate the feasibility of providing preventive, maintenance and repair services to PNL and FFTF facilities.

\section{Supporting Statement}

The HFD has effectively demonstrated their ability to provide the required services in a timely and competitive manner. Providing these same services to PNL and FFTF may enable a consolidation of resources and result in an increased benefit (economic savings or increased system reliability) to DOE.

9.9.3.2 Applicant certification requirements should include the following:

- Firefighter level 1 (as stipulated by NFPA 1001)

- EMT, "First Responder" level (as stipulated by WAC-246-976)

\section{$\underline{\text { Supporting Statement }}$}

The revised applicant requirements are intended to enable the HFD to hire qualified applicants and thereby limit the extent to which new applicants must be trained in order to perform their assigned duties. Hiring applicants who are already firefighter level 1 and EMT certified/qualified minimizes the initial training time required prior to resuming assigned duties as a firefighter or as a $T \& S$ firefighter.

9.9.3.3 When it is evident that continuing medical education and firefighter training for T\&S FF may result in a failure to meet applicable fire protection system requirements, applicable training shall be conducted on off-shift hours.

\section{Supporting Statement}

Fire protection inspection, testing and maintenance frequencies for all fire protection systems, and devices stipulated in WHC-CM-4-41, section 4.2 Rev. 1 are primarily those stipulated or recommended by the applicable NFPA Code or Standard. Requirements for Correction/Restoration of system impairment and system restrictions are reasonable. The extent to which these system responsibilities are not met so that $\mathrm{T} \& \mathrm{~S} \mathrm{FF}$ personnel can maintain necessary firefighter-EMT skills maintenance should be minimized.

Because of the desirability and efficiency of maintaining the T\&S FF personnel as trained, on-call emergency responders which augment station personnel, necessary firefighterEMT skills maintenance training during off shift hours is a reasonable measure. This measure will likely require overtime payment but is considered a cost effective methodology when it is necessary to fulfill fire protection system requirements. 
9.9.3.4 The HFD Programs for providing Fire Protection Systems Administration and Testing and Fire Protection Systems Maintenance shall be evaluated periodically to ensure that personnel resources are commensurate with the level of service that is required.

\section{Supporting Statement}

Increases or decreases in the number and type of devices and equipment that are serviced may warrant changes in personnel resource levels that perform these types of services.

\subsection{TRAINING}

\subsubsection{Training Program, Existing Conditions}

The HFD is responsible for training its own employees, including line personnel, T\&S $\mathrm{FF}$, and system maintenance craftsmen. HFD also provides Site workers with fire extinguisher use training.

Managing the HFD training program is an added responsibility of the Fire Marshal. who functions as "Team Leader."

The training section currently is staffed by two training officers, each assigned to the week day shift, and a part-time secretarial position. The station Captains have the responsibility for leading training sessions in their stations. The Battalion Chiefs are assigned a monitoring function. The Training officers are State Certified. Their responsibilities are outlined in the HFD Operations Manual:

\section{Training and Resources Section}

The training officers are responsible for implementing and administering the HFD training program. The Training and Resources Section will provide the following training elements:

- Interact with each HFD division to determine training needs

- Design and conduct training needs analysis

- Design training programs

- Develop and evaluate lesson plans

- Instruct classes and teach others to be instructors

- Manage all records related to training

- Coordinate all WHC required training

- Instruct and/or coordinate:

- $\quad$ Firefighter academies

- Firefighter certification classes

- Driver/Operator certification classes

- $\quad$ Fire Officer certification classes

- $\quad$ Fire Inspector certification classes

- Fire Inspector certification classes 
- $\quad$ Fire Investigator certification classes

- NFA, NFPA, and Washington State certification classes

- Hazmat certification classes

- $\quad$ EMT certification

- paramedic certifications

- Review of off-site and on-site training programs

- $\quad$ Provide written reports on training

- Maintain a current resource library for HFD members' use and access

- Serve as liaison to the Joint Apprenticeship Training Committee

The training and Resources Division will establish timelines for program delivery, review materials used in training programs to ensure they are current, and provide student critique forms to allow the students to evaluate both the instructor and the materials being presented.

The Training and Resources Division will generate reports of training delivered as needed. The group will develop and administrate a career development and enrichment program for all personnel."

The training program for emergency response personnel currently is based on a three year training schedule which recognizes three general categories of training: WHC required; EMS required, and Firefighter I and II required. Firefighter I and II level categories are defined by performance requirements and serve as a national standard (NFPA 1001, Standard for Fire Fighter Professional Qualifications).

The following three Figures 9-3, 9-4, and 9-5, "HFD 3 Year Training Schedule Years 1,2, and 3" provide the required number of training hours for each category and illustrate the necessity for intensive and continuing in-service training conducted both at the stations and at the central training facility.

Three additional figures, "HFD Student Training Hours. 1993-1995" illustrate the shifting emphasis toward EMS and Washing State driver training.

Training records are maintained which record the levels achieved by individual HFD members, using the NFPA professional qualification standards. These standards, as listed by $\mathrm{HFD}$, cover the following:

- Recruit Training

- Fire fighter (3 levels)

- Apparatus Driver/Operator

- Emergency medical Technician (4 levels)

- Paramedic

- Hazmat (3 levels)

- $\quad$ Fire Officer (4 levels)

- Fire Instructor (4 levels)

- Fire Inspector (2 levels) 


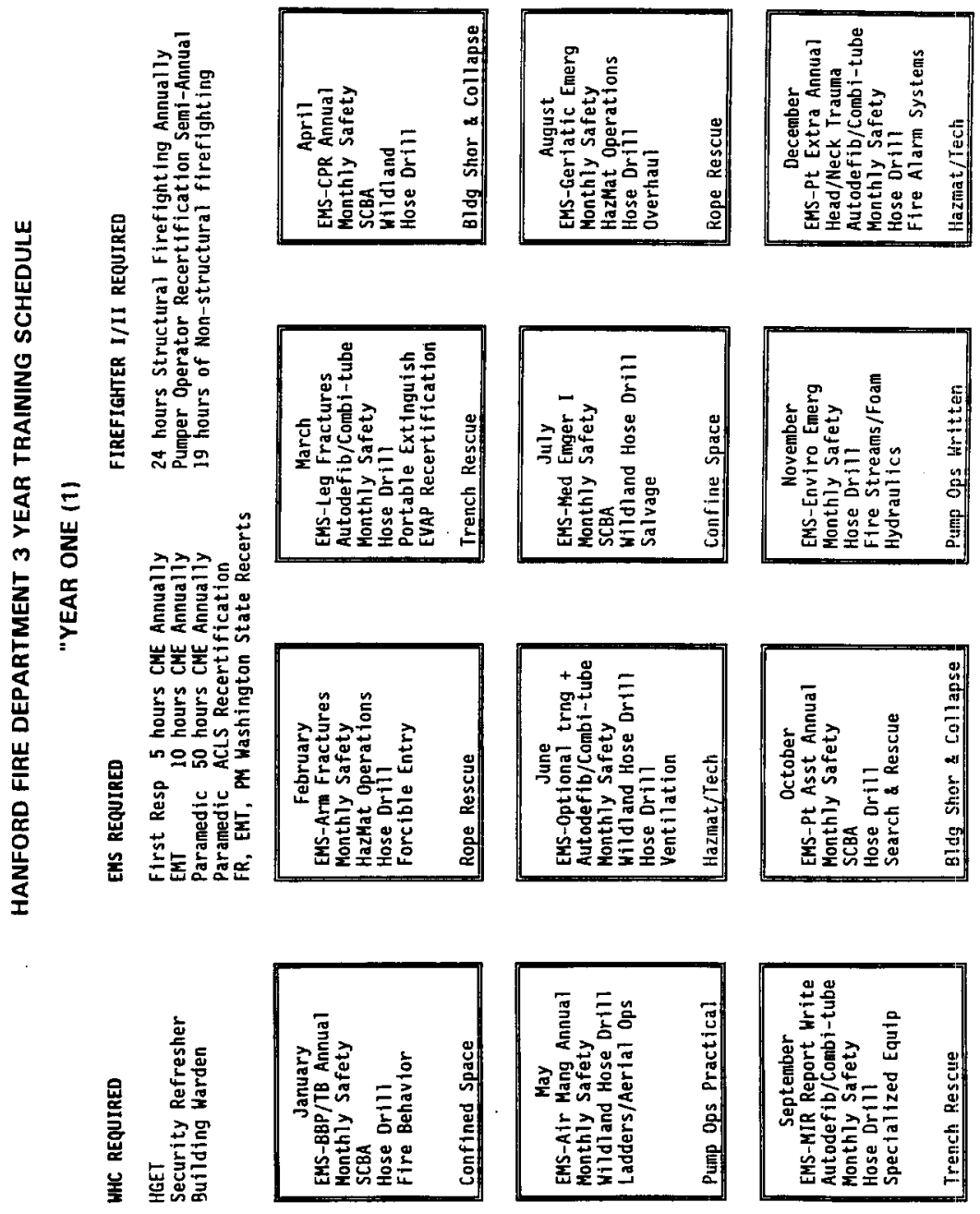

Figure 9-3 


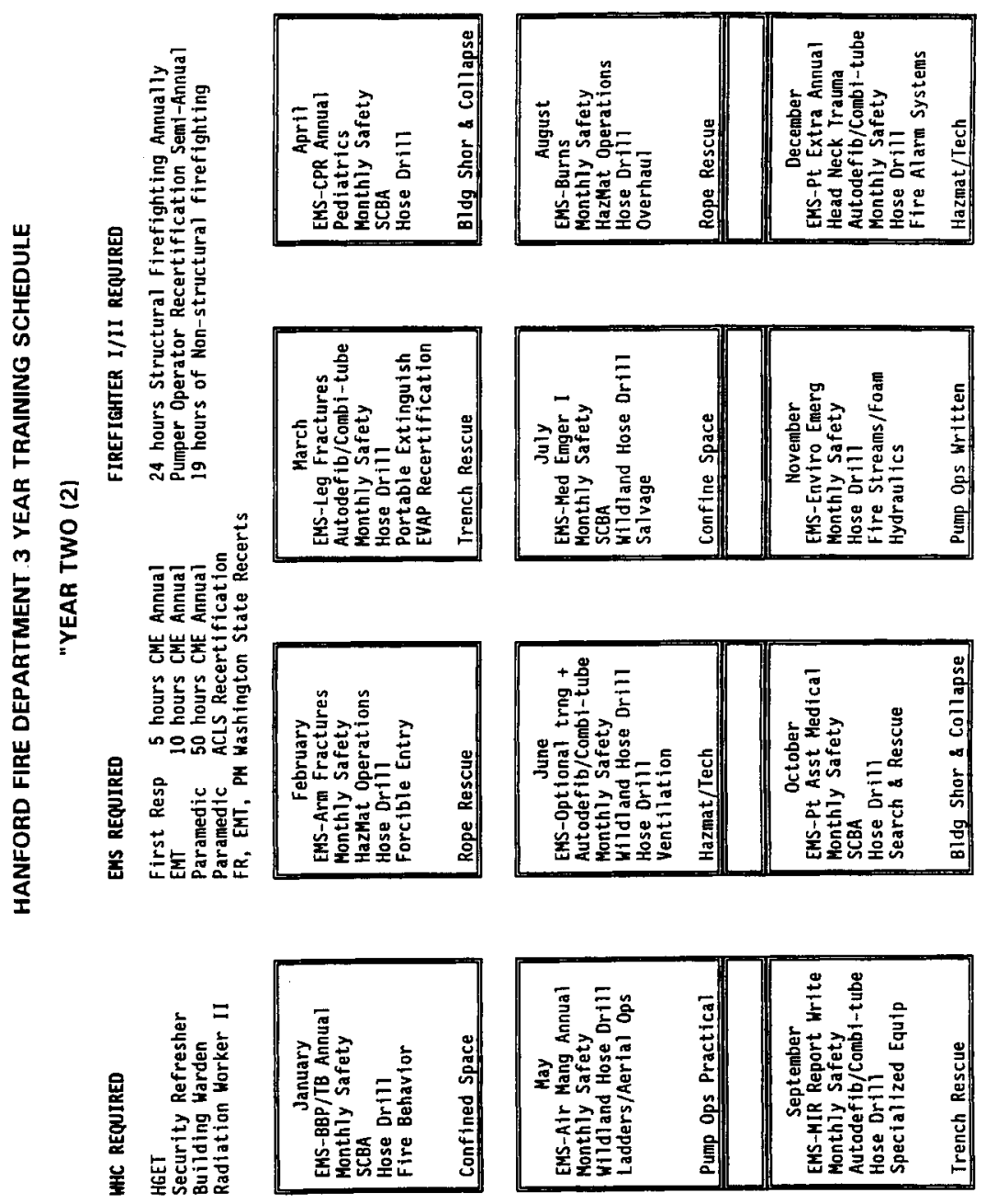

Figure 9-4 


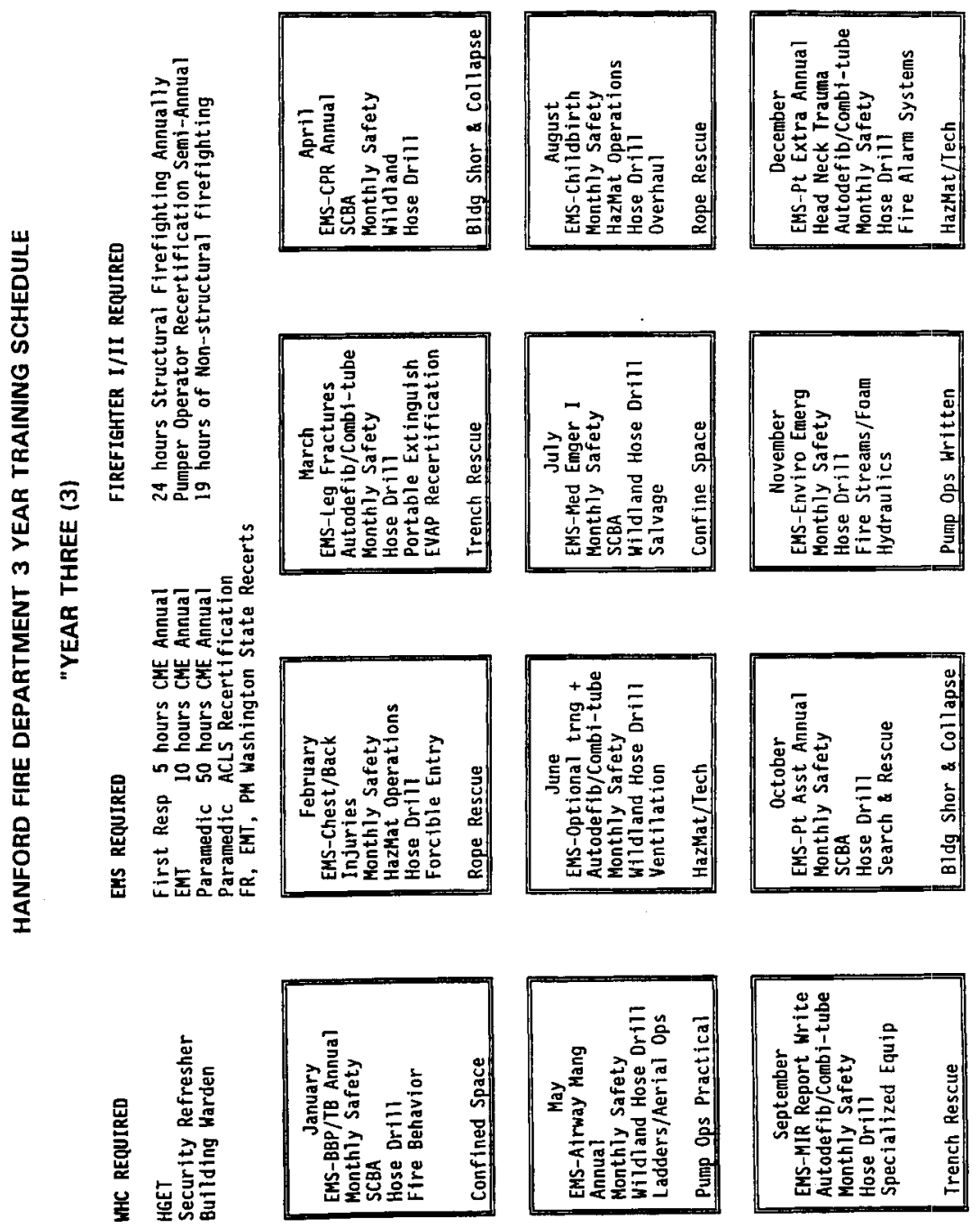

Figure 9-5 
Manipulative skills proficiency for individuals is evaluated on an appropriate form. All classes and drills attended by each individual are recorded on individual computerized records. The instructor's name and certification are not recorded.

The specialized training programs for HFD personnel involved in responding to medical emergencies is as follows:

\section{EMS}

The EMS personnel of the department have one of three levels of EMS training. Eight of the personnel are trained to the EMS "first responder" level. The majority of the firefighters are trained to "EMT level" with $90 \%$ also certified with the combi-tube and autodefibrillator. Those that are trained to "paramedic" level are all certified by the State of Washington and have completed a course of study approved by the Department of Health or the University of Washington. They have all met the skills requirement set forth in WAC 246-977-060 and have been approved by the County MPD (WAC 246-977-080) A number of the current paramedics come from the two year Central Washington State College course.

The HFD provides for the continuing medical education (CME) of paramedics through attendance of advanced cardiac life support (ACLS), pediatric advanced life support (PALS), and advanced trauma life support (ATLS) classes. The majority of the CME is provided in house by an OTEP program. This would include monthly didactic and practical inservice in a three year rotation to cover all appropriate subjects. These courses are taught and supervised by HFD paramedics.

For skills maintenance purposes, paramedics may spend compensated time as a "ride along" on one of the local busier ambulance services. Currently only one of the paramedics is taking advantage of the ride along opportunity.

EMT certification follows a similar course as outlined in the state WAC 246-976-160 and by the county guidelines for EMT-D. They will also have CME provided by the OTEP lectures.

There is a complete and well delineated HFD training schedule that encompasses a three year rotation of applicable classes.

\section{Training for T\&S FF}

There is an extensive training program for T\&S FF and for the maintenance crafts people. During the last five years, the training requirements for performing work in Site facilities have increased. The initial driver for the changes was an effort to ensure that anyone entering a radiation zone had proper training. This training was tracked through the Westinghouse Radiation Area Management (WRAM) computer program. Class roster data were received from the Training Records Information (TRI) system and automatically sent to WRAM. 
The WRAM program has been replaced by the ACES. The ACES program works essentially like WRAM in that it is used to ensure that those entering radiation zones have the proper training.

When WRAM was implemented, the various Site facilities began putting orientation classes together specific to their facility. These classes were designed to ensure those working in the facility were familiar with the specific hazards. Little consideration was given to groups like the HFD, who must enter nearly all Site facilities in the course of their work. The number of facility orientations grew rapidly. For the most part, these were the "plants," such as PFP, FFTF, and PUREX, and the plant laundry, Tank farms, inactive 100 Area facilities, etc.

A representative listing of required classes follows. Some of the listed classes are outdated, are no longer taught, and have been replaced by other classes. This complicates trying to keep HFD members current, since the requirements change without notice.

Each of these classes requires an initial training session generally lasting one hour, and annual retraining, also lasting one hour. It is common to have the zone entry requirements change in a given facility without prior notice. Other groups who work Site-wide, such as security and air conditioning personnel, are required to take the same training.

Representative training required for HFD members are illustrated in Figure 9-6.

In addition to firefighter training requirements, all T\&S FF are required by HFD Internal Policy IP-5.6, Rev. 3 to receive 24 hours of classroom training and 80 hours of onthe-job training, working with experienced T\&S FF. Annual requalification training consists of 8 hours of classroom and practical training. Additionally, all T\&S FF must have facility specific orientation training.

The extent of required training is significant. From discussions with the Manager of Fire Protection System Administration and Testing, approximately 25-30 percent of T\&S FF allocated work time is taken up by required training courses.

Maintenance engineers are required to take the same classes as the craft discipline they support, as well as classes on NFPA 71, 25, and 13. They also are required to be trained on two WHC documents: WHC-CM-6-1, Engineering Practices, and WHC-CM-4-3, Industrial Safety Manual. 


\author{
Class Number Class Name \\ 000001 Hanford General Employee Training (HGET) \\ 000052377 Facility Orientation \\ 000057 Facility Orientation - Hazardous Waste Site \\ 000061100 Areas Facility Orientation \\ $000062100 \mathrm{~K}$ Area Facility Orientation \\ 000071 Facility Orientation - 222S \\ 000072 Facility Orientation - PUREX \\ 000076 Facility Orientation - B Plant \\ 000078 Facility Orientation - Solid Waste \\ 00007A FFTF Facility Orientation \\ 00007B FFTF Plant Safety Tour \\ 000185200 Area HRO Facility Orientation \\ 003035 Lock and Tag Authorized Worker \\ 020001 Radiological Worker II Training - Initial \\ 020030. SCBA Annual Training \\ 020032 Scott SKAPAK-MSA PAPR \\ 020035 MSA PAPR (Powered Air-purifying Respirator) \\ 020040 DTPA Orientation \\ 020042 Fuels Supply Radiation Area Entrance Orientation \\ 02006A Hanford Site Orientation \\ 02006G Hazard Communication and Waste Management Awareness (4-hours) \\ 02006H Hazardous Material/Waste Job Specific Information \\ 03121024 hour hazardous Waste Operations Training \\ 03122040 Hour Hazardous Waste Operations Training \\ 0320208 hour Hazardous Waste Refresher Training \\ 03E060*Building Emergency Plan Review - Tank Farms \\ 034520 Personal Self Surveys - Alpha \\ 034530 Personal Self Surveys - Beta Gamma \\ 176000 Waste Sampling and Characterization Facility Orientation \\ 200700 Plutonium Finishing Plant Facility Orientation \\ 200750 PFP Facility Reorientation \\ 200760 PFP Supplemental Facility Orientation \\ 200850 PFP Alpha Self-Survey \\ 250700 PUREX Facility Orientation \\ 254700 Facility Orientation - UO3 \\ 300700 Facility Orientation Solid Waste Operations \\ 350560 Waste handling Segregation and Packaging - Tank Farms \\ 350710 Tank Farm Facility Orientation \\ 400710 Facility Orientation B Plant - Initial \\ 450700 Facility Orientation - T Plant \\ 500510 Grout Facility Orientation \\ 500550 Grout Radiological Orientation \\ 550700 Environmental Restoration Operations Facility Orientation \\ 550710 EO Facility Orientation Requalification
}

*Other Building Emergency Plan reviews have been required in the past.

Figure 9-6 Classes Required By ACES for HFD Members 
All electricians must meet site specific requirements (Lock and Tag, etc.). In addition, all electricians need to complete course work in the following areas:

- Inspection, Testing and Maintenance of Fire alarm \& Detection Systems

- Operations \& Maintenance of Fire Alarm Systems

- National Electric Code

This training is given by nationally recognized training centers. Electricians also are required to complete an On-the-Job (OJT) training checklist in which they are evaluated by subject matter experts.

All pipefitters must meet the specific requirements (Lock and Tag, etc.). In addition, all pipefitters are required to complete course work in the following areas:

- Inspection, Testing \& Maintenance of Automatic Sprinkler Systems or

- Automatic sprinkler Protection systems - Defense Against Disaster

- Inspection, Testing and Maintenance of Fire Hydrants. This training is given by nationally recognized training centers. Pipefitters are required to complete an OJT training checklist in which they are evaluated by subject matter experts.

Planners and schedulers must have site required training and be familiar with the Site Job Control System. There is no required training specific to fire systems.

Materials Coordinators have no training requirements.

\section{Technical Rescue}

Technical Rescue requires highly specialized skills. The HFD has trained personnel in vehicle extrication and confined space work, but is only beginning to develop sufficient expertise in other important specialties such as structure and earth collapse, machinery accidents, derailments, and high-angle rescue.

\subsubsection{Applicable Requirements/Criteria}

- $\quad$ Trained personnel are required by DOE 420.1, a variety of WHC manuals (WHC-CM-6-1 and WHC-CM-4-3, for example), OSHA, SARA III, and NFPA 1500,1201 , and 600 .

- Training records must be maintained in order to prove compliance. (NFPA 1401, "Recommended Practice for Training Records and Reports")

- Instructors must be qualified. (NFPA 1041, "Standard for Professional Qualifications For Fire Service Instructor")

- $\quad$ Training facilities must be adequate. (NFPA 1401, "Standard on Building Training Centers) 
- Live fire training must be conducted safely. (NFPA 1403, "Standard on Live Fire Training Evolutions in Structures")

The Training of the various level of EMS providers is based on National Curriculum as interpreted and applied by the State of Washington and regional authority. First Responder training and EMT training are based upon the Department of Transportation (DOT) 40 hour and 110 hour courses respectively. Paramedic training follows the basic requirements of the National Registry and the DOT Paramedic National Standard Course material.

Basic Requirements for training, Continuing Medical Education (CME) and skills maintenance are set forth in RCW's 18.71 and 18.73: WAC's 246-977- 060-080 (248$17-213$ and 248-977-030). County requirements are the province of the Bi-County medical program director.

In relationship to the Trauma Verified Service, WAC246-976-020 and WAC 246-976025 cover training and CME requirements for First Responders. WAC 246-976-030 and WAC 246-976-035 cover EMT education and CME requirements. WAC 246-976080 and WAC 246-976-085 cover Paramedic training and CME requirements. CME for the paramedics follows the State guidelines. The initial certification is for three years and at the end of that time the Paramedic must have:

- 50 hours of CME annually

- documented maintenance of skills

- Thirty six IV starts on injured, sick or preoperative patients

- Twelve endotracheal tubes annually: 6 on human subjects

Subsequently, the requirements call for 50 hours of CME and "proficiency in IV therapy as well as 4 Endotracheal tubes annually.

WAC 246-976-150 covers Certification and recertification requirements for First Responders. WAC 246-976-160 covers certification and recertification of EMTs. WAC 246-976-200 covers certification and recertification of paramedics. Statutory Authority for the above RCW 43.70 .040 and chapters 18.7118 .73 and 70.168 of RCW 93-01-148 (order 323).

The relevant sections are covered in WHC-EP-0575 section 23 page $38-44$ and WHC SRID fire protection section 12.5.1.

\subsubsection{Recommendations}

9.10.3.1 The Training and Resources Section shall be reorganized under a Team Leader Training Officer, with one additional full time Training Officer, and a full-time secretary. The Team Leader shall report to the Deputy Fire Chief. 


\section{Supporting Statement}

The volume of required training for all HFD operational personnel-many of whom work on 24-hour shifts and from five locations, requires intensive course development, implementation, evaluation, supervision, coordination, and recording, plus specialized teaching. Tasks must be performed according to schedule and in a timely manner.

9.10.3.2 All Station Captains and Battalion Chiefs shall maintain current certification at the fire instructors level 1 (as defined by NFPA 1041) in order to conduct in-service training and the necessary monitoring and oversight. .

\section{Supporting Statement}

Standardized in-service training for three 24-hour shifts, located at four fire stations, has to be taught by each Station Captain assigned to each shift. These twelve separate teaching venues (four per shift) need evaluation and coordination by the shift Battalion Chief.

9.10.3.3 The existing three year training topic outline requires expansion by a representative training curriculum task force. The expansion shall relate each training topic to a comprehensive performance based plan which provides for all components of the training program.

\section{Supporting Statement}

Once the plan is formulated, annual, monthly, weekly, and daily training schedules are drawn and distributed.

The following are crucial elements in a training plan:

1. Training topics, schedule, and curriculum goals

2. Standardized lesson plans with teaching methodologies identified

3. Performance evaluations for participants and instructors

4. National/state certification requirements

5. Quality control

6. Designation of indoor and outside facilities

7. Training aids and media resources

8. Study materials

9. Records and recordkeeping

10. Instructor certification

11. Off-site training identified

12. Feedback for curriculum redesign

All fire departments, including the HFD, need a comprehensive training plan based on a well-defined needs assessment, and composed of curricula which satisfy the needs. The knowledge level, skills, and attitudes of personnel can be raised effectively to higher levels only through careful planning. The training plan should address the needs of all levels of personnel and all types of specialists. In addition, the plan should extend over several years, providing basic, intermediate, advanced, and specialized technical training. 
9.10.3.4 The following specialized training needs for HFD emergency response personnel (some of which are already addressed in the training curricula) shall be met:

- Advanced work in hazardous materials incident mitigation

- $\quad$ Advanced work in radiological incident mitigation

- Personnel safety in work environments containing hazardous materials and radioactive materials

- $\quad$ Fire suppression and mitigation efforts using a variety of extinguishing agents

- Extensive application of regulatory and national standard drivers

- Advanced technical rescue specialties including confined space entry and rescue

- Wildland fire suppression

- Ground cover fires at hazardous waste storage sites

- Work with advanced built-in fire protection systems

- Rope rescue

\section{Supporting Statement}

The nature and scope of possible, credible emergency incidents at the Site necessitate training in topics not widely applicable to municipal firefighters. The topics identified above may not be all inclusive but represent the broad scope of special areas where training is required.

9.10.3.5 Appoint a standing advisory committee on training, with representation from all levels and types of HFD members, having the Deputy Chief as chair. This group would meet periodically to review training needs from the various types and levels of members, the training curriculum and training schedule, performance evaluations, and training resources.

\section{$\underline{\text { Supporting Statement }}$}

A quality assurance program for training is necessary to assure requirements are being met.

9.10.3.6 Upgrade the centralized HFD training facility to accommodate the various types of hands-on training required by response personnel or provide alternate locations for all training.

\section{Supporting Statement}

Realistic, hands-on training is necessary to reach the level of proficiency required by HFD responders. A study of training facility needs has been conducted and reported in "Functional Design Criteria, Hanford Fire Department Facilities" (WHC, 1993b). That report states:

"A fire ground training facility(s) is necessary to provide complete and comprehensive training of all aspects of fire fighting and emergency medical care. Training facilities will provide hand-on training capability required to fully comply with federal and state regulations and codes. Standards also require personnel to meed mandatory 'shall demonstrate' activities required by NFPA. 
If site training facilities are constructed with the purpose of fuifiling all or most of the HFD training facility needs, then the training facilities must provide the HFD with the ability to train HFD personnel as required per NFPA, state and federal codes and standards, and all other applicable requirements. The facilities shall as a minimum enable the following training elements/evolutions:

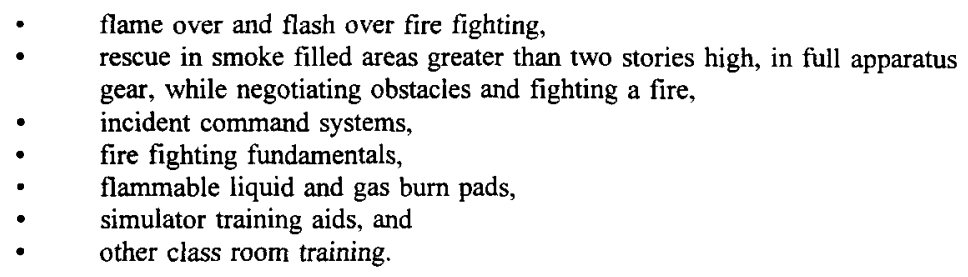

The classroom training facility portion of the project also shall include but not be limited to a training library and study area."

The Hazardous Materials Management and Emergency Response Training Center (HAMMER) is slated for operation adjacent to the city limits of Richland. The HAMMER functional design criteria indicates that the center will offer both chemical and radioactive hazards handling and emergency response training for fire fighters, emergency managers, and other responder organizations. The HAMMER will have an administration and classroom building, burn house with computerized burn system, multipurpose laboratory, change room, emergency operations center, a number of large training pads for craft specific and fire training, a manmade stream and pond, training tower, warehouse/equipment building, chemical/radiation laboratory, an above-ground pipeline, various transportation props, a remediation/characterization site, trench site, buried waste site, a junction/diversion box with tank and equipment decontamination facilities. This facility, if constructed with these features should meet most of training needs which have been cited.

9.10.3.7 The following recommendations are made to improve the quality of the in-station training program:

- Hold all stations to a minimum of one hour daily in-service training set by a mandated lesson plan. This training will be evaluated.

- Develop standardized instructional packages to be sent or transmitted to each station, such as video lessons, slide packages, and self-instruction and evaluation booklets.

9.10.3.8 Use selected off-Site training and visiting experts to enhance HFD training. Continue programs which send HFD Training Officers and in-service instructors to specialized "train-the-trainer" programs for advanced course work. 


\section{Supporting Statement}

Cost effective advanced and specialized training often is available at outside training centers. Having HFD instructors trained in those settings provides a multiplier effect. For some topics, an outside expert brought to the Site (and videotaped for future use) also provides cost effective advanced instruction.

9.10.3.9 The following EMS Skills maintenance items shall be made a priority for the EMS System.

- Close monitoring of Continuing Medical Education and field performance.

- All paramedics should be required to perform ride along or hospital time on a monthly basis.

- A medical director should be providing the paramedic OTEP training as well as overseeing the upgrading and maintenance of skills.

- QA/QI should focus on the issue of skills maintenance and appropriate procedural evaluations.

\section{Supporting Statement}

In order to maintain adequate skill levels, paramedics must be exposed to real life situations and continuing training. Because of the relatively small volume of true ALS calls on the site, the need for skills maintenance must assume an even greater priority than is normally required. WAC 246-9766-090 Continuing Medical Education Units, states: "The...units of learning (shall) include evaluation of knowledge and skill performance identified in the learning objectives through both written assessment and practical application." A medical director should be providing the paramedic OTEP (Ongoing Training Through Experience Program)training as well as overseeing the upgrading and maintenance of skills. $\mathrm{QA} / \mathrm{QI}$ should focus on the issue of skills maintenance and appropriate procedural evaluations. WAC 246-9766-090 states that "Training agencies...shall require students to demonstrate knowledge and skill performance to meet the approved objectives. The only legitimate judge of the skills demonstrated are a physician knowledgeable in EMS and emergency procedures.

\subsection{QUALITY ASSURANCE}

\section{$\underline{\text { EMS }}$}

Currently, all runs are reviewed by HFD Emergency Medical Program Director as noted in WHC-EP-0575, page 1. All MIR forms are forwarded to the off line medical director for his review. This review is primarily for chart completeness and appropriateness of treatment. The offline MPD does not meet with the paramedics for run review or incident evaluation.

Charts may be reviewed at the monthly meeting in Richland with online MPD if they are referred from the HFD Emergency Coordinator, from the offline MPD or from local facilities concerned about a specific patient. 
There is no review at the County MPD level unless specifically requested. There is no Regional QA/QI at this time

\section{Operations}

A comprehensive Quality Assurance Program which addresses essential operations and equipment does not exist. The HFD currently performs several operations in their daily routine that have implication to their basic mission. An example of some of these operations would be the daily and weekly check of apparatus, weekly checking of SCBA equipment, vehicle inventories, etc. There is no procedure whereby an officer would do a periodic quality assurance check to verify that the proper procedure was followed and the item checked on paper was actually reviewed.

\subsubsection{Applicable Requirements/Criteria}

The State requires all trauma verified providers to have a quality assurance program under RCW 70.168.090. The RWC document also provides for confidentiality of the records and protection from "discovery from subpoena or admissible as evidence." The EMS and trauma system regional quality assurance program is codified in WAC 246-970-910.

DOE Order 5480.19, "Conduct of Operation," and DOE 5700.6C, "Quality Assurance," both have the driving principle to ensure that operations and equipment are maintained at an acceptable level as stipulated by applicable standards and criteria.

\subsubsection{Recommendations}

9.11.2.1 A medical director should be responsible for all aspects of the initial QA/QI and should work towards developing a program of CQI (continuous quality improvement).

\section{Supporting Statement}

Of all the EMS issues evaluated in this report, the lack of close medical supervision and involvement as well as the limited QA/QI are the areas of greatest concern. A logical course would be to involve the off-line medical directly intimately with the operations component of HFD EMS.

WAC 246-976-9200 states that the MPD shall: "(i) periodically audit the educational performance, skill maintenance and field performance of EMS/TC certified personnel, for quality assurance purposes".

- Quarterly meetings with the medical director to review any cases outside standard or of particular interest would meet these criteria. This should include an educational component and skills maintenance review.

WAC 246-976-920 states that the MPD shall (a) be knowledgeable in the administration and management of prehospital emergency medical care and services. and (b) 
provide medical control and direction of EMS/TC certified personnel in their duties by oral and written communication.

The intent of the WAC is that the medical direction be ongoing and provide direction, education, and review. The CQI provided by the medical director should therefore include both retrospective and prospective anaiysis of performance.

\section{Retrospective Analysis}

"Retrospective analysis is the least beneficial way to assess quality in and EMS system. When done it should include the following elements:

- Debriefing: discussion with all involved individuals

- Critique session: Focussed discussion with involved EMS personnel

- Chart review: Chart is evaluated for completeness and accuracy

- Formal audit: Chart is reviewed in relation to established protocols and level of compliance is documented.

\section{Prospective Analysis}

Prospective analysis should include

- Primary education of personnel on polices and procedure expectations

- $\quad \mathrm{CME}$ is provided in response to deficiencies delineated during concurrent or retrospective analysis

- $\quad$ Periodic skills examinations

- Preceptorship or one-on-one assistance in response to real or perceived deficiencies" (Polsky, 1992)

Once the areas of concern are identified, the problems identified should be dispositioned using the "DEALER" method of CQI.

D - delineate problem

E - elaborate on cause(s)

A - aid the problem and develop a solution

L - lay out a plan of action

$\mathrm{E}$ - enforce the plan of correction

$\mathrm{R}$ - reexamine the problem

In the EMS arena, seconds can mean the difference. Rapid appropriate intervention is the key to success. Appropriate QA is a vital component to the provision of appropriate service in the EMS arena. Historically this has become the key to medical supervision.

At the Midpoint of the federally mandated 10 year plan for the development of EMS proscribed by the EMSS Act of 1973 The National Academy of Science (NAS) and the National Research Council (NRC) issued a report titled "EMS at midpassage" . This report 
devoted $25 \%$ of its text to QA and noted there were "serious deficiencies in both concept and execution" of QA activities in EMS.

The NRC defined three basic areas of Medical Supervision:

- assurance of immediately available expert direction

- assurance of continuing high quality field performance

- collection and evaluation of data to monitor field performance and medical control.

These are the components of a well run EMS system. They demand close medical supervision and CQI. This is especially important in a system without the constant reinforcement of repetitive exposure to situations of immediate necessity and situational reinforcement. Skills not used or reinforced disappear or become deficiencies. Lack of objective review provides a venue to facilitate rather than rectify system deficiencies.

9.11.2.2 A stand alone procedure shall be developed and implemented which provides independent validation that applicable HFD procedures are being followed.

\section{Supporting Statement}

DOE Order 5480.19, "Conduct of Operation," must be used in a graded approach. Existing Quality Assurance procedures which have been developed for HFD operations are critical to ensuring that the minimum level of HFD service is maintained. Periodic independent verification that these procedures are indeed being strictly adhered to performs three important functions (1) It validates compliance with the procedures. (2) It demonstrates to personnel responsible for carrying out the procedures that strict adherence to the procedures is required. (3) It provides a means for determining the effectiveness of the existing procedures.

This procedures can take the form of an inspection of procedural items (such as equipment checks, preventive maintenance, etc.) which is performed on a regular basis on a frequency of 1 to 2 times a week by HFD supervisors. The procedure should be documented and all identified deficiencies should be addressed as soon as possible. When implemented effectively, this procedure should instill confidence in both HFD management and HFD personnel that the level of QA inherent in the existing procedures is indeed the level of QA. that is being provided.

\subsection{SITE PROTECTION WATER SUPPLY}

\subsubsection{Site Fire Protection Water Supply, Existing Conditions}

The purpose of this review is to establish fire department related issues specifically applicable to the site water supply. Review of the existing site water supply system is based on the "Fire Protection Water Supply Analysis" (WSA) (Bucci, 1995), The WSA provides a comprehensive description of the water supply system for each area of the site and a depiction of the water supply piping. In addition, in the WSA details on each of the supply reservoirs and pumps are provided. 
In general, the existing site water supply to fire hydrants and fire suppression systems consists of two independent systems; raw and sanitary water; and various arrangements of tanks, pumps and reservoirs. The water supply method and available water flow and pressure to each area of the site varies. Based on the WSA, the existing systems do not comply with all applicable DOE criteria; however, recommendations are provided to upgrade the systems.

Conversations with site personnel indicated that the raw water system supplies a greater pressure and flow then the sanitary system. Information indicates that the use of the sanitary water system in some areas may result in insufficient water supply for fire department purposes. However, based on the WSA, both systems are proposed to be upgraded to comply with DOE criteria.

\subsubsection{Applicable Requirements/Criteria}

The assessment of the required fire flow for an area can be based on several methods. Methods for determining required fire flows include the following:

- DOE 6430.1A General Design Criteria Section 1530-3.3.3 (USDOE, 1989) - Based on supplying $0.03 \mathrm{gpm}$ per cubic foot of fuel in the largest fire area. This criteria appears to be based on criteria developed by Iowa State University in cooperation with British Fire Research Station (Royer, 1967), as modified by Warren Kimball (Kimball, 1970) for delay in response times. Sprinklered building water supplies are based on NFPA 13 criteria.

- $\quad$ NFPA 13, "Standard for the Installation of Sprinkler Systems," (NFPA, 1994) - Water supply demand and duration is based on hazard classification or hazards protected in the building and the resulting sprinkler and hose stream demands.

- Insurance Service Office (ISO)(ISO, 1980), "Guide for Determination of Required Fire Flow" - Based on total floor area and construction classification of the structure, the occupancy, fire loading exposures, and sprinkler protection.

- $\quad$ NFPA 1231, "Suburban and Rural Fire Protection" (NFPA, 1989) - Water supply is based on total cubic footage of the structure, the occupancy, exposures, the construction classification, and sprinkler protection.

- Uniform Fire Code (IFCI, 1991) - Water supply is based on construction type, total fire area, and automatic suppression.

- $\quad$ MIL-HDBK-1008B - Based on occupancy classification, with modifications allowed based on fire department response time, type of construction, number of stories, separation distances, building floor area, and firefighter access.

A summary of required fire flow calculation methods are provided in Table 9-12.1.

The demands specified in the WSA appear to be based on sprinklered facility criteria as specified in NFPA 13. The highest water supply demands for each site area based on 
nonsprinklered building fire department fire flow criteria such as DOE 6430.1A or ISO would be greater.

Tabie 9-12.1 Water Flow Requirements

\begin{tabular}{|c|c|}
\hline Reference & Criteria \\
\hline MIL-HDBK-1008B & $\begin{array}{l}\text { In sprinklered facilities, the total water demand is equal to the sum of the } \\
\text { domestic demand plus the sprinkler system water demand and hose streams. } \\
\text { In nonsprinklered facilities, water supply calculations utilize a three-step } \\
\text { procedure based on response time, type of construction, number of stories, } \\
\text { separation distances, firefighter access, and building floor area. Each factor is } \\
\text { assigned a point value and water demand is based on points and occupancy } \\
\text { classification. }\end{array}$ \\
\hline NFPA 13 & Fire Flow = Sprinkler demand and hose stream. \\
\hline DOE $6430.1 \mathrm{~A}$ & $\begin{array}{l}\text { Water supply }=0.03 \mathrm{gpm} \text { per cubic foot of fuel. } \\
\text { Modification allowed for sprinklers to NFPA } 13 \text { criteria. }\end{array}$ \\
\hline NFPA 1231 & $\begin{array}{l}\qquad Q=\frac{V_{s} \times C T}{C_{\sigma}} \\
\text { where } \\
Q=\text { Water supply } \\
\mathrm{V}_{\mathrm{s}}=\text { Volume of structure } \\
\mathrm{CT}=\text { Construction type } \\
\mathrm{C}_{\sigma}=\text { Occupancy ciassification } \\
\text { Modification to NFPA } 13 \text { Criteria if building is sprinklered. }\end{array}$ \\
\hline Uniform Fire Code (UFC) & $\begin{array}{l}\text { Minimum fire flow based on table. Variables are construction type and fire } \\
\text { area. } \\
\text { Modification allowed for sprinklers to reduce fire flow as much as } 75 \text { percent. }\end{array}$ \\
\hline ISO & $\begin{array}{l}\qquad Q=(C) O(X+P) \\
\qquad C=18 F(A)^{0.5}\end{array} \begin{array}{l}\text { where } \\
Q=\text { Required fire flow } \\
F=\text { Coefficient of type and construction } \\
A=\text { Effective area } \\
O=\text { Fire loading } \\
P=\text { Commuricating factor } \\
X=\text { Exposure factor } \\
\text { Modifications to allow NFPA } 13 \text { criteria allowed for sprinklered buildings. }\end{array}$ \\
\hline
\end{tabular}


WHC-SP-1180, Vol. 1

The "Fire Protection Water Supply Analysis" (WSA) (Bucci,1995) details the available water pressure and flow. The highest system water demands for each of the site areas are also specified in the WSA. The highest system demand for each area is specified in Table 9-12.2

Table 9-12.2 Water Suppiy Demand

\begin{tabular}{||l|l|l|}
\hline Site Area & $\begin{array}{l}\text { Highest Water Demand Required based on } \\
\text { WSA (Building/Approx. Demand) }\end{array}$ & Status of System based on WSA \\
\hline \hline 100 & $190 \mathrm{KE} / 1,020 \mathrm{gpm}$ & $\begin{array}{l}\text { Proposed to be upgraded as part of } \\
\text { Project W-405 }\end{array}$ \\
\hline 200 & $242-\mathrm{A} / 2,500 \mathrm{gpm}$ & $\begin{array}{l}\text { Proposed to be upgraded as part of } \\
\text { Project B-604 }\end{array}$ \\
\hline 300 & $331 / 1,350 \mathrm{gpm} @ 100 \mathrm{psi}$ & "Adequate" \\
\hline 400 & $4732 \mathrm{~B} / 1,400 \mathrm{gpm} @ 111 \mathrm{psi})$ & "Good" \\
\hline 1100 & $1163 / 1,973 \mathrm{gpm} @ 54.2 \mathrm{psi}$ & "Good" \\
\hline
\end{tabular}

\subsubsection{Recommendations}

9.12.3.1 Identify areas or specific fire hydrants on specific systems where insufficient water is available for fire protection purposes. Hydrants which will not meet the fire departments' needs should be easily field identifiable (e.g. painted a specific color). Develop a plan to address fire department activities based on water supply limitations.

\section{Supporting Statement}

Fire department response will require application of water onto a fire scene. Therefore, knowledge of specific locations/hydrants where limited quantities of water are available must be identified. Because two water supply systems with varying capabilities may be available at a specific location, fire department personnel must be able to identify specific hydrants which should not be used.

9.12.3.2 Upgrade the existing water supply systems to provide adequate water for fire protection needs (See WSA for details).

\section{Supporting Statement}

Based on the WSA, the existing water supply does not meet fire safety requirements. The fire department depends on sufficient water for fire protection purposes as well as for install fire safety systems. 
9.12.3.3 Assure limitations of water suppiy at specific facilities are addressed in prefire plans Supporting Statement

Fire department pre-plans must incorporate water supply limitations in order to assure water is not drawn from a hydrant affecting the ability of fixed fire suppression systems within a building to operate. 
THIS PAGE INTENTIONALLY LEFT BLANK 


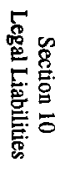


THIS PAGE INTENTIONALLY

LEFT BLANK 


\section{SECTION 10 - LEGAL LIABILITIES}

\subsection{PREFACE}

The firm, Peery, Hiscock, Pierson, Kingman \& Peabody, Attorneys at Law, was requested to address the following:

Evaluate the legal liabilities to the company, the government and fire department management that could result from providing emergency services at a level less than that required or recommended. Base this evaluation on an analysis of risks, applicable regulatory requirements and accepted national standards.

This task was undertaken with the understanding that the risks analysis, regulatory requirements and national standards referenced in the objective as the basis for the evaluation, were to be supplied or undertaken by others. The evaluation consists of a discussion of matters of general concern or applicability, followed by a consideration of those specific regulatory requirements which contain or reference specific penaities, liabilities, or other consequences for their breach.

\subsection{BACKGROUND AND SUMMARY}

Section 5 identifies a series of federal regulations, principally involving worker safety and other Occupational Safety and Health Administration concerns, with which the Hanford Fire Department must comply. Failure to comply with these requirements could result in civil penalties and other liabilities imposed under federal statutes, specifically, 29 U.S.C. $\$ 651$.

In addition, Section 5 identifies a series of regulations dealing, typically, with storage, handling, or transportation of oil, hazardous wastes, or extremely hazardous substances, as variously defined by federal reguiation. These regulations do not, on their face, apply to the operations of the Hanford Fire Department as a distinct entity. However, if the Hanford Fire Department is the mechanism through which another entity, to wit, Westinghouse Hanford Company, means to comply with such requirements, then consideration must be given to the imposition of civil and criminal penalties, set forth in those regulations, for noncompliance.

Lastly, Section 5 identifies national standards, typically promulgated by the National Fire Protection Association, which apply to specific fire fighting apparatus, equipment, organization, training, or other procedures. These standards, even if referenced in other regulations, do not have the force of law and do not carry with them any specific penalties or other liabilities for noncompliance.

However, such standards, together with regulations carrying their own penalties, are important for another reason bearing on potential legal liability: A person or other entity injured as a result of or in conjunction with Hanford Fire Department activities could bring a claim based upon the failure of the Hanford Fire Department to meet such standards and regulations. In that event, the standards and regulations would be admissible as evidence of a minimum standard of care to which the Hanford Fire Department, and it otherwise could be 
adjudged negligent and liable to the injured party. In the event of a claim brought against the Hanford Fire Department, the Westinghouse Hanford Company, or the Department of Energy, under either Washington law or under the Federal Tort Claims Act, a claimant thus would be entitled to introduce into evidence and refer to both applicable regulations and national standards, and compare the capabilities and performance of the Hanford Fire Department against those criteria. While a violation of a regulation or standard would not be conclusive on the issue of negligence or liability, it would be admissible into evidence and certainly would be argued to be the appropriate standard to which the Hanford Fire Department should be held.

Individuals employed by the company or fire department also could be subject to civil tort liability for actions which resulted in the provision of services falling below a recognized standard of care, i.e., for their negligence. Such individuals would not be liable as a consequence of the company's liability, but rather, the reverse is true. The company and the fire department only can act through employees, and their liability generally would be the result of one or more of their employees having acted negligently. Such an employee also would be liable for injuries resulting from that negligence, and this would not be affected by the fact that liability also may be imposed upon the employer. While several practical reasons often come into play which tend to make companies, rather than individual employees, the subject of lawsuits, no legal immunity is afforded individuals for liabilities arising from their negligence just because that negligence was committed during the course of employment rather than during purely personal activities.

While there are express indemnity provisions within the contract, they only apply to a limited category of "nuclear incidents." However, the Contract's allowance of costs to be paid by the Department of Energy encompasses all of the potential liabilities to the company identified in the needs assessment. In addition, it is stated "Government Policy" to defend claims brought against "any Contractor protective force or other employee" as a result of conduct undertaken in good faith performance of employment duties.

Applicable regulations requiring a Contingency Plan do not require that the plan conform to any particular regulation or standard. In the first place, a change in Hanford Fire Department resources would not automatically require an amendment to the Hanford Facility Contingency Plan (hereinafter "the Plan"). While certain categories of change -- reduction in emergency equipment, for example -- definitely would require an amendment, others are tested by a more subjective standard and only would require an amendment if they increased hazards associated with fire or dangerous wastes. If changes resulted in a Plan amendment, it would be necessary to request a modification of the Hanford Facility's RCRA Permit, a process which could entail public notice, comment, and hearing procedures. Even then, the request would be governed by regulations espousing performance standards (albeit stringent ones) rather than regulations or standards setting forth particular or arbitrary resource levels. 


\subsection{CIVIL TORT LIABILITY FOR FIRE DEPARTMENT EMERGENCY SERVICES GENERALLY}

Maintenance and operation of a fire department typically is carried out by municipalities or dedicated public districts. A consideration of the potential legal liability issues arising out of such activities generally focuses on matters of peculiar to such governmental bodies, such as sovereign immunity, the "public duty" doctrine, and the like, all which are discussed in further detail below. Stripped of these particular considerations, it is clear that any entity engaged in such activities will be required to act in accordance with applicable regulations having the force of law. Violations of such regulations may result in liability imposed directly by such regulation. Additionally, violation of such a regulation may result in tort liability being imposed, because proof of the violation amounts to proof of negligence. Lastly, even without a regulation having the force of law, codes and standards which nonetheless are generally recognized in the applicable community or industry, also may be used as evidence of the appropriate standard of care, the violation of which amounts to negligence. Civil tort liability thus follows for any damages proximately caused by such failure to adhere to regulations or standards.

One of the more recent Washington cases to consider the issue of negligence liability for functions undertaken by a municipality is Employco Personnel Services, Inc. v. Seattle, $117 \mathrm{Wn} .2 \mathrm{~d} 606,817$ P.2d 1373 (1991). In Employco, a large power outage resulted in the downtown Seattle area when a contractor drove piles into an underground electrical conduit, starting a fire which destroyed several major underground electrical feeder cables. The City of Seattle was held to be liable for its negligence for failing to properly perform "locate service" activities in the area of the pile driving, such that the underground electrical feeders owned and operated by the City's municipal power utility were not brought to the attention of the pile driving contractor. The Supreme Court held that, just as any entity, a Washington city may be liable on the theory of negligence. However, note that the case does not turn on the application of any particular requirements of regulations or codes amounting to a standard of care.

No Washington appellate court cases particularly concern themselves with the issue of liability for negligent or substandard provision of fire department emergency services. One case, however, is instructive as it deals with the related topic of municipal liability for failure to maintain a water system for firefighting purposes. In Shannon v. City of Grand Coulee, 7 Wn.App. 919, 503 P.2d 760 (1972), a fire broke out in a commercial building in the city of Grand Coulee. Responding firefighters found the nearest hydrant dry, but only after hooking up to it. Although water was obtained from other hydrants, the fire completely destroyed the building. A later investigation determined that the hydrant's service valve apparently had been shut off in conjunction with a construction project two years prior to the fire, and never reopened, and that the hydrant had not been inspected for at least the three years preceding the fire. The building owner brought suit against the City of Grand Coulee for failing to provide adequate water for fire fighting purposes. The court found that Washington statutes required water companies, including municipalities operating water systems, to maintain safe, adequate and efficient water service. The court found the circumstances of the hydrant being dry to be a breach of the statutory duty to provide an efficient water system. The case was 
remanded to the trial court for determination of whether this breach of duty was the proximate cause of the fire completely destroying the building.

In general, then, aside from particular issues relating to governmental immunities, consideration of the legal liabilities emanating from the provision of fire department emergency services pose no alteration from the rule of liability for harm resulting from negligent or substandard conduct.

\subsection{CIVIL TORT LIABILITY UNDER THE FEDERAL TORT CLAIMS ACT}

Civil tort liability refers to potential liability to another person in a civil action for damages brought in a court of law, as opposed to liability which might be created via a criminal or administrative fine or some other governmental action imposing a penalty or requiring an expenditure. Typically, such liability is imposed upon a party who has acted negligently.

As noted above, when the issue of civil tort liability is stripped of any particular considerations involving a government, provision of fire department emergency services is subject to the same negligence standard of care (and the same rules of evidence for establishing that standard of care) as any other activity. While some particular considerations are further discussed below, as an initial and general proposition, the situation should not change because of the involvement of the federal government. The Federal Tort Claims Act, 28 U.S.C. $\S 2671$ et seq., calls for the federal government to be liable for "tort claims, in the same manner and to the same extent as a private individual under like circumstances . . ." 28 U.S.C. $\S 2674$.

The Federal Tort Claims Act was designed to expressly abrogate the common-law principal of sovereign immunity: That the federal government was absolutely immune from civil tort liability, to anyone. Note, however, that in doing away with that principle and expressly creating a presumption of liability co-extensive as would be any private individual, several considerations particular to governments remain, and are discussed below.

The company's civil tort liability is not affected by the Federal Tort Claims Act. The Act broadly defines its scope to include all branches, departments, and agencies of the federal government, but excludes "any contractor with the United States." 28 USC §2671. (This provision apparently was inserted so that the Act would be read to comport with the law in most jurisdictions: That one who engages an independent contractor, including the federal government, is not liable for the negligence of that independent contractor in the performance of its work.) Therefore, the Act will not create any liability on the part of such an independent contractor that it did not already have. At the same time, however, the circumstance of being a contractor for the federal government normally has no affect on an entity's liability in the first place, and the general rule, of civil tort liability for harm caused by negligent or substandard conduct, prevails. 


\subsection{EXCEPTIONS TO GOVERNMENT LIABILITY: THE "PUBLIC DUTY" DOCTRINE}

As noted earlier, issues regarding potential liability for negligent or substandard provision of fire department emergency services usually are bound up with broader issues regarding the governments which typically undertake those activities. Two doctrines exist. which often result in municipal fire departments being found immune from liability for claims of negligence in their operations. The first is the "public duty" doctrine. Under this doctrine, a government is not held to be responsible to any particular individual for breach of a duty which it owes to the public at large. It sometimes is put, more cynically, as "a duty to everyone is a duty to no one." In many states, such a rule is used rather blanketly to prevent claims against municipalities for damages resulting from fire, whether it be claims for negligence in the provision of fire protection, Miller $v$. Morania Oil of Long Island, Inc., 599 N.Y.S. 303 (1993), or in such related activities as enforcement of building and housing regulations which affect fire safety. Jaramillo v. Callen Realty, 607 N.Y.S.2d 226 (1994). In both of those cases, for instance, claims for negligence were dismissed because the injured parties could not show themseives to be the particular beneficiaries of those services. As such, the "public duty" doctrine prevented them from being able to press claims for their individual losses against the municipalities.

There is no specific exception within the Federal Tort Claims Act creating an exception to liability similar to that seen in state cases applying the "public duty" doctrine, and there is a split amongst court cases which consider the issues. Some have characterized the underlying purpose of the Federal Tort Claims Act as putting the federal government on the same footing as local governments. By this logic, when the fecleral governmental assumes activities which customarily are undertaken by local, municipal corporations, the federal government may, in addition to defenses expressly afforded by the Federal Tort Claims Act, obtain the benefit of immunities (such as the public duty doctrine) which would inure to the benefit of such local municipal corporations. See, Ward v. United States, 208 F.Supp. 118 (D. Col. 19_). However, other cases hold that the Act expressly places the federal government on the same footing as a private individual, not a municipal corporation, and thus unable to claim the benefit of local governmental immunities. See, Herring $v$. United States, 98 F.Supp. 69 (D. Col. 19 _..

Whatever the outcome of this dispute, it matters little in light of the Hanford site's location in the State of Washington. Under Washington law, the "public duty" doctrine has been very narrowly construed. "We have almost universally found it unnecessary to invoke the public duty doctrine to bar a plaintiff's lawsuit." Bailey v. Town of Forks, $108 \mathrm{Wn} .2 \mathrm{~d}$ 262, 266, 737 P.2d 1257 (1987). The Bailey case is an instructive example of Washington's narrow application of the public duty doctrine: Plaintiff Bailey was injured in a motor vehicle accident involving an intoxicated driver. She claims that a Forks police officer had failed to prevent a man he knew to be intoxicated from driving. Both the trial court and the intermediate Washington Court of Appeals found this activity to be covered by the "public duty" doctrine. The city could not be liable to any particular individual as a result of an alleged failure to provide police protection and enforce ordinances, both of which are wholly for the good of the public at large. The Washington Supreme Court, however, reversed those decisions, in an opinion which questioned the very existence of the "public duty" doctrine in 
Washington law: "Close inspection of the doctrine and its myriad exceptions may well reveal that the exceptions have virtually consumed the rule." The court also attacked the underlying rationale of the doctrine, lending further credence to the proposition that it wished to expressly do away with it altogether. However, the court stopped short of doing so, and instead found an exception to the doctrine which could be applied to the facts of this particular case: The statutes prohibiting drunken driving were intended to protect not just the public, but the particular class of persons which included the plaintiff, travelers on the road. Thus, the "public duty" doctrine did not apply.

Another example is the previously discussed case of Shannon w. City of Grand Coulee, in which a municipality was held liable for fire damage to a particular individual based as a result of insufficient water for fire fighting purposes. Although the public duty doctrine is not directly addressed, it seems impossible to square its application with the result there: A municipality, charged under state law with maintaining safe and efficient water service to all, is found civilly liable in tort to a particular individual as the result of the condition of one of its hydrants on a city street.

In light of these considerations, Washington law also would seem to impose civil liability upon a governmental entity which negligently provides fire department emergency services, notwithstanding a claim that there is no duty to provide such services to any particular individual so as to allow that individual to bring suit alleging breach of duty. Such services cannot be differentiated from the water service at issue in Shannon, or the police protection in Bailey. Thus, even if we were to assume that the federal government would be entitled to take advantage of local immunities, there are little or none to be taken advantage of in this situation.

The same result can be derived in any analysis of the company's potential liability, and potential use of a "public duty" defense. It should first be noted that no case has been uncovered holding that a government contractor was immune from civil tort liability because the nature of its work fell within the scope of the "public duty" doctrine. However, a contractor in such a position might more plausibly argue that it did not owe any particular duty to the claiming plaintiff, without characterizing its activities as governmental in nature and without characterizing this defense as the "public duty" doctrine. In any event, as discussed above, whatever argument on this score the company might attempt, there is no basis for believing that Washington law would not find a duty owing from the company to someone affected by fire department emergency services, in the same manner as Washington courts have found actionable duties in the provision of police protection and of water service for fire fighting purposes.

\subsection{EXCEPTIONS TO GOVERNMENTAL LIABILITY: THE DISCRETIONARY FUNCTION DOCTRINE}

Another doctrine, separate from "public duty" might be invoked to argue that the government and the company are immune from civil tort liability for any substandard provision of fire department emergency services. Both Washington law, and the federal tort claims act, provide that the government cannot be liable in tort for activities which amount to a discretionary function or duty. 28 U.S.C. $\$ 2680$ (a). 
Washington's enunciation of this doctrine is found in Bailev v. Town of Forks, discussed earlier. There, the court discussed RCW 4.96.010, the Washington counterpart to the Federal Tort Claims Act which makes municipal corporations liable for their tortious conduct "to the same extent as if they were a private person or corporation . . . ," and noted that

This statute, however, does not render the state liable for all official misconduct. At some point, tort liability ends and governing begins. [Cite omitted.] Because judicial abstention is required where the responsibility for 'basic policy decisions has been committed to coordinate branches of government,' discretionary policy making decisions remain protected from suit. [Cite omitted.] Discretionary decisions by police officers in the field, however, are not immune."

\section{$108 \mathrm{Wn} .2 \mathrm{~d}$ at 265.}

Just as other states at times broadly invoke the public duty doctrine to immunize fire department activities from civil tort liability, they also broadly interpret the discretionary function doctrine to take in fire fighting activities. For instance, in Invest Casts, Inc. v. City of Blaine, 471 N.W.2d 368 (Minn.App. 1991) a city was held immune from liability for its decision not to provide water service for fire hydrants to certain areas. The decision to allocate funds was held to be a discretionary function, immune from being second guessed in a the context of a civil tort lawsuit. At the same time, allegations based on negligent fire fighting methods and tactics were held to not be discretionary, and thus subject to a claim for negligence. In Theodoro v. City of Herculaneum, 879 S.W.2d 755 (Mo.App. 1994) the city's provision of a waterworks system was held to be embraced within the governmental function of fire protection. The court held that fire protection was a governmental and not a proprietary capacity, notwithstanding the proprietary nature of some aspects of the waterworks system. Thus, deficiencies in the provision of water for fire protection services purposes was held to be immune for liability as a governmental function.

Under the Federal Tort Claims Act, a discretionary decision is one which must be made without reliance on a fixed standard. Conversely, if there is a standard by which to measure the government's activities, they are not within the discretionary function exception. Barton v. United States, 609 F.2d 977 (10th Cir. 1979). Put another way, the issue is whether the decision invokes policy considerations. For instance, in Alabama Electric Cooperative, Inc. v. United States, 769 F.2d 1523 (11th Cir. 1985) the court characterized potential decision by the Army Corps of Engineers as involving social, economic and political policy decisions. Other than such policy considerations, however, the Corps must follow professional standards as would applicable to private engineering firms, or face tort liability. In Starrett v. United States, 847 F.2d 539, the discretionary function question arose in the context of a claim that the Navy's waste disposal methods had contaminated the plaintiff's well. The court held that if the case involved a violation of specific, mandatory requirements, there was no issue regarding discretion on the part of the government about whether to comply, and the discretionary function exception could not be a defense.

Regulations having the force of law are not the only source of the "specific, mandatory requirements" described above. For instance, in Woodman v. United States, 764 F.Supp. 1455 
(M.D.Fla. 1991), the Navy allegedly violated contractual requirements regarding waste disposal, allegations which likewise were found to be outside of the discretionary function defense to the Federal Tort Claims Act. In Dickerson, Inc. v. United States, 875 F.2d 1577 (11th Cir. 1989, the court focused on an "internal agency policy" to find that no discretionary function was involved.

It might be argued that the government's liability falls within the discretionary function exception to tort liability to the extent that it does not, itself, determine the extent to which Hanford Fire Department emergency services comply with applicable regulations and standards, but allows such a determination to be made by the company, an independent contractor. Thus, for instance, in Kirchmann v. United States, 8 F.3d 1273 (8th Cir. 1993), the disposal of hazardous wastes was covered by applicable Air Force regulations, and would not have been a matter of discretionary function if undertaken by the Air Force itself. However, the disposal was by an independent contractor, and the only claim against the government was that it had failed to properly supervise this contractor. That was not a matter defined by regulations, but instead was something left for the Air Force to handle in its own best discretion, and thus fell within the discretionary function exception to the Federal Tort Claims Act. Similarly, in Totten v. United States, 618 F.Supp. 951 (E.D. Tenn. 1985), aff'd 806 F.2d 698 (6th Cir. 1986), the government was held to be without liability when a fire resulted in the death of an employee of a contractor. The contractor was cleaning up the site of a failed rocket test, but in a manner which violated military safety regulations. The discretionary function exception nonetheless immunized the government from liability for its decision to delegate the safety responsibilities, include compliance with such regulations, to the contractor.

Several noteworthy cases involve application of the discretionary function exception of the Federal Tort Claims Act to public firefighting activities. The first is Dalehite v. United States, 346 U.S. 15, 73 S.Ct. 956, 97 L.Ed. 1427 (1953), a case arising from the post-World War II explosion of a fertilizer-laden ship at Texas City, Texas. One claim against the government was that the Coast Guard had improperly fought a fire aboard the ship prior to the explosion. This claim was dismissed with the observation that the Federal Tort Claims Act "did not change the normal rule that an alleged failure or carelessness of public firemen does not create private actionable rights." 346 U.S. at 43 . However, in the later case of Rayonier v. United States, 352 U.S. 315, 77 S.Ct. 374, 1 L.Ed.2d 354 (1957), the court held that, whatever the traditional view as to the liabilities of municipal fire departments, the Act made the federal government liable in the same manner as private individuals. The federal government thus would be liable for its fire-fighting activities to the same extent as any individual, i.e., to the extent that it was shown to have been negligent, notwithstanding the traditional immunities afforded municipal fire departments. Rayonier was later distinguished in another fire-fighting case, Defrees v. United States, 738 F.Supp. 380 (D.Or. 1990), which noted that "in establishing priorities, assigning government personnel and equipment and deciding what private resources, if any, should be used, these employees were required to make social and economic policy decisions." Again, however, this discussion assumes that the decisions being made are truly discretionary and are not the subject of regulations, standards, or other policies. In the latter situation, the very existence of the external requirement rules out the possibility of a claim that a discretionary function is involved. 


\subsection{REGULATIONS AND STANDARDS AS EVIDENCE OF NEGLIGENT CONDUCT}

Lack of compliance with the referenced regulations and standards can be used as evidence on the issue of whether the company, or the government, has been negligent in its execution of fire department emergency services.

An action against the company would be based upon Washington evidentiary law, which provides:

A breach of a duty imposed by statutes, ordinance, or administrative rule shall not be considered negligence per se, but may be considered by the trier of fact as evidence of negligence;

\section{RCW 5.40 .050}

Thus, in the case of those regulations having the force of law, Washington statutes clearly would apply so as to allow their admissibility into evidence on the issue of negligence for their having not been met. This provision also would apply to national standards incorporated into regulations by reference. When we turn to private standards, including nationally recognized standards, their application and admissibility becomes slightly less clear. However, as a general matter, such standards likewise will be admissible to show negligence. For instance, in Raybell v. State, 6 Wn.App. 794, 496 P.2d 559 (1972), the court allowed a number of informal standards on highway safety into evidence, in a case involving a claim against the state for an unsafe guardrail. The major difference with regard to such "private" standards is that their application will not be deemed a matter of law for a judge to rule upon. It may be necessary for their application to a particular situation to be endorsed by an expert familiar with their application in the relevant field. However, by overcoming this relatively minor hurdle, a claimant would be able to offer their provision into evidence.

An action against the government under the Federal Tort Claims Act presumes, as discussed earlier, that the government will be liable "in the same manner and to the same extent as a private individual under like circumstances . . ." 28 U.S.C. $\S 2674$. To that end, the same rule regarding applicability and admissibility of regulations and standards applies: Both regulations having the force of law and privately-promulgated standards can be introduced into evidence to support a claim of negligence for their not having been met.

\subsection{APPLICATION, ENFORCEMENT, AND PENALTIES FOR VIOLATION OF GOVERNMENTAL REGULATIONS}

The following is a discussion of specific governmental regulations listed below and which may be applicable to the Needs Assessment. 


\section{OCCUPATIONAL SAFETY AND HEALTH (OSHA)}

29 CFR $1910.120 \quad$ Hazardous waste operations and emergency response.

This regulation covers clean-up operations: At uncontrolled hazardous waste sites required by a governmental body; at sites covered by the Resource Conservation and Recovery Act; at voluntary clean-up sites recognized by governmental authorities as an uncontrolled hazardous wastes site; and during emergency response operations for hazardous waste releases. It does not contain any enforcement or penalty provisions of its own. However, see the discussion, below, regarding penalties available, generally, for violation of regulations promulgated under the Occupational Safety and Health Act.

\section{CFR 1910.156 Fire brigades.}

This regulation covers the organization, training, and equipment for fire brigades, whenever they are established by an employer. It does not contain any enforcement or penalty provisions of its own. However, see the discussion, below, regarding penalties available, generally, for violation of regulations promulgated under the Occupational Safety and Health Act.

\section{CFR $1910.38 \quad$ Employee emergency plans and fire prevention plans.}

This regulation covers elements of emergency action plans required by other particular Occupational Safety and Health standards. It does not contain any enforcement or penalty provisions of its own. However, see the discussion, below, regarding penalties available, generally, for violation of regulations promulgated under the Occupational Safety and Health Act.

\section{CFR 1910.151 Medical services and first aid.}

This regulation requires first aid to be available when an employee's workplace is not in near proximity to other medical facilities, as well as medical consultation regarding "plant health." It does not contain any enforcement or penalty provisions of its own. However, see the discussion, below, regarding penalties available, generally, for violation of regulations promulgated under the Occupational Safety and Health Act.

\section{CFR 1910.1030 Bloodborne pathogens.}

This regulation requires an exposure control plan for employees having an occupational exposure to blood or other potentially infectious materials, as defined in the regulation. It does not contain any enforcement or penalty provisions of its own. However, see the discussion, below, regarding penalties available, generally, for violation of regulations promulgated under the Occupational Safety and Health Act. 
29 CFR 1926.23 First aid and medical attention.

This regulation requires first aid services and medical care to be made available. The regulation is within 29 CFR Part 1926, which is specifically applicable to construction, as opposed to 29 CFR Part 1910, discussed both above and below, which are occupational safety and health standards of general application. It refers to specific requirements for first aid and medical attention set forth in Subpart D of the regulation, consisting of Sections 1926.50 to 1926.66. It does not contain any enforcement or penalty provisions of its own. However, see the discussion, below, regarding penalties available, generally, for violation of regulations promulgated under the Occupational Safety and Health Act.

29 CFR $1926.50 \quad$ Medical services and first aid.

This regulation requires first aid to be available when an employee's workplace is not in near proximity to other medical facilities, as well as medical consultation regarding "occupational health." It does not contain any enforcement or penalty provisions of its own. However, see the discussion, below, regarding penalties available, generally, for violation of regulations promulgated under the Occupational Safety and Health Act.

29 CFR 1910.134 Respiratory protection.

This regulation requires respiratory protection when necessary to protect the health of employees. It does not contain any enforcement or penalty provisions of its own. However, see the discussion, below, regarding penalties available, generally, for violation of regulations promulgated under the Occupational Safety and Health Act.

29 CFR 1910.146 Permit-required confined spaces.

This regulation defines and establishes permit and other safety procedures for employee work in confined spaces. It does not contain any enforcement or penalty provisions of its own. However, see the discussion, below, regarding penalties available, generally, for violation of regulations promulgated under the Occupational Safety and Health Act.

\section{CFR 1910.1200 Hazard communication}

This regulation requires hazards of all chemicals produced or imported to be evaluated and information regarding their hazards transmitted to employers and their employees. It does not contain any enforcement or penalty provisions of its own. However, see the discussion, below, regarding penalties available, generally, for violation of regulations promulgated under the Occupational Safety and Health Act.

As noted above, Occupational Safety and Health regulations do not separately provide for enforcement or penalty provisions. Administrative procedures for enforcement are set forth in 29 CFR 1903.15, and refer to penalties available under $\S \S 10$ and 17 of the Occupational Safety and Health Act, 29 USC $\$ 651$ et seq. 29 USC $\$ 666$ ( $\$ 17$ of the Occupational Safety and Health Act) specifies penalties for violations. In general, it calls for civil penalties of up to $\$ 1,000$ for each violation, and of $\$ 1,000$ per day for failure to correct violations. Willful 
and repeated violations are subject to enhanced civil penalties of $\$ 10.000$. Willful violations resulting in death to an employee, and knowingly making a false statement or report in connection with any document required by the Act, are subject to criminal penalties including fines and imprisonment.

\section{ENVIRONMENTAL PROTECTION AGENCY (EPA)}

40 CFR 261.33 Discarded commercial chemical products, off- specification species, container residues, and spill residues thereof.

This regulation defines materials as hazardous wastes, for purposes of other administrative provisions regulating those wastes. It has no apparent direct applicability to the provision of emergency services by the Hanford Fire Department as such. However, to the extent that the company is utilizing the existence of the Hanford Fire Department to fulfill the requirements of regulations of other activities occurring at the Hanford reservation, a consideration of those other regulations, and the potential penalties which might me invoked for their breach, is warranted.

For instance, a separate provision, 40 CFR 263.30 requires immediate action in the event of a hazardous waste discharge. The regulation, on its face, applies to transportors of hazardous waste. Presumably the company, in the form of the Hanford Fire Department, is not particularly engaged in the transportation of hazardous waste. Note that one of the components of "immediate action" contemplated by this regulation is the notification of local authorities, i.e., an entity such as the Hanford Fire Department. Note also that 40 CFR 263.30(b) allows transporters not otherwise licensed or approved by the EPA to haul hazardous waste when doing so at the direction of a local official when cleaning a spill. Other provisions, specifically 40 CFR Part 264, regulate operators of hazardous waste storage/treatment facilities. Again, such regulations presumably would apply to the company in its capacities other than as the Hanford Fire Department.

As noted, if the company is using the facilities or capabilities of the Hanford Fire Department to fulfill a regulatory requirement that its separate activities have certain emergency capabilities, a consideration of the potential penalties for violation of such regulations is in order. The United States statutes underlying these regulations include the Resource Conservation and Recovery Act, 42 USC $\$ 6901$ et seq, and the Comprehensive Environmental Response, Compensation and Liability Act, 42 USC $\$ 9601$ et seq. Penalties available for violations of those statues, and the regulations promulgated under them, include civil fines of up to $\$ 25,000$ per day of noncompliance for each violation. 42 USC $\$ 6928, \S 9609$.

\section{CFR Part 112}

This regulation establishes procedures to prevent discharge of oil from non-transport facilities on navigable waters and adjacent shorelines. It applies to facility owners and operators. 40 CFR 112.3 require the establishment and maintenance of a Spill Prevention Control and Countermeasure Plan. Again, any applicability of this regulation does not appear to be as to the activities of the Hanford Fire Department, per se, but perhaps with other activities of the company. To the extent the capabilities of the Hanford Fire Department are being used to 
fulfill such a requirement, however, of the company, then a consideration of the potential consequences of a violation of these regulations is appropriate. These regulations themselves, in 40 CFR 112.6, call for civil penalties of up to $\$ 5,000$ per day for each violation of 40 CFR 112.3-5.

\section{CFR Part 68}

This regulation specifies regulated substances for purposes of $\$ 112(r)(3)$ of the Clean Air Act, 42 USC $\$ 7401$ et seq. No particular requirements are implemented within this regulation alone. Subpart B, entitled "Risk Management Plan Requirements," is reserved.

\section{CFR Part 311}

This regulation makes 29 CFR 1910.120 , separately discussed, applicable to state and local government employees engaged in hazardous waste operations (as defined in the regulation) in states without an approved OSHA plan.

\section{CFR Part 355}

This regulation establishes a list of extremely hazardous substances, and requires a facility to plan in the event of a release of such substances. Such planning includes notification of local emergency responders, but no particular requirements are set forth for such local emergency responders.

40 CFR 355.50 specifies that civil penalties of up to $\$ 25,000$ for each violation, and up to $\$ 25,000$ for each day of a continuing violation, may be assessed. In the event of a second or subsequent violation, enhanced penalties of up to $\$ 75,000$ per violation, and $\$ 75,000$ per day for continuing violations, are authorized. Criminal penalties, including fines and imprisonment, are specified for willful and knowing violations.

\section{NUCLEAR REGULATORY COMMISSION}

\section{CFR Part 835}

This regulation establishes procedures for occupational radiation protection. It contains no specific enforcement or penalty provisions.

\subsection{WESTINGHOUSE HANFORD COMPANY CONTRACTUAL LIABILITIES AND INDEMNIFICATION CLAUSES}

The previous sub-sections identified several areas of potential legal liabilities, which for present purposes can be grouped as: 1) penalties and other liabilities imposed by OSHA and other worker safety regulations; 2) civil and criminal penalties imposed by regulations dealing with the storage, handling, or transportation of hazardous wastes; 3) potential civil tort liability to third parties as a result of negligence, which negligence could be in part proven by violation of regulations, or by violation of recognized standards (even if the latter do not have force of law). 
42 USC $\$ 2210$ (d) ( $\$ 170$ of the Atomic Energy Act, hereinafter "the Act") states in pertinent part that "In addition to any other authority the Secretary of Energy may have, the Secretary shall, until August 1, 2002, enter into agreement of indemnification under this subsection with any person who may conduct activities under a contract with the Department of Energy that involve the risk of public liability . . . " (Note that this particular language was incorporated into the statute via an amendment dated August 20, 1988. The copy of the contract provided to the Needs Assessment Team was executed June 5, 1987, but was for a period ending September 30,1992. To the extent that any later extension of the contract occurred, it presumably would have been within the time in which the statute allowed the Secretary to make contracts of indemnification.) "Public liability," however, is given a limited definition under the Act: "The term 'public liability' means any legal liability arising out of or resulting from a nuclear incident . . . 42 USC \$2014(w). "Nuclear incident" in turn is defined to mean an occurrence resulting in injury or damage due to the radioactive or other hazardous properties of certain defined radioactive materials, principally uranium, thorium, or plutonium. 42 USC $\$ 2014(\mathrm{e}),(\mathrm{q})$, (z), and (aa).

In conformity with this authority, the Contract, in Clause I-58, provides a similarly restricted scope of express indemnity:

(c) (1) To the extent that the Contractor and other persons indemnified are not compensated by any financial protection . . . DOE will indemnify the Contractor and other persons indemnified against (i) claims for public liability as described in subparagraph (2) of this paragraph (c); and (ii) the reasonable cost of investigation and settling claims and defending suits for damage for such public liability. . .

(2) The public liability referred to in paragraph (c)(1) of this section is public liability which:

(i) arises out of or in connection with the contractual activity; and

(ii) arises out of or results from:

1 A nuclear incident which takes place at a contract location; or

2 A nuclear incident which takes place at any other location and arises out of or in the course of the performance of contractual activity under this contract by the contractor's employees . . .

This indemnity provision provides that the definition within the Act also apply to it. As we have seen above, the reference to the term "nuclear incident" means that the express indemnity provisions apply to incidents involving loss or damage resulting from certain nuclear materials, but not beyond. 
Other provisions of the contract indicate, however, that potential liability to third persons is an expense which shall be borne by the government, not as an express item of indemnity, but as an item within the scope of the contract's definitions of allowable costs to be reimbursed or paid. Clause I-65 states in pertinent part:

(d) Items of allowable cost.

Subject to the other provisions of this clause, the following items of cost or work done under this contract shall be allowable to the extent indicated:

(4) Litigation expenses, including reasonable Counsel fees, incurred in accordance with the clause of this contract entitled "Litigation and Claims."

(5) Losses and expenses (including settlements made with the consent of the Contracting Officer) sustained by the Contractor in the performance of this contract and certified in writing by the Contracting Officer to be reasonable, except the losses and expenses expressly made unallowable under other provisions of this contract.

(21) All costs incurred by the contractor with respect to any and all liabilities, claims, demands, damage costs, or penalties (such as civil sanctions including fines), arising out of, or related to environmental, safety, and health activities, including cost incurred with respect to investigation, removal, remedial action, ground and surface water or other clean-up of hazardous, toxic or contaminated material(s), except those costs that result from conduct identified in subparagraph (e)(17)(ii) of this Clause 1-65.

The referenced subparagraph (e)(17)(ii) sets forth a specific exception to this allowance of costs, and is a helpful contrast which provides, by negative implication, further information as to the items of costs which are allowed. Insofar as it is relevant, it only excepts:

... losses where such losses or expenses . . . result from willful misconduct or lack of good faith on the part of any of the Contractor's directors, corporate officers, or a supervising representative of the Contractor ...

Even if such losses resulted from a discrepancy between the level of resources for the Hanford Fire Department and applicable regulations or other standards, such a discrepancy, standing alone, presumably could not be equated to "willful misconduct or lack of good faith" taking the matter out of the scope of allowable costs into unallowed costs. (Bear in mind again that allowed costs can include "penalties" and "civil sanctions, including fines.") Thus, the potential imposition of virtually all liabilities to the company discussed in the needs assessment, ultimately would be transferred to the government in the form of additions to the costs allowed under the Contract.

(It has been previously noted that an employee retained potential individual liability to persons injured by negligent performance of duties within the scope of the contract, even though, as a practical matter, an injured party undoubtedly would seek to recover on any such claim against the company or the government. Section H-23 of the Contract virtually ensures 
that this will be the case, as it affirmatively states that it is "Government policy" to defend claims brought against "any Contractor protective force officer or other employee" as a result of conduct undertaken in good faith performance of employment duties.)

\subsection{POTENTIAL LEGAL LIABILITIES AND RESPONSIBILITIES RESULTING FROM CHANGES TO HFD RESOURCES WHICH DEVIATE FROM THOSE SET FORTH IN THE HANFORD FACILITY CONTINGENCY PLAN AND APPENDED TO THE RCRA PERMIT}

The Hanford Facility Contingency Plan has been promulgated to meet the contingency planning requirements contained in the Washington State Department of Ecology's Dangerous Waste Regulations, Chapter 173-303 of the Washington Administrative Code ("WAC"). Their content is prescribed by WAC 173-303-350. Copies must be submitted to all local police, fire, and state and local emergency response teams. WAC 173-303-350(4)(b). A Plan is required to be submitted as part of the application to operate and maintain a facility covered by the Dangerous Waste Regulations. WAC 173-303-806(4)(a)(vii). (While particular Dangerous Waste Regulations apply to the Washington State Extremely Hazardous Waste Management Facility at Hanford, WAC 173-303-700, none directly deal with the Plan.)

None of these provisions, nor anything else within Chapter 173-303 WAC, requires that the Plan utilize or have available a particular level of emergency response resources, such as that set forth in another defined regulation or national standard. Such criteria presumably could be used as means to evaluate the sufficiency of the Plan, or of any proposed changes to it, during the review process discussed below. However, changes to facility resources would not necessarily require an amendment of the Plan in the first place. The section governing such amendments reads in full as follows:

(5) Amendments. The owner or operator shall review and immediately amend the contingency plan, if necessary, whenever:

(a) Applicable regulations or the facility permit are revised;

(b) The plan fails in an emergency;

(c) The facility changes (in its design, construction, operation, maintenance, or other circumstances) in a way that materially increases the potential for fires, explosions, or releases of dangerous waste or dangerous waste constituents, or in a way that changes the response necessary in an emergency;

(d) The list of emergency coordinators changes; or

(e) The list of emergency equipment changes.

[WAC 173-303-350(5)]

In the event of circumstances necessitating an amendment to the Plan, a modification of the Permit is required. Permit changes are accomplished by modification requests that fall into three classes, with varying application and notice requirements. WAC 173-303-830. 
Changes to emergency procedures or removal of equipment from an emergency equipment list are Class 2 modifications. Replacement of equipment with functionally equivalent equipment or changes in emergency coordinator information are Class 1 modifications. WAC 173-303-830, Appendix 1. Class 1 modifications, in general, require notice to the Department of Ecology and to persons on the "facility mailing list maintained by the department," with further review only if requested by any person. WAC 173-303-830(4)(a). Class 2 modification require a request that "Describes the exact change to be made," "Explains why the modification is needed," and "Provides the applicable information required by" WAC 173-303-806, the section of the regulation governing an original application for a Permit. WAC 173-303-830(4)(b)(i). (Presumably the limitation to applicable information would, in the case of a Plan amendment, require submission of only the amendment rather than of all information required by WAC 173-303-806. Otherwise, the Hanford Facility essentially would be require to undergo the entire Permit application and documentation procedure if it were to undertake virtually any but the smallest modifications of its operations or procedures.) The request for a Class 2 Permit modification calls for notice by mail, public posting, and publication. After a public comment period and public hearing, the matter then is submitted to the Department of Ecology for determination. WAC 173-303-830(4)(b).

Again, however, nothing within this process invokes any particular regulation or standard governing emergency response resources. If Permit modification requests are reviewed under the same criteria applicable to applications for original permits, the focus would appear to be more on performance criteria under all the circumstances than any arbitrary standard. Permits will be denied "if it is determined that the proposed location and/or activity endangers public health and the environment as demonstrated by the permit applicant's failure to satisfy the performance standards of WAC 173-303-283." WAC 173-303-806(13). WAC 173-303-283, in turn, requires facilities to be operated in a manner which prevents degradation of the environment and endangerment of public health "to the maximum extent practical given the limits of technology." 
THIS PAGE INTENTIONALLY

LEFT BLANK 
曽 
THIS PAGE INTENTIONALLY

LEFT BLANK 


\section{SECTION 11 - SUMMARY OF RECOMMENDATIONS}

An assessment of the HFD was performed to evaluate the service level provided based on the site risks, response history, and applicable standards. Based on this assessment, recommendations were provided to address issues. A summary of the recommendations follows. Incorporation of the recommendations will result in a level of service complying with the intent of the applicable regulations, referenced criteria, and professional judgement.

These recommendations are summarized based on a priority scheme that allows incorporation of changes in an appropriate manner. The priority levels are defined as follows:

Priority I These recommendations result from requirements reflected in mandatory criteria. Additionally, these recommendations may stem from conditions, events or risks which if left unchanged could result in an imminent hazard to site employees, HFD firefighters, or could result in an environmental release in excess of allowed limits. Priority I items are considered an emergency condition and should receive highest priority for implementation.

Priority II These recommendations result from the professional judgement of the needs assessment team members and stem from conditions, events or risks which if left unchanged could reduce the level of fire/EMS protection below baseline levels. Priority II items impact baseline levels of fire/EMS protection and therefore should be implemented as soon as possible. However, when qualitatively evaluated in the context of site history and experience, these items are not considered to represent an immediate emergency condition.

Priority III These recommendations result from the professional judgement of needs assessment team members and stem from conditions, events or risks which if left unchanged could reduce the desirable level of fire/EMS protection, but not below baseline levels. Priority III items should be scheduled for implementation with due consideration of funds and resources.

\subsection{PRIORITY I}

I.1. Clarification is needed concerning firefighters returned to "full duty" by HEHF, but not allowed full duty assignments. HFD and HEHF officials must clear up this problematical situation ( $\operatorname{Rec}$ 9.3.3.6).

I.2. Site supervisory personnel must be made aware of the need to call 911 when medical situations occur and not transport a potentially critical and unstable patient to a first aid location. Medical situations shall include all cardiac complaints, serious injuries, or injuries with a potential neurological component and all severe respiratory complaints ( $\operatorname{Rec}$ 9.3.3.7). 
I.3. The HFD shall adhere to EMS patient care procedures, protocols, and guidelines established by the Benton Franklin county protocols and the State of Washington as stipulated by the Medical Program Director (MPD) (Rec. 9.3.3.9)

I.4. Consolidate the entire fire dispatch and emergency communications system function so that its functions are overseen by the HFD. Alternatively, reestablish a site emergency alarm-dispatch-communications feasibility task force which allows for equitable participation of all possible users and which examines, the feasibility of a Site-wide facility controlled by an equitable multi-agency policy board (Rec 9.6.3.3).

I.5. The HFD shall be provided with the capability of ensuring (and validating) that all emergency services can be performed within the applicable dose limitations (Rec 9.7.10.5).

I.6. The HFD dose limits shall be revised to reflect the criteria stipulated by 10 CFR 835 (Rec 9.7.10.6).

1.7. The following EMS Skills maintenance items shall be made a priority for the EMS System.

- $\quad$ Close monitoring of Continuing Medical Education and field performance.

- All paramedics should be required to perform ride along or hospital time on a monthly basis.

- A medical director should be providing the paramedic OTEP training as well as overseeing the upgrading and maintenance of skills.

- $\quad$ QA/QI should focus on the issue of skills maintenance and appropriate procedural evaluations.

(Rec 9.10.3.9)

I.8. A medical director should be responsible for all aspects of the initial QA/QI and should work towards developing a program of CQI (continuous quality improvement) (Rec 9.11.2.1).

1.9. A stand alone procedure shall be developed and implemented which provides independent validation that applicable HFD procedures are being followed. (Rec 9.11.2.2).

\subsection{PRIORITY II}

II.1. There shall be 17 response personnel on duty assigned to stations to handle, simultaneously, one hazardous materials or fire incident and one EMS incident(this number includes the Battalion Chief, but excludes the dispatcher). Actual deployment of the 17 baseline personnel shall be determined by HFD management, in order to achieve the service capabilities cited in Recommendation 9.3.3.2. A staffing multiplier to determine actual minimum on-duty staffing levels shall be developed by HFD officials to account for time off allowed by contract, shift arrangements, sick days lost, light duty personnel, station configuration and crew deployment, shifts in 
area populations and occupancies, activity, and resulting workloads, recalls, training assignments, fire watches, etc. $(\operatorname{Rec}$ 9.3.3.1)

II.2. Based on the existing and predicted hazards and conditions of the Site, critical baseline fire station operating times and service capabilities shall not be less than the following:

\section{$\underline{\text { Stations }}$}

100 Station: Open weekdays -fire and BLS-D (defibrillator) response capability; closed at times of low area population and activities; currertly, nights, weekends, and holidays.

200 Station: Open 24 hours - 7 days/week for fire response and *ALS response capability.

400 Station: Open 24 hours - 7 days/week for fire response and *ALS response capability.

300 Station: Open 24 hours - 7 days/week for fire, and BLS-D response capability.

*ALS is the preferred level of service at this station. This service level, at the HFD management discretion could be relocated to adjust to a change in site populations, activity or risk (Rec 9.3.3.2).

II.3. A trained incident command officer at the Battalion Chief (BC) level must be on duty at all times. This person will respond as Incident Commander to each reported working incident, all times, all shifts. Until the $\mathrm{BC}$ arrives on the scene, the first responding Captain shall assume the role of temporary incident commander as now (Rec 9.3.3.3).

II.4. A trained Safety Officer must be available on each shift for attendance at working incidents. Captains shall be so trained, since HFD protocols assign them this responsibility. Additional personnel also should be so trained so that the assignment may de delegated. (Rec 9.3.3.4).

II.5. Sufficient personnel must be trained as hazmat technicians to assure a six person response force available each shift, as now ( $\operatorname{Rec}$ 9.3.3.5).

II.6. The appropriate recommendations of the Draft Hanford Site Emergency Medical Plan identified below shall be instituted.

- Each DOE-RL and contractor supervisor is responsible for the safety of his/her work group. This responsibility includes the communication of designated first responders and the location of and procedures for use of the first aid kits. Contractors are responsible for insuring employees are knowledgeable in the use of the 911 system. 
- $\quad$ Each employee is responsible for recognizing and responding to a life or limb threatening illness/injury in a co-worker by activating 911 for emergency medical response.

- $\quad$ Each employee is responsible for knowledge of and access to the work group's designated first-responder to initiate immediate first-aid and CPR (if needed) while awaiting the arrival of Hanford site EMS.

(Rec 9.3.3.8)

II.7. The HFD and the signatory departments shall delineate--if necessary any and all restrictions related to the mutual aid that are defined in the mutual aid agreements (Rec 9.3.3.12)

II.8. The 100 Area Station shall undergo only those modifications necessary to meet applicable OSHA, Life Safety code, and structural integrity requirements (Rec 9.4.3.1).

II.9. Upgrade the existing 200 Area Station to meet all applicable codes and standards, or construct a new station at or near that site ( $\operatorname{Rec}$ 9.4.3.2).

II.10. If new construction takes place at the 200 Station Site, the design shall incorporate adequate provisions for a communications/alarm/dispatch facility. Should the communications function be moved to another location, all applicable provisions shall be met $(\operatorname{Rec}$ 9.4.3.4).

II.11. The 400 Area Station shall undergo those modification necessary to meet applicable OSHA, Life Safety Code and structural integrity requirements (Rec 9.4.3.6).

II.12. Postpone the decision to construct a new 300 Area Station until a decision is made concerning a Richland-HFD combined Station or an outsourcing arrangement. If such a decision is not forthcoming, proceed with planning for a new 300 Area Station on site (Rec 9.4.3.7).

II.13. Maintain as a minimum, one first-line Quint at each operational fire station (Rec 9.5.6.1)

II.14. Maintain a minimum of four reserve triple combination pumpers for the entire Hanford site ( $\operatorname{Rec}$ 9.5.6.2).

II.15. Maintain a minimum of one reserve ambulance unit for the entire Hanford site (Rec 9.5.6.3).

II.16. The HFD alarm, dispatch, and emergency communication systems for fire, rescue, and EMS services shall comply with the applicable requirements of NFPA 1221 and shall have as a minimum the following performance characteristics:

1. Fast, direct access by automatic alarm systems (as now) and by telephone callers (not now available). 
WHC-SP-1180, Vol. 1

2. Call switch-over capability from the 9-1-1 call taker (Public Safety Answering Point or PSAP).

3. Customized computer aided dispatch (CAD) hardware and software.

4. Customized computer aided systems to handle automatic alarm supervision and testing quickly and accurately.

5. Radio communication capability throughout the service area, with sufficient frequencies to handle routine business, emergency dispatch, tactical incidents, mutual aid communication, and recall of off-duty personnel by two-way pagers.

6. Capability to efficiently transmit data to the MDTs.

7. FAX capability to Stations, and MDT print-out capability to vehicles.

8. System redundancy.

9. Capability of being operated by a single dispatcher in medium volume call situations.

(Rec 9.6.3.1)

II.17. The HFD alarm, dispatch, and emergency communications system shall have the following process characteristics:

1. Capability of handling simultaneous events.

2. Capability of maintaining a continuous flow of information during a working incident while handling additional dispatches and firefighter recalls.

3. Capability of announcing relevant weather conditions, including wind speed and direction, during incidents for tactical purposes as now.

4. Capability of announcing "time into incident" in five minute increments for incident command purposes as now.

5. Capability of handling all calls for mutual aid.

6. Capability of notifying all relevant agencies promptly of incidents, and coordinating all responses as now.

7. Capability of handling EMS dispatches using standard protocols for advising EMS callers.

(Rec 9.6.3.2).

II.18. Design and implement a selective off-duty recall system with the following features:

- $\quad$ Rapid and simple transmission of the recall by single person

- Selective or small group or large group recall

- Recall transmission capability over long distances

- Responder to transmission point feedback capability

(Rec 9.6.3.7).

II.19. Quick Access prefire plans shall be accessible for personnel use within all first run units (Rec 9.7.10.1).

II.20. Prefire plans and quick access prefire plans shall be developed for all facilities and areas with significant hazards ( $\operatorname{Rec} 9.7 .10 .2)$. 
II.21. Hazmat incident operating guidelines shall be completed (Rec 9.7.10.4).

II.22. The pre-incident exercises and drills which involve the HFD should as a minimum be continued at a level and frequency which currently exists (Rec 9.7.10.7).

II.23. Periodic large scale training exercises which activate the firefighter rapid recall system, and utilize T\&S FF in line positions shall be conducted (Rec 9.7.10.10).

II.24. The HFM Office shall be modified to incorporate the following:

- Increase the number of fire inspector positions from one to two FTEs.

- Assign one FTE secretary to the Fire Marshal's office

- Remove administration and supervision of the HFD training program from the Fire Marshal's office.

- Augment the Site's Public Safety Education program by assigning 0.5 FTE time of one Fire Inspector to the program, including teaching fire extinguisher and related safety classes to workers.

- Maintain coordination between the Fire Marshal's office and the Hanford Fire Protection Forum.

- Establish an HFD internal standing committee (chaired by the Fire Marshal, with HFD officer representation) charged with on-going responsibility for maintaining inter-shift coordination of prevention efforts.

$(\operatorname{Rec}$ 9.8.3.1).

II.25. The following recommendations are designed to help assure continuing compliance Site-wide with the necessary and relevant fire and related safety codes and directives:

- Expand the permitting system to include the process outlined in NFPA 1, section 1-15. These may include: explosives, LP-gases, storage of oxidizers and organic peroxides, and use of tar kettles on roofs.

- Ensure that FM authority extends to private businesses moving onto the Site and to all contractors. Include construction plan approval.

- Operate as large municipalities do, and be sure the Fire Marshal's responsibility and authority extend to all new operations--public or private--which locate on the Site.

- $\quad$ Prepare a booklet--"Advice from the Hanford Fire Marshal"--for widespread distribution on site.

- Prepare a fire and related safety video tape for showing to new employees and at manager's meetings.

(Rec 9.8.3.2)

II.26. When it is evident that continuing medical education and firefighter training for T\&S FF may result in a failure to meet applicable fire protection system requirements, applicable training shall be conducted on off-shift hours (Rec 9.9.3.3). 
II.27. The Training and Resources Section shall be reorganized under a Team Leader Training Officer, with one additional full time Training Officer, and a full-time secretary. The Team Leader shall report to the Deputy Fire Chief $(\operatorname{Rec} 9.10 .3 .1)$.

II.28. The existing three year training topic outline requires expansion by a representative training curriculum task force. The expansion shall relate each training topic to a comprehensive performance based plan which provides for all components of the training program (Rec 9.10.3.3).

II.29. The following specialized training needs for HFD emergency response personnel (some of which are already addressed in the training curricula) shall be met:

- Advanced work in hazardous materials incident mitigation

- $\quad$ Advanced work in radiological incident mitigation

- Personnel safety in work environments containing hazardous materials and radioactive materials

- Fire suppression and mitigation efforts using a variety of extinguishing agents

- Extensive application of regulatory and national standard drivers

- Advanced technical rescue specialties including confined space entry and rescue

- Wildland fire suppression

- Ground cover fires at hazardous waste storage sites

- Work with advanced built-in fire protection systems

- Rope rescue

(Rec 9.10.3.4)

II.30. Upgrade the centralized HFD training facility to accommodate the various types of hands-on training required by response personnel or provide alternate locations for all training ( $\operatorname{Rec}$ 9.4.3.5 and 9.10.3.6).

II.31. Identify areas or specific fire hydrants on specific systems where insufficient water is available for fire protection purposes. Hydrants which will not meet the fire departments' needs should be easily field identifiable (e.g. painted a specific color). Develop a plan to address fire department activities based on water supply limitations ( $\operatorname{Rec}$ 9.12.3.1).

II.32. Upgrade the existing water supply systems to provide adequate water for fire protection needs (See WSA for details) (Rec 9.12.3.2).

II.33. Assure limitations of water supply at specific facilities are addressed in prefire plans (Rec 9.12.3.3).

\subsection{PRIORITY III}

III.1. Maintain record keeping in accordance with national fire incident reporting system formats (NFPA 901) (Rec 9.2.2.3.1). 
III.2. The Site shall implement a CPR training program which ensures that a cadre of personnel at each facility, or work site are CPR qualified and equipped to provide emergency CPR during normal hours of occupancy (Rec 9.3.3.10).

III.3. As the site operations change or transition, HFD should examine methods to minimize the response time to an EMS incident (Rec 9.3.3.11).

III.4. Provide additional administrative space and restroom facilities to the existing administrative wing or construct an administrative building at an approved site (Rec 9.4.3.3).

III.5. Perform seismic evaluations to determine the ability of all fire stations to maintain all essential services immediately following a seismic event. Criteria for evaluation shall as a minimum, reflect requirements stipulated by the 1991 UBC for Essential Facilities or site specific seismic requirements approved by DOE. Perform any and all required station modifications necessary to maintain all essential services immediately following a seismic event $(\operatorname{Rec}$ 9.4.3.8).

III.6. Obtain a mobile emergency Command-communications vehicle for use by all emergency agencies on Site (Rec 9.5.6.4).

III.7. Obtain a mobile decontamination unit for use at emergency hazardous material incidents and the decontamination of personnel ( $\operatorname{Rec}$ 9.5.6.5).

III.8. Expand the SRID to include a complete inventory of the required items for Access and Cardiac Care stipulated by WAC-246-976-390 (Rec 9.5.6.6).

III.9. The dispatcher job shall be assigned to a minimum of one trained person on each shift. There also must be a quick responding back-up dispatcher for each shift (Rec 9.6.3.4).

III.10. Install a "quick-call" trouble buzzer system in the communications room and a deadman notification system on all in-coming alarms and 911 calls (Rec 9.6.3.5).

III.11. EMS Dispatchers shall be trained in EMS dispatch operations, procedures, and protocols (Rec 9.6.3.6).

III.12. The HFD shall evaluate the necessity of HFD notification 24-hours in advance of confined space entry $(\operatorname{Rec} 9.7 \cdot 10.3)$.

III.13. The HFD shall evaluate the feasibility of providing preventive, maintenance and repair services to PNL and FFTF facilities (Rec 9.9.3.1).

III.14. Applicant certification requirements should include the following:

- Firefighter level 1 (as stipulated by NFPA 1001)

- EMT, "First Responder" level (as stipulated by WAC-246-976) (Rec 9.9.3.2) 
III.15. The HFD Programs for providing Fire Protection Systems Administration and Testing and Fire Protection Systems Maintenance shall be evaluated periodically to ensure that personnel resources are commensurate with the level of service that is required (Rec 9.9.3.4).

III.16. All Station Captains and Battalion Chiefs shall maintain current certification at the fire instructors level 1 (as defined by NFPA 1041) in order to conduct in-service training and the necessary monitoring and oversight ( $\operatorname{Rec}$ 9.10.3.2).

III.17. Appoint a standing advisory committee on training, with representation from all levels and types of HFD members, having the Deputy Chief as chair. This group would meet periodically to review training needs from the various types and levels of members, the training curriculum and training schedule, performance evaluations, and training resources.

(Rec 9.10.3.5)

III.18. The following recommendations are made to improve the quality of the in-station training program:

- Hold all stations to a minimum of one hour daily in-service training set by a mandated lesson plan. This training will be evaluated.

- Develop standardized instructional packages to be sent or transmitted to each station, such as video lessons, slide packages, and self-instruction and evaluation booklets.

(Rec 9.10.3.7)

III.19. Use selected off-Site training and visiting experts to enhance HFD training. Continue programs which send HFD Training Officers and in-service instructors to specialized "train-the-trainer" programs for advanced course work ( $\operatorname{Rec}$ 9.10.3.8). 
THIS PAGE INTENTIONALLY

LEFT BLANK 


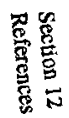


THIS PAGE INTENTIONALLY LEFT BLANK 


\section{SECTION 12 - REFERENCES}

AEC/DOE, 1951-1994. Annual Summary of Fire and Other Property Damage Experience, DOE or AEC Richland 1951-1994. U.S. Department of Energy, Richland, Washington.

AEC, 1964. Report, Fire Incident 233-S Facility, Chemical Processing Department. BNW110011 PT2, April, 1964. Atomic Energy Commission, Richland, Washington.

AEC, 1969. 1968 Annual Incident Summary of Fire and Other Property Damage Experience, March 1969. Atomic Energy Commission, Richland, Washington.

AEC, 1975. Operational Accidents and Radiation Exposure Experience Within the United States Atomic Energy Commission 1944-1975. WASH 1192. Fall, 1975. Washington, D.C.

CFR, 1992. Code of Federal Regulations, Title 29 CFR 1910, Occupational Safety and Health Standards, July, 1992 Edition.

Campbeil, not dated. Study, Earthquake Hazard Study in the Vicinity of Toppenish Basin, South Central Washington, Not Dated. N.P. Campbell, T. Ring and T. Repasky.

DOD, 1988. Department of Defense Instruction, Department of Defense Fire Protection Program, DODI 6055.6, August, 1988.

DOE, 1984, Environmental Protection, Safety, and Health Protection Standards, May, 1984. U.S. Department of Energy, Washington D.C.

DOE, 1989. General Design Criteria, DOE Order 6430.1A, April, 1989. U.S. Department of Energy, Washington, D.C.

DOE, 1993. Hanford Site Development Plan, DOE/RL-93-19, May, 1993. U.S. Department of Energy, Richland, Washington.

DOE, 1993b. Fire Protection, DOE Order 5480.7A, February, 1993. U.S. Department of Energy, Washington, D.C.

DOE, 1994. Richland Operations Office, Implementing Directive for Fire Protection, RLID 5480.7, January 17, 1994. U.S. Department of Energy, Richland, Washington.

DOE, 1995a. 1996 Baseline Environmental Management Report, (DRAFT). September, 1995. U.S. Department of Energy, Richland, Washington.

DOE, 1995b. Hanford Site Development Plan (DRAFT), RL-W94-044. January, 1995. U.S. Department of Energy, Richland, Washington.

DOE, 1995c. Implementation Guide for use with DOE Orders 420.1 and 440.1 Fire Safety Program, September, 1995. U.S. Department of Energy, Germantown MD. 
DOE, 1995d. Facility Safety (DRAFT), DOE Order 420.1, October, 1995. U.S. Department of Energy, Washington D.C.

DOE, 1995e. Fire Department Emergency Service Descriptions, May, 1995. U.S. Department of Energy, Richland Washington.

DOE, 1995f. Fire Protection Facility Assessments \& Prefire Plans 300/1100/600 (south) Areas, May, 1995. U.S. Department of Energy, Richland Washington.

HFD, 1994. Hanford Fire Department Implementing Procedure, WHC-IP-0939, Rev 2, dated April, 1994.

HFD, 1995. Hanford Fire Department Data. September-October, 1995.

HFD, 1995b. Hanford Fire Department Implementing Procedure (DRAFT), HFD-IP-0939. October, 1995.

HTS, 1995. HTS Seismic Monitoring Data, November, 1995.

Kaiser, 1995a. Letter to WHC President from ICF Kaiser, dated May 31, 1995. Subject: 30year Population Projection.

Kaiser, 1995b. Fire Systems Testing and Maintenance, Industrial Engineering Report, May 25, 1995. ICF Kaiser, Richland, Washington.

Kaiser, 1995c. Kaiser Reference Maps, dated August 1, 1995.

Mutual Aid, 1995. Tri-County Mutual Aid Agreement, June, 1995.

NFPA, 1995. NFPA 801, Standard for Facilities Handling Radioactive Materials, 1995 edition. National Fire Protection Association, Quincy, Massachusetts.

PNL, 1982. Report, Fire In Fiberglass-Reinforced Polyester Duct In A. Nuclear Facility, March 31, 1982. May 14, 1982. Pacific Northwest Laboratories, Richland Washington.

PNL, 1995. Hanford Site Environmental Report for Calendar Year 1994. PNL-10574. June 1995. Pacific Northwest Laboratories, Richland Washington.

Polsky, 1992. Polsky, Scott M.D. Continuous Quality Improvement in EMS, American College of Emergency Physicians, 1992.

Roush, 1994. William Roush, Medical Accountability, Principles of EMS Systems, 1994.

Washington, 1994. "Agency proposes no general rate increase for 1995." Employee News, October, 1994. Washington State Department of Labor and Industries, Public Affairs Division, Olympia, WA. 
WHC-SP-1180, Vol: 1

Weaver, 1986. Douglas Weaver, MD, Leonard Cobb, MD et al., Journal of American College of Cardiology, April 1986.

WHC, undated. Fire Protection Facilities Inventory, HFD, undated. Westinghouse Hanford Company, Richland, Washington.

WHC, 1992. Hanford Fire Department Emergency Medical Services Program Plan, WHCEP-0575, Westinghouse Hanford Company, Richland, Washington.

WHC, 1993. Fire Protection Program Manual, WHC-CM-4-41. Westinghouse Hanford Company, Richland, Washington.

WHC, 1993b. Functional Design Criteria HFD Facilities, WHC-SD-L094-FDC-001, dated December 17, 1993. Westinghouse Hanford Company, Richland, Washington.

WHC, 1993c. Radiological Worker II, Initial Training, Course Nurnber 020001 Study Guide, June, 1993. Westinghouse Hanford Company, Richland, Washington.

WHC, 1994a. Fire Protection Program Fiscal Year 1995 Site Support Program Plan, Hanford Fire Department (WHC-SP-1105). D.E. Good. September, 1994.

WHC, 1995b. Hanford Emergency Assessment Resource Manual (HEARM), DOE-0225, Revised September, 1995. Westinghouse Hanford Company, Richland, Washington.

WHC, 1995c. Standards/Requirements Identification Document, Fire Protection Functional Area, Draft C. Dated August, 1995. Westinghouse Hanford Company, Richland, Washington.

WHC, 1996. Standards/Requirements Identification Document, Fire Protection Functional Area, Rev.0, WHC-SD-SRID-002, dated January 10, 1996. 
THIS PAGE INTENTIONALLY LEFT BLANK 


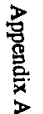

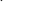


THIS PAGE INTENTIONALLY LEFT BLANK 
Appendix A

Resumes of HFD Needs Assessment Team 
643 E. LAKE ROAD

PENN YAN, NY 14527

(315) $536-3439$
2961 BOWSPRIT LANE

ST. JAMES CIY, FL 33956

(813) $283-2438$

FAX (813) 283-2464

January 1995

John Granito holds a doctoral degree in administration-psychology and he retired in 1987 as Professor and Vice President for Public Service and External Affairs of the State University of New York. Earlier he served as Dean of the Graduate School of Professional Education at the State University at Binghamton. Prior to that he was Vice President at a research institute in New York City.

He first joined a fire department in 1949 and has spent 42 years in, and working with, the fire service. For 21 of those years he was an active firefighter and officer. He has been Supervisor of Fire Training for New York State and Director of the International Fire Administration Institute for the IAFC. He is a member of the International Association of Fire Chiefs, the New York State Association of Fire Chiefs, the Florida Fire Chiefs Association, the International Disaster Research Committee, the National Police Chiefs Association, and other related security groups.

John teaches and lectures at the National Staff and Command School, at the National Emergency Training Center, for the International City Management Association, for many departments, universities, and state and local agencies. He authored the "Management Overview" course for the Federal Emergency Management Agency and taught that course throughout the country.

He is currently consultant and lecturer for the National Fire Protection Association, the ICMA, the Maryland Fire and Rescue Institute, the National Emergency Management Institute, and a number of governmental agencies and private industries. He has been protection and security consultant to the IBM Corporation, the National Transportation Safety Board, and the Agency for International Development. During the past eight years he instructed teams of city and county officials from more than 800 municipalities in emergency planning and management at the National Emergency Training Center.

John is the author of over 150 book chapters, articles, technical monographs and books on the subject of the organization and administration of municipal protection programs. He wrote the chapter on evaluating community fire defenses for the NFPA Fire Protection Handbook, and is co-editor of the ICMA "greenbook" Managing Fire Services. For that book he wrote the chapter on community fire protection. He wrote Fifty Years of Fire Service Management for the NFPA, The Future of the American Fire Service for the U.S. Fire Administration,

Fire Protection

Emergency \& Crisis Managemene

Corporate Security

CONFIDENTIAL CONSULTING SERVICES TO GOVERNMENT, BUSNESS, AND NDUSTRY 
643 E. LAKE ROAD

PENN YAN, NY 14527

(315) $536-3439$
2961 BOWSPRTT LANE

ST. JAMES CITY, FL 33956

(813) 283-2438

FAX (813) 283-2464

Granito Resumé Continued

$-2-$

Strategic Planning for Hazardous Materials for the US DOT, Improving Crisis Decision Making for FEMA, Department Personnel Practices for ICMA, The Review of Fire Suppression Crew Size for NFPA, and a series of fifty department management cases for Chief Fire Executive Magazine and NFPA Fire Command Magazine, over the past several years. $\mathrm{He}$ is the author of the chapter on the future of fire protection for the 1994 edition of The Fire Chiefs' Handbook.

In recent years he has worked with approximately 150 municipalities in the US and abroad, evaluating total protection capability, or special requirements, and developing long-range plans for comprehensive community protection. He surveyed protection throughout Venezuela for that government, hazardous materials incident response in England, and emergency response in Spain and the Soviet Union. He frequently works with architectural firms in developing plans for security and response type structures.

Dr. Granito has experience in planning for fire, rescue, and emergency medical services to achieve effective, yet affordable, protection in places ranging from several million in population to small communities of several thousand. He has planned for and helped implement, in five states, the consolidation of fire/rescue departments in townships and counties seeking a high level of cost effectiveness. Also, he has worked with numerous municipalities in formulating action plans for the cost saving consolidation and sharing of selected functions/resources.

Dr. Granito is the facilitator of the Urban Fire F'orum, sponsored by the National Fire Protection Association. The Urban Fire Forum is a group of fire department executives from the largest cities of the United States, England, Canada and Australia, and focuses on key issues in protection in the 1990 's. In 1991 he completed an extensive review of crew size standards in the US in order to develop valid staffing and operational standards for the fire service, and he serves as technical consultant to the NFPA Fire Department Analysis Project. His column, "First Response", appears in. each issue of the NFPA Journal, and he is consulting editor to the NFPA. $\mathrm{He}$ is a member of the NFPA 1201 Committee on Public Fire Service Organization and Operation. He frequently is asked to speak at conferences and professional meetings. He serves as Principal Public Safety consultant: to MMA Consulting Group, Inc. of Boston, and as excercise controller in. security and protection for the National Emergency Training Center. 
WHC-SP-1180, Vol. 1

\section{GORDON L. VEERMAN}

EDUCATION

CAREER-RELATED

TRAINING

CERTIFICATIONS

WORK

EXPERIENCE
Bachelor of Arts Degree

Fire Science Management

Associate Degree

Arts \& Fire Science Technology

Business and Public Service

National Fire Academy

- Executive Development III

- Hazardous Materials III

Fire Department Instructors' Training

Ansul Fire School

Fire Loss Management School; University of Maryland

American Management Association Seminars

Certified as a Master Fire Service Instructor and Fire Officer II

State of Illinois; Division of Personnel Standards and Education

\section{Argonne National Laboratory Fire Department}

1962 to Present.

Fire Chief since 1976. Physical Security Manager, in addition

to Fire Chief, February 1982-83.

Argonne National Laboratory has a paid force of 28 firefighters and officers and provides fire prevention, fire protection, emergency medical services (paramedics), and hazardous material response to the Laboratory.

\section{East Joliet Volunteer Fire Department}

1956-1971.

Responsibilities included Firefighter, Fire Lieutenant, Fire Captain, and

Chief of the Fire Prevention Bureau. Organized and directed the Fire

Prevention Bureau.

Ioliet Junior College

10 years, part time.

Instructor in the Fire Science Program, including numerous classes in Fire Science: Introduction to Fire Science, Fire Prevention, Fire Investigation, Apparatus, Fire Fighting Techniques, Building Construction, Fire Protection and Suppression Systems, and Fire Administration, all of which are accredited college courses.

Lewis University

Coordinator and member of the Advisory Board in their undergraduate degree Fire Science Management Program. 


\section{Additional Experience}

Consulted extensively in fire protection and safety survey of existing facilities, with types of facilities including nuclear power plants, hydroelectric generating facilities, explosives manufacturing facilities, and high protected risks.

Developed and wrote fire brigade training manuals and basic fire protection engineering course for specialized clients.

Served on consulting team of fire protection experts that investigated and made recommendation to Tennessee Valley Authority after the Brown's Ferry Fire.

Lectured and instructed at numerous Fire Fighting Schools, and for private organizations, including The State University of New York at Binghamton, NY, The National Safety Council, and The International Association of Fire Chiefs.

\section{ORGANIZATIONS}

- National Fire Protection Association

-International Association of Fire Chiefs

-Illinois Fire Chiefs' Association

- Local Fire Chiefs' Organization

- Chairman, Local Mutual Aid Hazardous Material Response Team

- Trustee, New Lenox Fire Protection District

\section{COMMITIEEMEMBERSHIPS}

Secretary for the International Association of Fire Chiefs' Hazardous Materials Committee. Member of the Fire Safety Committee for Department of Energy Headquarters, Washingtor,

D.C., and Chairman of same groups' Fire Department Subcommittee.

Member of the Department of Energy Transportation External Coordination Working Group. (Representing the International Association of Fire Chiefs)

Member of the President Stakeholders Committee, organized by EPA to look at hazardous material regulations at the Federal level.

Member of the Federal Emergency Management Agency. The purpose of this committee is to audit and critique the activities associated with a simulated Nuclear Reactor Accident Emergency.

\section{PUBLICATIONS}

Authored several articles on various fire service related subjects (i.e., pcbs, laser and fire service, SARA Title III, etc.) for the Fire Chief and Fire House magazines.

Quoted on various occasions in USA Today in the areas of hazardous materials emergencies. 
C.E. Snodgrass M.D.

F.A.C.E.P

Address: $\quad 2305$ 43rd Street SE

Payallup, Washington 98373

Telephone: 206-848-0777

Year of Birth: $\quad$ January 7, 1949

Place of Birth: Grangeville, Idaho

U.S. Citizen

Marital Status: $\quad$ Married, two children

Military Service: U.S. Public Health Service

Two years active duty

Education: M.D. University of Washington

College of Medicine

Seattle, Washington

1976

University of Washington

College of Arts and Science

Seattle, Washington

1971 - Major, Zoology

Minor, Swedish

Puyallup High School

Puyallup, Washington

1967

Residency: Pacific Medical Center

San Francisco, California

1976 rotating internship

Training: $\quad$ Advanced Trauma Life Support

Advanced Cardiac Life Support, Instructor

Board Certified Emergency Medicine

Diplomat, American Board Emergency Medicine

Fellow of the American College of Emergency Physicians 
WHC-SP-1180, Vol. 1

Professional Experience:

September 1983 - present

Director of the Emergency Room at Good Samaritan Hospital, 1983-1990

Developed base station at Good Samaritan

Developed trauma receiving center

Paramedic advisor and training officer

National Registry Paramedic examiner

Pierce County select EMS advisory committee, 1986

Trauma Specialist in charge of Tacoma Grand Prix, 1988

Advisor, Pówers Ambulance Service

February 1980 - September 1983

Director of Emergency Services at Northgate General Hospital

Lecturer, North Seattle Community Center

Secretary of Medical Staff

June 1978 - February 1980

Emergency Physician with Copenhaver, Bell and Associates, Tampa, Florida

Volunteer Service: Member, Washington State Trauma Steering Committee, 1989

Chairman, State Trauma Rehab Subcommittee, 1989

Chairman, State Injury Prevention TAC, 1990-1994

Appointed by Governor to State EMS and Trauma Committee, 1990-1994

Charter member, Washington Medical Association Seat Belt Committee

Regional Spokesman, State Coalition against drunk driving

Washington State Medical Association Representative to Senate Law and Justice Committee (testify on sobriety checkpoints), 1992

Washington ACEP panel member, University of Washington Medical School Career Day, 1992

Major contributor and developer of Sober Roadways campaign

Chairman, Washington State Medical Association Drunk Driving Coalition

State EMS and Trauma Committee, 1992-1994

Wrote and developed video on impaired driving for State of Washington:

Lethal Weapon, Liquid Death

Developed "EMS Day" for the State EMS Committee

Board Member, Washington Advocates for Highway and Auto Safety

Member, Pierce County Helmets on Wheels Coalition

Board Member, Think First Council of Washington

Association, Harborview Injury Prevention

Washington Physicians for Social Responsibility

Task Force on Violence

Special Advisor to the Board of Directors, Washington Chapter of the American College of Emergency Physicians, 1992-1994 
Current Local Projects:

Advisor, Puyallup Fire Department, developed paramedic program

Advisor and Medical Officer, Western Washington Fair (eighth largest in nation)

Developed Puyallup Helmets for Kids

Miscellaneous Community Service:

Member committee to elect Senator Marc Gaspard

Medical advisor, community mental health program

Speaker, Good Samaritan Community Healtheare Community Education Member, Puyallup Schools Advisory Council

Medical Staff: $\quad$ Emergency Services Committee

Critical Care Committee

Emergency Room Design Committee

Trauma Committee

EMS and Base Station Committee 
WHC-SP-1180, Vol. 1

\author{
Michael E. Ricketts
}

Education: $\quad$ Whitman College, B.A., 1976

University of Washington School of Law, J.D., 1979

Admitted to Bar: Washington, 1979

United States District Courts, Western District of Washington, 1979

Eastern District of Washington, 1980

United States Ninth Circuit Court of Appeals, 1980

Professional Associations:

Seattle-King County

Washington State

American Bar Association

Practice Emphasis: Trial practice

Insurance law

Subrogation of property losses

Insurance coverage litigation

Product liability

Construction law

Mr. Rickett's practice consists of civil trial work, principally on behalf of property and casualty insurers. His experience includes the defense of bodily injury claims, and he also devotes a substantial portion of his practice to property insurance matters such as subrogation and coverage litigation. He is a former regional editor of the Property Insurance Newsletter for the American Bar Association's Torts and Insurance Practice Section. He has considerable experience dealing with fire claims and with property losses involving product failure, electrical malfunction, construction projects, and spread of fire due to defect in building materials, construction, or design. 
WHC-SP-1180, Vol. 1

\section{ERIC R. ROSENBAUM, P.E., Project Manager}

\section{EDUCATION:}

B.S., Fire Protection Engineering, University of Maryland, 1985

M.S., Fire Protection Engineering, University of Maryland (in progress)

Selected technical courses (e.g., fire dynamics, fire hazard analysis)

\section{EXPERIENCE SUMMARY:}

Corporate Affiliations:

Hughes Associates Inc., 1992-present

Science Application International Corporation, 1991-1992

Rolf Jensen \& Associates, 1985-1992

National Institute of Standards and Technology, 1983-1985

Areas of Specialization:

Fire Hazards/Risk Analysis

Fire Modeling/Analytical Analyses

Large/Small Scale Testing

Industrial/Special Hazards Analyses

Fire Detection/Suppression Analyses

Life Safety Evaluation

Code Compliance

Total Years of Experience: 12

\section{PROFESSIONAL AFFILIATIONS:}

Licenses/Certifications/Memberships:

SFPE (including various standing committees)

NFPA (including NFPA 101 Means of Egress committees)

Salamander Honorary Society

Tau Beta Pi, National Engineering Society

Professional Engineer, Maryland, Virginia, Massachusetts, North Carolina, and Florida

Security Clearances:

DOD Secret
DOE "Q" (Inactive) 
WHC-SP-1180, Vol. 1

CODES AND STANDARDS EXPERIENCE:

DOE/WHC Orders and Procedures:

5480.7A, Fire Protection

5480.23, Nuclear Safety Analysis Reports

6430.1A, General Design Criteria

Engineering Standards/Codes:

NFPA 101, Life Safety Code

NFPA 13, 13R, 13D, Sprinkler Standards

NFPA 72, Fire Alarm Systems

NFPA 92B, Smoke Control

ASTM Fire Test Standard

FM Data Sheets

\section{RELEVANT EXPERIENCE SUMMARY:}

As a senior engineer at Hughes Associates, Inc. (HAI), Mr. Rosenbaum has analyzed code requirements and their intent relating to the fire safe design of DOE structures. Experience includes fire hazard analyses at Building 242A, the 340 Complex, and Building 327 at the Hanford Site. This includes reviewing structures and processes for fire safety. Mr. Rosenbaum performed risk assessments associated with fires in various occupants based on specific fuels. Structures evaluated include hazardous waste processing facilities (e.g., waste evaporators), high hazard uses (explosion potential and flammable liquids), and storage structures. Fire hazard analyses include computational analysis and detailed review of processing to determine elements of compliance with DOE Orders.

Mr. Rosenbaum has been the project manager for HAI for task order contracts at WHC and WSRC. Management experience also includes fire hazard analysis project for the New York and New Jersey Port Authority and architects throughout the United States. Mr. Rosenbaum was also project manager and engineer for the large and small scale fire testing and computational analysis of fires in arrays of solicl waste drums.

As a fire protection engineer for SAIC, Mr. Rosenbaum was acting lead Fire Protection Engineer for Department of Energy, Environmental Restoration and Waste Management Division (EM). He was responsible for early development of a fire protection program, and reviewed and recommended action on exemption requests for EM facilities. Duties also included project manager responsible for analysis of various facilities for fire safety. Occupancies evaluated included nuclear reactors, radioactive material processing facilities and commercial properties such as hotels, offices and dormitories.

As a consulting fire protection engineer at Rolf Jensen \& Associates, Mr. Rosenbaum was the project manager responsible for the design of various types of suppression systems for different occupancies including flammable liquid storage and processing facilities, tire storage areas, department stores and embassies. He performed systems design for automatic sprinklers, Halon, fire alarm, detection and voice communication systems. Mr. 
Rosenbaum identified code requirements that apply to the design of hospitals, mixed use high-rise buildings, atriums and industrial occupancies. This code analysis included negotiating with code officials and developing variances.

\section{PROFESSIONAL REFERENCES:}

Mr. Bud Bucci

Westinghouse Hanford Co.

Building 328, L6-51

2355 Stevens Drive

P.O. Box 1970

Richland, WA 99352

509-376-1735

Mr. Scott S. Allen

Battelle Pacific Northwest Laboratories

Senior Fire Protection Engineer

Health and Safety Section

Battelle Boulevard

Richland, WA 99352

509-376-1042

Mr. Enoch Lipson, R.A.

The Port Authority of New York and New Jersey

Engineer of Projects, Design Division

Engineering Department

One World Trade Center, 73E

New York, NY 10048

212-435-2885 
WHC-SP-1180, Vol. 1

\section{STEPHEN D. THORNE, P.E., Senior Engineer}

\section{EDUCATION:}

B.S., Fire Protection Engineering, University of Maryland

\section{EXPERIENCE SUMMARY:}

Corporate Affiliations:

Hughes Associates, 1995-present

Thorne \& Associates, 1991-1995

Central Intelligence Agency 1985-91

National Institute of Standards and Technology 1982-84

Areas of Specialization:

Fire Hazards Analysis

Fire Risk Assessment

Fire Department Evaluation/Analysis

Fire Protection System Design/Evaluation

Fire/Accident Analysis for Safety Analysis Reports (SARs)

Total Years of Experience: 12

PROFESSIONAL AFFILIATIONS:

Licenses/Certifications/Memberships:

Society of Fire Protection Engineers (SFPE, including Pacific Northwest Chapter President)

National Fire Protection Association (including Means of Egress

Subcommittee 1988-91)

Salamander Honorary Society

Tau Beta Pi Honorary Society

Professional Engineer, Washington, No 28863

Security Clearances:

DOE "Q" (Inactive)

Central Intelligence Agency TOP SECRET

\section{CODES AND STANDARDS EXPERIENCE:}

DOE/ Westinghouse Hanford Company (WHC) Orders, Directives, and Procedures:

DOE Order 5480.7A, Fire Protection

RLID 5480.7, Fire Protection

DOE Order 6430.1A, General Design Criteria

DOE Order 5480.23, Nuclear Safety Analysis Reports 
DOE-STD-3009-94, Preparation Guide for Nonreactor Nuclear Facility Safety Analysis Reports

WHC-CM-4-41, Fire Protection Program Manual

WHC-SD-GN-FHA-30001, Integration of Fire Hazards Analysis and Safety Analysis Report Requirements

DOE Filter Plenum Fire Protection Standard (Draft, Rev. 4)

Engineering Standards/Codes:

NFPA 101, Life Safety Code,

NFPA 101M, Manual on Alternative Approaches to Life Safety

NFPA 13, Installation of Sprinkler Systems

NFPA 72, National Fire Alarm Code

Other codes, standards, and manuals, and methodologies related to facility fire protection \& life safety.

\section{RELEVANT EXPERIENCE SUMMARY:}

Mr. Thorne specializes in fire protection engineering analysis, life safety evaluations, fire department evaluations and fire risk assessment services with emphasis on providing cost effective countermeasures and solutions for controlling or abating fire risks. These tools include analytical methods found in FPETOOL and CFAST and the Society of Fire Protection Engineering Handbook as well as NFPA 101M (Manual on Alternative Approaches to Life Safety). Most recent DOE related project/services include: Preparation of Fire Hazard Analysis Reports for WHC T Plant, WHC Radioactive Mixed Waste Trenches, the Special Case Solid Waste Temporary Storage Facility, the WHC Solid Waste Burial Grounds, and the Tank 241-C-106 Waste Retrieval; His most recent Fire Department work include a DOE Sitewide Fire Department Apparatus Survey as well as a Needs Assessment of the Hanford Fire Department (ongoing); As a DOE fire protection subject matter expert, he reviewed for adequacy and completeness, Standards Requirements Identification Documents (S/RIDs) fire protection functional areas prepared for DOE Tank Farms, New Waste Calcining facility, Fernald facilities, and the Defense Waste Processing Facility (DWPF); He assisted EM-23 in developing a generic fire protection S/RID(Draft); and the DOE Rocky Flats Field Office in preparing field guidance on the preparation of FHAs and Fire Risk Assessments (Draft); As a member of the Technical Review Group, he has reviewed Safety Analysis Reports (SARs) prepared for DOE Hazard Category 1 and 2 facilities with emphasis on fire protection and fire hazard analysis. Facilities include the DWPF, West Valley Vitrification Facility and the In-Tank Processing Facility.

He has completed Hazardous Waste Operations Training, Radiological Worker II training, and respirator fit training/qualification and has performed surveys within radiologically controlled areas.

In addition to DOE facilities work, other recent work includes fire risk assessments and life safety evaluations of select facilities for the General Services Administration (GSA). Evaluations included confidence testing and inspection of fire detection, protection, and alarm systems, and preparation of fire risk assessment reports with recommendations for 
controlling and abating fire risks to an acceptable level. Occupancies evaluated and assessed include business, storage/warehouses, laboratories, mixed use, essential data/communications, and printing and photoprocessing. The use of proven analytical methods and tools such as NFPA $101 \mathrm{M}$ and FPETOOL were used when strict code compliance was inappropriate or not cost effective. He has also provided life safety and fire protection plan review, system testing and inspection services to GSA and other clients.

As the manager of the Central Intelligence Agency's (CIA) fire protection and prevention program, he was responsible for directing the fire protection activities for staff of three fire protection engineers. He advised senior management on fire protection policies, and priorities and conducted fire hazard analyses and Life Safety evaluations of essential Agency facilities and operations.

As a senior engineer for the ClA, he designed fire protection, fire detection and fire extinguishing systems for new construction and renovation projects and reviewed architectural and engineering plans and specifications for compliance with applicable codes/Agency criteria. He also managed Agency facility construction and renovation projects. Projects included asbestos abatement, construction of cafeteria facility, and business office alterations. Other duties included review fire protection shop drawings for compliance with contract plans and specifications as well as conduct briefings on pertinent issues relating to fire protection and life safety.

As a fire protection engineering trainee at the National Institute of Standards and Technology, he assisted in the development of the Fire Safety Evaluation Systern for National Park Service Overnight Accommodations was co-author of the publication on the subject (NBSIR 84-2896). He also utilized computer modeling to evaluate occupant safety and tenability under fire conditions. 


\title{
THIS PAGE INTENTIONALLY
}

\author{
LEFT BLANK
}


1 
THIS PAGE NTENTIONALLY LEFT BLANK 
WHC-SP-1180, Vol. 1

Appendix B

Site Operations and Activities

B-1 


\section{APPENDIX B. SITE OPERATIONS AND ACTIVITIES}

\section{B1.0 100 AREA OPERATIONS AND ACTIVITIES}

The 100 Area encompasses 17,000 acres, which are divided into six main operating areas: $\mathrm{B}, \mathrm{C}, \mathrm{D}, \mathrm{F}, \mathrm{H}, \mathrm{K}$ and N Areas (Figure B-1). These operating areas contain Hanford's nine production reactors, more than 200 inactive support buildings, 110 former waste disposal sites, and 170 acres of surface contamination. As noted earlier, eight of the reactors had been shut down by 1971 and the final reactor shut down in 1987. Only a few facilities are being used at the present time, primarily in support of deactivation work at the N-Reactor and storage of reactor fuels (DOE, 1995a).

\section{B1.1 K Basins}

The $\mathrm{K}$ Area fuel storage basins (i.e. $\mathrm{K}$ Basins) located in the $100 \mathrm{~K}$ area are unlined concrete pools located approximately $1 / 4$ mile from the banks of the Columbia River. The $\mathrm{K}$ Basins were originally built to support K-Reactor operation. Uranium metal fuel with zirconium cladding was used in the $\mathrm{N}$ reactor for its dual mission (i.e. produce plutonium and generate power). The $2100 \mathrm{MTU}$ of remaining spent fuel presently in storage at K Basins was generated from the operation of the $\mathrm{N}$-reactor during the period from 1970 to 1986 . The original plan was to reprocess the fuel at the Plutonium-Uranium Extraction Plant and remove the plutonium for defense purposes. With the changes in national needs and priorities, the fuel was not reprocessed but left in storage. Beginning in 1975, with the need for additional spent fuel storage capacity and later with the termination of $\mathrm{N}$-Reactor operations, spent fuel from $\mathrm{N}$ reactor was transferred to the two K Area storage basins (DOE, 1995a). As the spent waste was brought to the $\mathrm{K}$ Basins, it was loaded into storage and handling canisters and placed in the water-filled basins. Almost 7,500 canisters of fuel are stored at the 100-K Basins, approximately 3,800 in the K-West Basin, and approximately 3,600 in the K-East Basin (the K-East Basin has a history of leaking) (DOE, 1995a). This represents $80 \%$ of DOE's spent nuclear fuel inventory (DOE, 1995b).

\section{B1.2 100 Area Population}

The October 1995 population estimate is as follows:

$\begin{array}{lcc}\text { Area } & \text { Total Personnel } & \text { *Approximate } \% \text { of Personnel on Day Shifts } \\ -100 \mathrm{~B} & 4 & 100 \\ -100 \mathrm{~K} & 313 & 50 \\ -100 \mathrm{~N} & 372 & >80 \\ -100 \mathrm{D} & 4 & 100 \\ -100 \mathrm{H} & 3 & \text { Not Available } \\ -100 \mathrm{~F} & 0 & 0\end{array}$

100 Area Total: 696

* These data reflect personnel whose day shift begins between 0600 and 0830 . It reflects WHC/BCSR/ICFKH personnel data identified in the PeopleCore database search dated $11 / 24 / 95$. 
WHC-SP-1180, Vol. 1

\section{B1.3 100 Area Future Development/Changes}

\section{B1.3.1 General}

The long term future of the 100 Area is assumed to be Open Area or Wilderness. The area along the southern shoreline of the Columbia River is assumed to be restored to a condition compatible with uses such as recreation, wildlife preserves, and historical/cultural preservation. Contamination in surface and subsurface soils will be removed as will contamination that threatens the Columbia River. Use of the ground water is assumed to be restricted (DOE, 1995a).

\section{B1.3.2 100 Area Reactors}

The removal of the eight retired plutonium production reactors is being planned. Haul roads from the 100 Areas to the 200 Areas will be constructed to transport the waste material. The first reactor scheduled to be dismantled is C Reactor by 1999 (DOE, 1995b). Deactivation work at the N-Reactor is expected to be completed by 1997. Storage of reactor fuels is expected to continue until 2004 (DOE, 1995a).

Decontamination of the 100 Area buildings will involve removing 100,000 tons of equipment and pressure washing, surface grinding, and grit blasting more than 50 football fields of floor space. When each reactor is decommissioned, up to 700 cubic meters of asbestos will be removed, and 100 tons of lead shielding surrounding the reactor core must be dismantled, and the intact reactor blocks (each weighing more than 9,000 tons) will be transported over the specially constructed roadways to a reactor block disposal vault on the Central Plateau (roughly 10 to 15 miles) (DOE, 1995a).

Environmental restoration and building decommissioning in the 100 Area will require final disposal for approximately 8 million cubic yards of low-level waste and hazardous materials. It is estimated that 7.6 million cubic yards of contaminated soils will be excavated and replaced (DOE, 1995a). These soils will be transported for permanent disposal in the Environmental Restoration Disposal Facility on the Central Plateau.

\section{B1.3.4 K Basins}

The first priority of the Spent Nuclear Fuel Project is to expeditiously remove the spent fuel from the two fuel storage basins located in the 100-K Area. Plans call for a plan for handling and storing the $\mathrm{K}$ Basin fuel in a new staging/storage facility (Canister Storage Building) on the 200 Area plateau. The plan involves placing the fuel into an overpack container in the $\mathrm{K}$ Basin, conditioning the fuel to dry it, transporting it to the Canister Storage Building and placing it in storage there. Action conditioning operations is expected to begin in fiscal year (DOE, 1995a).

\section{B1.3.5 100 Area Population Projection}

Population projections for the 100 Area through the year 2000 indicate the population to remain between 500 and 525 persons each year (Kaiser, 1995a). 


\section{B1.3.6 Costs}

All remediation, including decommissioning of the remaining buildings, is expected to be completed by 2047 and is an effort that represents $40 \%$ of the estimated cost of environmental restoration at Hanford (DOE, 1995a).

\section{B2.0 200 Areas Operations and Activities}

\section{B2.1 General}

The 200 Area (also referred to as the central plateau), is located on an expansive plateau near the center of the Hanford site (Figures B-2) and encompasses 6000 acres. It contains six chemical processing plants, more than 250 support buildings, several waste disposal sites, and 265 acres of contaminated surface soil. The 200 Area contains all of the liquid waste storage tanks and most of Hanford's waste disposal sites, as well as many support and research facilities (DOE, 1995a). The 200 East Area, 200 West Area, and the 200 Area Corridor (the land between the 200 East and West Areas) comprise the 200 Areas (DOE/RL-92-29). The primary facilities and operations are summarized below.

\section{B2.2 Tank Waste Remediation}

Approximately 350 million liters (92.4 million gallons) of radioactive high-level waste from Hanford Site processes were put into single-shell tanks between 1944 and 1980 . As a result of waste transfers to double-shell tanks, the tanks currently hold about 230 million liters ( 60.8 million gallons) of waste, including low-level, hazardous, or plutonium-contaminated salt cake and sludge. Most of it is now solid, though pockets of liquids and semi-liquids also are in the tanks. There are 12 single shell and six double shell tank farms in the 200-East and 200-West Areas (WHC, 1995b). Sixty-six of the 149 single-shell tanks may have leaked as much as 3.8 million liters (1 million gallons) or more of waste into the nearby soil. In addition to the singleshell tanks, there are 28 newer double shell tanks holding about 90 million liters (23.8 million gallons) of liquid radioactive high-level waste. The first of these tanks was put in use in 1971. No double-shell tanks have leaked to date (DOE, 1995a).

In 1990, all Hanford Site high-level waste tanks were evaluated and organized into four categories of watch list tanks to ensure increased attention and monitoring. Tanks were classified

as ferrocyanide, flammable gas, high-heat, and organic watch list tanks. Two other safety concerns that involve some or all of the tanks include criticality and noxious vapor safety issues. (PNL, 1995)

\section{Ferrocyanide}

The ferrocyanide safety issue involves the potential for uncontrolled exothermic reactions of ferrocyanide and nitrate/nitrite mixtures. Laboratory studies show that temperatures must exceed $250^{\circ} \mathrm{C}$ for a reaction to propagate. The hottest ferrocyanide tank temperature is $530^{\circ} \mathrm{C}$ and decreasing. Of the original 24 ferrocyanide tanks, 18 are now on the watch list. Four were removed in 1993 and two were removed in 1994 . The remaining tanks will be taken off the watch list as core samples are obtained and analytical analyses confirm that the ferrocyanide has decreased in fuel content from hydrolysis and radiolysis ("aging") to acceptable low levels (PNL, 1995). 


\section{Flammable Gas}

The flammable gas tanks safety issue involves the potential release of flammable gases from wastes in selected tanks. In prior years, work controls were instituted to prevent introduction of spark sources in these tanks and evaiuations were completed to ensure that installed equipment was intrinsically safe. The worst-case tank, 241-SY-101, was successfully mitigated in 1994 with the insertion of a mixing pump. The pump is operated up to three times a week to mix the waste and release gases that accumulate in the waste. Hydrogen monitors are being installed on all 25 flammable gas tanks. These monitors, called standard hydrogen monitoring systems, consist of a cabinet equipped with piping and instrumentation that support an on-line hydrogen detector and a "grab sampler" (PNL, 1995).

\section{High-Heat Tank}

This safety issue concerns tank 241-C-106, single shell tank that requires water additions and forced ventilation for evaporative cooling. Without the water additions, which would be discontinued in the event of a tank leak, the tank could exceed structural temperature limits, resulting in potential concrete degradation and possible tank collapse. This tank is on an accelerated program for early retrieval and transfer of waste to a double-shell tank (PNL, 1995).

\section{Organic Tanks}

The organic tanks safety issue involves the potential for uncontrolled exothermic reactions of organic chemicals and nitrates/nitrites and for vapors from semivolatile organic entrained in the waste to exceed the flammability limits. Recent laboratory tests showed that fuel concentrations and temperatures required to support propagating exothermic reactions are comparable to those for ferrocyanide. In addition, moisture levels above $20 \%$ will prevent reactions from propagating regardless of fuel concentrations (PNL, 1995).

Work controls were implemented in 1990 to prevent the introduction of ignition sources to these tanks. In May 1994, vapor sampling and safety analyses were completed that provided the technical basis for closing the unreviewed safety question on the flammability of the floating organic layer in tank 241-C-103. Ten tanks that contained organic complexants were added to the organic tanks watch list following a review of sampling data and waste transfer records (PNL, 1995).

Other work indicates that aging processes have also destroyed or significantly lowered the energy content of the organic tanks. In addition, work by others shows that the more energetic complexants and the primary degradation products of tributyl phosphate are water soluble in saturated nitrate-nitrite salt solutions. Thus, a high percentage of organic chemicals were removed from the single-shell tanks when their pumpable liquid supernatant was pumped out as part of the interim stabilization process for the single-shell tanks (PNL, 1995).

\section{Criticality}

An unreviewed safety question on the potential for criticality in the high-level waste tanks was closed in 1994 by completing additional analyses, strengthening tank criticality prevention controls, and improving administrative procedures and training. The analyses showed that criticality is highly unlikely during storage. All of the single- and double-shell tanks at the Hanford Site contain sufficient neutron absorbers to ensure safe storage; however, additional 
WHC-SP-1180, Vol. 1

sampling and controls will be required for retrieval and pretreatment-related activities (PNL, 1995).

\section{Noxious Vapor}

Some of the Hanford Site tanks contain chemicals that release toxic vapors to the environment. These vapors pose a potential health risk to Hanford Site employees who work in the tank farms. The safety issue stems from an insufficient understanding of the cause of reported exposures of personnel to unacceptable levels of noxious vapors and the concern that, until the vapors in the tanks are well characterized, the risks to worker health and safety cannot be determined or controlled (PNL, 1995).

\section{B2.3 Plutonium Finishing Plant}

The Plutonium Finishing Plant (PFP) complex, located in the 200 West Area, includes nine major buildings and structures in a double fenced security enclosure. The principal structure is the PFP (building 234-5Z) and its main supporting buildings, the Waste Treatment Facility (241-Z) and the Exhaust Ventilation Building, all constructed in 1949. The 234-5Z building is about $54.9 \mathrm{~m}$ (180 feet) wide and $152.4 \mathrm{~m}$ (500 feet) long. It extends from $2.9 \mathrm{~m}$ ( 9.5 feet) below grade to $14.3 \mathrm{~m}$ ( $46.8 \mathrm{feet})$ above grade. It houses the plutonium processing operations as well as the major service and support facilities. The PFP is now used to store special nuclear materials from previous activities. Its current inventory includes over 4,000 kilograms (8818 lb) of plutonium. Special nuclear material contaminates some of the infracture, the soil, and the immediate environment around the plant. The plant also contains over 4,600 liters (1215.2 gal) of organic solutions containing plutonium (DOE, 1995a). Of particular concern is scrap material temporarily stored in gloveboxes (shielded compartments) since the plant was put in standby in 1990. These materials include rags, liquid, and sludge containing plutonium, which are chemically unstable and unsuited for long-term storage (DOE, 1995b).

\section{B.2.4 PUREX}

The Plutonium-Uranium Extraction (PUREX) facility, located in the 200 East Area was originally used to reprocess irradiated fuels for the recovery of uranium and plutonium. The PUREX plant was one of the mainstays in the United States' nuclear fuel separations program, processing irradiated production reactor fuels for the recovery of uranium and weapons- or fuelsgrade plutonium. The PUREX complex is comprised of the main canyon building (202-A), a structure 306 meters (1000 feet) in length and 9.14 meters (30 feet) in width, and 31.7 meters (104 feet) high, and a number of auxiliary structures and facilities, including waste disposal sites and contaminated equipment burial tunnels. In addition, other facilities such as tank farms, cribs, retention basins, etc are in place to support the PUREX facility. The present mission is to establish a passively safe and environmentally secure configuration at the PUREX facility and preserve that condition for 10 years (WHC, 1995b).

\section{B2.5 U Plant}

The Uranium Tri-oxide (UO3) Plant, located in the 200-West Area is part of the U-Plant Complex. The plant consists of 224-U and 224-UA Buildings and storage areas for $\mathrm{UO}_{3}$ products and recovered nitric acid. At the $\mathrm{UO}_{3}$ Plant, uranyl nitrate hexahydrate (UNH), a product of 
PUREX, is converted into uranium trioxide, $\mathrm{UO}_{3}$ (HEARM). Because the $\mathrm{UO}_{3}$ Plant follows up PUREX operations, it has been put into standby mode.

\section{B2.6 B Plant}

The B Plant Project facilities, located in the 200 East Area, consist of the B Plant canyon, the Waste Encapsulation Storage Facility (WESF), and ancillary buildings. Built between 1943 and 1945, B Plant is one of the three original (T Plant, B Plant and U Plant) canyon buildings at Hanford. The main canyon building is $810 \mathrm{ft}$ long and has 40 cells. The WESF is a two-story structure, 157 feet long, 97 feet wide, and 40 feet high. It is partitioned into 8 hot cells, hot cell service areas, operating areas, building service areas, and the storage pool area (DOE, 1995a).

B Plant supplies cooling water and deionized water for pool cells at the WESF. B Plant accepts low-level liquid waste streams and liquid effluents and stores solid waste, all from the WESF. B Plant has been in a standby mode since May 1991; no future mission has been identified. The WESF, however, has an ongoing mission to continue safe storage of the cesium and strontium capsules. The costs in 1989 for continuing operations to ensure safe storage of the capsules and to manage the residual contamination were approximately $\$ 42$ million. The cost of surveillance and maintenance at B Plant has been reduced by $\$ 5$ million per year as a result of prestabilization activities (DOE, 1995a).

\section{B2.7 T Plant}

T Plant, located in the 200 West Area, provides low-level radioactive decontamination services for the Hanford Site. It is comprised of two primary decontamination buildings, and four support buildings (WHC-SD-CP-FHA-002). Among items that are decontaminated are railroad equipment, buses, trucks, automobiles, road-building equipment, and plant process equipment. Items are decontaminated either to release the item for reuse or to reduce the amount of radioactive materials before disposal.

T Plant also stores core 2 fuel from the Shippingport Pressurized Water Reactor (DOE, 1995a), and 2,400 lb of frozen sodium (WHC-SD-CP-FHA-002).

\section{B2.8 Central Waste Storage Complex}

The Hanford Central Waste Storage Complex is an existing and planned series of facilities to centralize the management of solid waste operations (DOE, 1995a). Large volumes of radioactive solid wastes from spent fuel reprocessing and offsite nuclear operations are stored or disposed in the Central Waste Storage Complex located in the 200 West Area and comprises several facilities. Facilities such as burial grounds, trenches, and buildings are use to store and dispose of waste in compliance with RCRA (DOE, 1995b).

\section{B2.9 WRAP}

The Waste Receiving and Processing (WRAP) Module 1 facility is located in the 200 West Area. As designed, the building is a $4806 \mathrm{~m}^{2}\left(51,736 \mathrm{ft}^{2}\right)$ structure intended to characterize, treat and repackage radioactive solid wastes at Hanford. It will also process 
transuranic waste that can be handled without radiation shielding. Construction began in 1994 and is expected to be completed in 1996 (DOE, 1995a).

\section{B2.10 TRUSAF}

The Transuranic Waste Storage and Assay Facility (TRUSAF) is located in the 200 West Area of the Hanford Site and provides approximately $1.068 \mathrm{~m}^{2}\left(11,500 \mathrm{ft}^{2}\right)$ of floor storage space. The facility primarily provides transuranic waste storage and assay operations, currently performing exterior container inspection, real-time radiography inspection, neutron assay for fissile material content, and interim storage in facility storage modules (DOE, 1995a).

\section{B2.11 222-S Laboratory Complex}

The 222-S Laboratory Complex, located in the 200 West Area, provides analytical chemistry support to PUREX, T-Plant, Plutonium Finishing Plant, Tank Farms, B-Plant, as well as other facilities. The Laboratory supports preparation and characterization of radiochemical standards, process development to support plant processes, and process upset conditions. The 222-S Laboratory also has a glass fabrication facility (WHC, 1995b).

The 222-S Building is a two story building of fire resistant reinforced concrete 98.1 meters ( 322 feet) in length and 32.6 meters (107 feet) wide. The $222-\mathrm{S}$ along with eight other support buildings comprise the 222-S Laboratory Complex (WHC, 1995b).

\section{B2.12 Waste Sampling and Characterization Facility}

The Waste Sampling and Characterization Facility (WSCF) was recently constructed and became operational in December 1994. The facility houses an environmental laboratory, a field sampling support facility, and a sophisticated computer system. The computer system provides the capability to track and handle data on thousands of environmental samples and test results from other Hanford analytical laboratories and offsite laboratories. About 80 chemists, chemical technologists and support staff are capable of working at the facility (DOE, 1995b).

\section{B2.13 Liquid Effluent Facility}

The Liquid Effluent Facility (LERF), located in the 200 East Area, provides treatment for industrial wastewater generated in the 200 Area of the Hanford Site. The LERF treats up to 300 gallons per minute of process sewer wastewater from site laboratories, support and inactive facilities, using sulfuric acid and other chemicals (WHC, 1995b).

\section{B2.14 Environmental Restoration Waste Disposal Facility}

The Environmental Restoration Waste Disposal Facility is located on a portion of the land between the 200 East and the 200 West Areas. This facility will provide trench disposal capacity for low-level and hazardous wastes, primarily contaminated soil as needed to accommodate remedial actions. The facility will contain a RCRA-compliant double liner to be installed beneath the contaminated material, and an effluent collection system will be placed between the liners to collect any liquid that may leak through the first liner. Construction of the first phase of the 
Environmental Restoration Disposal Facility started in 1995 and is expected to be completed in July 1996.

\section{B2.15 200 Area Population}

In 1994, the population in the 200 area was estimated to be 5,890 personnel (Kaiser, 1995). In October 1995, the population was estimated to be 3,118 in the 200 East Area, and 1,889 in the 200 West area for a total of 5,007 personnel. Of these over $65 \%$ in the east area and over $75 \%$ in the west area work *day shift hours.

*This data reflects personnel whose day shift begins between 0600 and 0830 . It reflects WHC/BCSR/ICFKH personnel data identified in the PeopleCore database search dated 11/24/95.

\section{B2.16 200 Areas Future Development/Changes}

\section{B2.16.1 General}

From review of site documentation and discussion with knowledgeable individuals future development and/or changes occurring in the 200 Area are consistent with the overall site mission to remedy environmental contamination that has occurred over the past decades. The development and/or changes identified below is not all inclusive but is considered to be representative of the activities expected to occur in the 200 Area in the near future.

\section{B2.16.2 Tank Waste Remediation}

Current plans call for the issuance of tank characterization reports for all 177 Hanford waste tanks by September 1999 . Waste will be retrieved from double-shell and single shell tanks. Retrieval also includes tank farm closure and long-term monitoring. Retrieving waste from double-shell tanks will require designing, constructing, and operating devices to mobilize, retrieve, and transfer wastes out of the tanks. Eventually, such retrieval systems will be installed in all 28 double-shell tanks to mobilize waste solids and pump them out. Waste will be removed from the tanks by pumping slurry (supernate liquid with solids mobilized within it) out of each tank. Four retrieval systems (for four tanks) are planned before 2002. Private firms will remove the waste from the 24 remaining double-shell tanks (DOE, 1995a).

Sluicing techniques will be used to retrieve waste from the single-shell tanks, beginning with a tank having a high heat safety issue. Although Westinghouse Hanford Company is currently developing the single-shell tank waste retrieval system, a private vendor will retrieve waste for the remaining 148 tanks (DOE, 1995a).

The retrieved high-level waste will require pretreatment to reduce its volume for shipment and storage. Pretreatment consists of both physical separation techniques and chemical processing. The remaining large volume of low-activity waste will be immobilized and disposed of at the Hanford Site (DOE, 1995a).

Pretreatment of liquid high-level wastes, performed by commercial firms, will chemically separate such radionuclides as cesium, strontium, and technetium. These radionuclides will be vitrified (solidified) with other high-level waste for offsite disposal. Prior to offsite disposal, the high-level waste sealed in canisters will be transported to an interim storage facility at Hanford 
until the geologic repository is ready to accept them, currently estimated begin in 2035 . The remaining low-activity liquid wastes will be vitrified for disposal in near-surface vaults on the Hanford site (DOE, 1995a).

Several technical issues must be resolved before the tank farms can be closed, including remediation approaches for residual tank wastes and ancillary equipment; the disposal strategy for single-shell and double-shell tanks; a subsidence prevention approach for single-shell tanks left in place; and a decision about using surface barriers. Under the current schedule, a tank closure plan will be submitted by December 2004; closure of an operable unit or tank farm will begin by 2012; all single-shell tank farms will be closed by September 2024; and all double-shell tank farms will be closed by 2032 . The tank closure plan will determine the levels and methods of long-term monitoring that will be required for the tank farm areas after 2032 (DOE, 1995a).

\section{B2.16.3 Plutonium Finishing Plant}

The plant's infrastructure is beyond its design lifetime; is costly to maintain; and contains special nuclear material which can be hazardous to workers, the environment, and the public. Stabilization of the PFP by fiscal year 2002 has been identified as a major activity milestone for Nuclear Materials \& Facility Stabilization Activities (DOE 1995a). Beyond the temporary storage of special nuclear material and laboratory support, no future use of the Plutonium Finishing Plant facilities has been confirmed (DOE, 1995a).

Special nuclear material (as well as scrap materials (PNL, 1995)) is stored at the PFP pending a national decision on plutonium disposal. Until that decision has been made, however, the plant must maintain security on the plutonium at all times. For planning purposes, the plant's storage mission is assumed to continue until 2025. Deactivation is scheduled for 2025 and has been identified as a major activity milestone for Nuclear Materials \& Facility Stabilization Activities. Actual decommissioning of PFP is planned for 2050 (DOE, 1995a).

In addition, Hanford has been consolidating unirradiated plutonium and highly enriched uranium at the Plutonium Finishing Plant for several years. When the unirradiated and non-selfprotecting irradiated fuel from the Fast Flux Test Facility is moved there, the plant will have nearly all of Hanford's unirradiated special nuclear material except the low enriched uranium (DOE, 1995a).

\section{B2.16.4 PUREX}

Personnel are currently deactivating the complex to establish a safe and environmentally secure configuration that can be preserved for a 10-year horizon. The completion of PUREX deactivation by 1998 has been identified as a major activity milestone for Nuclear Materials \& Facility Stabilization Activities (DOE, 1995a). The ten year time frame represents the typical duration expended to defined, authorize and initiate follow-on decommissioning and decontamination activities (WHC, 1995b). The facility can then be classified as non-occupied, and decontamination and decommissioning activities can proceed. Hazardous and radioactive materials will be removed from the facilities or stabilized sufficiently to ensure long-term safety and regulatory compliance. When deactivation is complete, the facilities will be locked and maintained with minimum entry requirements (DOE, 1995a). 
WHC-SP-1180, Vol. 1

\section{B2.16.5 U Plant}

Future plans for the U-Plant complex were not identified in the 1996 Baseline Environmental Management Report. Development plans issued August 1993 identify the schedule for decommissioning to be 2004 to 2015 (DOE/RL-92-29).

\section{B2.16.6 B Plant}

B Plant proper will be stabilized and transitioned to the Environmental Restoration Program. Stabilization activities will include deactivating systems; removing hazards such as acid waste; reducing effluent flows; removing equipment such as nine 8000 -gallon vertical chemical tanks, piping, conduit, ductwork, and spare parts; and reducing internal and external radiological contamination zones. The WESF is expected to continue to store cesium and strontium capsules until about 2011. Current plans assume the cesium and strontium will have been removed by 2011. An engineering study is under way to determine the best way to isolate the two facilities from each other so they can be deactivated independently. Assuming that the B-Plant and the WESF can be isolated, B-Plant would be deactivated. WESF is currently scheduled for deactivation approximately 15 years after B-Plant. Deactivation is expected to take 5 years for B-Plant and 3 years for the WESF (DOE, 1995a).

\section{B2.16.7 T Plant}

T Plant primarily provides low-level radioactive decontamination services for the Hanford Site. No changes to its primary mission have been identified.

\section{B2.16.8 Central Waste Storage Complex}

Transuranic waste containers have been retrievably stored in 25 trenches in four burial burial grounds in the 200 Areas. Design work for retrieval of transuranic waste containers is expected to begin in 1996. Retrieval will be split into three phases: (1) Phase 1, retrieving the portion of the stored waste expected to be intact and stored in a single burial ground trench, (2) Phase 2, handling the remainder of retrievably stored waste in trenches, and (3) Phase 3 caisson retrieval, removing remote-handled waste from burial ground caissons. Phases 1 and 2 will remove mainly contact-handled transuranic waste in 55-gallon drums and large metal and fiberglass-reinforced plywood boxes; however a variety of containers and some remote-handled waste are expected to be encountered (DOE, 1995a).

As part of the solid waste program, the central waste complex is expected to receive lowlevel, low-level mixed, and hazardous wastes resulting from deactivation activities (DOE, 1995a).

\section{B2.16.9 WRAP}

WRAP Module 1 is designed to process 2,625 drums of retrieved wastes; 2,100 drums of newly generated transuranic waste; and 2,100 drums of newly generated low-level waste per year for a total of 6,825 drums per year. Also, the facility is designed to provide nondestructive examination/nondestructive assay of 70 standard waste boxes of newly generated transuranic per year. Operation is scheduled for 1997 (DOE, 1995a). 


\section{B2.16.10 TRUSAF}

The facility primarily provides transuranic waste storage and assay operations, currently performing exterior container inspection, real-time radiography inspection, neutron assay for fissile material content, and interim storage in facility storage modules. No changes to its primary mission have been identified.

\section{B2.16.11 222-S Laboratory Complex}

The 222-S Laboratory primarily provides analytical chemistry support. No changes to its primary mission have been identified.

\section{B2.16.12 Waste Sampling and Characterization Facility}

The Waste Sampling and Characterization facility houses an environmental laboratory, a field sampling support facility, and a sophisticated computer system. No changes to its primary mission have been identified.

\section{B2.16.13 Liquid Effluent Retention Facility}

The Liquid Effluent Retention Facility provides treatment for industrial wastewater generated in the 200 Area of the Hanford Site. No changes to the primary mission have been identified.

\section{B2.16.14 Environmental Restoration Waste Disposal Facility}

Construction of the first phase of the Environmental Restoration Disposal Facility started in 1995 and will be completed in July 1996, with the facility fully operational by October 1, 1996. This facility will provide trench disposal capacity for low-level and hazardous wastes as needed to accommodate remedial actions over the next 30 to 40 years (DOE, 1995a).

Informal discussions between Bechtel and HFD personnel indicate that beginning fall, 1996, contaminated dirt and demolition materials will be hauled from the 100 Area to the 200 Area Environmental Restoration Disposal facility at the rate of 62 truckloads per day with each truck hauling one 20 cubic yard container of waste. By sometime in calendar year 1997, a second shift will be added and will be expected to make the same number of truckloads per day.

\section{B2.16.15 Other Proposed Projects/Uses}

\section{B2.16.15.1 Canister Storage Building}

Current plans call for a Canister Storage Building to be located in the 200-East Area of Hanford, contingent on the Spent Nuclear Fuel Environmental Impact Statement Record of Decision. This building will handle and store the K Basin fuel. Current plans are to use a facility that already been partially completed to support the Waste Vitrification Project. During FY 1996, the design of the Canister Storage Building will be complete and construction will be in progress. Current estimates for the interim storage period are approximately 40 years. The 
Richland Operations Office has taken action to allow for extension to 70 years. After this interim storage period, the Canister Storage Building will be closed and turned over for decontamination and decommissioning (DOE, 1995a).

\section{B2.16.15.2 Remote-Handled Transuranic Waste}

Currently, there is no capability for processing newly generated remote-handled transuranic waste. However, negotiations are currently underway to provide this capability. Among the alternatives that have been considered are converting existing Department facilities, constructing either a single or modular facilities, and converting a commercial nuclear reactor (built but never operated) at the Hanford Site. Fiscal planning assumes that design activities would be initiated in FY 2003 and would last 3 years. After the design phase, construction would begin in FY 2006 and would be completed in FY 2008. Processing would begin in FY 2009 (DOE, 1995a).

\section{B2.16.15.3 Hanford Waste Vitrification Plant}

The high-level Hanford Waste Vitrification plant will process high-levei radioactive waste into glass which will be poured into stainiess-steel canisters. The construction of the plant started in April 1992, but was halted and rescheduled to continue in June 2002 (DOE, 1995b).

\section{B2.16.15.4 US Ecology}

Informal discussions between HFD management representatives and a representative of US Ecology on February 27, 1996 indicate that presently there are approximately 13 million cubic yards of material stored as low level radiological waste. The US Ecology representative indicated that additional waste is expected to come to be received at the rate of 80,000 to 120,000 cubic feet per year, and that deliveries will average 25 to 30 tractor trailer loads per month.

\section{B2.16.16 200 Area Population Projection}

Population projections for the 200 Area prepared in September 1992 estimate a total population of 7,395 personnel in 1995 and 8,625 personnel in 1998 (DOE/RL-92-29). More recent estimates indicate an existing population of 4,400 in 1995 with a general trend toward reduction by the year 2000 to a population of between 4,110 and 3,700 personnel (Kaiser, 1995).

\section{B3.0 300 Area Description}

The 300 Area is a 115-acre industrial area just north of the city of Richland (Figure B-3) and contains approximately 99 facilities (Kaiser, 1995c).

\section{B3.1 Existing 300 Area Operations and Activities}

The facilities in this area have been used for fabrication of reactor fuel assemblies, reactor research and development, metal working, chemical process development, and other research and development sponsored by the Department of Energy. 
Many of the buildings in the 300 Area are still used for research and development, while others are currently being cleaned out and refurbished for new uses (DOE, 1995a).

Most of the significant facilities (i.e. $340,308,324,325,337$ and the $\mathrm{N}$-reactor fuels) facilitates contain radiological materials (PNL, 1995 FP assessments). Much of the contamination found within the 300 Area is very similar to what might be found in any industrial area in the United States (solvents, petrochemicals, etc.). However, radioactive materials were also introduced into the environment through pipeline leaks, spills, airborne releases from shops, burial of process wastes, and release of liquids into ponds. The bulk of all contamination is concentrated in buildings and in approximately 50 acres of soil within the main industrial area (DOE, 1995a).

\section{B3.2 N Fuels Reactor Fuel Fabrication and Storage Facility}

The 300 Area N Reactor Fuel Fabrication and Storage Facility provides storage for uranium fuel. Buildings included as part of the facility included: building 303-A, 303-B, 303-E, 303-G, 3712, and 3716. The facility stores as much as 1900 metric tons of uranium (WHC, 1995b).

\section{B3.3 315 Building}

The 315 Water Filtration Plant and Support Buildings take water from the Columbia River, filter and disinfect it for supply to the 300 Area as sanitary irrigating, and process water. Chlorination is the method used to disinfect water. The plant maintains a minimum inventory of liquid chlorine of about $900 \mathrm{~kg}(2,000 \mathrm{lb})$. The maximum inventory is two full, ton containers or $1,800 \mathrm{~kg}(4,000 \mathrm{lb})$ (WHC, 1995b).

\section{B3.4 325 Building}

The Applied Chemistry Building (Building 325) building is 89.2 meters (272 feet) in length and 86.9 meters ( 285 feet) in width and approximately 12.2 meters ( 40 feet) in height. It houses laboratories and specialized facilities for work with nonradioactive materials as well as work with microgram to kilogram quantities of fissionable materials and megacurie activities of other radionuclides. 325 operations have historically included microgram to kilogram quantities of fissionable materials and megacurie quantities of other radionuclides. Current programs involve smaller inventories of radionuclides. The 325 building also includes general purpose chemical laboratories, a high level radiochemistry facility, a shielded analytical laboratory and a fissionable material storage room. The general purpose laboratories characterize fuel, single-and double-shell tank wastes, environmental samples, and samples from various other programs. The radiochemistry facility includes areas for cells, cask-handling, storage, and the catalyzed electrochemical plutonium oxide dissolution process for dissolving plutonium oxide and leaching plutonium-containing scrap and waste (WHC, 1995b).

\section{B3.5 324 Building}

The Waste Technology Engineering Laboratory (Building 324) is 79.2 meters (260 feet) in length, 71.6 meters ( 235 feet) in width and approximately 13.4 meters ( 44 feet) in height. The 
Laboratory provides a diversified capability for study of radioactive and non-radioactive processes from laboratory to pilot scale. It contains chemistry laboratories, hot cells, glove boxes, and support facilities (DOE, 1995c). It also houses resources used in the examination and mechanical testing of irradiated specimens (WHC, 1995b).

\section{B3.6 327 Building}

The Post-Irradiation Testing Laboratory (327 Building) is 215 feet in length, 140 feet in width, and approximately 35 feet in height. It provides shielded, ventilated, and specially equipped cells for physical and metallurgical examination and testing of irradiated fuels, concentrated fission products, and structural materials. The irradiated fuel examined consists primarily of breeder reactor test fuel pins containing plutonium oxide and uranium oxides. Other fuel forms such as metal, carbides, and nitrides are handled occasionally (WHC, 1995b).

\section{B3.7 331 Building}

The Life Science Laboratory (331 Building) is $65.5 \mathrm{~m}(223 \mathrm{ft})$ in length, 130 feet in width and approximately $10.7 \mathrm{~m}$ (35 ft) in height. The building is used to conduct research in chemical exposures, carcinogens, and radiation biology. There is no radioactive waste storage. The first floor contains a toxicology exposure laboratory, a cobalt irradiation room, an electron microscope suite, and research laboratories; the second floor contains the ventilation and exhaust equipment; the third floor contains small animal facilities, low- and high-level radiochemistry laboratories, life sciences research laboratories, and associated storage and change areas (WHC, 1995b).

\section{B3.8 337 High Bay Wing/3718-M}

The 337 High Bay Wing is approximately $58.5 \mathrm{~m}$ (192 ft) in length, $232.2 \mathrm{~m} \mathrm{(76} \mathrm{ft)} \mathrm{in}$ width and $29.0 \mathrm{~m}$ ( $95 \mathrm{ft}$ ) in height. The 337 High Bay Wing is a laid away facility designed to perform full scale tests of pumps and valves to be used in the liquid metal (sodium ( $\mathrm{Na}$ ) and sodium/potassium $(\mathrm{NaK})$ ) circulation loops for the FFTF reactor. It provided equipment and facilities for sodium storage and purification, inert gas supply, computerized data handling and a controlled environment for tests in support of the Breeder Reactor Program. The large work spaces are currently being used as a robotics demonstration area. Adjacent to the 337 High Bay Wing is the $3718-\mathrm{M}$ Sodium Storage Building which stores approximately $157,950 \mathrm{~kg}$ $(351,000 \mathrm{lb})$ of sodium (WHC, 1995b).

\section{B3.9 340 Building}

The 340 Building receives and processes radioactive liquid and associated solid wastes in the Radioactive Liquid Waste System (RLWS). It is used for temporary storage of packaged solid radioactive waste (generated from (RLWS operations only), a staging area for hazardous waste, and decontamination of low-level contaminated equipment. The building is also used to load liquid waste into rail cars for shipment to the 200-Areas for transfer to liquid waste underground storage tanks.(WHC, 1995b, DOE, 1995f). 


\section{B3.10 Treated Effluent Disposal Facility}

The 300 Area Treated Effluent Disposal Facility was completed in July 1994. This facility became operational in December, 1994 to handle 300 Areas laboratory waste water. The facility contains commercial-quality treatment equipment to remove solids, organic, and metals, as well as equipment for $\mathrm{pH}$ adjustment. Chemicals used in the treatment process include ferric chloride, sodium hydroxide, sulfuric acid, and hydrogen peroxide (DOE, 1995f). The treated liquid effluent will meet EPA standards and be discharged into the Columbia River (DOE, 1995b)

\section{B3.11 Plutonium Fuels Utilization Program}

The Plutonium Fuels Utilization Program (309 Building) has been in a minimum cost surveillance mode for several years and is now being prepared for transfer to the Environmental Restoration Program.

\section{B3.12 Other Buildings}

The following buildings contain research laboratories which may store radioactive, hazardous chemicals or both. The types of hazardous materials and inventories vary depending on the projects: $305 \mathrm{~B}, 314,318,320,321,323,326,331,329,3708,3730,3720,3718 \mathrm{E}, 3718 \mathrm{G}$, $306 \mathrm{E}, 305,308,309,328,3705,3706,335,335 \mathrm{~A}, 336,377,384,306 \mathrm{~W}$,

\section{B3.13 300 Area Population}

In 1994, the population in the 300 Area was estimated to be 2,450 personnel. In October 1995, the population was estimated to be 1,869 personnel (Kaiser, 1995). From review of information found within the database, approximately, $90 \%$ of the 300 area population work during day shift hours.

*This data reflects personnel whose day shift begins between 0600 and 0830 . It reflects WHC/BCSR/ICFKH personnel data identified in the PeopleCore database search dated 11/24/95. It should be noted that the database reflects a population of 589 , significantly below the estimate of 1,869 personnel cited above.

\section{B3.14 300 Area Future Development/Changes}

\section{B3.14.1 General}

The 300 Area waste sites, materials and facilities will be remediated to allow industrial and economic transition opportunities. The Federal government may retain ownership of land in and adjacent to the 300 Area, but may lease land for private and public uses to support regional industrial and economic development.

Restoration of the 300 Area, including decommissioning activities, is expected to be complete by 2047 (DOE, 1995a). 


\section{B3.14.2 Hazardous Materials User Facility (HAMMER)}

The Hazardous Materials Management and Emergency Response (HAMMER) user facility is a centralized regional training and education center under construction at the Hanford Site. At this 80 -acre facility, hazardous materials and emergency workers will be trained in state-of-the-art response procedures. Xavier and Tulane Universities are developing the curriculum and providing the accreditation (DOE, 1995a).

\section{B3.14.3 300 Population Projection}

Population projections for the 300 Area indicate a slight decline during fiscal years 1996 and 1997 and stabilizing at between 1,710 and 1,425 persons by 1998 and remaining between these levels through the year 2000 (Kaiser, 1995).

\section{B3.14.4 Costs}

The estimated cost of restoration of the 300 Area represents 5 percent of the total environmental restoration cost for Hanford (DOE, 1995a).

\section{B4.0 400 Area Operations and Activities}

\section{B4.1 General}

This area is approximately 15 kilometers (9 miles) north of Richland (Figure B-4). The 400 Area contains the Fast Flux Test facility (FFTF), and several related support facilities formerly involved in the liquid metal reactor program (WHC, 1995b).

FFTF, is the largest, most modern, liquid metal-cooled test reactor in the world. Originally constructed to support the U.S. Liquid Metal Fast Breeder Reactor Program, the FFTF has demonstrated its ability to perform fuel and material tests in support of both national and international fast breeder reactor programs, produce medical and industrial isotopes, perform materials tests for the fusion and space programs, perform passive safety tests, and provide customized neutron environments to meet customer needs. In December 1993, the DOE ordered the FFTF to be placed in a radiologically and industrially safe shutdown condition. This shutdown transition is expected to take approximately five years. FFTF contains 980,000 liters (259,000 gallons) of liquid sodium contained within the primary and secondary loops of the plant (WHC, 1995b).

\section{B4.2 400 Area Population}

In 1994, the population of the 400 Area was estimated to be 590 personnel. In October 1995, the population was estimated to be 503 personnel. It is estimated that more than $80 \%$ work during *day shift hours.

*These data reflect personnel whose day shift begins between 0600 and 0830 . It reflects WHC/BCSR/ICFKH personnel data identified in the PeopleCore database search dated 11/24/95. 


\section{B4.3 400 Area Future Development/Changes}

\section{B4.3.1 General}

Extensive assessment of the 400 Area has not yet been initiated. However, the reactor and associated facilities are expected to be decommissioned beginning in 2001, with the bulk of the area made available for private uses. The current assumption is that the Fast Flux Test Facility itself will be dismantled, decontaminated, and the reactor core will be entombed at its current location. Wastes removed from the 400 Area during building decommissioning are assumed to be disposed of in the Environmental Restoration Disposal Facility (DOE, 1995a).

\section{B4.3 400 Area Population Projection}

Population projections for the 400 Area indicate a steady decline to between 345 and 225 persons by the year 2000 .

\section{B5.0 600/1100 Area Description}

\section{B5.1 General}

The 600 and 1100 Areas have been used primarily for nonweapons support operations (offices, bus garages, buffer spaces, research, warehouses, etc.) and have been very lightly developed (DOE, 1995a).

The 1100 Area occupies approximately 720 acres in the southern-most portion of the Hanford site (Figure B-5) (DOE/RL-93-58). The 1100 Area serves as a central warehousing, vehicle maintenance, and transportation and distribution center for the entire Hanford Site.

\section{B5.2 1100 Area Population}

In 1994, the population in the 1100 Area was estimated to be 720 personnel. In October 1995, the population in the 1100 Area was estimated to be 563 personnel. It is estimated that greater than $95 \%$ of the personnel work during *day shift hours.

*These data reflect personnel whose day shift begins between 0600 and 0830 . It reflects WHC/BCSR/ICFKH personnel data identified in the PeopleCore database search dated 11/24/95.

\section{B5.3 600 Area Population}

In 1994, the population for the 600 Area was estimated to be 405 personnel. In October 1995 , the population in the 600 Area was estimated to be 380 personnel. It is estimated that greater than $70 \%$ of the personnel work during *day shift hours.

*These data reflect personnel whose day shift begins between 0600 and 0830 . It reflects WHC/BCSR/ICFKH personnel data identified in the PeopleCore database search dated 11/24/95. 


\section{B5.4 600/1100 Area Future Development/Changes}

\section{B5.4.1 General}

Recent strategic planning documentation indicates that excess land within the 1100 area may be targeted for transition to non-Federal ownership .

Remediation of the interior area of the Hanford Site (i.e. the 600 Area) will be completed to the same standards as the 100 Area, even though most of this acreage will be under the Department of Energy's continued control. Only a few, minor projects are required, primarily to address storage areas, abandoned tanks, and solid waste burial areas from very early Hanford operations (DOE, 1995a).

\section{B5.4.2 LIGO}

In February, 1992, the Hanford Site was selected by the National Science Foundation as a preferred site for their Laser Interferometer Gravitational-Wave Observatory (LIGO). The facility will detect cosmic gravitational waves for scientific research (DOE, 1993). The facility is expected to be completed in 1998 (DOE, 1995b).

\section{B5.4.3 600 Area Population Projection}

Population projections for the 600 Area indicate the population to decline in 1996 and 1997 and then remain relatively stable with between 200 and 230 persons by the year 2000 (Kaiser, 1995).

\section{B5.4.4 1100 Area Population Projection}

Population projections for the 1100 Area indicate the population to decline in 1996 and 1997 and then remain relatively stable with between 465 and 380 persons by the year 2000 (Kaiser, 1995)

\section{B6.0 Other Area Operations and Activities}

The Hanford Site also contains the following facilities that are not owned and/or operated by DOE/RL and its site contractors. HFD is obligated to provide Emergency Services to these facilities.

\section{B6.1 500 Area (WPPS)}

The Washington Public Power Supply System (WPPSS), operates a publicly owned commercial nuclear power plant, Washington Nuclear Power Plant No. 2 (WNP-2). The facility is located on approximately 1,089 acres, leased from the Federal government on the eastern side of the site, near the Columbia River and about 15 kilometers $(9$ miles) north of Richland. The power plant has a generating capacity of 1,112 megawatts (MW). This facility is operated in accordance with U.S. Nuclear Regulatory Commission (NRC) licensing requirements and rules (WHC, 1995b). From discussions with the WPPSS fire protection engineer, the area has an 
estimated working population of approximately 1200 people of which approximately $2 / 3$ thirds work day shift hours.

\section{B6.2 U.S. Ecology}

Washington State has a 99-year lease on 404.7 hectares (1,000 acres) along the south border of the "corridor" area. The State has subleased 40.5 hectares (100 acres) to California Nuclear, Inc. (U.S. Ecology), who operates this site for the disposal of commercial low-level nuclear waste. While it is not officially part of the 200 Areas, state leased land is served by the 200 Areas infrastructure (DOE/RL-92-29).

\section{B6.3 Richland Specialty Extrusions}

Richland Specialty Extrusions, an aluminum design and manufacturing company, leases a portion of the 313 building, located in the 300 Area, from the Federal Government. The facility is operated as a metalworking facility.

\section{B7.0 Site Infrastructure Changes/Modifications}

There are significant changes to site infrastructure that are being planned. Changes which could impact the required resources and services of the HFD are identified below.

\section{B7.1 Steam}

Steam, or some other energy source, will be required to support existing and new facilities. Alternatives are being evaluated for replacing the aging central steam plants and reducing steam requirements in the 200 and 300 Areas. Natural gas(as well as other alternatives) and a decentralized system are among the alternatives being considered to replace coal-fired steam production (DOE, 1995b).

\section{B7.2 Construction of new HFD Station Facilities}

Construction of a combined station in the 300 Area which will house station 3 and the city of Richland as well as a new 200 Area Fire Station is being considered. Project L-094, Emergency Services Facilities Options Study, Value Engineering Study Report, dated August 28, 1995 outlines options for redeployment of equipment and personnel to adjust to the changing Hanford mission. Options being considered include the following:

- A replacement fire station servicing the 200 Area with departmental headquarters to include the function of fire department management, administrative, technical services, fire prevention, and training personnel. Redeployment of 100 Area fire station equipment and personnel to the new 200 Area fire station.

- A replacement fire station serving the 300 Areas, and possibly first response for north Richland, with response personnel and equipment. 
Due to the estimated cost, in excess of $\$ 20 \mathrm{M}$, the project was initially submitted as a series of line items. It has been validated but remains unfunded. Presently, the project has been tabled pending completion of the HFD Needs Assessment.

\section{B7.3 Safeguards and Security, Combined Dispatch Center}

The emergency response requirements for the site (security, fire and emergency control) have changed as a result of the cleanup mission. The proposed Hanford Emergency Alarm Dispatch System is a planned project to consolidate industrial security and emergency dispatch centers. This project is intended to reduce maintenance and operating costs and replace inadequate dispatch equipment (DOE, 1995b).

\section{B7.4 Railroad}

Railroad hauling requirements are expected to increase significantly as the cleanup mission progresses. The railroad network is required by all programs for receipt and movement of commodities (e.g. construction materials, contaminated soils, and closure materials) onsite and offsite during the cleanup mission. The existing rail system in the 200 Areas will not accommodate the number of cars that have been forecasted by the programs. Additional railroad sidings are expected to be required to handle the projected increase in the number of railcars (DOE, 1995b).

\section{B7.5 Roads}

The road network north of the WYE Barricade is expected to require major upgrades to support construction, operation, and disposal activities. The shift in location of major work centers, significant construction and disposal hauling requirements, and the age and load design of existing roads drives this upgrade (DOE, 1995b).

Construction of a new access road from SR 240 to the 200 West area was completed in December 1994 to alleviate traffic congestion and associated safety risks during peak traffic flows. A four-lane high is planned to be constructed to the 200 East Area to permanently resolve traffic concerns (Project L-102). It is expected that outer area traffic will continue to increase, in addition to significant increases in construction worker and heavy equipment traffic during the next 10 years (DOE, 1995b). 
WHC-SP-1180, Vol. 1

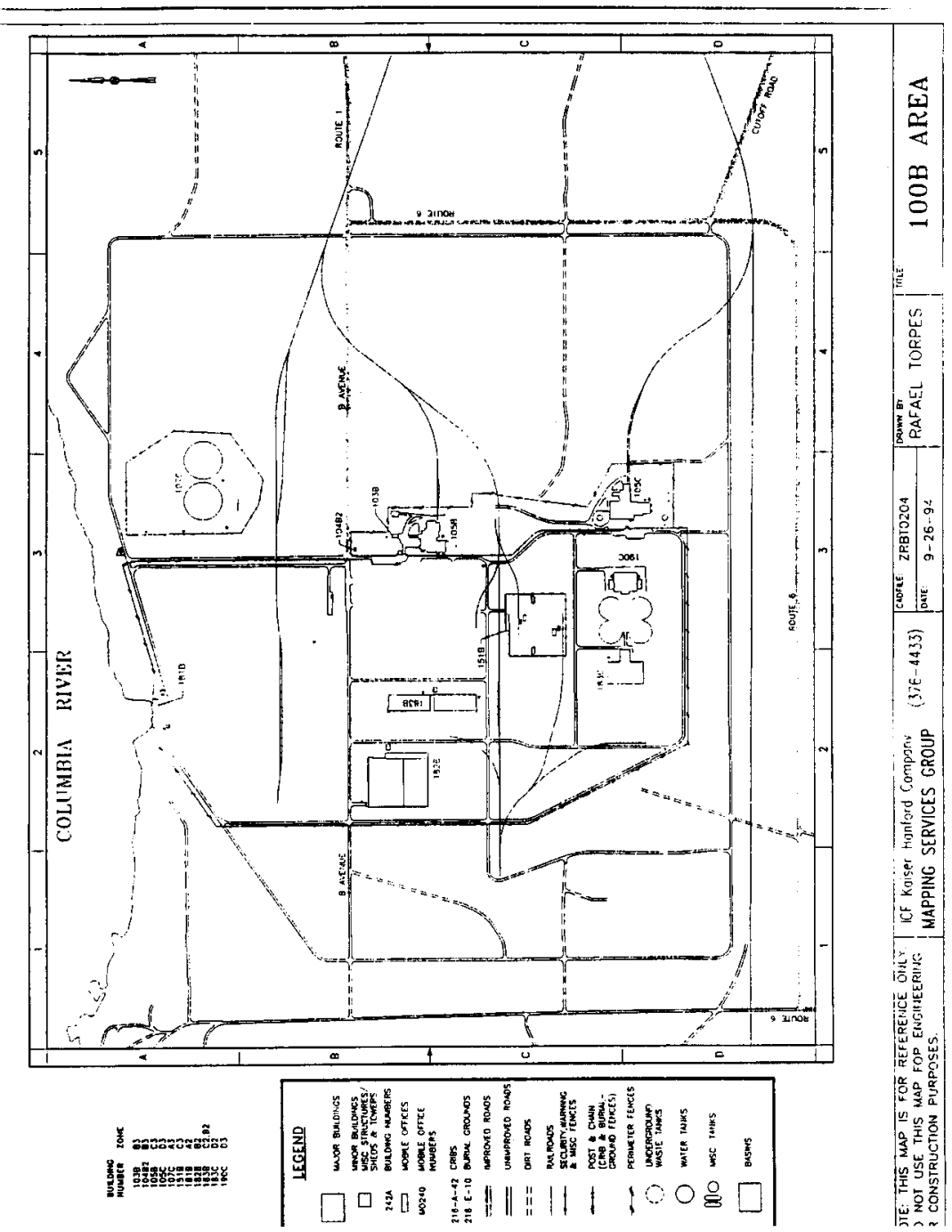

Figure $\mathrm{B}$ - 1a 
WHC-SP-1180, Vol. 1

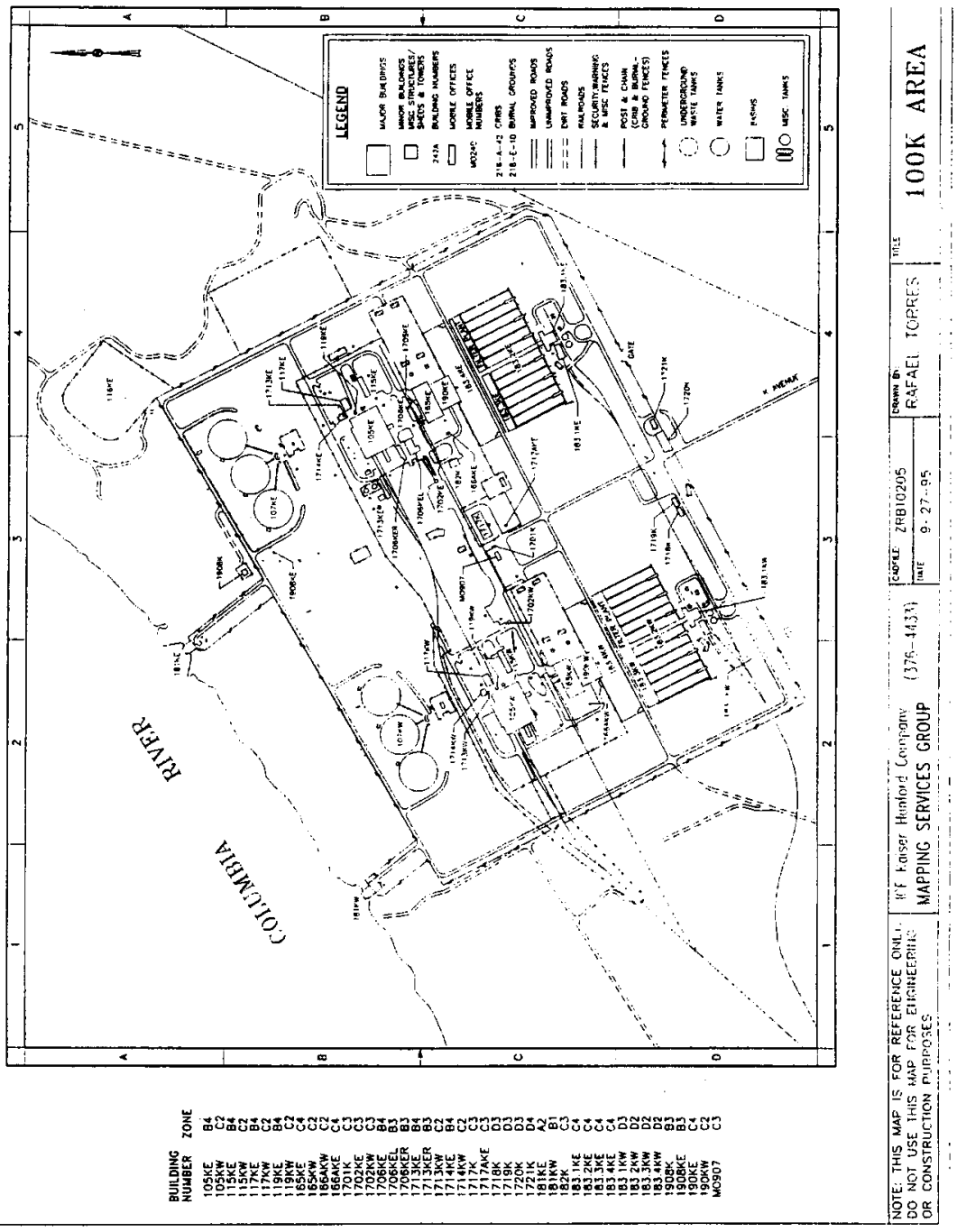

Figure B - 1b 
WHC-SP-1180, Vol. 1

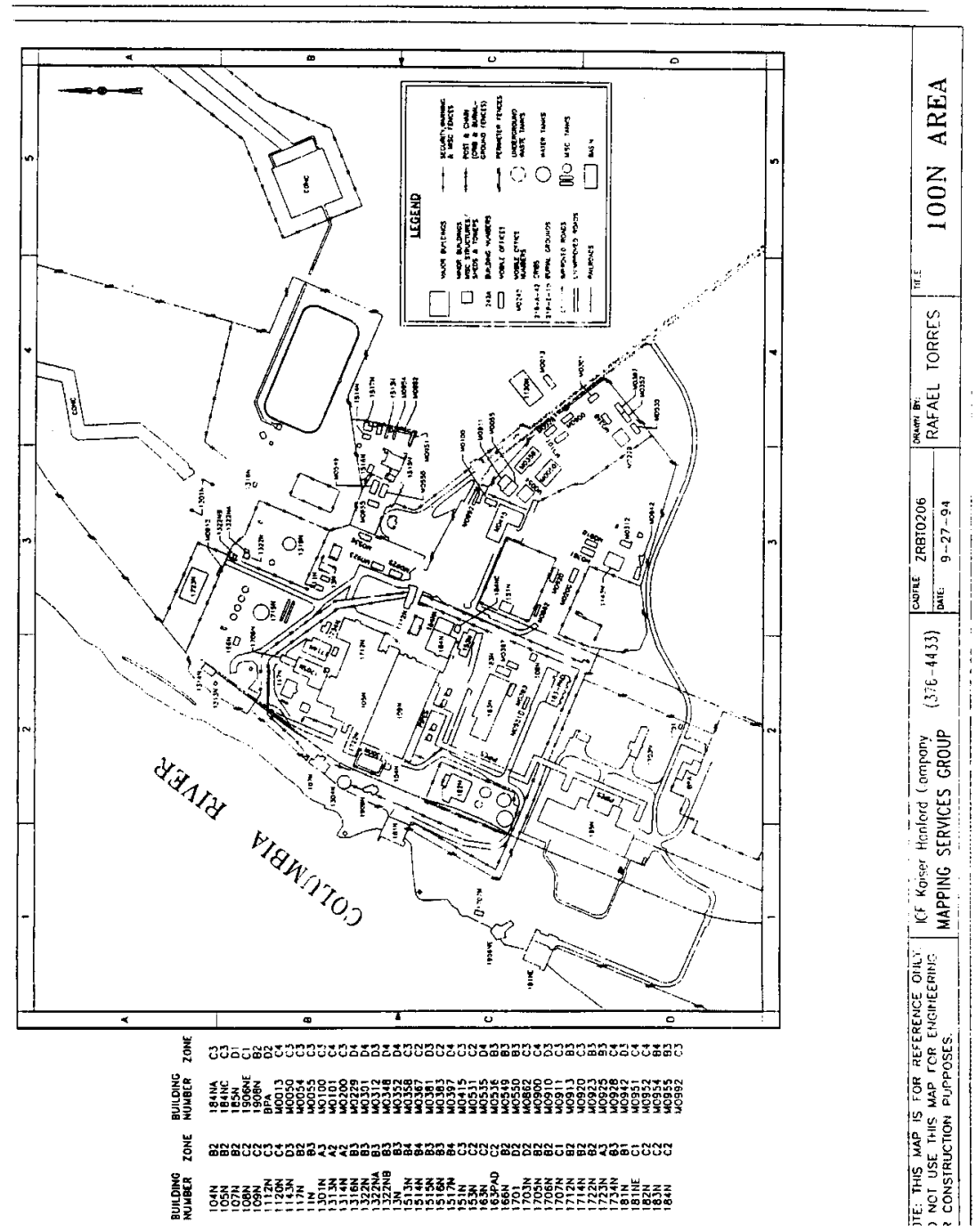

Figure B - 1c 
WHC-SP-1180, Vol. 1

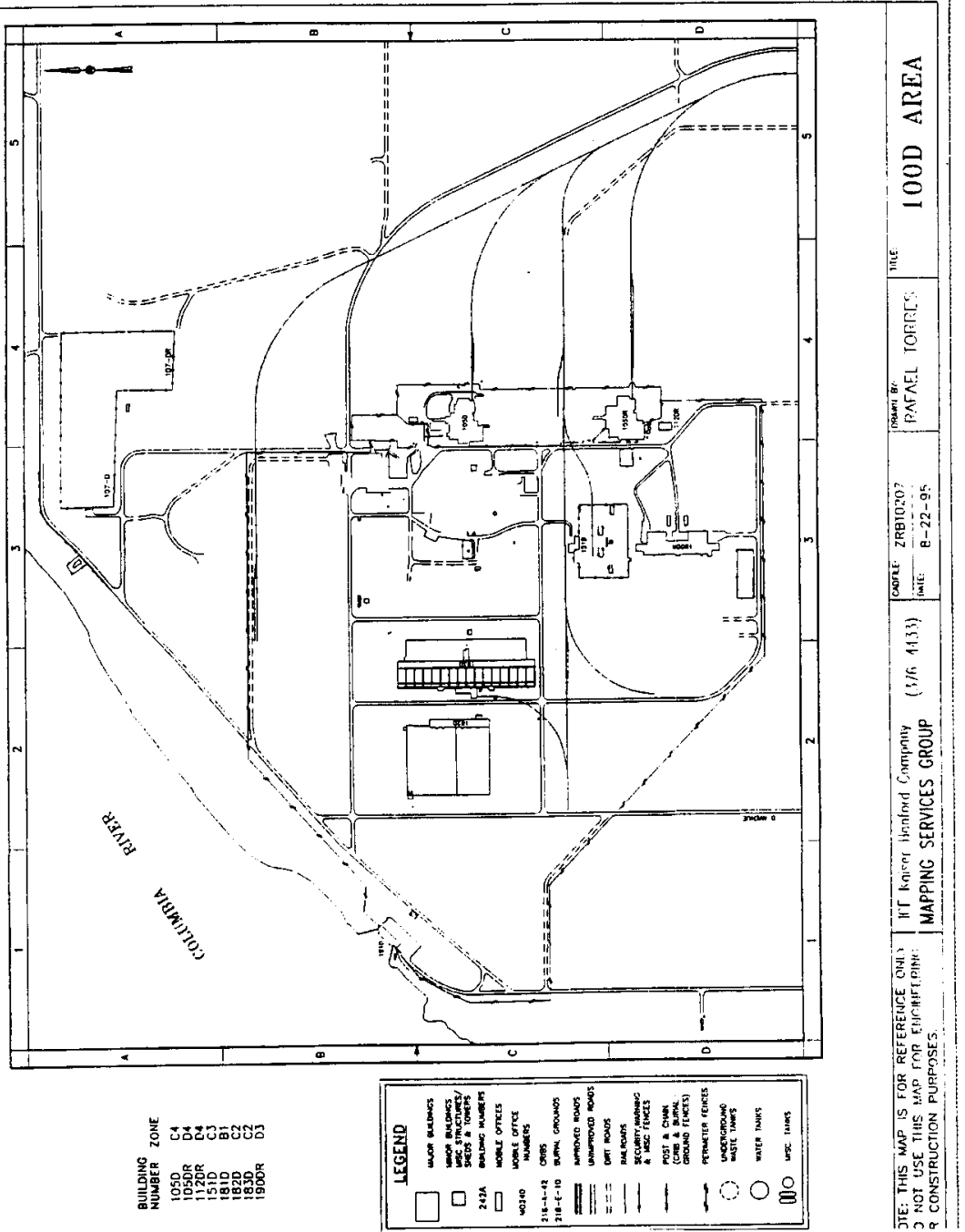

Figure B - 1d 
WHC-SP-1180, Vol. 1

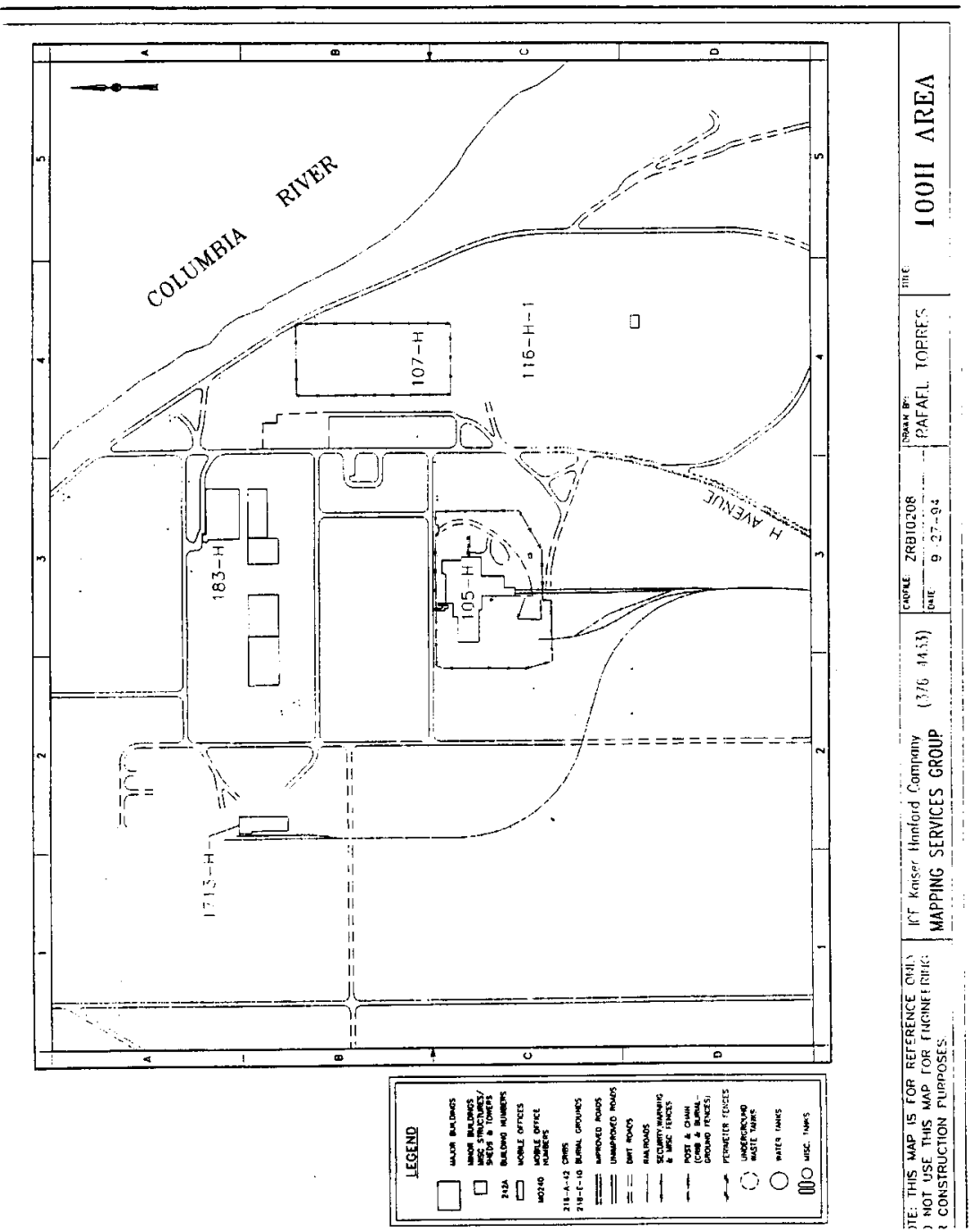

Figure B - le 


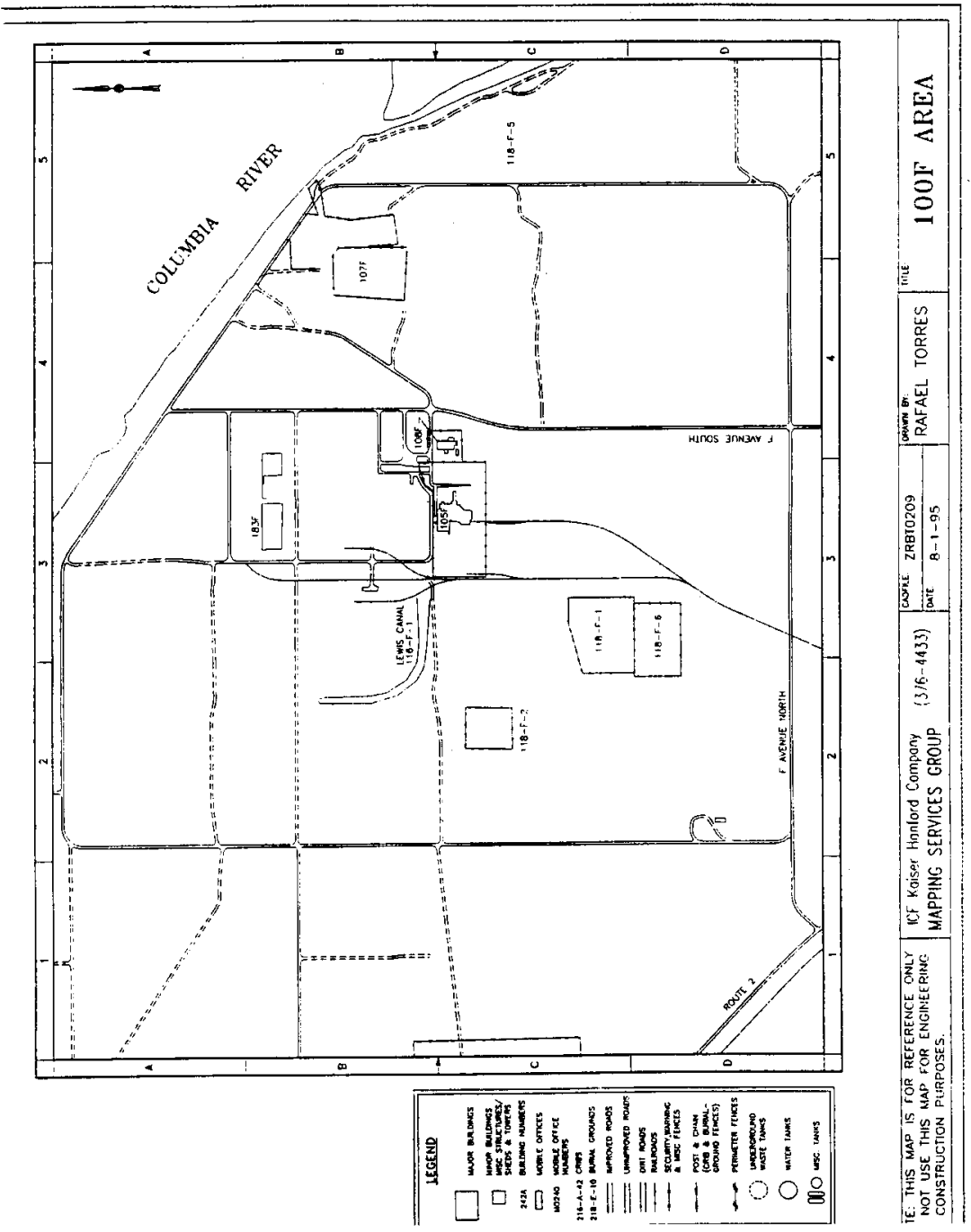

Figure B - If 


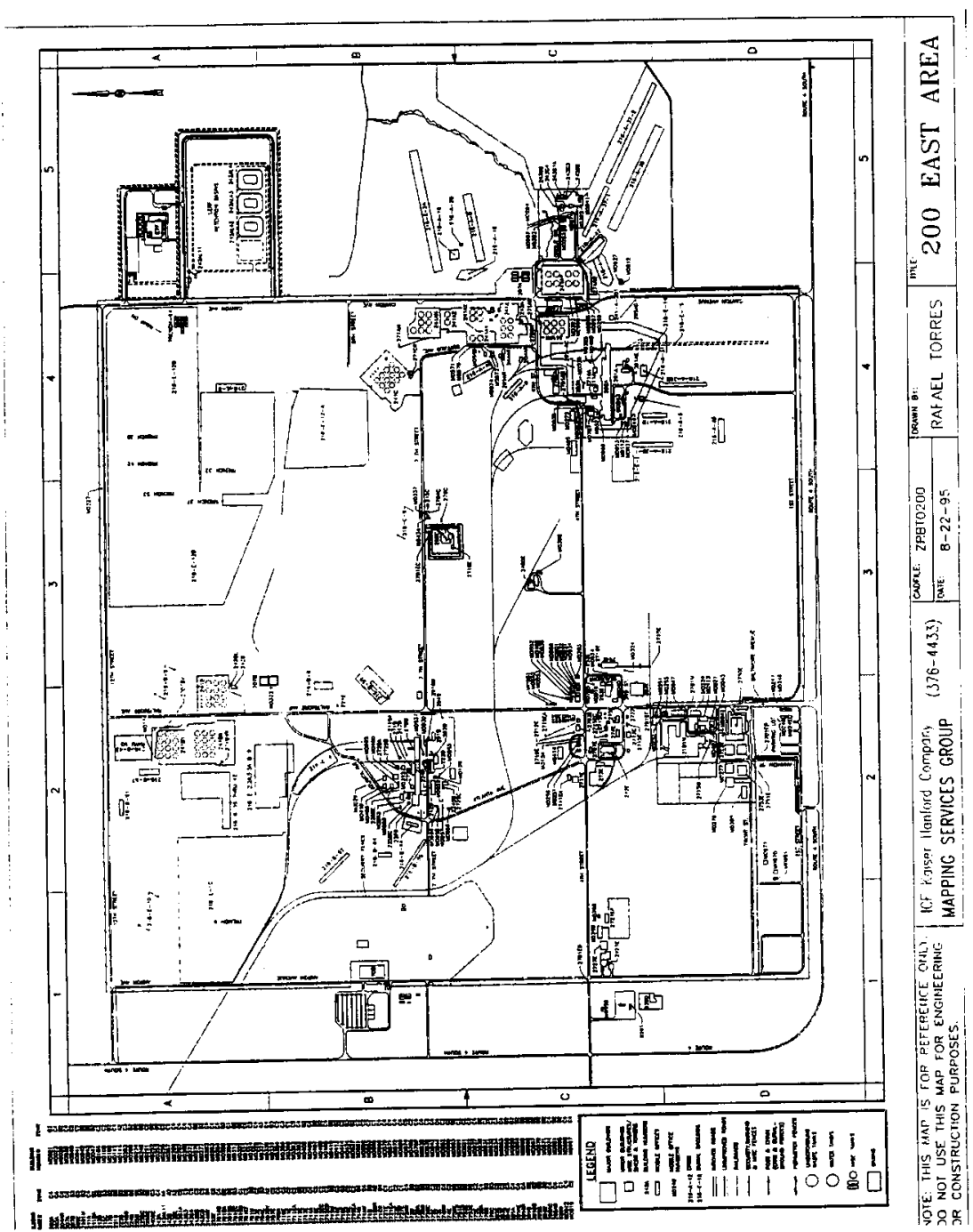

Figure $B-2 a$ 


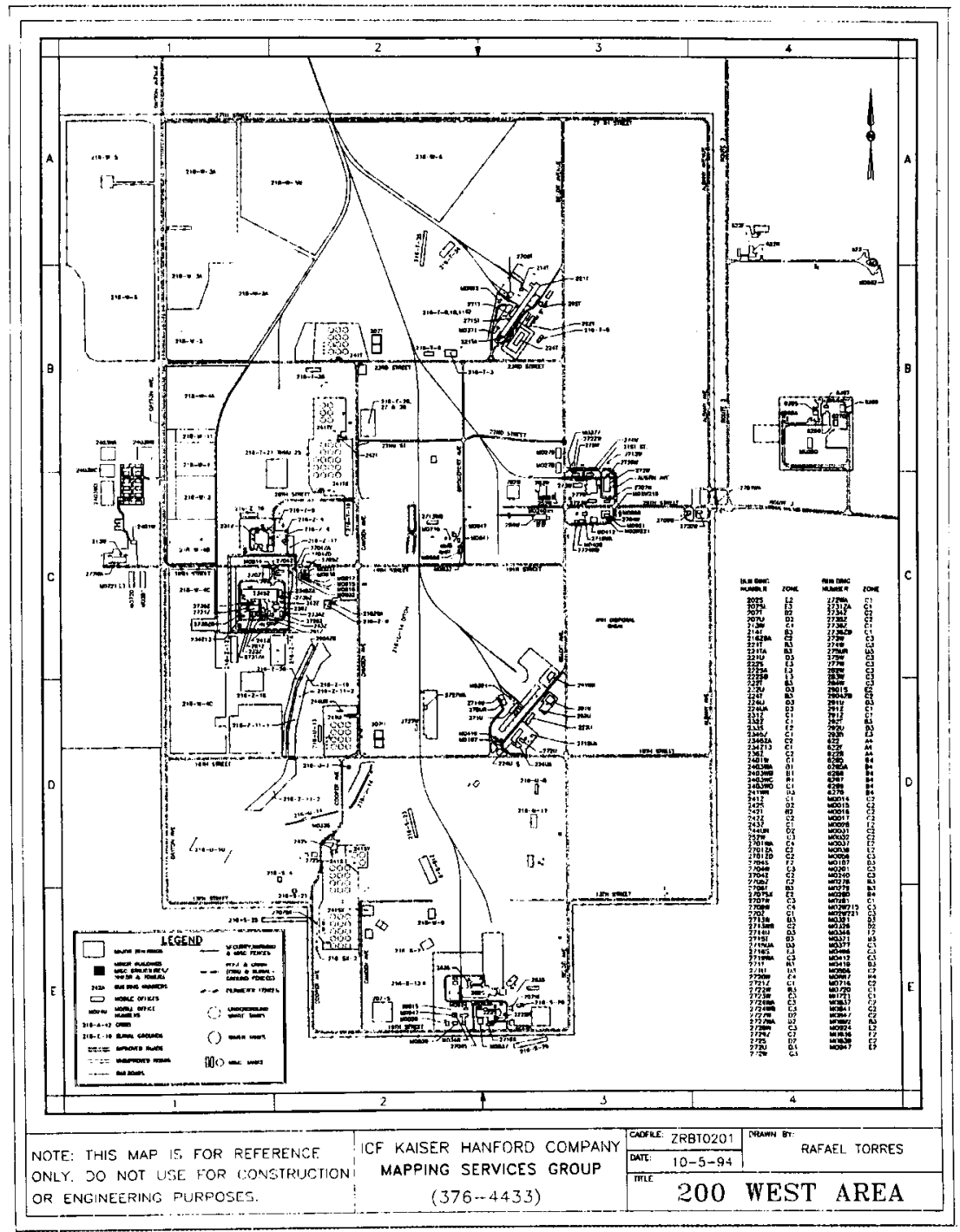

Figure $B-2 b$ 


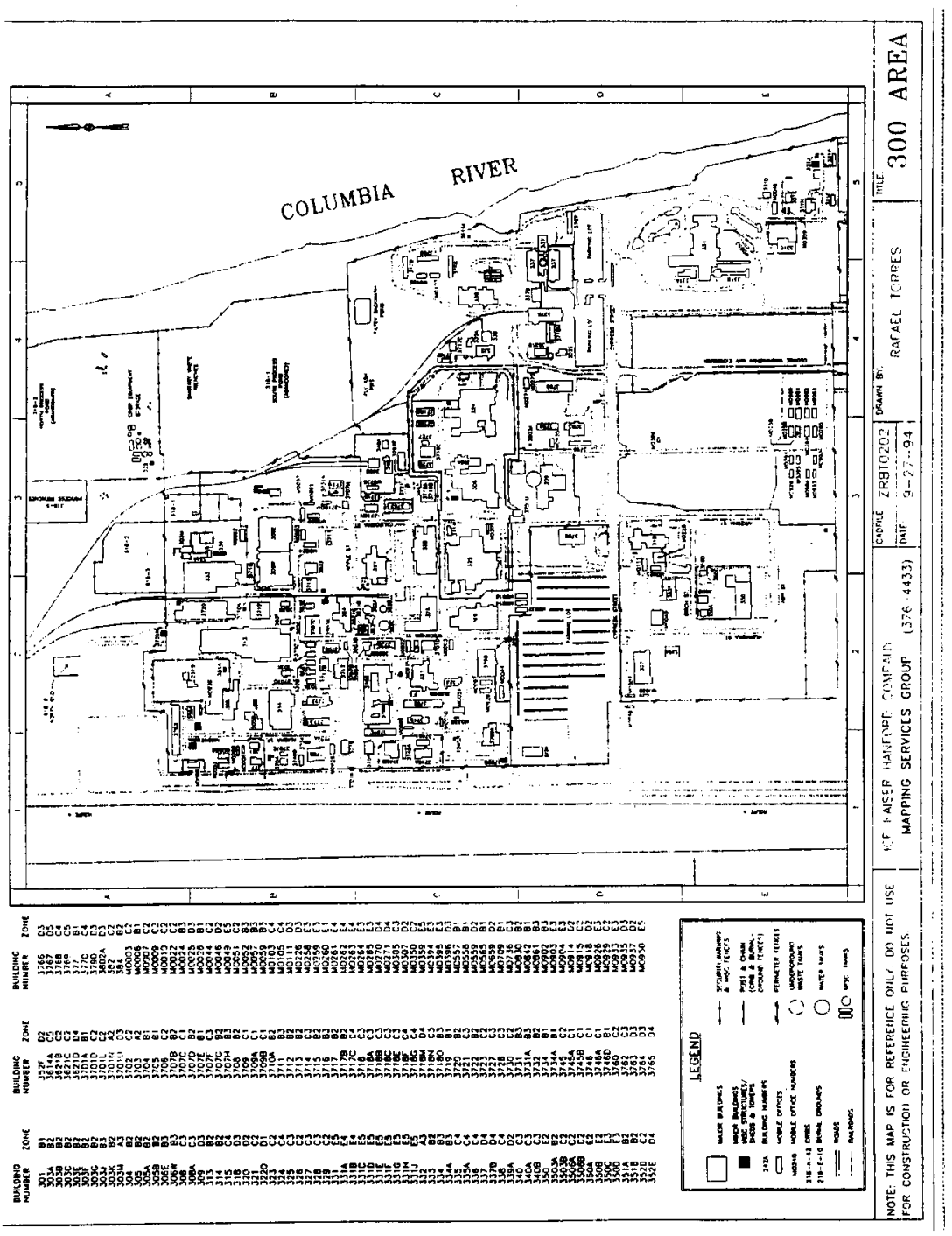

Figure B - 3 
WHC-SP-1180, Vol. 1

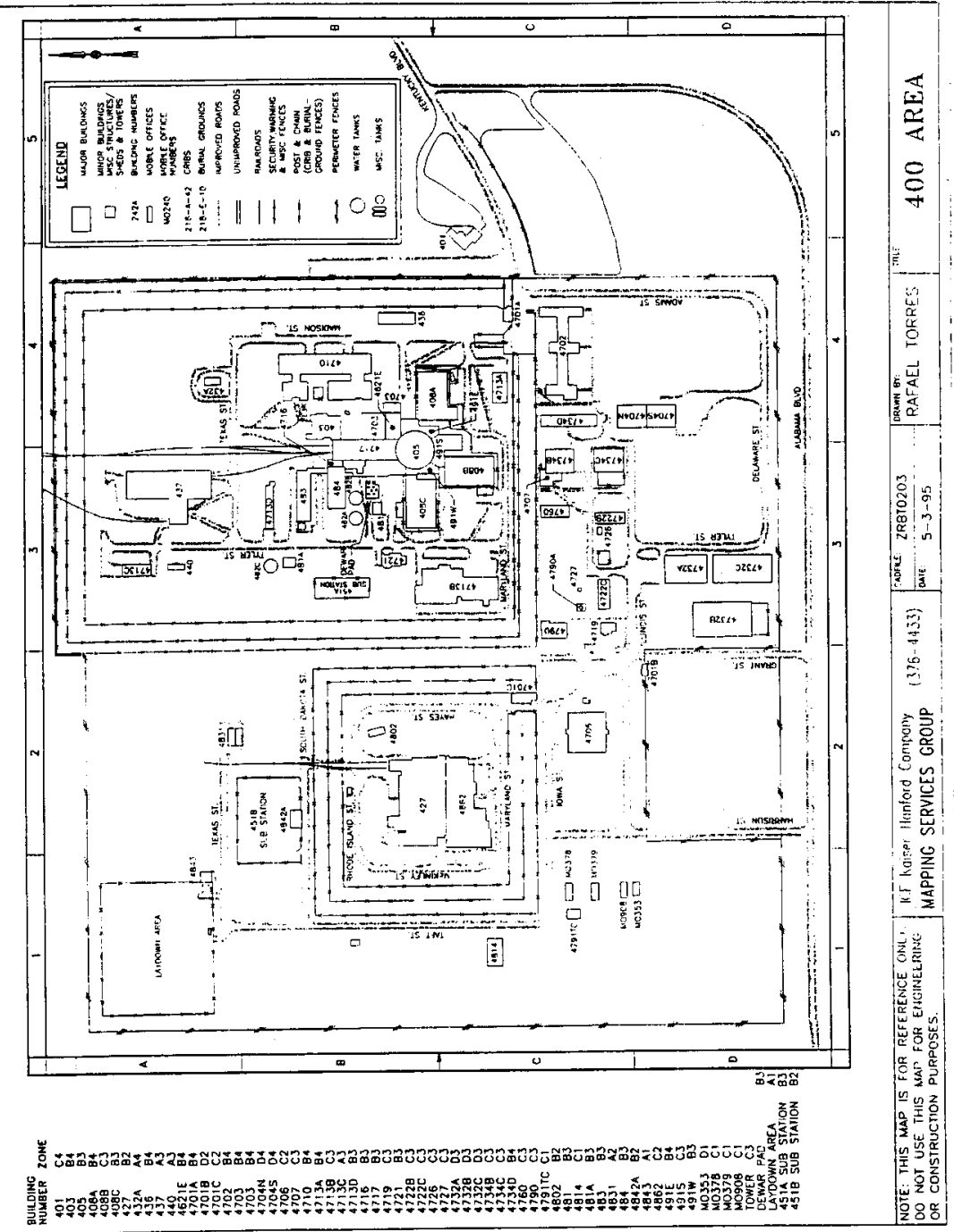

Figure B - 4 


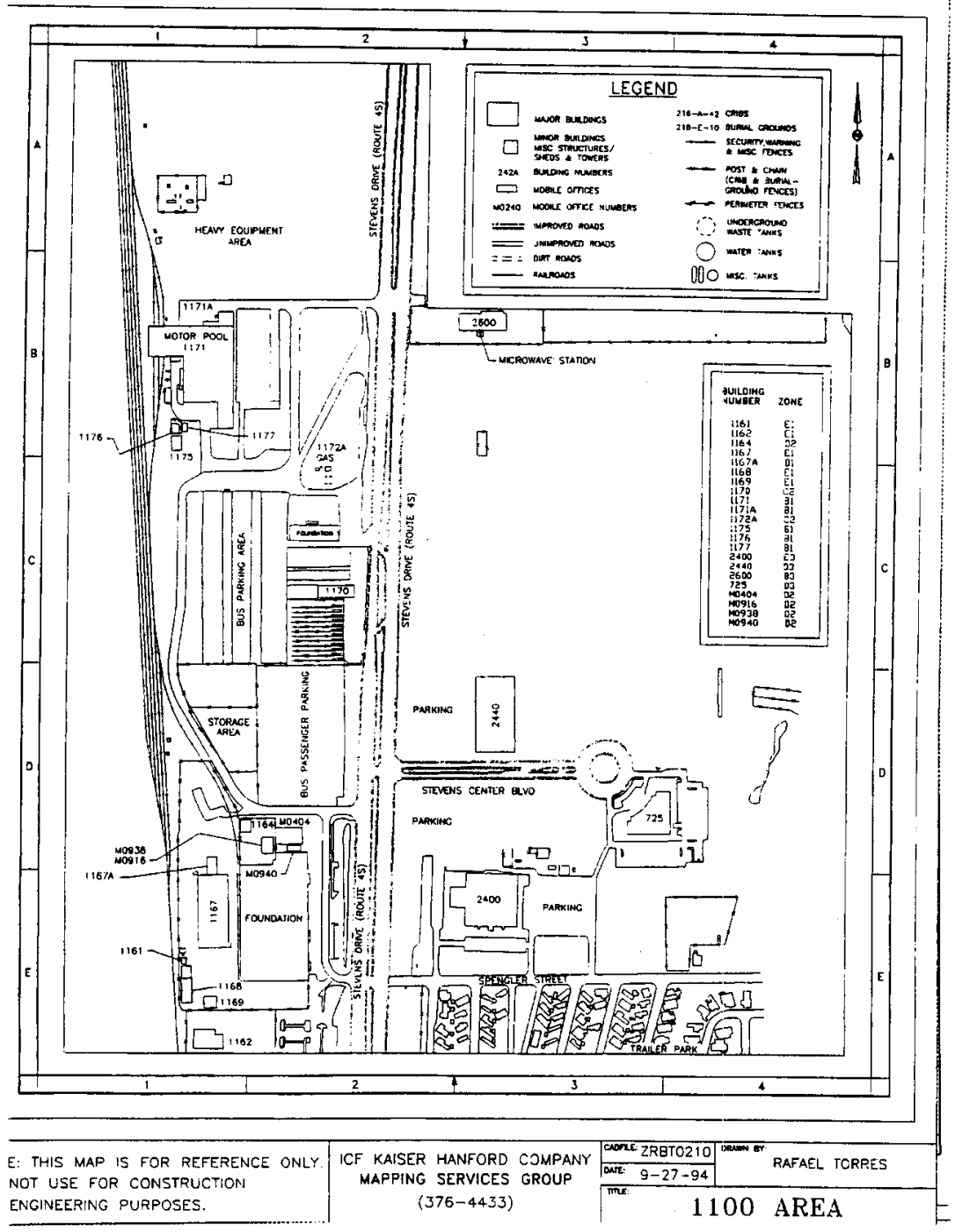

Figure B - 5 
THIS PAGE INTENTIONALLY

LEFT BLANK 
WHC-SP-1180, Vol. 1

Appendix C

Risks On and Off-site

by Facility/event Identification 
Appendix C, Hazard Identification, is a summary of representative hazards and events which exist or could exist at the Hanford site which are likely to require HFD control or mitigation. The hazards and associated consequences were identified from facility and operational reports. analyses, and assessments. These documents rarely identify HFD control or mitigation. No documents were identified which require HFD control or mitigation in order for the applicable facility to operate within its established safety basis. Nevertheless, HFD control or mitigation of the event is anticipated to minimize the consequences of the accident or event.

\section{Explanation of Hazard Identification Tables}

The reviewed documentation varies in description of events and consequences. For example, some consequences relating to nonradiological releases are categorized in terms of Emergency Response Planning Guidelines (ERPG). Definitions of ERPGs are provided in table 7-1. Alternatively, they may be described in terms of emergency action levels as defined in table 7-2. Releases may also be described in terms of concentration at a given location (receptor), often the nearest site or facility boundary, for a given set of meteorological conditions. Pasquill stability classes are often used to define meteorological atmospheric conditions and typically range from $A$ to $F$. Often, the maximum concentration is associated with ' $F$ ' stability. Hazardous material concentration may be given in parts per million (ppm) or mass per unit volume concentration (e.g. $\mathrm{mg} / \mathrm{m}^{3}$ ). Others will categorize the event in terms of probability and severity. Examples of probability and severity are identified in table 7-3. For radiological events some documents characterize the event in terms of the effective dose equivalent (EDE) in rem at a specific location, often the nearest site boundary. 
Table C7-1 Emergency Response Planning Guidelines for Nonradiological Releases (DOE/RL-94-02, May 1995)

ERPG-1

ERPG-2

ERPG-3
The maximum airborne concentration below which it is believed that nearly all individuals could be exposed for up to one hour without experiencing other than mild transient adverse health effects or perceiving a clearly defined objectionable odor

The maximum airborne concentration below which it is believed that nearly all individuals could be exposed for up to one hour without experiencing or developing irreversible or other serious health effects or symptoms that could impair their abilities to take protective action.

The maximum airborne concentration below which it is believed that nearly all individuals could be exposed for up to one hour without experiencing or developing lifethreatening health effects. 
WHC-SP-1180, Vol. 1

Table C7-2 Hanford Site Emergency Event Classification (DOE/RL-94-02. May 1995)

\begin{tabular}{|c|c|c|}
\hline ALERT & SITE AREA EMERGENCY & GENERAL EMERGENCY \\
\hline $\begin{array}{l}\text { ERPG-1 }{ }^{1} \& \text { ERPG-2 at facility } \\
\text { boundary }^{2} \text {. }\end{array}$ & >=ERPG-2@ facility boundary & $>=$ ERPG-2@Hanford Site boundary \\
\hline $\begin{array}{l}>=100 \text { mrem } \mathrm{CEDE}^{3} \text {, or } 0.5 \mathrm{rem} \text { to } \\
\text { the thyroid, or } 5 \mathrm{rem} \text { to the skin }(a) \\
\text { facility boundary. }\end{array}$ & $\begin{array}{l}>=1 \text { rem } C E D E \text {, or } 5 \text { rem to the } \\
\text { thyroid, or } 50 \text { rem to the skin }(9) \\
\text { faciltty boundary. }\end{array}$ & $\begin{array}{l}>=1 \text { rem } C E D E \text {, or } 5 \text { rem to the } \\
\text { thyroid. or } 50 \text { rem to the skin }(a \\
\text { Hanford Site Boundary }\end{array}$ \\
\hline
\end{tabular}

'Appropriate ERPG values or equivalent as stated in the Hazard Assessment Guidance Document. Solubility class "D" uranium compounds are limited by chemical toxicity.

2Facility boundary is defined as the property-protected area perimeter fence when present or a distance of 200 meters from the release location unless otherwise specified in the hazards assessment documentation.

${ }^{3}$ The committed dose includes the summation of the doses delivered from plume submersion, ground shine, and inhalation from accidental releases. 
WHC-SP-1180, Vol. 1

\begin{tabular}{|c|c|c|}
\hline \multicolumn{3}{|c|}{ Table C $7-3$ Probability category definition } \\
\hline Annual frequency category & Category description & Frequency range (events/year) \\
\hline Anticipated & $\begin{array}{l}\text { An off normal condition that } \\
\text { individually may be expected to occur } \\
\text { once or more during plant lifetime. }\end{array}$ & $10^{-2}$ to 1 \\
\hline Unlikely & $\begin{array}{l}\text { Individually, condition is not expected } \\
\text { to occur during the plant lifetime, but } \\
\text { collectively, events in this category } \\
\text { may occur several times. }\end{array}$ & $10^{-4}$ to $10^{-2}$ \\
\hline Extremely Unlikely & $\begin{array}{l}\text { Extremely low probability conditions } \\
\text { that are not expected during the plant } \\
\text { lifetime, but that represent extreme or } \\
\text { limiting cases of faults identified as } \\
\text { possible. This category includes } \\
\text { design basis accidents. }\end{array}$ & $10^{-6}$ to $10^{-4}$ \\
\hline Incredible & $\begin{array}{l}\text { Accidents for which no creditable } \\
\text { scenario can be identified. }\end{array}$ & $<10^{-6}$ \\
\hline \multicolumn{3}{|c|}{ Qualitative accident severity levels } \\
\hline Severity category & \multicolumn{2}{|c|}{ Consequences to the public, workers or environment } \\
\hline Category I & \multicolumn{2}{|c|}{$\begin{array}{l}\text { May cause death onsite or loss of the facility ioperation, major injuries or } \\
\text { illnesses offsite, radiation exposure to offsite individuals, to individuals in exces: } \\
\text { of annual limits, or severe impact on the environment. }\end{array}$} \\
\hline Category II & \multicolumn{2}{|c|}{$\begin{array}{l}\text { May cause severe injuries or severe occupational illnesses onsite, exposure to } \\
\text { onsite individuals in excess of annual limits, major damage to a facility } \\
\text { operation, minor illnesses or injury offsite, exposure to offsite individuals to } \\
\text { radiation below annual limits, or major impact on the environment. }\end{array}$} \\
\hline Categary III & \multicolumn{2}{|c|}{$\begin{array}{l}\text { May cause minor injury or minor occupational illness onsite, or exposure of } \\
\text { onsite individuals to radiation below annual limits, or major impact on the } \\
\text { environment. }\end{array}$} \\
\hline Category IV & \multicolumn{2}{|c|}{$\begin{array}{l}\text { Will not result in injury, occupational iliness, exposure onsite or offsite, or resul } \\
\text { in a significant impact on the worker. }\end{array}$} \\
\hline
\end{tabular}




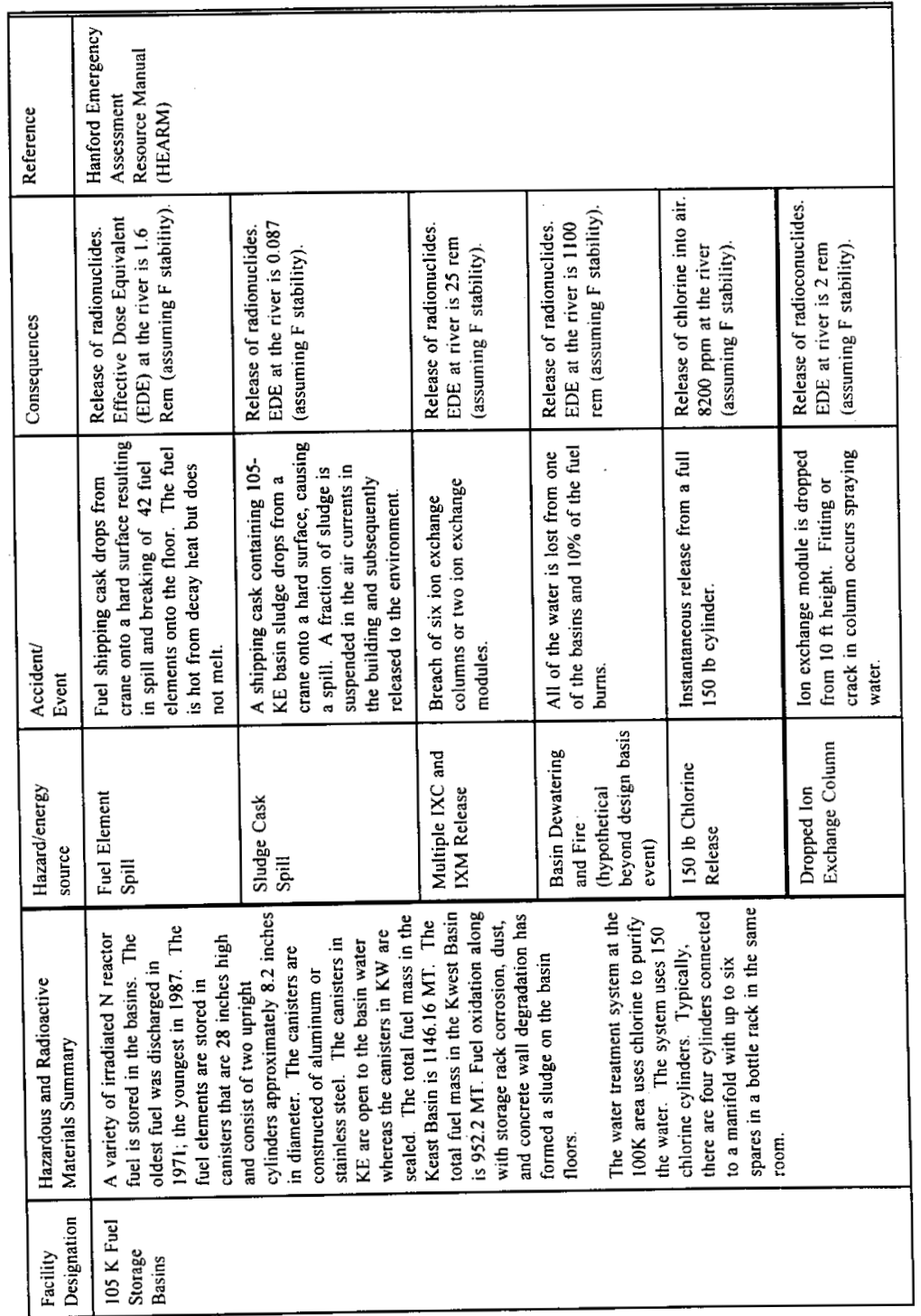




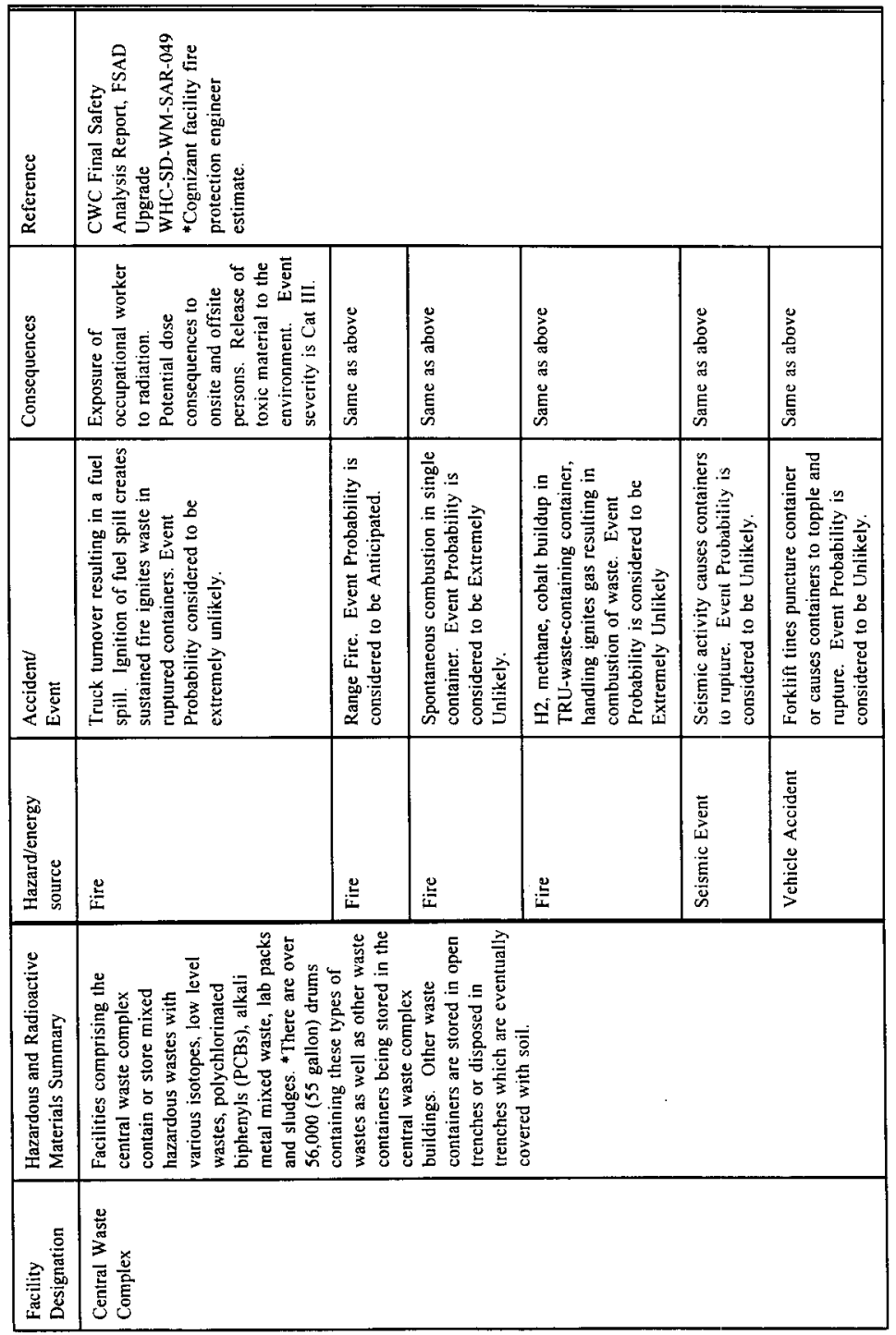


WHC-SP-1180, Vol. 1

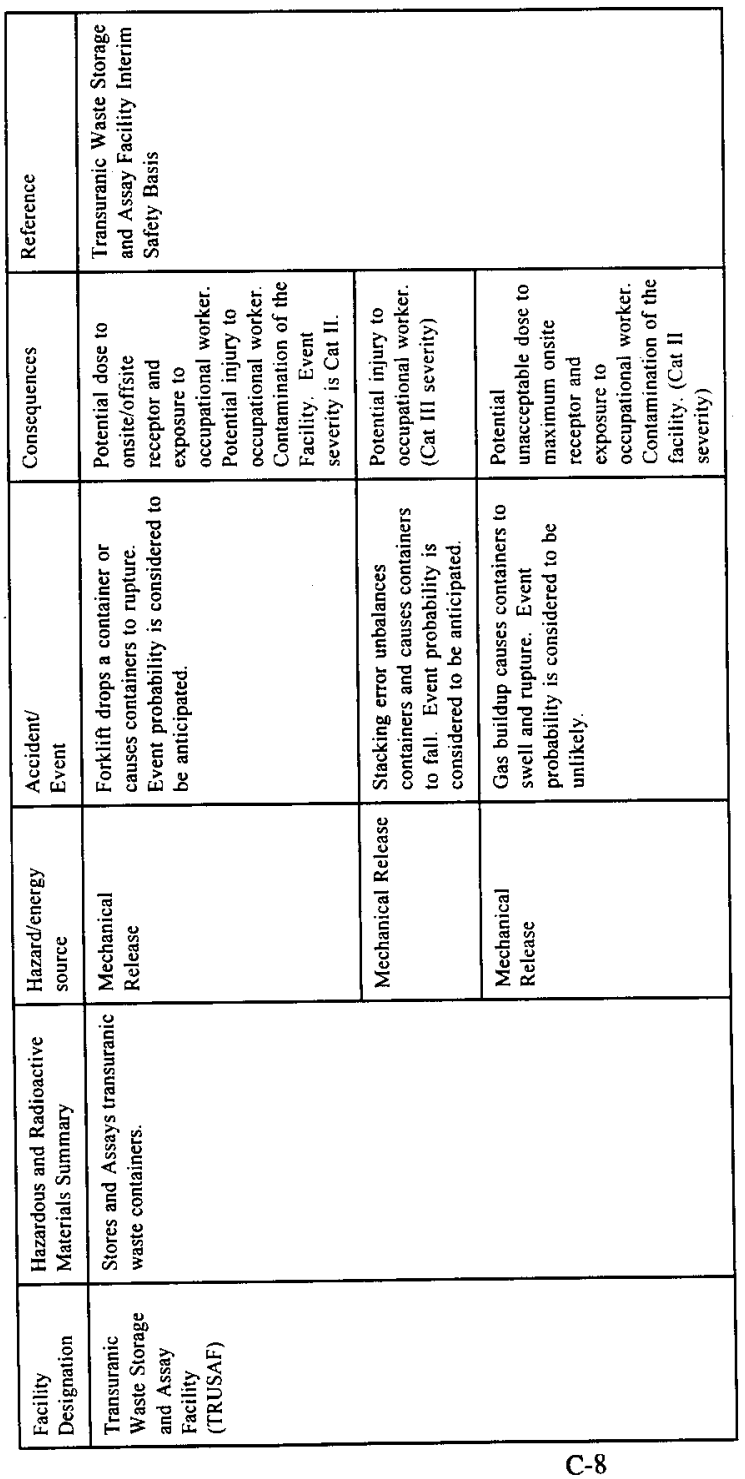


WHC-SP-1180, Vol. 1

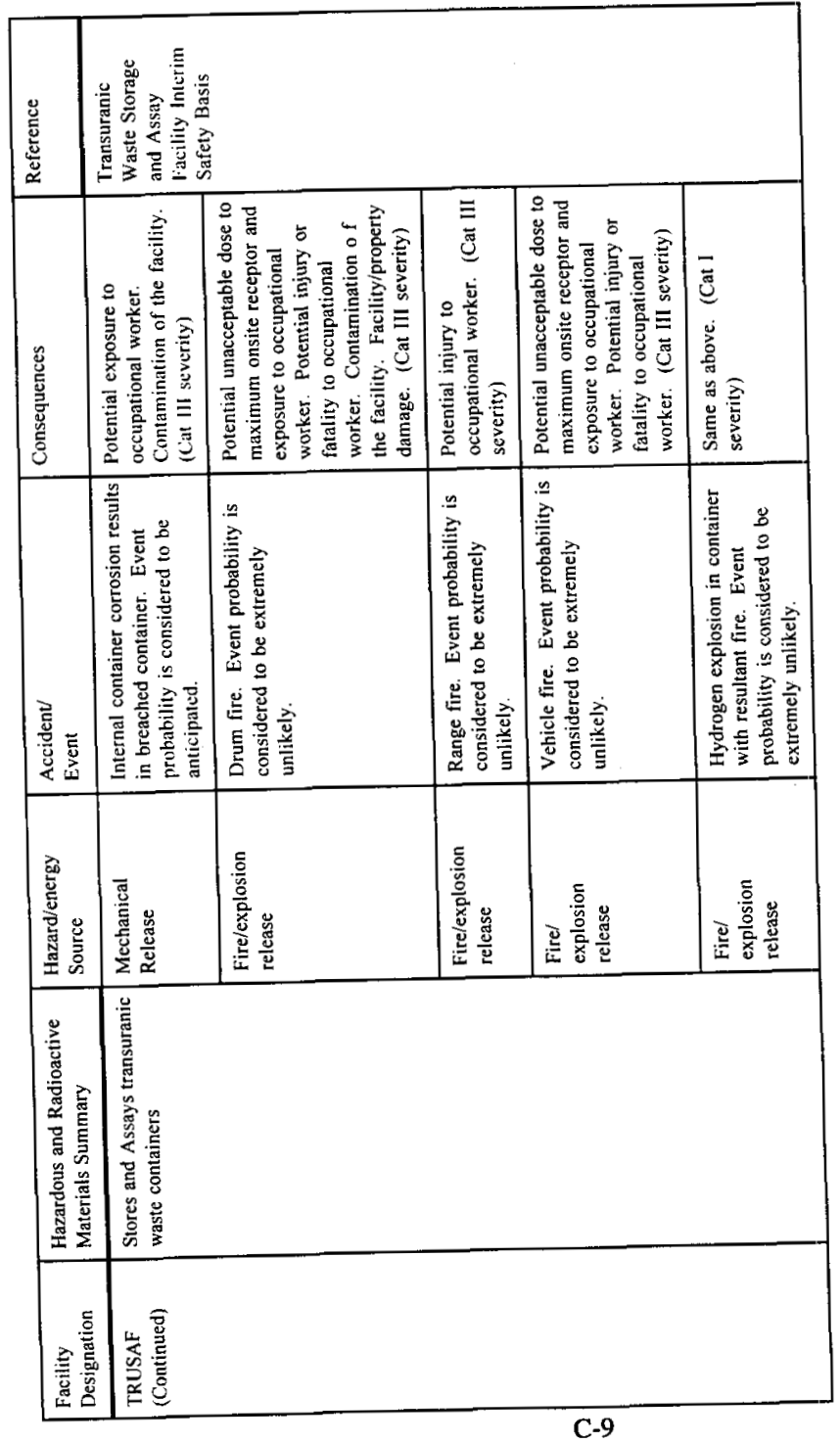


WHC-SP-1180, Vol. 1

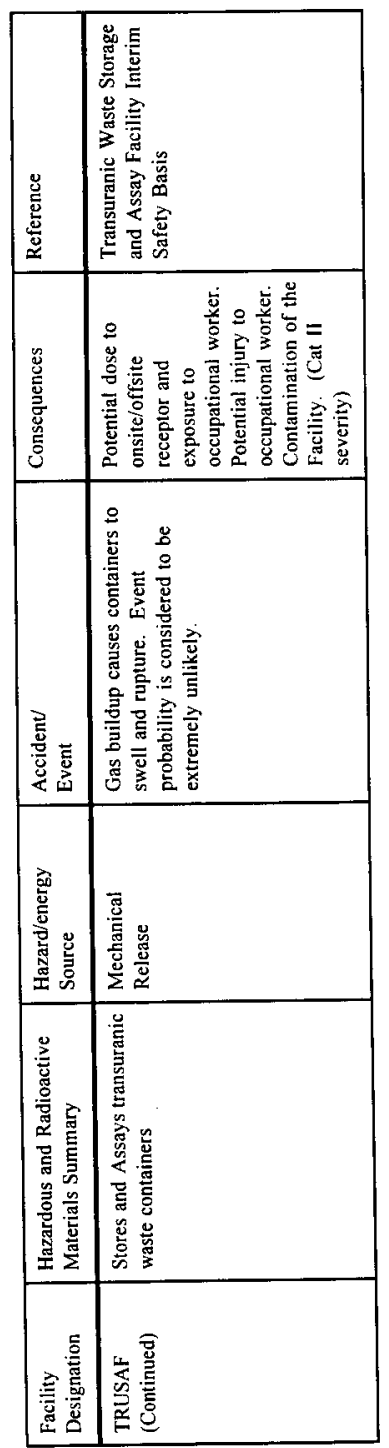




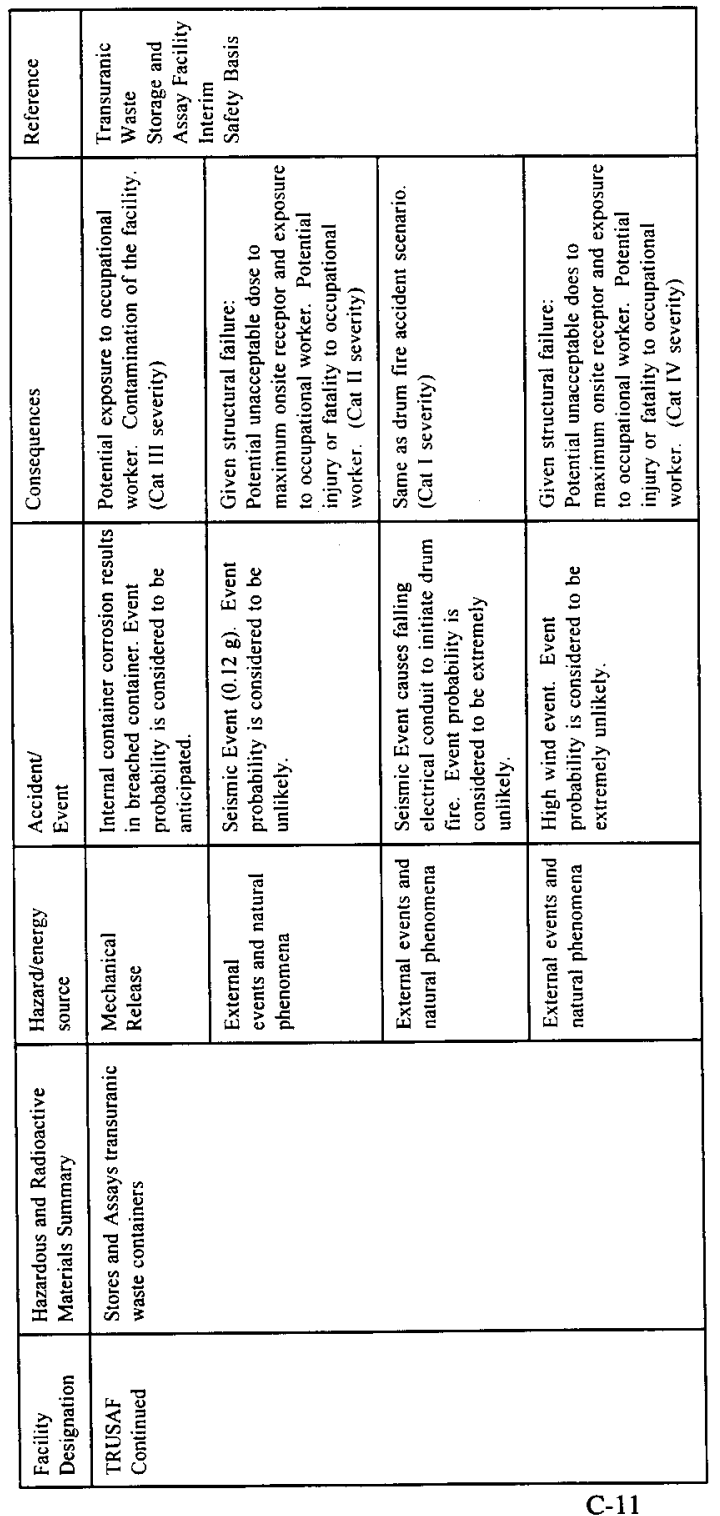


WHC-SP-1 180, Vol. 1

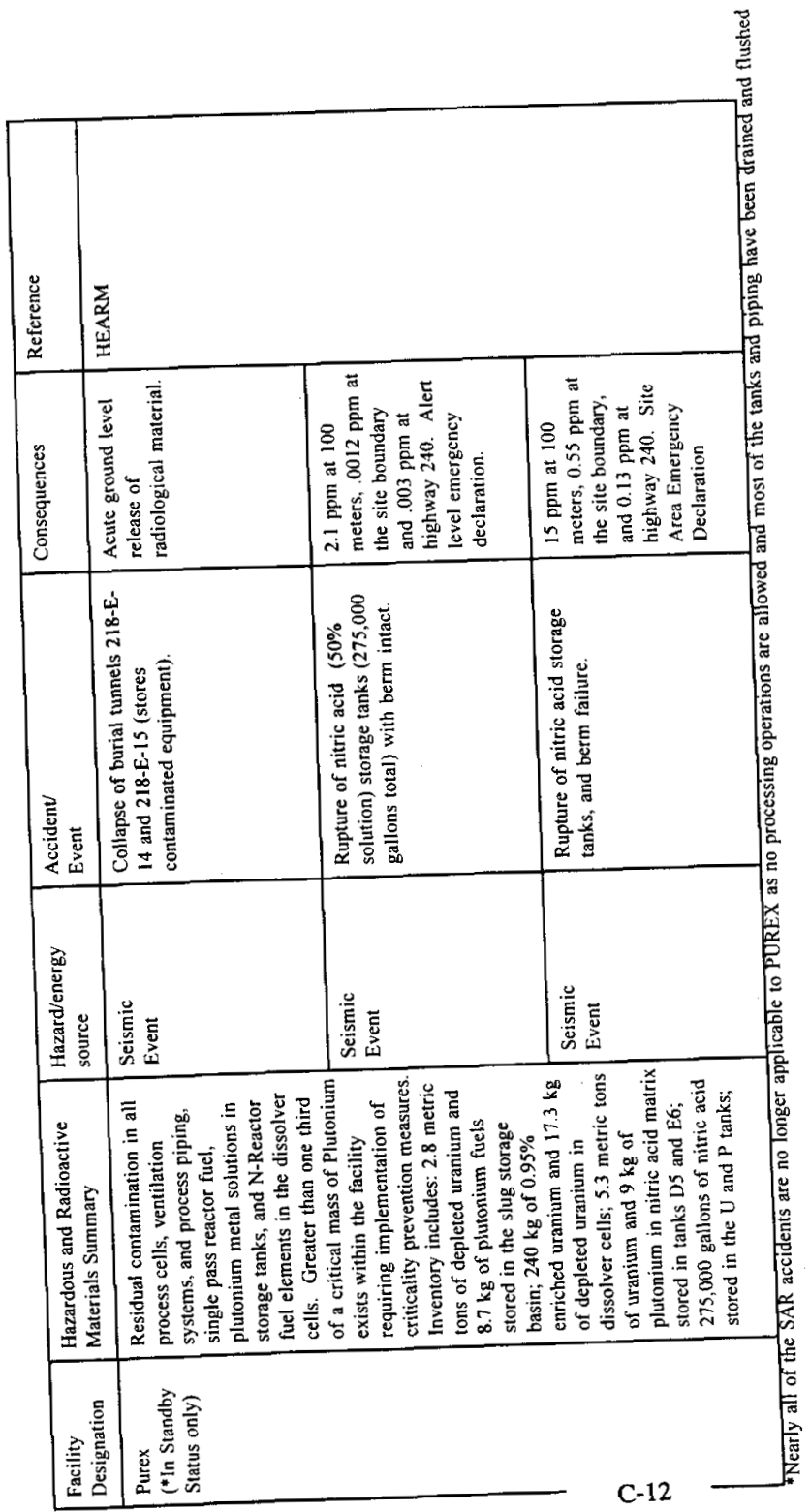


WHC-SP-1180, Vol. 1

\begin{tabular}{|c|c|c|c|c|c|c|}
\hline 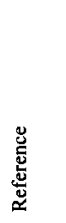 & \multicolumn{6}{|l|}{ 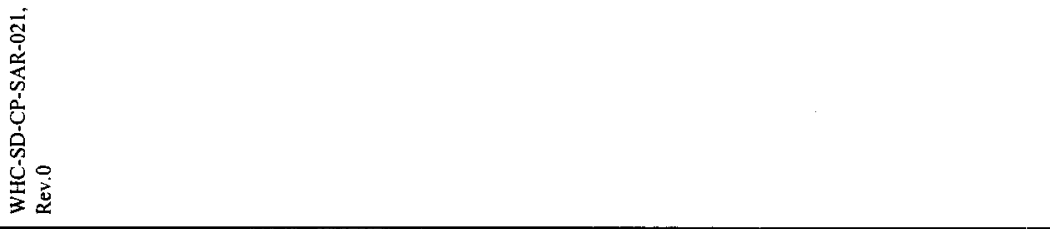 } \\
\hline 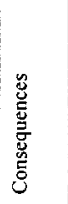 & 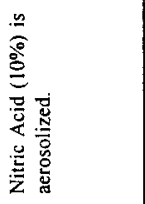 & 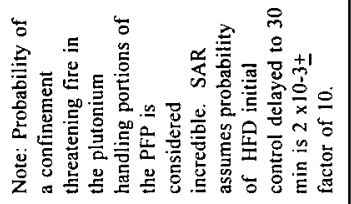 & 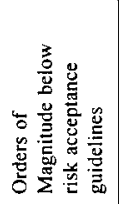 & 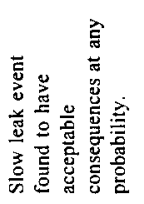 & 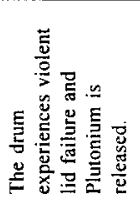 & 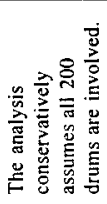 \\
\hline 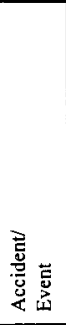 & 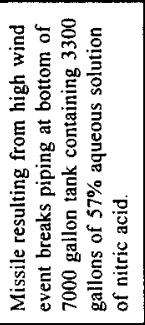 & 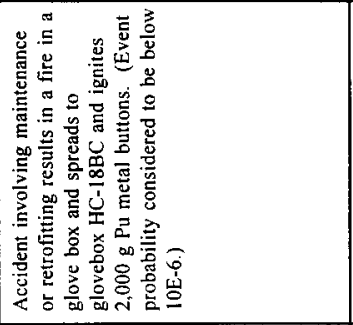 & 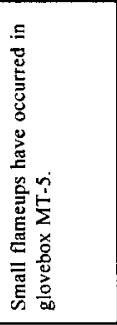 & 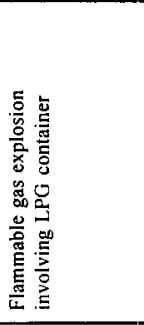 & 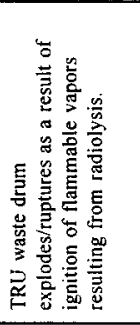 & 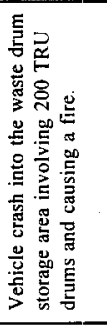 \\
\hline 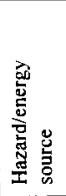 & 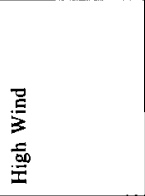 & 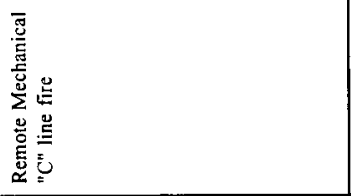 & 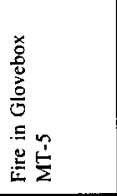 & 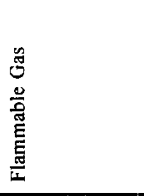 & 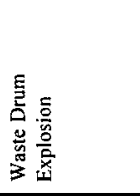 & 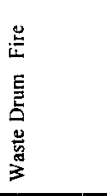 \\
\hline 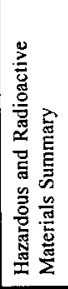 & 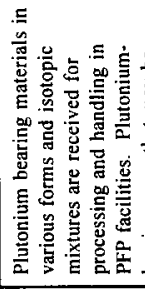 & 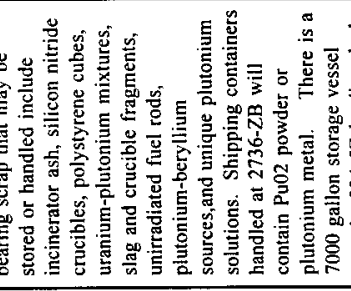 & 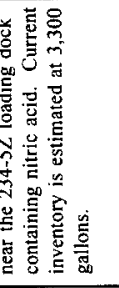 & & & \\
\hline 童 & 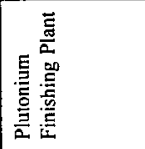 & & & & & \\
\hline
\end{tabular}


WHC-SP-1180, Vol. 1

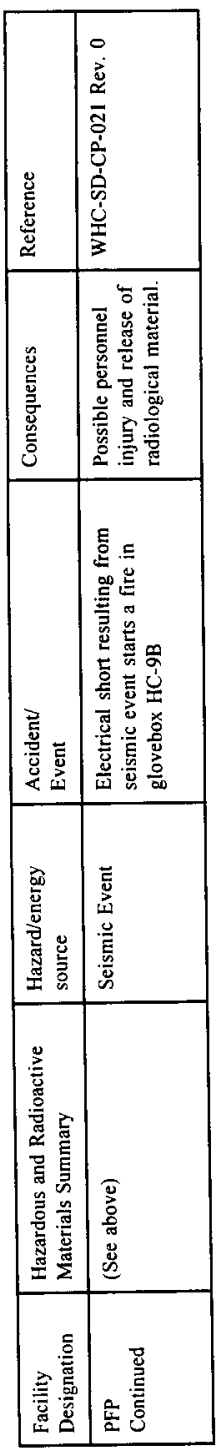


WHC-SP-1180, Vol. 1

\begin{tabular}{|c|c|c|c|c|}
\hline $\begin{array}{l}\frac{\mathscr{L}}{5} \\
\frac{5}{2} \\
\approx\end{array}$ & \multicolumn{4}{|c|}{ 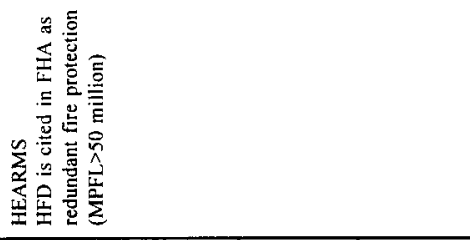 } \\
\hline 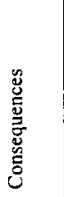 & 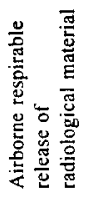 & 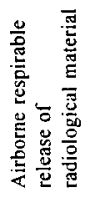 & 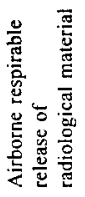 & 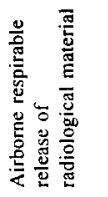 \\
\hline 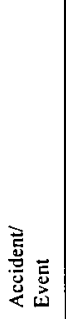 & 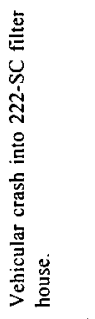 & 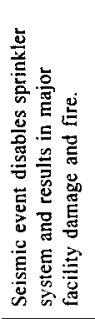 & 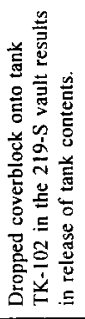 & 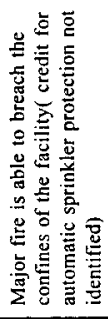 \\
\hline 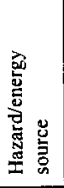 & 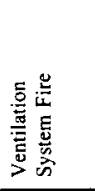 & 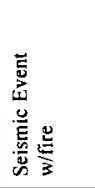 & 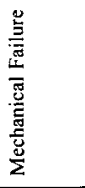 & 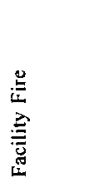 \\
\hline 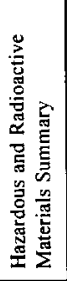 & \multicolumn{4}{|c|}{ 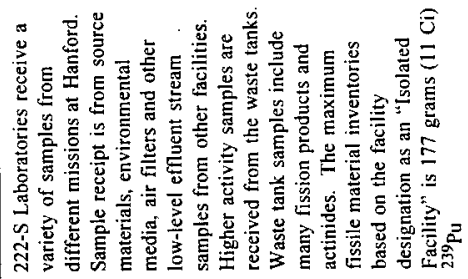 } \\
\hline 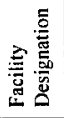 & \multicolumn{4}{|l|}{ 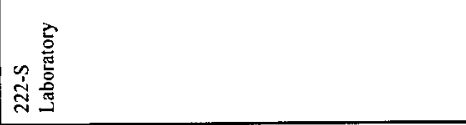 } \\
\hline
\end{tabular}

C-15 
WHC-SP-1180, Vol. 1

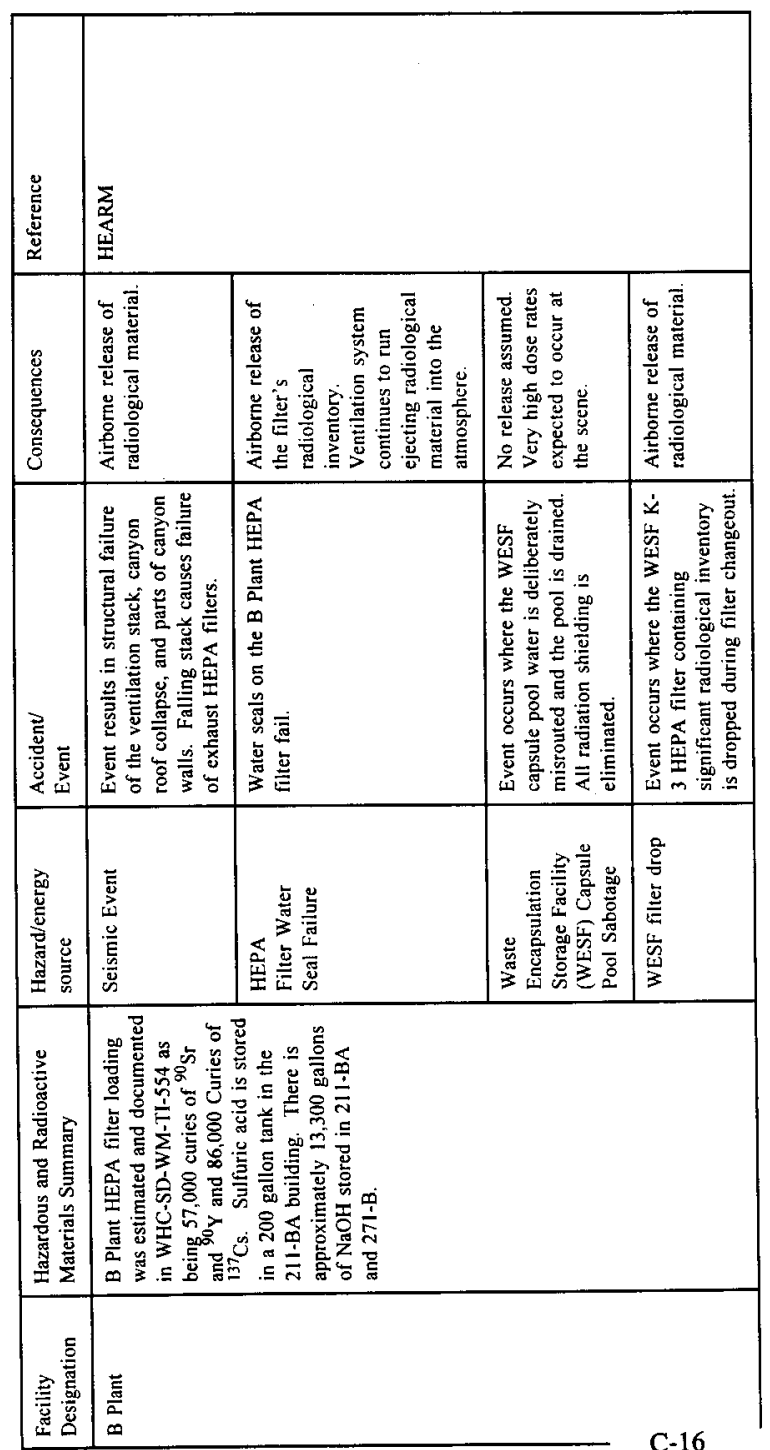


WHC-SP-1180, Vol. 1

\begin{tabular}{|c|c|c|c|c|}
\hline 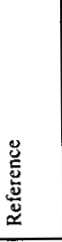 & 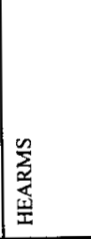 & 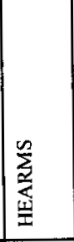 & 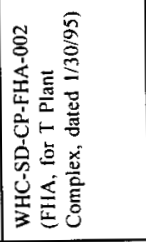 & 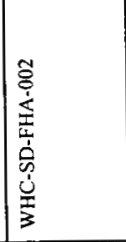 \\
\hline 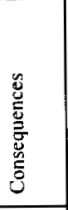 & 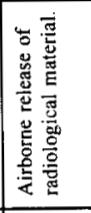 & 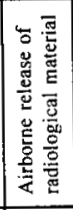 & 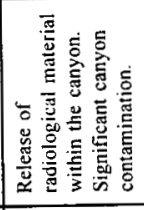 & 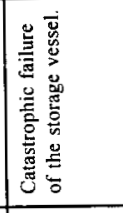 \\
\hline 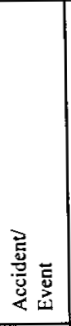 & 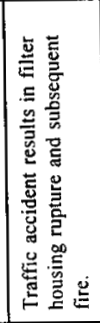 & 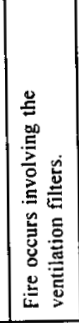 & 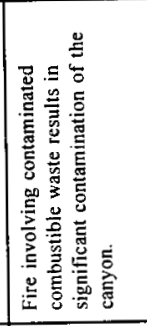 & 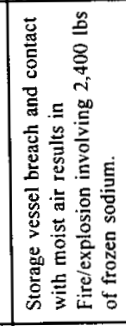 \\
\hline 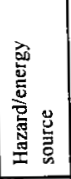 & 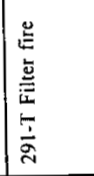 & 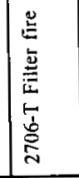 & 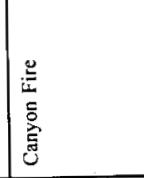 & 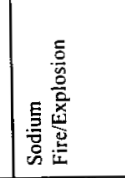 \\
\hline 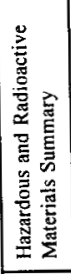 & \multicolumn{4}{|c|}{ 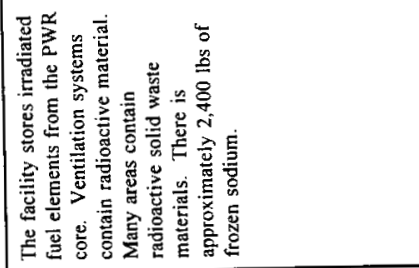 } \\
\hline 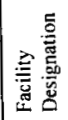 & $\begin{array}{l}\frac{\pi}{5} \\
\frac{3}{2} \\
F\end{array}$ & & & \\
\hline
\end{tabular}


WHC-SP-1180, Vol. 1

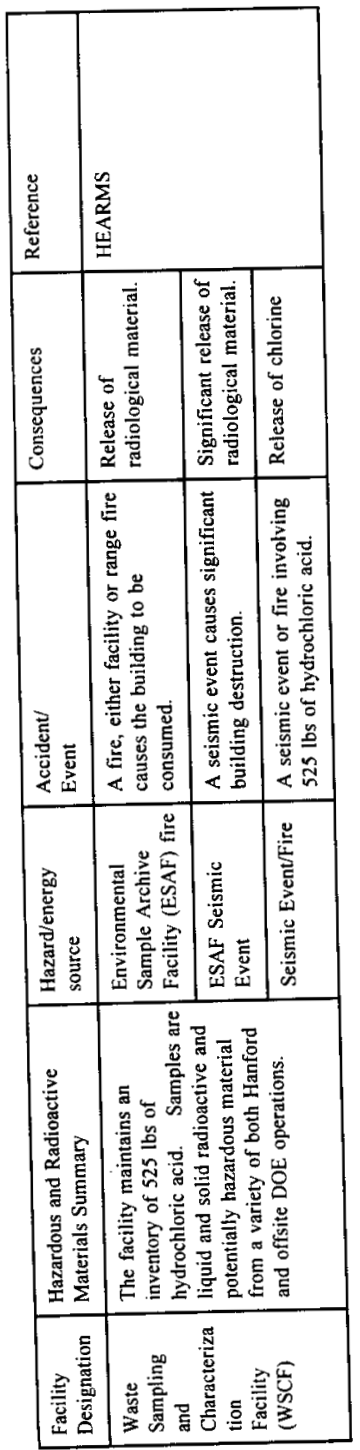


WHC-SP-1180, Vol. 1

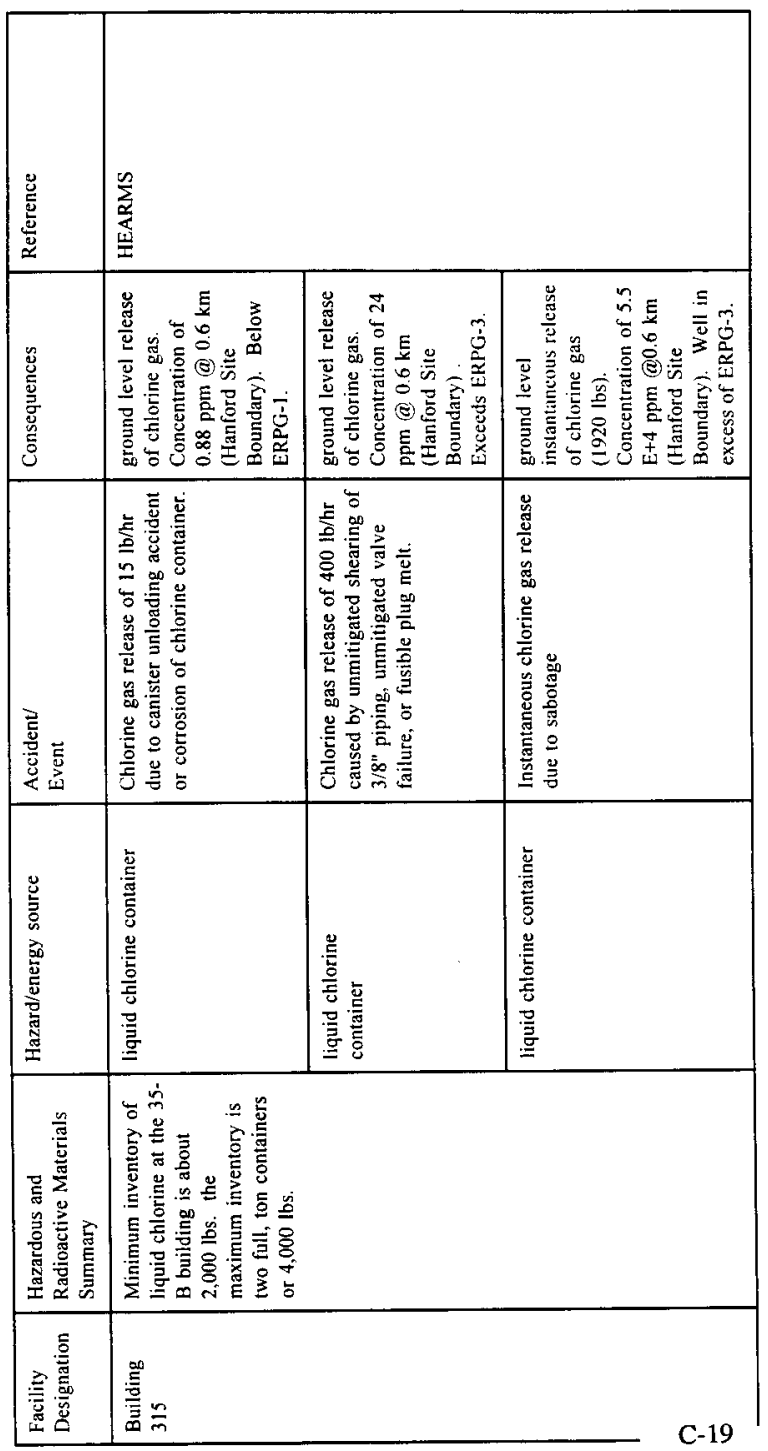




\begin{tabular}{|c|c|c|c|c|}
\hline 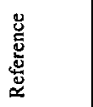 & \multicolumn{4}{|l|}{ 恣 } \\
\hline 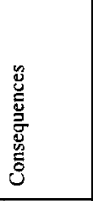 & 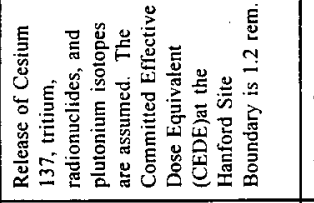 & 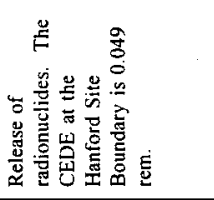 & 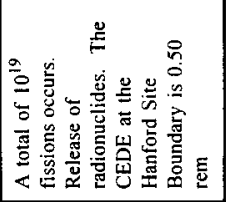 & 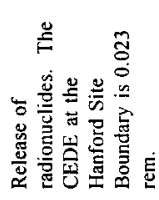 \\
\hline 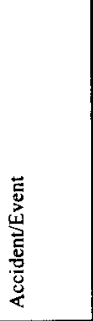 & 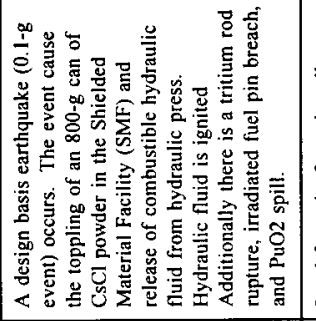 & 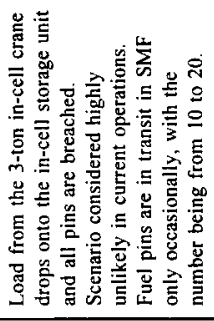 & 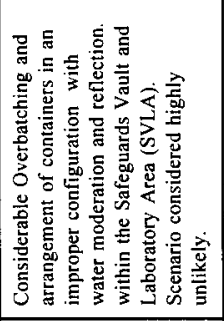 & 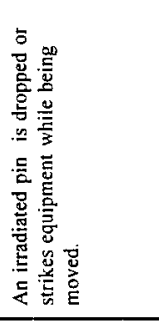 \\
\hline 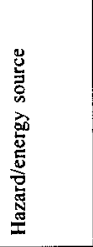 & 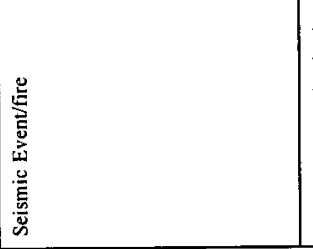 & 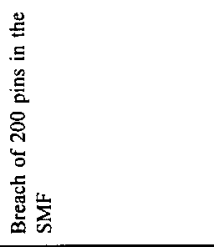 & 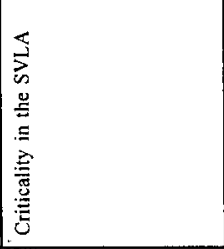 & 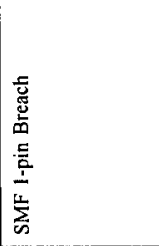 \\
\hline 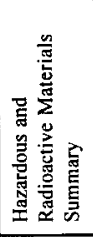 & 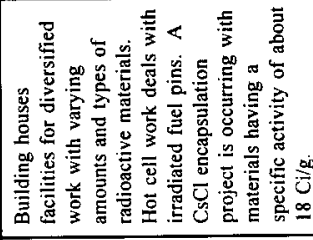 & 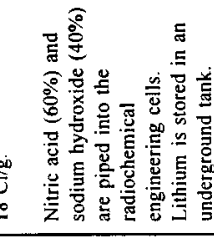 & & \\
\hline 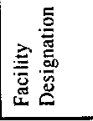 & 产 & & & \\
\hline
\end{tabular}


WHC-SP-1180, Vol. 1

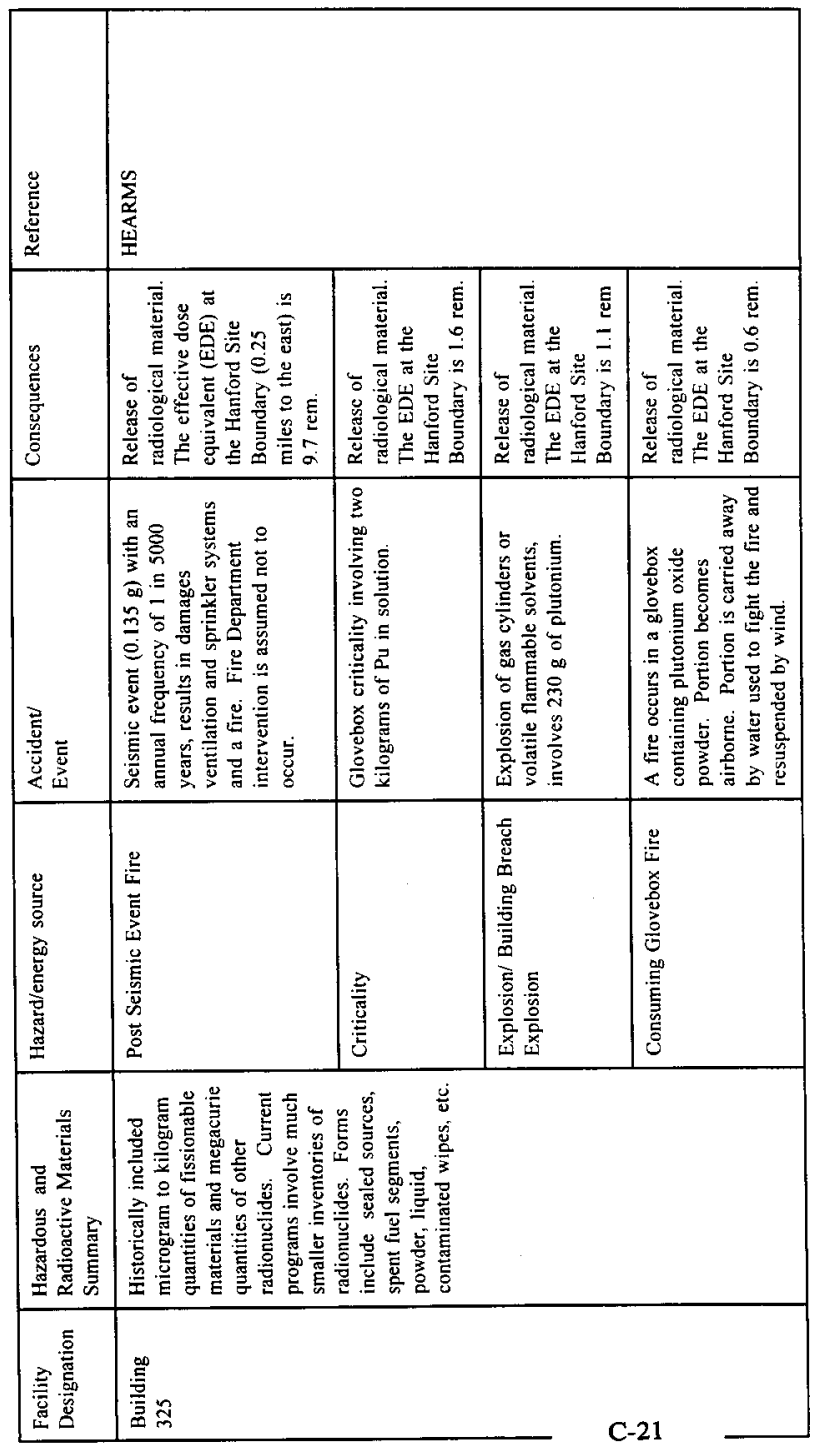


WHC-SP-1180, Vol. 1

\begin{tabular}{|c|c|c|c|c|}
\hline 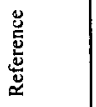 & \multicolumn{4}{|l|}{ 点 } \\
\hline 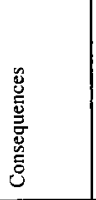 & 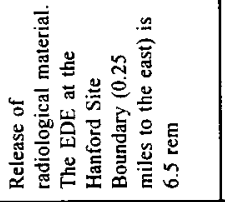 & 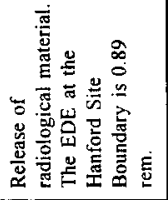 & 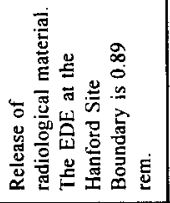 & 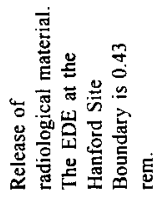 \\
\hline 密 & 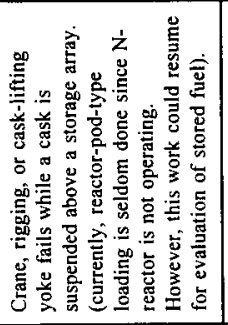 & 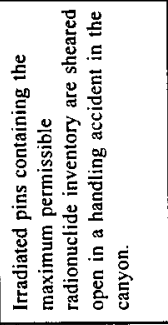 & 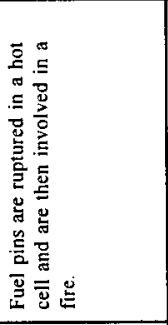 & 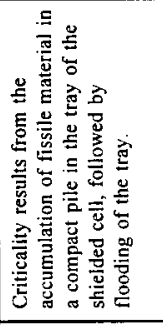 \\
\hline 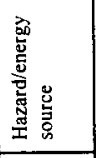 & $\begin{array}{l}\text { 음 } \\
\text { ta } \\
\text { 竘 } \\
\end{array}$ & 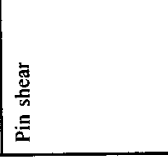 & 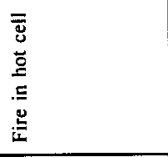 & 窵 \\
\hline 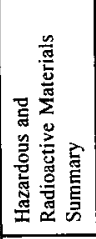 & 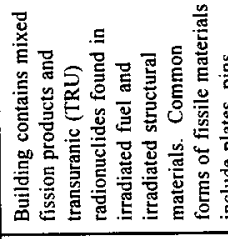 & 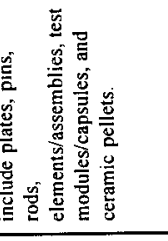 & & \\
\hline 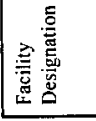 & 咅 & & C-22 & \\
\hline
\end{tabular}


WHC-SP-1180, Vol. 1

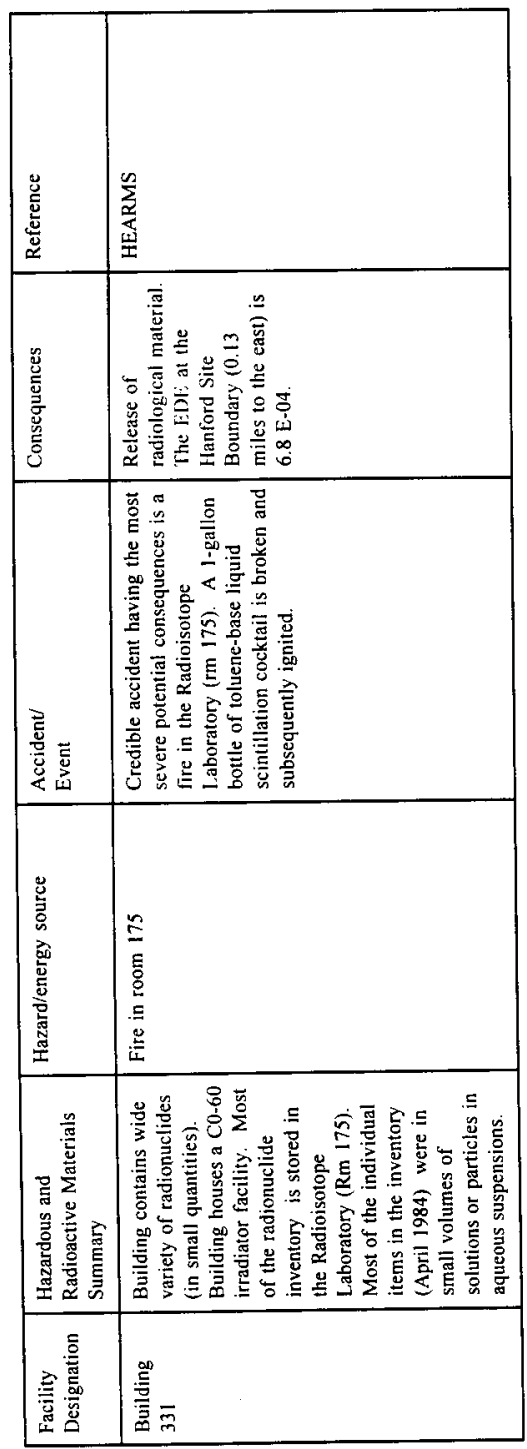


WHC-SP-1180, Vol. 1

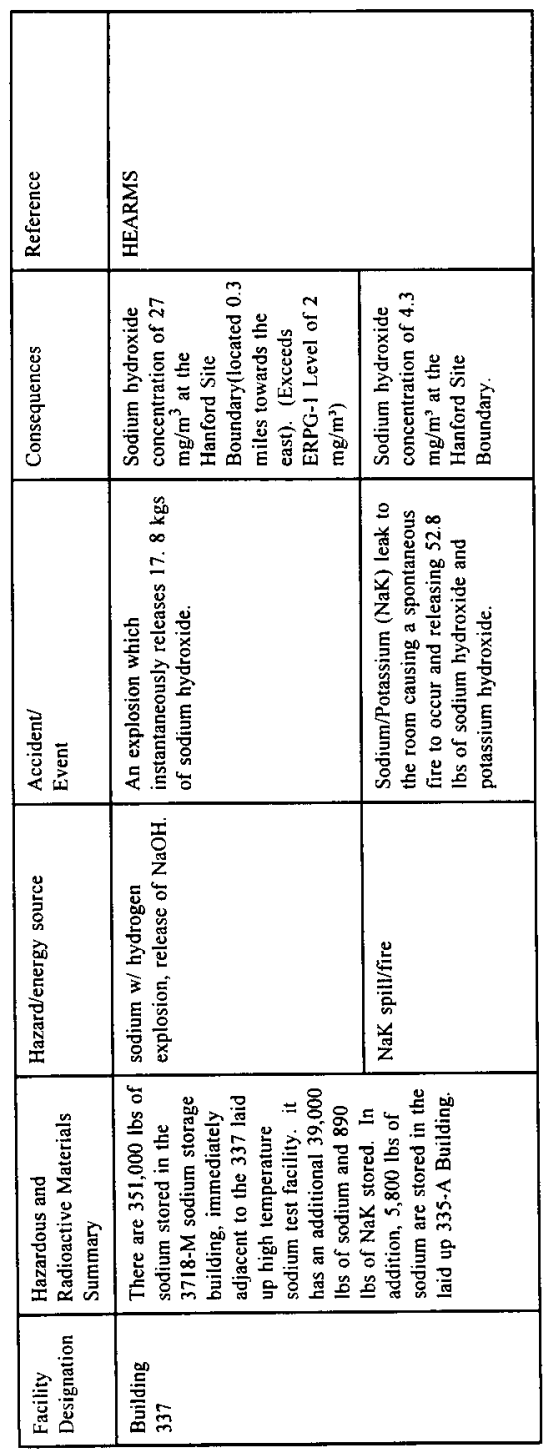


WHC-SP-1180, Vol. 1

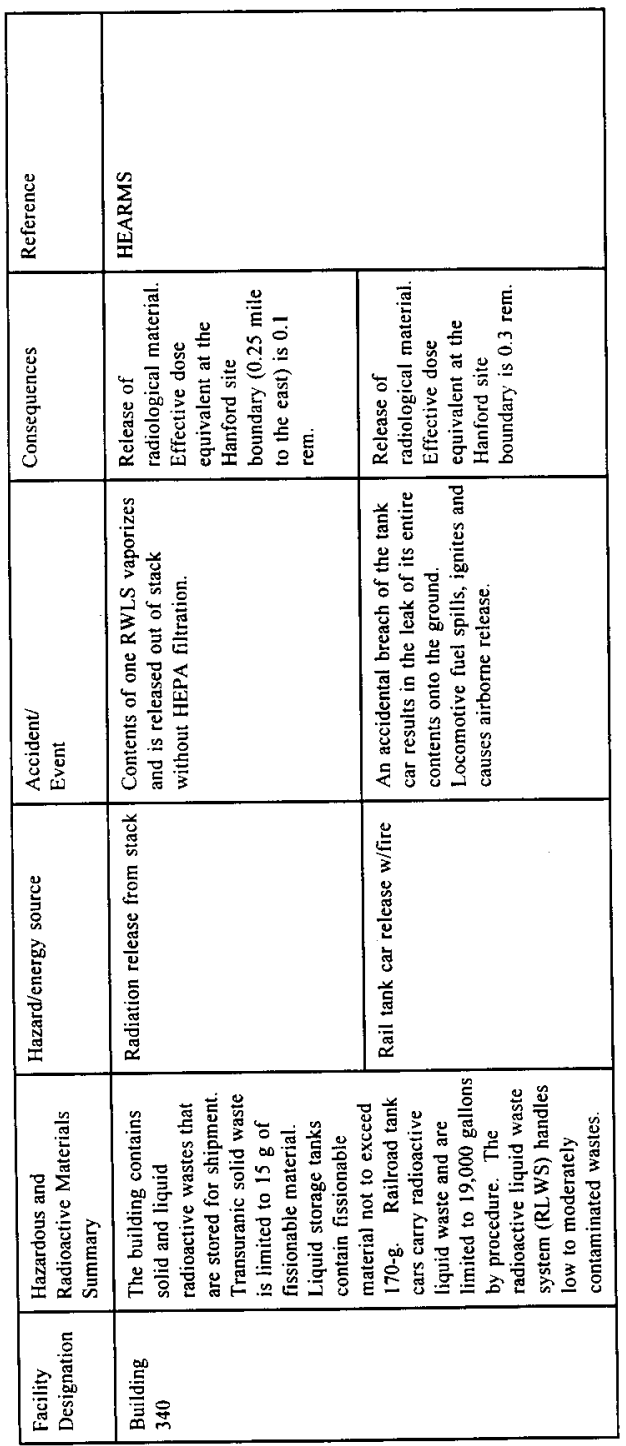


WHC-SP-1180, Vol. 1

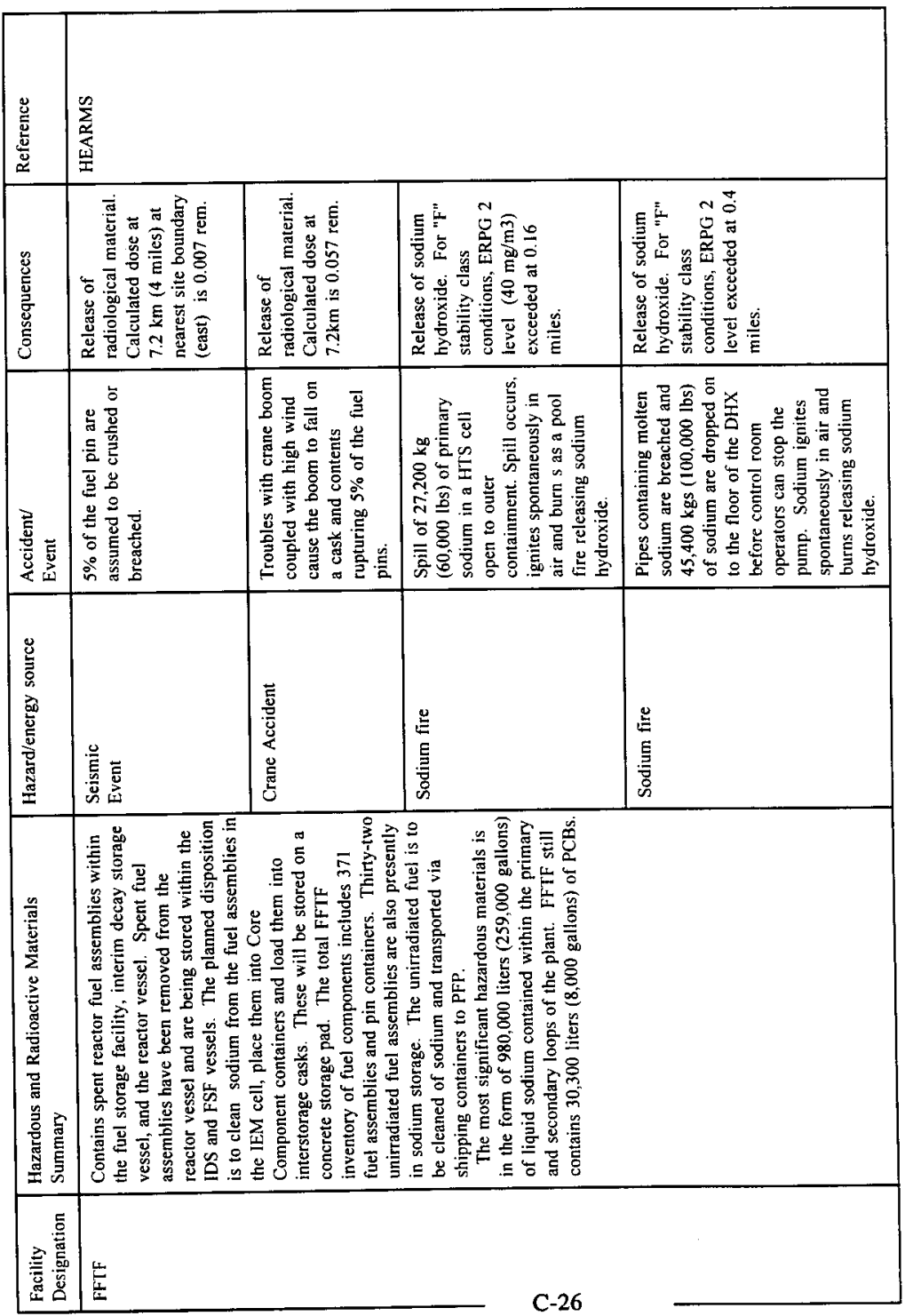


WHC-SP-1180, Vol. 1

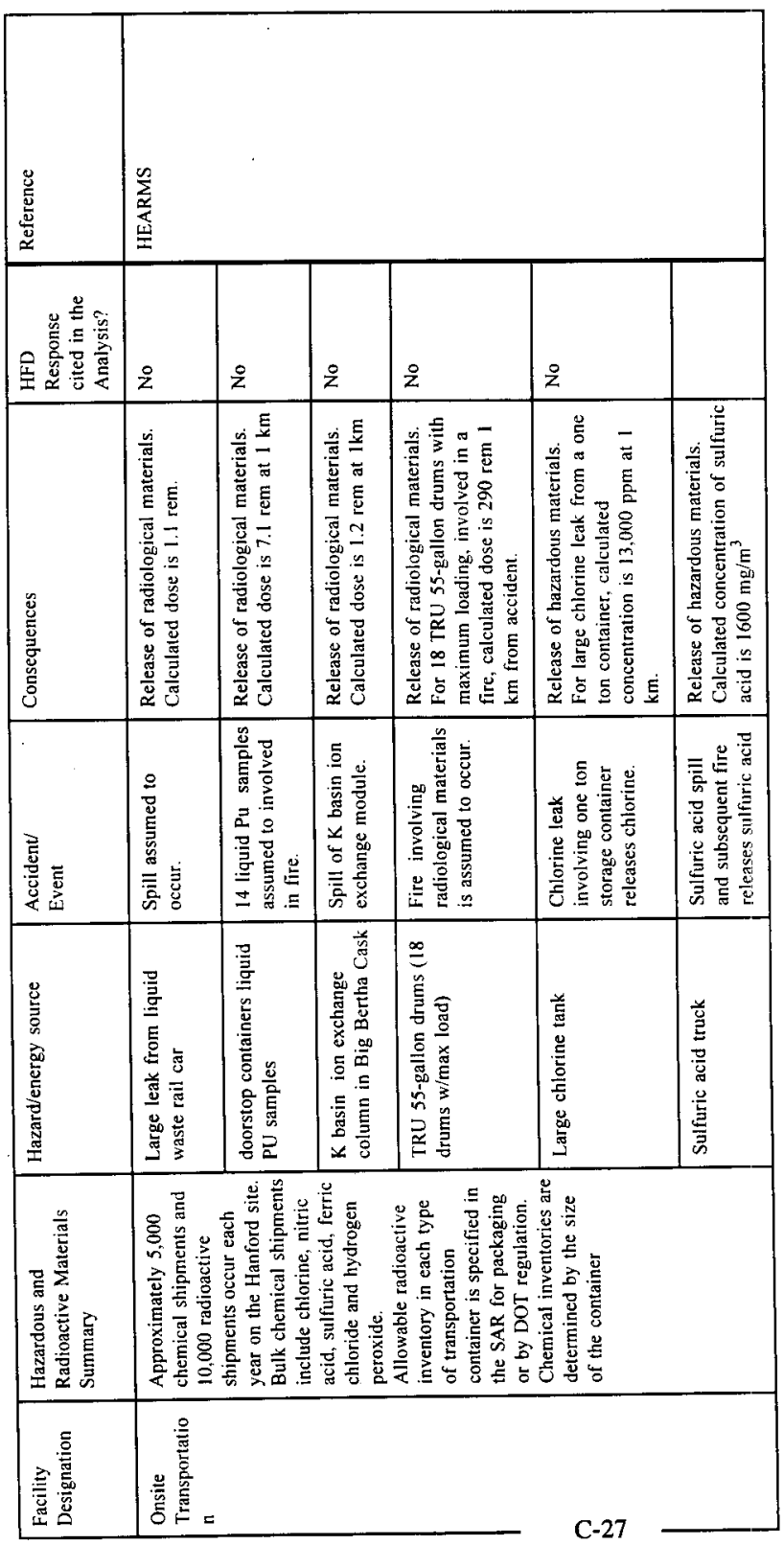


THIS PAGE INTENTIONALLY LEFT BLANK 
THIS PAGE INTENTIONALLY LEFT BLANK 
WHC-SP-1180, Vol. 1

Appendix D

Emergency Response Times 


\section{Emergency Response Times}

The computer aided dispatch system currently in use by the HFD records response times in minutes only, and not in minutes and seconds. Thus it is possible for records to be inaccurate up to 1 minute and 58 seconds. To provide a visual aid to an understanding of the running time component of HFD response, a series of computer generated time/distance maps are included in this Report.

A listing of these maps and an explanation follow:

The time-speed-distance computer generated maps provided in this needs assessment report are prepared using a licensed Geographic Information System (GIS) software program and the Federal Census Bureau's TIGER (Topologically Integrated Geographic Encoding and Referencing) files. While these digitized maps have been corrected to correlate with the Hanford Site area, discrepancies still may occur. The mileage distances are measured in links and exact distances should be measured "on-the-ground" when needed. The maps are reproduced in this report for comparison purposes. It is assumed that all units are in-quarters ready to respond.

The mathematical formula applied by the software assumed $45 \mathrm{mph}$ average speed for fire apparatus, from station departure to incident scene arrival. A $50 \mathrm{mph}$ average speed is used for ambulance vehicles. Distances are produced only along major response routes. Lower speeds are necessary once inside a fenced Site area.

Higher speeds along any open stretches of highway could increase the average speeds of 50/45 mph selected, but higher averages are not recommended. Longer running times obviously would increase the distance covered. Extensive distances inside fenced areas obviously increase the running times.

It is important to note that not every type of vehicle is duplicated in each HFD station. Thus running time/distances for any specialized vehicle must be taken from that vehicle's home station, for example, the Hazmat truck at the 200 Area Station.

The following time/distance maps are included:

1. A Site prepared map showing station locations only

2. Computer generated Base map showing major roadways and north Richland only

3. Hanford Station \#1 at $45 \mathrm{mph}$

4. Hanford Station \#2 at $45 \mathrm{mph}$

5. Hanford Station \#3 at $45 \mathrm{mph}$

6. Hanford Station \#4 at $45 \mathrm{mph}$

7. Hanford Station \#3 ISO map

8. Hanford Alternate Site ISO map

9. Hanford Richland North ISO map

10. Hanford Stations \#1 and \#2 Coverage at $45 \mathrm{mph}$

11. Hanford Stations \#3 and \#4 Coverage at $45 \mathrm{mph}$

12. Hanford Stations \#2 and \#4 Coverage at $45 \mathrm{mph}$

13. Hanford Ambulance from Station \#1 at $50 \mathrm{mph}$ 
14. Hanford Ambulance from Station $\# 2$ at $50 \mathrm{mph}$

15. Hanford Ambulance from Station $\# 3$ at $50 \mathrm{mph}$

16. Hanford Ambulance from Station $\# 4$ at $50 \mathrm{mph}$

Hanford Station and Vehicle Deployment

The existing four HFD fire/ambulance stations were located at their sites in order to place them in closest possible proximity to the areas of presumed greater need, but outside of credible hot zones. Considering that the number of stations financially possible to construct and staff is limited, the existing locations appear reasonably adequate for initial fire attack and hazardous materials incident response purposes. Neither Stations \#1 nor \#2 (as designated on the computer generated maps) can reach all currently important structural and facility subareas in five minutes running time, but a 6.5 minutes running time definition provides extended distances of approximately one mile. With the noted exception of certain (100-H) facilities in the 100 Area, a 6.5 minute running time would appear to enable HFD emergency response vehicles from the 100 Area Station to reach 100 Area target hazard facilities. This is an illustration of why quick dispatch and "station get-out" times (based on good station design) are critical for good coverage purposes. Anything which can reduce total response time is helpful.

For a fire response to take place within 7 minutes "of the receipt of the initial alarm" at the alarm-dispatch center, and assuming the national average cumulative time of 2 minutes before the first apparatus departs, a five minute running time maximum is desirable for "arrival at the scene." If the DOE Guideline's 7 minute response count begins at the time the dispatch transmission is received at the station, and assuming a rapid 30 second station departure time requirement, then a 6.5 minute running time to the scene of the incident for the initial vehicle and crew arrival generally is sufficient.

Since the Hanford Site benefits from extensive sprinkler (and related) fire protection coverage, the existing running times appear adequate to the task for structural calls, wildland fire calls, and for hazardous materials incidents at existing hazard locations. As site D\&D occurs and as new Site tenants and storage areas emerge, station locations will need to be verified. Also, the deployment of specialized vehicles--including ambulances--may need to be adjusted, even if for an interim period.

Should intensive D\&D or other activities in a specific sub-area appear to necessitate, an ambulance and crew may need to be temporarily relocated to enable a quicker response. Conversely, should an entire area become decommissioned and its population significantly reduced, the covering response station might be closed.

The computer generated maps which illustrate approximate two station coverage within 10 minutes running time at $45 \mathrm{mph}$ are especially important. They illustrate the approximate locations which can be reached in the stated time frame by the back up vehicle, assuming both stations are available for dispatching. Reducing the alarm handling and get-out time to one minute (from two minutes total) adds $2 / 3$ mile to the distances covered. Back up coverage is best when Stations \#1 and \#2 or Stations \#3 and \#4 are each free to be dispatched to cover each other in those pairs. 
Considering the numerous medical recommendations that appropriate pre-hospital service be given to cardiac victims, trauma victims, and non-breathing victims within four minutes, it is obvious that not all of the site can receive that quick an ambulance response. Sub-area CPR and initial stabilization efforts by workers on-the-scene appear essential.

As noted earlier in this Report, consideration is being given to the construction of a fire station to be located on a site in the northern section of the City of Richland. This station would provide coverage for Richland's development in the north and northwest, and also for the 300 and 1100 sections of the Hanford Site. The existing HFD Station \#3 would be closed under this arrangement. A computer generated map is provided which illustrates approximately the Insurance Services Office (ISO) 1.5 (engine) and 2.5 (ladder) mile distances from the proposed "combination station" site. A computer generated map also is provided which illustrates approximately these ISO distances from the existing northernmost station in Richland. This issue is beyond the scope of this needs assessment study, but the maps are included at the request of HFD officials.

Whether any station on the Hanford Site is closed or differentially staffed is a function of two major issues: Does that station's area of immediate response (the so-called "first-due" zone) still need continuing fire, EMS, rescue, and hazardous materials response coverage, and, if so, could some other station provide timely enough response within an acceptable degree of risk? Also, would there still be a sufficient total number of response personnel and vehicles remaining on the Site to handle a potential credible incident?

Should HFD close its 300 Area station and relocate to the Kelly road-Horn Rapids road intersection, it would be reducing its northern "reach" by approximately 1.5 miles. Thus, its running times north to Site areas, specifically the 300 and 400 Areas would be lengthened. The time differential, depending on traffic conditions, could extend to three minutes additional running time--the running time currently required to reach the existing 300 fire station location from the Kelly road-Horn Rapids road intersection.

It appears to the Needs Assessment Team that the response time benefits of the proposed shared station would accrue much more to Richland than to Hanford.

Should the HFD enter into proposed Agreement for Automatic Reciprocal Fire Department Assistance with Richland, simultaneous dispatching of each department would be needed. Despite a statement to the contrary in the draft agreement, significant modifications to the existing communications systems appear necessary to ensure simultaneous dispatch. Otherwise a dispatch time-lag will exist for one department or the other in the proposed fire alarm response.

Since HFD responds with more than the three persons per vehicle specified by the draft agreement, and presuming Richland responds with a pumper, the volume of response will favor Richland, as will the HFD Quint responding as an aerial ladder company into Richland.

There would be an advantage to Hanford in that its response would be with three Richland firefighters arriving prior to the 400 Area Station crew, at least in the southern and 
central sections of the 300 Area, assuming the units run from a shared station. (This would not hold if Richland were responding from the Jadwin Avenue station.)

The draft Agreement appears to focus on fire response only, and does not appear to include EMS. The agreement precludes Richland's direct work in hazmat or radiological incidents.

The proposed automatic mutual aid agreement, with Richland responding from the Jadwin Avenue station, does not appear at face value to be of significant benefit to HFD, beyond the existing Tri-County agreement.

It is cost effective to have the HFD function as a multiple purpose emergency response department providing fire, EMS, rescue, hazmat, and related service delivery. The number of crew members made available for immediate response to those workloads over the entire site should be governed by the nature and distribution of credible hazards, the life-safety load distributed among the various site areas, the degree of risk willing to be assumed by policy makers, the response distances, and the timeliness of response necessary to handle the types of calls anticipated safely. 


\section{HANFORD SITE \\ MAJOR ROADWAYS AND FIRE STATIONS}

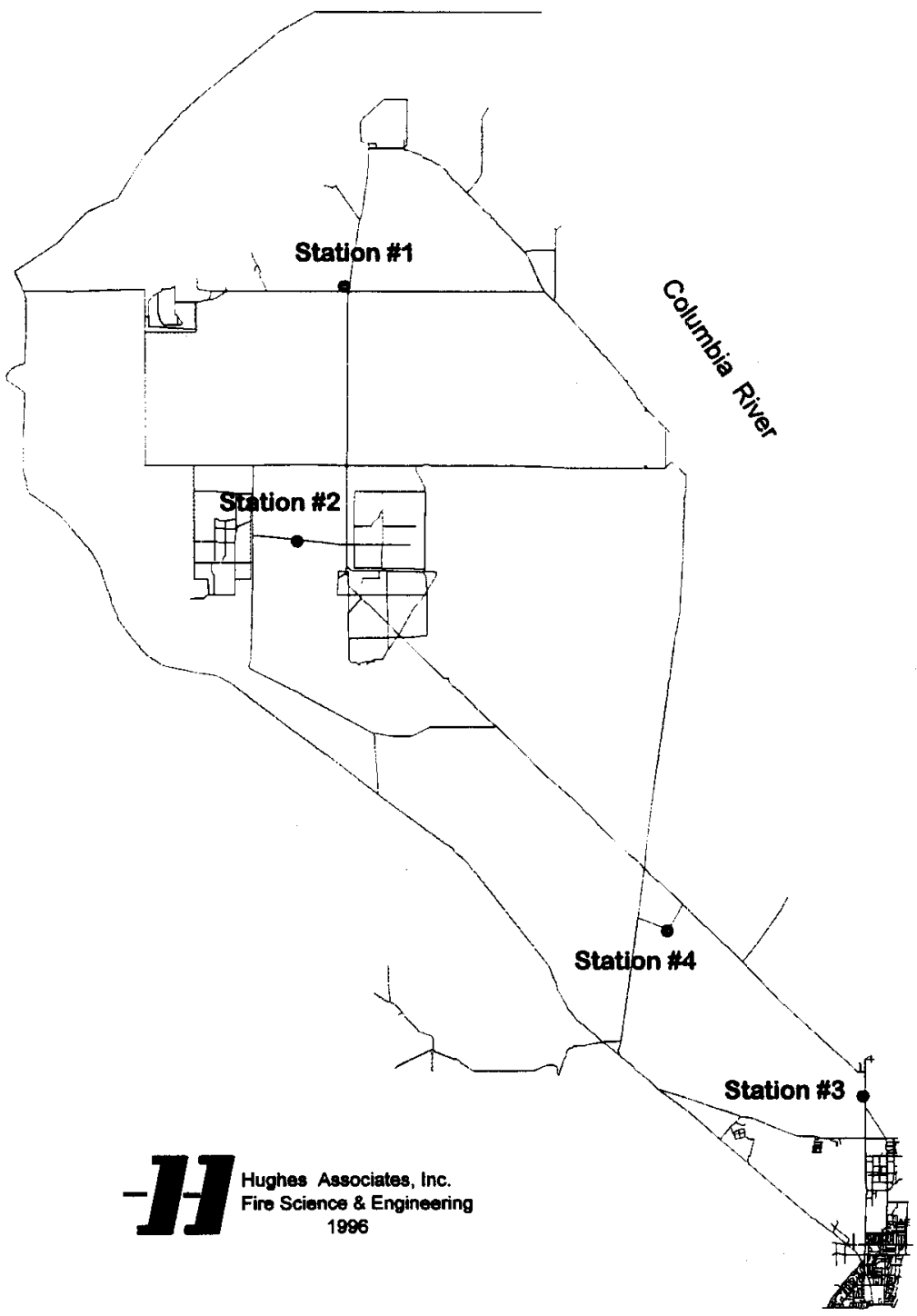

D - 6 
HANFORD FIRE DEPARTMENT

MAJOR RESPONSE ROUTE COVERAGE

FROM STATION \#1 AT AVERAGE 45 MPH

(Travel Time/Distance:

Assumes additional 1 minute for dispatch

and 1 minute to depart station)

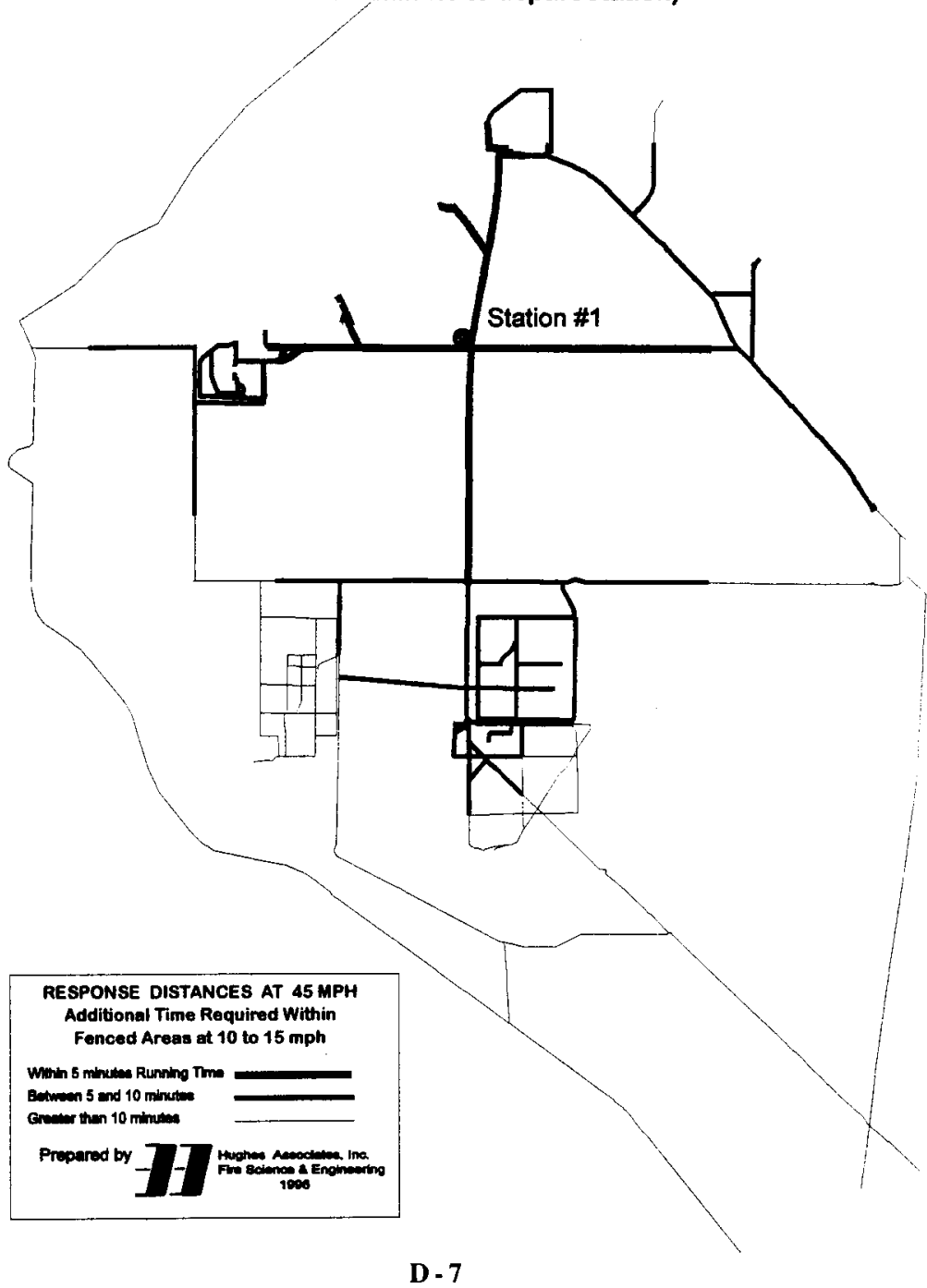




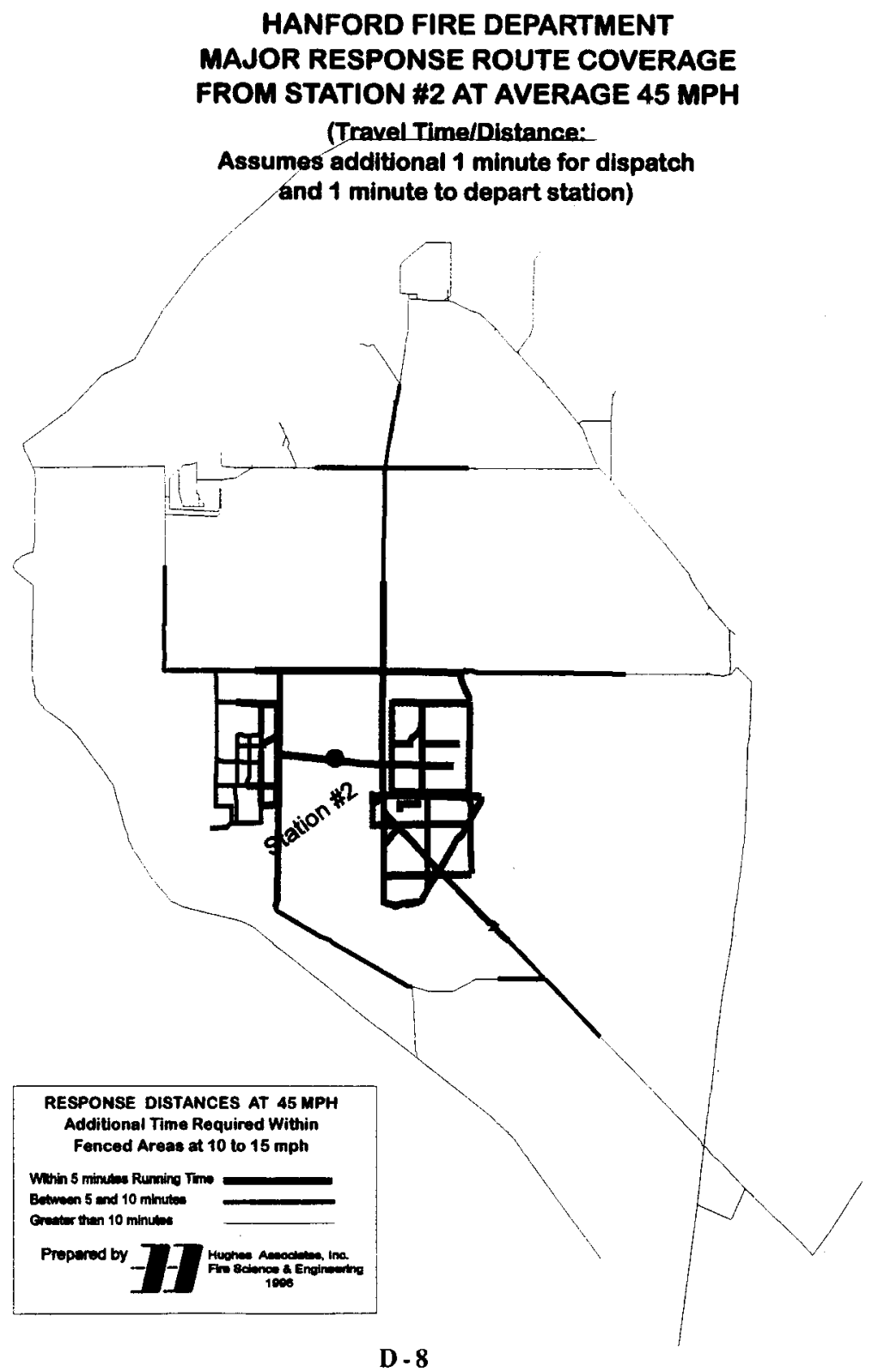




\section{HANFORD FIRE DEPARTMENT \\ MAJOR RESPONSE ROUTE COVERAGE \\ FROM STATION \#3 AT AVERAGE 45 MPH}

(Travel Time/Distance:

Assumes additional 1 minute for dispatch

and 1 minute to depart station)

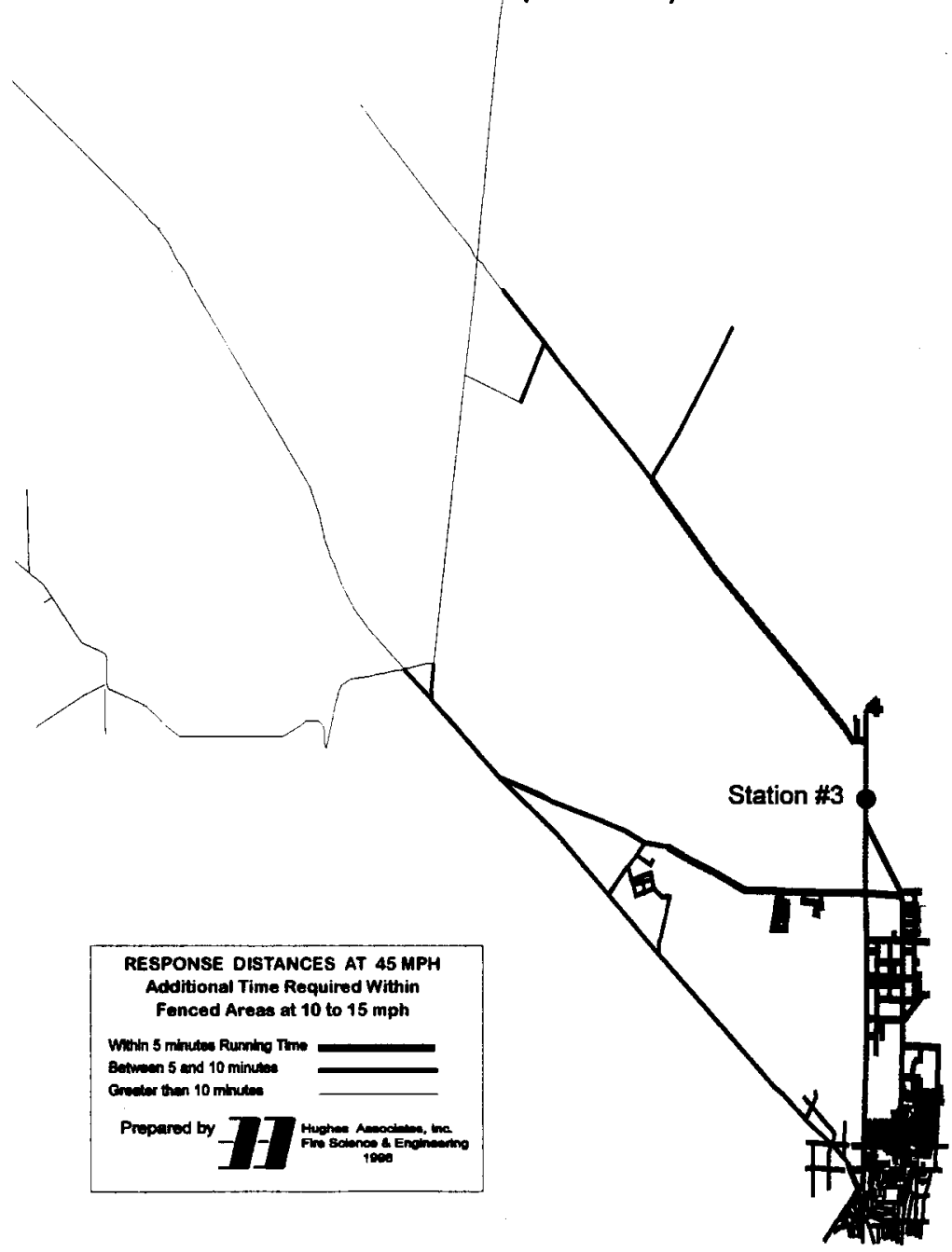

D. 9 


\section{HANFORD FIRE DEPARTMENT}

MAJOR RESPONSE ROUTE COVERAGE

FROM STATION \#4 AT AVERAGE 45 MPH

(Travel TIme/Distance:

Assumes additional 1 minute for dispatch

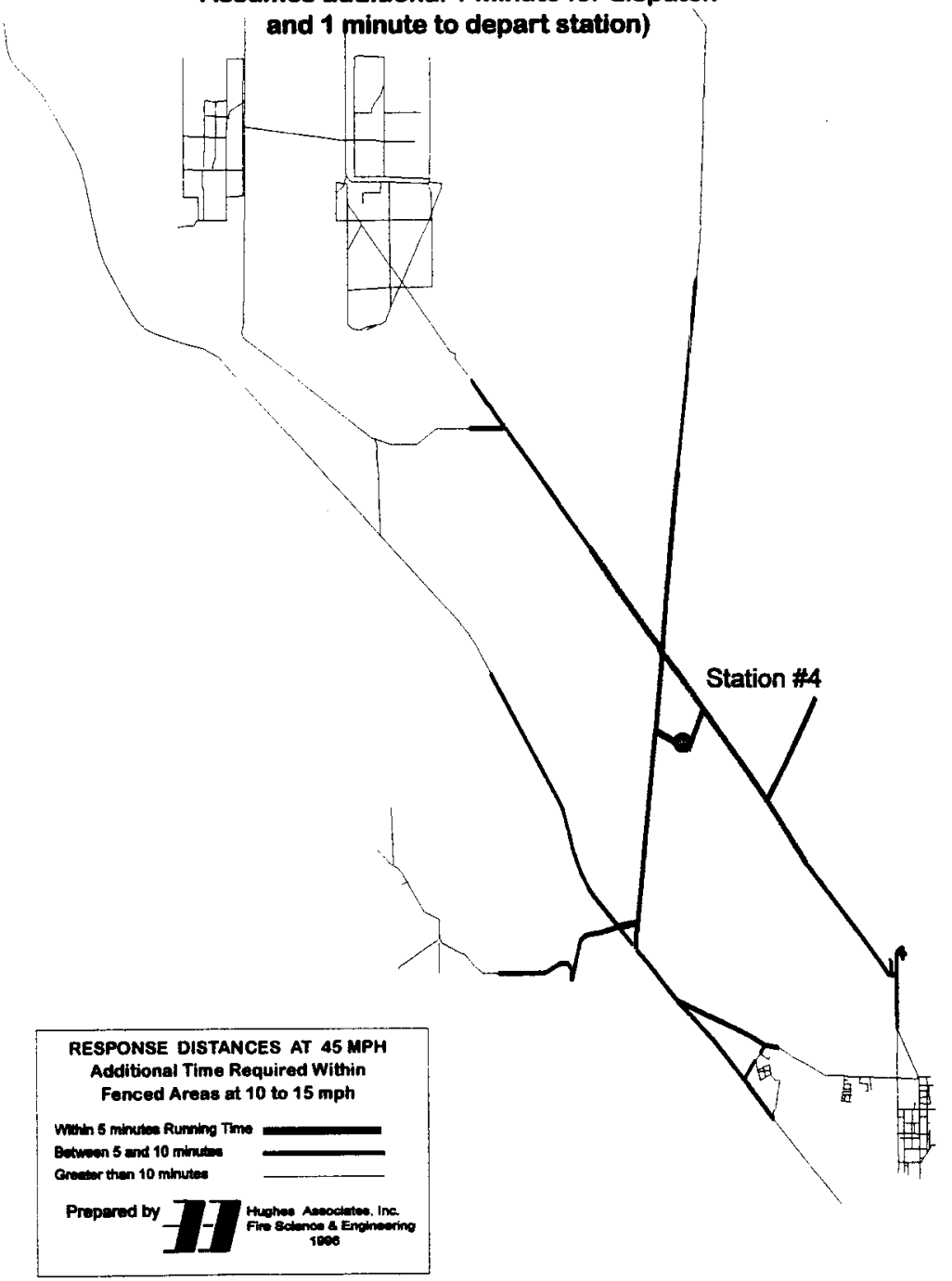

D. 10 
WHC-SP-1180, Vol. 1

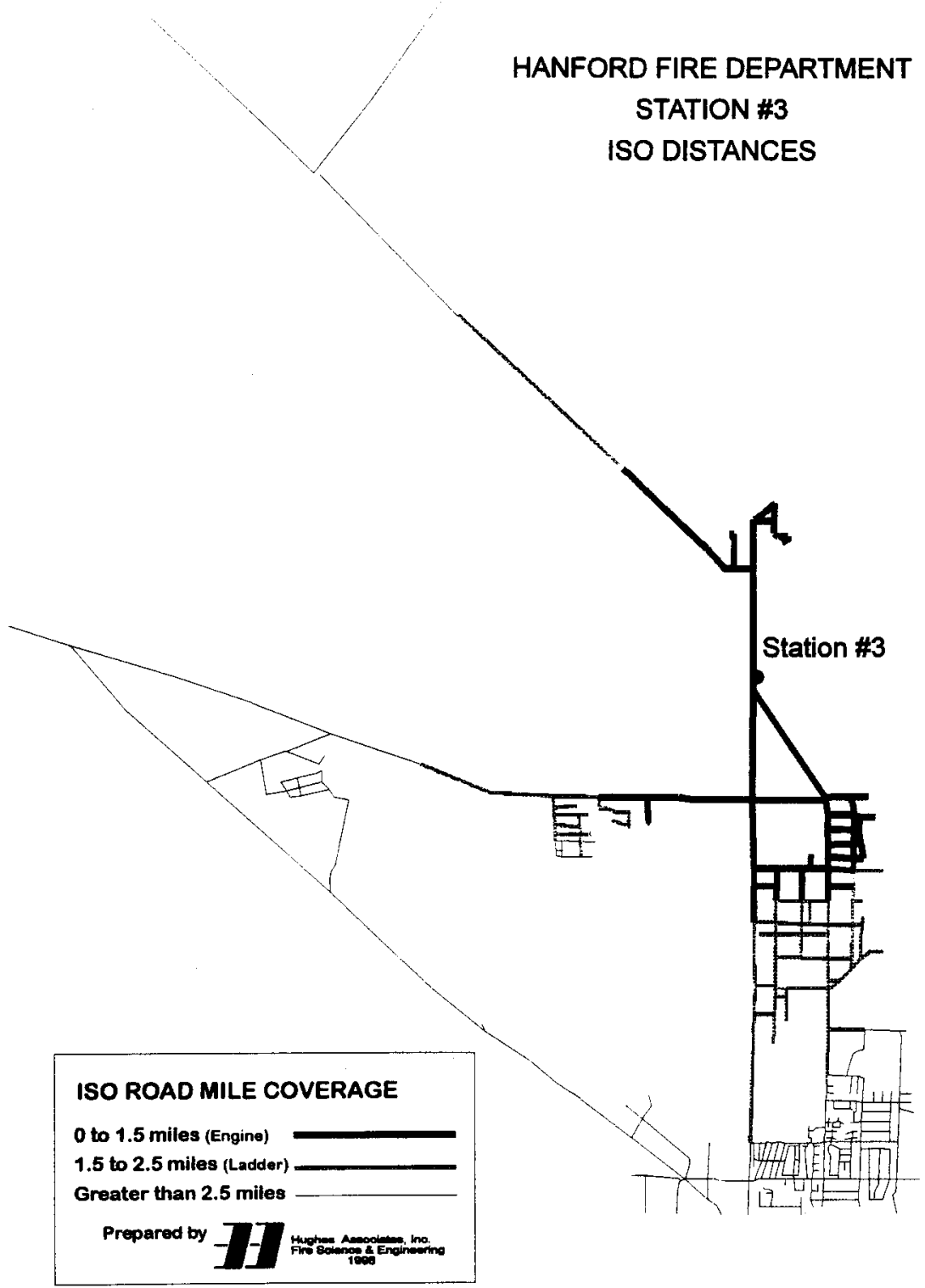

D - 11 


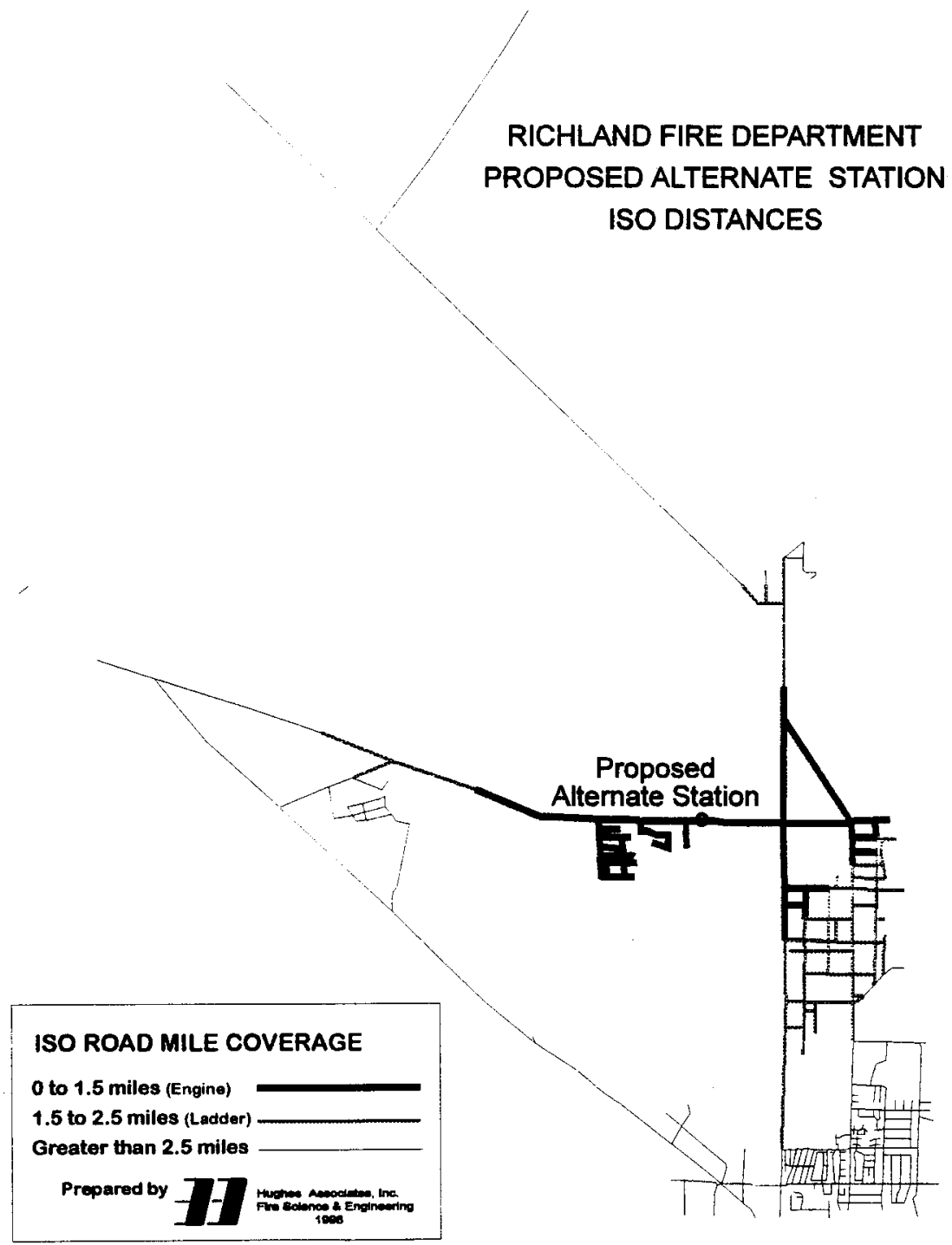

D - 12 


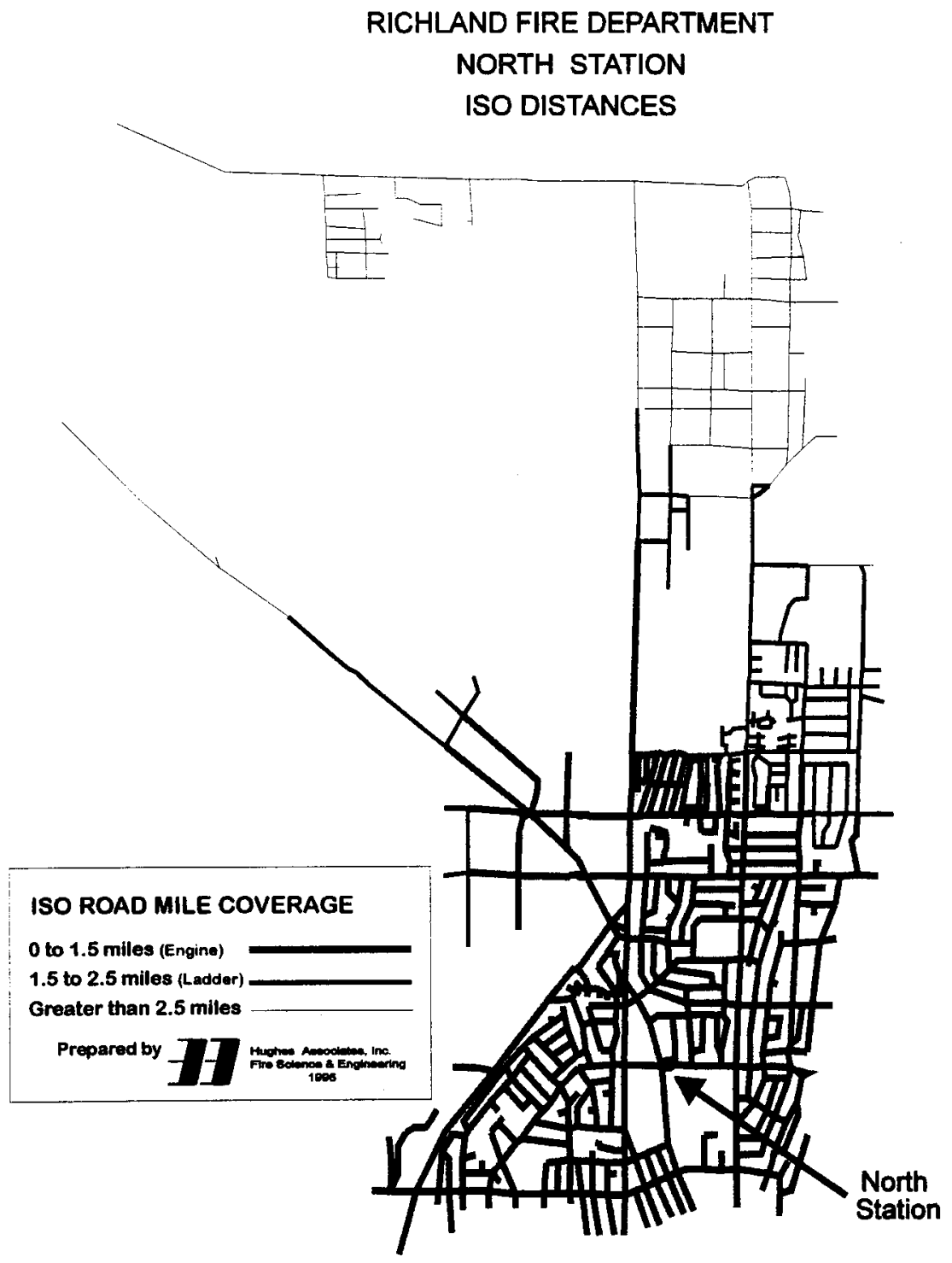


WHC-SP-1180, Vol. 1

\section{HANFORD FIRE DEPARTMENT \\ MAJOR RESPONSE ROUTE COVERAGE \\ FROM STATIONS \#1 AND \#2 \\ AT AN AVERAGE $45 \mathrm{mph}$}

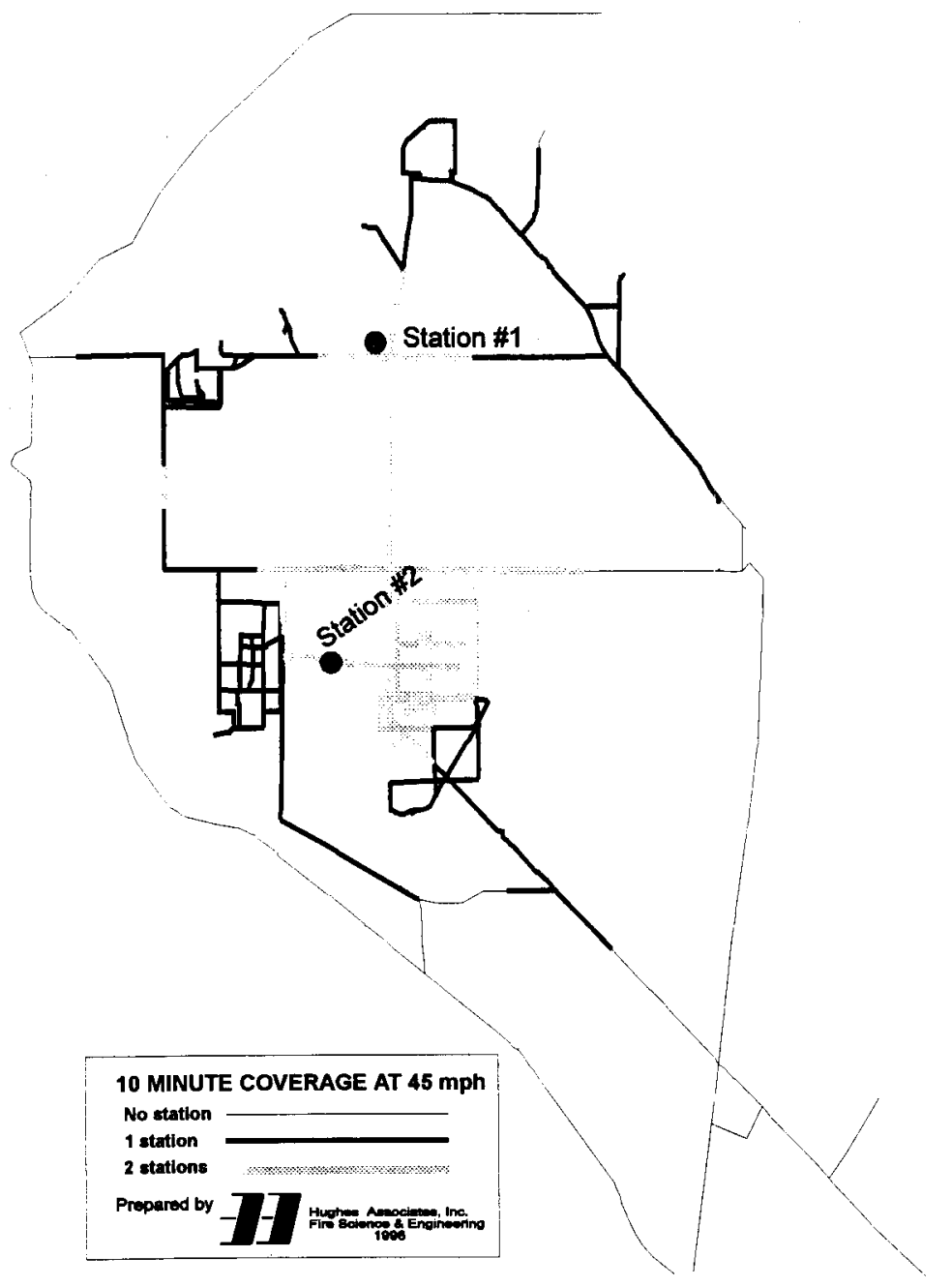

D - 14 
WHC-SP-1180, Vol. 1

HANFORD FIRE DEPARTMENT

MAJOR RESPONSE ROUTE COVERAGE

FROM STATIONS \#3 AND \#4

AT AN AVERAGE $45 \mathrm{mph}$

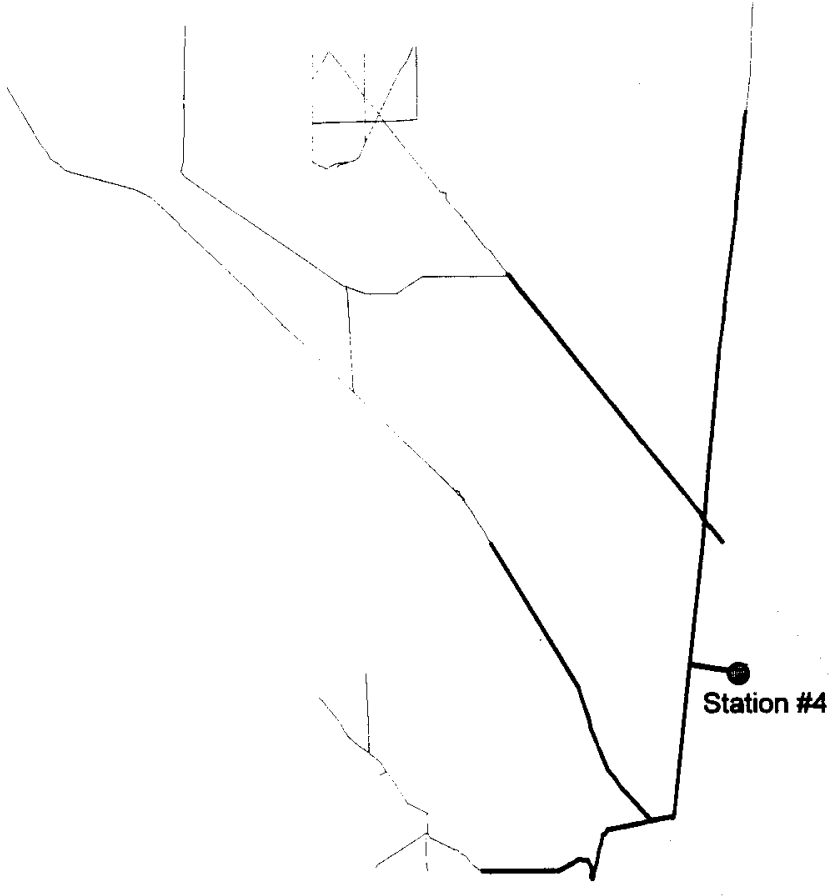

10 MinUte COVERAGE AT $45 \mathrm{mph}$

No station

1 station

2 stations

$\ldots+\infty$

Prepared by
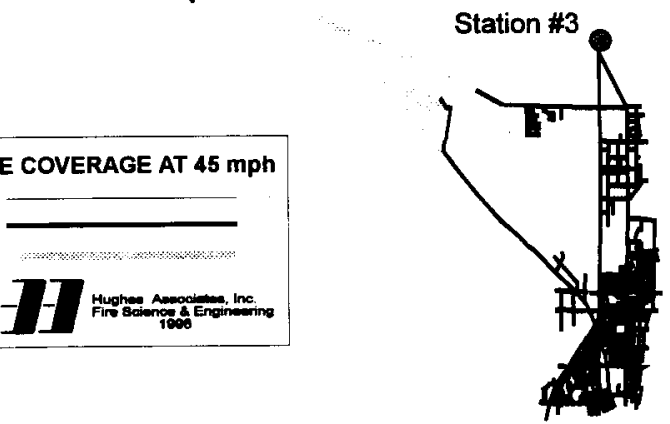

D - 15 
WHC-SP-1180, Vol. 1

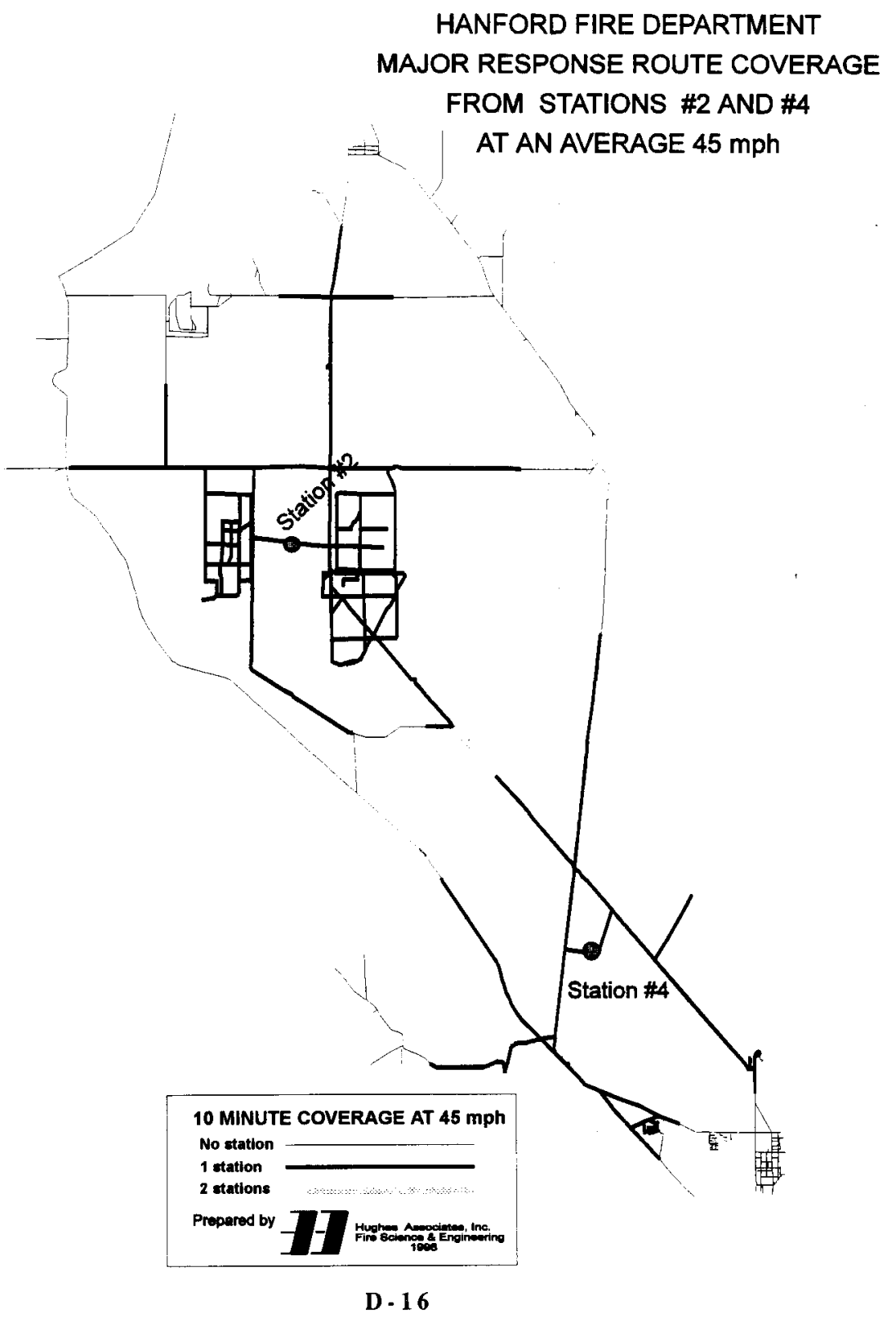




\section{HANFORD FIRE DEPARTMENT AMBULANCE} MAJOR RESPONSE ROUTE COVERAGE FROM STATION \#1 AT AN AVERAGE $50 \mathrm{MPH}$

(Travel time/Distance: Assumes 1 minute for dispatch and 1 minute to depart station)

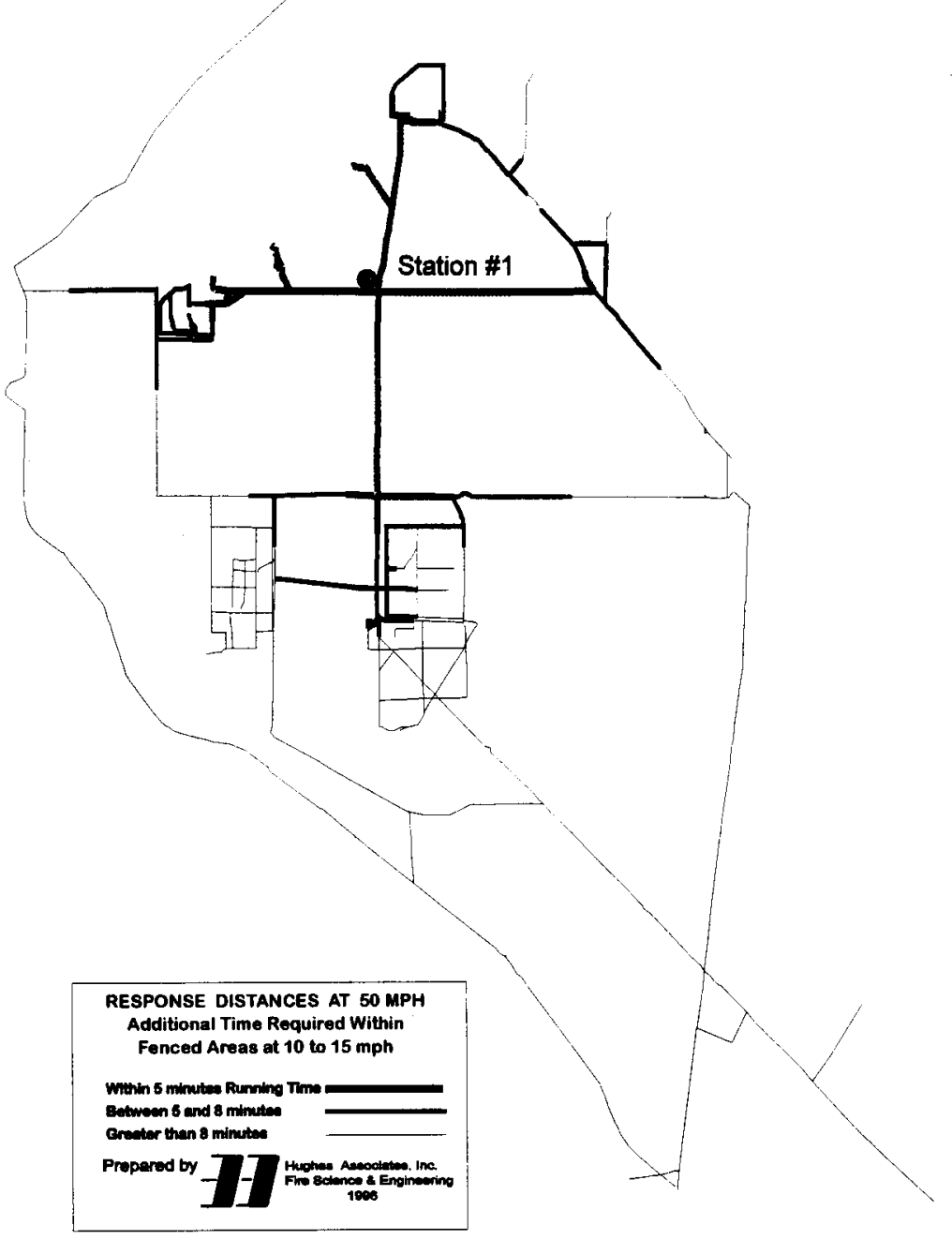




\section{HANFORD FIRE DEPARTMENT AMBULANCE MAJOR RESPONSE ROUTE COVERAGE}

FROM STATION \#2 AT AN AVERAGE $50 \mathrm{MPH}$

(Travel time/Distance: Assumes 1 minute for dispatch and 1 minute to depart station)

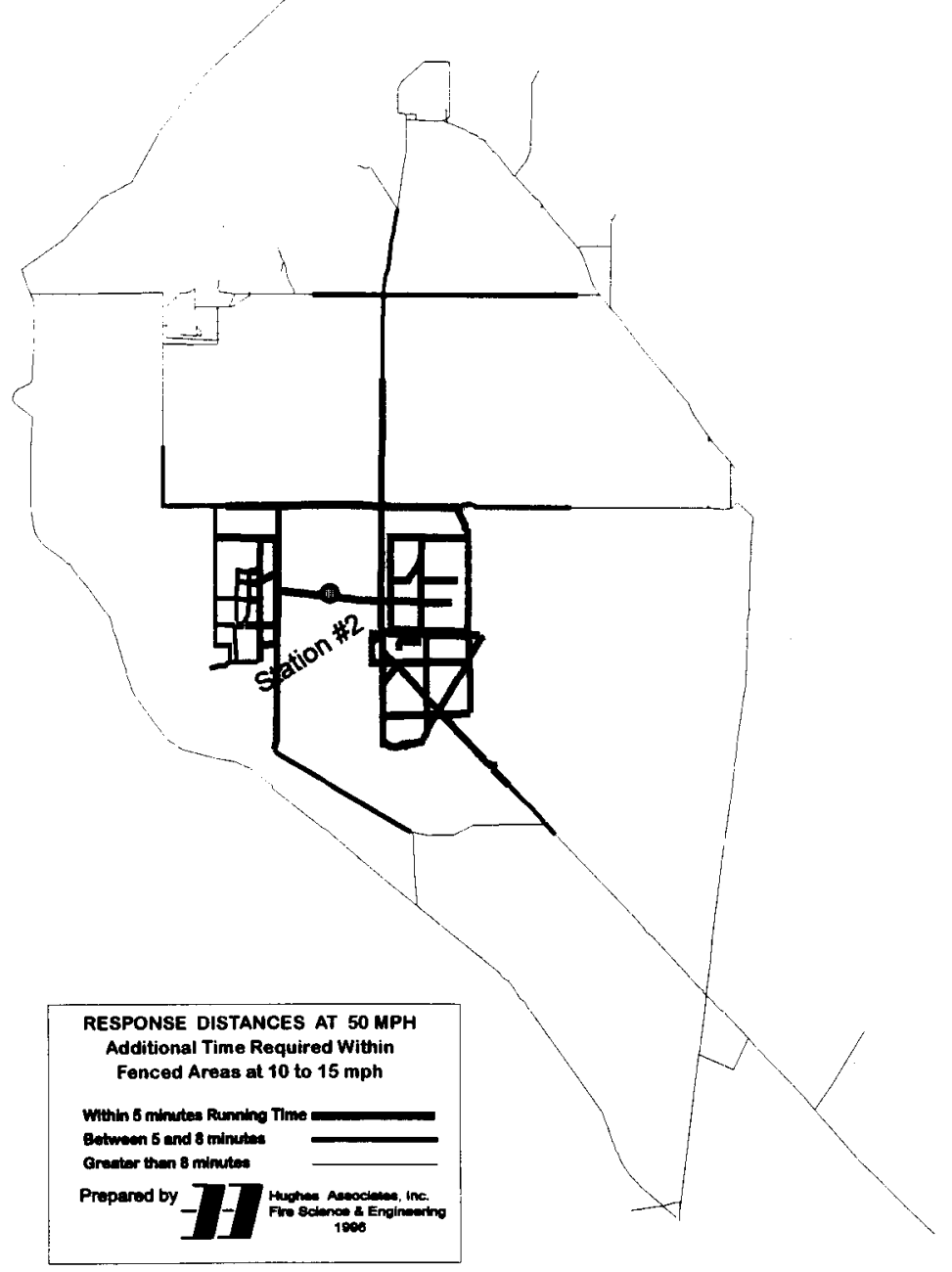

D -18 
HANFORD FIRE DEPARTMENT AMBULANCE MAJOR RESPONSE ROUTE COVERAGE

FROM STATION \#3 AT AN AVERAGE $50 \mathrm{MPH}$

(Travel time/Distance: Assumes 1 minute for dispatch and 1 minute to depart station)

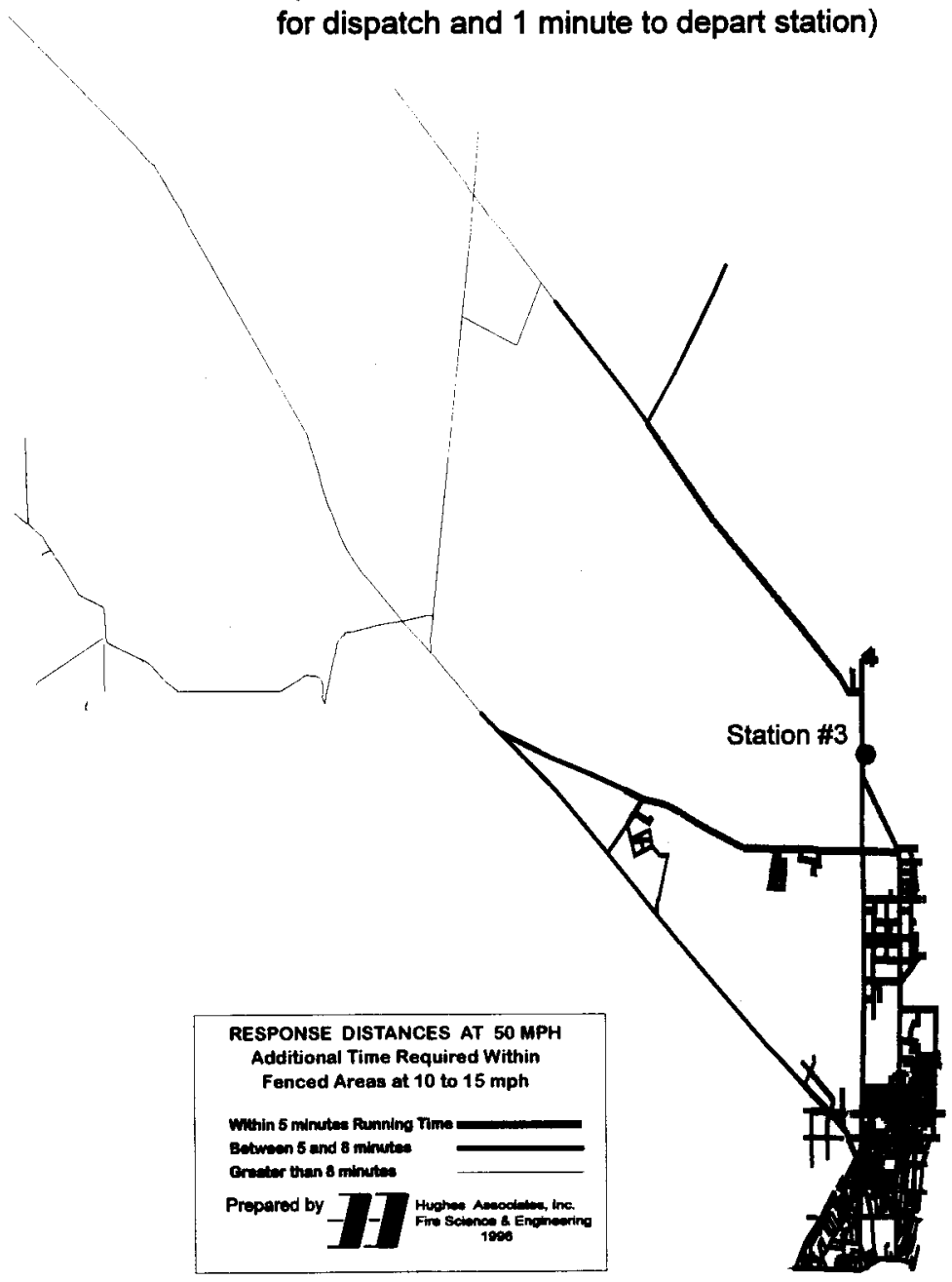


WHC-SP-1180, Vol. 1

HANFORD FIRE DEPARTMENT AMBULANCE MAJOR RESPONSE ROUTE COVERAGE

FROM STATION \#4 AT AN AVERAGE $50 \mathrm{MPH}$

(Travel time/Distance: Assumes 1 minute

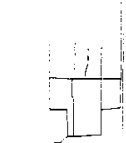

for dispatch and 1 minute to depart station)
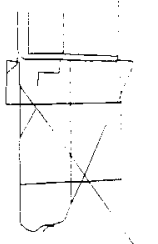

RESPONSE DISTANCES AT $50 \mathrm{MPH}$

Additional Time Required Within

Fenced Areas at 10 to $15 \mathrm{mph}$

With 8 minutes Ruming Tine

Butween 5 and 8 mimute:

Greater then 8 minutes:

Prepared by

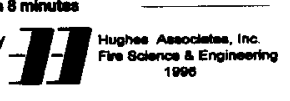

\section{Station \#4}
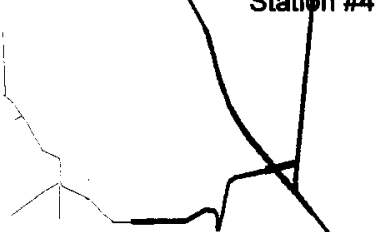
WHC-SP-1180

Volume 1

\section{Distribution Sheet}

$\mathrm{RL}$

S. J. Veitenheimer (3) A5-55

WHC

D. E. Good

S3-97

D. E. Hare

N1-97

W. R. Hayes

S3-97

R. E. Jordan

S3-97

W. M. Knight

S3-96

R. M. Messer

S3-97

C. E. Swift

S3-97

R. E. Traister

B3-63

Document Processing Center

A3-94 
THIS PAGE INTENTIONALLY LEFT BLANK 
WHC-SP-1180

Revision 0

Volume 2

\section{Master Plan}

Prepared by

Hughes Associates

3610 Commerce Drive, Suite 817

Baltimore, Maryland 21227-1652

Date Published

April 1996

Prepared for the U.S. Department of Energy

Assistant Secretary for Environmental Management

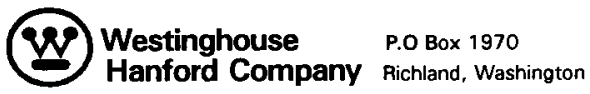

Management and Operations Contractor for the

U.S. Department of Energy under Contract DE-AC06-87RL10930

Approved for public release; distribution is unlimited 
THIS PAGE INTENTIONALLY LEFT BLANK 
LEGAL DISCLAMER

This report was prepared as an account of work sponsored by an agency of the United States Government. Neither the United States Government nor any agency thereof, nor any of their employees, nor any of their contractors, subcontractors or their employees, makes any warranty, express or implied, or aseumes any legel liability or responsibility for the eccurecy, completeness, or any third party's use or the results of auch use of any information, epparatus, product, or process disclosed, or represents that its use would not infringe privately owned rights. Reference herein to any specific cormmercial product, process, or senvice by trade name, trademark, manufacturer, or otherwise, does not necessarily constitute or imply its ondorsement, recommendation, or favoring by the United States Government or any ageney thereof or its contractors or subcontractors. The views and opinions of authors expressed herein do not necessarily state or reflect those of the United States Government or any egency thereot.

This roport has been reproduced from the best available copy. Available in paper copy and microfiche.

Available to the U.S. Department of Energy

and its contractors from

U.S. Department of Energy

Office of Scientitic and Technical Information (OSTI)

P.O. Box 62

Oak Ridge, TN 37831

(615) 576-8401

Printed in the Unitod States of Americe

DISCLM-3.CHP (1-91) 
THIS PAGE INTENTIONALLY LEFT BLANK 


\section{RELEASE AUTHORIZATION}

Document Number: $\quad W H C-S P-1180$, Rev. 0 Volume 2

Document Title: Hanford Site Emergency Response Needs

Release Date: $\quad 4 / 16 / 96$

This document was reviewed following the procedures described in WHC-CM-3-4 and is:

APPROVED FOR PUBLIC RELEASE

WHC Information Release Administration Specialist:

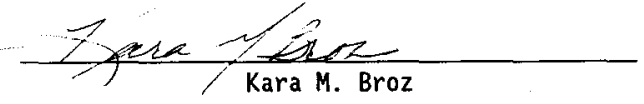

Apri1 16, 1996 
THIS PAGE INTENTIONALLY

LEFT BLANK 


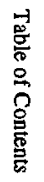


THIS PAGE INTENTTONALLY LEFT BLANK 


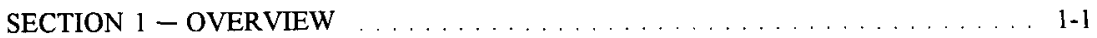

1.1 BACKGROUND ....................... $1-1$

1.2 MASTER PLAN PURPOSE ................. . . . .

1.3 MASTER PLAN DEVELOPMENT AND ASSUMPTIONS $\ldots \ldots \ldots \quad 1-2$

1.4 NEEDS ASSESSMENT BASIS AND PRIORITIES . . . . . . . . 1-3

1.5 MASTER PLAN FORMAT $\ldots \ldots \ldots \ldots \ldots \ldots \ldots \ldots \ldots$

SECTION 2 - RECOMMENDATIONS BY PRIORITY CLASSIFICATION . . . . 2 2-1

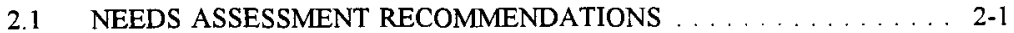

2.2 PRIORTYY I RECOMMENDATIONS $\ldots \ldots \ldots \ldots \ldots \ldots \ldots \ldots . \ldots \ldots$

2.3 PRIORITY II RECOMMENDATIONS $\ldots \ldots \ldots \ldots \ldots \ldots \ldots \ldots .2-5$

2.4 PRIORITY III RECOMMENDATIONS $\ldots \ldots \ldots \ldots \ldots \ldots \ldots .2-23$

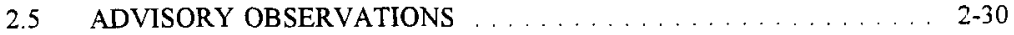

2.5.1 Applicable Requirements . . . . . . . . . . . . . 2-30

2.5.2 Comprehensive Fire Prevention . . . . . . . . . . . 2-31

2.5.3 Disaster Preparedness . . . . . . . . . . . . . . . 2-31

2.5 .4 EMS . . . . . . . . . . . . . . . . . . . . . . 2-32

2.5.5 Emergency Response Procedures . . . . . . . . . . . 2-32

2.5 .6 Legal Issues . . . . . . . . . . . . . . . . . . . . 2-33

2.5 .7 Mission and Goals . . . . . . . . . . . . . . . 2-33

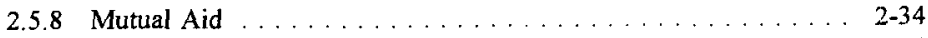

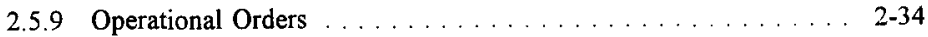

2.5.10 Organizational Structure $\ldots \ldots \ldots \ldots \ldots \ldots \ldots \ldots .2-35$

2.5.11 Shared Response Station ................. 2-35

2.5.12 Technical Rescue Incident Response . . . . . . . . . 2-36

2.5.13 Testing and Service Firefighters . . . . . . . . . . 2-36

2.5 .14 Training Facilities . . . . . . . . . . . . . . . . . . 2-37

2.5.15 HFD Vehicles ..................... 2-38

2.6 RECOMMENDATIONS LISTED BY TECHNICAL SUBJECTS . . . . 2-45

SECTION 3 - MASTER PLAN IMPLEMENTATION TIME FRAME . . . . . . 3-1

3.1 MASTER PLAN IMPLEMENTATION $\ldots \ldots \ldots \ldots \ldots \ldots \ldots \ldots . \ldots .1$

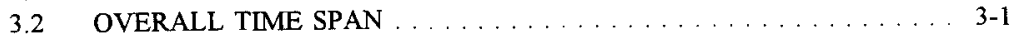

3.3 STRATEGIC ISSUES TIMING $\ldots \ldots \ldots \ldots \ldots \ldots \ldots \ldots \ldots . \ldots \ldots$

3.4 IMPLEMENTATION ACTION TIMING $\ldots \ldots \ldots \ldots \ldots \ldots \ldots . \ldots \ldots$

3.5 TIMING VARIATIONS $\ldots \ldots \ldots \ldots \ldots \ldots \ldots \ldots \ldots \ldots \ldots$

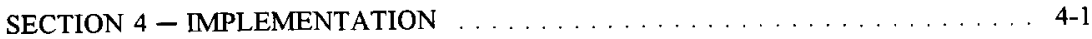

SECTION $5-$ CONTINUATION OF THE PLANNING PROCESS $\ldots \ldots \ldots \ldots$. 5 .

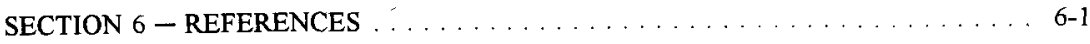


WHC-SP-1180, Vol. 2

ABBREVIATIONS, ACRONYMS, AND INITIALISMS

$\begin{array}{ll}\text { ALS } & \text { Advanced Life Support } \\ \text { ASAP } & \text { As Soon As Possible } \\ \text { BC } & \text { Battalion Chief } \\ \text { BLS } & \text { Basic Life Support } \\ \text { BLS-D } & \text { Basic Life Support Defibrillator } \\ \text { CAD } & \text { Computer Aided Dispatch } \\ \text { CFR } & \text { Code of Federal Regulations } \\ \text { CPR } & \text { Cardiopulmonary Resuscitation } \\ \text { CQI } & \text { Continuous Quality Improvement } \\ \text { D\&D } & \text { Demolition and Decontamination } \\ \text { DOE } & \text { Department of Energy } \\ \text { DOE-RL } & \text { US Department of Energy, Richland Operations Office } \\ \text { DOT } & \text { Department of Transportation } \\ \text { EMS } & \text { Emergency Medical Services } \\ \text { EMT } & \text { Emergency Medical Technician } \\ \text { ENG } & \text { Engine } \\ \text { FAX } & \text { Facsimile Transmission } \\ \text { FEMA } & \text { Federal Emergency Management Agency } \\ \text { FFTF } & \text { Fast Flux Test Facility } \\ \text { FTE } & \text { Full Time Equivalent } \\ \text { HAMMER } & \text { Hazardous Material Management \& Emergency Training \& Education } \\ & \\ \text { HEHF } & \text { Hanford Environmental Health Foundation } \\ \text { HFD } & \text { Hanford Fire Department } \\ \text { IC } & \text { Incident Commander } \\ \text { LIGO } & \text { Laser Interferometer Gravitational-Wave Observatory } \\ \text { MDT } & \text { Mobile Data Terminal } \\ \text { MPD } & \text { Medical Program Director } \\ \text { MRT } & \text { Mobile Response Terminal } \\ \text { NFPA } & \text { National Fire Protection Association } \\ \text { OSHA } & \text { Occupational Safety \& Health Administration } \\ \text { OTEP } & \text { Ongoing Training Through Experience Program } \\ \text { PM } & \text { Preventive Maintenance } \\ \text { PNL } & \text { Pacific Northwest Laboratories } \\ \text { QA/QI } & \text { Quality Assurance/Quality Improvement } \\ \text { RCT } & \text { Radiological Control Technician } \\ \text { SRID } & \text { Standard Regulation Identification Document } \\ \text { T\&S FF } & \text { Testing and Service Firefighters } \\ \text { UBC } & \text { Uniform Building Code } \\ \text { WAC } & \text { Washington Administrative Code } \\ \text { WHC } & \text { Westinghouse Hanford Company } \\ \text { WPPSS } & \text { Washington Public Power Supply System } \\ \text { WSA } & \text { Fire Protection Water Supply Analysis } \\ & \end{array}$




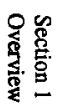


THIS PAGE INTENTIONALLY

LEFT BLANK 
WHC-SP-1 180, Vol. 2

\section{SECTION 1 - OVERVIEW}

\subsection{BACKGROUND}

Hughes Associates, Inc. (HAI) was requested by the Westinghouse Hanford Company (WHC) to prepare a third party assessment of fire department services for the U.S. Department of Energy's Hanford site (HAI, 1996) and an accompanying planning document (Master Plan) presenting implementation methods for any recommended modifications in fire department service methodologies. The statement of work for the project recognized that: "We are presently in a time of rapidly changing federal budgets and significantly changing missions for U.S. Department of Energy (DOE) sites such as Hanford... In light of these changes, it is imperative that we re-evaluate our emergency services to assure that the services being offered meet the changing needs of the site, while simultaneously reducing costs to the lowest possible level." (Swift, 1995)

This Master Plan document is based on, and accompanies, the Hanford Fire Department Needs Assessment (Needs Assessment) (HAI, 1996). The Master Plan is directed to cover a total time span of from five to seven years.

A new contract for Hanford Site management is being prepared for release later in 1996. For purposes of implementing the master plan, irrespective of whomever the contract is awarded to, the fire department and related emergency services organization are referred to in the Needs Assessment and in the Master Plan as the Hanford Fire Department (HFD). The HFD management contractor (currently, WHC) is referred to in the Master Plan as either WHC or 'the Contractor".

\subsection{MASTER PLAN PURPOSE}

The purpose of the Master Plan is to present the recommendations for HFD service methodology modifications described in the HFD Needs Assessment, and to outline a change process to achieve them. The modifications are based on the recommendations described in the Needs Assessment. Because the basic fire suppression, emergency medical, and the other related services delivered to the Hanford site by HFD cannot be interrupted, any modifications or changes to the HFD and its services must be accomplished without compromising baseline service levels. This may necessitate a transitional process.

The baseline service level is defined as the minimum level of fire/EMS protection which the needs assessment team judges to be in compliance with mandatory criteria.

The Hanford site is in a long-term transitional mode, with goals including the decontamination and decommissioning of plants and facilities as well as site remediation. Considering this change of mission and the multiplicity of new uses for selected site areas emerging, the Master Plan must be subjected to continuing scrutiny and adjustment. Detailed predictions of site status over the medium-term future are based on the Contractor documentation. However, site redevelopment plans are dynamic, and so must be the Master Plan for site protection. In light of this somewhat fluid situation, an important facet of the 
Master Plan must be to identify a viable process for continuing master planning in recognition of the unanticipated but important factors which may emerge.

\subsection{MASTER PLAN DEVELOPMENT AND ASSUMPTIONS}

As noted, the Master Plan reflects and is based on the recommendations which are set forth and prioritized in the Needs Assessment. Through an extensive involvement, comment, and review process, HFD senior staff have a detailed understanding of those recommendations and their intent. Thus this Master Plan is designed to guide implementation and not replicate the details of the Needs Assessment. The Master Plan must be treated as a follow-on document.

The Master Plan has been developed using the following assumptions concerning Hanford site protection for the five to seven year period covered by the plan:

1. U.S. Department of Energy (or similar) oversight will be continued;

2. A "Hanford Fire Department," either free-standing or subsumed under another emergency response organization will be maintained;

3. Various Federal requirements, national and industry standards, and site contractor requirements will continue to be applicable. In some instances, there will be modifications of existing criteria and "drivers," or, possibly significantly changed versions;

4. Service delivery by the HFD to the Hanford site will continue to encompass comprehensive fire prevention, pre-emergency planning, systems testing and maintenance, fire suppression, disaster response, Emergency Medical Services (EMS), hazardous materials incident mitigation, technical rescue, and related functions;

5. The focus on adequate service delivered in the most cost effective manner will continue;

6. Innovative and flexible approaches by HFD to the challenges and problems of affordable site protection will become increasingly necessary;

7. Implementation methodologies outlined in the Master Plan are guidelines for DOE, the Contractor, and HFD officials. They are not intended to force particularized management decisions or to micro-manage HFD.

8. All of the recommendations detailed in the Master Plan stem from specific recommendations in the Needs Assessment and are identified using the Recommendation numbering system. Other Master Plan statements, so indicated, are advisory observations, not specific recommendations. 


\subsection{NEEDS ASSESSMENT BASIS AND PRIORITIES}

The needs assessment process required an analysis of the risks associated with Hanford's current and planned mission and activities, and the identification of the resulting postulated/credible events and incidents to which the HFD likely would be called upon to respond. Additionally, the needs assessment process identified other, non-emergency, services provided by the HFD's mission (such as facility inspection and system testing) plus HFD internal organizational functions (such as training and record keeping)

Each of these service types and organizational functions led to the recommendations contained in the Needs Assessment, and, consequently, to the implementation guidelines presented in the Master Plan. As an indication of urgency levels, the Needs Assessment placed the various recommendations into three categories, as follows:

Priority I These recommendations result from requirements reflected in mandatory criteria. Additionally, these recommendations may stem from conditions, events or risks which if left unchanged could result in an imminent hazard to site employees, HFD firefighters, or could result in an environmental release in excess of allowed limits. Priority I items are considered an emergency condition and should receive highest priority for implementation.

Priority II These recommendations result from the professional judgment of the needs assessment team members and stem from conditions, events or risks which if left unchanged could reduce the level of fire/EMS protection below baseline service levels. Priority II items impact baseline service levels of fire/EMS protection and therefore should be implemented as soon as possible. However, when qualitatively evaluated in the context of site history and experience, these items are not considered to represent an immediate emergency condition.

Priority III These recommendations result from the professional judgment of needs assessment team members and stem from conditions, events or risks which if left unchanged could reduce the desirable level of fire/EMS protection, but not below baseline service levels. Priority III items should be scheduled for implementation with due consideration of funds and resources.

Generally, the timing of an implementation measure for a given recommendation is a function of priority classification. However, the unavailability of enabling policy, or budget constraints, or other compelling blockages can necessitate shifts in the timing sequence. For any recommendations which are sequentially interdependent, a delay in implementation of one recommendation may affect the timely implementation of a related recommendation.

\subsection{MASTER PLAN FORMAT}

Following Section 1, Background and Overview, the Master Plan lists the Needs Assessment Recommendations by priority category (Section 2). These constitute the recommended changes for which implementation action is needed. For each Recommendation, various types of information are presented: 
1. The Recommendation and its priority classification, with the same numbering system used in the Needs Assessment;

2. Impact and supporting summary, plus any options/alternatives;

3. Implementation steps.

Section 2 also lists Recommendations by Technical subject, for ease of reference.

Sections 3 and 4 of the Master Plan provide additional information concerning the implementation time frame. The HFD Chief and managers, working with DOE and contract officials, will develop a strategic schedule to implement the recommendations of the Needs Assessment. As policy decisions are formulated, operational change concurrences obtained, and cost/savings identified and approved, each of the recommendations will be phased-in appropriately. The complexity of the Site's transitional period and the resultant operational changes necessary for HFD necessitate both a phased development of the implementation plan itself and the cost/savings factors which will be identified in each section.

Section 5 of the Master Plan discusses the necessity to conduct reviews of the Master Plan periodically.

Section 6 of the Master Plan lists references. 


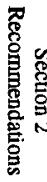


THIS PAGE INTENTIONALLY

LEFT BLANK 


\section{SECTION 2 - RECOMMENDATIONS BY PRIORITY CLASSIFICATION}

\subsection{NEEDS ASSESSMENT RECOMMENDATIONS}

The Needs Assessment presents recommendations in three priority classifications. To aid in the development of an implementation plan by HFD officials, this Master Plan lists the recommendations by priority, and provides additional information concerning each. The recommendations are identified by the numbering system used in the Needs Assessment.

\subsection{PRIORITY I RECOMMENDATIONS}

\section{Recommendation 9.3.3.6}

"Clarification is needed concerning firefighters returned to "full duty" by Hanford Environmental Health Foundation (HEHF), but not allowed full duty assignments. HFD and HEHF officials must clear up this problematical situation."

Impact and Supporting Statement:

The recommendation to rectify the existing situation--which has firefighters returned to "full-duty", but with operating restrictions--creates numerous staffing problems in small departments which have little or no flexibility in response assignments. In firefighting, one can either do the entire set of response tasks or not be assigned to respond. Additionally, the existing situation would appear to have potential for legal exposure. All personnel returned to duty must be physically able to perform all tasks.

Options/Alternatives: None identified.

Implementation: Immediate.

\section{Recommendation 9.3.3.7}

"Site supervisory personnel must be made aware of the need to call 911 when medical situations occur and not transport a potentially critical and unstable patient to a first aid location. Medical situations shall include all cardiac complaints, serious injuries, or injuries with a potential neurological component and all severe respiratory complaints."

Impact and Supporting Summary:

Increasing the use of HFD ambulances and trained emergency medical personnel to stabilize and transport critical patients directly from the work place to the hospital--rather than private autos first transporting to a first aid station--will increase the level of safety of site occupants.

Options/Alternatives: None identified 
Implementation: Annual facility-wide supervisors' advisory is needed to create personal awareness. Concurrence of the Site Medical Director is needed.

\section{Recommendation 9.3.3.9}

"The HFD shall adhere to EMS patient care procedures, and protocols, and guidelines established by the Benton Franklin County protocols and the State of Washington as stipulated by the Medical Program Director (MPD)."

Impact and Supporting Summary:

It should be clear that where conflicts involve the HFD EMS personnel, the EMS patient care procedures, protocols, and guidelines established by the MPD take precedence in all cases. This is inherent to the existing EMS system which certifies EMS personnel and requires them to act under the license of the MPD granted by the State of Washington.

Options/Alternatives: None identified.

$$
\text { Implementation: As Soon As Possible (ASAP). }
$$

\section{Recommendation 9.6.3.3}

"Consolidate the entire fire dispatch and emergency communications system function so that its functions are overseen by the HFD. Alternatively, reestablish a site emergency alarm-dispatch-communications feasibility task force which allows for equitable participation of all possible users, and which examines the feasibility of a Site-wide facility controlled by an equitable multi-agency policy board."

\section{Impact and Supporting Summary:}

Recommendation 9.6.3.3 calls for HFD administration to bring about a change in the way 9-1-1 telephone calls are handled. The recommendation provides for the fire dispatcher to be "handed" the call from the public safety answering point call taker immediately, with the necessary information given directly by the caller to the fire dispatcher. Because of response distances at Hanford, time cannot be wasted. This recommendation assumes that all emergency communication and dispatch on site will not be centralized under the Hanford Patrol. Should that decision be made, and a centralized facility planned for, then both the planning group and the operating/policy board for the center must have full and equitable HFD representation.

Options/Alternatives: None identified.

Implementation: Following DOE and the Contractor decision on fire/EMS communication. 


\section{Recommendation 9.7.10.5}

"The HFD shall be provided with the capability of ensuring (and validating) that all emergency services can be performed within the applicable dose limitations."

Impact and Supporting Summary:

Emergency responders must make appropriate decisions regarding radiological exposures. This capability requires either that HFD personnel be furnished additional radiological equipment and training, or that a Radiological Control Technician (RCT) be assigned as a first responder to all radiological incidents.

Options/Alternatives: None identified.

Implementation: Immediate.

\section{Recommendation 9.7.10.6}

"The HFD dose limits shall be revised to reflect the criteria stipulated by 10 Code of Federal Regulations (CFR) 835."

Impact and Supporting Summary:

HFD personnel must comply with applicable dose limits stipulated by CFR 835 .

Options/Alternatives: None identified.

Implementation: ASAP

\section{Recommendation 9.10.3.9}

"The following EMS Skills maintenance items shall be made a priority for the EMS System:

- $\quad$ Close monitoring of Continuing Medical Education and field performance;

- All paramedics should be required to perform ride along or hospital time on a monthly basis;

- A medical director should be providing the paramedic ongoing training through experience program (OTEP) training as well as overseeing the upgrading and maintenance of skills;

- Quality Assurance/Quality Improvement (QA/QI) should focus on the issue of skills maintenance and appropriate procedural evaluations."

Impact and Supporting Summary:

Washington Administrative Code (WAC)-246-9766-090 (Continuing Medical Education Units) calls for evaluation of knowledge and skill performance ... through written 
assessment and skill performance. Recommendation 9.10 .3 .6 provides for training, oversight, and evaluation by a medical director.

Options/Alternatives: None identified.

Implementation: ASAP

\section{Recommendation 9.11.2.1}

"A medical director should be responsible for all aspects of the initial QA/QI and should work towards developing a program of continuous quality improvement (CQI))"

Impact and Supporting Summary:

Close medical supervision of EMS services is essential and must be part of a CQI program. The Needs Assessment, in 9.11.2.1, provides details concerning this needed program.

Options/Alternatives: None identified.

Implementation: Immediate and on-going.

\section{Recommendation 9.11.2.2}

"A stand alone procedure shall be developed and implemented which provides independent validation that applicable HFD procedures are being followed."

Impact and Supporting Summary:

In accordance with DOE $57006 \mathrm{C}$, "Quality Assurance," and DOE Order 5480.19, "Conduct of Operations," a program should be developed whereby the operational readiness of critical apparatus, equipment, and operations are overseen to the extent that a high level of assurance exists that equipment and personnel will function as required when needed. The program should provide a structure for an independent review of routinely checked items.

This review would require a supervisor to periodically revisit a routine operation with the individual who performs the checking function. The supervisor reviews the process with the individual who originally reviewed the item to determine if the check was performed following appropriate procedures. The benefit of such a program is that it places emphasis on the importance of doing a job correctly. It provides a stand-aione procedure which, when applied regularly, will assure that employee quality assurance checks are carried out and followed-up on properly.

Options/Alternatives: None identified.

Implementation: Immediate 


\subsection{PRIORITY II RECOMMENDATIONS}

\section{Recommendation 9.3.3.1}

"There shall be 17 response personnel on duty assigned to stations to handle, simultaneously, one hazardous materials or fire incident and one EMS incident (this number includes the Battalion Chief, but excludes the dispatcher). Actual deployment of the 17 baseline service level personnel shall be determined by HFD management, in order to achieve the services capabilities cited in Recommendation 9.3.3.2. A staffing multiplier to determine actual minimum on-duty staffing levels shall be developed by HFD officials to account for time off allowed by contract, shift arrangements, sick days lost, light duty personnel, station configuration and crew deployment, shifts in area populations and occupancies, activity, and resulting workloads, recalls, training assignments, fire watches, etc."

Impact and Supporting Summary:

In keeping with a purpose of the Needs Assessment as stated in the Statement of Work, "...it is imperative that we re-evaluate our emergency services to assure that the services being offered meet the changing needs of the site, while simultaneously reducing costs to the lowest possible level" (p.1), the Needs Assessment describes a minimum critical baseline service level number of HFD responders assigned to the Site.

Options/Alternatives: Staff station response crews at numbers higher than baseline service level deployment if a significant increase in workload occurs in the future.

Implementation: Baseline service level assumptions include specific recommendations. These recommendations must be implemented prior to or simultaneously with this recommendation.

\section{Recommendation 9.3.3.2}

"Based on the existing and predicted hazards and conditions of the Site, critical baseline service level fire station operating times and service capabilities shall not be less than the following:

$\underline{\text { Stations }}$

100 Station: Open weekdays - fire and Basic Life Support Defibrillator (BLS-D) response capability; closed at times of low area population and activities; currently, nights, weekends, and holidays.

200 Station: Open 24 hours - 7 days/week for fire response and *Advanced Life Support (ALS) response capability.

400 Station: Open 24 hours - 7 days/week for fire response and *ALS response capability.

300 Station: Open 24 hours - 7 days/week for fire, and BLS-D response capability. 
WHC-SP-1180, Vol. 2

*ALS is the preferred level of service at this station. This service level, at the HFD management discretion could be relocated to adjust to a change in site populations, activity or risk."

\section{Impact and Supporting Statement:}

The baseline service level station operating times and service capabilities are considered to be critical minimum baseline service levels necessary to provide adequate initial response to credible Site events.

Adjusting the operational hours of the 100 Area Station will assist HFD in maintaining the most cost effective baseline service level deployment of response personnel assigned to station duty, while providing adequate area service.

The baseline service level station operating times and service capabilities for the 100 Area fire station stipulate that the station be open on weekdays to provide fire and basic life support (BLS) response capability and closed at times of low area population and activities such as nights, weekends, and holidays. This recommended change from existing station response capability is based upon the 100 Area HFD response history, the current and projected 100 Area population, as well as current and projected 100 Area activities.

Options/Alternatives: Maintain 100 Area Station operating hours and/or crew staffing at higher than baseline service level deployment if 100 Area response needs should increase significantly beyond current levels.

Implementation: Requires DOE and the Contractor concurrence plus personnel shifts and establishment of full-time Battalion Chief Site coverage.

\section{Recommendation 9.3.3.3}

"A trained incident command officer at the Battalion Chief (BC) level must be on duty at all times. This person will respond as Incident Commander (IC) to each reported working incident, all times, all shifts. Until the $\mathrm{BC}$ arrives on the scene, the first responding Captain shall assume the role of temporary incident commander as now.

Impact and Supporting Summary:

Currently there are two Battalion chiefs on duty simultaneously, week-days only. This arrangement precludes any incident commander or administrative officer on-site nights, weekends, and holidays. Recommendation 9.3.3.3 insures continuing coverage.

This change in organizational structure necessitates increasing the Battalion Chief Full time equivalent (FTE) count by 1.0. Implementation of this recommendations will enable the HFD to respond to all incidents with a command level officer. A command level officer 
allows adequate command level management decision making on-site at all times to meet internal needs for training, and external needs for site-wide comprehensive fire protection.

With one additional FTE Battalion Chief's position, one B/C can be assigned to each 24-hour shift group, with fill-ins used to cover absences.

Additionally, the response functions of the HFD--subject to the national standards and Occupational Safety Health Administration (OSHA) regulations concerning incident command--must be conducted under the supervision of a full-time incident commander. This is especially true of hazmat responses, where the responding Captains should function as hot zone team leaders, safety officer, and rapid intervention team leader. Having a Battalion Chief present on Site nights, weekends, and holidays provides the additional benefits of continuous management at the Chief Officer level plus the presence of an additional emergency responder at the command level.

Options/Alternatives: None identified.

Implementation: Implementation follows concurrence by DOE and the Contractor.

\section{Recommendation 9.3.3.4}

"A trained Safety Officer must be available on each shift for attendance at working incidents. Captains shall be so trained, since HFD protocols assign them this responsibility. Additional personnel also should be so trained so that the assignment may be delegated."

Impact and Supporting Summary:

Both National Fire Protection Association (NFPA) standards (NFPA 1500 and NFPA 1521) and OSHA require that a qualified Safety Officer be present and functioning at major incidents, high risk incidents, and working hazardous materials incidents. NFPA 1521 details the responsibilities of the Incident Safety Officer and provides categories of necessary training. HFD procedures call for Captains to function as Safety Officers, and for the HFD Fire Inspector to assume that role at certain incidents.

The purpose of this recommendation is to incorporate sufficient training, as detailed in NFPA 1521, for all designated HFD Safety Officers. In addition, sufficient personnel, must be identified and trained to allow for the delegation of that responsibility of Safety Officer at major incidents to persons other than the Captains, who already have multiple duties.

Options/Alternatives: None identified.

Implementation: Implementation requires specific training be taken by designated HFD personnel. This may be accomplished in any of several ways, both on and off site. One cost-effective methodology is to have an HFD instructor trained as a Safety Officer trainer for continuing on-site work with other designated personnel. Ongoing implementation. 


\section{Recommendation 9.3.3.5}

"Sufficient Personnel must be trained as hazmat technicians to assure a six person response force available each shift, as now."

Impact and Supporting Summary:

The necessity for having sufficient technician level hazmat responders available on each shift to staff hot zone task requirements plus a stand-by rapid intervention back-up team is aiready recognized and in place for the HFD. The purpose of this recommendation is to assure that a sufficient number of personnel are trained to this higher level and always available for shift assignment, and that a sufficient budget allocation is made annually to cover the negotiated salary differential. (Note that the baseline service level deployment provides for a hazmat team response.)

Options/Alternatives: None identified.

Implementation: Present practice provide a minimum acceptable number of trained hazmat technicians.

\section{Recommendation 9.3.3.8}

"The appropriate recommendations of the Draft Hanford Site Emergency Medical Plan identified below shall be instituted."

- $\quad$ Each Department of Energy, Richland Operations Office (DOE-RL) and contractor supervisor is responsible for the safety of his/her work group. This responsibility includes the communication of designated first responders and the location of and procedures for use of the first aid kits. Contractors are responsible for insuring employees are knowledgeable in the use of the 911 system.

- $\quad$ Each employee is responsible for recognizing and responding to a life or limb threatening illness/injury in a co-worker by activating 911 for emergency medical response.

- Each employee is responsible for knowledge of and access to the work group's designated first-responder to initiate immediate first-aid and Cardiopulmonary Resuscitation (CPR) (if needed) while awaiting the arrival of Hanford site EMS."

Impact and Supporting Summary:

As stated in the Needs Assessment, "The recommendations are consistent with ensuring that all site personnel are aware of the EMS system and their personal responsibilities associated with activating the system. Failure to immediately activate the 
EMS system in a medical emergency situation delays response and consequently may put the patient at undue risk."

Options/Alternatives: None identified.

Implementation: A continuing program of notifications and education of a changing workforce is needed. Project to begin ASAP following concurrences by appropriate officials.

\section{Recommendation 9.3.3.12}

"The HFD and the signatory departments shall delineate--if necessary--any and all restrictions related to the mutual aid that are defined in the mutual aid agreements."

Impact and Supporting Summary:

The mutual aid documents furnished by HFD, entitled "Tri-Cities/County Mutual Aid Agreement," and dated 26 April 1985 and 6 June 1995, each signed by representatives of HFD, Richland, Kennewick, Pasco, Benton County Fire Protection districts 1,2,3,4, and 6, Franklin County 3, and Walla Walla County 5 do not appear to restrict response activities in any way. The Needs Assessment team notes that what it has seen in writing is typical of regular mutual aid agreements and, except for the draft automatic aid document, lists no restrictions. HAI was told, however, that restrictions do exist. Delineating these restrictions in the Mutual Aid Agreement is critical to understanding and making reasoned judgments regarding the effective utilization of all available mutual aid resources. If, as in the draft, unsigned automatic mutual aid document, there are incident type response restrictions, these must be noted in the existing mutual aid agreements.

Options/Alternatives: None identified.

Impiementation: Modifications are necessary to conform to applicable codes and standards to provide for the safety of HFD personnel. As soon as possible, a meeting or meetings shall be held between the HFD Chief and the Chiefs of the other signatory departments.

\section{Recommendation 9.4.3.1}

"The 100 Area Station shall undergo only those modifications necessary to meet applicable OSHA, Life Safety code, and structural integrity requirements."

Impact and Supporting Summary:

Modifications necessary to provide an acceptable level of safety for HFD personnel as stipulated by applicable codes and standards are required. In light of anticipated reduced operating times for the 100 Area Station, only code compliance and structural integrity issues should be addressed. The number of emergency calls answered from the 100 Area Station during off-shift hours has been relatively low. However, minimized running times of 
approximately ten minutes to the primary 100 Area facilities, including the $\mathrm{K}$ Basin, are facilitated by the 100 Area Station, as are running times to the 200 Area on initial response or back-up assignments.

Options/Alternatives: None identified, unless Site population and activity levels increase or decrease significantly in the 100 Area and prompt a reexamination of the operating schedule.

Implementation: Rehabilitation to the recommended extent requires concurrence of the Contractor and DOE. Structural survey already available. Initiate request as soon as decision is made to move to baseline service level deployment.

\section{Recommendation 9.4.3.2}

"Upgrading the existing 200 Area Station to meet all applicable codes and standards, or construct a new station at or near that site."

\section{Impact and Supporting Statement:}

Modifications necessary to provide an acceptable level of safety for HFD personnel as stipulated by applicable codes and standards are required. Additional requirements cited by other recommendations in this report may warrant construction of a new station at or near the site.

The Hanford site's 200 area includes both the 200 East and the 200 West facility complexes, each with a significant number of structures to be serviced by emergency response fire apparatus and the ambulance housed at the 200 Area fire station. The station's location, approximately at mid-point between the two areas, minimizes response time to both facility complexes, with most of the 200 Area reachable within five minutes running time, and the remainder of the built-up 200 area within ten minutes.

In addition, the 200 Area Station allows running times to much of the 100 Area within approximately twelve minutes. Therefore, the 200 Area Station provides either initial coverage during off-shift hours, or full initial response (second apparatus) coverage when the 100 Area Station is staffed.

The 200 Area Station is necessary in order to maintain the existing response times and patterns of coverage for the Site areas north of the Wye Barricade. In addition, the 200 Area Station houses vehicles necessary for that area's protection, as well as the HFD communications center and the outdoor training area.

Options/Alternatives: Rehabilitation or Reconstruction of the 200 Area Station

Implementation: Following build or rehabilitation decision. 


\section{Recommendation 9.4.3.4}

"If new construction takes place at the 200 Station Site, the design shall incorporate adequate provisions for a communications/alarm/dispatch facility. Should the communications function be moved to another location, all applicable provisions shall be met."

\section{Impact and Supporting Statement:}

This Recommendation calls for an adequate emergency communications facility, meeting all code requirements.

Options/Alternatives: None identified.

Implementation: Proper design and construction of the communications center is necessary. Decision for new construction follows the decision concerning the site-wide communication system, plus decision concerning 200 Area Station construction.

\section{Recommendation 9.4.3.6}

"The 400 Area Station shall undergo those modification necessary to meet applicable OSHA, Life Safety Code and structural integrity requirements."

Impact and Supporting Summary:

Modifications are necessary to conform to applicable codes and standards to provide for the safety of HFD personnel.

Options/Alternatives: None identified.

Implementation: As soon as possible, following necessary concurrences.

\section{Recommendation 9.4.3.7}

"Postpone the decision to construct a new 300 Area Station until a decision is made concerning a Richland-HFD combined Station or an outsourcing arrangement. If such a decision is not forthcoming, proceed with planning for a new 300 Area Station on site."

\section{Impact and Supporting Summary:}

Modifications are necessary to conform to applicable codes and standards to provide for the safety of HFD personnel. Assuming that a joint Richland-Hanford Fire Station is not planned, a renovated or new HFD 300 Area Station is essential to provide acceptable initial service response times to the 300 Area's major facilities. A minimized running time of approximately ten minutes is facilitated to the extended 300 Area and those other designated Site Areas (such as the 1100 Area) where HFD response is necessary. 
Additionally, the 300 Area Station's existing location minimizes back-up service running time to the $400 \mathrm{Area}$, and also allows for timely mutual aid response to the City of Richland.

Any major existing building, OSHA, or NFPA code deficiencies presenting health or safety problems require corrective action.

Options/Alternatives: Construct an adequately sized and properly located shared station with the City of Richland

Implementation: Prior decision concerning shared station is needed. Should that decision be not to proceed with a shared station, then rehabilitation or reconstruction of the 300 Area Station should proceed ASAP.

\section{Recommendation 9.5.6.1}

"Maintain as a minimum, one first line Quint at each operational fire station."

Impact and Supporting Statement:

This recommendation calls for a continuation of the present vehicle deployment pattern. The nature of site structures and risks, plus baseline service level deployment of response crews clearly warrants the use of Quint type apparatus.

Options/Alternatives: None identified

Implementation: Retain existing vehicle deployment pattern. Replace existing Quints as necessary.

\section{Recommendation 9.5.6.2}

"Maintain a minimum of four reserve triple combination pumpers for the entire Hanford Site."

\section{Impact and Supporting Summary:}

Presently, there are four reserve (or second line) pumper apparatus, one for each of the four fire stations. These apparatus are intended to be used by recalled firefighters and/or Testing and Service Firefighters (T\&S FF) who are called to respond to an ongoing incident, to provide mutual aid off Site, and to cover the stations in case of additional alarms. In addition, these vehicles are used to replace first-line apparatus undergoing maintenance and repair, which is sometimes lengthy. Without these four pumpers, recalled emergency responders or T\&S FF would be without structural firefighting vehicles and the equipment they carry. Each of the four stations needs a reserve vehicle.

Options/Alternatives: None identified. 
Implementation: Retain existing vehicle deployment pattern. Replace existing reserve pumpers as necessary.

\section{Recommendation 9.5.6.3}

"Maintain a minimum of one reserve ambulance unit for the entire Hanford site."

Impact and Supporting Summary:

Under existing workload, one reserve ambulance appears sufficient to provide breakdown coverage. Should EMS transportation runs increase due to Site D and D work or other causes, or should a standby ambulance be necessary to provide special project coverage for extended periods, then a reexamination of this Recommendation is warranted.

Options/Alternatives: Maintain two reserve ambulances

Implementation: Do not discard any of the six existing ambulances. At appropriate time, assuming workload so indicates, move to one reserve ambulance.

\section{Recommendation 9.6.3.1}

"The HFD alarm, dispatch, and emergency communication systems for fire, rescue, and EMS services shall comply with the applicable requirements of NFPA 1221 and shall have as a minimum the following performance characteristics:

1. Fast, direct access by automatic alarm systems (as now) and by telephone callers (not now available).

2. Call switch-over capability from the 9-1-1 call taker.

3. Customized Computer Aided Dispatch (CAD) hardware and software."

4. Customized computer aided systems to handle automatic alarm supervision and testing quickly and accurately.

5. Radio communication capability throughout the service area, with sufficient frequencies to handle routine business, emergency dispatch, tactical incidents, mutual aid communication, and recall of off-duty personnel by two-way pagers.

6. Capability to efficiently transmit data to the mobile data terminal (MDT)s.

7. Facsimile Transmission (FAX) capability to Stations, and MDT print-out capability to vehicles.

8. System redundancy.

9. Capability of being operated by a single dispatcher in medium volume call situations."

\section{Recommendation 9.6.3.2}

"The HFD alarm, dispatch, and emergency communications system shall have the following process characteristics: 
1. Capability of handling simultaneous events.

2. Capability of maintaining a continuous flow of information during a working incident while handling additional dispatches and firefighter recalls.

3. Capability of announcing relevant weather conditions, including wind speed and direction, during incidents for tactical purposes, as now

4. Capability of announcing "time into incident" in five minute increments for incident command purposes, as now.

5. Capability of handling all calls for mutual aid.

6. Capability of notifying all relevant agencies promptly of incidents, and coordinating all responses, as now.

7. Capability of handling EMS dispatches using standard protocols for advising EMS callers."

Impact and Supporting Summary:

Recommendations 9.6.3.1 and 9.6.3.2, when fully implemented, will result in an emergency communications system able to meet all of the Hanford site needs. Emergency communications consist of the following: 1) receipt of calls for aid; 2) the dispatch of HFD units to provide that aid; 3) communication to and among those units; 4) calls relating to mutual aid fire departments or other relevant organizations; 5)recall of off-duty personnel; and 6) fire related transmissions by automatic alarm systems, radio, telephone, mobile response terminal (MRT), FAX, etc. HFD maintains a free standing emergency communications facility, except the telephoned calls to 9-1-1 are answered and handled by the Hanford Patrol communications facility, which--after taking down the information--relays it to HFD.

Several emergency communication difficulties and shortcomings stem from the HFD lack of a multiplex emergency radio system. Multiplex emergency radio systems are supported by DOE. The main driver is the NFPA Standard 1221, "Installation, Maintenance, and Use of Public Fire Service communication systems," 1994 edition, Section 3-4. This standard requires dispatch centers to have redundant methods of contacting responding fire equipment by radio. The NFPA standards are mandatory in DOE orders. The current base radio system does not allow communication on the HFD tactical channel or on frequencies used by surrounding fire districts. When the HFD responds to incidents in the mutual aid area and switches to the frequency used by an off-site agency, the dispatch center can no longer communicate with the HFD apparatus. The same situation occurs on-site when onscene units switch to the fire tactical channel. The requested equipment update would replace the current outdated base radios in the central dispatch center with multiplex units. these new units would allow the dispatch center to communicate on all currently used frequencies, as required by NFPA 1221 .

Options/Alternatives: None identified

Implementation: Continuation of the current equipment up-grade program. Design and implementation of an upgraded recall system. Contractor budgetary approval needed following a cost estimate. Implementation necessary to support baseline service level deployment. 
WHC-SP-1180, Vol. 2

\section{Recommendation 9.6.3.7}

"Design and implement a selective off-duty recall system with the following features:

- Rapid and simple transmission of the recall by single person

- Selective or small group or large group recall

- Recall transmission capability over long distances

- $\quad$ Responder to transmission point feedback capability"

Impact and Support Summary:

The HFD has recalled off-duty personnel whenever additional crew members are needed for large scale incidents or station standby coverage. The method used to recall is sequential telephone dialing, typically done by the HFD dispatcher upon orders from the ranking officer. This method takes dispatcher time, is slow, and typically works only when the firefighter is at home and willing to answer the phone. Most departments using this method with any frequency switch to radio pagers for wider recall coverage and to overcome the problems caused by telephone answering machines and busy dispatchers.

Because of the distances involved between the home of off-duty HFD personnel and some Hanford site locations, sixty minutes can elapse before a crew member arrives at an incident scene or the duty station. Therefore, time is of the essence. The Needs Assessment states:

"A major incident occurring at night or on a weekend could result in the deployment of 20 to 24 responders. A recall of off-duty personnel, depending on the incident location on site, could take 60 minutes for staff augmentation at the incident scene. Under existing operating protocols, personnel are recalled by individual telephone calls. They then drive to their duty fire station on site to obtain their protective clothing. If so instructed, they then proceed to the incident location. The time required for mutual aid departments to arrive could be similar, although they would proceed either to the incident directly, or to cover an HFD station."

A more efficient and effective recall system will provide good support for baseline service level staffing. An effective recall system allows the quick recall of key individuals or pre-selected groups through the pressing of one transmitter button. The dispatcher should be able to recall personnel by a single transmission and quickly determine how many are responding. If an insufficient number respond, a larger group can be recalled. Because of travel distances involved, personnel should be required to notify the dispatcher indicating they are responding. All potential response personnel, including T\&S FF, should be equipped with the necessary paging device. Radio type devices typically offer the best capability.

Options/Alternatives: Use an automatic dialing telephone system if a paging system is not available. 
Implementation: Feasibility, cost estimate, and system design needed.

Negotiations with personnel to carry pagers will be potentially required.

\section{Recommendation 9.7.10.1} units."

"Quick Access prefire plans shall be accessible for personnel use within all first nu

Impact and Supporting Statement:

The complexity of a number of site facilities and their associated risks necessitates that careful planning be accomplished by HFD so that suitable and timely actions may be taken in the event of an incident.

Responding officers and firefighters need quick and ready access to an on-scene action pre-plan. These typically are contained in an indexed, up-dated, hard-copy notebook carried in each vehicle, and available over the vehicles MRT, often in a more detailed format. These quick access pre-fire plans are being prepared by HFD personnel as existing pre-fire plans are updated.

Options/Alternatives: None identified.

Implementation: Continue with existing update program.

\section{Recommendation 9.7.10.2}

"Prefire plans and quick access prefire plans shall be developed for all facilities and areas with significant hazards."

Impact and Supporting Summary:

Areas with replacement costs assigned currently have prefire plans (with quick access pre-fire plans in preparation). Some areas, such as Washington Public Power Supply System (WPPSS), are outside that category but have significant hazards and warrant pre-fire planning. This Recommendation requires additional pre-fire planning--both quick access and in additional detail--beyond that in the existing program.

Options/Alternatives: Proceed with both the existing preplanning program and a parallel program for the new category facilities, or Proceed with the existing program and formulate only quick access pre-fire plans for the new category facilities until existing program work is completed. At that time, formulate detailed preplanning for the new category facilities.

Implementation: As described above in Options/Alternatives 


\section{Recommendation 9.7.10.4}

"Hazmat incident operating guidelines shall be completed."

Impact and Support Summary:

Because of the nature of the site, and especially because of the transition to more extensive waste remediation work, all operating protocols for hazardous materials incident mitigation should be prepared, written, and disseminated to HFD personnel. These hazardous materials incident protocols will provide essential information for hazmat responders, safety officers, incident commanders, and supporting mutual aid departments.

Options/Alternatives: None. Existing protocols from a model hazmat program may be reviewed to facilitate HFD writing.

Implementation: Continuation of the existing "hazmat guideline" production effort, with a target completion date of 12 months.

\section{Recommendation 9.7.10.7}

"The pre-incident exercises and drills which involve the HFD should as a minimum be continued at a level and frequency which currently exists."

Impact and Supporting Summary:

Continuation of an existing program is recommended.

Options/Alternatives: None identified

Implementation: To continue existing program

\section{Recommendation 9.7.10.10}

"Periodic large scale training exercises which activate the firefighter rapid recall system, and utilize T\&S FF in line positions shall be conducted."

Impact and Supporting Summary:

Both the recall system itself and the participating personnel will need periodic exercises so that improvements can be made.

Options/Alternatives: None identified.

Implementation: Implementation following activation of an updated recall system. 


\section{Recommendation 9.8.3.1}

"The Hanford Fire Marshal's office shall be modified to incorporate the following:

- Increase the number of fire inspector positions from one to two FTEs.

- Assign one FTE secretary to the Fire Marshal's office.

- Remove administration and supervision of the HFD training program from the Fire Marshal's office.

- $\quad$ Augment the Site's Public Safety Education program by assigning 0.5 FTE time of one Fire Inspector to the program, including teaching fire extinguisher and related safety classes to workers.

- Maintain coordination between the Fire Marshal's office and the Hanford Fire Protection forum.

- Establish an HFD internal standing committee (chaired by the Fire Marshal, with HFD officer representation) charged with on-going responsibility for maintaining inter-shift coordination of prevention efforts."

Impact and Supporting Statement:

The many duties assigned to the Fire Marshal warrant additional staff support. Further, as DOE continues to increase the number of contractors, the Fire Marshal will need the time and resources to devote to an ever increasing fire prevention program. Efforts to optimize inspections and subsequent reports should be considered. Additional public education is necessary.

Alternatives/Options: None identified.

Implementation: Following approvals for new positions.

\section{Recommendation 9.8.3.2}

"The following recommendations are designed to help assure continuing compliance Site-wide with the necessary and relevant fire and related safety codes and directives:

- $\quad$ Expand the permitting system to include the process outlined in NFPA 1, section 1-15 These may include: explosives, LP-gases, storage of oxidizers and organic peroxides, and use of tar kettles on roofs.

- Ensure that Fire Marshal authority extends to private businesses moving onto the Site and to all contractors. Include construction plan approval.

- Operate as large municipalities do, and be sure the Fire Marshal's responsibility and authority extend to all new operations--public or private--which locate on the Site.

- $\quad$ Prepare a booklet--"Advice from the Hanford Fire Marshal"--for widespread distribution on site. 
- Prepare a fire and related safety video tape for showing to new employees and at manager's meetings.

Impact and Supporting Statement:

As stated in the Needs Assessment:

"The permitting system outlined in NFPA 1 encompasses many more areas than are presently addressed and can be effectively applied to the site fire prevention program. Currently, there are private business moving onto the site that may be unfamiliar with the inherent hazards of the site. For the sake of site activities as well as their own, these business need to be subject to the applicable fire prevention program requirements. Finally, in order to maintain an effective site fire prevention program, the fire marshal's authority should extend to all contractors, site populations, areas and aspects of the site. Site populations, areas or contractors which are exempt may inadvertently expose other areas to undue hazard and risk. This was evidenced recently when it was discovered that a contractor had transported high explosives onto the site without notification or approval of the Hanford Fire Marshal. Expanding the site public safety education program through development and distribution of fundamental fire prevention "advice" and/or requirements may be an effective way to achieving some of the fire prevention program goals. Fire Marshal staffing levels may require reevaluation as these recommendations are implemented."

Options/Alternatives: None identified.

Implementation: Following necessary concurrences.

\section{Recommendation 9.9.3.3}

"When it is evident that continuing medical education and firefighter training for T\&S FF may result in a failure to meet applicable fire protection system requirement, applicable training shall be conducted on off-shift hours."

Impact and Supporting Summary:

As stated in the Needs Assessment,

"Fire protection inspection, testing and maintenance frequencies for all fire protection systems and devices stipulated in WHC-CM-4-41, section 4.2 Rev.1 are primarily those stipulated or recommended by the applicable NFPA Code or Standard. Requirements for correction/restoration of system impairment and system restrictions are reasonable. The extent to which these system responsibilities are not met so that T\&S FF personnel can maintain necessary firefighter-Emergency Medical Technician (EMT) skills maintenance should be minimized.

Because of the desirability and efficiency of maintaining the T\&S FF personnel as trained, on-call emergency responders who augment station personnel, necessary firefighterEMT skills maintenance training during off-shift hours is a reasonable measure. This measure 
will likely require overtime payment but is considered a cost effective methodology when it is necessary to fulfill fire protection system requirements."

Options/Alternatives: Continue as now, if overtime costs are not available.

Implementation: When overtime budget allows.

\section{Recommendation 9.10.3.1}

"The Training and Resources Section shall be reorganized under a Team Leader Training Officer, with one additional full time Training Officer, and a full-time secretary. The Team Leader shall report to the Deputy Fire Chief."

Impact and Supporting Summary:

The volume of required training requires concentrated and timely work. With the Training and Resource section moved from oversight by the Fire Marshal (as recommended by the Master Plan) a Training Team Leader is needed.

Options/Alternatives: None identified.

Implementation: Following assignment change for Fire Marshal and approval for Training Team Leader position and one FTE secretarial position.

\section{Recommendation 9.10.3.3}

"The existing three year training topic outline requires expansion by a representative training curriculum task force. The expansion shall relate each training topic to a comprehensive performance based plan which provides for all components of the training program."

Impact and Supporting Summary:

The training plan should address the needs of all levels of personnel and all types of specialists. In addition, the plan should extend over several years, providing basic, intermediate, advanced, and specialized technical training.

Options/Alternatives: None identified.

Implementation: On-going curriculum development guided by curriculum task force, following initiation of curriculum task force.

\section{Recommendation 9.10.3.4}

"The following specialized training needs for HFD emergency response personnel (some of which are already addressed in the training curricula) shall be met: 
- Advanced work in hazardous materials incident mitigation

- Advanced work in radiological incident mitigation

- Personnel safety in work environments containing hazardous materials and radioactive material

- Fire suppression and mitigation efforts using a variety of extinguishing agents

- Extensive application of regulatory and national standard drivers

- Advanced technical rescue specialties including confined space entry and rescue

- Wildland fire suppression

- Ground cover fires at hazardous waste storage sites

- Work with advanced built-in fire protection systems

- Rope Rescue"

Impact and Supporting Summary:

The nature and scope of possible, credible emergency incidents at the Site necessitate training in topics not widely applicable to municipal firefighters. The topics identified above may not be all inclusive but represent the broad scope of special areas where training is required.

Options/Alternatives: None identified.

Implementation: On-going

\section{Recommendation 9.10.3.6}

"Upgrade the centralized HFD training facility to accommodate the various types of hands-on training required by response personnel or provide alternate locations for all training." (and)

\section{Recommendation 9.4.3.5}

"Upgrade the existing 200 Area training facility and drill area, to provide adequate training aids for major technical rescue exercises (includes live fire training, confined space and collapse work, hazmat incident response, and radiologic incident simulation). Alternatively, make provisions to obtain the necessary training at an alternative facility."

\section{Impact and Supporting Summary:}

Adequate training and exercises are essential to the success of the emergency responder. Training facilities must provide accurate training replicas of the primary response duties, particularly in such areas as technical rescue and hazmat response. Providing this training capability at the 200 Area station maximizes the HFD's ability to adapt training, and training replicas to match specific site hazards and conditions. Should providing this capability at the HFD station be determined to not be feasible, the appropriate training and drilling should be obtained at an alternative location such as Hazardous Material Management \& Emergency Training and Education Center (HAMMER). An alternative facility already used by HFD for live training is located at WPPSS. 
Construction of the HAMMER training facility has just begun, and while planning indicates that it will be suitable for HFD training, changes may yet be made. Should training at the HAMMER site occur--as currently contemplated--HFD management will adjust deployment to provide area coverage. Methodologies include fill-in personnel using overtime payments.

HFD training programs have a strong need for an outdoor training facility with areas set-up for technical rescue instruction and exercises. These include confined space, vehicle extrication, and rope work. The existing 200 Area training area would appear suitable and advantageous for this type of training, with modest and simple rescue training aids added in the open area.

Options/Alternatives: None identified.

Implementation: Continuation of use of 200 Area training facility and WPPSS. Modest upgrading of rescue training aids at 200 Area facility. Wait for completion of HAMMER project.

\section{Recommendation 9.12.3.1}

"Identify areas or specific fire hydrants on specific systems where insufficient water is available for fire protection purposes. Hydrants which will not meet the fire departments' needs should be easily field identifiable (e.g. painted a specific color). Develop a plan to address fire department activities based on water supply limitations."

Impact and Supporting Summary:

Responding fire units must be able to know quickly the capability (or lack) of any hydrant.

Options/Alternatives: None identified.

Implementation: Requires hydrant identification and painting. Concurrence needed from appropriate site organization.

\section{Recommendation 9.12.3.2}

"Upgrade the existing water supply systems to provide adequate water for fire protection needs (See Fire Protection Water Supply Analysis (WSA) for details)."

Impact and Supporting Summary:

Safety of the Site and its attractiveness to new tenants will depend in part on fire protection adequacy.

There are three types of problems relative to the water supply/hydrant systems on the Hanford site. The first is created by an inadequate supply in certain areas (the raw water 
system or the sanitary water system) and may involve volume or pressure, or both. The second occurs when the management of the water supply system fails to confer with the HFD regarding the taking of hydrants, pumps, water storage tanks, etc. out of service, or even fails to notify HFD of such actions about to be taken. The third relates to water surges which activate alarms.

Options/Alternatives: HFD must maintain emergency water supply plans until system is upgraded.

Implementation: Long term

\section{Recommendation 9.12.3.3}

"Assure limitations of water supply at specific facilities are addressed in prefire plans." Impact and Supporting Summary:

All responding units must understand where adequate water sources are located.

Options/Alternatives: None identified.

Implementation: Continuation of existing pre-planning project.

\subsection{PRIORITY III RECOMMENDATIONS}

\section{Recommendation 9.2 .2 .3 .1}

"Maintain record keeping in accordance with the national fire incident reporting system format (NFPA 901)."

Impact and Supporting Summary:

A commercial software program is necessary so that HFD fire reports can be recorded in the format required by DOE. Standardized fire incident reporting is necessary for data collection. future planning, and research purposes.

Options/Alternatives: None identified.

Implementation: Within 60 days of obtaining software program, following orientation of record keepers to the new format.

\section{Recommendation 9.3.3.10}

"The Site shall implement a CPR training program which ensures that a cadre of personnel at each facility, or work site are CPR qualified and equipped to provide emergency CPR during normal hours of occupancy." 
Impact and Supporting Summary:

Rapid application of CPR by a trained co-worker typically will lessen the possibility of worse consequences.

Options/Alternatives: $\quad$ None identified.

Implementation: $\quad$ Encouragement of the program by HFD

\section{Recommendation 9.3.3.11}

"As the site operations change or transition, HFD should examine methods to minimize the response time to an EMS incident."

Impact and Supporting Summary:

Temporary changes in the location of major site operations might create increased need for emergency medical services at a particular location. To address these EMS concerns, a temporary and closer ambulance position, such as at an existing first aid station, may be preferable.

Options/Alternatives: Place a reserve ambulance in service using project reimbursed overtime pay for off-duty personnel providing the coverage.

Implementation: As needed

\section{Recommendation 9.4.3.3}

"Provide additional administrative space and restroom facilities to the existing administrative wing, or construct an administrative building at an approved site."

Impact and Supporting Summary:

The Needs Assessment study concurs with a WHC Study in determining that the existing HFD administrative wing, located at the 200 Area Station, is inadequate. Room for necessary functions is either not available, or inadequate. One Division (Fire Systems Testing and Maintenance) is located in an annex. Two separate operating units are located in the same "bull pen" room, with an unacceptable noise and activity level.

An earlier WHC study resulted in the recommendation for a free-standing administrative structure. Plans for such a structure--to be located at the 200 Area Station site-are now available.

Options/Alternatives: A larger and more functionally designed facility (with restrooms) is needed. There are two apparent options: Construct an addition to the existing administrative wing or construct a freestanding facility, preferably at the 200 Area site. 
Implementation: Following decision concerning rehabilitation or reconstruction of the 200 Area Station. Construction agreement plus budget approval necessary. Timing to be determined by DOEContractor prerequisite decisions.

\section{Recommendation 9.4.3.8}

"Perform seismic evaluations to determine the ability of all fire stations to maintain all essential services immediately following a seismic event. Criteria for evaluation shall as a minimum, reflect requirements stipulated by the 1991 Uniform Building Code (UBC) for Essential Facilities or site specific seismic requirements approved by DOE. Perform any and all required station modifications necessary to maintain all essential services immediately following a seismic event."

Impact and Supporting Summary:

There is a necessity to keep fire stations in operating condition following an earthquake. Since seismic events have potential to cause damage in the Hanford area, seismic structural evaluations and essential modifications to fire stations are warranted.

Options/Alternatives: Perform structural modifications during Station rehabilitation work, or design new stations to withstand anticipated seismic shock.

Implementation: Following Station facility decisions.

\section{Recommendation 9.5.6.4}

"Obtain a mobile emergency Command-communications vehicle for use by all emergency agencies on Site."

Impact and Supporting Summary:

A mobile facility (vehicle) serves as an on-scene, multi-agency command post and communication center. Also, it provides an alternate, redundant emergency communications facility for the Site, with basic capabilities.

Options/Alternatives: None to satisfy a long-term need.

Implementation: Approval process to begin with concurrence by the Contractor and DOE of long-range vehicle replacement and acquisition plan. 


\section{Recommendation 9.5.6.5}

"Obtain a mobile decontamination unit for use at emergency hazardous material incidents and the decontamination of personnel."

Impact and Supporting Summary:

A mobile decontamination unit brought directly to the scene of a hazardous materials incident will decrease the chance of injurious chemical or radiologic contamination to site workers and emergency responders.

Options/Alternatives: Obtain a lower cost towable trailer.

Implementation: Approval of existing specifications and budget expenditure necessary.

\section{Recommendation 9.5.6.6}

"Expand the Standard Regulation Identification Document (SRID) to include a complete inventory of the required items for Access and Cardiac Care stipulated by WAC246-976-390."

Impact and Supporting Summary:

The cited materials and materials are mandated by WAC-246-976-390.

Options/Alternatives: None identified.

Implementation: Expansion of the SRID will provide formal and documentation readily available for quality control efforts.

\section{Recommendation 9.6.3.4}

"The dispatcher job shall be assigned to a minimum of one trained person on each shift. There also must be a quick responding back-up dispatcher for each shift."

Impact and Supporting Summary:

Accurate and timely emergency communications require trained personnel.

Options/Alternatives: None identified.

Implementation: Following identification of personnel qualified for prerequisite training. 


\section{Recommendation 9.6.3.5}

"Install a "quick-call" trouble buzzer system in the communications room and a deadman notification system on all in-coming alarms and 911 calls."

Impact and Supporting Summary:

Emergency alerting systems are necessary for fire department alarm and dispatch systems so that no incoming alarms are missed.

Options/Alternatives: None identified.

Implementation: As soon as possible.

\section{Recommendation 9.6.3.6}

"EMS Dispatchers shall be trained in EMS dispatch operations, procedures, and protocols."

Impact and Supporting Summary:

All dispatchers working in a system which dispatches EMS units need EMS dispatch training in operations, procedures, and protocols.

Options/Alternatives: None identified.

Implementation: EMS dispatch training to be scheduled as course becomes available.

\section{Recommendation 9.7.10.3}

"The HFD shall evaluate the necessity of HFD notification 24-hours in advance of confined space entry."

Impact and Supporting Statement:

As the number of confined spaces on site has increased above 500 , meeting the requirement of 24 hour notification of entry has become cumbersome. In addition, the ability of HFD to manage those notifications as part of a daily, standard routine has become less useful.

Options/Alternatives: Retain existing notification requirement.

Implementation: Examine the requirement and modify if warranted. 


\section{Recommendation 9.9.3.1}

"The HFD shall evaluate the feasibility of providing preventive maintenance and repair services to Pacific Northwest Laboratories (PNL) and Fast Flux Test Facility (FFTF) facilities."

\section{Impact and Supporting Summary:}

The goal of the recommendation is to consider an expansion of existing services allowed by the mission statement in order to obtain any possible economies of scale and/or improve system quality.

Furnishing preventive maintenance (PM) and repair services to additional facilities will add to existing work- load. Additional budget allocations to HFD would offset additional workload costs. Alternatively, separate contractual arrangements could be made to cover additional costs. The HFD has effectively demonstrated its ability to provide the required services in a timely and competitive manner. Providing these same services to PNL and FFTF may enable a consolidation of resources and result in an increased benefit (economic savings or increased system reliability) to DOE.

Options/Alternatives: None identified.

Implementation: Feasibility exploration. Implementation, if decided. Budget coverage or cost-offset funding may be needed.

\section{Recommendation 9.9.3.2}

"Applicant certification requirements should include the following:

- $\quad$ Fire fighter level 1 (as stipulated by NFPA 1001)

- $\quad$ EMT, "First Responder" level (as stipulated by WAC-246-976)"

Impact and Supporting Summary:

It may be possible to hire new T\&S FF who already have basic firefighter and EMT training, thus reducing the HFD initial training effort for firefighting duties

Options/Alternatives: The possibility of employing pre-trained personnel should be evaluated and determined. Requiring EMT certification for new hires is common in fire departments.

Implementation: Evaluation of possibility, including review of existing recruitment and employment protocols. Implementation, if feasible. 


\section{Recommendation 9.9.3.4}

"The HFD Programs for providing Fire Protection systems Administration and Testing and Fire Protection systems Maintenance shall be evaluated periodically to ensure that personnel resources are commensurate with the level of service that is required."

Impact and Supporting Summary:

Increases or decreases in the number and type of systems tested and maintained may necessitate changes in the number of systems service personnel.

Options/Alternatives: None identified.

Implementation: Periodic assessments.

\section{Recommendation 9.10.3.2}

"All Station Captain and Battalion Chiefs shall maintain current certification at the fire instructors level 1 (as defined by NFPA 1041) in order to conduct in-service training and the necessary monitoring and oversight."

\section{Impact and Supporting Summary:}

Standardized in-service training for three 24-hour shifts, located at four fire stations, has to be taught by each Station Captain assigned to each shift. These twelve separate teaching venues (four per shift) need evaluation and coordination by the shift Battalion Chief or Training Officer.

Options/Alternatives: None identified.

Implementation: Continuation of present practice.

\section{Recommendation 9.10.3.5}

"Appoint a standing advisory committee on training, with representation from all levels and types of HFD members, having the Deputy Chief as chair. This group would meet periodically to review training needs from the various types and levels of members, the training curriculum and training schedule, performance evaluations, and training resources."

Impact and Supporting Statement:

The knowledge level, skills, and attitudes of personnel can be raised effectively to higher levels only through careful planning. A quality assurance program for training is necessary to assure requirements are being met.

Options/Alternatives: None identified. 
Implementation: On-going following appointment of Committee.

\section{Recommendation 9.10.3.7}

"The following recommendations are made to improve the quality of the in-station training program:

- Hold all stations to a minimum of one hour daily in-service training set by a mandated lesson plan. This training will be evaluated.

- Develop standardized instructional packages to be sent or transmitted to each station, such as video lessons, slide packages, and self-instruction and evaluation booklets."

Impact and Supporting Summary:

In-service training is necessary both to bring new information and skills to firefighters and to reviews skills taught earlier. Daily in-service training is necessary to reach all firefighters on all shifts. Standardize training units are efficient and cost effective.

Options/Alternatives: None identified.

Implementation: Expansion of the existing program.

\section{Recommendation 9.10.3.8}

"Use selected off-Site training and visiting experts to enhance HFD training. Continue programs which send HFD Training Officers and in-service instructors to specialized "trainthe-trainer" programs for advanced course work."

Impact and Supporting Summary:

Cost effective advanced and specialized training often is available at outside training centers. Having HFD instructors trained in those settings provides a multiplier effect. For some topics, an outside expert brought to the Site (and videotaped for future use) also provides cost effective advanced instruction.

Options/Alternatives: None identified.

Implementation: Expansion of existing program.

\subsection{ADVISORY OBSERVATIONS}

\subsubsection{Applicable Requirements}

The Needs Assessment lists a representative compilation of the applicable requirements which set forth the responsibilities, duties, authority, operating parameters, directives, etc. which govern the structure and conduct of HFD. These requirements originate in DOE, 
NFPA, the WAC, OSHA, and other authorities and sources. The requirements undergo frequent alterations, modifications, additions, and other forms of change.

During the study which produced the Needs Assessment there were several orders and directives which were, apparently, about to be issued. For example, the DOE Fire Protection Program Implementation Guide was issued officially in February, 1996. DOE 360.]

"Training" is a new document. In some instances, DOE orders such as 420.1 "Facility Safety" and 440.1 "Worker Protection Management..." have applicability to individual contractors depending on contract renegotiation. Without a new contract or formal direction from DOE, the former Orders apply.

There are no general recommendations concerning "Applicable Requirements" in the Needs Assessment. Obviously, HFD Officials need to keep well informed concerning changes and must continually review and consequently modify operations accordingly.

\subsubsection{Comprehensive Fire Prevention}

As additional facilities emerge at Hanford which are operated by private companies, it will be necessary for clear agreements to be in place concerning the role, responsibility, and authority of the various service delivery units of HFD, certainly including the functioning of the Fire Marshal. Without clear responsibility and authority vested in the HFD, it would appear possible for unsafe conditions or conditions which might be beyond the capability of HFD to mitigate to emerge. In addition, response workload must be kept manageable for HFD resources.

Basic decisions will need to be reached concerning site control and related issues, including financial consideration for protection (possibly in the form of contracts) as is the case with WPPSS protection. This process should begin immediately.

As site remediation and facility decontamination and decommissioning progress, it appears likely that, at certain time periods in certain site areas, HFD will be called upon to provide special coverage by project groups engaged in defined demolition and decontamination (D\&D) project activity requiring--for example--stand-by fire, rescue, hazmat, or EMS teams. With HFD deployed in a cost effective baseline service level model, special coverage activities may require the use of overtime and/or off-duty crew members. These costs--above the HFD budget--could be borne by the project.

\subsubsection{Disaster Preparedness}

Disasters generally are defined as large scale emergency incidents which require resources for mitigation, termination, and recovery that exceed significantly those readily available to the local agencies. These large scale, sometimes long-lasting, emergencies may be "natural" or "man-made". The Hanford site is susceptible to both types.

The Needs Assessment has identified events which have the potential for significant on-site and/or off-site consequences and which would require an HFD response in order to control or mitigate. In Site drill scenarios testing Site readiness for handling credible events, 
HFD response is almost always assumed. Consideration is being given by Site emergency planners to having HFD function as incident command in a broader range of incident types

The Needs Assessment contains no Recommendations in the category of disaster preparedness. Never-the-less, several advisory observations emerge:

1. HFDs involvement in the Tri-county mutual aid plan can bring a substantial emergency response to the Site, if needed;

2. The Federal Emergency Management Agency (FEMA), through Site emergency planning and HFD urging, may be able to figure significantly in a large scale Site emergency;

3. HFD should continue to cooperate fully in Site Disaster planning and practice exercises, emphasizing its broad abilities;

4. FEMA sponsored "Urban Search and Rescue Team" operations and protocols should be reviewed by HFD, and preliminary contacts established, in the event that such services are ever necessary at a Site disaster;

5. HFD should review the Site's master list of available outside resources to be sure that any speciai items which are unique to fire department operations are identified, with sources.

\subsubsection{EMS}

The Needs Assessment contains the following Recommendations relating to Hanford Emergency Medical Services:

1. Only certain off-line control authority has been given to the HEHF by the MPD, and these are listed in the Needs Assessment.

2. EMS program interfaces (County, State, HEHF, MPD) need continuous reconciliation in order to maintain consistency.

3. HEHF has developed a mass casualty plan for Hanford, and a mass casualty traiier is kept in the 100 Area Station. A multi-county mass casualty mutual aid plan exists, and includes the HFD.

\subsubsection{Emergency Response Procedures}

The Needs Assessment study reviewed the reported current response procedures of HFD and found them to be satisfactory.

The following Master Plan advisory observations relate tangentially to Recommendations. None involve critical issues. 
1. Incident command procedures, including the functioning of a scene safety officer, should be followed at all except very minor incidents.

2. Baseline service level, or near baseline, deployment will necessitate more frequent recalls of at least some off-duty personnel.

3. Response to requests for mutual aid off-site should not place the site in protracted periods of reduced station crew strength.

4. The existing protocol which does not allow HFD hazmat team response off-site should be continued.

5. Barring extreme circumstances, at least one quint type apparatus ideally should remain in quarters for a simultaneous alarm, crewed--if needed--by T\&S FF or recalled personnel. This implies that the "reserve" pumpers might be viewed as possible first-line response apparatus.

6. Experience with a recall system used more often than currently may indicate that off-duty personnel should have their protective clothing at home/in personal auto, to facilitate response direct to an on-site location or to a mutual aid location. An HFD cascade-mask unit vehicle might proceed directly to the incident scene--on or off site--to furnish breathing apparatus to HFD off-duty personnel responding with protective clothing.

7. HFD mutual aid response to an outside department which has an aerial ladder might be with a reserve pumper, unless an HFD telesquirt quint is specifically needed.

\subsubsection{Legal Issues}

An extensive review of relevant legal issues is contained in the Needs Assessment.

\subsubsection{Mission and Goais}

The HFD mission is documented in the Needs Assessment as follows:

"The HFD provides services to the Hanford site under contract agreement between WHC (the Contractor) and the DOE. The HFD is an emergency service organization whose mission is to provide fire suppression, emergency rescue, basic and advanced life support, ambulance service, and hazardous material responses capable of dealing with and terminating emergency situations which threaten the employees, operations, environment, or interest of the Department of Energy (DOE) Hanford Site. These services include emergency support to Bonneville Power Administration facilities, response to surrounding fire districts under a mutual aid agreement, and contractual fire fighting and ambulance response to the WPPSS, Laser Interferometer Gravitational-Wave Observatory (LIGO), the Port of Benton County 400 Area Incubator Project, the Kaiser aluminum activity in the 300 Area, the U.S. ecology activity in the 200 Area, as well as other non-DOE governmental agencies and private 
contractors operating on the site. The HFD is also responsible for site-wide fire safety and fire prevention programs including fire alarm system functional testing and inspection, self contained breathing apparatus maintenance, building tours and inspections, pre-fire planning, and employee fire safety training. In providing these services the HFD has the objective of meeting or exceeding all applicable federal, state, and DOE mandated standards, requirements and guidelines."

Increasingly, the HFD will provide services under separate contracts to site facilities operated by private business. These contracts enable HFD to carry out its primary goal of site protection while off-setting additional operating expenses.

Also HFD will be called upon to provide special services to Hanford Project groups, or to accomplish special training, or to acquire special equipment in order to assure safety. These may be beyond the scope of activities assured through the HFD budget. In those instances, accurate cost accounting measures will be needed so that a "charge-back" system can be instituted to cover extraordinary costs.

There are no recommendations in the Needs Assessment which would curtail the existing mission statement.

\subsubsection{Mutual Aid}

The HFD is a signatory in the mutual aid agreement which creates a tri-county supportive force of fire departments. Also, there is an agreement with an adjacent property owner's association to provide mutual aid for wildland firefighting. The concept of mutual aid is important to HFD. Few, if any, fire departments in the United States have sufficient resources to ignore mutual aid, and this certainly is true of HFD and nearby departments.

However, mutual aid presents several challenges in the Hanford setting, essentially due to three reasons: nearby fire departments apparently are reluctant or unwilling to engage directly in hazardous materials and radiological or mixed waste incident mitigation on Site; there is not yet a strong, nearby hazardous materials team formally organized and agreeable to responding to the Site; and the HFD hazardous materials team--should it depart the Site to assist in the tri-county area--leaves the Site understaffed.

Additionally, an HFD baseline service level deployment force, if depleted by being sent off-site on a mutual aid assist run, leaves the Site insufficiently covered.

\subsubsection{Operational Orders}

The Needs Assessment contains no general recommendations relating to operational orders. HFD is already in the process of compiling documentation for certain of their operations, as recommended by Recommendation 9.7 .10 .5 , relating specifically to hazmat operating guidelines. The existing operational orders. which stem from several sources, appear adequate. In addition, sections of the Washington Administrative Code likely will become directly relevant to HFD. 


\subsubsection{Organizational Structure}

The needs assessment study reviewed the HFD organizational structure and found it appropriate and functional. There are no general recommendations for changes in organizational structure contained in the Needs Assessment. There are, however, specific recommendations for modifications in the Fire Marshal's Office and in the Training and Resource Section. Additionally, there is a Recommendation relevant to several key issues (incident command, shift management, plus baseline service level deployment and response) which calls for the creation of an additional Battalion Chief's position and the assignment of one Battalion Chief to each of the three 24-hour shifts.

\subsubsection{Shared Response Station}

A proposal exists to create a new fire station to be located in the northern end of Richland which would house both Richland and HFD apparatus and crews. This station, apparently, would replace the existing HFD 300 Area Station.

There are no recommendations contained in the Needs Assessment relating to the construction of a shared station. The following is presented here as an advisory observation:

Should HFD close its 300 Area Station and relocate to the Kelly Road - Horn Rapids Road intersection, it would be reducing its northern "reach" by approximately 1.5 miles. Thus, its nunning times north to Site areas, specifically the 300 and 400 Areas would be lengthened. The time differential, depending on traffic conditions, could extend to three minutes additional running time--the running time currently required to reach the existing 300 fire station location from the Kelly Road - Horn Rapids Road intersection.

Should the HFD enter into the proposed Agreement for Automatic Reciprocal Fire Department Assistance with Richland, simultaneous dispatching of each department would be needed. Despite a statement to the contrary in the draft agreement, significant modifications to the existing communications systems appear necessary to ensure simultaneous dispatch. Otherwise a dispatch time-lag will exist for one department or the other in the proposed first alarm response.

Since HFD responds with more than the three persons per vehicle specified by the draft agreement, and presuming Richland responds with a pumper, the volume of response will favor Richland, as will the HFD quint responding as an aerial ladder company into Richland.

There would be an advantage to Hanford in that its response would be with three Richland firefighters arriving prior to the 400 Area Station crew, at least in the southern and central sections of the 300 area, assuming the units run from a shared station. (This would not hold if Richland were responding from the Jadwin Avenue station.)

The draft Agreement appears to focus on fire response only, and does not appear to include EMS. The agreement precludes Richland's direct work in hazmat or radiologic incidents. 
The proposed automatic mutual aid agreement, with Richland responding from the Jadwin Avenue station, does not appear at face value to be of significant benefit beyond the existing Tri-County agreement.

\subsubsection{Technical Rescue Incident Response}

As indicated by Table 7-1 "Summary of Representative Hazards by Area," technical rescue (also referred to in the literature as heavy rescue, rescue, and urban rescue) is an "Anticipated Fire Department Requirement" for all areas of the Hanford site. This is reflected in the inclusion of "rescue", as distinct from emergency medical service, in the HFD mission.

Technical rescue includes a wide variety of specialty areas, each requiring specialized training and equipment. These specialties range from vehicle extrication and earth movement rescue to confined space rescue and high angle rope work. The increasing volume on Site of $\mathrm{D}$ and $\mathrm{D}$ work, with increased movement of large vehicles, structure removal, etc. and the growing number of confined spaces may create a larger number of construction and industrial accidents, plus operating incidents.

The HFD is well aware of the necessity to focus operating attention and training programs on the acquisition of technical rescue knowledge and operating skills. A good deal of technical rescue equipment already is available in the HFD inventory

\subsubsection{Testing and Service Firefighters}

The Testing and Service Firefighters ( T\&S FF) have as their primary assignment work with the Fire Systems Testing and Maintenance Division. They typically are assigned to work ten hour days, Monday - Thursday or Tuesday - Friday. Each is trained and equipped as a firefighter, and some have basic life support (EMS) certification.

Work as firefighters is described in the Needs Assessment as follows

"The T\&S FF may crew the fire apparatus to respond to an emergency, and act as backup crews for second alarms or to fill in for a station firefighter for short-term absences. T\&S FF have been recalled during the day 4-7 times per "active" wildland fire season. They also respond to hazmat events when needed, approximately 5-10 times per year. Other emergency incidents requiring T\&S FF support, including structure fires, mutual aid requests, and other emergencies, average 6-10 per year. Thus, overall, emergencies may require T\&S FF to man backup fire apparatus approximately 15-27 times per year to respond to emergencies. They are called in from the field to crew the reserve pumpers at the stations approximately 15-20 times per year. Commonly, this occurs when station personnel are tied up on multiple incidents, particularly EMS responses.

T\&S FF aiso cover short term absences of station firefighters. In some cases, T\&S FF can respond from the field in their vehicles. If a key position must be filled (pumper operator, EMT, paramedic), the T\&S FF must report to the station and remain with the response crew." 
The volume of training required for all aspects of a T\&S FF position is high, with those personnel having to maintain technical certification in a variety of fields, plus receiving firefighter/hazmat in-service training.

The Needs Assessment reports:

"In addition to firefighter training requirements, all T\&S FF are required by HFD Internal Policy IP-5.6, Rev. 3 to receive 24 hours of classroom training and 80 hours of onthe-job training, working with experienced T\&S FF. Annual requalification training consists of 8 hours of classroom and practical training. Additionally, all T\&S FF must have facility specific orientation training.

The extent of required training is significant. From discussions with the Manager of Fire Protection System Administration and Testing, approximately 25-30 percent of T\&S FF allocated work time is taken up by required training courses."

Discussed in the Needs Assessment is the possibility of HFD specifying that all new hires be pre-certified at the Firefighter I level, and at the EMS First Responder or BLS level. Also, it is desirable that as many $T \& S$ FF as possible be trained to the Technician level in hazmat incident mitigation, but this would take place, in most instances, following employment and significant on-the-job training.

The role of T\&S FF relative to the baseline service level deployment model is important, since they will continue to be dispatched as firefighters--as they now are--for response to the incident or to crew the reserve apparatus and ambulances for station coverage.

\subsubsection{Training Facilities}

Adequate training facilities, including classrooms, but especially outdoor areas for live fire training, hazardous materials incident response, and technical rescue exercises are essential to the success of the HFD training program goals. Without suitable facilities, the HFD mission in emergency response will not be attainable.

Providing adequate and suitable outdoor training facilities presents several problems to all fire departments: 1)The facilities must be close enough to the response district for quick return, if needed, or the department must have sufficient resources to enable companies (and individuals) to be sent to more distant training centers with adequate response coverage remaining; 2)either the facility must be able to have live fires for training, or there must be elaborate substitute provisions made; 3 )there must be adequate weather-protected classroom facilities on-site or very nearby; 4)the outdoor facilities must be able to support realistic training representative of the types of incidents to which the department actually responds.

These "requirements" are important to note for HFD training, since alternative sites to the 200 Area Station site are now being considered by HFD officials. 


\subsubsection{HFD Vehicles}

The following Master Plan advisory observations are made here concerning HFD vehicle maintenance and repair:

The size of the Hanford Site necessitates longer apparatus runs than are typically experienced in municipalities. Therefore, vehicle mileage tends to create more frequent maintenance and repair challenges. HFD officials report difficulty in maintaining adequate maintenance and repair of vehicles which are essential to the safety of the Site.

The Needs Assessment review of vehicle maintenance experience indicates that it is not unusual to have a pumper in the shop for as long as three months. Engine (ENG)-91, spent more than 9 months in the shop in 1994 and has been back on many occasions in 1995. Additionally, the specialized apparatus used in fire departments require specific training and experience with this equipment. As reported by HFD officiais: the HFD has paid to train onsite mechanics in the past, but this training has been uneven; there is no guarantee that a trained mechanic will be assigned to work on a vehicle once it is taken to the garage; there is an on-going problem with getting fire equipment designated as priority for repair; and efforts have been made to get HFD equipment designated as top priority, with only short-term agreement from maintenance.

Fire Departments experiencing this reported volume of difficulty frequently initiate their own maintenance and repair program using outcontracting or their own mechanic. It may be that a joint program could be initiated and maintained in cooperation with adjacent fire departments.

Advisory information concerning HFD apparatus replacement:

Relevant tables $(9.5 .2 ; 9.5 .3 ; 9.5 .5)$ are duplicated here to facilitate review, as are Needs Assessment endorsed requests for the mobile decontamination unit and the mobile command/communications vehicle:

Two capital equipment requests have been submitted for fiscal years 1997 and 1998 . the 1997 request is for a mobile hazardous material incident decontamination unit. The 1998 request is for a mobile tactical incident command unit.

The mobile decontamination unit will be used for decontamination of HFD personnel at emergency hazardous material incidents.

The mobile tactical incident command unit will enhance the fire department's ability to control tactical information during emergency operations. The unit will be a motor home body with various computer work stations, FAX machines, radios, telephone equipment and technical reference books and files. 


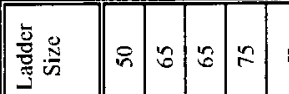

盖

莺产

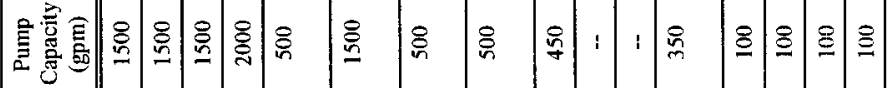

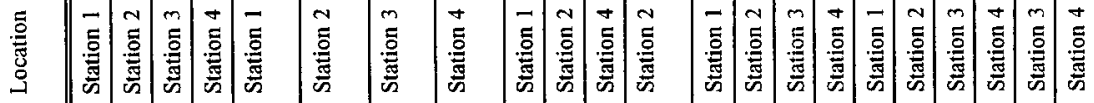

岁嵒

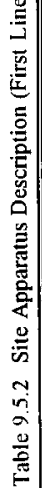

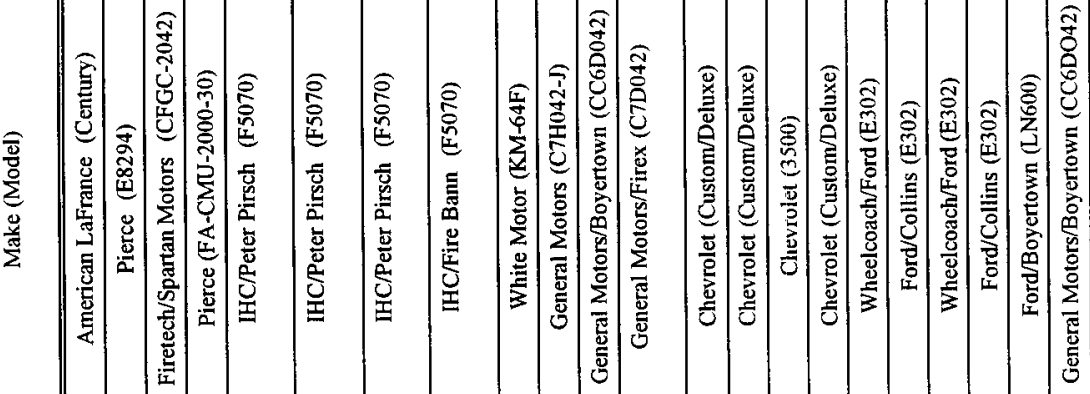
ב.

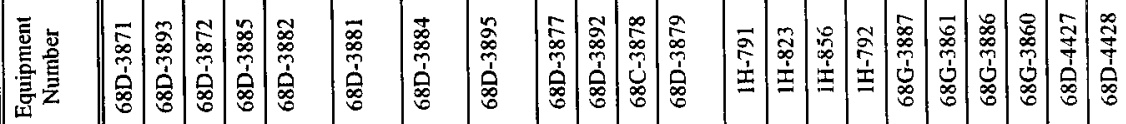

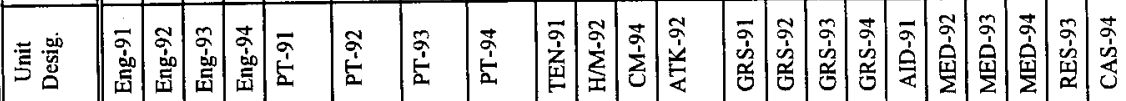




\begin{tabular}{|c|c|c|c|c|c|c|c|c|}
\hline 总芯 & I & : & I & I & $!$ & 1 & & I \\
\hline 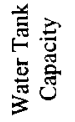 & $\stackrel{\Xi}{n}$ & \& & 8 & $\stackrel{8}{n}$ & 气ิ & $\stackrel{\mathscr{\Xi}}{\underline{n}}$ & & I \\
\hline 总害 & $\stackrel{8}{\check{n}}$ & $\stackrel{8}{\varrho}$ & $\stackrel{\S}{\mathscr{D}}$ & $\stackrel{8}{\mathscr{6}}$ & 芯 & 용 & 1 & 1 \\
\hline 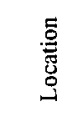 & 苞 & 离 & $\frac{n}{5}$ & 吉 & 告 & 告 & $\stackrel{\sim}{\tilde{\Xi}}$ & 㺃 \\
\hline 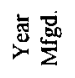 & $\stackrel{2}{\Omega}$ & $\stackrel{\infty}{\varrho}$ & $\stackrel{\infty}{\Xi}$ & $\frac{2}{2}$ & $\stackrel{\infty}{\infty}$ & $\stackrel{\infty}{\stackrel{2}{=}}$ & $\stackrel{\infty}{\varrho}$ & $\begin{array}{l}\infty \\
\stackrel{\infty}{\Xi}\end{array}$ \\
\hline 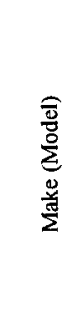 & 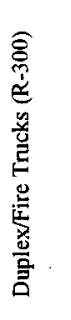 & 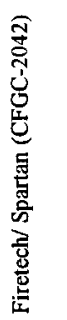 & 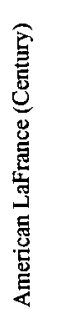 & 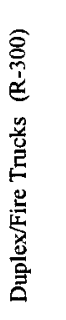 & 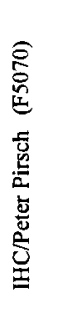 & 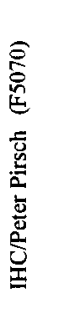 & 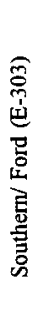 & 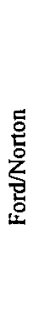 \\
\hline 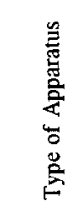 & 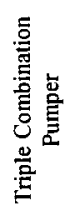 & 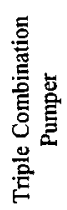 & 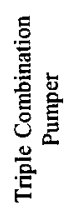 & 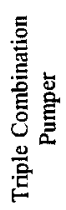 & 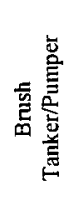 & 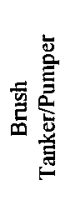 & 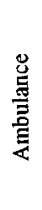 & $\begin{array}{l}\text { 总 } \\
\text { 总 } \\
\text { 吾 }\end{array}$ \\
\hline 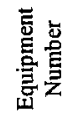 & $\underset{\infty}{\infty}$ & $\begin{array}{l}\stackrel{n}{0} \\
\infty \\
\stackrel{\tilde{b}}{8}\end{array}$ & 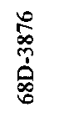 & $\begin{array}{l}\vec{T} \\
\infty \\
\stackrel{D}{0} \\
\ddot{0}\end{array}$ & 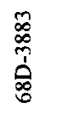 & 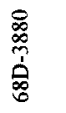 & $\begin{array}{l}\Delta \\
\infty \\
0 \\
0 \\
0 \\
0 \\
0\end{array}$ & $\begin{array}{l}\stackrel{0}{\infty} \\
\infty \\
0 \\
0 \\
0\end{array}$ \\
\hline 寻礐 & $\begin{array}{l}\frac{1}{3} \\
\dot{3}\end{array}$ & $\begin{array}{l}\tilde{S} \\
\dot{\delta} \\
\dot{0}\end{array}$ & 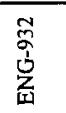 & 吝 & $\frac{\widetilde{a}}{\stackrel{\mathfrak{L}}{2}}$ & $\frac{\stackrel{2}{\hat{~}}}{\stackrel{亡}{a}}$ & $\begin{array}{l}\text { ล̊ } \\
\stackrel{1}{\alpha}\end{array}$ & 余 \\
\hline
\end{tabular}

WHC-SP-1180, Vol. 2 


\begin{tabular}{|c|c|c|c|c|c|c|c|c|c|c|c|c|c|c|c|c|c|c|c|c|}
\hline 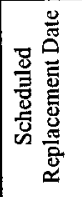 & 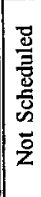 & 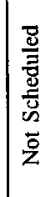 & 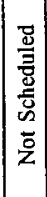 & 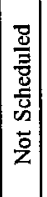 & 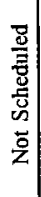 & 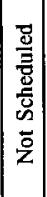 & 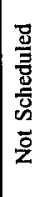 & 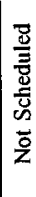 & 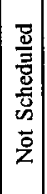 & 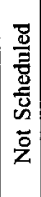 & $\stackrel{\circ}{2}$ & 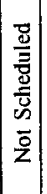 & 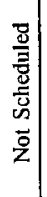 & 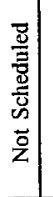 & $\stackrel{8}{9}$ & 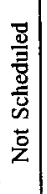 & 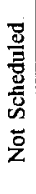 & $\stackrel{\circ}{2}$ & 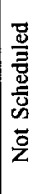 & 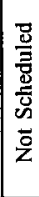 \\
\hline
\end{tabular}

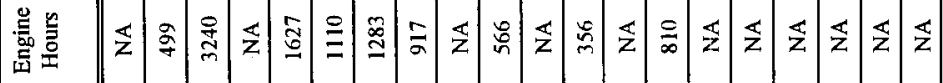

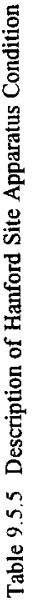

总

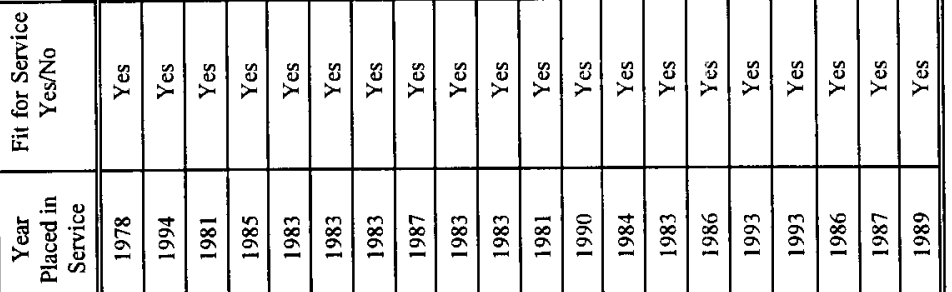

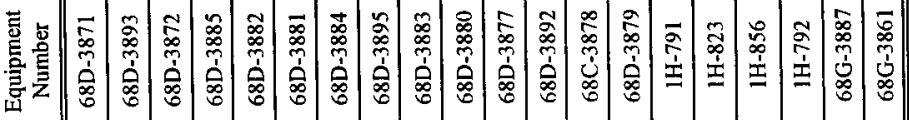

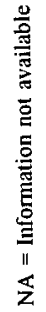


WHC-SP-1180, Vol. 2

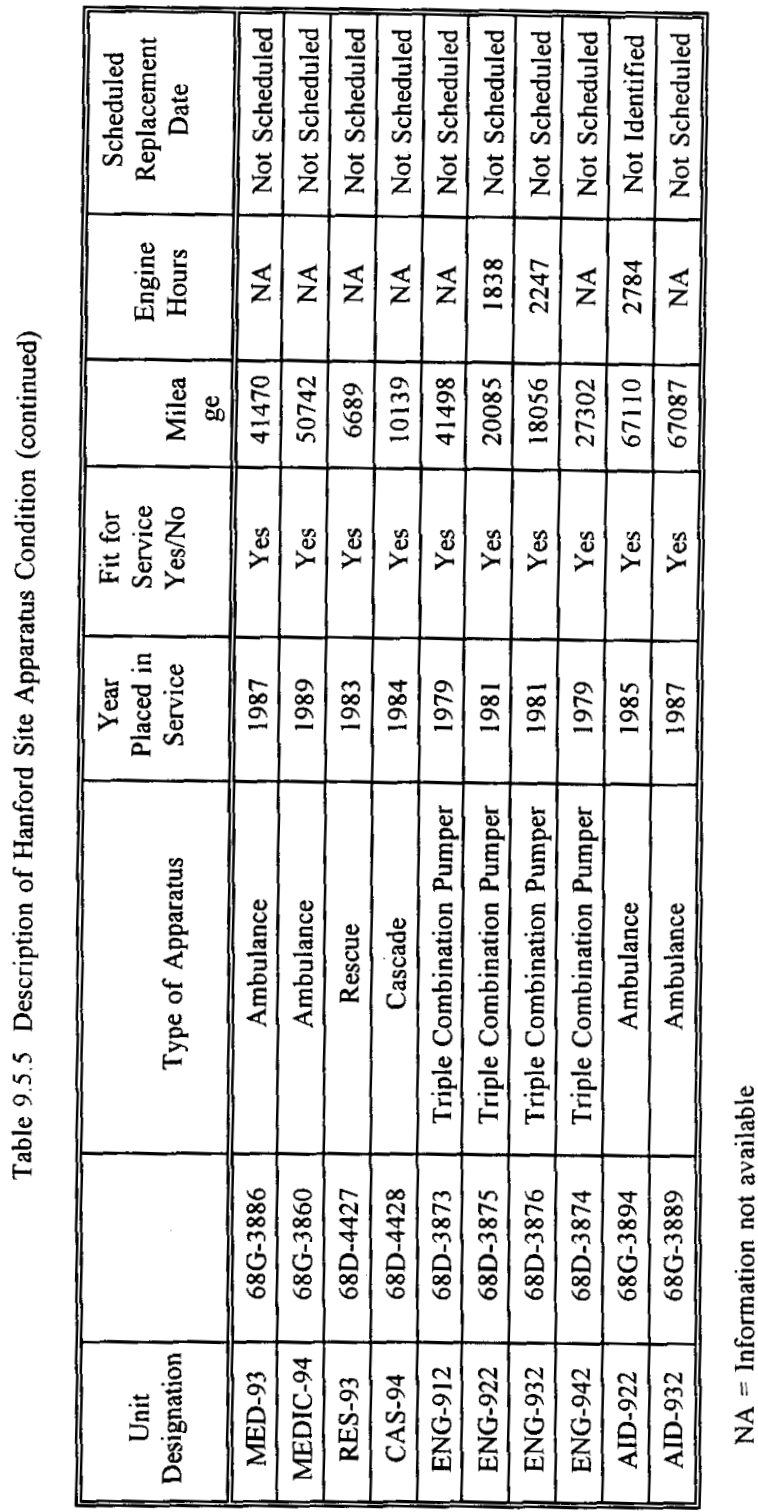


The following estimated fire apparatus replacement costs (in 1996 dollars) do not include discounted prices. Low range apparatus assumes the purchase of basic apparatus with a "commercial" style cab and chassis, complying with NFPA Standards 1901, 1902, 1903, 1904 , and 1500 , a 1500 gpm pump and 500 gallon water tank, a 100' aerial device where applicable, and compliance with Department of Transportation (DOT) gross weight and axle loading requirement. The high cost is based on an equipped custom unit:

ESTIMATED FIRE APPARATUS REPLACEMENT COSTS: 1996 OPEN MARKET

\begin{tabular}{|c|c|c|c|}
\hline CATEGORY & LOW RANGE & MIDDLE RANGE & HIGH RANGE \\
\hline Heavy Rescue & $\$ 140,000-\$ 150,000$ & $\$ 230,000-\$ 240,000$ & $\$ 300,000-\$ 350,000$ \\
\hline Light Rescue & $\$ 55,000-\$ 60,000$ & $\$ 75,000-\$ 80,000$ & $\$ 95,000-\$ 100,000$ \\
\hline Mini-Pumper & $\$ 55,000-\$ 60,000$ & $\$ 75,000-\$ 80,000$ & $\$ 95,000-\$ 100,000$ \\
\hline Pumper & $\$ 130,000-\$ 140,000$ & $\$ 180,000-\$ 200,000$ & $\$ 250,000-\$ 270,000$ \\
\hline Pumper-Aerial & $\$ 450,000-\$ 470,000$ & $\$ 470,000-\$ 500,000$ & $\$ 550,000-\$ 600,000$ \\
\hline Pumper-Platform & $\$ 535,000-\$ 540,000$ & $\$ 550,000-\$ 600,000$ & $\$ 600,000-\$ 650,000$ \\
\hline Tanker & $\$ 130,000-\$ 140,000$ & $\$ 180,000-\$ 200,000$ & $\$ 250,000-\$ 270,000$ \\
\hline
\end{tabular}

A key issue for HFD officials concerns the acquisition of the two new types of vehicles and the replacement of vehicles which no longer can provide the required service levels. A review of Tables 9.5.2, 9.5.3, and 9.5.5 indicates that as noted in the Needs Assessment, the average age for replacement of HFD apparatus has been:

$\begin{array}{lr}\text { Ambulances } & 9 \text { years } \\ \text { Pumper } & 17 \text { years } \\ \text { Water Tender } & 15 \text { years } \\ \text { Brush Trucks } & 10 \text { years }\end{array}$

Municipal fire department experience suggests that a 15-year life span for pumpers (with rotation of vehicles between stations to even-out usage) is desirable. The difference between many city fire departments and HFD is that HFD vehicles tend toward higher mileage and lower pumping hours than city apparatus. Setting aside any inherent design weaknesses in HFD apparatus, the major "wear out" feature appears to be road miles rather than pump and aerial ladder usage.

If this estimate is accurate, then an alternative consideration for the replacement of fire apparatus is to refurbish the existing apparatus. Estimates for this expenditure vary considerably, as the range of costs is extensive and seldom predictable. A basic presumption when considering refurbishing is that the existing apparatus is capable of continued use (operationally, structurally and mechanically viable). A second consideration for refurbishing apparatus is whether to replace all or part of the basic truck chassis. No price figure is provided for chassis replacement as the range of chassis sizes and styles varies. Consideration should be given to chassis replacement include the pricing and feasibility of a "glider" kit (replaces engine, transmission, differential and rear axle; retains cab and chassis). Glider kits can effect savings of $\$ 50,000$ to $\$ 60,000$ per vehicle.

While refurbishing costs may look attractive at first glance, it is necessary to obtain an exact estimate prior to making the decision to replace or refurbish. If structural repairs are 
required for aerial devices. then the cost of refurbishing can be much greater, particularly if major component parts of the device must be replaced. Each piece of apparatus represents a unique decision-making process that must be followed. Refurbishing costs typically will include significant body work, including a complete repainting of the vehicle, and replacement of compartments.

Using a fairly typical municipal fire apparatus life span cycle of 15 years for first line pumpers and Quints, 20 years total for reserve pumpers, 20 years for pumper tankers, 10 years for Brush trucks, 20 years for tankers, 5 years for ambulances, and 8 years total for reserve ambulances, a representative HFD replacement schedule follows:

\begin{tabular}{|c|c|c|c|c|c|c|}
\hline Vehicle & Year in Service & $5 \mathrm{Yrs}$ & $8 \mathrm{Yrs}$ & $10 \mathrm{Yrs}$ & $15 \mathrm{Yrs}$ & $20 \mathrm{Yrs}$ \\
\hline$\overline{\text { Eng } 91}$ & 1978 & & & & 1993 & 1998 \\
\hline Eng 92 & 1994 & & & & 2009 & 2014 \\
\hline Eng 93 & 1981 & & & & 1996 & 2001 \\
\hline Eng 94 & 1985 & & & & 2000 & 2005 \\
\hline PT 91 & 1983 & & & & & 2003 \\
\hline PT 92 & 1983 & & & & & 2003 \\
\hline PT 93 & 1983 & & & & & 2003 \\
\hline PT 94 & 1987 & & & & & 2007 \\
\hline PT 922 & 1983 & & & & & 2003 \\
\hline PT 932 & 1983 & & & & & 2003 \\
\hline TEN 91 & 1981 & & & & & 2001 \\
\hline GRS 91 & 1986 & & & 1996 & & \\
\hline GRS 92 & 1993 & & & 2003 & & \\
\hline GRS 93 & 1993 & & & 2003 & & \\
\hline GRS 94 & 1986 & & & 1996 & & \\
\hline AID 91 & 1987 & 1992 & 1995 & & & \\
\hline MED 92 & 1987 & 1992 & 1995 & & & \\
\hline MED 93 & 1987 & 1992 & 1995 & & & \\
\hline MED 94 & 1989 & 1994 & 1997 & & & \\
\hline
\end{tabular}

While most apparatus replacement cycles are based on years of use, that system is founded on the premise that road miles and pumping hours are evened out considerably through vehicle rotation from slow to busy stations. Also, preventive maintenance programs are very important to prolonged use.

A review of the above representative replacement schedule for HFD apparatus indicates that a replacement for Engine 91, with its relative high mileage, needs immediate planning for, or partial or total refurbishment (glider kit, etc.) needs careful consideration. A careful inspection of the vehicle and its repair records by a master apparatus mechanic is warranted, with a recommendation made.

Note, also, that a series of "refurbishment/replacement" inspections is needed for other vehicles whose presumed service life grows short 
HFD ambulances and pumpers have been giving considerably more years of service than in a typical larger city with many weekly emergency runs, but a replacement program must be designed as part of the long-range planning process, and funds must be made available to make purchases on that scheduled basis. Management must establish an apparatus refurbishment/replacement fund, with planned for, annual, allocations designated for that sole purpose.

\subsection{RECOMMENDATIONS LISTED BY TECHNICAL SUBJECTS}

Recommendations are listed below by technical subjects:

\section{Technical Subject $\quad$ Recommendation \# Priority Classification}

Administrative Facility

Comprehensive Fire Prevention

Department Administration

Emergency Communications

Emergency Medical Services

Emergency Response Staffing

Fire Stations
9.4.3.3.

9.8 .3 .1

9.8 .3 .2

9.3.3.6

9.6 .3 .3

9.7 .10 .4

9.6 .3 .1

9.6 .3 .2

9.5 .6 .4

9.6.3.4

9.6 .3 .5

9.6 .3 .6

9.3.3.8

9.3 .3 .9

9.3.3.10

9.5.6.6

9.10 .3 .9

9.11.2.1

9.3.3.1

9.4.3.1

9.4 .3 .2

9.4 .3 .4

9.4.3.6

9.4 .3 .7

9.4 .3 .8
III

II

II

I

I

II

II

II

III

III

III

III

II

I

III

III

I

I

II

II

II

II

II

II

III 
Fire Protection Systems

Inspection, Testing, and Maintenance

$\begin{array}{ll}9.9 .3 .2 & \text { III } \\ 9.9 .3 .3 & \text { II } \\ 9.9 .3 .4 & \text { III }\end{array}$

Hazardous Materials

Incident Response

9.7.10.6

I

Management Information System

9.2 .2 .3 .1

III

Mission and goals

9.9 .3 .1

III

Mutual Aid

9.3.3.12

II

Organizational Structure

9.3.3.3

II

Quality Assurance and Standards of Operation

$\begin{array}{ll}9.11 .2 .2 & \mathrm{I}\end{array}$

Pre-Emergency Planning

9.7 .10 .1

9.7 .10 .2

9.7 .10 .5

9.7 .10 .7

9.6 .3 .7

II

Service Types and Levels

$\begin{array}{ll}9.3 .3 .7 & \text { I } \\ 9.3 .3 .2 & \text { II } \\ 9.5 .6 .5 & \text { III } \\ 9.7 .10 .3 & \text { III }\end{array}$

Site Incidents

9.3.3.11

III

Staff and Line Management

9.3.3.5

II

9.3.3.4

II

Testing and Service Firefighters

9.7 .10 .10

II

Training Facilities

9.4.3.5

II

9.10 .3 .6

II 
$\underline{\text { Technical Subject }}$

Training Programs

Vehicles
Recommendation \# Priority Classification

$\begin{array}{ll}9.10 .3 .1 & \text { II } \\ 9.10 .3 .2 & \text { III } \\ 9.10 .3 .3 & \text { II } \\ 9.10 .3 .4 & \text { II } \\ 9.10 .3 .5 & \text { III } \\ 9.10 .3 .7 & \text { III } \\ 9.10 .3 .8 & \text { III }\end{array}$

9.5 .6 .1

II

9.5 .6 .2

II

9.5 .6 .3

II

Water Supply for Fire Protection

$\begin{array}{ll}9.12 .3 .1 & \text { II } \\ 9.12 .3 .2 & \text { II } \\ 9.12 .3 .3 & \text { II }\end{array}$

Additional technical subjects were examined during the Needs Assessment study, but did not warrant recommendations. General information concerning these technical subjects is contained in appropriate sections of the Needs Assessment and/or in the Advisory Observations section of the Master Plan. These Additional technical subjects are as follows:

\author{
Applicable Requirements \\ Contract Services \\ Disaster Preparedness \\ Emergency Response Procedures \\ Legal Issues \\ Operationai Orders \\ Personnel Practices \\ Shared Response Station \\ Support Services \\ Technical Rescue Incident Response
}


THIS PAGE INTENTIONALLY LEFT BLANK 


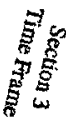


THIS PAGE INTENTIONALILY

LEFT BLANK 


\section{SECTION 3 - MASTER PLAN IMPLEMENTATION TIME FRAME}

\subsection{MASTER PLAN IMPLEMENTATION}

Implementation of the Master Plan will follow an implementation action plan developed by HFD officials. This plan will focus on the tactical steps necessary to implement the prioritized recommendations and will follow the designated time span.

\subsection{OVERALL TIME SPAN}

3.2.1 The overall time span encompassed by actions outlined in the Master Plan is, by direction, five to seven years. This indicates that some actions, projects, or programs are anticipated to be completed within a five year period, while others may extend to seven years.

3.2.1.1 The seven year parameter assumes that the overall time span period begins with the implementation of the Master Plan. This concept generally holds when master plans are adopted en toto by the policy group. Should only components of the HFD master plan be endorsed for implementation, then a coordinated, 5 to 7 year implementation may not be possible. Therefore, the various time periods for completion of certain specific recommendations outlined in this Master Plan may be staggered over an indeterminate period. Sequential projects provide an example of how master plan time frames may be extended.

3.2.2 Certain actions, projects, or programs outlined in the HFD master plan may be initiated at any time during the initial five to seven year period. Even though the time required to complete a project is less than seven years, the actual completion date necessarily may fall beyond the designated overall time span of this Master Plan.

3.2.3 As with many master plans, certain actions, projects, or programs may start at any time during the designated overall time span and continue throughout the life of the organization. An apparatus replacement program is an example.

3.2.4 Master plans typically are general in nature and focus more on broad goals rather than specific objectives. They often take the form of strategic plans. Since detailed planning often is necessary to accomplish organizational aims, master plans usually cause a variety of tactical, implementation plans to be formulated, each dedicated to the achievement of specific objectives or milestones.

The formulation by HFD and other officials of several tactical, shorter-term plans-each focusing on the implementation of one or more related recommendations listed in this Master Plan--will be necessary.

3.2.5. A continuation of the HFD master planning process will be necessary to extend this plan into a longer-term future. A suggested methodology to accomplish this is outlined in Section 5.0 . 


\subsection{STRATEGIC ISSUES TIMING}

3.3.1 Organizational missions are accomplished through the attainment of broadly stated goals. These goals are achieved through successful strategic planning.

Each organizational goal is composed of several or more objectives, all with the aim of helping to attain the goal. Each objective is achieved through tactical, implementation planning

3.3.2 The proper timing of strategic actions taken to achieve related goals must take into account whether goal attainment has to be sequential (building block concept) or parallel (spiral concept). The HFD Master Plan contains both types of goal attainment. An example of the former type is technical rescue training where basic rope work classes must come before high angle rescue work classes. An example of the latter type is the development of a regional mutual aid agreement, where various departments are approached at the same time, likely at the same meeting.

In some instances, two or more recommendations will need to be implemented simultaneously because of their direct interrelationship. for example, the recommended minimum baseline service level staffing model cannot be implemented prior to the establishment of an Incident Commander's position at the Battalion Chief's level, to be on duty at all times on all shifts.

HFD officials, with detailed local knowledge of mandated policy and budget request protocols, must categorize the various strategic actions required to achieve master plan goals and assign detailed implementation steps, and projected costs/savings.

3.3.3 The following major categories of action (non-inclusive) are judged by the needs assessment study team to require attainment as part of a planned sequence:

Major Action Category Examples

- The addition of FTE positions

- Construction work

- The implementation of new operating procedures

- The implementation of a baseline service level deployment model

- The extension of contract services

- the move to a shared station

- Capital expenditures

- The reorganization of Site emergency communication

- A major extension of service delivery

- Adjustment of station operating hours

- Implementation of a pager recall system

- Major change in personnel policy

- Changes in EMS oversight, policy, or practices 
For at least the Master Plan recommendations which are listed above, a sequential implementation appears needed. Additionally, each should be categorized by an assigned priority. Except for Priority Classification I, where the study team judged there to be compelling reasons for immediate implementation, some flexibility may be available.

Where a Priority III goal may be achieved with the expenditure of an insignificant amount of human and/or financial resources, then its implementation can be advanced. The same is true for Priority II goals.

When establishing the strategic implementation time line, all Priority I Recommendations must be planned for implementation as soon as possible.

Of these Priority I Recommendations, \#9.11.2.2 can be accomplished internally, within HFD, as can \#9.7.10.7. The remainder of the Priority I Recommendations will require prior policy decisions to be made. All of this remainder involve medical policy except one, which requires a basic DOE-Contractor decision concerning Site emergency communications.

\subsection{IMPLEMENTATION ACTION TIMING}

Implementation action refers to those steps planned to be taken in order to accomplish specific and relatively narrowly focused objectives.

The Priority II category contains a wide variety of Recommendations, each of which requires one or more tactical actions. The major clusters of Priority II Recommendations which require prior policy decisions are as follows:

- Station facilities

- Baseline service level response crew deployment

- Fire Marshal Office restructuring

- Training and Resource section restructuring

- Training facility

- Upgrade of water supply

- Site emergency medical self-help awareness

- Expansion of Fire Prevention Program

The major clusters of Priority II Recommendations which may be accomplished primarily through HFD internal mechanisms are as follows:

- Training for Hazmat responders

- Training for Safety Officers

- Apparatus deployment, including reserve apparatus

- Communication system and recall system modifications (budget approvals necessary)

- $\quad$ Pre-fire planning continued

- Operating guidelines completed

- Exercises and drills continued

- Improvements to training program (also Priority III) 
WHC-SP-1180, Vol. 2

\subsection{TIMING VARIATIONS}

As noted above, variations in the time span and its component sections will be necessary. In master planning, there are three important concepts of time:

- Overall time for plan implementation;

- Timing for major goal attainment efforts through strategic actions;

- Timing for the various tactical actions which make up each broad strategic action.

Timing for specific implementation actions which will be necessary can be ascertained following the establishment of the broad, strategic action time frame. 

THIS PAGE INTENTIONALLY

LEFT BLANK 


\section{SECTION 4 - IMPLEMENTATION}

Implementation steps and cost/savings for each category of recommendations will be prepared by HFD officials as part of the plan to be developed. This plan will guide officials in sequencing action steps, in determining needed policy changes and additions, in identifying necessary operational concurrences, and in preparing budget requests. 
THIS PAGE INTENTIONALLY LEFT BLANK 


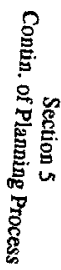


THIS PAGE INTENTIONALLY LEFT BLANK 


\section{SECTION 5 - CONTINUATION OF THE PLANNING PROCESS}

For HFD master planning to be effective at the Hanford site, a methodology is needed to keep the process continuing. Because of the dynamic nature of Hanford's future, the Master Plan will need to be revised annually. Ideally, this revision process will take place prior to the end of each fiscal year, with recognition of what has been accomplished and necessary adjustments made for next steps.

Revisions to a current master plan will be made by a planning team established by the HFD Chief, with input from division and section heads. The typical process of master plan extension is to add one or more years to a plan immediately prior to the conclusion of the current year. This "add-on" process assures that the HFD will always have a Master Plan extending to the desired planning horizon. 
THIS PAGE INTENTIONALLY

LEFT BLANK 


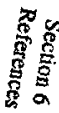


THIS PAGE INTENTIONALLY LEFT BLANK 


\section{SECTION 6 - REFERENCES}

Swift, 1995. Third Party Assessment of Fire Department Services for the Department of Energy's Hanford Site, Statement of Work, Attachment I MJL-SVV-391623, July, 1995. Westinghouse Hanford Company, Richland, Washington.

Hughes Associates, Inc., 1996. Hanford Fire Department Needs Assessment, WHC-SP-1180 Rev. 0, March, 1996. Prepared for Westinghouse Hanford Company, Richland, Washington. Hughes Associates, Inc., Baltimore, Maryland. 
THIS PAGE INTENTIONALLY
LEFT BLANK 
WHC-SP-1180

Volume 2

\section{Distribution Sheet}

RL

S. J. Veitenheimer (3)

A5-55

WHC

D. E. Good

D. E. Hare

S3-97

W. R. Hayes

N1-97

R. E. Jordan

S3-97

W. M. Knight

S3-97

R. M. Messer

S3-96

C. E. Swift

R. E. Traister

S3-97

S3-97

Document Processing Center

B3-63

A3-94 
THIS PAGE INTENTIONALLY

LEFT BLANK 